Sicherheit und Gesellschaft.

Freiburger Studien des Centre for Security and Society

\title{
Elisa Orrù
}

\section{Legitimität, Sicherheit, Autonomie}

Eine philosophische Analyse der EU-Sicherheitspolitik im Kontext der Digitalisierung 
Sicherheit und Gesellschaft.

Freiburger Studien des Centre for Security and Society

herausgegeben von

Prof. Dr. Hans-Helmuth Gander

Prof. Dr. Walter Perron

Prof. Dr. Ralf Poscher

Prof. Dr. Gisela Riescher

Prof. Dr. Thomas Würtenberger

Band 15 
Elisa Orrù

\section{Legitimität, Sicherheit, Autonomie}

Eine philosophische Analyse der EU-Sicherheitspolitik im Kontext der Digitalisierung 
The book processing charge was funded by the Baden-Württemberg Ministry of Science, Research and Arts in the funding programme Open Access Publishing and the University of Freiburg.

Die Deutsche Nationalbibliothek verzeichnet diese Publikation in der Deutschen Nationalbibliografie; detaillierte bibliografische Daten sind im Internet über http://dnb.d-nb.de abrufbar.

1. Auflage 2021

(c) Elisa Orrù

Publiziert von

Nomos Verlagsgesellschaft $\mathrm{mbH} \& \mathrm{Co} . \mathrm{KG}$ Waldseestraße 3-5 | 76530 Baden-Baden www.nomos.de

Gesamtherstellung:

Nomos Verlagsgesellschaft mbH \& Co. KG

Waldseestraße 3-5 | 76530 Baden-Baden

ISBN (Print): 978-3-8487-7928-4

ISBN (ePDF): 978-3-7489-2316-9

DOI: https://doi.org/10.5771/9783748923169

Onlineversion Nomos eLibrary

\section{(c)}

Dieses Werk ist lizenziert unter einer Creative Commons Namensnennung Weitergabe unter gleichen Bedingungen 4.0 International Lizenz. 


\section{Danksagung}

Dieses Buch ist das Ergebnis der Forschungsarbeit, die ich im Rahmen meiner Habilitation an der Philosophischen Fakultät der Albert-LudwigsUniversität Freiburg durchführen durfte. Für das uneingeschränkte Vertrauen und die Freiheit, die ich in diesen Jahren genießen konnte, sowie die wertvollen Ratschläge bin ich Prof. Dr. Hans-Helmuth Gander zu großem Dank verpflichtet. Für seine Unterstützung und seine konstruktiven Kommentare zur Habilitationsschrift bedanke ich mich bei Prof. Dr. Oliver Müller. Prof. Dr. Miriam Ronzoni hat mit ihrer wertschätzenden und scharfsinnigen Kritik an der Habilitationsschrift maßgeblich zur Präzisierung meiner Argumentationen beigetragen. Dafür bin ich ihr ausgesprochen dankbar.

Einige Kapitel dieser Arbeit wurden in Kolloquien, Seminaren und Workshops besprochen. Besonders profitiert habe ich von den regelmäßigen Kolloquien am Freiburger Husserl-Archiv, wo ich vorläufige Arbeitsergebnisse präsentiert habe. Meinen dortigen Kolleg_innen danke ich herzlichst für die zahlreichen und fruchtbaren Besprechungen. Ich danke zudem den Kolleg_innen am Centre for Security and Society, den Teilnehmenden am Forschungskolloquium von Prof. Dr. Stefan Kaufmann sowie den Organisator_innen und den Teilnehmenden der Tagung für Praktische Philosophie in Salzburg (2014), des Workshops für Politische Philosophie an der Freien Universität Berlin (2018) und des Workshops Technikphilosophie an der ETH Zürich (2019). Ihre Bemerkungen haben mir geholfen, den Blick zu schärfen und meine Argumentationen weiterzuentwickeln. Zu danken habe ich auch Dr. Till Bettels, Dr. Regula Giuliani, Dr. Anja Haut und Andreas Metzner, die frühere Fassungen einiger Teile des Manuskripts gelesen und mir wertvolle Rückmeldungen gegeben haben. Marianne Grzondziel und Elena Gritzner haben an der Herstellung der Verzeichnisse mitgewirkt. Dr. Philipp Teichfischer hat mit einmaliger Professionalität das Manuskript lektoriert.

Zu danken habe ich ferner den Reihenhherausgeber_innen für die Aufnahme des Buches in die Schriftenreihe Sicherheit und Gesellschaft. Freiburger Studien des Centre for Security and Society des Nomos-Verlags, sowie Carsten Rehbein und Eva Lang für die verlegerische Betreuung. Die Veröffentlichung dieser Arbeit im OpenAccess-Modus wurde dank großzügiger Förderung der Wissenschaftlichen Gesellschaft Freiburg und des baden- 


\section{Danksagung}

württembergischen Ministeriums für Wissenschaft, Forschung und Kunst ermöglicht.

Nicht genug danken kann ich meinen Familienmitgliedern für die Begeisterung, mit der sie meine Pläne aufgenommen, und die Selbstverständlichkeit, mit der sie mich bei der Durchführung dieses Projekts unterstützt haben.

Freiburg im Breisgau, im April 2021 


\section{Anmerkung}

Dieses Manuskript wurde im April 2021 fertiggestellt. Eine frühere Version wurde im Juli 2019 als Habilitationsschrift mit dem Titel „Zur Legitimität der Sicherheitsmaßnahmen im europäischen ,Raum der Freiheit, der Sicherheit und des Rechts'. Eine philosophische Analyse" an der Philosophischen Fakultät der Albert-Ludwigs-Universität Freiburg vorgelegt. Die Habilitation erfolgte im Januar 2020. Die Habilitationsschrift wurde daraufhin inhaltlich überarbeitet und alle Angaben zu den aktuellen Entwicklungen der EU-Politik wurden auf den Stand vom Februar 2021 aktualisiert. 


\section{Inhaltsübersicht}

$\begin{array}{ll}\text { Abbildungs- und Tabellenverzeichnis } & 21\end{array}$

$\begin{array}{ll}\text { Abkürzungsverzeichnis } & 23\end{array}$

Einführung 25

1 Bestrittene Legitimität und öffentliche Autonomie 25

2 Ein philosophisches Unterfangen 27

3 Aufbau des Buches 31

Teil I Eine in der Realität verankerte Normativität. Ansatz und theoretische Grundlagen der Untersuchung 41

Kapitel 1 Fakten und Normen: der kritisch-realistische Ansatz in der politischen Philosophie 43

1 Der „kritische Realismus“: eine (Re-)Konstruktion 43

2 Grundzüge des kritischen Realismus 47

3 Entfaltung des kritischen Potenzials des gegenwärtigen Realismus 75

4 Kritik am kritischen Realismus und Lösungsansätze 86

5 Eine kritisch-realistische Annäherung an die EU-Sicherheitspolitik 92

Kapitel 2 Legitimität im Kontext der EU 95

1 Operationalisierung des realistischen Ansatzes 95

2 Begriffliche Annährungen: Legalität, Legitimation und Legitimität als machtstabilisierende Faktoren 96

3 Fünf Bedingungen einer kritisch-realistischen Erforschung politischer Legitimität $\quad 98$

4 Legitimationsmodelle der EU 102

5 Grundsätze des demokratischen Rechtsstaates: Bausteine einer Genealogie 112

6 Kriterien der Legitimität der EU-Normen $\quad 121$ 
Teil II Die Digitalisierung der EU-Sicherheitspolitik: Erhebung, Austausch und Auswertung von personenbezogenen Informationen - Fallstudien

Einführung zur Analyse der Fallbeispiele

Kapitel 3 Freiheit, Sicherheit und Recht im europäischen Raum: eine kurze Genealogie der „Sicherheitsunion“

1 Charakterisierung des RFSR: ein Raum ohne Binnengrenzen

2 Die Entwicklung des RFSR von der Nachkriegszeit bis zur Gegenwart

3 Grundbegriffe des RFSR

4 Die Wechselbeziehungen innerhalb der Trias Freiheit Sicherheit - Recht

5 Auf dem Weg zu einer Sicherheitsunion

Kapitel 4 Grenzen und Kontrolle: der Ausbau der EUSicherheitspolitik nach Schengen

1 Das Schengener Informationssystem (SIS): die erste europäische Datenbank

2 Die Entstehung des SIS: vom zwischenstaatlichen Abkommen zum EU-Recht

3 Normeninhalt: Fahndung nach Personen und Gegenständen 163

4 Rechtfertigungsargumente und Effektivität des SIS

5 Die institutionellen Verhältnisse bei der Entscheidungsfindung im Falle des SIS

6 Sicherheitstheoretische und normative Implikationen des SIS:

Flexibilität und Erweiterung der Machtbefugnisse

Kapitel 5 Erhebung und Austausch biometrischer Daten zu kriminalistischen Zwecken: der Fall von Prüm

1 Die Prümer Regelungen: Austausch biometrischer Daten 200

2 Entstehung der Prümer Regelungen: ein SIS III? 201

3 Inhalt der Prümer Beschlüsse 
4 Rechtfertigungargumente und Effektivität der Prümer Regelungen für die Bekämpfung von Terrorismus und grenzüberschreitender Kriminalität

5 Die Prümer Regelungen im Kontext des institutionellen und rechtlichen Rahmens der EU

6 Sicherheitstheoretische und normative Implikationen der Prümer Regelungen: Sicherheit als Machtkatalysator

Kapitel 6 Mobilität und Sicherheit: Passagierdaten als Risikoindikatoren nach der PNR-Richtlinie

1 Die Fluggastdatensätze-Richtlinie (PNR-Richtlinie): zentralisierte Speicherung von Fluggastdaten auf nationaler Ebene

2 Im Schatten der Terrorismusbekämpfung: die Entstehung der EUNormen und der internationalen PNR-Abkommen

3 Inhalt der PNR-Richtlinie: Übermittlung, Speicherung und Überarbeitung von Fluggastinformationen zu kriminalistischen Zwecken

4 Rechtfertigungsargumente und Effektivität der PNR-Richtlinie zur Bekämpfung von Terrorismus und schwerer Kriminalität

5 Die institutionellen Verhältnisse in der EU und der Einfluss der USA

6 Sicherheitstheoretische und normative Implikationen der PNRRichtlinie: Mobilitätsdaten als Indizien für Straftaten

Kapitel 7 Fluchtlinien der EU-Sicherheitspolitik: Ausbau der Datenbanken und gesteigerte Interoperabilität

1 Von den spezifischen Analysen zum Gesamtbild des Informationsaustausches im RFSR

2 Der Informationsaustausch in der EU: Überblick 260

3 Aktuell betriebene Informationssysteme 262

4 Der Ausbau der Datenbanken und ihrer Interoperabilität: kürzlich eingeführte und geplante Maßnahmen 


\section{Inhaltsübersicht}

Teil III Sicherheit als Präemption, Autonomie als Infragestellung. Theoretische und normative Anregungen

Kapitel 8 Ein neuer sicherheitspolitischer Ansatz:

Grundeigenschaften und Herausforderungen für die normative Ordnung

1 Die Logik der EU-Sicherheitspolitik im RFSR

2 Zirkuläre Sicherheit

3 Sicherheit als Präemption

Kapitel 9 Autonomie als Möglichkeit der Infragestellung 304

1 Von der Kritik zur Transformation 304

2 Eine provisorisch für gültig gehaltene Legitimität 305

3 Die defizitäre Legitimität der Sicherheitsmaßnahmen im RFSR 309

4 Ein Vorschlag für die Transformation der Legitimationsprinzipien

5 Die Reaktivierung der Vision von einem Europa als Raum des Wohlstands und des Friedens

Schlussbetrachtung

Literaturverzeichnis

Verzeichnis der Internetquellen 


\section{Inhaltsverzeichnis}

Abbildungs- und Tabellenverzeichnis $\quad 21$

Abkürzungsverzeichnis $\quad 23$

Einführung 25

1 Bestrittene Legitimität und öffentliche Autonomie 25

2 Ein philosophisches Unterfangen 27

3 Aufbau des Buches 31

3.1 Methodologische und theoretische Aspekte 31

3.2 Analyse konkreter Sicherheitsmaßnahmen 34

3.3 Von der Analyse zur Transformation 36

Teil I Eine in der Realität verankerte Normativität. Ansatz und theoretische Grundlagen der Untersuchung

Kapitel 1 Fakten und Normen: der kritisch-realistische Ansatz in der politischen Philosophie

1 Der „kritische Realismus“: eine (Re-)Konstruktion 43

2 Grundzüge des kritischen Realismus 47

2.1 Die Priorität der Politik vor der Moral 48

2.2 Realismus als Empirismus: Zu den Fakten selbst! 56

2.3 „Im Anfang war die Tat“: die Kontextgebundenheit der politischen Philosophie $\quad 60$

2.4 Negativismus: die Erfahrung der „institutionellen

Grausamkeit" als Ausgangspunkt des kritischen Realismus $\quad 65$

2.5 Immanenz der Leitprinzipien und der Kritik 71

3 Entfaltung des kritischen Potenzials des gegenwärtigen Realismus $\quad 75$

3.1 Die epistemologische Plausibilisierung einer nicht fundierenden Kritik: das Wissenssystem als „Lebenselement der Argumente"

3.2 Foucaults Genealogie als „historische Auflösung“ von Selbstverständlichkeiten

3.3 Jaeggis Auffassung der immanenten Kritik $\quad 80$ 
3.4 Fruchtbarkeit der nicht transzendentalen Kritik für die Untersuchung der Legitimität der EU-Sicherheitspolitik

4 Kritik am kritischen Realismus und Lösungsansätze

5 Eine kritisch-realistische Annäherung an die EU-Sicherheitspolitik

1 Operationalisierung des realistischen Ansatzes

2 Begriffliche Annährungen: Legalität, Legitimation und Legitimität als machtstabilisierende Faktoren

3 Fünf Bedingungen einer kritisch-realistischen Erforschung politischer Legitimität

4 Legitimationsmodelle der EU

4.1 Diskussion konkurrierender Legitimationsmodelle: internationale Legitimation

4.2 Technokratische Legitimation 104

4.3 Rechtfertigungsbasierte Legitimation 105

4.4 Demokratie und Rechtsstaatlichkeit als Grundsätze der normativen Ordnung der EU

5 Grundsätze des demokratischen Rechtsstaates: Bausteine einer Genealogie

5.1 Historische Prämissen und philosophische Grundannahmen des Rechtsstaates

5.2 Das demokratische Prinzip 118

6 Kriterien der Legitimität der EU-Normen 121

6.1 Rechtfertigung und Effektivität 122

6.2 Verfahrenskonformität 124

6.3 Rückwirkung auf die normative Ordnung 126

Teil II Die Digitalisierung der EU-Sicherheitspolitik: Erhebung, Austausch und Auswertung von personenbezogenen Informationen - Fallstudien

Einführung zur Analyse der Fallbeispiele

Kapitel 3 Freiheit, Sicherheit und Recht im europäischen Raum: eine kurze Genealogie der "Sicherheitsunion“

1 Charakterisierung des RFSR: ein Raum ohne Binnengrenzen 
2 Die Entwicklung des RFSR von der Nachkriegszeit bis zur Gegenwart

2.1 Die Gründungsverträge

2.2 Vor dem Vertrag von Maastricht: informelle Kooperation

2.3 Die Regelung des RFSR im EU-Primärrecht ab Maastricht: vom Intergouvernementalismus zur Supranationalität

2.3.1 Die Maastricht-Ära

2.3.3 Die Erneuerungen des Lissaboner Vertrags

2.4 Die politischen Vorgaben des Europäischen Rates

3 Grundbegriffe des RFSR

3.1 Raum

3.2 Freiheit

3.3 Sicherheit

3.4 Recht

3.5 Grundrechte

4 Die Wechselbeziehungen innerhalb der Trias Freiheit Sicherheit - Recht

4.1 Die Darstellung nach dem EU-Primärrecht

4.2 Die Gestaltung der Wechselbeziehungen nach den Ratsprogrammen sowie in der Praxis

5 Auf dem Weg zu einer Sicherheitsunion

Kapitel 4 Grenzen und Kontrolle: der Ausbau der EUSicherheitspolitik nach Schengen

1 Das Schengener Informationssystem (SIS): die erste europäische Datenbank

2 Die Entstehung des SIS: vom zwischenstaatlichen Abkommen zum EU-Recht

2.1 Die Errichtung des europäischen Binnenmarktes

2.2 Die zwischenstaatlichen Bemühungen zum Abbau der Grenzkontrollen

2.3 Die Überführung in den EU-Rechtsrahmen

2.4 Der Übergang zum SIS der zweiten Generation

3 Normeninhalt: Fahndung nach Personen und Gegenständen

3.2 Systemarchitektur und Zuständigkeiten 
3.3 Daten- und Ausschreibungskategorien 166

$\begin{array}{ll}3.4 \text { Zugriffsberechtigte } & 168\end{array}$

4 Rechtfertigungsargumente und Effektivität des SIS 170

4.1 Entstehung des SIS - Legitimation 170

4.1.1 Der Wortlaut der Dokumente $\quad 170$

4.1.2 Die polizeiliche Position 171

4.1.3 Die Ansicht der EU-Kommission und Positionen in der Politik

4.1.4 Rechts- und politikwissenschaftliche Studien und Einschätzung des BKA

4.2 Die Effektivität des SIS I 180

4.3 Die Funktion des SIS I 181

4.4 Übergang zum SIS II - Legitimation 183

4.4.1 Wortlaut der Dokumente 184

4.4.2 Veränderte Zielsetzung während der Entwicklung des SIS II

4.5 Effektivität des SIS II 187

4.6 Die Funktion des SIS II 189

5 Die institutionellen Verhältnisse bei der Entscheidungsfindung im Falle des SIS 192

5.1 Von der Interstaatlichkeit zur Supranationalität 192

5.2 Die Präeminenz der Exekutive 193

6 Sicherheitstheoretische und normative Implikationen des SIS:

Flexibilität und Erweiterung der Machtbefugnisse 194

6.1 Das SIS: ein „flexibles Instrument“ 194

6.2 Die Legitimierungskraft des Sicherheits- und Ausgleichsarguments 196

6.3 Die Erweiterung der Ermittlungsmöglichkeiten durch das SIS 197

Kapitel 5 Erhebung und Austausch biometrischer Daten zu kriminalistischen Zwecken: der Fall von Prüm 200

1 Die Prümer Regelungen: Austausch biometrischer Daten 200

2 Entstehung der Prümer Regelungen: ein SIS III? 201

2.1 Der Prümer Vertrag als völkerrechtliches Abkommen 201

2.2 Die Überführung in den EU-Rechtsrahmen und geplante Erweiterungen 
3 Inhalt der Prümer Beschlüsse 203

3.1 Ziel des Datenaustausches: Vertiefung der Zusammenarbeit 204

3.2 Datenkategorien und Formen des Datenaustausches 204 3.2.1 DNA-Daten 205

3.2.2 Daktyloskopische Daten 206

3.2.3 Daten aus Fahrzeugregistern 207

3.3 Weitere Normen betreffend den Informationsaustausch 207

3.4 Weitere Schritte des Austausches von DNA-Informationen 208

4 Rechtfertigungargumente und Effektivität der Prümer Regelungen für die Bekämpfung von Terrorismus und grenzüberschreitender Kriminalität

5 Die Prümer Regelungen im Kontext des institutionellen und rechtlichen Rahmens der EU

5.1 Eine „verstärkte Zusammenarbeit“ außerhalb der EU: Schengen als Vorbild?

5.2 Vergleich mit konkurrierenden Projekten im RSFR

5.3 Die Konsequenzen des Ausweichens in den intergouvernementalen Raum im Fall von Prüm

5.4 Die Art der Überführung in den EU-Rechtsrahmen und insbesondere die Rolle des EU-Parlaments

6 Sicherheitstheoretische und normative Implikationen der Prümer Regelungen: Sicherheit als Machtkatalysator

Kapitel 6 Mobilität und Sicherheit: Passagierdaten als Risikoindikatoren nach der PNR-Richtlinie

1 Die Fluggastdatensätze-Richtlinie (PNR-Richtlinie): zentralisierte Speicherung von Fluggastdaten auf nationaler Ebene

2 Im Schatten der Terrorismusbekämpfung: die Entstehung der EUNormen und der internationalen PNR-Abkommen

3 Inhalt der PNR-Richtlinie: Übermittlung, Speicherung und Überarbeitung von Fluggastinformationen zu kriminalistischen Zwecken

4 Rechtfertigungsargumente und Effektivität der PNR-Richtlinie zur Bekämpfung von Terrorismus und schwerer Kriminalität

4.1 Die Ansicht der Kommission

4.2 Überprüfung der Rechtfertigungsargumente und Ergebnisse der ersten Umsetzungsevaluation 
4.3 Kosten und Umfang der Datenübermittlung und -verarbeitung

5 Die institutionellen Verhältnisse in der EU und der Einfluss der USA

6 Sicherheitstheoretische und normative Implikationen der PNRRichtlinie: Mobilitätsdaten als Indizien für Straftaten

6.1 Datensammlung, -übermittlung und -speicherung: Zweckbindung, Datenminimierung und andere datenschutzrechtliche Erwägungen

6.2 Datenverarbeitung zur Risikobewertung

6.3 Datenverarbeitung zur Aktualisierung und Herstellung der Risikokriterien

6.4 Exkurs: algorithmische Regulierung zwischen Mythos und Realität

Kapitel 7 Fluchtlinien der EU-Sicherheitspolitik: Ausbau der Datenbanken und gesteigerte Interoperabilität

1 Von den spezifischen Analysen zum Gesamtbild des Informationsaustausches im RFSR

2 Der Informationsaustausch in der EU: Überblick 260

3 Aktuell betriebene Informationssysteme 262

3.1 Das VIS

3.2 Eurodac

4 Der Ausbau der Datenbanken und ihrer Interoperabilität: kürzlich eingeführte und geplante Maßnahmen

4.1 Potenzierung existierender Datenbanken

4.2 Einführung zusätzlicher Informationssysteme

4.3 Interoperabilität der Informationssysteme: der Aufbau einer zentralen EU-Superdatenbank

Teil III Sicherheit als Präemption, Autonomie als Infragestellung. Theoretische und normative Anregungen

Kapitel 8 Ein neuer sicherheitspolitischer Ansatz:

Grundeigenschaften und Herausforderungen für die normative Ordnung

1 Die Logik der EU-Sicherheitspolitik im RFSR 
2 Zirkuläre Sicherheit

2.1 Von der Unterstützung des Marktes zum selbstständigen Zweck

2.2 Die „Logik der Lückenschließung“ des EUInformationsaustauschs und seine Paradoxa

3 Sicherheit als Präemption

3.1 Die Durchsetzung der präemptiven Logik als richtungsweisend für die EU-Sicherheitspolitik

3.2 Der präemptive Ansatz unter besonderer Berücksichtigung der PNR-Maßnahmen

3.2.1 Effektvermeidung statt Ursachenbekämpfung

3.2.2 Profile und die Erstellung von Gefährlichkeitsprognosen

3.2.3 Opazität der Bewertungskriterien

3.2.4 Opazität der Überprüfungsmaßnahmen

3.2.5 Opazität der Verhaltensnormen

3.3 Das Modell der präemptiven Sicherheit

3.4 Die normativen Implikationen des präemptiven

Sicherheitsmodells

Kapitel 9 Autonomie als Möglichkeit der Infragestellung

1 Von der Kritik zur Transformation

2 Eine provisorisch für gültig gehaltene Legitimität

3 Die defizitäre Legitimität der Sicherheitsmaßnahmen im RFSR

4 Ein Vorschlag für die Transformation der

Legitimationsprinzipien

4.1 Stärken und Schwächen der geltenden

Legitimationsmechanismen

4.2 Öffentliche Autonomie als Möglichkeit der Infragestellung

4.3 Ein modifiziertes Legitimitätsmodell

4.4 Mechanismen der Teilnahme und der Kontrolle nach dem vorgeschlagenen Autonomieverständnis

5 Die Reaktivierung der Vision von einem Europa als Raum des Wohlstands und des Friedens 
Inhaltsverzeichnis

$\begin{array}{ll}\text { Schlussbetrachtung } & 328\end{array}$

$\begin{array}{ll}\text { Literaturverzeichnis } & 331\end{array}$

Verzeichnis der Internetquellen 349 
Abbildungs- und Tabellenverzeichnis

Tabelle 1: $\quad$ Treffer im SIS II (2014-2019) 189

Tabelle 2: $\quad$ Treffer im SIS I (1997-2009) und SIS II (2014-2019) im Vergleich 190

Abbildung 1: Geplante Komponenten für die Interoperabilität der EU-Informationssysteme (Quelle: EU-Kommission 2018) 


\section{Abkürzungsverzeichnis}

$\begin{array}{ll}\text { AEUV } & \text { Vertrag über die Arbeitsweise der Europäischen Union } \\ \text { AFIS } & \text { Automated Fingerprint Identification System } \\ \text { AFSJ } & \text { Area of Freedom, Security and Justice } \\ \text { APIS } & \text { Advance Passenger Information System } \\ \text { BDSG } & \text { Bundesdatenschutzgesetz } \\ \text { BKA } & \text { Bundeskriminalamt } \\ \text { BLD } & \text { Basic Legitimation Demand } \\ \text { BMS } & \text { Dienst für den Abgleich biometrischer Daten } \\ \text { CIR } & \text { Common identity repository/Gemeinsamer Speicher für Identi- } \\ \text { DNA } & \text { tätsdaten } \\ \text { DSGV } & \text { Deoxyribonucleic Acid/Desoxyribonukleinsäure } \\ \text { ECRIS } & \text { Datenschutz-Grundverordnung } \\ \text { EES } & \text { European Criminal Records Information System/Europäisches } \\ \text { EG } & \text { Strafregisterinformationssystem } \\ \text { EGKS } & \text { Exit-Entry-System/Einreise-/Ausreisesystem } \\ \text { EGV } & \text { Europäische Gemeinschaft } \\ \text { EIS } & \text { Europäische Gemeinschaft für Kohle und Stahl } \\ \text { EMRK } & \text { Vertrag über die Europäische Gemeinschaft } \\ \text { EPRIS } & \text { Europol-Informationssystem } \\ \text { ESP } & \text { Europäische Konvention zum Schutz der Menschenrechte und } \\ \text { ETIAS } & \text { Guropandfreiheiten } \\ \text { EU } & \text { European Police Records Index System/Europäisches Polizeire- } \\ \text { eu-LISA } & \text { gisterinformationssystem } \\ \text { European search portal/Europäisches Suchportal } \\ \text { European Travel Information and Authorization System/Euro- } \\ \text { päisches Reiseinformations- und Reisegenehmigungsystem } \\ \text { Europäische Union } \\ \text { European Agency for the operational management of large-scale } \\ \text { Eurstems in the area of freedom, security and justice } \\ \text { Eutschof }\end{array}$


EWG Europäische Wirtschaftsgemeinschaft

FlugDaG Fluggastdatengesetz

Frontex

EU-Agentur für die Grenz- und Küstenwache

iBorderCtrl

Intelligent portable control system

ICAO International Civil Aviation Organisation

INDECT Intelligent information system supporting observation, searching and detection for security of citizens in urban environment

$\mathrm{Kfz}$ Kraftfahrzeug

NATO North Atlantic Treaty Organization/Nordatlantikpakt-Organisation

NSA National Security Agency

PB Prümer Beschlüsse

PDB Prümer Durchführungsbeschluss

PM Political Moralism

PNR Passenger Name Record

RFSR Raum der Freiheit, der Sicherheit und des Rechts

SDÜ Schengener Durchführungsübereinkommen

SIRENE Supplementary Information REquest at National Entry

SIS

SLTD

Schengener Informationssystem

TESTA Trans European System for Telematics between Administrators

TRESSPASS Robust risk based screening and alert system for passengers and luggage

TREVI Terrorisme, radicalisme, et violence international

USA

United States of America/Vereinigte Staaten von Amerika

VIS Visa Information System 


\section{Einführung}

\section{Bestrittene Legitimität und öffentliche Autonomie}

„Von Legitimitäten wird immer nur gesprochen, wenn sie bestritten werden". ${ }^{1}$ Historisch betrachtet sind Debatten über politische Legitimität in Europa nie reine akademische Übungen gewesen. Vielmehr waren sie stets mit Krisen der Legitimität verbunden und haben tiefere gesellschaftliche Auseinandersetzungen aufgegriffen, reflektiert und vorangetrieben. ${ }^{2}$ Jean Bodins Prägung des Konzepts der Souveränität, ${ }^{3}$ seine Weiterentwicklung durch Thomas Hobbes ${ }^{4}$ und die damit angestoßene vertragstheoretische Tradition sind dafür nur einige Beispiele. Diese Legitimitätsdebatten haben auf den gewaltigen politischen Umbruch der Neuzeit reagiert und sich mit dem politischen, rechtlichen und gesellschaftlichen Problem der Legitimität der sich durchsetzenden neuen politischen Form des modernen Staates auseinandergesetzt. Dabei sind die gesellschaftlichen und politischen Krisen der Legitimität symptomatisch für eine wachsende Kluft zwischen Prinzipien (die sich etwa an einer „alten“ Konzeption der politischen Legitimität orientieren) und Praktiken (derer sich etwa eine neue Machtform bedient). ${ }^{5}$

Dass heute die Legitimität politischer Initiativen der Europäischen Union (EU) im Fokus kontroverser Debatten steht, kann vor diesem Hintergrund verstanden werden. Denn einerseits übernimmt die EU mehr und mehr Aufgaben und Funktionen, die seit der Neuzeit Prärogative der staatlichen Macht sind, ohne andererseits unmittelbar auf die Legitimationsgrundlagen des Staates zurückgreifen zu können. Diese Dynamik ist besonders ausgeprägt in dem Politikfeld der EU, das als „Raum der

1 Blumenberg, Hans, Die Legitimität der Neuzeit. Frankfurt am Main: Suhrkamp 1996, 107.

2 Vgl. Beetham, David; Lord, Christopher, Legitimacy and the EU. London; New York: Routledge 2013, 1.

3 Vgl. Bodin, Jean, Über den Staat, hg. v. Niedhart, Gottfried. Stuttgart: Reclam 2005 (zuerst veröffentlicht 1576).

4 Vgl. Hobbes, Thomas, Leviathan: oder Stoff, Form und Gewalt eines kirchlichen und bürgerlichen Staates, hg. v. Fetscher, Iring. Frankfurt am Main: Suhrkamp 1994 (zuerst veröffentlicht 1651).

5 Vgl. Beetham; Lord, Legitimacy and the EU, 2. 
Freiheit, der Sicherheit und des Rechts" (RFSR) bezeichnet wird. Diese Formel bündelt die EU-Maßnahmen ${ }^{6}$ in den Bereichen Justiz und innere Sicherheit unter einem gemeinsamen Nenner. Seitdem die EU 1997 im Amsterdamer Vertrag zum ersten Mal als ein RFSR bezeichnet wurde, ${ }^{7}$ hat sich der europäische RFSR rasant entwickelt und sein Kompetenzbereich entscheidend ausgeweitet. Wie schon der Name suggeriert, hat diese Entwicklung Kernbereiche der staatlichen Macht betroffen, oder präziser ausgedrückt: den Bereich, der seit der Neuzeit als der innere Kern der staatlichen Souveränität gilt, nämlich die Gewährleistung der Sicherheit. Dieser Wandel der EU-Kompetenzen gilt als beispielhaft für die Überführung der EU in ein neues politisches Paradigma, das dezidiert über die wirtschaftliche Integration hinausgeht, ${ }^{8}$ und steht im Mittelpunkt vorliegender Untersuchung.

Ausgehend von diesen Entwicklungen lautet die zentrale Forschungsfrage dieser Untersuchung, ob die grundlegenden Legitimitätsprinzipien der EU in der Lage sind, ibre machteingrenzende und grundrechtsschützende Funktion im RFSR effektiv auszuüben, und, wenn nicht, in welche Richtung sie ergänzt oder modifiziert werden sollten, um diese Defizite zu überwinden.

Die Beantwortung dieser Frage erfordert ihrerseits Teiluntersuchungen, die um die folgenden Fragenkomplexe gruppiert werden können. Erstens stellen sich Fragen in Bezug auf die theoretische Grundlage der Untersuchung, nämlich aus welcher philosophischen Perspektive die Frage der Legitimität der EU-Politik erforscht werden soll und welche Prinzipien dabei als Grundlage dienen sollen. Zweitens stellt sich eine Reihe von Fragen in Bezug auf die empirischen Analysen der Sicherheitsmaßnahmen, nämlich wie konkret diese Maßnahmen gerechtfertigt und institutionell verwirklicht wurden und wie sie auf die normative Beschaffenheit der

6 Der Begriff „Maßnahme“ wird in diesem Buch nicht im spezifisch juristischen Sinne als eine hoheitliche Einzelfallregelung, sondern in einem allgemeineren Sinne als eine Bündelung von Normen und durch diese Normen vorgeschriebene Praxen verstanden. Dies ist auch die Verwendung in den offiziellen EU-Dokumenten, vgl. beispielsweise die EU-Sicherheitsagenda, Mitteilung der Kommission an das Europäische Parlament, den Rat, den Europäischen Wirtschafts- und Sozialausschuss und den Ausschuss der Regionen „Die Europäische Sicherheitsagenda“, $\operatorname{COM}(2015) 185$ final, 28.04.2015, 2.

7 Vgl. Vertrag von Amsterdam zur Änderung des Vertrags über die Europäische Union, der Verträge zur Gründung der Europäischen Gemeinschaften sowie einiger damit zusammenhängender Rechtsakte vom 02.10.1997, Art. 1 Ziff. 5).

8 Vgl. Lenaerts, Koen, Foreword, in: Fletcher, Maria; Herlin-Karnell, Ester; Matera, Claudio (Hg.), The European Union as an Area of Freedom, Security and Justice. London; New York: Routledge 2017, xv-xvii. 
EU-Politik zurückwirken. Schließlich ist ein Fragenkomplex aufgeworfen, der wieder stärker theoretisch und normativ geprägt ist, nämlich welche Tendenzen des sicherheitspolitischen Ansatzes die Analyse verdeutlicht, welche Herausforderungen diese Tendenzen der Legitimitätsprinzipien stellen und wie diese darauf reagierend transformiert werden sollten. Der Behandlung jedes dieser Fragenkomplexe ist jeweils ein Teil des Buches gewidmet. Die Hauptthese, zu der ich gelange, ist, dass sich der sicherheitspolitische Ansatz der EU zu einem präemptiven Paradigma verschiebt, angesichts dessen die uns vertrauten Legitimitätsprinzipien ihre machteingrenzende und grundrechtsschützende Funktion nicht effektiv ausüben können. Um diese Defizite zu überwinden, so meine These weiter, bedarf es einer Transformation der Legitimitätskonzeption, die philosophisch auf einem Verständnis der öffentlichen Autonomie als Möglichkeit der Infragestellung gründet.

\section{Ein philosophisches Unterfangen}

Bislang hat sich eine Reihe von Untersuchungen aus rechtlicher Perspektive mit einigen der EU-Sicherheitsmaßnahmen im RFSR und deren spezifischen juristischen Herausforderungen auseinandergesetzt. ${ }^{9}$ Einige dieser Arbeiten haben die gleichen Normenkomplexe analysiert, die auch im Fokus der vorliegenden Untersuchung stehen. Dabei haben sie sich aber auf die Überprüfung von deren Kompatibilität mit Grundsätzen oder Grundrechten der EU oder des nationalen Rechts konzentriert. Andere rechtswissenschaftliche Arbeiten haben Fragen des Abgleichs der nationalen Rechtsrahmen zum Zwecke der europäischen Zusammenarbeit behandelt. Darüber hinaus wurde das Thema bereits aus politikwissenschaftlicher Perspektive untersucht. Vor diesem disziplinären Hintergrund wurden etwa

9 Auf diese Untersuchungen wird im zweiten Teil des Buches Bezug genommen, hier seien nur einige genannt: Schindehütte, Alexandra, Das Schengener Informationssystem unter besonderer Berücksichtigung der Vereinbarkeit einer verdeckten Registrierung nach Art. 99 SDÜ mit Art. 8 der Charta der Grundrechte der Europäischen Union. Göttingen 2013; Pörschke, Julia Victoria, Der Grundsatz der Verfügbarkeit von Informationen am Beispiel des Prümer Modells. Berlin: Duncker \& Humblot 2014; Boehm, Franziska, EU PNR: European Flight Passengers under General Suspicion - The Envisaged European Model of Analyzing Flight Passenger Data, in: Gutwirth, Serge; Poullet, Yves; De Hert, Paul; Leenes, Ronald (Hg.), Computers, Privacy and Data Protection: an Element of Choice. Dordrecht: Springer 2011, 171199 und Müller-Graff, Peter-Christian (Hg.), Der Raum der Freiheit, der Sicherheit und des Rechts. Baden-Baden: Nomos 2005. 
Fragen der institutionellen Architektur und der demokratietheoretischen Implikationen der Entwicklungen im RFSR behandelt. ${ }^{10}$ Genuin philosophische Untersuchungen der Entwicklungen im RFSR und deren Legitimität sind dagegen bislang ausgeblieben.

Der Grund für diese Forschungslücke könnte in einem Missverständnis über die Aufgaben der politischen Philosophie liegen. Diese wird durch Selbst- sowie Fremdzuschreibungen häufig als eine Disziplin verstanden, die sich primär mit der Identifizierung von idealen Kriterien der gerechten bzw. legitimen Regierung beschäftigt und sich nur zweitrangig mit konkreten politischen und rechtlichen Phänomenen und Fakten auseinandersetzt. ${ }^{11}$ Obwohl dieses Verständnis der politischen Philosophie seit der Jahrtausendwende immer dezidierter kritisiert wird, fokussieren Gegenentwürfe weiterhin hauptsächlich auf methodologische Fragen. Inhaltsbezogene Untersuchungen, die sich mit konkreten politischen und rechtlichen Realitäten auseinandersetzen, konnten sich dementsprechend noch nicht voll entfalten.

In Abgrenzung zu der dominanten Konzeption der politischen Philosophie als idealer, prinzipiell normativ ausgerichteter Disziplin und als Konkretisierung des Gegenentwurfs dazu ist die vorliegende Abhandlung dem Unterfangen gewidmet, eine genuin philosophische Untersuchung der Legitimität konkreter Maßnahmen der europäischen Sicherheitspolitik durchzuführen.

Dabei knüpft die vorliegende Untersuchung an den jüngsten Methodenstreit in der politischen Philosophie an, in dem ideal-normative Ansätze rawlsscher Prägung für ihre mangelnde Anschlussfähigkeit an die politi-

10 Auf diese Arbeiten wird im zweiten Kapitel unten Bezug genommen, hier sei nur pars pro toto auf folgende Untersuchungen hingewiesen: Daase, Christopher; Geis, Anna; Nullmeier, Frank (Hg.), Der Aufstieg der Legitimitätspolitik: Rechtfertigung und Kritik politisch-ökonomischer Ordnungen. Baden-Baden: Nomos Verlagsgesellschaft 2012 (insbesondere auf die Kapitel, die sich mit der Legitimität der EU auseinandersetzen); Guild, Elspeth; Carrera, Sergio; Eggenschwiler, Alejandro (Hg.), The area of freedom, security and justice ten years on: successes and future challenges under the Stockholm Programme. Brüssel: CEPS 2010; Léonard, Sarah; Kaunert, Christian (Hg.), Searching for a strategy for the European Union's area of freedom, security and justice. London; New York: Routledge 2017.

11 Als Beispiel einer Selbst- und einer Fremdzuschreibung in diesem Sinne vgl. jeweils Becker, Michael; Schmidt, Johannes; Zintl, Reinhard, Politische Philosophie. Paderborn: Ferdinand Schöningh 2017, 17 und Beetham; Lord, Legitimacy and the EU, 1. Vertiefend dazu unten in dieser Einführung und im Kapitel 1 dieses Buches. 
schen Gegebenheiten kritisiert wurden. ${ }^{12}$ Als Gegenentwurf zu diesem Ansatz wurde eine Konzeption der politischen Philosophie vorgeschlagen, die sich den politischen Phänomenen zuwendet, eine strikte Trennung zwischen Deskription und Präskription (oder Sein und Sollen) ablehnt und trotzdem normative Bestrebungen nicht aufgibt. Zur Bezeichnung dieses Ansatzes würde sich angesichts seiner jüngsten Entwicklung der Ausdruck „Neu-Realismus“ anbieten. Jedoch scheint mir der innovative Kern dieses Ansatzes besser durch die von mir vorgeschlagene Bezeichnung „kritischer Realismus“ zur Geltung gebracht zu werden. ${ }^{13}$ Denn seine Spezifizität besteht darin, eine kritische Distanz zum Untersuchungsgegenstand aufrechtzuerhalten, ohne auf externe, transzendente Ideale und Werte zu rekurrieren. Anders ausgedrückt ermöglicht es ein solcher Ansatz, von den - normativ geprägten - politischen Fakten auszugehen und diese gleichzeitig infrage stellen zu können.

Dieser Ansatz hat sich zwar wie erwähnt als Strömung der politischen Philosophie konstituiert, er ist aber inhärent interdisziplinär. Demensprechend ist auch dieses Buch, obwohl in der politischen Philosophie verortet, durch Interdisziplinarität geprägt. Insbesondere bestehen in der vorliegenden Untersuchung Überschneidungen mit angrenzenden Disziplinen innerhalb der Rechtswissenschaften sowie mit der Technikphilosophie.

Berührungspunkte mit den Rechtwissenschaften bestehen vor allem im disziplinären Feld der Rechtsphilosophie, -theorie und -geschichte. Denn in der vorliegenden Abhandlung erfolgt die Identifizierung der Prinzipien der Legitimität in Bezug auf die Theorie des demokratischen Rechtsstaates und der Grundrechte und durch deren Kontextualisierung im Rahmen der „kopernikanischen Wende“ 14 der Neuzeit, durch die das Individuum, seine Grundrechte und seine Freiheiten ins Zentrum der politischen Legi-

12 Vgl. als Überblick Schaub, Jörg, Ideale und/oder nicht-ideale Theorie - oder weder noch? Ein Literaturbericht zum neuesten Methodenstreit in der politischen Philosophie, in: Zeitschrift für philosophische Forschung, 64/3, 2010, 393-409. Vertiefend dazu Kapitel 1 des Buches.

13 Diese Bezeichnung hat zudem den Vorteil, eventuelle Verwechslungen mit dem „neuen“ (ontologischen) Realismus, in primis durch den Philosophen Markus Gabriel geprägt, auszuräumen. Andererseits soll die Verwendung der Bezeichnung „kritischer Realismus“ nicht zu einer Verwechslung mit dem gleichnamigen epistemologischen Ansatz, der am prominentesten von Karl Albert vertreten wird, führen. Ausführlicher zur Abgrenzung von anderen „Realismen“ vgl. Kapitel 1 dieses Buches.

14 Bobbio, Norberto, Das Zeitalter der Menschenrechte: ist Toleranz durchsetzbar? Berlin: Wagenbach 1998, 48. 
timität gerückt sind. ${ }^{15}$ Darüber hinaus hat die Untersuchung der Fallbeispiele Einsichten in das EU-Recht gefordert, insbesondere in Form einer intensiven Auseinandersetzung mit dem Primär- und Sekundärrecht der EU sowie der Berücksichtigung der Rechtsprechung des Europäischen Gerichtshofes. ${ }^{16}$

An die technikphilosophische Forschung knüpft diese Untersuchung dort an, wo sie sich mit Digitalisierungsphänomenen sowie mit dem Einsatz von big data und künstlicher Intelligenz für sicherheitspolitische Zwecke im RFSR auseinandersetzt. ${ }^{17}$ Tatsächlich spielt Digitalisierung in der Entwicklung des sicherheitspolitischen Ansatzes der EU eine konstitutive Rolle. Nicht nur bestehen die EU-Initiativen in diesem Bereich größtenteils in der Intensivierung und in dem Ausbau des Informationsaustausches durch die Einrichtung großer Datenbanken. Zusätzlich sind die neuesten und bedeutendsten Tendenzen der EU-Sicherheitspolitik, die sich in einer präemptiven Ausrichtung konkretisieren, den technischen Möglichkeiten von big data und künstlicher Intelligenz besonders affin. In dieser Hinsicht beeinflussen und verstärken sich technische und sicherheitspolitische Entwicklungen gegenseitig.

Die interdisziplinären Überschneidungen dieser Untersuchung könnten noch breiter aufgefasst werden, denn weitere Verknüpfungen bestehen mit den an sich interdisziplinären Feldern der new und critical security studies, der surveillance studies und der science and technology studies. An dieser Stelle begnüge ich mich mit dem Hinweis auf die Anbindung an das sich konstituierende interdisziplinäre Feld der zivilen Sicherheitsforschung, wozu sich dieses Buch als ein spezifisch philosophischer Beitrag versteht. ${ }^{18}$

15 Vgl. vertiefend Kapitel 2 des Buches.

16 Insbesondere in den Kapiteln 3-7 unten.

17 Vgl. insbesondere die Kapitel 6 und 8 des Buches.

18 Als Grundtexte dieser Forschungsrichtung sei hier auf folgende Publikationen hingewiesen: Gander, Hans-Helmuth et. al (Hg.), Resilienz in der offenen Gesellschaft: Symposium des Centre for Security and Society. Baden-Baden: Nomos 2012; Gander, Hans-Helmuth; Riescher, Gisela (Hg.), Sicherheit und offene Gesellschaft: Herausforderungen, Methoden und Praxis einer gesellschaftspolitischen Sicherheitsforschung. Baden-Baden: Nomos 2014; Zoche, Peter; Kaufmann, Stefan; Haverkamp, Rita (Hg.), Zivile Sicherheit. Gesellschaftliche Dimensionen gegenwärtiger Sicherheitspolitiken. Bielefeld: transcript Verlag 2011 und auf das European Journal for Security Research. Die hier vertretenen Disziplinen reichen neben der Philosophie unter anderem von der Soziologie über die Rechtswissenschaften, die Politikwissenschaften, die Informatik bis hin zur Psychologie und Volkswirtschaftslehre. 


\section{Aufbau des Buches}

Das Buch ist in drei Teile gegliedert. Jeder Teil bearbeitet einen der oben erwähnten Fragenkomplexe und widmet sich jeweils den theoretischen Grundlagen, den empirischen Fallbeispielen und den theoretischen und normativen Schlussfolgerungen der durchgeführten Fallstudien.

\subsection{Methodologische und theoretische Aspekte}

Teil I besteht aus zwei Kapiteln. Im ersten Kapitel stelle ich den Ansatz der Untersuchung dar. Wie oben erwähnt schließe ich mich dort den Autor_innen an, die politische Philosophie als ein realistisches Unterfangen verstehen, das sich intensiv mit den Phänomenen des Politischen auseinandersetzt. Meine Darstellung ist dabei gleichzeitig eine Re- und eine Konstruktion des realistischen Ansatzes. Denn einerseits systematisiere und strukturiere ich Aspekte des Denkens der ausgewählten Autor_innen. Dabei identifiziere ich die grundlegenden Charakteristika dieser Strömung, schärfe deren Konturen durch Abgrenzung zu ihren Gegenbegriffen und durch Vergleich mit korrespondierenden Aspekten des „klassischen“ Realismus. Darüber hinaus verankere ich diese Grundeigenschaften in den Werken der Autor_innen, die ich als Kernfiguren dieser Strömung identifiziere, nämlich die mit der Universität Cambridge in Verbindung stehenden Bernard Williams und Raymond Geuss sowie die, wie ich sie begreife, lettisch-US-amerikanische Realistin ante litteram Judith Sklar. ${ }^{19}$ Auf dieser Grundlage konstruiere ich andererseits einen kohärenten Ansatz - und dies ist der erste originelle Forschungsbeitrag dieses Buches -, der als solcher nicht bereits gegeben ist, und entwickle einige Aspekte der Werke der genannten Autor_innen weiter.

Nach meiner (Re-)Konstruktion ist dieser Ansatz zunächst dadurch charakterisiert, dass er seinen theoretischen und normativen Ausgangspunkt in der Politik selbst nimmt, anstatt an gegenüber der Politik externe, etwa moralische, Prinzipien zu appellieren. Dabei verzichtet dieser Realismus

19 Vgl. Williams, Bernard Arthur Owen, In the beginning was the deed: realism and moralism in political argument. Princeton, NJ: Princeton Univ. Press 2005; Geuss, Raymond, Kritik der politischen Philosophie: eine Streitschrift. Hamburg: Hamburger Ed. 2011 und Shklar, Judith N., Der Liberalismus der Furcht. Berlin: Matthes \& Seitz 2013 (Originalausgabe The Liberalism of Fear. Cambridge: Harvard University Press 1989). 
nicht auf Normativität: Politik ist nicht als reines Machtfeld konzipiert, sondern zu den grundlegenden politischen Kategorien gehört, neben Macht, auch ihr normatives Korrelat, nämlich Legitimität. Legitimität wird konsequenterweise als eine genuin politische Kategorie verstanden, die dort entsteht, wo sich Macht als politische Macht konstituiert. Denn politisch ist eine Macht nur dann, wenn sie einerseits Ordnung und Sicherheit garantiert und andererseits sicherstellt, dass sie dabei nicht die gleichen Übel reproduziert, die sie beseitigen sollte. Durch die erste Bedingung grenzt sich politische Macht von einem anarchischen Zustand, durch die zweite von einer „Terrorherrschaft“ ab. Eine Macht ist dann politisch, wenn sie den Legitimitätsanspruch erhebt, Ordnung und Sicherheit zu garantieren und dabei nicht „Teil des Problems“ ${ }^{20}$ das sie beseitigen sollte, zu werden. Damit ist ein Zustand gemeint, der durch Unsicherheit, Terror und andere grundlegende Grundrechtsverletzungen geprägt ist. Hierbei wird meiner Ansicht nach die erste Stärke dieses Ansatzes deutlich, die darin besteht, auf den individualistischen Prämissen der oben erwähnten "kopernikanischen Wende" der Neuzeit zu bestehen, ohne dabei die Legitimität einer politischen Ordnung an den hypothetischen Konsensus der Individuen rückzubinden. ${ }^{21}$ Diese Stärke ist im Kontext der vorliegenden Abhandlung besonders fruchtbar. Denn, wie ich im ersten Teil andeute und im letzten Kapitel des Buches weiter ausführe, die Gründung der Legitimität in dem hypothetischen Konsensus der Normenadressaten führt zu einer Eingrenzung der Kontestationsmöglichkeiten. Diese sind jedoch angesichts der gegenwärtigen Entwicklungen der EU-Sicherheitspolitik unverzichtbar, um Macht effektiv einzuschränken und dabei zu vermeiden, dass Sicherheitsmaßnahmen „Teil des Problems“ werden. ${ }^{22}$

Darüber hinaus besteht meines Erachtens eine weitere Stärke des gegenwärtigen realistischen Ansatzes in seinem kritischen und transformativen Potenzial. Deswegen schlage ich im ersten Kapitel den Ausdruck „kritischer Realismus" als treffende Bezeichnung dieser Strömung vor. Denn trotz der Verankerung in der Realität verzichtet dieser Ansatz, wie bereits angedeutet, nicht auf eine kritische Überprüfung der gegebenen Zustände. Das wird durch die Ausübung einer Kritik ermöglicht, die nicht den Anspruch hat, den kritisierten Zustand zu transzendieren. Dabei kann der

20 Williams, In the beginning was the deed, 4, Übersetzung E.O.

21 Vgl. Kapitel 1, Abschnitt 2.1.

22 Vgl. Kapitel 2, Abschnitt 5.2 und Kapitel 9, Abschnitt 4. 
kritische Realismus an normativ gültigen Prinzipien festhalten, obne diese als objektiv, letztbegründet, universell und rational begreifen zu müssen..$^{23}$

Obwohl diese Konzeption der Kritik bereits in den Werken der genannten Autor_innen vorhanden ist, erscheint sie mir bislang nur im Ansatz entwickelt. Daher verdeutliche ich im ersten Kapitel, wie diese Konzeption der Kritik konkret entfaltet werden kann. ${ }^{24}$ Dabei baue ich auf die Hinweise der realistischen Autor_innen auf die genealogische Vorgehensweise Michel Foucaults als „historische Auflösung “25 von Selbstverständlichkeiten auf und verknüpfe diese mit Rahel Jaeggis Konzept der immanenten Kritik. ${ }^{26}$ In der Entfaltung des realistischen Ansatzes in eine konsequent normativkritische Richtung besteht der zweite wichtige Forschungsertrag dieser Untersuchung. Denn eine der schwerwiegendsten Kritiken gegen den realistischen Ansatz besteht in dem Vorwurf des Konservativismus, wonach er normativ in den faktischen Gegebenheiten verfangen bleiben würde und nicht in der Lage wäre, diese kritisch zu hinterfragen. ${ }^{27}$ Dabei argumentiere ich nicht nur, dass es möglich ist, aus einer realistischen Perspektive kritische Distanz gegenüber den untersuchten Realitäten zu gewinnen, sondern zeige durch meine Abhandlung auch, wie eine solche realistisch-kritische Analyse konkret durchgeführt werden kann.

Diese Konkretisierung beginnt im zweiten Kapitel, in dem ich die grundlegenden normativen Prinzipien erarbeite, die als Grundlage der kritischen Überprüfung der analysierten Maßnahmen gelten. Gemäß den realistischen Prämissen der Untersuchung identifiziere ich die Legitimitätsprinzipien, die hier und jetzt für die EU normativ gelten, anstatt eine ideale Theorie der Legitimität zu entwickeln. ${ }^{28}$ Nachdem ich verschiedene konkurrierende Legitimationsmodelle besprochen habe, wie das internationale, das technokratische, das rechtfertigungsbasierte und das demokratisch-rechtsstaatliche Paradigma, stelle ich fest, dass das Modell des demokratischen Rechtsstaates nunmehr die primäre Quelle der Legitimationsprinzipien der EU-Sicherheitspolitik liefert. Dabei meine ich nicht, dass sich die institutionelle Architektur der EU an diejenige des demokratischen Rechtsstaa-

23 Vgl. Kapitel 1, insbesondere die Abschnitte 2.5 und 3.

24 Vgl. Kapitel 1, Abschnitt 3.

25 Geuss, Raymond, Kritik, Aufklärung, Genealogie, in: Deutsche Zeitschrift für Philosophie, 50/2, 2002, 273-282, hier 278.

26 Vgl. Foucault, Michel, Was ist Kritik? Berlin: Merve 1992; Jaeggi, Rahel, Was ist Ideologiekritik?, in: Jaeggi, Rahel; Wesche, Tilo (Hg.), Was ist Kritik? Frankfurt am Main: Suhrkamp 2009, 266-295.

27 Vgl. Kapitel 1, Abschnitt 4.

28 Vgl. Kapitel 2, insbesondere Abschnitte 1 und 3. 
tes angleichen soll, um legitime Macht in diesem Bereich auszuüben. Vielmehr liefern Rechtsstaatlichkeit und Demokratie die grundlegenden philosophischen Prinzipien der Legitimation der EU-Sicherheitspolitik. ${ }^{29}$

Diese Prinzipien rekonstruiere ich im zweiten Kapitel aus historischer und philosophischer Sicht. Nach dieser Rekonstruktion wurzeln sie in der individualistischen Wende der Neuzeit und drücken zwei philosophische Grundannahmen aus: den Machtpessimismus und den juristischen Optimismus. Nach dem ersten ist Macht gleichzeitig notwendig, um die Sicherung der Ordnung zu garantieren, und gefährlich, weil ihr eine konstitutive Neigung zur Ausdehnung innewohnt. Nach dem zweiten Prinzip bietet das Recht effektive Mechanismen, um diese Neigung der Macht einzugrenzen. ${ }^{30} \mathrm{Zu}$ diesen genuin rechtsstaatlichen Aspekten kommt im Legitimitätsmodell der EU ein weiteres Element hinzu: das Demokratieprinzip. Der philosophische Kern dieses Prinzips ist die kantische Idee der Autonomie des Menschen als Selbstgesetzgebung, wonach jedes Individuum nur an diejenigen Gesetze gebunden sein darf, denen es seine Zustimmung hätte geben können. ${ }^{31}$

Schließlich operationalisiere ich im zweiten Kapitel diese Legitimitätsprinzipien, um konkrete Legitimitätskriterien herauszuarbeiten. Diese Kriterien beziehen sich auf Rechtfertigung und Effektivität, Verfahrenskonformität und Rückwirkung auf die normative Ordnung und fungieren als Analyseraster der EU-Sicherheitsmaßnahmen, die ich im zweiten Teil des Buches näher beleuchte. ${ }^{32}$

\subsection{Analyse konkreter Sicherheitsmaßnahmen}

Der zweite Teil des Buches besteht aus fünf weiteren Kapiteln. Das dritte Kapitel dient als Einführung zu den Fallanalysen. Dort stelle ich sowohl historisch als auch begrifflich den europäischen RFSR dar. In diesem Kapitel untersuche ich im foucaultschen Sinne, wie ein marktwirtschaftliches Phänomen, nämlich die Realisierung der vier Grundfreiheiten des europäischen Marktes, als Sicherheitsproblem neu interpretiert wurde und wie

29 Vgl. Kapitel 2, Abschnitt 4.

30 Vgl. Kapitel 2, Abschnitt 5.1.

31 Vgl. Kant, Immanuel, Grundlegung zur Metaphysik der Sitten, hg. v. Kraft, Bernd; Schönecker, Dieter. Hamburg: Felix Meiner Verlag 2016 (zuerst veröffentlicht 1785) und Kapitel 2, Abschnitt 5.2.

32 Vgl. Kapitel 2, Abschnitt 6. 
diese Problematisierung eine Reihe von Wissens- und Machtmechanismen hervorgebracht hat, die sich mit der Lösung dieses Sicherheitsproblems beschäftigt haben. Dabei zeige ich - und das ist das Hauptergebnis dieses Kapitels - wie der RFSR sich zu einem ,europäischen Raum der Inneren Sicherheit" 33 entwickelt hat und wie das Verhältnis zwischen den Elementen der Trias Freiheit - Sicherheit - Recht im Laufe der Zeit umgekehrt wurde, sodass das ursprünglich der Freiheit untergeordnete Ziel der Sicherheit Priorität vor den anderen beiden Elementen der Trias gewonnen hat. ${ }^{34}$

Die Kapitel 4, 5 und 6 analysieren jeweils ein paradigmatisches Beispiel der europäischen Zusammenarbeit im Bereich Justiz und Inneres: das Schengener Informationssystem (SIS), die Prümer Regelungen und die Fluggastdatensätze-Richtlinie. Das Schengener Informationssystem ist die älteste Datenbank der EU. Sie ist seit 1995 in Betrieb und ermöglicht den Behörden der Schengen-Mitgliedstaaten die automatisierte Fahndung nach Personen, die entweder polizeilich gesucht werden oder deren Einreise oder Aufenthalt im Schengener Raum nicht erlaubt wird. Kapitel 5 analysiert die Prümer Beschlüsse vom Jahr 2008, die den Austausch von daktyloskopischen und DNA-Daten zwischen den behördlichen Datenbanken der Mitgliedstaaten regeln. Schließlich widmet sich Kapitel 6 der Fluggastdatensätze-Richtlinie (auch PNR-Richtlinie), die seit Mai 2018 umgesetzt ist und die Speicherung, Weitergabe und Verarbeitung von Flugpassagierdaten vorschreibt. Nach einer historischen und inhaltlichen Einführung folgt für jedes Beispiel die Analyse anhand der Legitimitätskriterien, die ich im zweiten Kapitel fixiert habe.

Anhand des ersten Kriteriums der Rechtfertigung analysiere ich, wie diese Maßnahmen in Bezug auf ihren vorgegebenen Zweck und ihre Effektivität gerechtfertigt wurden. ${ }^{35}$ Gemäß dem zweiten Kriterium (Verfahrenskonformität) untersuche ich, ob die Maßnahmen nach Maßgabe der auf EU-Ebene gültigen Verfahren beschlossen und eingeführt wurden. Insbesondere gehe ich auf das Verhältnis zwischen Legislative, Exekutive und Judikative sowohl auf nationaler als auch auf europäischer Ebene, aber auch auf die Dynamik zwischen Interstaatlichkeit und Supranationalität ein. ${ }^{36}$ Schließlich frage ich anhand des dritten Kriteriums, wie die eingeführten Sicherheitsmaßnahmen auf die rechtlich-politische Ordnung der EU zurückwirken. Dabei beleuchte ich die theoretischen und normati-

33 „Die Europäische Sicherheitsagenda“, $\operatorname{COM(2015)~} 185$ final, 28.04.2015, 2.

34 Vgl. Kapitel 3, Abschnitte 3 bis 5.

35 Vgl. Kapitel 4, 5 und 6, jeweils Abschnitt 4.

36 Vgl. Kapitel 4, 5 und 6, jeweils Abschnitt 5. 
ven Implikationen der analysierten Maßnahmen. ${ }^{37}$ Ziel dieser Analyse ist es, im Sinne von Jaeggis immanenter Kritik, die Widersprüche hervorzuheben, die sich aus der Konfrontation der Sicherheitsmaßnahmen im RFSR mit den gültigen EU-Legitimitätsprinzipien ergeben.

Schließlich stellt das siebte Kapitel die Ergebnisse der Fallstudien in den Kontext der gesamten EU-Politik im RFSR und seiner neuesten Entwicklungen. Hier werden das aktuelle Gesamtbild des Informationsaustausches im RFSR sowie die für die Zukunft geplanten Ausbaumaßnahmen dargestellt. So baut die EU derzeit unter dem Stichwort „Interoperabilität“ Umfang und Vernetzung der Datenverarbeitung auf europäischer Ebene umfänglich aus. Dabei wird nicht nur die Vernetzung verschiedener Informationssysteme miteinander, sondern es werden auch die Suchmöglichkeiten anhand biometrischer Daten erheblich potenziert.

Ergebnis der Analysen dieses Teils ist, dass der sicherheitspolitische Ansatz der EU grundlegend im Spannungsverhältnis zu den eigenen Legitimitätsprinzipien steht. Nun liegt es aber nicht im Sinne des kritisch-realistischen Ansatzes, so wie ich ihn im ersten Teil des Buches (re-)konstruiert habe, es bei einer rein negativistischen Kritik zu belassen oder aber bloß eine vollständige Angleichung der defizitären Praxen mit den Legitimitätsprinzipien einzufordern. Vielmehr ist die Intention der immanenten Kritik als Vorgehensweise eines realistischen Ansatzes inhärent transformativ: Die aufgezeigten Widersprüche deuten nach diesem Ansatz auf eine notwendige Transformation hin, die sowohl die Praktiken als auch die Prinzipien selbst umschließt. Diesem transformativen Bestreben eines kritisch-realistischen Ansatzes gehe ich im dritten Teil des Buches nach.

\subsection{Von der Analyse zur Transformation}

Der dritte Teil des Buches besteht aus zwei Kapiteln.

Kapitel 8 fixiert die Grundcharakteristika des sich-profilierenden sicherheitspolitischen Ansatzes der EU auf allgemeiner Ebene. Dieser Ansatz ist durch zwei Eigenschaften gekennzeichnet: Zirkularität und Präemption.

Zirkularität wird besonders in der Logik sichtbar, die den Entwicklungsprozess der Sicherheitsmaßnahmen vorantreibt. Diese ist eine Logik der "Lückenschließung“: Durch die neu eingeführten Systeme werden Bereiche abgedeckt, die vorher nicht Gegenstand von Sicherheitsmaßnahmen waren. Doch dabei werden neue Sicherheitslücken identifiziert, wofür

37 Vgl. Kapitel 4, 5 und 6, jeweils Abschnitt 6. 
ein erhöhter Ressourceneinsatz benötigt wird. Da aber das Versprechen einer umfassenden Sicherheit nie eingelöst werden kann, wird sich auch der neue Ressourceneinsatz als defizitär und ergänzungsbedürftig erweisen. Dieses Paradoxon, auch als "Sicherheitsspirale“ bekannt, verstärkt die Eigenlogik der Sicherheitsmaßnahmen, die anhand der durchgeführten Analyse identifiziert wurde: Wurde dieser Mechanismus einmal eingeleitet, weitet sich die Reichweite der sicherheitsrelevanten Maßnahmen aus eigenem Antrieb aus, anstatt auf erhöbte äußere Bedrohungen oder Gefahren $z u$ reagieren. ${ }^{38}$ Anknüpfend an die philosophischen Grundprinzipien des Rechtsstaates, die ich im zweiten Kapitel fixiert habe, nämlich den Machtpessimismus und den juristischen Optimismus, kann diese Erkenntnis im Lichte des ersteren Prinzips verstanden werden: nämlich als Ausdruck der inneren Tendenz der Macht, sich auszuweiten. Die ausgeführte Analyse deutet darüber hinaus darauf hin, dass das andere grundlegende Prinzip, nämlich die machteingrenzende Funktion des Rechts (juristischer Optimismus), in diesem Fall nur partiell wirken konnte.

Die zweite Grundtendenz des aktuellen Sicherheitsansatzes besteht in seiner Transformation hin zu einem mehrheitlich präemptiven Sicherheitsparadigma. Im achten Kapitel schärfe ich die Konturen dieses Modells durch die Kontrastierung mit präventiven Ansätzen, mit denen sich präemptive Modelle die Ausrichtung auf die Zukunft teilen. Die beiden Modelle unterscheiden sich aber in Bezug auf Gegenstand, epistemische Strategien und Ziele. Die Spezifizität des präemptiven Modells besteht nach meiner Darstellung in der Fokussierung auf Anzeichen statt Ursachen, in der Aufstellung von Korrelationen statt kausaler Zusammenhänge, in der Verschiebung von Theorien zu Beobachtungen und von Diagnosen zu Prognosen sowie in der Intention, spezifischen Ereignissen zuvorzukommen, anstatt Phänomene als Ganze zu beseitigen.

Obwohl Ansätze dieser Art keine absolute Neuheit im Instrumentarium der Macht sind, haben ihnen die aktuellen technischen Entwicklungen im Zuge der Digitalisierung einen Schub verliehen. Die Durchforschung großer Datenmengen und die Möglichkeit, automatisiert Verbindungen und Korrelationen in diesen Datenmengen aufzuspüren, stellen die idealen technischen Voraussetzungen für die Entfaltung der erwähnten Charakteristika des präemptiven Sicherheitsansatzes dar. Zudem öffnen diese technischen Entwicklungen Möglichkeiten, die häufig den Horizont dessen, was die relevanten geltenden Normen zu regulieren suchen, transzendieren. Denn zu der Zeit, in der diese Normen formuliert wurden, gehörten

38 Vgl. Kapitel 8, Abschnitt 2. 
bestimmte Verfahren und Vorgehensweisen noch nicht zu den möglichen Szenarien.

Diese und weitere normative Implikationen des Modells erarbeite ich schließlich ebenfalls im achten Kapitel. Diesem Modell ist eine allumfassende Tendenz immanent: Denn das, was aus sicherheitspolitischen Gründen gesucht werden muss, wird nicht im Voraus vorgegeben. Vielmehr soll sich aus der Suche selbst die Richtung abzeichnen, in die weiter gefahndet werden soll. Das bedeutet, dass die Selektion der relevanten und $\mathrm{zu}$ beobachtenden Gegenstände nicht im Vorfeld stattfinden kann: Im Gegenteil sollen - und dank der digitalisierten Verfahren können heutzutage auch - möglichst viele Individuen oder Ereignisse erfasst werden. Zweitens sind präemptive Sicherheitsmaßnahmen durch eine Offenheit der Zwecke und Mittel gekennzeichnet. Denn um effektiv zu sein, dürfen sie nicht im Vorfeld übermäßig eingeschränkt werden; stattdessen müssen sie auf neue Erkenntnisse adaptierbar bleiben. Darüber hinaus sind diese Maßnahmen durch Opazität gekennzeichnet. Diese besteht in der NichtErklärbarkeit der Korrelationen, die zwischen Anzeichen und Prognosen erstellt werden, und in der Intransparenz der Maßnahmen zur Steigerung von deren Effektivität. Diese Eigenschaften des präemptiven Sicherheitsmodells, so meine These, stellen die demokratisch-rechtsstaatlichen Legitimitätsprinzipien vor Herausforderungen, die mit den aktuell vorhandenen Mechanismen nicht $z u$ bewältigen sind. ${ }^{39}$ Denn obwohl die Rationalität dieses Modells einigen rechtsstaatlichen Grundsätzen widerspricht, wie etwa demjenigen der Verhältnismäßigkeit, konnte es sich trotzdem durchsetzen und als prima facie legitim darstellen. Diese Maßnahmen konnten, trotz der Ausweitung der Machtbefugnisse und der Bedrohung der individuellen Rechte, die sie hervorbringen, legitimiert und nicht als „Teil-des-Problems“ angesehen werden.

Dies wurde durch die präemptive Deutung des sicherheitspolitischen Ansatzes ermöglicht. Denn die empirischen Gegebenheiten, anhand derer kein dramatischer Anstieg der Kriminalität bewiesen werden konnte, hätten eine solche Erhöhung des Sicherheitsbedarfs nicht rechtfertigen können. Durch die Umlenkung auf das präemptive Modell kann die Ernsthaftigkeit des Sicherheitsproblems in die Zukunft projiziert und plausibilisiert werden, ohne dafür den gewöhnlichen Einschränkungen unterliegen zu müssen, die zum Beispiel rechtlich in der Eingriffsschwelle der „konkreten Gefahr" und in den Einschränkungen des Verhältnismäßigkeitsgrundsatzes konkretisiert werden.

39 Vgl. Kapitel 8, Abschnitt 3.4. 
Wenn also die uns vertrauten rechtsstaatlichen Mechanismen der Logik der präemptiven Sicherheitsmaßnahmen kaum Widerstand leisten können, wie kann trotzdem garantiert werden, dass „die Lösung nicht Teil des Problems" wird? Die These, die ich im neunten Kapitel aufstelle, ist, dass es dafür ein Verständnis von Autonomie braucht, dessen Kern von der Selbstgesetzgebung auf die Möglichkeit der Infragestellung verschoben wird. ${ }^{40}$ Dies bedeutet nicht, dass die bestehenden rechtsstaatlichen Mechanismen überwunden werden sollen. Im Gegenteil: Sie stellen weiterhin unverzichtbare Elemente der Machteingrenzung und des Grundrechteschutzes dar. Damit sie aber diese Funktion weiterhin effektiv ausüben können, müssen sie durch eine revidierte Form der Autonomie als Möglichkeit der Infragestellung gestützt werden. Diese Konzeption ermöglicht eine Transformation der Prinzipien des demokratischen Rechtsstaats, die meiner Meinung nach den machteingrenzenden Mechanismen einen stärkeren Rückhalt bieten könnte.

Nach diesem Verständnis von Autonomie sind legitime Maßnahmen diejenigen, die rational begründbar sind und zusätzlich in einem gegebenen Kontext den konkreten Kritiken und Kontestationen Stand halten können oder sich durch diese modifizieren lassen. Kontrollmechanismen, die durch dieses Verständnis von Autonomie inspiriert werden, wären meiner Meinung nach eine wertvolle Ergänzung zu den aktuellen, um den präemptiven Charakter der EU-Sicherheitsmaßnahmen zu adressieren. Denn nach diesem Autonomieverständnis kann die Legitimität der Maßnahmen immerfort infrage gestellt werden und wird nur provisorisch bis zur nächsten Herausforderung durch Kritik festgehalten. Das scheint angesichts der Zukunftsausrichtung und Offenheit des präemptiven Ansatzes, wie ich ihn oben dargestellt habe, in besonderem Maße erforderlich zu sein.

Zum Schluss des neunten Kapitels hebe ich die Übereinstimmungen dieses Vorschlages mit dem realistischen Ansatz des Buches hervor und skizziere seine konkreten Implikationen für Entscheidungs- und Kontrollmechanismen. ${ }^{41}$ Abschließend erhelle ich die mögliche Bedeutung des vorgeschlagenen Ansatzes im breiteren Kontext der aktuellen Kontestationen, welche die EU als gesamtes Projekt erschüttern, und die Möglichkeit, die Vision von einem Europa als Raum des Wohlstandes und des Friedens zu wahren. ${ }^{42}$

40 Vgl. Kapitel 9, Abschnitt 4.2.

41 Vgl. Kapitel 9, Abschnitte 4.3 und 4.4.

42 Vgl. Kapitel 9, Abschnitt 5. 


\section{Teil I Eine in der Realität verankerte Normativität. Ansatz und theoretische Grundlagen der Untersuchung}

Wir sind auf Glatteis geraten, wo die Reibung fehlt, also die Bedingungen in gewissem Sinne ideal sind, aber wir eben deshalb auch nicht gehen können. Wir wollen gehen; dann brauchen wir die Reibung.

Zurück auf den rauhen Boden!

L. Wittgenstein, Philosophische Untersuchungen, $\mathbb{} 107$

Le plus fort n'est jamais assez fort pour être toujours le maitre, s'il ne transforme la force en droit et l'obéissance en devoir.

Jean-Jacques Rousseau, Du contrat social, ou principes du droit politique, III 


\section{Kapitel 1 Fakten und Normen: der kritisch-realistische Ansatz in der politischen Philosophie}

\section{Der „kritische Realismus“" eine (Re-)Konstruktion ${ }^{43}$}

Realismus hat eine lange Tradition in der Geschichte des politischen Denkens. Von Thukydides über Niccolò Machiavelli bis Karl Marx und Max Weber - um nur einige Vertreter zu nennen - hat der Realismus das politische Denken von der Antike bis zur Moderne geprägt. Als Ansatz der politischen Philosophie kann dieser „klassische“ Realismus als eine Kombination zweier Elemente charakterisiert werden. Er stellt zunächst eine grundlegende Stoßrichtung dar, welche die Beschreibung der politischen Fakten der Setzung von Idealen und ethischen Prinzipien vorzieht. Diese Stoßrichtung ist, zweitens, mit einer Konzeption des Politischen verbunden, wonach der Konflikt ein grundlegendes, endemisches und letztendlich nicht aufhebbares Charakteristikum der Politik ist. ${ }^{44}$

In der zweiten Hälfte des 20. Jahrhunderts ist jedoch ein solcher Ansatz in der politischen Philosophie in den Hintergrund geraten. Wenn in den Politikwissenschaften, und insbesondere in der Theorie der internationalen Beziehungen, realistische Ansätze auch weiterhin erfolgreich waren, so schien doch der Realismus im Bereich der politischen Philosophie mit

43 Hier wird vom Realismus als Strömung der politischen Philosophie gehandelt. Die Grenzen zu benachbarten Disziplinen, beispielsweise der Rechtsphilosophie und -theorie, sind jedoch häufig fließend, unter anderem aufgrund der Verschränkung von Macht und Recht, wie ich sie im zweiten Kapitel skizzieren sowie im zweiten Teil dieses Buches deutlich machen werde. Es würde den Rahmen dieses Buches sprengen, auf mögliche Parallelen zu einem realistischen Ansatz in der Rechtsphilosophie und in der Rechtstheorie einzugehen. Pars pro toto verweise ich hier auf Matthias Jestaedts Plädoyer für eine skeptische und realistische Theorie des Rechts, die viele Ähnlichkeiten mit dem hier vertretenen Ansatz aufweist. Einige dieser Berührungspunkte werde ich in diesem Kapitel weiter unten erwähnen. Vgl. Jestaedt, Matthias, Das mag in der Theorie richtig sein ... vom Nutzen der Rechtstheorie für die Rechtspraxis. Tübingen: Mohr Siebeck 2006.

44 Vgl. Portinaro, Pier Paolo, Grundsätzliches oder Selbstverständliches zum Politischen Realismus, in: Brodocz, André et al. (Hg.), Die Verfassung des Politischen. Festschrift für Hans Vorländer. Wiesbaden: Springer 2014, 351-362, hier 352 und Portinaro, Pier Paolo, Il realismo politico. Roma-Bari: Laterza 1999, 16, $26-29$. 
der dominanten normativen Ausrichtung schlichtweg unvereinbar. Nach der Prophezeiung des Todes der politischen Philosophie in den 1950er Jahren ${ }^{45}$ und nach ihrer baldigen Wiederbelebung dank der Rehabilitierung der Begründungsansprüche im praktisch-philosophischen Raum durch John Rawls ${ }^{46}$ prägten ideal-normativistische Ansätze die Ausrichtung der politischen Philosophie. Alternative Ansätze, wie etwa in Judith Shklars Liberalismus der Furcht verkörpert, existierten zwar, konnten sich aber nur begrenzt als eigenständige und selbstbewusste philosophische Tradition durchsetzen. ${ }^{47}$

Dieser Zustand scheint sich seit etwa der Jahrtausendwende zu ändern. Seitdem haben einige Philosoph_innen einen Ansatz entwickelt, der sich explizit als Gegenentwurf zu dem dominanten Paradigma der ideal-normativen politischen Theorie, dem „Moralismus“, versteht. Mittlerweile hat dieser gegenwärtige Realismus großes Interesse geweckt, sodass es auch im deutschsprachigen Raum eine zunehmende Zahl von Studien und Aus-

45 Vgl. Strauß, Leo, What Is Political Philosophy?, in: Strauß, Leo, What Is Political Philosophy? And other studies. New York: The Free Press 1968, 9-55 und Schaal, Gary S., Zwischenbetrachtung. Totgesagte leben länger. Über die Vitalität politischer Theorie und Philosophie in den USA nach 1945: Institutionelle und theoriegeschichtliche Aspekte, in: Brodocz, André; Schaal, Gary S. (Hg.), Politische Theorien der Gegenwart I. Opladen: Leske und Budrich 2002, 503-538.

46 Vgl. insbesondere Rawls, John, Eine Theorie der Gerechtigkeit. Frankfurt am Main: Suhrkamp 2012 (Originalausgabe A Theory of Justice, 1971). Weitere einflussreiche Vertreter dieses normativ-idealen Ansatzes sind Robert Nozick und Ronald Dworkin.

47 Vgl. Shklar, Der Liberalismus der Furcht. Ein weiteres Beispiel ist der sog. italienische Realismus, wozu etwa Norberto Bobbio und Danilo Zolo gezählt werden, vgl. Bobbio, Norberto, Democracy and dictatorship. The nature and limits of state power. Cambridge: Polity Press 1997; Zolo, Danilo, Die demokratische Fürstenherrschaft. Für eine realistische Theorie der Politik. Göttingen: Steidl 1997 und Buchstein, Hubertus; Jörke, Dirk, Das Unbehagen an der Demokratietheorie, in: Leviathan, 31/4, 2003, 470-495, hier 488. Für einige Autor_innen stellt der Realismus keine Erneuerung der politischen Philosophie dar, sondern ist eine Rückkehr zu einer Art, politische Philosophie zu betreiben, die vor dem „normativen Bruch“ üblich war. Vgl. Rossi, Enzo, Can Realism Move Beyond a Methodenstreit?, in: Political Theory, 44/3, 2016, 410-420; Scheuerman, William E., The realist revival in political philosophy. Or: Why new is not always improved, in: International Politics, 50/6, 2013, 798-814 und Rossi, Enzo; Sleat, Matt, Realism in Normative Political Theory, in: Philosophy Compass, 9/10, 2014, 689-701, hier 696-697. 
einandersetzungen mit ihm gibt. ${ }^{48}$ Eine systematische Charakterisierung dieses Realismus fehlt jedoch immer noch.

Eine erste Schwierigkeit auf dem Weg zu einer solchen Darstellung besteht darin, dass der Kreis der Denker_innen, die dieser neuen Ausrichtung angehören, nicht scharf konturiert ist. Ein zweites Problem ist, dass manchmal verschiedene Aspekte des gegenwärtigen Realismus miteinander gebündelt und vermischt, Begriffe unscharf oder in verschiedenen Darstellungen widersprüchlich benutzt werden. Drittens ist das Verhältnis des gegenwärtigen Realismus zu anderen realistischen Denkrichtungen, etwa zum Realismus in den internationalen Beziehungen oder zum „klassischen" Realismus, nicht immer klar definiert. ${ }^{49}$ Alle drei Schwierigkeiten in der Auffassung des gegenwärtigen Realismus haben nachvollziehbare Gründe, da der gegenwärtige Realismus in der politischen Philosophie selbst alles andere als eine klar definierte, kohärente und fest etablierte Schule darstellt.

48 Als Überblicksdarstellungen vgl. etwa Galston, William A., Realism in political theory, in: European Journal of Political Theory, 9/4, 2010, 385-411; Honig, Bonnie; Stears, Marc, The new realism: From modus vivendi to justice, in: Floyd, Jonathan (Hg.), Political philosophy versus history? Contextualism and real politics in contemporary political thought. Cambridge: Cambridge University Press 2011, 177205; Rossi; Sleat, Realism in Normative Political Theory; Schaub, Ideale und/oder nicht-ideale Theorie - oder weder noch? und Menke, Christoph, Weder Rawls noch Adorno? Raymond Geuss' Programm einer realistischen Philosophie, in: Deutsche Zeitschrift für Philosophie, 58/3, 2010, 445-455.

49 Ich werde das Verhältnis zwischen dem gegenwärtigen und dem „klassischen“ Realismus unten ausführlicher erörtern. Im Hinblick auf das Verhältnis des gegenwärtigen Realismus in der politischen Philosophie zu realistischen Ansätzen in den Theorien der internationalen Beziehungen gilt, dass der Realismus in der politischen Philosophie sich in Abgrenzung zu der realistischen Tradition in den internationalen Beziehungen definiert, die mit Namen wie Hans Morgentau, E. H. Carr und Reinhold Niebuhr assoziiert wird. Vgl. dazu Runciman, David, Political Theory and Real Politics in the Age of the Internet, in: Journal of Political Philosophy, 25/1, 2017, 3-21 und Geuss, Raymond, Realismus, Wunschdenken, Utopie, in: Deutsche Zeitschrift für Philosophie, 58/3, 2010, 419-429, hier 427. William E. Scheuerman hat die Lektüre des Realismus in den internationalen Beziehungen durch Raymond Geuss und Bernard Williams als simplifiziert kritisiert, vgl. Scheuerman, The realist revival in political philosophy. Der hier rekonstruierte Realismus ist zudem nicht mit erkenntnistheoretischen und ontologischen Ansätzen zu verwechseln, die als „realistisch“ bezeichnet werden. Dazu gehört der „kritische Realismus“ von Hans Albert sowie die durch Markus Gabriel geprägte philosophische Strömung des „neuen Realismus“. Der hier dargestellte kritische Realismus hat sich unabhängig von diesen Ansätzen entwickelt. 
Trotzdem bin ich der Überzeugung, dass eine fest umrissene und übersichtliche Darstellung des gegenwärtigen Realismus möglich ist. Ich werde daher auf den nächsten Seiten die grundlegenden Charakteristika des gegenwärtigen Realismus anhand eines Kerns von Autor_innen umreißen, die mir mit jeweils eigenen Akzenten in die gleiche Stoßrichtung zu zeigen scheinen. Dazu gehören zunächst der US-amerikanisch-britische Philosoph Raymond Geuss und der britische Philosoph Bernard Williams. Beide Autoren werden beinahe einstimmig als die prägendsten Figuren dieser Strömung bezeichnet. Da beide Autoren institutionelle Verbindungen mit der Universität Cambridge, an der sie lehrten, aufweisen, wird der gegenwärtige Realismus auch als "Cambridge realism" bezeichnet. ${ }^{50}$ Nach meiner Charakterisierung des kritischen Realismus gilt die lettischUS-amerikanische Politologin Judith Shklar als zentrale Vorläuferin (oder zeitgenössische Realistin ante litteram) dieser Denkrichtung. ${ }^{51}$

50 Runciman, David, What Is Realistic Political Philosophy?, in: Metaphilosophy, 43/1/2, 2012, 58-70, hier 62.

51 Das Werk Shklars hat zuletzt zunehmend Interesse geweckt, auch im deutschsprachigen Raum. Vgl. beispielweise den Schwerpunkt: Judith N. Shklars politische Philosophie, in: Deutsche Zeitschrift für Philosophie, 62/4, 2014; vgl. zudem die 2013 erschienene deutsche Übersetzung von Shklars Liberalism of Fear, die auch eine Diskussion durch Autor_innen wie u. a. Seyla Benhabib, Axel Honneth, Michael Walzer und Bernard Williams enthält: Shklar, Der Liberalismus der Furcht und den Schwerpunkt: Die politische Theorie von Judith N. Shklar, in: Zeitschrift für Politische Theorie, 9/2, 2018. Für eine breitere Auffassung des gegenwärtigen Realismus in der politischen Philosophie vgl. Galston, Realism in political theory und Sleat, Matt, Bernard Williams and the possibility of a realist political theory, in: European Journal of Political Theory, 9/4, 2010, 485-503. Galston und Sleat zählen zusätzlich zu den realistischen politischen Philosoph_innen Richard Bellamy, John Dunn, Bonnie Honig, Chantal Mouffe, Glen Newey, Mark Philp u. a. Seltener wird zusätzlich James Tully als realistischer Autor in die Diskussion des Realismus einbezogen, vgl. etwa Schaub, Jörg, Politische Theorie als angewandte Moralphilosophie? Die realistische Kritik, in: Zeitschrift für politische Theorie, 1, 2012, 8-24 und Honig, Bonnie; Stears, Marc, James Tully's Agonistic Realism, in: Tully, James, On Global Citizenship. London; New York: Bloomsbury Academic 2014, 131-153. Obwohl meines Erachtens Tully nicht zu den realistischen Kernautor_innen gehört, können einige seiner Argumente zur Stärkung des realistischen Ansatzes beitragen. Ich werde daher gelegentlich auf seine Schriften verweisen. Für eine kritische Diskussion der Zuordnung Shklars zum gegenwärtigen politischen Realismus vgl. Forrester, Katrina, Judith Shklar, Bernard Williams and political realism, in: European Journal of Political Theory, 11/3, 2012, 247-272. Forrester hat sich bemüht zu zeigen, dass Shklars realistische Positionen nicht durch eine Kritik am rawlsschen idealnormativen Ansatz motiviert sind. Obwohl dementsprechend die Abgrenzung zwischen ideal-normativen Ansätzen und Shklars Position nach Forrester weni- 
In diesem Sinne ist meine Darstellung gleichzeitig eine Re- und eine Konstruktion des Realismus. Denn einerseits systematisiere und strukturiere ich vorhandene Aspekte des Denkens der erwähnten Autor_innen, andererseits forme ich dabei einen kohärenten Ansatz, der als solcher nicht bereits gegeben ist, und entwickle diejenigen Aspekte, die mir ausbaufähig scheinen, über die Werke dieser Autor_innen hinaus. Bei der Rekonstruktion werde ich zudem zeigen, worin meiner Meinung nach die Besonderheiten des gegenwärtigen philosophischen Realismus in Abgrenzung zu anderen realistischen Ansätzen (und insbesondere zum „klassischen“ Realismus) bestehen. Denn obwohl die Bezeichnung „Realismus“ teilweise von diesen Autor_innen selbst benutzt wird, werden nicht nur Kontinuitäten, sondern auch Zäsuren zum klassischen Realismus deutlich. Bei der Weiterentwicklung des realistischen Ansatzes werde ich mich vor allem darauf konzentrieren, das kritische und transformative Potenzial dieser realistischen Strömung zu entfalten. Denn in diesem Potenzial liegt meiner Meinung nach die grundsätzliche Originalität des gegenwärtigen Realismus, wodurch er sich letztendlich am deutlichsten von anderen Formen des Realismus abhebt. Aus diesem Grund kann er am besten als „kritischer Realismus" bezeichnet werden, obwohl diese Bezeichnung nicht von den erwähnten Autor_innen selbst verwendet wird. Seine grundlegenden Aspekte werden in der folgenden Charakterisierung geschildert.

\section{Grundzüge des kritischen Realismus}

Die von mir vorgeschlagene Charakterisierung des gegenwärtigen Realismus fußt auf den folgenden fünf Grundelementen: (1) Priorität der Politik vor der Moral, (2) Priorität der (historischen) Fakten vor den Prinzipien, (3) Kontextgebundenheit, (4) Negativismus und (5) Immanenz der Leitprinzipien. Wie ich herausstellen werde, bestehen diese fünf Elemente mehr aus methodologischen Hinweisen als aus inhaltlichen Postulaten, weshalb diese neue Variante des Realismus auch als „methodologischer Realismus" bezeichnet werden kann. ${ }^{52}$ Für jeden Aspekt werde ich als

ger bedeutend erscheint als hier dargestellt, werde ich im Folgenden weiter auf Forresters Abhandlungen verweisen, weil sie nichtdestotrotz fruchtbare Hinweise für die Interpretation der Werke Williams' und Shklars liefern.

52 Für eine Diskussion der Frage, ob der gegenwärtige Realismus eine substanzielle Position oder eher eine methodologische Ausrichtung darstellt, vgl. Rossi; Sleat, Realism in Normative Political Theory, 695-696. Im Folgenden werde ich die 
erste Annäherung eine generelle Definition bieten. Anschließend werde ich jeden Aspekt spezifizieren, zunächst durch Abgrenzung zu dem für ihn spezifischen Gegenbegriff, zweitens durch Verweis auf die relevanten Stellen in den Werken der Vertreter_innen des gegenwärtigen Realismus und schließlich durch den Vergleich mit den korrespondierenden Aspekten des „klassischen“ Realismus.

\subsection{Die Priorität der Politik vor der Moral}

Das erste Grundprinzip des gegenwärtigen kritischen Realismus besteht in der Aufforderung an die politische Philosophie, von innerhalb der Politik her anzufangen. Sowohl die Fragen als auch die Antworten der politischen Philosophie sollen in Auseinandersetzung mit den spezifischen Charakteristika des Politischen erarbeitet werden.

Aus dieser Perspektive betrachtet setzt sich der Realismus dem Moralismus entgegen und manifestiert seinen Ursprung als Gegenentwurf zum rawlsschen Ansatz am deutlichsten. ${ }^{53}$ Der Kern des rawlsschen Ansatzes, den die Realist_innen kritisieren, besteht darin, zunächst eine kohärente moralische Theorie zu entwickeln, die grundlegende Prinzipien festlegt und ordnet sowie die Maßstäbe liefert, um in einem zweiten Schritt unsere soziale Realität zu bewerten und „gerechter“ zu gestalten. ${ }^{54}$ Politik erscheint somit als ein Anwendungsfeld der Ethik: Vorformulierte moralische Werte und Vorstellungen sollen im politischen Bereich realisiert werden. ${ }^{55}$ Dagegen soll eine realistische politische Philosophie vorrangig

Adjektive „kritisch“, „gegenwärtig“ und „methodologisch“ synonym zur Bezeichnung des von mir rekonstruierten Ansatz verwenden.

53 Für Williams ist Moralismus - verstanden als Ansatz, der der Moral Priorität vor der Politik verleiht - kein exklusives Problem von Rawls' Theorie (und den von ihm inspirierten Theorien) allein. Nach Williams vereint vielmehr der Moralismus den rawlsschen Ansatz mit dem Utilitarismus. Vgl. Williams, In the beginning was the deed, 1-3.

54 Vgl. Geuss, Kritik der politischen Philosophie, 18-22; Schaub, Ideale und/oder nicht-ideale Theorie - oder weder noch?, 394.

55 Vgl. Schaub, Politische Theorie als angewandte Moralphilosophie? Die realistische Kritik, 9. Zu der Frage, ob Rawls dieser Charakterisierung seines Ansatzes zustimmen würde, und dazu, wie Rawls Geuss' Einwände erwidern würde, vgl. Freyenhagen, Fabian; Schaub, Jörg, Hat hier jemand gesagt, der Kaiser sei nackt? Eine Verteidigung der Geussschen Kritik an Rawls' idealtheoretischem Ansatz, in: Deutsche Zeitschrift für Philosophie, 58/3, 2010, 457-477. Zur Verteidigung der Position Rawls' gegen die realistische Kritik vgl. Thomas, Alan, Rawls and 
mit Begriffen arbeiten, die das Spezifikum des Politischen ausmachen, wie Macht und sein „normatives Korrelat" ${ }^{\text {“ }} 56$ nämlich Legitimation. ${ }^{57}$

Was dies für eine realistische Konzeption von Politik bedeutet, wird aus der Gegenüberstellung der bekannten Behauptung von Rawls, Gerechtigkeit sei „die erste Tugend sozialer Institutionen“, 58 mit der "ersten politischen Frage“ von Williams ersichtlich. Nach Williams' Auffassung besteht diese darin, wie ein politisches System „Ordnung, Schutz, Sicherheit, Vertrauen und die Bedingungen der Kooperation"59 sichern kann. Diese ist „die erste politische Frage“, weil sie das Problem darstellt, das die Politik als erstes lösen muss. Die erste politische Tugend, so könnte Rawls paraphrasiert werden, ist daher Ordnung, nicht Gerechtigkeit. ${ }^{60}$

Die Erschaffung und Aufrechthaltung der Ordnung ist also für Williams eine notwendige Voraussetzung, um einen politischen von einem un- oder vorpolitischen Zustand zu unterscheiden. Sie ist aber noch keine hinreichende Bedingung, um eine politische Ordnung als solche anzusehen. Als solche unterscheidet die Sicherung der Ordnung eine politische Organisation von einem anarchischen Zustand, nicht aber notwendigerweise von anderen organisierten Formen der Koordination menschlichen Handelns. Schließlich, wie bekanntlich bereits Augustinus bemerkte, weisen auch „Räuberbanden“ eine bestimmte Form von Organisation und Koordinierung auf, denn auch sie sind „eine Schar von Menschen, geleitet vom Willen eines Führers, die durch einen Gesellschaftsvertrag zusammengehalten werden und die Beute nach einem Gesetz der Übereinkunft verteilen“. ${ }^{61}$

political realism: Realistic utopianism or judgement in bad faith?, in: European Journal of Political Theory, 16/3, 2017, 304-324 und Jubb, Robert, Playing Kant at the Court of King Arthur, in: Political Studies, 63/4, 2015, 919-934.

56 Williams, In the beginning was the deed, 77, Übersetzung E.O. Vgl. auch ähnlich: Geuss, Kritik der politischen Philosophie, 52-56, 124-128. Dazu Schaub, Politische Theorie als angewandte Moralphilosophie? Die realistische Kritik, 10.

57 Für eine kompakte Formulierung des Hauptarguments des Realismus und für einen Fokus auf Legitimität vgl. auch Runciman, What Is Realistic Political Philosophy?, 65-66.

58 Rawls, Eine Theorie der Gerechtigkeit, 19.

59 Williams, In the beginning was the deed, 3, Übersetzung E.O.

60 Diese wirkungsvolle Formulierung stammt von Galston, Realism in political theory, 388 .

61 Der vollständige Passus lautet: „Was sind schließlich Reiche ohne Gerechtigkeit andres als große Räuberbanden, da doch Räuberbanden auch nichts andres sind als kleine Reiche? Sie sind eben eine Schar von Menschen, geleitet vom Willen eines Führers, die durch einen Gesellschaftsvertrag zusammengehalten werden und die Beute nach einem Gesetz der Übereinkunft verteilen. Wächst solch eine üble Bande durch den Beitritt verworfener Menschen derart an, daß sie Gebiete 
Der Unterschied zwischen einer politischen Organisation und anderen Systemen, die zu einem gewissen Grad auch Ordnung sichern und menschliche Kooperation ermöglichen, ist dementsprechend woanders zu suchen. Williams weist den Weg dorthin, indem er argumentiert, dass zur Lösung des ersten politischen Problems auch die Garantie gehört, dass diese Lösung „nicht Teil des Problems wird“.62 Die politische Ordnung soll dabei vermeiden, die gleichen grundsätzlichen Übel zu reproduzieren, die sie eigentlich beseitigen soll, nämlich „physischen Zwang, Folter, Erniedrigung, Leid und Tod". ${ }^{63}$ Eine politische Ordnung muss also auch diese zweite Voraussetzung erfüllen, woraus sich die Bedingungen ihrer Legitimität ergeben. Williams' Gedankengang weist eine gewisse Zirkularität auf, wenn er diese Bedingung als notwendig für die Unterscheidung zwischen einem legitimen Staat und einer Terrorherrschaft bezeichnet. Wie ich gezeigt habe, kann aber diese Bedingung als notwendig für die Unterscheidung zwischen einem politischen und einem (organisierten, jedoch) nicht politischen Zustand erachtet werden, ohne die Bedingung der Legitimität durch die Bezeichnung des Staates als „legitim“ von vornherein vorauszusetzen. Williams scheint diese Interpretation zu unterstützen, indem er den möglichen Einwand, seine Bedingungen der Legitimität seien selbst moralische Prinzipien, dadurch entkräftet, dass er behauptet:

If it is [a moral principle], it does not represent a morality which is prior to politics. It is a claim that is inherent in there being such a thing as politics: in particular, because it is inherent in there being first a political question. ${ }^{64}$

besetzt, Niederlassungen gründet, Staaten erobert und Völker unterwirft, dann legt sie sich ganz unverhüllt den Namen ,Reich` bei, den ihr die Öffentlichkeit deshalb um so lieber zugesteht, weil ihr auf solche Weise ihre Habgier nicht verwehrt wird, sondern sich nur die Straflosigkeit erhöht. Darum war auch die Antwort fein und wahr, die ein ertappter Seeräuber jenem großen Alexander gab: Der König fragte, wie er denn dazu käme, das Meer unsicher zu machen. Da sagte der Mann in seinem freimütigen Stolz: , Machst du es mit dem Erdkreis anders? Ich freilich mit meinem winzigen Schiff werde Räuber genannt, aber dich mit der großen Flotte nennen sie den siegreichen Feldherrn.““ Augustinus, Der Gottesstaat, hg. V. Perl, Carl Johann. Paderborn: Ferdinand Schöningh 1979, Buch IV, 4.

62 Williams, In the beginning was the deed, 4, Übersetzung E.O.

63 Schaub, Politische Theorie als angewandte Moralphilosophie? Die realistische Kritik, 18.

64 Williams, In the beginning was the deed, 5. Williams scheint jedoch insgesamt zwischen diesen zwei Positionen zu schwanken: der ersten, zirkulären, wonach Legitimität die Bedingung einer legitimen Herrschaft sei, und der zweiten, wonach Le- 
Somit besteht die Stärke dieses Ansatzes darin, nicht nur die Kategorien der Macht und der Ordnung als charakteristisch für das Politische anzuerkennen, sondern auch darin, die Kategorie der Legitimität als konstitutiv für die Politik zu beweisen. Die normative Dimension der Legitimität muss nicht von außerhalb der Politik in den Bereich des Politischen eingeführt werden, sondern sie ist der Politik eigentümlich. ${ }^{65}$ Das Konzept der Legitimität und die Notwendigkeit für eine politische Organisation, sie zu berücksichtigen, sind in der Politik selbst begründet, weil sie genau in dem Moment entstehen, in dem sich politische Macht konstituiert. Anders ausgedrückt: Die Sicherung der gesellschaftlichen Ordnung, welche die erste Aufgabe einer politischen Macht ist, enthält gleichzeitig auch die Beschränkung der Macht selbst. Diese Beschränkung ist in Williams' Formel, dass die Lösung nicht „Teil des Problems“ werden darf, enthalten. Diese Bedingung der Legitimität ist somit begrenzt, bleibt aber gleichzeitig offen. Sie ist begrenzt, weil die Bedingung durch eine Einschränkung der Macht erfüllt werden muss (welche vermeidet, dass die Ausübung der Macht wieder Leid, Tod, Angst, Unsicherheit etc. herbeiführt). Sie ist aber auch gleichzeitig offen, weil sie nicht vorschreibt, wo die Grenze zu ziehen ist, nach der die Lösung „Teil des Problems“ wird.66

gitimität den Unterschied zwischen einer politischen Herrschaft und irgendeiner anderen Form der erfolgreichen Machtausübung markiere. Als Beispiel für die erste Position vgl.: „At the basic level, the answering of the ,first' question does involve a principle, the BLD [Basic Legitimation Demand, Anmerkung E.O.]. The approach is distinguished from that of PM [Political Moralism, Anmerkung E.O.] by the fact that this principle, which comes from a conception of what could count as answering a demand for justification of coercive power, if such a demand genuinely exists, is implicit in the very idea of a legitimate state, and so is inherent in any politics." Ebd., 8, Kursivsetzung E.O. Als Beispiel der zweiten Position vgl.: „The situation of one lot of people terrorizing another lot of people is not a political situation; it is, rather, the situation which the existence of the political is in the first place supposed to alleviate (replace).“ Ebd., 63, Kursivsetzung E.O.

$65 \mathrm{Zu}$ einer ähnlichen Interpretation der Konzeption von Williams, wonach der Legitimitätsanspruch der Politik inhärent ist, gelangen auch Sleat, Bernard Williams and the possibility of a realist political theory, 487, 493; Hall, Edward, Bernard Williams and the Basic Legitimation Demand: A Defence, in: Political Studies, 63/2, 2015, 466-480, hier 469 und Galston, Realism in political theory, 389. Den gleichen Gedanken, den ich hier in Anlehnung an Williams rekonstruiere, drückt auch Geuss aus, indem er behauptet, dass Macht in der politischen Praxis unvermeidbar mit Legitimierungsanstrengungen verflochten ist. Vgl. Geuss, Realismus, Wunschdenken, Utopie, 422.

66 Wie diese Legitimitätsbedingung von verschiedenen politischen Systemen erfüllt wird, ist, mit anderen Worten, historisch bedingt und kontextabhängig. Wil- 
Hiermit wird auch klar, dass für den gegenwärtigen Realismus die Forderung an die politische Philosophie, von innerhalb der Politik her ihren Ausgangspunkt zu nehmen, keinerlei Abwertung der Normativität impliziert. Priorität der Politik vor der Moral bedeutet weder vollständige Autonomie der Politik von der Moral noch die Unbedeutsamkeit der Moral für die Politik noch schließlich die apriorische Ablehnung moralischer Prinzipien. Wie Geuss dies auf den Punkt bringt, lehnt der methodologische Realismus den Vorrang der Moral bei der Beantwortung politischphilosophischer Fragen ab, jedoch nicht die Auffassung, dass Wertvorstellungen relevant für die Politik sind. Geuss stimmt sogar einer Konzeption der Politik als „angewandter Ethik“ zu, solange diese auf die allgemeine Behauptung der Nicht-Wertfreiheit der Politik beschränkt wird. ${ }^{67}$ Werteinstellungen spielen eine Rolle in der Politik und können das politische Handeln beeinflussen. Diese Wertvorstellungen sind aber, anders als von den idealen Theorien der Politik postuliert, in der menschlichen Realität „unausgegoren, veränderlich, unscharf umrissen und in ihrem Inhalt nur sehr grob artikuliert" und können daher nicht in einer konsistenten, widerspruchsfreien Theorie systematisiert werden, die das politische Handeln leiten soll. ${ }^{68}$

Wie erwähnt, geht das Werk Shklars der Diskussion über den methodologischen Realismus voraus. Dabei kann ihr Werk als eine ante-litteramVerwirklichung von dessen Prinzipien angesehen werden.

Rückwirkend betrachtet ist die Behauptung von der Autonomie der Politik gegenüber der Moral zumindest vereinbar mit Shklars Liberalismus

liams, der diese Auffassung teilt, gelangt jedoch letztendlich zu einem Legitimitätskern, der universal gilt. Mehr dazu unten Abschnitt 2.3.

67 Vgl. Geuss, Kritik der politischen Philosophie, 11.

68 Parallelen zur Rechtstheorie sind bei Jestaedt zu finden. Jestaedt betont im Hinblick auf die Rechtstheorie, dass diese „ein realistisches, d.h. den normativen (!) Realitäten [...] entsprechendes Bild zu zeichnen" hat. Jestaedt, Das mag in der Theorie richtig sein ... vom Nutzen der Rechtstheorie für die Rechtspraxis, 32. Zum Zusammenhang von Recht und Tatsachen vgl. ebd., 42 und Kelsen, Hans, Was ist juristischer Positivismus?, in: Juristenzeitung, 20/15/16, 1965, 465-468. Für das Verständnis von Recht als „normativem Faktum“ und den spezifischen Existenzmodus der Rechtsnormen, nämlich die Geltung, vgl. Jestaedt, Das mag in der Theorie richtig sein ... vom Nutzen der Rechtstheorie für die Rechtspraxis, 28 und Kelsen, Hans, Reine Rechtslehre. Einleitung in die rechtswissenschaftliche Problematik, hg. v. Jestaedt, Matthias. Studienausg. der 1. Aufl. 1934. Tübingen: Mohr Siebeck 2008, 22. 
der Furcht. ${ }^{69}$ Shklars Liberalismus ist dezidiert moralisch "eklektisch“, ${ }^{70}$ in dem Sinne, dass er sich zu keiner besonderen moralischen Theorie verpflichten muss. Diese politische Konzeption fußt etwa weder auf einer Theorie des moralischen Pluralismus, noch muss sie sich zwischen kantianischen und utilitaristischen Ethiken entscheiden. ${ }^{71}$ Der Liberalismus der Furcht nimmt sozusagen eine minimalistische moralische Position ein:

[...] er bietet [...] kein summum bonum, nach dem alle politischen Akteure streben sollten, sondern geht von einem summum malum aus, das wir alle kennen und nach Möglichkeit zu vermeiden trachten. Dieses Übel ist die Grausamkeit und die Furcht, die sie hervorruft, und schließlich die Furcht vor der Furcht selbst. ${ }^{72}$

Shklars philosophisch-politischer Vorschlag fußt auf diesen minimalistischen Gründen: Er setzt keine moralischen oder ideologischen Endziele voraus. Vor diesem Hintergrund steht Shklars Ansatz durchaus im Einklang mit der späteren Auffassung des methodologischen Realismus, dass politische Philosophie keine ihr vorrangige ausgearbeitete Theorie der Moral braucht.

In Anerkennung der Relevanz der Ethik wird die Distanz des gegenwärtigen Realismus zum klassischen Realismus offensichtlich. Wie Pier Paolo Portinaro ausgeführt hat, konkretisiert sich das Grundprinzip der Autonomie der Politik gegenüber der Moral in dem klassischen Realismus entweder in der Amoralität der Politik, in ihrer Immoralität oder in ihrer Sittlichkeit. ${ }^{73}$ Nach ersterer Auffassung darf Politik nicht nach moralischen Kriterien (etwa gerecht/ungerecht) evaluiert werden, sondern nur nach ihren eigenen Maßstäben, wie etwa Erfolg/Misserfolg. ${ }^{74}$ Moralische

69 Zusammengefasst kann die These von der Autonomie der Politik gegenüber der Moral in der „schwachen“ Formulierung des gegenwärtigen Realismus als Aufforderung verstanden werden, von der Politik selbst auszugehen, um die Politik $\mathrm{zu}$ verstehen und zu evaluieren.

70 Shklar, Der Liberalismus der Furcht, 46.

71 Vgl. ebd., 43-49.

72 Ebd., 43.

73 Vgl. Portinaro, Il realismo politico, 56-60.

74 Bekanntlich wurde diese Position von Machiavelli vertreten, vgl. Machiavelli, Niccolò, Der Fürst, hg. v. Rudolph, Enno. Hamburg: Meiner 2019, XVIII (Originaltitel De Principatibus, verfasst 1513, zuerst veröffentlicht als Il Principe, 1532) und Machiavelli, Niccolò, Discorsi. Gedanken über Politik und Staatsführung, hg. v. Zorn, Rudolf. Stuttgart: Kröner 1977, III, 41 (Originaltitel Discorsi sopra la prima Deca di Tito Livio, postum zuerst veröffentlicht 1531). Vgl. Portinaro, Il realismo politico, 56-57. 
und rechtliche Prinzipien sind nicht nur inadäquat für die Beurteilung politischen Handelns, sondern auch ineffektiv, um die Willkür und Exzesse der Macht einzugrenzen. ${ }^{75}$ Die zweite Auffassung, welche die Immoralität der Politik behauptet, geht von der Unvereinbarkeit der Handlungsmaximen der Politik und derjenigen der Moral aus. Moralische und politische Handlungsprinzipien sind gegensätzlich, und ethische Prinzipien sind für das politische Handeln sogar schädlich. ${ }^{76}$ Die letzte Position, welche die Sittlichkeit der Politik postuliert, verneint die Relevanz von Wertvorstellungen für die Politik nicht. Die relevanten Prinzipien sind aber nicht von der Ethik abzuleiten, die für das Handeln einzelner Menschen gilt. Politische Akteur_innen, in primis der Staat, haben ein eigenes Wertesystem, das demjenigen der einzelnen Menschen überlegen ist. An der Spitze eines solchen Systems steht typischerweise das Prinzip der Selbsterhaltung des Staates, in dessen Namen das Prinzip der individuellen Selbsterhaltung geopfert werden kann. ${ }^{77}$

In Bezug auf die ersten zwei Varianten von der Autonomie der Politik gegenüber der Moral ist der Unterschied zwischen dem klassischen und dem gegenwärtigen Realismus offensichtlich. Das, was die erste Variante des klassischen Realismus ausschließt (die Relevanz der moralischen Wertvorstellungen für das politische Handeln), wird vom gegenwärtigen Realismus akzeptiert, wie oben dargestellt. Was die zweite Variante der Autonomie der Politik gegenüber der Moral angeht, kann der Unterschied am besten wie folgt charakterisiert werden: Während der klassische Realismus die Unvereinbarkeit von Moral und Politik affirmiert, ist die Priorität der Politik vor der Moral im gegenwärtigen Realismus methodologisch gesetzt. Diese methodologische Voraussetzung gibt vor, wo die politische Theorie ihren Anfang nehmen soll (nämlich in der Politik selbst), bleibt aber in Bezug auf die Zielrichtung (Vereinbarkeit der politischen und moralischen Prinzipien) offen.

Der Unterschied zwischen dem alten und dem neuen Realismus ist aber in Bezug auf die dritte Modulation der Autonomie der Politik von der Moral, oben als „Sittlichkeit“ der Politik definiert, am bedeutendsten. Denn der gegenwärtige Realismus - und das ist meiner Meinung nach eines sei-

75 Vgl. Portinaro, Il realismo politico, 56-57.

76 Vgl. ebd., 58-59. Portinaro zeigt aber auch, dass diese Position selten in Reinform vertreten wird, sondern häufig mit der ersten These (von der Amoralität der Politik) kombiniert wird.

77 Vgl. ebd., 59-60. Die klarste Auslegung dieser Auffassung ist in Hegels Rechtsphilosophie zu finden. Vgl. Hegel, Georg Wilhelm Friedrich, Grundlinien der Philosophie des Rechts. Hamburg: Meiner 2015, $\$ 337$ (zuerst veröffentlicht 1820). 
ner entscheidendsten Merkmale - ermöglicht die Vereinigung der Priorität der Politik mit dem Individualismus. Indem das politische System, um genuin politisch zu sein, auch in der Ausübung der eigenen Macht - und nicht nur, wenn sie von anderen Akteur_innen ausgeht - die Erzeugung von Unsicherheit, Angst und Terror vermeiden soll, wird der Respekt vor dem Einzelnen und seiner Würde als mögliche Begründung der Legitimität in die Verfassung des Politischen selbst eingebaut. Es ist kein Zufall, dass Williams die „erste politische Frage“ in hobbesschen Begriffen formuliert. Denn bei Hobbes wird mit der individualistischen Auffassung der Politik der Bruch mit der antiken und mittelalterlichen Konzeption der Politik markiert, obwohl Hobbes selbst die Implikationen eines solchen Bruchs in seiner Theorie nicht entfaltet. ${ }^{78}$ Ebenfalls bedeutend ist die Auffassung von Williams, dass sein Ansatz zu einer Konzeption führt, die in die gleiche Richtung wie Shklars Liberalismus der Furcht geht, also zu einer liberalen

78 Über das Verhältnis seiner Theorie zur politischen Philosophie von Hobbes vgl. Williams, In the beginning was the deed, 3-4. Hobbes (vgl. Leviathan: oder Stoff, Form und Gewalt eines kirchlichen und bürgerlichen Staates) konzentriert seine Anstrengungen darauf, den politischen vom anarchistischen Zustand zu unterscheiden, ist aber weniger daran interessiert, den politischen Zustand von einer - mit Williams' Worten - „Terrorherrschaft“ klar zu differenzieren, sodass der Leviathan sich in einem absolutistischen Staat entfaltet. Williams' Ansatz unterscheidet sich aber, nach meiner Interpretation, genauso von Lockes Lösung des Problems der Machtbegrenzung (vgl. Zwei Abhandlungen über die Regierung, hg. v. Euchner, Walter. Frankfurt am Main: Suhrkamp 2006, zuerst veröffentlicht 1689). Für Locke sind die Grenzen der Macht bekanntlich durch die natürlichen Rechte des Individuums (Eigentum, Leben, Freiheit) definiert, also Rechte, die außerhalb der Politik (im Naturzustand) ihren Ursprung haben und von dort in den politischen Bereich überführt werden. Williams' Originalität besteht dagegen darin, die Legitimitätsbedingung zu setzen, ohne an extrapolitische Prinzipien zu appellieren, sondern als Lösung zu einem spezifisch politischen Problem. Williams' Ansatz hat zudem meiner Meinung nach gegenüber klassischen und neu-kontraktualistischen Theorien den Vorteil, dass er die problematische These, dass politische Gehorsam im Konsensus der Individuen begründet sei, vermeidet. Zur Diskussion des Problems des Konsensus als Basis der politischen Verpflichtung vgl. insbesondere Pateman, Carole, The Problem of Political Obligation. A Critical Analysis of Liberal Theory. Chichester: John Wiley \& Sons 1979; Simmons, Alan John, Justification and legitimacy: essays on rights and obligations. Cambridge: Cambridge University Press 2001; vertiefend zum Individualismus vgl. Kapitel 2 des vorliegenden Buches. Zur Frage, ob der Kompromiss-Begriff einen Ersatz für den Konsensus innerhalb einer realistischen politischen Philosophie bieten kann, vgl. Rossi, Enzo, Consensus, compromise, justice and legitimacy, in: Critical Review of International Social and Political Philosophy, 16/4, 2013, 557-572. Die wichtigen Implikationen der Abkopplung der Legitimität vom Konsensus werde ich im neunten Kapitel dieses Buches verdeutlichen. 
politischen Konzeption. ${ }^{79}$ In Hinblick auf die Konzeption der Beziehung zwischen Politik und Moral kann der gegenwärtige Realismus also auch als „schwacher" ${ }^{\text {80 }}$ Realismus bezeichnet werden, weil die behauptete Autonomie der Politik von der Moral viel unschärfer ist als in den früheren Varianten des Realismus. ${ }^{81}$

\subsection{Realismus als Empirismus: Zu den Fakten selbst! ${ }^{82}$}

Im vorigen Abschnitt habe ich das Verhältnis zwischen Politik und Moral so geschildert, wie es vom kritischen Realismus definiert wird. In diesem Abschnitt werde ich nun das Verhältnis zwischen Theorie und Praxis als Gegenstand einer realistischen politischen Philosophie erörtern.

Nach den Verfechter_innen des gegenwärtigen Realismus soll die politische Philosophie zuerst untersuchen, wie Politik in einer Gesellschaft tatsächlich gestaltet wird, wie Institutionen funktionieren und warum Menschen so handeln, wie sie handeln. Raymond Geuss hat das Motto einer solchen Philosophie in der Formel respice finem kondensiert. Dies

79 Über die Vereinbarkeit von moralischem Skeptizismus und politischem Liberalismus bei Williams und Shklar vgl. Sagar, Paul, From Scepticism to Liberalism? Bernard Williams, the Foundations of Liberalism and Political Realism, in: Political Studies, 64/2, 2016, 368-384.

80 So etwa Schaub, Politische Theorie als angewandte Moralphilosophie? Die realistische Kritik, 9.

81 Mit Christoph Menke gesagt, könnte die antinormativistische Auffassung des gegenwärtigen Realismus auch wie folgt charakterisiert werden: Sie ist keine antinormativistische Konzeption der Politik, sondern eine „antinormativistische Betrachtung der politischen Normativität“. Vgl. Menke, Christoph, Weder Rawls noch Adorno?, 448.

82 Die Anspielung auf Husserls bekanntes Schlagwort soll nicht als ein Parallelismus zwischen Phänomenologie und Realismus verstanden werden. Jedoch wurde die Nähe zur phänomenologischen Vorgehensweise bereits in Bezug auf Shklar hervorgehoben. Vgl. Liebsch, Burkhard, Bajohr, Hannes, Geschichte, Negativismus und Skepsis als Herausforderungen politischer Theorie: Judith N. Shklar, in: Deutsche Zeitschrift für Philosophie, 62/4, 2014, 633-659, hier 639. Für die Autoren ist Shklar eine „primär phänomenologisch vorgehende Autorin“, die „theoria" im Sinne Gadamers als „dabei sein und infolge dessen [sic] sehen lassen, was ist" betreibt, indem sie uns zuerst Beschreibungen anbietet und erst dann zu normativen Rekonstruktionen übergeht. Ebd., 644. Vgl. auch Gadamer, Hans-Georg, Lob der Theorie: Reden und Aufsätze. Frankfurt am Main: Suhrkamp 1983, 44-45. Zur Bedeutung von Husserls Ausspruch „zurück zu den Sachen selbst!" vgl. Waldenfels, Bernhard, Einführung in die Phänomenologie. München: Fink 1992, 17-19. 
wird aber nicht als Gebot verstanden, an den Tod zu denken, sondern als Aufforderung, „nicht bloß darauf“ zu schauen, „was sie sagen, denken, glauben, sondern darauf, was sie tatsächlich tun und was infolgedessen tatsächlich geschieht". ${ }^{83}$

In dieser Hinsicht lautet der Gegenbegriff zum Realismus „Idealismus“. Letzterer kann allgemein als eine „Orientierung des Denkens und des Handelns auf eine urbildliche ,Idee' oder [...] ein normatives Ideal" verstanden werden. ${ }^{84}$ Auf diesen Aspekt bezogen ist dann der methodologische Realismus eine Form von Empirismus. ${ }^{85}$ Er verweist auf die Grenzen dessen, was durch logische Ableitung und „reine Vernunft" erreichbar und beherrschbar ist, und erinnert uns an die Widersprüchlichkeit und Unreinheit der politischen Realität. ${ }^{86}$

Die Kontrastierung von Realismus und Idealismus betont einen anderen (wenn auch verwandten) Aspekt des Realismus als die oben erwähnte Abgrenzung von Politik und Moral, obwohl die beiden Aspekte häufig vermischt werden. Denn prinzipiell können sowohl eine moralische Theorie wie auch eine politische Theorie ideal oder realistisch (empiristisch) ausgerichtet sein, je nachdem, ob sie sich vorrangig mit Ideen und Idealen beschäftigen oder mit Fakten und Tatsachen. ${ }^{87}$ Natürlich muss sich jede politische Philosophie, wie jede Ethik auch, letztendlich auch mit Idealen

83 Geuss, Kritik der politischen Philosophie, 25.

84 Hoffmann, Thomas S., Idealismus, in: Hartmann, Martin; Offe, Claus (Hg.), Politische Theorie und Politische Philosophie. Ein Handbuch. München: C.H. Beck 2011, 26-30, hier 26.

85 Christoph Menke behauptet dagegen, der Realismus sei kein Empirismus. Vgl. Menke, Weder Rawls noch Adorno?, 447-448. Menke benutzt jedoch „Empirismus“ als Gegenbegriff zu „Normativismus“: Geuss' Realismus sei dementsprechend kein Empirismus, weil er nicht negieren würde, dass Normen, Prinzipien und Wertungen keinen Platz in der Politik hätten und dass Politik nur ein Macht- und Interessenspiel wäre. In der Substanz stimmt also Menkes Argument mit meiner Diskussion der Normativität des Realismus, wie ich sie oben geführt habe, überein (vgl. Abschnitt 2.1).

86 Diese Widersprüchlichkeit und Unreinheit gelten nämlich nicht nur für die Politik, sondern auch für das Recht, wie es Jestaedt prägnant auf den Punkt gebracht hat: „Recht kann auch gelten, wenn es unlogisch, ja widersprüchlich ist“, Jestaedt, Das mag in der Theorie richtig sein ... vom Nutzen der Rechtstheorie für die Rechtspraxis, 84.

87 Dass die beiden Ebenen (Priorität der Politik vor der Moral und die der Fakten vor Idealen) häufig vermischt werden, ist auch dem Umstand geschuldet, dass der gegenwärtige Realismus hauptsächlich als Gegenentwurf zum rawlsschen Ansatz entstanden ist, welcher gleichzeitig Moral über Politik und (als ideale Theorie) Prinzipien über Fakten priorisiert. 
und Prinzipien beschäftigen. Die Frage ist aber, wovon sie ihren Ausgangspunkt nimmt. Denn auch hier ist die Aufforderung des gegenwärtigen Realismus eine methodologische: Sie gibt den Ausgangspunkt vor - nämlich die Fakten -, schließt aber die Relevanz von Prinzipien und Ideen für die Politik nicht aus. Der Einstieg der politischen Philosophie erfolgt über das Handeln, gelangt aber über das Handeln zu Überzeugungen und Wertvorstellungen, die das Handeln beeinflussen. ${ }^{88}$

Die Priorität der Fakten und des Handelns für die politische Philosophie lässt zwei weitere Charakteristika einer realistischen politischen Philosophie in den Vordergrund rücken: die Zentralität der Institutionen und die heuristische Bedeutsamkeit der Geschichte.

Für den gegenwärtigen kritischen Realismus sind politische Institutionen keine Mittel zur Realisierung von im Voraus gesetzten Prinzipien, wie sie in einer ideal-ausgerichteten Theorie erscheinen. Vielmehr, indem sie allgemeine und abstrakte Prinzipien ausdifferenzieren und konkretisieren müssen, um sie in konkreten Praktiken durchzusetzen, beeinflussen sie selber aktiv die Gestaltung des öffentlichen Verständnisses von Werten und Prinzipien. ${ }^{89}$ Zudem sind Institutionen aus einer realistischen Perspektive deswegen wichtig, weil sie das politische Handeln strukturieren und die zentralen Mechanismen verkörpern, die der Ausuferung der Macht Einhalt gebieten können. Der kritische Realismus ist sich dabei gleichzeitig der Wichtigkeit und der Zerbrechlichkeit der politischen Institutionen bewusst: Komplexe institutionelle Mechanismen, wie eine „begrenzte Regierung und die Kontrolle ungleich verteilter politischer Macht" ${ }^{“ 90}$, sind unverzichtbar, um Individuen gegen Machtmissbrauch zu schützen. Sie bieten aber auch an sich keine Garantie gegen das, was Shklar „öffentliche“ oder „institutionalisierte Grausamkeit“ nennt. ${ }^{91}$

Ebenfalls wichtig für den kritischen Realismus ist die Geschichte: Politik ist immer „historisch verortet ${ }^{\text {(92 }}$ - nur die Geschichte kann nach dieser Auffassung den Schlüssel dafür liefern, um Politik zu verstehen.

88 Vgl. Geuss, Kritik der politischen Philosophie, 26.

89 Vgl. Galston, Realism in political theory, 393.

90 Shklar, Der Liberalismus der Furcht, 42.

91 Ebd., 44 und 45.

92 Geuss, Kritik der politischen Philosophie, 28. Ähnlich vgl. auch Williams, „political philosophy requires history" (In the beginning was the deed, 53) und Tully, der seinen Ansatz als „practical and historical“ definiert (Public Philosophy in a New Key [Ideas in Context]. Cambridge: Cambridge University Press 2008, 18). Diese Sensibilität für die historische Verortung der politischen Konzepte und Probleme eint den methodologischen Realismus und die sogenannte Cambridge historical 
Was die gegenwärtigen Realisten programmatisch zum Ausdruck bringen, tritt bereits im Werk von Judith Shklar hervor. Die politische Konzeption, die sie vertritt (nämlich den Liberalismus der Furcht), ist eine Reaktion auf „die unleugbaren Fakten“, die uns die „Weltgeschichte seit 1914“ präsentiert. Dazu gehören die Rückkehr der Folter als institutioneller Praktik und die „Schrecken der modernen Kriegsführung“ ${ }^{93}$ Diese Fakten und die Erfahrung des Machtmissbrauchs als historischer Konstante müssen die Reflexion über Politik begründen und leiten. Das politische Denken soll von der Erinnerung an die Übel der Vergangenheit geprägt sein und das Verständnis der Politik auf diese aufbauen:

Jedes Blatt im Buch der politischen Geschichte rechtfertigt die Annahme zur Genüge, dass es immer Vertreter staatlicher Behörden geben wird, die sich im Großen wie im Kleinen regelmäßig gesetzwidrig und brutal verhalten werden, wenn man sie nicht daran hindert. ${ }^{94}$

Die konsequente Strategie des Liberalismus der Furcht fokussiert auf Schadensbegrenzung: Es müssen institutionelle Mechanismen geschaffen und am Leben gehalten werden, welche durch die Verteilung und Streuung der Macht Willkür und Brutalität abwenden können.95

Auch in diesem Fall ist ersichtlich, dass der gegenwärtige Realismus hauptsächlich als eine methodologische Ausrichtung zu verstehen ist: Er reduziert politische Philosophie nicht auf die Auflistung historischer Einzelfälle, noch verdammt er sie auf die Blickrichtung nach hinten, auf die Vergangenheit. Es ist möglich, auf die historische Reflexion aufzubauen, um diese für die Zukunft fruchtbar zu machen.

In Bezug auf die Zentralität der Geschichte ist eine klare Kontinuität zwischen dem klassischen und dem gegenwärtigen Realismus zu beobachten. Portinaro hat gezeigt, wie die Genese des Realismus in der Historiografie von Herodot und Thukydides zu verorten ist. Die epistemische Strategie des Realismus besteht auch in dessen alter Version in der Auseinandersetzung mit der Geschichte: „[S]ein Erkenntnismittel ist reflektieren-

school, vgl. Galston, Realism in political theory, 386. Andere Autor_innen sprechen wie erwähnt von einem „Cambridge realism“, wozu Raymond Geuss, John Dunn und Bernard Williams zählen, vgl. Runciman, What Is Realistic Political Philosophy?, 62 und als Referenzwerke: Geuss, Kritik der politischen Philosophie; Dunn, John, The cunning of unreason: making sense of politics. New York: Basic Books 2003; Williams, In the beginning was the deed.

93 Shklar, Der Liberalismus der Furcht, 40.

94 Ebd., 41.

95 Vgl. ebd., 42-43, 48. 
de Urteilskraft, eine Form der Erkenntnis, die nicht aus der Logik, sondern aus der Geschichte gelernt wird. “96

Auch in Bezug auf die Rolle der Institutionen ist es möglich, eine gewisse Kontinuität zwischen dem klassischen und dem gegenwärtigen Realismus zu erkennen. Der klassische Realismus ist durch das Bewusstsein der Zerbrechlichkeit der Institutionen geprägt. Historisch hat er aber eine ausdifferenzierte Auffassung der politischen Institutionen entwickelt, die letztendlich als ein wichtiges Instrument der Stabilisierung der politischen Macht angesehen werden. Die klassische realistische Konzeption der Institutionen wird ebenso wie die gegenwärtige, aber dezidierter durch eine materielle (statt formelle) Ausprägung charakterisiert. Ihr ist stets bewusst, dass hinter den Institutionen Menschen stehen, von denen das aktuelle Funktionieren der Institutionen abhängt, dass politische (oder exekutive) Institutionen wichtiger sind als die Kontrollinstanzen und dass Institutionen auf materiellen Zuständen fußen, die häufig durch Konflikt, Chaos und Irrationalität geprägt sind. ${ }^{97}$

\section{3 „Im Anfang war die Tat“: die Kontextgebundenheit der politischen Philosophie}

Für den gegenwärtigen Realismus sind Fakten nicht nur aus einer deskriptiven Perspektive wichtig, sondern auch normativ bedeutend. Denn die Geschichte liefert nicht nur die Mittel, um unsere Gegenwart zu verstehen,

96 Portinaro, Il realismo politico, 33, Übersetzung E.O. Vgl. auch Portinaro, Grundsätzliches oder Selbstverständliches zum Politischen Realismus, 353-354, 359. Die Historiografie von Thukydides wird auch explizit von Williams und Geuss als Vorbild deklariert: vgl. Geuss, Raymond, Outside Ethics. Princeton: Princeton University Press 2009, 219-233 und Williams, Bernard Arthur Owen, Scham, Schuld und Notwendigkeit: eine Wiederbelebung antiker Begriffe der Moral. Berlin: Akademie Verlag 2000.

97 Vgl. Machiavelli, Discorsi, I, 2; für eine Rekonstruktion des machiavellischen Realismus vgl. Ritter, Gerhard, Die Dämonie der Macht. Betrachtungen über Geschichte und Wesen des Machtproblems im politischen Denken der Neuzeit. München: Leibniz-Verlag 1948. Für eine realistische Konzeption der politischen Institutionen vgl. auch Portinaro, Il realismo politico, 104-110; Portinaro, Grundsätzliches oder Selbstverständliches zum Politischen Realismus, 358-359 und Zolo, Die demokratische Fürstenherrschaft. 
sondern auch die normative Ausrüstung, um zu verstehen, was als „richtig“ oder "legitim“ gilt. ${ }^{98}$

Williams drückt dieses Prinzip des methodologischen Realismus durch eine Neudeutung des faustischen „Im Anfang war die Tat“ aus. Nach Williams kann die politische Theorie nicht allein entscheiden, was als legitim gilt, sondern sie muss dafür Bezug auf konkrete Praktiken nehmen. Legitimitätskonzeptionen sind, mit anderen Worten, eingebunden in die historischen Gegebenheiten:

No political theory, liberal or other, can determine by itself its own application. The conditions in which the theory or any given interpretation of it makes sense to intelligent people are determined by an opaque aggregation of many actions and forces. ${ }^{99}$

Der gegenwärtige Realismus kann in dieser Hinsicht als eine Form von Kontextualismus verstanden werden - den Gegenbegriff dazu bildet dann der Universalismus. Der Anti-Universalismus des gegenwärtigen Realismus hat aber eine schwache, hauptsächlich methodologische Natur. Er verneint nicht die Möglichkeit, allgemeine Aussagen zu treffen oder allgemeine Prinzipien festzulegen. Doch erstens dürfen diese nicht aus höheren Prinzipien abgeleitet werden. Stattdessen müssen sie durch die Auseinandersetzung mit Fakten und den historischen Erfahrungen erarbeitet werden. Wie Axel Honneth es in Bezug auf Shklars Werk ausgedrückt hat, sind generelle Aussagen „legitim nur auf dem Weg des Herauspräparierens von Gemeinsamkeiten zwischen möglichst vielen Einzelfällen zu gewinnen“. ${ }^{100}$ Zweitens können abstrakte, allgemeine Prinzipien allein keine Maximen für das Handeln liefern: Konkrete Lösungen für spezifische Probleme können nur unter Berücksichtigung des Kontextes erarbeitet werden. ${ }^{101}$

98 Vgl. Geuss, Kritik der politischen Philosophie, 47-56 und Williams, In the beginning was the deed, 62-74.

99 Williams, In the beginning was the deed, 28.

100 Honneth, Axel, Vorwort, in: Shklar, Der Liberalismus der Furcht, 7-25, hier 10. Dieses methodologische Vorgehen vereint, wie auch Honneth unterstreicht, Shklar und Arendt. Vgl. vertiefend Arendt, Hannah, A Reply, in: The Review of Politics, 15/1, 1953, 76-84 und Orrù, Elisa, The Schengen Information System and Data Retention. On Surveillance, Security and Legitimacy in the European Union, in: Orrù, Elisa; Porcedda, Maria Grazia; Weydner-Volkmann, Sebastian (Hg.), Rethinking Surveillance and Control. Beyond the "Security vs. Privacy" Debate. Baden-Baden: Nomos 2017, 115-136, hier 119-120.

101 Vgl. Galston, Realism in political theory, 396. In eine ähnliche Richtung die Wichtigkeit der Kontextualisierung im Bereich der Rechtstheorie betonend vgl. 
Wenn sich der gegenwärtige Realismus in dieser Hinsicht vom Universalismus distanziert, pflegt er gleichzeitig nicht in eine Form von Relativismus zu geraten. Williams arbeitet eine sehr ausdifferenzierte Position aus, die darauf abzielt, die vorgeschlagene Form von Kontextualismus als nicht universalistisch und gleichzeitig als nicht relativistisch zu charakterisieren. Er lehnt das ab, was er als „Falle des Universalismus“ bezeichnet, nämlich die Überzeugung, dass eine korrekte moralische oder politische Theorie für alle Zeiten und Menschen gelten muss. ${ }^{102}$ Wenn das nicht der Fall ist, so der Rückschluss des Universalismus, dann ist die Theorie falsch und sollte aufgegeben werden - oder, wie Williams mit Bezug auf Rorty schlussfolgert, sollten wir sie in der Praxis aufrechterhalten, aber uns theoretisch davon distanzieren. ${ }^{103}$

Um diese Entweder-oder-Alternative zu umgehen, schlägt Williams eine Unterscheidung zwischen normativen und evaluativen Auffassungen - etwa in Bezug auf die Legitimität einer Herrschaftsform - vor. Wenn wir eine Autorität als legitim anerkennen, tun wir es in einem normativen Sinn, einem Sinn, den wir als Orientierung für unser Handeln anerkennen. Diese „interne“ Art, eine Form von Autorität als sinnvoll anzuerkennen (als sinnvoll „für uns“), unterscheidet sich von einer evaluativen, aber nicht normativen Art, in der wir eine Autoritätsform als sinnvoll in Bezug auf einen anderen Kontext anerkennen. In diesem zweiten Fall sehen wir die „sinnvolle“ Autoritätsform nicht als Orientierung für unser Handeln. ${ }^{104}$

Jestaedt, Das mag in der Theorie richtig sein ... vom Nutzen der Rechtstheorie für die Rechtspraxis, 78-79.

102 Das hat auch die Konsequenz, dass nach dieser Auffassung diejenigen, die die Richtigkeit der Theorie nicht anerkennen, sich irren oder irrational sein müssen. Vgl. Williams, In the beginning was the deed, 68-69.

103 Vgl. ebd.

104 Vgl. ebd., 9-11. Hier ist Williams Polemik hauptsächlich gegen Habermas gerichtet. Williams teilt bis zu einem gewissen Grad Habermas' Prämisse, dass die Untersuchung moderner Gesellschaften sich zwischen „Faktizität und Geltung“ bewegen sollte. Jedoch kritisiert er die universalistischen Züge, die Habermas' Theorie annimmt, und insbesondere lehnt er dessen Auffassung ab, wonach nur liberal-demokratische Staaten legitim seien (vgl. Habermas, Jürgen, Faktizität und Geltung: Beiträge zur Diskurstheorie des Rechts und des demokratischen Rechtsstaats. Frankfurt am Main: Suhrkamp 1998). Für Williams hat es durchaus nicht liberale Autoritätsformen gegeben, die legitim waren. 
Aufgrund dieser Unterscheidung wurde Williams für einen Kommunitaristen gehalten. ${ }^{105}$ Diese Zuordnung ist aber irrtümlich, denn die Linie, die Williams zwischen „wir“ und den „anderen“ zieht, ist vielmehr historisch als kulturell, vielmehr politisch gesetzt als gegeben. ${ }^{106}$ Weder behauptet er vereinfachend, dass für jede Gesellschaft dasjenige das Gute ist, was sie dafür hält, noch versteht er Gesellschaften als homogen und in sich geschlossene Einheiten:

Confronted with a hierarchical society in the present world, we cannot just count them as them and us as us: we may well have reason to count its members as already some of "us". ${ }^{107}$

Eine relativistische Haltung ist für Williams nur insofern gerechtfertigt, als die Umstände, die wir beurteilen, außerhalb unserer kausalen Reichweite sind, weil sie, zum Beispiel, in der Vergangenheit liegen. Williams verdeutlicht das mit einem anschaulichen Beispiel:

Of course, we can imagine ourselves as Kant at the Court of King Arthur, disapproving of its injustices, but exactly what grip does this get on one's ethical or political thought? ${ }^{108}$

Dieses Schwanken zwischen Antiuniversalismus und Antirelativismus spiegelt sich auch in Williams' Konzeption der Legitimität wider. Einerseits schlägt Williams keine geschlossene Konzeption der Legitimität vor. Obwohl für ihn die liberale Lösung der Legitimitätsfrage die einzige ist, die "now and around here" 109 gültig ist, hat es historisch andere Formen legitimer Herrschaft gegeben. Die Tatsache, dass eine liberal-demokratische Form der Autorität heute als die einzig legitime erscheint, hat mit den historischen Bedingungen zu tun, welche seit der Aufklärung unsere Gesellschaft prägen. Andererseits kann nicht jede Form politischer Herrschaft als legitim gelten. Die Trennlinie liegt für Williams dort, wo die Lösung zur „ersten politischen Frage“ anfängt, selbst Teil des Problems zu wer-

105 Vgl. Hawthorn, Geoffrey, Introduction, in: Williams, Bernard Arthur Owen, In the beginning was the deed: realism and moralism in political argument. Princeton: Princeton University Press 2005, xi-xx, hier xiv. Vgl. auch Rossi; Sleat, Realism in Normative Political Theory, 695-696.

106 Vgl. insbesondere Williams, In the beginning was the deed, 68-69.

107 Ebd., vgl. auch S. 14.

108 Ebd., 66. Andererseits bedeutet die effektive Akzeptanz einer Autorität in einer bestimmten Gesellschaft nicht, dass diese Autorität auch legitim ist. Für die Möglichkeit einer immanenten Kritik vgl. unten Abschnitt 2.5.

109 Ebd., 8. 
den. Das passiert, wie ich bereits verdeutlicht habe, wenn die politische Autorität dieselben grundlegenden Übel verursacht, die sie beseitigen soll, nämlich: „die grundlegendsten Menschenrechtsverletzungen, Folter, Überwachung, willkürliche Verhaftungen und Mord“. ${ }^{110}$ Die Legitimation der politischen Autorität ist also direkt mit unserer Idee der Menschenrechte verbunden und impliziert die Vermeidung von grundlegenden Menschenrechtsverletzungen als ihren Kern. ${ }^{111}$

Hier besteht auch die einzige minimalistische und negativistische Spur von Universalismus in der Theorie von Williams. Sowohl für die Gegenwart als auch für die Vergangenheit gilt, dass „might is not per se right" ${ }^{112}$ dass eine Banditenbande noch keine politische Autorität ist, nur weil sie die Zwangsmittel besitzt, und dass eine politische Autorität ihren Adressat_innen Gründe schuldet, die erklären, warum sie die Lösung gegen eine Terrorherrschaft ist und nicht die Terrorherrschaft selbst.

Die Kontextgebundenheit der normativen Aussagen hat aber auch radikalere Implikationen auf der epistemischen Ebene. Denn das, was die Realisten damit infrage stellen, ist das grundlegende Postulat der Trennung von Sein und Sollen, die so fundamental für rawlssche Ansätze ist. ${ }^{113}$

Wenn nur die historischen und kontextuellen Gegebenheiten der politischen Philosophie den Schlüssel dafür liefern könnten, um das Legitime vom Illegitimen zu unterscheiden, dann würde eine strikte Trennung zwischen präskriptiven und normativen Aussagen die politische Theorie auf eine rein deskriptive Disziplin reduzieren. Der gegenwärtige Realismus verzichtet aber nicht auf die normative Dimension, stattdessen relativiert er die Trennung zwischen Sein und Sollen. Geuss hat diesen Aspekt des realistischen Ansatzes am klarsten verdeutlicht:

110 Williams, In the beginning was the deed, 69, Übersetzung E.O.

111 Vgl. Williams, In the beginning was the deed, 63 und Galston, Realism in political theory, 390. Obwohl hier Williams' Theorie besonders nah an Shklars politische Konzeption rückt, nimmt Shklar grundsätzlich eine viel offensivere universalistische Position ein. Vgl. Shklar, Der Liberalismus der Furcht, 43, 5457. Beide Autor_innen wurden aufgrund des Zulassens einer (wenn auch minimalistischen) universalistischen Konzeption der Menschenrechte als inkohärent kritisiert, vgl. Forrester, Judith Shklar, Bernard Williams and political realism, 265 und Flathman, Richard, In and out of the ethical: The realist liberalism of Bernard Williams, in: Contemporary Political Theory, 9/1, 2010, 77-98.

112 Williams, In the beginning was the deed, 69.

113 Die Trennung zwischen Sein und Sollen wurde bekanntlich durch David Hume geprägt, vgl. Hume, David, Ein Traktat über die menschliche Natur, hg. v. Brandt, Horst D. Hamburg: Meiner 2013 (Originalfassung A Treatise of Human Nature, 1739-1740). 
In manchen Kontexten mag eine relative Unterscheidung zwischen "den Fakten" und den menschlichen Bewertungen dieser Fakten (oder „Normen“) ganz nützlich sein. Aber die Einteilung ergibt nur bezogen auf den Kontext wirklich Sinn und kann nicht aus diesem Kontext herausgelöst und für sich genommen aufgewertet werden, sodass man letztlich erklärt, sie habe unbedingten Status. ${ }^{114}$

Die Position des gegenwärtigen Realismus ist also auch in diesem Fall sehr nuanciert und in einem gewissen Sinne „schwach“: Sie verkörpert keinen "Frontalangriff“ 115 auf die Unterscheidung zwischen Fakten und Normen, sondern verneint nur ihre universale Gültigkeit. Wie es überhaupt möglich ist, ohne diese Trennung und mit dem Festhalten an der Priorität der Fakten vor den Prinzipien eine Form von Normativität beizubehalten, werde ich im Abschnitt 2.5 näher erörtern.

Bezüglich des Verhältnisses zum klassischen Realismus habe ich im Vorigen verdeutlicht, dass die Kontextgebundenheit des gegenwärtigen Realismus nicht mit der oben erwähnten klassischen realistischen Position übereinstimmt, nach welcher der Erfolg das Hauptkriterium für die Bewertung des politischen Handelns ist. ${ }^{116}$ Wie erwähnt können etwa bei Williams die Bedingungen der Legitimität in einem besonderen Kontext nicht auf die erfolgreiche Durchsetzung der Macht reduziert werden. Williams' grundlegende Bedingung der Legitimität, nämlich dass „die Lösung nicht Teil des Problems wird“, enthält zwar die Effektivität (ihre erfolgreiche Durchsetzung) als eine Grundbedingung, erschöpft sich aber nicht darin. ${ }^{117}$ Dagegen setzt die Legitimitätsbedingung von vornherein der Macht Grenzen, die, wie ich argumentiert habe, zum Kern politischer Macht gehören.

2.4 Negativismus: die Erfahrung der „institutionellen Grausamkeit“ als Ausgangspunkt des kritischen Realismus

Der gegenwärtige Realismus nimmt eine negativistische Ausgangsposition ein: Er fokussiert auf die grundlegenden Übel und auf die Annahme

114 Geuss, Kritik der politischen Philosophie, 33. Dazu vgl. auch Geuss, Realismus, Wunschdenken, Utopie, 421.

115 Geuss, Kritik der politischen Philosophie, 33.

116 Vgl. oben Abschnitt 2.1, insbesondere die Fußnote 74.

117 Vgl. Williams, In the beginning was the deed, 14-16. 
von deren permanenter Möglichkeit. ${ }^{118}$ Sein Endziel besteht darin, diese grundlegenden Grausamkeiten zu verhindern, statt einen ideal definierten guten Zustand herbeizuführen.

In dieser Hinsicht stellt der gegenwärtige Realismus eine Form von Anti-Utopismus dar. Er bietet kein summum bonum und keine politische Vision, wie dies zu verwirklichen wäre. Stattdessen identifiziert er ein summum malum und definiert das Ziel der politischen Theorie darin, $\mathrm{zu}$ zeigen, wie dies verhindert werden kann. ${ }^{119}$ Der politische Realismus ist, wie Shklar es ausgedrückt hat, keine „Partei der Hoffnung“, die auf die Verwirklichung des Guten hofft, sondern, indem er sich auf die Erfahrung des Bösen konzentriert, eine „Partei der Erinnerung". ${ }^{120}$ Jedoch ist auch in diesem Fall die anti-utopische Aufforderung des Realismus auf die Vorgehensweise bezogen. Sie gibt den Ausgangspunkt vor (der in der Realität und ihren Unzulänglichkeiten verankert sein soll), verbietet aber nicht absolut den Rekurs auf utopisches Denken. Utopische Vorstellungen, so Geuss, sind dem Realismus nicht verboten und können sogar eine wichtige Rolle auch im politischen Bereich spielen. Sie dürfen aber weder mit der Wirklichkeit verwechselt werden noch den „nüchternen“ Blick auf die politische Realität als unabdingbaren Ausgangspunkt der Reflexion

118 Negativismus wird hier im Sinne Michael Theunissens als die Einstellung verstanden, nach der die Philosophie von der Diagnose negativer Phänomene ausgehen sollte, oder, in Theunissens Worten, als die Methode, nach der „sich das Positive vom Negativen anzeigen lässt“, Theunissen, Michael, Der Begriff Verzweiflung: Korrekturen an Kierkegaard. Frankfurt am Main: Suhrkamp 1993, 40 und Theunissen, Michael, Das Selbst auf dem Grund der Verzweiflung. Kierkegaards negativistische Methode. Frankfurt am Main: Hain 1991, 16-18. Für eine Charakterisierung des dialektischen Negativismus vgl. Angehrn, Emil (Hg.), Dialektischer Negativismus: Michael Theunissen zum 60. Geburtstag. Frankfurt am Main: Suhrkamp 1992, insbesondere die Einleitung und Wesche, Tilo, Dialectical negativism: Michael Theunissen, 1932-2015, in: Radical Philosophy, 192, 2015, 66-68.

119 Vgl. Shklar, Der Liberalismus der Furcht, 37, 43 und Honneth, Vorwort, 8. Über die Nähe Shklars zu „dialektisch-negativistischen Denkformen“ vgl. Liebsch; Bajohr, Geschichte, Negativismus und Skepsis als Herausforderungen politischer Theorie, 639.

120 Die Ausdrücke sind von Ralph Waldo Emerson entlehnt, Shklar, Der Liberalismus der Furcht, 37 und der dort zitierte Emerson, Ralph Waldo, Essays \& lectures, hg. v. Porte, Joel. New York: Literary Classics of the United States 1983, 173. Vertiefend zur Position Shklars gegenüber utopischem Denken, auch in Bezug auf ihr früheres Werk, vgl. Forrester, Katrina, Hope and Memory in the Thought of Judith Shklar, in: Modern Intellectual History, 8/3, 2011, 591-620. 
ersetzen. ${ }^{121}$ In diesem Sinne ist der methodologische Realismus besser als nicht utopisch denn als anti-utopisch zu begreifen. ${ }^{122}$

Was ist aber das summum malum, das der politische Realismus immer vor Augen haben soll? Das ist die Erfahrung der „institutionellen Grausamkeit", ${ }^{123}$ die durch Machtmissbrauch erzeugte Furcht. Diese Grausamkeit soll von der politischen Philosophie „an erste Stelle“ gesetzt werden, sie soll der Ausgangspunkt der Reflexion sein. ${ }^{124}$

Dieser negativistische Ansatz des gegenwärtigen Realismus spezifiziert, welches die wichtigsten Fakten und Praktiken sind, von der die politische Philosophie ausgehen soll. ${ }^{125}$ Dies sind die grundlegenden Übel, die Williams als Begründung des ersten politischen Problems identifiziert, nämlich, wie ich aufgeführt habe, die grundlegendsten Menschenrechtsverletzungen. ${ }^{26}$ Shklar definiert diese als "die Grausamkeit und die Furcht, die sie hervorruft, und schließlich die Furcht vor der Furcht selbst". ${ }^{127}$ Allgemeiner können sie als Erfahrungen der Unterdrückung definiert werden, sowohl die vergangenen als auch die gegenwärtigen. Die politische Philosophie, so der gegenwärtige Realismus, soll diese Erfahrungen als Problem aufgreifen und darauf aufbauen. ${ }^{128}$

Der gegenwärtige Realismus orientiert sich also am worst case. Er soll in erster Linie über Gefahren nachdenken, statt stolz die Vorzüge der

121 Eine ähnliche Position vertritt auch Judith Shklar, vgl. Forrester, Judith Shklar, Bernard Williams and political realism, 258-259. Zur Verteidigung der Fruchtbarkeit utopischen und dystopischen Denkens für eine realistische politische Philosophie vgl. Thaler, Mathias, Hope Abjuring Hope: On the Place of Utopia in Realist Political Theory, in: Political Theory, 46/5, 2018, 671-697 und ausgehend von Tullys Realismus vgl. Honig; Stears, James Tully's Agonistic Realism.

122 Vgl. Forrester, Judith Shklar, Bernard Williams and political realism, 260.

123 Shklar, Der Liberalismus der Furcht, 45.

124 Ebd., mit Verweis auf Shklar, Judith N., Ganz normale Laster. Berlin: Matthes \& Seitz 2014, 8. Vertiefend zu Shklars Diktum vgl. Stullerova, Kamila, The knowledge of suffering: On Judith Shklar's 'Putting Cruelty First', in: Contemporary Political Theory, 13/1, 2014, 23-45.

125 Vgl. oben Abschnitt 2.2.

126 Williams, In the beginning was the deed, 69.

127 Shklar, Der Liberalismus der Furcht, 43.

128 Tully, Public Philosophy in a New Key (Ideas in Context), 16. Das entspricht übrigens laut Shklar auch der ursprünglichen Haltung des Liberalismus, der auf der „aus tiefstem Schrecken geborene[n] Überzeugung“ fußt, dass „Grausamkeit ein absolut Böses ist" und aus der Erfahrung der Religionskriege in Europa im 16. und 17. Jahrhundert entstanden ist. Shklar, Der Liberalismus der Furcht, 31. Vgl. auch Honneth, Vorwort, 15. 
(erreichten oder zu erreichenden) Zustände zu loben. ${ }^{129}$ Aus dem oben Ausgeführten ist nun klar, aus welcher Perspektive der worst case zu identifizieren ist. Es sind nämlich die „Verlierer der Geschichte“ 130 bzw. deren Erfahrung der Beherrschung und der Ohnmacht, die als Ausgangspunkt für den Realismus gelten sollen. Aus dieser Perspektive betrachtet ist der gegenwärtige Realismus in einem doppelten Sinne negativistisch: erstens, weil er sich auf Übel und Schadensbegrenzung konzentriert, und zweitens, weil er sich auf die Übel der am schlechtesten Gestellten fokussiert. Aus diesem doppelten Negativismus folgt, dass die Grausamkeit, die es am dringendsten zu vermeiden gilt, diejenige ist, die von den Mächtigsten ausgeht, und die Freiheit, die an erster Stelle geschützt werden soll, „die Freiheit von Machtmissbrauch und der Einschüchterung Wehrloser"131 ist. Der gegenwärtige Realismus stellt sich in dieser Hinsicht dezidiert als ein Realismus „von unten“ dar. ${ }^{132}$

Hier knüpft auch die Polemik des Realismus gegen anthropologische Ansätze, die politische Subjekte in erster Linie als rationale Wesen begreifen, an. ${ }^{133}$ Stattdessen sind die politischen Subjekte des Realismus in ihren konkreten politischen Positionen zu begreifen, nämlich als "Schwache“ und „Mächtige“, 134 und nicht nur von reiner Rationalität, sondern auch von basalen Gefühlen und Empfindungen Geleitete. ${ }^{135}$ Denn die Übel, die der gegenwärtige Realismus zu vermeiden beabsichtigt, bestehen in konkreten körperlichen und psychischen Leiderfahrungen. Und die Motive, die seitens der jeweils „Mächtigsten“ zu Grausamkeiten führen können, sind nicht ausschließlich Kalkül und Interessen, sondern auch Machtstreben, Hass und destruktive Impulse gehören dazu. Dies führt zudem zu einem gewissen Skeptizismus, die Mechanismen politischer Entscheidungen als Prozesse der Bildung eines rationalen Konsensus beschreiben zu

129 Vgl. Shklar, Der Liberalismus der Furcht, 40-41. Vgl. auch Williams, In the beginning was the deed, 54-55.

130 Honneth, Vorwort, 17. Vgl. in eine ähnliche Richtung auch Tully, Public Philosophy in a New Key (Ideas in Context), 16.

131 Shklar, Der Liberalismus der Furcht, 41.

132 Honneth, Vorwort, 16. Vertiefend vgl. Kateb, George, Foreword, in: Shklar, Judith N., Political thought and political thinkers, hg. v. Hoffmann, Stanley. Chicago: University of Chicago Press 1998, vii-xx.

133 Vgl. Shklar, Der Liberalismus der Furcht, 40. Vertiefend zur "negativen Anthropologie“ Shklars vgl. Bajohr, Hannes, „Am Leben zu sein heißt Furcht zu haben."Judith Shklars negative Anthropologie des Liberalismus, in: Shklar, Der Liberalismus der Furcht, 131-167.

134 Shklar, Der Liberalismus der Furcht, 41.

135 Vgl. Galston, Realism in political theory, 398. 
können. Noch einmal erinnert uns der gegenwärtige Realismus daran, dass Politik durch Konflikt statt durch Konsens geprägt ist, und dass seine grundlegende Kategorie Macht ist. Diese kann nur gezähmt und eingegrenzt, nicht aber auf rationale Verfahren reduziert werden.

Der gegenwärtige Realismus nimmt also seinen Ausgangspunkt negativistisch in der Diagnose der grundlegenden politischen Übel. Er beschränkt sich aber nicht auf diese Diagnose, sondern schlägt eine, wenn auch minimalistische, Therapie vor. Diese besteht, wie bereits erwähnt, in der Schadensbegrenzung. Der Blick nach hinten, in die Vergangenheit, zeigt, dass Machtmissbrauch eine historische Konstante ist. Der Blick „nach unten“ in der heutigen Welt zeigt, dass Machtmissbrauch noch immer sehr verbreitet ist. Also soll das Bewusstsein von der stetigen Möglichkeit institutioneller Grausamkeit auch den Blick in die Zukunft leiten und Richtlinien für die politische Philosophie begründen. ${ }^{136}$ Williams kondensiert diese Auffassung in der Formulierung der grundlegenden Bedingungen der Legitimität, die besagen, dass politische Macht nicht selbst Ursache für die grundlegenden Übel werden darf und dass sie stets die Lösung zu diesen Übeln bieten soll, anstatt selbst Teil des Problems zu werden. Auf diesen Prämissen fußt auch die bereits erwähnte Zentralität der politischen Institutionen für den gegenwärtigen Realismus. Institutionen stellen die wichtigsten, obwohl komplexen und fragilen, Mechanismen dar, um das Ausufern und die Willkür der Macht abzuwenden. ${ }^{137} \mathrm{Um}$ effektiv zu sein, sollen sich diese Mechanismen nicht auf eine formal statuierte, rechtliche Gleichheit beschränken, sondern auch die gesellschaftliche Verteilung der Macht auf mehrere Gruppen und die Sicherung eines gewissen Grades materieller Gleichheit umfassen. ${ }^{138}$

136 Vgl. Shklar, Der Liberalismus der Furcht, 41-46; Honneth, Vorwort, 18.

137 Vgl. oben Abschnitt 2.2. Ebenso gehört zum Kern des Realismus die Gewissheit, dass politische Institutionen (und politische Macht) notwendig für die Erhaltung der sozialen Ordnung sind und dass dazu ein gewisses Bedrohungsvermögen gehört. Für Shklar ist die einzige Ausnahme zur Regel der Vermeidung von Grausamkeit die Verhinderung noch größerer Grausamkeiten, wodurch der Staat legitimiert ist, Zwangsmittel einzusetzen (Vgl. Shklar, Der Liberalismus der Furcht, 46). Williams drückt diesen grundlegenden Gedanken in der Idee aus, dass die Grenze, wonach die Lösung Teil des Problems wird, von der Ernsthaftigkeit der ursprünglichen Übel, die verhindert werden müssen, abhängt. Vgl. oben Abschnitt 2.1. Ich werde auf diese zweideutige Funktion der politischen und rechtlichen Institutionen im zweiten Kapitel und auf ihre Bedeutung für die Bewertung der Sicherheitspolitik im letzten Kapitel dieses Buches zurückkommen.

138 Vgl. ebd., 42-43, 48. 
Unter dem Aspekt des Negativismus unterhält der gegenwärtige Realismus ein komplexes Verhältnis zum klassischen Realismus. Einerseits sind die Gemeinsamkeiten offensichtlich: Auch für den klassischen Realismus kann Macht nicht auf Recht reduziert werden - kratos bestimmt die politischen Verhältnisse, nicht logos. Zudem sind sich die beiden Formen des Realismus darüber einig, dass der Macht eine konstitutive Neigung zur Ausdehnung innewohnt. ${ }^{139}$

Andererseits besteht aber im Hinblick auf die hier eingenommene Perspektive des Negativismus ein radikaler Unterschied zwischen dem klassischen und dem gegenwärtigen Realismus. Ersterer besteht nämlich in seiner gewöhnlichsten Form in einer Regierungskunst, einer Technologie der Macht, deren Hauptziel es ist, die Selbsterhaltung des Staates zu sichern. ${ }^{140}$ Dagegen nimmt der gegenwärtige Realismus dezidiert die Perspektive der Regierten ein, wie ich oben verdeutlicht habe. Zwar wird die Möglichkeit einer realistischen politischen Philosophie „von unten“ nicht prinzipiell vom klassischen Realismus ausgeschlossen. Wie Portinaro gezeigt hat, ist sie bereits in Platons Politeia neben der „hyperrealistischen“ Position des Thrasymachos vertreten. Im zweiten Buch der Politeia begründet nämlich Glaukon die Notwendigkeit der Gesetze und der Institutionen aus der Perspektive derjenigen, die Ungerechtigkeit erleiden und keine Möglichkeit haben, sich ihr zu entziehen. Aus der Perspektive der Wehrlosen ist es vorteilhaft, sich darauf zu einigen, anderen keine Ungerechtigkeit zuzufügen und selbst keine zu erleiden. ${ }^{141}$ Wenn auch also die Möglichkeit eines Realismus „von unten“ von Anfang an gegeben war, wurde diese vom klassischen Realismus weder dezidiert übernommen noch konsequent artikuliert. Die Hauptperspektive dieses Realismus ist diejenige der Regierenden, wofür der Realismus als Theorie der Politik beratend zur Seite steht. Zwar erschöpfen sich die Maximen und Empfehlungen des Realismus

139 Vgl. Portinaro, Il realismo politico, $80,85-86$.

140 Vgl. Portinaro, Il realismo politico, 20, 28-29.

141 Der einschlägige Passus aus der Politeia lautet: „Man behauptet, Unrechttun sei von Natur aus ein Gut, Unrechtleiden aber ein Übel; doch sei das Unrechtleiden ein größeres Übel als das Unrechttun ein Gut. Wenn demnach die Menschen einander Unrecht tun und voneinander Unrecht leiden und sie somit beides auskosten, so dünkt es diejenigen, die diesem nicht entgehen aber auch nicht jenes wählen können, von Vorteil, sich miteinander dahin zu verständigen, daß sie weder Unrecht tun noch Unrecht leiden. Und daher habe man dann angefangen, Gesetze zu geben und miteinander Verträge zu schließen, und was das Gesetz bestimmt, habe man als gesetzlich und gerecht bezeichnet." Plato, Der Staat, hg. v. Szlezák, Thomas Alexander. Berlin: de Gruyter 2014, zweites Buch, 359a. Vgl. auch Portinaro, Il realismo politico, 53. 
nicht in der Aufforderung zur Unterdrückung der Beherrschten mit allen zur Verfügung stehenden Mitteln, um die Macht beizubehalten. Auch der klassische Realismus kennt eine milde Variante, in welcher Legalität, nämlich die Ausübung der Macht innerhalb rechtlicher Grenzen, eine wichtige Komponente guten Regierens ist. ${ }^{142}$ Trotzdem besitzt auch in dieser Variante die Legalität lediglich instrumentelle Bedeutung, und zwar zur Erhaltung der Macht und ihrer Stabilität, und keinen Wert an sich.

\subsection{Immanenz der Leitprinzipien und der Kritik}

Im vorigen Abschnitt habe ich geschildert, wie der kritische Realismus durch einen negativistischen Ansatz geprägt ist. Aus dieser Perspektive zeichnet sich der gegenwärtige Realismus vor allem in Abgrenzung zum Utopismus aus. Der gegenwärtige Realismus bietet keine Vision eines optimalen politischen Zustandes, keine ideale Polis, die es zu verwirklichen gilt. Und doch nimmt der kritische Realismus, wie oben angedeutet, keine resignierte oder gar fatalistische Position ein. Er strebt vielmehr eine Transformation der politischen Realität zum Besseren an, selbst wenn diese Transformation zunächst nur auf eine Schadensbegrenzung abzielt.

Diese angestrebte Verbesserung der politischen Zustände darf jedoch weder an universale Werte appellieren noch von obersten Prinzipien abgeleitet werden, wie ich oben ausgeführt habe. ${ }^{143}$ Ferner: Der kritische Realismus verneint auch die Möglichkeit einer letzten Begründung. Der Normativität des gegenwärtigen Realismus kommen also weder von oben (in Form von höchsten Prinzipien) noch aus der Ferne (als universale Werte) und auch nicht von unten (als letzte Begründungen) fixe Anhaltsoder Orientierungspunkte zur Hilfe.

Die Negation der Letztbegründbarkeit stellt den kritischen Realismus konträr zu jeglicher Form des erkenntnistheoretischen Fundamentalismus: Die Leitprinzipien politischen Handelns müssen aus der Immanenz unserer Realität herausgearbeitet werden und können nicht mit Verweis auf einen festen Boden gerechtfertigt werden, der nicht selbst infrage gestellt werden könnte.

Dabei wendet sich der gegenwärtige Realismus gegen das, was seinerseits als ein Missverständnis in der politischen Philosophie aufgefasst wird. Dieses besteht in der Überzeugung, dass Freiheit und Rationalität nur

142 Vgl. Portinaro, Il realismo politico, 53-55.

143 Vgl. Abschnitte 2.2 und 2.3. 
dann im Politischen realisiert werden können, wenn das politische Handeln auf Grundnormen basiert, welche die situierte Welt unserer alltäglichen Aktivitäten transzendieren. ${ }^{144}$ Die Kritik ist hier insbesondere gegen Habermas gerichtet, aber auch wieder gegen Rawls und gegen Positionen, die gewöhnlich als gegensätzlich zum rawlsschen Liberalismus verstanden werden, wie Charles Taylors kommunitaristischer Ansatz. ${ }^{145}$ Diesen Autoren ist die Überzeugung gemeinsam, so die realistische Kritik, dass ohne eine die Realität transzendierende Normenbegründung jegliche Möglichkeit der Kritik verbaut wäre und dass der politischen Philosophie lediglich die nackte Akzeptanz des Gegebenen bleiben würde. ${ }^{146}$ Der gegenwärtige Realismus beansprucht dagegen für sich die Möglichkeit einer nicht transzendentalen Kritik der politischen Realität und wendet letztendlich den Vorwurf des Konservativismus, wie ich unten zeigen werde, gegen die transzendentalen Theorien selbst. ${ }^{147}$

Der methodologische Realismus betrachtet jeden Versuch, von der Weltimmanenz zu abstrahieren und einen „objektiven“ oder „universalen“ oder „rein rationalen“ Standpunkt einzunehmen, als illusorisch. Zwar ist der Wunsch, unsere Situierung und Immanenz zu überwinden, ein sehr reeller Wunsch, der in gewisser Weise aus unserer menschlichen Kondition entsteht. Jedoch kann er nicht erfüllt werden. Wie Anna Fenichel Pitkin in Anlehnung an Wittgenstein geschrieben hat: „The desire to escape our human condition [...] is a real desire, but not a desire for something real. It is a vain desire. " 148 Ein anderer Zugang zum Politischen

144 Vgl. Tully, Public Philosophy in a New Key (Ideas in Context), 39 und Geuss, Raymond, Die Idee einer kritischen Theorie. Königstein: Hain 1983, 78-79.

145 Für eine Auseinandersetzung mit Habermas' und Taylors Transzendentalismus vgl. Tully, Public Philosophy in a New Key (Ideas in Context), 39-70; für eine Kritik des habermasschen und rawlsschen Ansatzes vgl. Geuss, Die Idee einer kritischen Theorie und Geuss, Kritik der politischen Philosophie, 82-128.

146 Diese Kritik wird manchmal durch eine missverständliche Vermischung des Realismus in der politischen Philosophie mit dem realistischen Ansatz in den internationalen Beziehungen begründet und in der Behauptung ausgedrückt, „der Realismus wäre immer auf der Seite des Staates“. Runciman, Political Theory and Real Politics in the Age of the Internet, 15. Für eine Verteidigung der Vereinbarkeit von negativistischen Ansätzen mit normativem Streben vgl. auch Allen, Jonathan, The Place of Negative Morality in Political Theory, in: Political Theory, 29/3, 2001, 337-363.

147 Vgl. Williams, In the beginning was the deed, 29-39; Tully, Public Philosophy in a New Key (Ideas in Context), 39-70.

148 Pitkin, Hanna Fenichel, Wittgenstein and justice: on the significance of Ludwig Wittgenstein for social and political thought. Berkeley: University of California Press 1972, 339. 
als unser Standpunkt, so der kritische Realismus, ist uns verbaut: Wir können und sollen nur an unserem „Hier und Jetzt“ ansetzen und dabei unsere Situierung bewusst anerkennen, anstatt sie zu verschleiern. ${ }^{149}$ Doch der Versuch, unsere Gebundenheit und Befangenheit zu überwinden, ist nicht nur illusorisch, sondern - wenn nicht als solcher erkannt - er wirkt auch mystifizierend. Unsere Vorurteile und Vorannahmen fließen notwendigerweise in jede vermeintlich „ideale“ (bzw. objektive, rein rationale oder universale) Konzeption des Politischen und seiner Leitprinzipien. Indem wir sie aber als „ideal“ deklarieren, verstärken wir letztendlich die darin enthaltenen Vorurteile, weil sie nun als notwendig, universal und objektiv dargestellt werden. ${ }^{150}$ Ferner: Diese ideellen Prinzipien werden selbst der Kritik entzogen - wenn sie rational, universal und unparteiisch sind, dann ist jede Infragestellung irrational, partikularistisch und ideologisch. Anstatt die Grenzen unserer politischen Realität zu testen und kritisch zu hinterfragen, führen transzendentale Theorien dazu, die vorhandenen Grenzen als notwendig und unüberwindbar zu bestätigen. ${ }^{151}$ Damit wird der Vorwurf des Konservativismus vom methodologischen Realismus nicht nur abgelehnt, sondern auch gegen alternative ideale Ansätze gewendet.

Einerseits unterscheidet sich also der gegenwärtige Realismus wegen seiner Verankerung in der Immanenz von idealen Ansätzen. Andererseits, weil er den transformativen Anspruch aufrechterhält, grenzt er sich auch vom klassischen Realismus entscheidend ab.

Drei Einstellungen gegenüber der Welt wurden als typisch für den klassischen Realismus identifiziert: Weltbeherrschung, -anpassung und

149 Vgl. Galston, Realism in political theory, 395-396; Williams, In the beginning was the deed, 61.

150 Vgl., polemisch gegen Rawls, Geuss, Die Idee einer kritischen Theorie, 122-128. Christoph Menke hat diesen Aspekt der geussschen Kritik an Rawls und den Zusammenhang mit Rawls' Konsensus-orientierter Theorie besonders klar dargestellt. Rawls sieht die von ihm identifizierten Prinzipien als Gegenstand eines gesellschaftlichen Konsensus und betrachtet diese Prinzipien als Maßstäbe, die eine Kritik der politischen Realität ermöglichen. Geuss kritisiert diese beiden Thesen. Die von Rawls aufgestellten Prinzipien sind erstens das Ergebnis einer hochumstrittenen Interpretation: Weil Rawls dies verkennt, kann er zweitens nicht erkennen, dass seine Position affirmativ - und nicht kritisch - gegenüber der Realität ist. Mit anderen Worten verschleiert der Moralismus, dass seine Behauptungen auch politische Stellungnahmen sind. Vgl. Menke, Weder Rawls noch Adorno?, 447.

151 Vgl., kritisch gegenüber Habermas, Tully, Public Philosophy in a New Key (Ideas in Context), 83-93. 
-ablehnung. ${ }^{152}$ Keine dieser drei typischen Einstellungen des klassischen Realismus passt zum kritischen Selbstverständnis des gegenwärtigen Realismus. ${ }^{153}$ Denn weder zielt der gegenwärtige Realismus auf eine selbstgefällige Beherrschung der Machtspiele (Weltbeherrschung), noch resigniert er skeptisch und kompromissbereit gegenüber der Unvermeidbarkeit der politischen Übel (Weltanpassung) und wendet sich schließlich auch nicht enttäuscht von der Welt und den Menschen ab (Weltablehnung). Entsprechend steht seine grundlegende Haltung dem Konservativismus antithetisch gegenüber: Sein Bestreben ist inhärent transformativ. ${ }^{154}$

Der methodologische Realismus muss dabei mit dem scheinbaren Paradoxon umgehen, von der Realität auszugehen und gleichzeitig diese infrage zu stellen, um zu ihrer Transformation beitragen zu können. Das ist meines Erachtens die zentrale Herausforderung des realistischen Ansatzes, wofür er, wie ich unten darlegen werde, noch keine überzeugende Überwindungsstrategie entwickelt hat. Meines Erachtens ist die Auflösung dieses Paradoxons aber möglich und kann durch den Rekurs auf Formen einer nicht fundierenden und nicht transzendentalen Kritik erreicht werden. In den nächsten Abschnitten werde ich nun erkunden, wie sich durch diese Ergänzung das kritische und transformative Potenzial des gegenwärtigen Realismus entfalten lässt.

152 Vgl. Portinaro, Il realismo politico, 17. Die Kategorien werden von Max Webers' Religionssoziologie übernommen, vgl. Weber, Max, Gesammelte Aufsätze zur Religionssoziologie, Bd. 1. Tübingen: Mohr 1986, 512-535.

$153 \mathrm{Zu}$ Shklars Ablehnung der Selbstgefälligkeit des klassischen Realismus und seiner Glorifizierung des Konflikts und des Dezisionismus, insbesondere in Bezug auf Machiavelli und Weber, vgl. Forrester, Judith Shklar, Bernard Williams and political realism, 253-255. Für eine Untersuchung der Möglichkeit, Machiavellis Werk als positive Quelle für den Liberalismus der Furcht im Sinne Shklars und Williams' zu lesen, vgl. Osborne, Thomas, Machiavelli and the liberalism of fear, in: History of the Human Sciences, 30/5, 2017, 68-85.

154 Dagegen neigte der klassische Realismus zu einer Form des „universalen Konservativismus", wonach sowohl die menschliche Natur als auch die Grundmechanismen der Politik unveränderbar seien. Dieser grundlegende Konservativismus hätte sich seit der Französischen Revolution häufig in eine Affinität des klassischen Realismus zu politisch konservativen und nationalistischen Positionen gewandelt. Vgl. Portinaro, Il realismo politico, 116. 


\section{Entfaltung des kritischen Potenzials des gegenwärtigen Realismus}

Die Weiterentwicklung des gegenwärtigen Realismus in eine dezidiert kritisch-transformative Richtung, die ich hier beabsichtige, benötigt meines Erachtens eine dreistufige Erweiterung. Erstens muss epistemologisch plausibilisiert werden, wie es möglich ist, innerhalb eines Wissenssystems bestimmte Voraussetzungen dieses Systems infrage zu stellen, ohne einerseits auf dem System gegenüber externe Anhaltspunkte zu rekurrieren und andererseits die Voraussetzungen, die einmal als Grundlage der Infragestellung dienen, als absolut gültig zu betrachten. Diesen Schritt werde ich durch Verweis auf die späte Philosophie Ludwig Wittgenstein vollziehen. Zweitens muss konkretisiert werden, wie eine solche nicht transzendentale Kritik geübt werden kann. Diese Konkretisierung werde ich durch Rekurs auf Michel Foucaults genealogischen Ansatz aufzeigen. Dieser besteht in der Aufdeckung unserer Historizität als (politischer) Subjekte und ermöglicht es, eine kritische Distanz gegenüber den politischen Gegebenheiten und Wertvorstellungen zu gewinnen, die uns sonst als selbstverständlich, objektiv und universell erscheinen. Wie ich darlegen werde, bleibt aber diese Form der kritischen Rekonstruktion an der Grenze dessen stehen, was unseren Werthorizont konstituiert. Foucaults Genealogie verdeutlicht meines Erachtens, dass es möglich ist, bestimmte Vorstellungen und Praktiken, die als „gegeben“ gelten, zu transformieren; sie sagt aber nichts darüber aus, wie diese Transformation erfolgen kann. Um diesen weiteren Schritt zu gehen, liefert Rahel Jaeggis Konzept der immanenten Kritik eine fruchtbare Methode, die den kritischen Realismus um eine konstruktivnormative Komponente ergänzen kann. Diese hat ihren Ausgangspunkt in der Kontrastierung der analysierten Handlungen mit den Leitprinzipien, die diesen Handlungen vorgeschrieben wurden, und zielt darauf ab, Widersprüche in diesem Verhältnis der Praxis zu den Prinzipien aufzudecken. Diese Widersprüche verweisen dann auf die Notwendigkeit einer Transformation, die aber nicht auf die reine Angleichung der Praktiken an die Ideale abzielt, sondern die Ideale selbst in diese Transformation miteinbezieht.

Während Verweise auf die späte Philosophie Wittgensteins und auf den genealogischen Ansatz Foucaults teilweise auch in den Werken realistischer Autor_innen zu finden sind, liefert die Ergänzung um Jaeggis 
Ansatz einen genuin originellen Beitrag zur Weiterentwicklung des gegenwärtigen Realismus. ${ }^{155}$

\subsection{Die epistemologische Plausibilisierung einer nicht fundierenden Kritik: das Wissenssystem als „Lebenselement der Argumente“}

Die Möglichkeit einer nicht fundierenden Kritik fußt auf epistemologischen Voraussetzungen, die unter Anknüpfung an das Werk des späten Wittgensteins nachvollziehbar dargestellt werden können. ${ }^{156}$

Insbesondere Wittgensteins Auffassung der Urteilssysteme als „Lebenselement der Argumente" erweist sich als überaus fruchtbar zu diesem Zweck. Nach dieser Konzeption stellt das Hintergrundwissen, das wir mit anderen teilen, die Bedingungen der Möglichkeit von spezifischen Infragestellungen dar. Diese Bedingungen ermöglichen und schränken gleichzeitig das Infragestellen ein:

Alle Prüfung, alles Bekräften und Entkräften einer Annahme geschieht schon innerhalb eines Systems. Und zwar ist dies System nicht ein mehr oder weniger willkürlicher und zweifelhafter Anfangspunkt aller unsrer Argumente, sondern es gehört zum Wesen dessen, was wir ein Argument nennen. Das System ist nicht so sehr der Ausgangspunkt, als das Lebenselement der Argumente. ${ }^{157}$

Dieses System von Urteilen lernen wir als Ganzes; Urteile begreifen wir immer schon in ihrem Zusammenhang mit anderen Urteilen. Die meisten davon „schlucken“ wir ganz einfach als Folgerungen aus anderen Urteilen als Teil eines Systems „hinunter“, ohne uns dessen bewusst zu sein und ohne sie infrage zu stellen. ${ }^{158}$ Das, was uns als besonders fest und uner-

155 Für einen aktuellen Beitrag, der die transformativ-normativen Grenzen des gegenwärtigen Realismus durch die Operationalisierung genealogischer Vorgehensweisen zu überwinden versucht, vgl. Rossi, Enzo, Being realistic and demanding the impossible, in: Constellations, 26/4, 2019, 638-652.

156 Vgl. Wittgenstein, Ludwig, Philosophische Untersuchungen. Frankfurt am Main: Suhrkamp 2017 (zuerst veröffentlicht 1953); Wittgenstein, Ludwig, Über Gewißheit. Frankfurt am Main: Suhrkamp 2018 (zuerst veröffentlicht 1969).

157 Wittgenstein, Über Gewißheit, $\$ 105$. Vgl. dazu Tully, Public Philosophy in a New Key (Ideas in Context), 32. Ich werde im letzten Kapitel des Buches verdeutlichen, welche Bedeutung diese Auffassung für die Legitimität im Kontext der EU-Sicherheitspolitik hat.

158 Wittgenstein, Über Gewißheit, $\mathbb{\$} 140-144$, insb. $\$ 143$. Wittgenstein verdeutlicht die These durch folgendes Beispiel: „Es wird mir erzählt, jemand sei vor vielen 
schütterlich erscheint, tut es nicht, weil es transzendent, universal oder besonders begründet ist, sondern weil es von anderen Überzeugungen und Urteilen als deren Hintergrund verlangt wird. Folglich müssen wir, wenn wir bestimmte Teile eines Systems kritisch überprüfen, notwendigerweise an anderen Teilen festhalten, die aber potenziell jeweils selbst Gegenstand einer kritischen Untersuchung werden können. ${ }^{159}$

Es erschließt sich somit die Möglichkeit einer nicht fundierenden Kritik, in der wir bei der Überprüfung einer Norm bestimmte andere Normen oder Urteile als vorausgesetzt annehmen, ohne diese als absolut fundierbar anzusehen. Diese zunächst für vorausgesetzt gehaltenen und nicht infrage gestellten Normen können aber in einem anderen Vorgang selbst kritisiert, revidiert oder gegebenenfalls aufgegeben werden. So ist es in der politischen Philosophie möglich, bestimmte Praktiken kritisch zu überprüfen und dabei andere Zustände oder Machtbeziehungen als gemeinsam geteiltes System im Hintergrund zu belassen, für vorausgesetzt zu halten oder sogar als Anhaltspunkt für die Kritik zu nutzen. Dies verbietet aber nicht, in einem weiteren Schritt die zunächst für gültig erachteten Normen, Zustände und Beziehungen ihrerseits zu kritisieren. ${ }^{160}$

Die kritische Überprüfung der Legitimität der EU-Sicherheitsmaßnahmen, die in diesem Buch erfolgt, fußt auf dieser Konzeption. Wie ich in den nächsten Kapiteln ausführen werde, ist es möglich, die in der EU geltenden Legitimitätskonzeptionen als Maßstäbe der Überprüfung zu verwenden (wie im Teil II dieses Buches), ohne die Möglichkeit auszuschließen, dieselben Prinzipien später (hier im Teil III) infrage zu stellen und womöglich für ihre Transformation zu plädieren.

Jahren auf diesen Berg gestiegen. Untersuche ich nun immer die Glaubwürdigkeit des Erzählers und ob dieser Berg vor Jahren existiert habe? Ein Kind lernt viel später, daß es glaubwürdige und unglaubwürdige Erzähler gibt, als es Fakten lernt, die ihm erzählt werden. Es lernt, daß jener Berg existiert habe, gar nicht; d. h., die Frage, ob es so sei, kommt gar nicht auf. Es schluckt, sozusagen, diese Folgerung mit dem hinunter, was es lernt."Wittgenstein, Über Gewißheit, $\$ 143$.

159 Vgl. Wittgenstein, Über Gewißheit, $\mathbb{\$} 144$; Tully, Public Philosophy in a New Key (Ideas in Context), 32.

160 Vgl. Schaub, Politische Theorie als angewandte Moralphilosophie? Die realistische Kritik, 22. 


\subsection{Foucaults Genealogie als „historische Auflösung " ${ }^{\text {"161 }}$ von Selbstverständlichkeiten}

Einmal auf epistemologischer Ebene geklärt, wie überhaupt eine Kritik möglich ist, die weder auf externen noch auf universalen und auch nicht auf fundamentalen Prinzipien basiert, kann nun eine konkrete Form dieser nicht fundierenden und nicht transzendentalen Kritik eingeführt werden. Diese besteht in der historischen Rekonstruktion der Ereignisse und Praktiken, die uns als diejenigen Subjekte, die wir sind, konstituiert haben. Diese Form der Kritik ist eine Infragestellung dessen, was uns als selbstverständlich, und deswegen natürlich und notwendig, erscheint. ${ }^{162}$

Foucault hat dieses genealogische Vorgehen exemplarisch geprägt. Nach Foucault lautet die kritische Frage: „Welchen Ort nimmt in dem, was uns als universal, notwendig und verpflichtend gegeben ist, das ein, was einzig, kontingent und das Produkt willkürlicher Beschränkungen ist?" 163 Diese Form der Kritik impliziert die Übernahme dessen, was Foucault als Ethos der Aufklärung bezeichnet, ohne aber auch ihre „Erpressung“ akzeptieren zu müssen. Während das Ethos der Aufklärung, ihre spezifische Haltung, nach Foucault in der „permanenten Kritik unseres historischen Seins“164 besteht, besteht die Erpressung der Aufklärung in der Aufstellung der Alternative zwischen Akzeptanz und Ablehnung ihrer Rationalitätsformen. Diese Alternative impliziert, entweder die Grenzen, innerhalb derer sich unsere Rationalität bewegen soll, zu akzeptieren, oder eine - de facto unmögliche - Stellung außerhalb dieser Rationalität zu suchen und zu übernehmen. Nach Foucault kann diese Alternative umgangen werden, indem die Grenze weder als solche akzeptiert noch überschritten wird, sondern als eigener Standpunkt angenommen wird. „Wir müssen an der Grenze sein",165 die Grenze analysieren und reflektieren. Nur dadurch wird es möglich, die Grenze nicht mehr als notwendige Beschränkung zu sehen, sondern die Bedingungen ihrer Überschreitung ausfindig zu machen.

Diese genealogische Analyse ist offensichtlich keine reine Akzeptanz, aber auch keine bloße Ablehnung des Gegebenen. Vielmehr nimmt sie das Gegebene als Ausgangspunkt der Rekonstruktion und akzeptiert es als

161 Vgl. Geuss, Raymond, Kritik, Aufklärung, Genealogie, 278.

162 Geuss, Kritik, Aufklärung, Genealogie.

163 Foucault, Michel, Was ist Aufklärung?, in: Erdmann, Eva; Forst, Rainer; Honneth, Axel (Hg.), Ethos der Moderne. Foucaults Kritik der Aufklärung. Frankfurt am Main: Campus 1990, 35-54, hier 48.

164 Ebd., 45.

165 Foucault, Was ist Aufklärung?, 45. 
real (anstatt es als bloß konstruiert abzulehnen). Aber in der Untersuchung seiner Historizität eröffnet sie auch die Möglichkeit einer Transformation des Gegebenen. ${ }^{166}$ Indem sie es uns ermöglicht, bestimmte Praktiken von innerhalb in einem neuen Licht zu sehen, ist genealogische Kritik zudem nicht transzendental. ${ }^{167}$ Indem sie aber durch diese neue Perspektive über das Gegebene die Möglichkeit eröffnet, die historische Bedingtheit der eigenen Grenzen zu erkennen, hat sie das Potenzial, über diese Grenzen hinauszugehen: „Alles in allem geht es darum, die in Form der notwendigen Begrenzung ausgeübte Kritik in eine praktische Kritik in Form einer möglichen Überschreitung zu transformieren. " 168 Die praktische Transformation wird somit ermöglicht, ohne ein ideales, externes Vorbild aufzubauen oder vorauszusetzen.

Zentraler Bestandteil der genealogischen Kritik als Transformation von Selbstverständlichkeiten in Fragen ist die Rekonstruktion der geschichtlichen Prozesse, durch die sich Gegebenheiten in Probleme verwandelt haben. ${ }^{169}$ Die Frage lautet, wie Phänomene (etwa im Bereich der Psychiatrie, der Delinquenz und der Sexualität) sich zu Problemen entwickeln und eine Reihe von Verknüpfungen zwischen Wissen und Machtmechanismen hervorbringen, die sich mit der Lösung dieses „Problems“ beschäftigen. ${ }^{170}$ Ziel der genealogischen Analyse ist es, zu untersuchen

[...] welche Verbindungen, welche Verschränkungen zwischen Zwangsmechanismen und Erkenntniselementen aufgefunden werden können, welche Verweisungen und Stützungen sich zwischen ihnen

166 Vgl. Geuss, Kritik, Aufklärung, Genealogie.

167 Vgl. Tully, Public Philosophy in a New Key (Ideas in Context), 82-83.

168 Foucault, Was ist Aufklärung?, 48.

169 Dieses Vorgehen soll sozusagen zeigen, dass das, was uns selbstverständlich als Problem erscheint, eigentlich das Produkt eines historischen Prozesses ist, in dem eine Reihe von Zuständen als Probleme erfasst und konstituiert wurde. Es ist - anders ausgedrückt - die Infragestellung der Problematisierung dessen, was uns selbstverständlich als Problem erscheint.

170 Vgl. Foucault, Was ist Kritik?, 31. Obwohl die vorgeschlagenen Lösungen vielfältig und sogar untereinander widersprüchlich sein können, gehen sie alle aus einer gemeinsamen Problematisierung hervor, welche die Elemente setzt, worauf die vorgeschlagenen Lösungen reagieren. Vgl. Foucault, Michel, Polemics, Politics and Problematizations: An interview conducted by Paul Rabinow in May 1984, in: Rabinow, Paul (Hg.), Essential Works of Foucault, Bd. 1 "Ethics". New York: The New Press 1998, 381-390 und Tully, Public Philosophy in a New Key (Ideas in Context), 106. Zu Foucaults Konzeption der Kritik vgl. auch Butler, Judith, Was ist Kritik?, in: Deutsche Zeitschrift für Philosophie, 50/2, 2002, 249266. 
entwickeln, wieso ein bestimmtes Erkenntniselement [...] Machtwirkungen hervorbringt und wieso ein bestimmtes Zwangsverfahren rationale, kalkulierte, technisch effiziente Formen und Rechtfertigungen annimmt. ${ }^{171}$

Im Einklang mit der Verpflichtung zum Vorrang der Fakten und der Kontextgebundenheit des politischen Realismus benötigt eine solche Genealogie eine Reihe von spezifischen, partikulären Analysen, die sich mit konkreten Praktiken und Phänomenen auseinandersetzen. Dagegen wird in diesem historisch-philosophischen Vorgehen auf allgemeine Grundlegungen verzichtet: Eine solche Analyse muss sich „im Immanenzfeld der reinen Singularitäten halten “ ${ }^{172}$ Eine solche Analyse zielt nicht darauf ab, verschiedene Ereignisse auf eine einzige Ursache zurückzuführen, sondern vielmehr die Bedingungen zu identifizieren, die eine „Singularität“ in verschiedenen Elementen zur Erscheinung kommen lassen. Diese Singularität wird nicht als kausales Produkt der Erscheinungsbedingungen, sondern als deren Effekt aufgefasst. ${ }^{173}$

\subsection{Jaeggis Auffassung der immanenten Kritik}

Die Möglichkeit der Transformation, die durch das genealogische Vorgehen zunächst einmal nur aufgezeigt wird, kann im Sinne einer immanenten Kritik realisiert werden. Dieser Ansatz, der in der Tradition der Kritischen Theorie zu verorten ist, eignet sich meines Erachtens sehr gut, um das kritische Potenzial des gegenwärtigen Realismus zu entfalten. ${ }^{174}$

171 Foucault, Was ist Kritik?, 31.

172 Ebd., 36.

173 Vgl. ebd., 37.

174 Jenseits einiger Verweise auf die Tradition der Kritischen Theorie wurde bisher diese Form der Kritik vom kritischen Realismus nicht rezipiert. Vgl. etwa Geuss, Realismus, Wunschdenken, Utopie, 423 und 427. Bei Williams findet sich ein Hinweis auf das „critical theory principle“, mit dessen Hilfe es möglich wird, die freie Akzeptanz einer politischen Ordnung von einer durch Zwang produzierten zu unterscheiden. Vgl. etwa Williams, In the beginning was the deed, 6. Ferner ist meiner Meinung nach Jaeggis Interpretation der immanenten Kritik dazu geeignet, die Schwierigkeiten zu überwinden, die Geuss' Distanzierung von Adornos Ideologiekritik motiviert. Wie Menke verdeutlicht hat, besteht die Hauptschwierigkeit aus Geuss' Sicht in der Überzeugung Adornos, dass wir nur über das Misslingen der Ideologien Zugang zur Realität haben. Nach Menkes Interpretation gäbe es aber heute für Geuss keine umfassende Ideologie, die in der Lage wäre, durch ihr Scheitern uns Zugang zum Wahren 
Wie die Variante des Realismus, die hier stark gemacht wird, zielt auch die immanente Kritik auf die Überwindung der Dichotomie zwischen „innen“ und „außen“ als normativen Standpunkten, zwischen bloßer Akzeptanz und vollständiger Ablehnung der untersuchten Realität. Ebenfalls verzichtet die immanente Kritik darauf, Bewertungsmaßstäbe von außerhalb der Realität heranzuziehen, gleichzeitig zielt sie auf eine positive Transformation der Realität. ${ }^{175}$

In Anlehnung an Georg Wilhelm Friedrich Hegel, Karl Marx, Theodor W. Adorno und Axel Honneth hat Rahel Jaeggi immanente Kritik als eine Art Kritik beschrieben, die von der Analyse des Gegebenen ausgeht, die dort auftretenden Widersprüche oder Paradoxien offenbart und darauf aufbauend neue normative Maßstäbe für deren Überwindung ausarbeitet. ${ }^{176}$

Immanente Kritik unterscheidet sich von interner Kritik. Letztere besteht ebenfalls aus der Konfrontation einer Gesellschaft mit den Normen und Idealen, die in ihr gelten. Ihre Analyse konzentriert sich jedoch auf die Aufdeckung der unzureichenden Verwirklichung dieser Ideale. Ihr Ziel ist dementsprechend die Angleichung der Realität an die Ideale bzw. deren Vervollständigung. Diese Form der Kritik hat nach Jaeggis Überzeugung keine Möglichkeit, die in der Gesellschaft geltenden Werte und Normen zu transzendieren, sie bleibt in der tatsächlich geltenden Normativität verfangen. Dagegen beschränkt sich immanente Kritik im Sinne Jaeggis nicht auf den Hinweis auf die unvollständige Verwirklichung gesellschaftlicher Normen. Sie zielt vielmehr auf die Transformation der Realität und der Normen ab.

Konkret besteht immanente Kritik für Jaeggi aus der Kombination der folgenden fünf Merkmale. ${ }^{177}$ Erstens dienen als Ausgangspunkt der Kritik Normen, die einer gegebenen Gesellschaft immanent und für bestimmte soziale Praktiken konstitutiv sind. Diese Normen werden als solche ernst

der Realität zu verschaffen. Die heutigen Ideologien seien demnach dort, wo sie scheitern, keine Wegweiser zum Wahren, sondern „einfach falsch“, vgl. Menke, Weder Rawls noch Adorno?, 452-454. Meiner Meinung nach spricht Jaeggi dieses Problem an, wenn sie von einer „Vervielfältigung von Widersprüchen“ schreibt, die immanente Kritik berücksichtigen soll. Kritik soll demnach nicht bei einem zentralen Widerspruch der dominanten Ideologie ansetzen, sondern damit rechnen, dass es viele, teilweise miteinander kollidierende Widersprüche gibt. Vgl. Jaeggi, Was ist Ideologiekritik?, 293.

175 Vgl. Jaeggi, Was ist Ideologiekritik?

176 Vgl. ebd., 286.

177 Vgl. Jaeggi, Was ist Ideologiekritik?, 286-288. 
genommen: Sie sind nicht bloß oder zufällig gültig, sondern werden als vernünftig begründete, gerechtfertigte Normen anerkannt. In diesem Sinne ist immanente Kritik alles andere als nihilistisch oder relativistisch. Die Normen, die kritisch betrachtet werden, werden weder als bloße Vorwände angesehen noch als willkürlich. Vielmehr, wie schon Adorno hervorhob, wird in diesen Normen ein rationaler Kern vorausgesetzt. Diese Normen und Ideale sind auch nicht ,an sich" falsch oder widersprüchlich, sondern werden es erst im Prozess der Verwirklichung, in dem sie in der Realität wirksam werden. ${ }^{178}$

Zweitens betrachtet diese Form der Kritik das Verhältnis zwischen Realität und Normen nicht als geschwächt (etwa weil die Realität den Normen nur unvollständig entspricht), sondern als verkehrt. Die Werte sind in der Realität wirksam, führen aber bei ihrer Verwirklichung zu Widersprüchen, in denen dieselben Ideale unterminiert werden. Das macht auch eine direkte, präzise Analyse der Gegebenheiten für die immanente Kritik unerlässlich: Die Fokussierung auf abstrakte und ideale Normen allein kann keine Widersprüche aufdecken, weil sich letztere erst im Verhältnis zwischen Realität und Idealen entfalten.

Diese Widersprüche werden drittens nicht als kontingent, sondern (zugegeben problematischerweise) als notwendig angesehen: Die geltenden Ideale lassen sich in der analysierten Realität nur widersprüchlich verwirklichen, indem sie entweder miteinander konfligierende Normen verkörpern oder in der Realität zu Folgen führen, die den ursprünglichen Intentionen zuwiderlaufen.

Viertens zielt immanente Kritik auf eine Transformation ab: Sie will nicht einfach die Realität und die Ideale in ein funktionierendes Verhältnis zueinander stellen, sondern die widersprüchliche Situation in etwas Neues überführen. Die Transformation soll aber nicht als Angleichung an ein vorgefertigtes Muster erfolgen. Vielmehr soll das Ideal aus der Wirklichkeit herausgearbeitet werden.

Dabei sind, fünftens, sowohl die Realität als auch die Normen Gegenstand dieser Transformation. Denn im Verfahren der immanenten Kritik wird sowohl eine Praxis anhand von Normen kritisiert als auch diese Nor-

178 Vgl. auch Adorno, Theodor W., Beitrag zur Ideologienlehre, Gesammelte Schriften, Bd. 8: Soziologische Schriften I. Frankfurt am Main: Suhrkamp 1972, 457477. 
men selbst. Die Maßstäbe der Kritik, die aus der Realität herausgearbeitet werden, verändern sich sozusagen im Verfahren der Kritik. ${ }^{179}$

Um zu erklären, wie eine solche Transformation möglich ist, ohne auf externe Maßstäbe zu rekurrieren, weist Jaeggi auf Hegels Moment der „bestimmten Negation“ hin. Das Alte, das überwunden werden soll, wird nicht vollständig abgelehnt, sondern im Neuen aufbewahrt. Mit Hegels Worten ist das die Erkenntnis, dass

[...] das sich Widersprechende sich nicht in Null, in das abstrakte Nichts auflöst, sondern wesentlich nur in die Negation seines besonderen Inhalts, oder daß eine solche Negation nicht alle Negation, sondern die Negation der bestimmten Sache, die sich auflöst, somit bestimmte Negation ist [...]. Sie ist ein neuer Begriff, aber der höhere, reichere Begriff als der vorhergehende; denn sie ist um dessen Negation oder Entgegengesetztes reicher geworden, enthält ihn also, aber auch mehr als ihn, und ist die Einheit seiner und seines Entgegengesetzten. ${ }^{180}$

Der Verweis auf Hegel macht noch einen weiteren Aspekt der immanenten Kritik ersichtlich. In ihrer kritischen Überprüfung deckt immanente Kritik, so wie auch die klassische Form der Ideologiekritik bei Adorno, ${ }^{181}$ Mechanismen der Legitimierung von Herrschaftsformen auf. Diese sind Mechanismen der „Selbstverständlichmachung“ 182 und bestehen typischerweise in der Naturalisierung von gesellschaftlich bedingten Phänomenen und in der Universalisierung von Partikularitäten. Die Verknüpfungen mit dem Zweck der genealogischen Kritik Foucaults, wie oben beschrieben, sind offensichtlich. Und doch beschränkt sich immanente Kritik nicht auf den Verweis auf die historische oder gesellschaftliche Konstitution

179 Jaeggi verdeutlicht diese Idee mit Verweis auf Marx’ Kritik der bürgerlichen Ideale der Gleichheit und Freiheit. In der bürgerlichen Gesellschaft gilt eine naturrechtliche Auffassung von Freiheit und Gleichheit, die aber in ihrer Realisierung in der Praxis zu Widersprüchen und zu einer Verkehrung der Ideale selbst führt. Nun liegt die Auflösung dieser Widersprüche laut Marx nicht in einer besseren Angleichung der bürgerlichen Praxis an die naturrechtlichen Konzeptionen der Gleichheit und der Freiheit, sondern sie bedarf auch einer Transformation der normativen Konzepte hin zu einer positiven Freiheit und einer materiellen Gleichheit. Vgl. Jaeggi, Was ist Ideologiekritik?, 288.

180 Hegel, Georg Wilhelm Friedrich, Werke. Band 5: Wissenschaft der Logik. Teil 1: Die objektive Logik, hg. v. Moldenhauer, Eva. Frankfurt am Main: Suhrkamp 1990, 49 (zuerst veröffentlicht 1812).

181 Vgl. Adorno, Beitrag zur Ideologienlehre.

182 Jaeggi, Was ist Ideologiekritik?, 269. 
von dem, was uns als universal oder natürlich präsentiert wird. Anders als genealogische Kritik, die lediglich die Möglichkeit der Transformation begreifbar machen will, zielt immanente Kritik darauf ab, eine Transformation „zum Besseren" herbeizuführen.

Wie ist dies aber möglich, ohne auf eine - problematische - Teleologie im Stil Hegels zu rekurrieren?183 Für Jaeggi ist die Lösung dieses Problems in einer situierten Konzeption des „Besseren“ zu suchen: Das, was einen Zustand oder einen Lösungsvorschlag besser im Vergleich zu dem kritisierten macht, ist seine Fähigkeit, die konkreten Widersprüche und Probleme des analysierten Zustandes effektiv zu adressieren. Das macht diese Form immanenter Kritik besonders fruchtbar als Vorgehensweise des kritischen Realismus, weil sie der Kontextgebundenheit der realistischen Lösungsansätze entspricht, die ich oben als konstitutiv für den methodologischen Realismus herausgearbeitet habe. ${ }^{184}$

Eine weitere Eigenschaft immanenter Kritik im Sinne Jaeggis, die sie für besonders geeignet als Vorgehensweise des gegenwärtigen Realismus erscheinen lässt, ist die Durchdringung von Analyse und Kritik, von Deskription und Präskription. Wie ich oben geschildert habe, relativiert der gegenwärtige Realismus die strikte Trennung zwischen Fakten und Normen oder zwischen Deskription und Evaluation, die typisch für ideale Ansätze ist. ${ }^{185}$ Einerseits weist immanente Kritik, so wie Ideologiekritik auch, auf die normativen Elemente jeder Weltauffassung hin. Entsprechend identifiziert die Analyse der gesellschaftlichen Realität sowohl die Fakten als auch die Normen, die in ihr konstitutiv sind. Andererseits sind die Evaluationen und Präskriptionen der immanenten Kritik fest in der Analyse der Realität verankert, weil sie, wie ich geschildert habe, darauf abzielen, die für die analysierte Realität spezifischen, konkreten Widersprüche und Probleme zu bewältigen. Auch das macht immanente Kritik besonders affin zum Unternehmen des gegenwärtigen Realismus, der die Validität

183 Über die teleologischen Voraussetzungen der immanenten - oder in Honneths Worten: der „rekonstruktiven“ - Kritik vgl. Honneth, Axel, Rekonstruktive Gesellschaftskritik unter genealogischem Vorbehalt. Zur Idee der „Kritik“ in der Frankfurter Schule, in: Deutsche Zeitschrift für Philosophie, 48/5, 2000, 729-737.

184 Vgl. oben Abschnitt 2.3.

185 Vgl. oben Abschnitt 2.3. 
bestimmter Lösungsansätze daran bemisst, ob sie sich in ihrer Einbettung in sozialen Praktiken als wirksam bewähren. ${ }^{186}$

\subsection{Fruchtbarkeit der nicht transzendentalen Kritik für die Untersuchung der Legitimität der EU-Sicherheitspolitik}

In den vorigen Abschnitten habe ich den Umgang des methodologischen Realismus mit dem scheinbaren Paradoxon von Immanenz und Kritik verdeutlicht.

Die zwei vorgestellten kritischen Vorgehensweisen (genealogisch und immanent) ermöglichen es, eine kritische Distanz gegenüber den Gegebenheiten zu schaffen, ohne auf eine externe (ideale, objektive, universale) Perspektive zu rekurrieren. Dabei eröffnen diese zwei kritischen Ansätze die Möglichkeit einer Transformation der Realität, indem das, was als notwendig und natürlich gilt, als historisch konstituiert erscheint, und indem die Aufdeckung und Lösung der vorhandenen Widersprüche den konkreten Weg einer möglichen Transformation aufzeigen.

In den nächsten Kapiteln dieses Buches werde ich insbesondere auf Foucaults und Jaeggis Formen der Kritik zurückgreifen. Zunächst werde ich im zweiten Kapitel den normativen Kontext rekonstruieren, der die immanenten Ideale und Werte liefert, an welche die nicht transzendentale Kritik anknüpft. Dabei werde ich auch die groben Linien ihrer historischen Entstehung skizzieren. Im zweiten Teil des Buches (Kapitel 3 bis 7) werde ich dann sowohl Foucaults als auch Jaeggis Form der Kritik für die Analyse der EU-Sicherheitsmaßnahmen fruchtbar machen. Einerseits, im Sinne der genealogischen Kritik Foucaults, werde ich rekonstruieren, wie bestimmte Phänomene im RFSR als Sicherheitsprobleme aufgefasst wurden und eine Reihe von Maßnahmen hervorgerufen haben, die sich mit deren Lösung beschäftigen. Andererseits, im Sinne von Jaeggis immanenter Kritik, werde ich die konkrete Durchführung dieser Maßnahmen analysieren und die Widersprüche hervorheben, die sich aus der Konfrontation der Maßnahmen mit den Idealen, die ihrer Legitimation dienen, ergeben. Im dritten Teil, und insbesondere im neunten Kapitel, werde ich dann aufgrund dieser Analyse die Richtung einer möglichen Transformation aufzeigen, die

186 Vgl. Schaub, Politische Theorie als angewandte Moralphilosophie? Die realistische Kritik, 22; Tully, Public Philosophy in a New Key (Ideas in Context), 27 und Geuss, Kritik der politischen Philosophie, 31-32. 
durch Modifizierung sowohl der Praktiken als auch der Ideale zur Lösung der identifizierten Widersprüche und Probleme beitragen kann.

\section{Kritik am kritischen Realismus und Lösungsansätze}

Ich wende mich nun den Kritiken zu, die gegen den gegenwärtigen Realismus erhoben wurden, um anschließend womöglich Perspektiven für ihre Überwindung aufzuzeigen. Die Kritiken lassen sich in drei Stränge bündeln.

Ein Strang bemängelt, dass der kritische Realismus die philosophische Tradition, von der er sich abgrenzen will, vereinfacht darstellt. So hat zum Beispiel Robert Jubb argumentiert, dass Rawls' Ansatz realistischer sei, als von den Realist_innen angenommen wird. ${ }^{187}$ Ganz ähnlich hat etwa William E. Scheuerman bemängelt, dass Geuss' Kritik der habermasschen Theorie keine akkurate Auseinandersetzung mit Habermas' Hauptwerk Faktizität und Geltung enthält. ${ }^{188}$ Obwohl diese Kritiken wichtig sind, werden sie hier nicht weiter diskutiert, weil dies einer tiefgreifenden Analyse der Werke von Rawls, Habermas und den anderen Anhänger_innen des politischen Moralismus bedürfen würde, die außerhalb der Reichweite dieser Abhandlung liegt. Darüber hinaus braucht der gegenwärtige Realismus die Kritik an sogenannten moralistischen Ansätzen, um die eigene Spezifizität zu verdeutlichen, nicht aber, um sie zu konstituieren. Daher stellt die oben genannte Kritik meines Erachtens nicht infrage, dass der methodologische Realismus eine originelle Denkrichtung in der politischen Philosophie ist. ${ }^{189}$

Der zweite Strang der Kritik besteht aus Auseinandersetzungen mit Williams' Ansatz. Williams ist unter den hier vorgestellten Autor_innen derjenige, der bislang die realistischen Anforderungen an die politische Philosophie am ausführlichsten in Form eines positiven Vorschlags konkretisiert hat. Daher ist es auch nicht überraschend, dass die meisten konkreten Kritiken sich an seine Theorie richten. Ich werde hier nicht

187 Vgl. Jubb, Playing Kant at the Court of King Arthur.

188 Vgl. Scheuerman, The realist revival in political philosophy, 800.

189 Die Originalität des gegenwärtigen Realismus wurde unabhängig von diesen Kritiken ausführlich belegt, vgl. etwa Sleat, Matt, Realism, Liberalism and Nonideal Theory. Or, Are there Two Ways to do Realistic Political Theory?, in: Political Studies, 64/1, 2016, 27-41. 
alle Kritiken aufgreifen, sondern nur diejenigen, die Aspekte betreffen, die auch konstitutiv für den realistischen Ansatz insgesamt sind. ${ }^{190}$

Meiner Meinung nach besteht die schwerwiegendste dieser Kritiken an Williams in dem Vorwurf, die geforderte Trennung zwischen Politik und Moral durch die Legitimitätsanforderungen zu verwischen. Dieser Vorwurf ist für den gesamten realistischen Ansatz bedeutend, nicht nur weil die Idee, dass Legitimität konstitutiv für das Politische ist, auch von anderen realistischen Autor_innen geteilt wird. Vielmehr ist diese Idee der Schlussstein, der die für den Realismus zentrale Forderung der Trennung zwischen Politik und Moral trägt. Denn die Behauptung, dass politische Philosophie keine angewandte Ethik sein darf, kann nur dann sinnvoll vom gegenwärtigen Realismus vertreten werden, wenn gezeigt wird, dass das Politische über eine eigene Quelle der Normativität verfügt. Sonst würde der politische Realismus in eine Konzeption des Politischen als ein durch reine Macht- und Interessenkonflikte definiertes Feld zurückfallen, die er explizit ablehnt. Also lässt sich die Kernidee des methodologischen Realismus, dass Politik durch eigenständige politische Konzepte verstanden und evaluiert werden kann, nur durch die Möglichkeit einer genuin politischen Normativität begründen, welche durch die Kategorie der Legitimität verkörpert wird.

Nun bietet Williams eine Darstellung dessen, was eine realistische Konzeption der Legitimität sein könnte. Er tut das durch die Idee eines grundlegenden Legitimitätsanspruchs, der charakteristisch für politische Autorität sein soll, nicht aber für reine Machtbeziehungen. Ich habe bereits oben ausgeführt, wie die Idee von Williams, dass dies eine der Politik immanente Eigenschaft sei, plausibel gemacht werden kann. ${ }^{191}$ Ich habe dort argumentiert, dass dieser Anspruch auf Legitimität das ist, was politische Ordnungen von nicht politischen Machtsystemen, die einen gewissen Grad von Organisation besitzen (Augustinus' Räuberbande oder Williams' Terrorherrschaft), unterscheidet. Es könnte jedoch weiterhin eingewendet werden, dass es historisch Machtsysteme gegeben hat, die sich politischer Institutionen (etwa des Staatsapparats) bedient haben, die aber unter keinen Umständen einen ernsthaften Legitimitätsanspruch erfüllen könnten. Ein Beispiel dafür wäre Deutschland unter dem Nationalsozialismus. Es gibt meiner Meinung nach zwei Wege, auf einen solchen Einwand zu antworten. Einer bestünde darin, zu behaupten, dass der Nationalsozialis-

190 Für eine Replik auf die Kritiken, die hier nicht diskutiert werden, vgl. Hall, Bernard Williams and the Basic Legitimation Demand.

191 Vgl. oben Abschnitt 2.1. 
mus wohl einen Legitimitätsanspruch erhoben hätte. Dieser Anspruch wäre nach den eigenen Maßstäben der nationalsozialistischen rechtlichpolitischen Konzeption gültig gewesen, er läuft aber anderen damaligen und unseren heutigen freiheitlich-demokratischen Legitimitätsvorstellungen zuwider. Nach dieser Argumentationslinie wäre jede Machtorganisation politisch, die einen Legitimitätsanspruch erhebt, unabhängig davon, ob dieser nach irgendwelchen Maßstäben erfüllt werden kann. Meiner Meinung nach würde aber eine solche Argumentationslinie den Vorwurf des Relativismus bestätigen und den realistischen Ansätzen jegliche normativ-evaluative Kraft gegenüber politischen Systemen absprechen. Dies ist außerdem nicht der Weg, den Williams einschlägt. Denn Williams fügt als Bedingung für die Erfüllung des Legitimationsanspruchs die Idee hinzu, dass politische Macht sich dadurch rechtfertigen muss, dass die realisierte politische Ordnung nicht „Teil des Problems ist“, nämlich nicht die gleichen basalen Übel reproduziert, die sie beseitigen soll. Diese Bedingung war offensichtlich durch das NS-Regime nicht erfüllt. Wenn nun behauptet würde, dass das NS-Regime wohl politisch war, nicht aber legitimiert, wäre Williams' These, wie oben angedeutet, zirkulär, weil die Erfüllung des Legitimitätsanspruchs zwar eine Bedingung für eine legitime politische Organisation, nicht aber für eine politische Organisation tout court wäre. ${ }^{192}$

Die Lösung zu diesem Problem besteht meiner Meinung nach in einer zweiten Argumentationslinie, die von Mark Philp aufgezeigt wurde. Einerseits räumt Philp ein, dass das NS-Regime sich eindeutig politischer Institutionen bediente und politische Autorität ausübte. Die spezifische Machtbeziehung, die das NS-Regime aufrechterhielt, ist jedoch nicht als politische Beziehung, sondern viel treffender als „Beherrschung“ zu begreifen. Der Staat unter dem NS-Regime wurde durch einen inneren Machtkern regiert, der über keine Legitimität verfügte und auch nicht daran interessiert war, die eigene politische Autorität zu sichern, sondern nur darauf aus war, Beherrschung aufzubauen. ${ }^{193}$ Verallgemeinert verdeutlicht das Beispiel die These, dass es Machtorganisationen geben kann, die prima facie politisch erscheinen, weil sie sich politischer Formen und Institutionen bedienen, jedoch keine genuin politischen Beziehungen mit den Personen, die ihrer Macht unterstehen, unterhalten. In diesem Sinne stellt die

192 Vgl. oben Abschnitt 2.1.

193 Vgl. Philp, Mark, Political Conduct. Harvard: Harvard University Press 2007, 7173, zitiert in Hall, Bernard Williams and the Basic Legitimation Demand, 477. 
Existenz solcher Regime keinen Einwand gegen Williams' (und Geuss') Auffassung dar, dass Legitimität eine inhärente politische Kategorie ist. ${ }^{194}$

Der Kritik an Williams' Auffassung, relevante normative Kriterien könnten im Politischen verortet werden, wurde auch mit der Behauptung entgegnet, dass wir institutionelle Gewalt aufgrund von moralischen Vorstellungen ablehnen und nicht, weil sie die politische Ordnung gefährden. ${ }^{195}$ Jedoch ist diese Kritik meiner Meinung nach nicht entscheidend: Selbst wenn wir die Ablehnung von institutionalisierter Folter auch durch moralische Argumente begründen können, schließt das nicht aus, dass wir auch eine genuin politische Erklärung bieten können, warum von einem Staat gebilligte oder ausgeübte Folter diesem die Legitimität abspricht - was Williams' Ansatz meiner Meinung nach erfolgreich tut.

Ein dritter Strang der Kritik besteht schließlich aus Einwänden, die das Fehlen einer konkreten Analyse und Kritik der Politik bemängeln oder sogar dem methodologischen Realismus die Fähigkeit absprechen, eine solche Analyse liefern zu können. Dieser Strang kann in die folgenden drei Subargumente unterteilt werden.

Das erste Argument setzt am kritischen Potenzial des gegenwärtigen Realismus an und weist darauf hin, dass noch unklar sei, wie dieser

194 Weitere Kritiken, die Williams' Ansatz vorwerfen, die Moral durch die Hintertür wieder hereinzulassen, setzen an seiner Idee an, dass eine politische Organisation jeder Person eine Rechtfertigung schulde, was nach diesen Kritikern nur durch den moralischen Status des Menschen begründet werden könne. Vgl. Sleat, Bernard Williams and the possibility of a realist political theory und, als Antwort darauf, Hall, Bernard Williams and the Basic Legitimation Demand. Auch wurden Williams und Shklar wegen ihres Universalismus der Menschenrechte als inkohärent kritisiert: vgl. Flathman, In and out of the ethical; Forrester, Judith Shklar, Bernard Williams and political realism, 265. Schließlich wurde Williams' Auffassung kritisiert, dass im „Hier und Jetzt“, nämlich in den modernen westlichen Gesellschaften, das demokratisch-liberale Modell das einzige ist, das als legitim erscheint. Dieser Kritik zufolge übersieht Williams den (den westlichen Gesellschaften) internen Dissens mit dem liberaldemokratischen Modell. Für zwei verschiedene Repliken auf diese Kritik vgl. Runciman, Political Theory and Real Politics in the Age of the Internet, 11 und Hall, Bernard Williams and the Basic Legitimation Demand, 470-472. Hier werden diese Kritiken und mögliche Gegenargumente nicht weiter vertieft, weil sie meiner Meinung nach nur partikuläre Aspekte der Theorie von Williams betreffen, die nicht konstitutiv für den gesamten gegenwärtigen realistischen Ansatz sind.

195 Vgl. Scheuerman, The realist revival in political philosophy, 807-808. 
kritisch sein könne. ${ }^{196}$ Diese Kritik ist sozusagen die Kehrseite der Distanzierung des gegenwärtigen Realismus vom politischen Moralismus. Letzterer würde eine Reihe von Werten fixieren, die unabhängig von den politischen Fakten wären und dadurch externe, rationale und objektive Kriterien liefern würden, um die Fakten der Politik zu bewerten. Wie oben dargestellt, verneint der methodologische Realismus, dass ein solches Verfahren erfolgreich sein kann, weil wir keinen Zugang zu objektiven, letztlich begründeten oder universalen Werten haben. Andererseits will der gegenwärtige Realismus nicht auf eine kritische Beurteilung und auf die Möglichkeit einer Transformation der Realität verzichten. Damit steht er vor dem scheinbaren Paradoxon, von den Fakten der Politik auszugehen und diese infrage stellen zu wollen. Wie dieses Paradoxon gelöst werden kann, habe ich oben unter Bezugnahme auf die Epistemologie des späten Wittgensteins und durch Rekurs auf das genealogische Vorgehen und auf die immanente Kritik geschildert. ${ }^{197}$ Wie oben bereits angedeutet, werde ich in den nächsten Kapiteln auf diese Verknüpfung des Realismus mit den Formen der nicht transzendentalen Kritik aufbauen und sie für die Frage nach der Legitimität der EU-Sicherheitspolitik fruchtbar machen.

Eine zweite Kritik wirft dem Realismus vor, zu fokussiert auf die traditionellen Konzeptionen der Macht und der Legitimität zu sein, die als institutionelles Zentrum den Staat haben. Dies würde dem Realismus das Verständnis von informelleren Machtphänomenen und insbesondere von den durch die Digitalisierung hervorgebrachten Veränderungen verbauen. Der Realismus hätte zwar das Potenzial, über diese staatszentrierte Konzeption hinauszugehen, hätte dieses Potenzial aber bisher nicht entfaltet. ${ }^{198}$

Ich werde im Teil II dieses Buches versuchen, den realistischen Ansatz für eine Analyse der gegenwärtigen politischen Realität fruchtbar zu machen. Für diese Analyse spielen politische Institutionen zwar eine wichtige Rolle, sie werden aber nicht mit den Staatsinstitutionen gleichgesetzt. Vielmehr fokussiert die Analyse auf dynamische und hybride institutionelle Komplexe, wie sie sich gegenwärtig im RFSR abzeichnen. In diesem Kontext spielt die Digitalisierung für den sicherheitspolitischen Ansatz der EU eine konstituierende Rolle, wie ich zeigen werde. Damit wird sich, wie ich hoffe, eine kritisch-realistische Annäherung auch für die Untersu-

196 Vgl. Schaub, Politische Theorie als angewandte Moralphilosophie? Die realistische Kritik, 16.

197 Vgl. oben Abschnitt 3 in diesem Kapitel.

198 Vgl. Runciman, Political Theory and Real Politics in the Age of the Internet, 4. 
chung der im Zuge der Digitalisierung hervorgebrachten Veränderungen als fruchtbar erweisen.

Eine dritte Ausrichtung der Kritik behauptet, dass der politische Realismus bei einer bloßen Haltung bleibe, die aber bislang nicht in der Lage gewesen sei, eine echte Analyse der politischen Realität durchzuführen und stattdessen nur sehr abstrakte Aussagen formuliert habe. ${ }^{199}$

Für einige Autor_innen besteht das Haupthindernis des Realismus, weswegen er bisher keine Analyse der Realität bieten konnte, in seinem Eklektizismus. Der gegenwärtige Realismus beruft sich auf eine Reihe von Autor_innen, die für die Interpretation der politischen Realität in verschiedene, konkurrierende Richtungen weisen, wie die ökonomischen Produktionsverhältnisse bei den Marxisten, die Konstruktion der modernen Subjektivität bei Nietzsche oder die staatlichen Institutionen bei Weber und Shklar. ${ }^{200}$

Manche Autor_innen gehen einen Schritt weiter und behaupten, der Realismus solle bei der Aufforderung, die Politik „realistisch“ zu betrachten, bleiben, sich aber nicht als eigenständige Schule etablieren. Denn jeder Versuch, eine realistische politische Philosophie näher zu bestimmen, werde unvermeidlich mit der Hervorhebung der Einschränkungen einer solchen Philosophie enden, sodass am Ende nur der Eindruck einer defizitären Denkrichtung bleibe. ${ }^{201}$

In Bezug auf diese Richtung der Kritik hoffe ich, im vorliegenden Kapitel eine Darstellung des gegenwärtigen Realismus geboten zu haben, die sich zu einem kohärenten Bild zusammenfügt. Dieses Unternehmen musste einen Preis in Bezug auf die Vollständigkeit bezahlen: Meine Charakterisierung des methodologischen Realismus bleibt notwendigerweise

199 Vgl. Scheuerman, The realist revival in political philosophy. Vgl. auch, obwohl konform mit der grundlegenden Ausrichtung des politischen Realismus, Horton, John, Realism, liberal moralism and a political theory of modus vivendi, in: European Journal of Political Theory, 9/4, 2010, 431-448. Für die These, dass der politische Realismus innerhalb der politischen Philosophie nicht weiterentwickelt werden kann, vgl. Sagar, From Scepticism to Liberalism?

200 Vgl. Scheuerman, The realist revival in political philosophy, 811.

201 Vgl. Runciman, What Is Realistic Political Philosophy?, 68-69. Für Runciman kann Philosophie allein zu keinem vollständigen Verständnis der Politik gelangen, sondern nur in Anlehnung an andere Disziplinen. Die Offenheit gegenüber Interdisziplinarität und die Ablehnung scharfer Abgrenzungen, etwa zwischen politischer Philosophie einerseits und Soziologie, politischer Theorie und Politikwissenschaften andererseits, ist auch ein Anliegen der Realist_innen, vgl. etwa Geuss, Realismus, Wunschdenken, Utopie, 419 und Forrester, Judith Shklar, Bernard Williams and political realism, 250. 
selektiv. Mein Ziel dabei war es, ausgehend von verschiedenen Ansätzen des gegenwärtigen Realismus einen kohärenten Komplex zu konstruieren, wobei das Ziel der Rekonstruktion nicht in erster Linie war, philologisch, vollständig und treu die Positionen der einzelnen Autor_innen widerzuspiegeln, sondern sie brauchbar für eine kritische Analyse gegenwärtiger politischer Phänomene zu machen. Diese Charakterisierung ist nicht, wie dem Realismus von manchen Kritiken vorgeworfen wird, rein negativ geblieben, sondern enthält auch eine Beschreibung positiver Bestandteile des kritischen Realismus. Den Einwand, dass der Beitrag des Realismus zur politischen Philosophie nicht über einen reinen Methodenstreit hinausgehen kann, möchte ich in den folgenden Teilen des Buches konkret widerlegen.

Im nächsten Abschnitt werde ich zu diesem Zweck zunächst erläutern, wie die fünf Grundmerkmale des kritischen Realismus, die ich im zweiten Abschnitt dieses Kapitels herausgearbeitet habe, für die Erforschung der Legitimität politischer Maßnahmen operationalisiert werden können. Auf dieser Basis werde ich dann im nächsten Kapitel die philosophischen Grundprinzipien herausarbeiten, die für die Legitimität der EU-Maßnahmen im RFSR maßgeblich sind. Diese werden die Grundlage liefern, sowohl für die Analyse der konkreten Maßnahmen im zweiten Teil als auch für deren theoretische und normative Auswertung im dritten Teil dieses Buches.

\section{Eine kritisch-realistische Annäherung an die EU-Sicherheitspolitik}

Wie können die Grundzüge des kritischen Realismus, so wie ich sie rekonstruiert habe, die Untersuchung der Frage nach der Legitimität der EU-Politik leiten? Diese Frage möchte ich nun beantworten, indem ich spezifizieren werde, wie die fünf Grundcharakteristika des kritischen Realismus und seine vorgeschlagene Erweiterung um transformativ-normative Aspekte die Durchführung dieser Untersuchung leiten werden. Dabei werde ich mich auf die grundlegende Stoßrichtung der Untersuchung konzentrieren. Die konkrete Art und Weise, wie ich den kritisch-realistischen Ansatz für die Analyse der Legitimität der EU-Maßnahmen operationalisiere, werde ich in Kapitel 2 verdeutlichen. ${ }^{202}$

Die ersten zwei Grundcharakteristika des gegenwärtigen Realismus, nämlich die Priorität der Politik vor der Moral und die der Fakten vor den Prinzipien, werden die folgenden Erörterungen insofern prägen, als

202 Vgl. unten Kapitel 2, Abschnitt 3. 
ich keine ideale Theorie der Legitimität anbiete, die in moralischen Prinzipien gründet. Vielmehr nehme ich das Konzept der Legitimität als politischen Begriff zum Ausgangspunkt der Analyse und versuche ihn so zu konturieren, wie er als normatives Konzept in der Realität wirksam ist. ${ }^{203}$ Darüber hinaus werde ich mich im zweiten Teil dieses Buches auf konkrete politische Maßnahmen konzentrieren und ihre Entstehung, die Argumente, durch die sie gerechtfertigt werden, ihre tatsächliche Anwendung sowie ihre Auswirkungen rekonstruieren. Entsprechend dem Prinzip der Priorisierung der politischen Fakten über Ideale basieren die theoretischen Aussagen und Generalisierungen, die im dritten Teil des Buches formuliert werden, auf den im zweiten Teil durchgeführten konkreten Analysen. Ebenfalls durch die Verankerung in den Fakten geprägt ist die besondere Aufmerksamkeit, welche die durchgeführte Analyse den Institutionen als fragilen und gleichzeitig unverzichtbaren Mechanismen der Durchführung, aber auch der Eingrenzung der Macht schenkt.

Die dritte Grundeigenschaft des gegenwärtigen Realismus, nämlich die Kontextgebundenheit der politischen Philosophie, inspiriert die hier durchgeführte Analyse in folgender Hinsicht: Im zweiten Kapitel wird ein Konzept der Legitimität herausgearbeitet, das „hier und jetzt“, nämlich gegenwärtig auf EU-Ebene und im Kontext der europäischen Sicherheitspolitik, gilt. Dieses Modell wird nicht als ein universelles, ahistorisches oder rein rationales Legitimitätsmodell präsentiert und verteidigt, sondern als ein Modell, das historisch gewachsen ist und aus diesem historischen Hintergrund heraus gegenwärtig für uns normativ „Sinn ergibt“.

Der Negativismus des kritischen Realismus wird in der Untersuchung dadurch ersichtlich, dass sie durch die Annahme der permanenten Möglichkeit des Machtmissbrauchs geleitet wird. Bei der Analyse der EU-Maßnahmen im zweiten Teil des Buches werde ich in diesem Sinne auf Risiken der Sicherheitsmaßnahmen als Ausweitung der Machtbefugnisse hinweisen. Sehr im Sinne der negativistischen Prägung des kritischen Realismus ist auch die Ausrichtung des dritten Teils des Buches, in dem Ansätze vorgeschlagen werden, welche die konkret identifizierten Möglichkeiten des Machtmissbrauchs verhindern, anstatt einen optimalen, ideal definierten Zustand herbeiführen sollen.

Dabei wird die Fruchtbarkeit der nicht transzendentalen Kritikmethoden besonders sichtbar. Diese ermöglichen es, das scheinbare Paradoxon von Immanenz und Kritik zu überwinden.

203 Vgl. das Kapitel 2 dieses Buches. 
Das genealogische Vorgehen ermöglicht es, eine kritische Distanz gegenüber den Gegebenheiten zu schaffen, ohne auf eine externe (ideale, objektive, universale) Perspektive zu rekurrieren. Indem er das, was als notwendig und objektiv gilt, als historisch konstituiert erscheinen lässt, eröffnet der genealogische Ansatz die Möglichkeit einer Transformation der Realität. Der konkrete Weg dieser Transformation wird dann im Sinne einer immanenten Kritik durch Aufdeckung und Lösung der vorhandenen Widersprüche aufgezeigt.

In den nächsten Kapiteln dieses Buches werde ich auf diese kritischen Ansätze zurückgreifen. Zunächst werde ich im zweiten Kapitel den normativen Kontext rekonstruieren, der die immanenten Ideale und Werte liefert, an welche die nicht transzendentale Kritik anknüpft. Dabei werde ich auch die groben Linien ihrer historischen Entstehung skizzieren. Im zweiten Teil des Buches (Kapitel 3 bis 7) werde ich dann sowohl Foucaults als auch Jaeggis Form der Kritik für die Analyse der EU-Sicherheitsmaßnahmen fruchtbar machen. Einerseits werde ich rekonstruieren, wie bestimmte Phänomene im RFSR als Sicherheitsprobleme aufgefasst wurden und eine Reihe von Maßnahmen hervorgerufen haben, die sich mit deren Lösung beschäftigen. Andererseits werde ich die konkrete Durchführung dieser Maßnahmen analysieren und die Widersprüche hervorheben, die sich aus der Konfrontation der Maßnahmen mit den Idealen, die ihrer Legitimation dienen, ergeben. Im dritten Teil, und insbesondere im neunten Kapitel, werde ich dann aufgrund dieser Analyse die Richtung einer möglichen Transformation aufzeigen, die durch Modifizierung sowohl der Praktiken als auch der Ideale zur Lösung der identifizierten Widersprüche und Probleme beitragen kann. 


\section{Kapitel 2 Legitimität im Kontext der EU}

\section{Operationalisierung des realistischen Ansatzes}

Im ersten Kapitel habe ich den methodologischen Ansatz dieser Untersuchung vorgestellt. Ich werde nun diesen realistischen Ansatz operationalisieren, um der Frage nach den Legitimationsprinzipien der EU nachzugehen.

Zunächst werde ich einen kurzen begrifflichen Überblick bieten, der das Konzept der Legitimität in sehr abstrakter Art und Weise skizziert und es sowohl vom Begriff der Legalität als auch vom Begriff der Legitimation abgrenzt. Dies wird eine vorläufige Fixierung des Begriffes ermöglichen, die als Grundlage der darauffolgenden Analyse dient.

Im dritten Abschnitt dieses Kapitels werde ich ferner verdeutlichen, wie die fünf Merkmale des gegenwärtigen Realismus, die ich im ersten Kapitel dargestellt habe, konkret in diesem Buch entfaltet werden. Die fünf Hauptcharakteristika des kritischen Realismus sind die Priorisierung der Politik über die Moral und die der Fakten über Ideale, die Verdeutlichung der Kontextgebundenheit der Werturteile, ein gewisser Negativismus und die Ausübung einer nicht transzendentalen Kritik.

Im vierten Abschnitt dieses Kapitels gehe ich der Frage nach, welche Konzeptionen der Legitimität für die EU maßgeblich sind. Hier werde ich den realistischen Ansatz operationalisieren, indem ich kein ideales Konzept der Legitimität für die EU entwerfe, sondern die Legitimitätsprinzipien identifizieren werde, die „hier und jetzt“ für die EU normativ gelten. Wie im ersten Kapitel erläutert, bedeutet dies nicht, die normative Dimension auszuschließen, sondern die normativen Aspekte zu rekonstruieren, in Bezug auf welche die EU ihren Legitimitätsanspruch erhebt und die Gültigkeit dieses Anspruchs von seinen Adressat_innen bewertet wird. ${ }^{204}$ Dabei werde ich verschiedene konkurrierende Legitimationsmodelle be-

204 Für den Zusammenhang zwischen deskriptiven und normativen Aspekten in Bezug auf die Legitimität vgl. zusätzlich zum Kapitel 1 und der darin ausgeführten Literatur auch Schmelzle, Cord, Politische Legitimität und zerfallene Staatlichkeit. Frankfurt am Main: Campus Verlag 2015, insbesondere Kapitel 1 und Loh, Wulf, Konsens und Autonomie - Zur Legitimität völkerrechtlicher Normen, in: Rechtsphilosophie - Zeitschrift für Grundlagen des Rechts, 1, 2018, 58-77. 
sprechen, die als Modell der Legitimation der EU-Politik vorgeschlagen wurden, etwa das internationale, das technokratische, das rechtfertigungsbasierte und das demokratisch-rechtsstaatliche Paradigma. Ich werde dann die These aufstellen, dass das Modell des demokratischen Rechtsstaates nunmehr die primäre Quelle für die Legitimationsprinzipien der EU liefert.

Hiermit verdeutlicht sich aber ein Problem: In welchem Sinne kann der demokratische Rechtsstaat Legitimationsansätze für die EU liefern, wenn die EU offensichtlich keine staatliche Form besitzt? Soll die Schlussfolgerung gezogen werden, dass die EU, um legitim zu sein, eine staatliche Form annehmen muss? Diese Frage werde ich negativ beantworten und im fünften Abschnitt darlegen, dass Rechtsstaatlichkeit und Demokratie die grundlegenden philosophischen Prinzipien der Legitimation der EU-Politik liefern, ohne eine Angleichung der EU an die staatliche institutionelle Architektur vorauszusetzen. Ich werde darüber hinaus das Modell des demokratischen Rechtsstaates entsprechend historisch und philosophisch rekonstruieren, um den Kern des Legitimitätsanspruchs der EU zu identifizieren.

Schließlich werde ich im sechsten Abschnitt die Legitimitätskriterien herausarbeiten, die in den folgenden Kapiteln meine Analyse spezifischer EU-Sicherheitsmaßnahmen im Sinne einer immanenten Kritik leiten werden.

\section{Begriffliche Annäbrungen: Legalität, Legitimation und Legitimität als machtstabilisierende Faktoren}

Im ersten Kapitel habe ich in Anlehnung an Bernard Williams argumentiert, dass Legitimität eine konstitutive Kategorie des Politischen ist. In diesem Kapitel werde ich untersuchen, wie diese Kategorie im Kontext der EU-Politik konkretisiert werden kann. Zunächst ist es aber nötig, die Funktion des Begriffs der Legitimität im politischen Denken zu definieren, insbesondere in Abgrenzung zu den Begriffen der Legalität und der Legitimation, sowie auch seine doppelte Natur als zugleich Anspruch seitens der Autorität und Akzeptanz seitens der Normadressat_innen.

Aus philosophischer Sicht setzt die Legitimität einer rechtlich-politischen Ordnung zwei Bedingungen voraus: dass die politische Autorität berechtigt ist, politische Macht auszuüben, und dass die geltenden Rechtsprinzipien und die eingesetzten Herrschaftstechniken gerechtfertigt 
sind. ${ }^{205}$ Insofern transzendiert der Begriff der Legitimität denjenigen der bloßen Legalität. Legalität als Rechtskonformität bedeutet die Übereinstimmung mit dem gesatzten Recht, während Legitimität sich auf Prinzipien bezieht, die über das positive Recht hinausgehen. ${ }^{206}$

Legitimität unterscheidet sich auch von Legitimation. Während Legitimität den Zustand des Legitimseins (von Ordnungen, Entscheidungen oder Akteur_innen) betrifft, wird Legitimation als das Ensemble der Prozesse und Praktiken verstanden, die Legitimität verleihen. ${ }^{207}$ Dies verweist auf die Dimension der Legitimität als Ergebnis eines Prozesses, wodurch Strategien der Legitimation sich als erfolgreich oder nicht erfolgreich erweisen.

Aus dieser Perspektive kann Legitimität zunächst als Anspruch seitens der Autorität gesehen werden. Denn jede Autorität versucht, ihre Existenz und ihr Fortbestehen nicht als bloßes Faktum oder als rein zweckrational darzustellen, sondern versucht auch, sich als legitime Autorität zu präsentieren. Zugleich impliziert Legitimität als Zustand des Legitimseins aber auch die Akzeptanz dieses Anspruchs seitens der Adressat_innen (in der Terminologie Max Webers: den „Legitimitätsglauben“). ${ }^{208}$

205 Vgl. Özmen, Elif, Politische Philosophie zur Einführung. Hamburg: Junius-Verlag 2013, 33 und Celikates, Robin; Gosepath, Stefan, Grundkurs Philosophie. Politische Philosophie. Stuttgart: Reclam 2013, 34-36.

206 Vgl. Würtenberger, Thomas, Legitimität, Legalität, in: Brunner, Otto; Conze, Werner; Koselleck, Reinhart (Hg.), Geschichtliche Grundbegriffe, Bd. 3. Heidelberg: Klett-Cotta 1982, 677-740, hier 677; Schmitt, Carl, Legalität und Legitimität. Berlin: Duncker \& Humblot 1988 (zuerst veröffentlicht 1932). Dass die Legitimitätsprinzipien über das „bloß gesatzte Recht“ hinausgehen, bedeutet nicht, dass diese Prinzipien nicht auch - wenigstens teilweise - positiviert werden können, etwa in den staatlichen Verfassungen. Über die Beziehung zwischen Legitimität und Legalität und die Nicht-Reduzierbarkeit der einen auf die andere vgl. auch Habermas, Jürgen, Wie ist Legitimität durch Legalität möglich?, in: Kritische Justiz, 1, 1987, 1-16.

207 Vgl. Zürn, Michael, Autorität und Legitimität in der postnationalen Konstellation, in: Geis, Anna; Nullmeier, Frank; Daase, Christopher (Hg.), Der Aufstieg der Legitimitätspolitik. Rechtfertigung und Kritik politisch-ökonomischer Ordnungen. Baden-Baden: Nomos 2012, 41-62, hier 42 und Nullmeier, Frank; Geis, Anna; Daase, Christopher, Der Aufstieg der Legitimitätspolitik. Rechtfertigung und Kritik politisch-ökonomischer Ordnungen, in: Geis; Nullmeier; Daase (Hg.), Der Aufstieg der Legitimitätspolitik, 11-38, hier 13.

208 Weber, Max, Wirtschaft und Gesellschaft: Grundriss der verstehenden Soziologie. Frankfurt am Main: Zweitausendeins 2010, 157. Über Legitimität als Anspruch und Glauben zugleich vgl. auch Orrù, Elisa, Sorveglianza e potere nella Unione Europea, in: Filosofia Politica, 29/3, 459-474, hier 471; Orrù, The Schengen Information System and Data Retention,129; Bader, Veit-Michael, Max Webers 
Diese Akzeptanz steigert das Vertrauen in das System und liefert der Autorität eine weit stabilere Basis für ihr Fortbestehen als der bloße Zwang oder das bloße Interesse. ${ }^{209}$ Nach Habermas können „soziale Ordnungen nur als legitime Ordnungen auf Dauer gestellt werden“:210 Je weniger eine Ordnung als legitim erscheint, umso mehr muss diese Ordnung auf alternative stabilisierende Faktoren (wie „Einschüchterung, Macht der Umstände, Sitte und schiere Gewohnheit" ${ }^{211}$ zurückgreifen. Legitimität ist also ein normativer Begriff, der aber gleichzeitig eine zentrale Funktion bei der Koordinierung und Steuerung des tatsächlichen Handelns im politischen Bereich ausübt. Legitimität als normativ geleitete Akzeptanz eines Anspruchs seitens einer Ordnung, einer Norm oder einer Institution beeinflusst somit die Befolgung und die Stabilität dieser Ordnung. Diese Verbindungsfunktion der Legitimität zwischen Fakten und Idealen macht sie zum Kernbegriff einer realistischen Untersuchung politischer Phänomene.

\section{Fünf Bedingungen einer kritisch-realistischen Erforschung politischer Legitimität}

Im Rahmen eines realistischen Ansatzes, wie ich ihn im ersten Kapitel dieses Buches dargestellt habe, wird die Legitimität einer rechtlich-politischen Ordnung unter fünf aufeinander verweisenden Bedingungen erforscht.

Erstens werden die Legitimitätsbedingungen aus dem Feld der Politik selbst herausgearbeitet, anstatt aus moralischen Prinzipien abgeleitet. Dies ist im Kern die erste methodologische Vorgabe des gegenwärtigen Realismus, die ich im ersten Kapitel als „Priorität der Politik vor der Moral“ eingeführt und ausführlich diskutiert habe. Dabei, wie im ersten Kapitel beleuchtet, wird sowohl der empirischen als auch der normativen Dimension der Politik Rechnung getragen.

Eine auf den Bereich der Politik zugeschnittene Legitimitätskonzeption zu entwickeln bedeutet, von der „ersten politischen Frage“ ${ }^{\text {“212 }}$ auszugehen,

Begriff der Legitimität. Versuch einer systematisch-kritischen Rekonstruktion, in: Weiss, Johannes (Hg.), Max Weber heute: Erträge und Probleme der Forschung. Frankfurt am Main: Suhrkamp 1989, 296-334.

209 Vgl. Luhmann, Niklas, Vertrauen: ein Mechanismus der Reduktion sozialer Komplexität. Stuttgart: Lucius \& Lucius 2009; Würtenberger, Legitimität, Legalität, 678; Habermas, Faktizität und Geltung, 48.

210 Habermas, Faktizität und Geltung, 92.

211 Ebd., 48.

212 Williams, In the beginning was the deed, 3 und das erste Kapitel dieses Buches. 
so wie Bernard Williams sie formuliert hat, nämlich wie Ordnung und die Bedingungen der Kooperation gesichert werden können. Die Effektivität in der Verwirklichung dieses Ziels ist ein grundlegendes Element der Legitimation politischer Systeme und Normen. Effektivität bei der Sicherung der Ordnung enthält aber zugleich die Einschränkung der Machtausübung: Die Lösung (nämlich die politische Ordnung) darf nicht „schlimmer als das Problem“ werden, i. e., darf nicht selbst Ursache für die Probleme werden (Unsicherheit, Gewalt, Tod, Terror usw.), die sie eigentlich beseitigen sollte. ${ }^{213}$ Das zeigt auch, wie eine realistische Konzeption der Politik keineswegs impliziert, dass Politik aus reinen Machtbeziehungen besteht. Nach dieser Konzeption ist Politik eine Organisationsform des menschlichen Zusammenlebens, die sich gleichzeitig auf Gewalt und Werte stützt, sowohl für die Realisierung der sozialen Ordnung als auch für die Einschränkung der Machtausübung. ${ }^{214}$ Dementsprechend, wie ich im vorigen Abschnitt gezeigt habe, weist auch Legitimität auf diese doppelte Dimension, auf den zweifachen Bezug auf Fakten und Normen, hin: Legitimität erschöpft sich nicht in der empirischen Akzeptanz, sondern schließt auch die Anerkennungswürdigkeit von Ordnungen, Entscheidungen oder Akteur_innen ein. ${ }^{215}$ Dabei geht es nicht nur um die faktische Akzeptanz zu einem bestimmten Zeitpunkt, sondern um die „tiefer liegende Frage, ob und inwieweit die Herrschaftspraktiken mit normativen Grundprinzipien kompatibel sind, die in der betreffenden Gesellschaft geteilt werden und verankert sind". 216

Zweitens wird aus einer realistischen Perspektive die relevante Legitimitätskonzeption nicht ideal-theoretisch entwickelt, sondern in Auseinander-

213 Williams, In the beginning was the deed und Schaub, Politische Theorie als angewandte Moralphilosophie? Die realistische Kritik, 8-24.

214 Diese Spannung zwischen Faktizität und Geltung wurde von Jürgen Habermas bis ins Detail nachgezeichnet. Vgl. Habermas, Faktizität und Geltung. Wie deutlich wird, teile ich Habermas' Ausgangsüberlegung, dass rechtlich-politische Ordnungen nur durch Berücksichtigung beider Dimensionen verstanden werden können. Jedoch folge ich der rationalisierenden und universalisierenden Richtung der habermasschen Theorie nicht.

215 Vgl. Zürn, Autorität und Legitimität in der postnationalen Konstellation, 43; Bellamy, Richard; Castiglione, Dario, Legitimizing the Euro-'polity' and its 'Regime': The Normative Turn in EU Studies, in: European Journal of Political Theory, 2/1, 2003, 7-34 und Habermas, Jürgen, Legitimationsprobleme im Spätkapitalismus. Frankfurt am Main: Suhrkamp 1977, Teil III.

216 Zürn, Autorität und Legitimität in der postnationalen Konstellation, 43. Vgl. auch Nullmeier; Geis; Daase, Der Aufstieg der Legitimitätspolitik. Rechtfertigung und Kritik politisch-ökonomischer Ordnungen, 25. 
setzung mit den konkreten Gegebenheiten erörtert. Die Frage, von der ausgegangen wird, ist nicht: Wie soll ein ideales Legitimitätskonzept aufgebaut sein? Sondern die zentrale Frage lautet: In Bezug auf welche Werte und Prinzipien werden bestimmte Praktiken in einer konkreten rechtlichpolitischen Ordnung legitimiert? Im Rahmen eines realistischen Ansatzes werden die relevanten Leitprinzipien aus der rechtlichen und politischen Praxis selbst herausgearbeitet.

Drittens wird folglich die so herauskristallisierte Legitimitätskonzeption nicht als universell, geschichts- und gesellschaftsübergreifend verstanden. Vielmehr wird ihre historische und kulturelle Prägung anerkannt und explizit gemacht. ${ }^{217}$ Im Hinblick auf diesen Kontext ist Legitimität jedoch keine Frage der bloßen Überzeugung oder der bloßen Konvention. Legitimität geht aus der historisch konstituierten, tiefgreifenden Verfassung der zu beurteilenden Ordnung hervor. Diese Verfassung, weil historisch bedingt und nicht rational a priori bestimmt, ist an sich kontingent. ${ }^{218}$ Die daraus resultierende Beurteilung der Legitimität von Normen, Akteur_innen oder gesamten Ordnungen ist aber nicht willkürlich, weil sie sachlich in den Charakteristika der zu beurteilenden Ordnung begründet ist. ${ }^{219}$

Diese ersten drei methodologischen Prämissen eines realistischen Ansatzes werden im vorliegenden Kapitel fruchtbar gemacht. Insbesondere werde ich die spezifische Antwort auf die „erste politische Frage“ rekonstruieren, welche in der EU heute normativ gilt. Dabei geht es darum, zu verstehen, auf welchen Prinzipien diese spezielle normative Ordnung (diejenige der EU) ihren Legitimitätsanspruch gründet. Ich werde diese Zielsetzung in zwei Schritten verfolgen. Erstens, im Abschnitt 4, werde ich klären, ob die EU als nicht staatliche Organisation eine Legitimität sui generis beansprucht, oder ob sie vielmehr ihren Legitimitätsanspruch auf ähnliche Prinzipien wie ihre Mitgliedstaaten gründet. Zweitens werde ich im Abschnitt 5 explizit machen, in welchem Sinne die aktuell für die EU gültigen Legitimitätsprinzipien historisch verankert sind. Vor diesem historischen Hintergrund werde ich zudem ihren philosophischen Kern herausarbeiten.

217 Vgl. Hinsch, Wilfried, Legitimität, in: Gosepath, Stefan; Hinsch, Wilfried; Rössler, Beate (Hg.), Handbuch der politischen Philosophie und Sozialphilosophie. Berlin: de Gruyter 2008, 704-712, hier 707; Beetham, David, The legitimation of power. Basingstoke: Macmillan 1991, 14 und das Kapitel 1 des vorliegenden Buches.

218 Vgl. Foucault, Was ist Aufklärung?

219 Vgl. Hinsch, Legitimität, 708. 
Die vierte Bedingung einer Untersuchung der Legitimität aus der Perspektive des kritischen Realismus besteht in der negativistischen Ausrichtung. Diese besteht in der Fokussierung auf die permanente Möglichkeit des Machtmissbrauchs und, präskriptiv, auf Mechanismen für seine Eingrenzung anstatt auf die Herbeiführung eines optimalen Idealzustandes. Diese negativistische Ausprägung wird im Teil III des Buches sichtbar. Dabei werde ich erkunden, wie aus den Unzulänglichkeiten der aktuellen Machteingrenzungsmechanismen ein Ansatz zur Transformation der EUPolitik skizziert werden kann. Ziel des gebotenen Ausblicks wird nicht sein, Maßnahmen zur Errichtung eines optimalen Zustandes vorzuschlagen, sondern von den akutesten Problemen des gegenwärtigen Zustandes auszugehen und die wichtigsten Bausteine zu ihrer Beseitigung zu identifizieren.

Schließlich besteht die fünfte methodologische Prämisse des gegenwärtigen Realismus in der Immanenz der Kritik. Die spezifischen Legitimationsprinzipien der EU-Politik, die ich in diesem Kapitel identifizieren werde, werden als normativ gültig festgehalten und provisorisch als „geteilter Horizont" angenommen, nicht aber vorbehaltlos akzeptiert. ${ }^{220}$ Vielmehr werde ich sie in einem zweiten Schritt einer kritischen Überprüfung im Sinne einer immanenten Kritik unterziehen. Denn der spezifische Mehrwert eines realistischen Ansatzes besteht in der Anerkennung und Hervorhebung der Spezifizität und historischen Gebundenheit normativer Prinzipien und in der Fähigkeit, diese Prinzipien trotz der Anerkennung ihrer Kontingenz normativ ernst zu nehmen. Konkret werde ich im Abschnitt 6 dieses Kapitels aus dem Legitimitätsmodell der EU die Kriterien spezifizieren, anhand derer ich die kritische Analyse der EU-Politik vollziehen werde.

220 Für den Begriff des geteilten Horizonts vgl. Gadamer, Hans-Georg, Wabrheit und Methode. Grundzüge einer philosophischen Hermeneutik. Tübingen: Mohr Siebeck 2010, 307-312, 379-380. Zur Idee eines provisorisch festgehaltenen Hintergrunds, der aber in einem zweiten Moment selbst als Gegenstand der Kritik in den Fokus geraten kann, vgl. Wittgenstein, Über Gewißheit, $\mathbb{1} 105,140-144$ und 205 sowie Wittgenstein, Philosophische Untersuchungen, $\mathbb{S} 122$ und 130-131. Für das Konzept einer immanenten Kritik vgl. Jaeggi, Was ist Ideologiekritik?, 285-293. Über beide Konzepte im Kontext einer kritischen Philosophie vgl. Tully, Public Philosophy in a New Key (Ideas in Context). Für alle genannten Aspekte vgl. ausführlicher oben Kapitel 1. 


\section{Legitimationsmodelle der $E U$}

Wenn Legitimitätskonzeptionen und die entsprechenden Legitimationsansätze historisch bedingt und kontextgebunden sind, stellt sich die Frage, welche Prinzipien der Legitimität für die EU angemessen sind. Wie wir im Abschnitt 4.4 unten sehen werden, lässt die EU selbst keine Zweifel bestehen, dass das Modell, das sie für sich selbst beansprucht, auf Demokratie und Rechtsstaatlichkeit basiert. Jedoch wurden seit Gründung der EU verschiedene konkurrierende Modelle als ausschlaggebend für die EU vorgeschlagen. Bevor ich mich der Diskussion des demokratisch-rechtsstaatlichen Modells widme, werde ich daher diese verschiedenen konkurrierenden Legitimitätsmodelle präsentieren und deren Bedeutung für die EU diskutieren.

\subsection{Diskussion konkurrierender Legitimationsmodelle: internationale Legitimation}

Das liberal-demokratische Legitimitätsmodell des Nationalstaates identifiziert die Subjekte, welche durch Legitimation die politische Ordnung anerkennen, in den Bürger_innen. Die erste Alternativkonzeption der Legitimität, die hier analysiert wird, lehnt diese Prämisse in Bezug auf die EU ab. Es sind nicht die Bürger_innen die Subjekte, deren Akzeptanz relevant für die Legitimation der EU ist, sondern die Mitgliedstaaten.

Dieses Modell der Legitimität ist typisch für internationale Organisationen. Freiwillige und langfristige Kooperation innerhalb einer Ordnung setzt die Legitimation dieser Ordnung durch die Subjekte, auf deren Kooperation die Organisation angewiesen ist, voraus. Konsequenterweise ist im Fall der internationalen Organisationen, so das Argument, in erster Linie die Legitimation durch die Mitgliedstaaten und deren offizielle Vertreter_innen notwendig, weil deren Kooperation zentral für das Funktionieren internationaler Organisationen ist. Seitens der Bürger_innen genügt eine indirekte Legitimation: Indem sie ihre eigenen Staaten als legitim anerkennen, akzeptieren sie auch die Legitimität der Organisationen, welche die Staatsvertreter_innen autorisiert haben. ${ }^{221}$ Die indirekte Legitimation

221 Vgl. beispielsweise Wallace, Helen, Deepening and Widening: Problems of legitimacy for the EC, in: García, Soledad (Hg.), European Identity and the Search for Legitimacy. London: Pinter 1993, 95-105; dazu Beetham; Lord, Legitimacy and the EU, 11-12. Für eine breitere Diskussion der internationalen Legitimität 
ist zudem dadurch verstärkt, dass die nationalen Minister_innen, die den Staat in den internationalen Organisationen vertreten, durch politische Wahlen autorisiert sind und sich gegenüber den nationalen Parlamenten verantworten müssen.

Wenn dieses Modell auch wichtige Aspekte der Legitimität der EU auffängt, wie zum Beispiel die Relevanz der staatlichen Anerkennung und der parlamentarischen Kontrolle der nationalen Exekutive, scheint es doch vor allem im Hinblick auf die stete Erweiterung der EU-Kompetenzen unvollständig. Die EU ist ein dynamisches System: Jede Ausdehnung ihrer Kompetenzen wirft die Frage nach ihrer Autorisierung und Verantwortlichkeit erneut auf. 222 Das Modell der internationalen Legitimation hat sicherlich in den früheren Phasen der EG- und EU-Integration eine wichtige Rolle gespielt, seine Relevanz scheint jedoch angesichts der zunehmenden Supranationalisierung der EU zu schrumpfen. Der RFSR, der im Fokus der vorliegenden Untersuchung steht, ist ein prominentes Beispiel für eine der jüngsten signifikanten Erweiterungen der EU-Kompetenzen. Selbst wenn der Erfolg der im RFSR beschlossenen Maßnahmen noch maßgeblich von der Kooperation der staatlichen Behörden abhängt, ist der potenzielle Einfluss dieser Maßnahmen auf die Grundrechte und -freiheiten der Individuen so gestiegen, dass nunmehr eine reine indirekte Legitimation unzureichend scheint.

Darüber hinaus, wie David Beetham und Christopher Lord treffend angemerkt haben, ist die Legitimationsdynamik zwischen Mitgliedstaaten und EU nicht unidirektional. ${ }^{223}$ Nicht nur die Staaten können der EU Legitimität verleihen, sondern auch die EU-Politik kann auf die Legitimität der Mitgliedstaaten stärkend oder schwächend rückwirken. Wenn die EU die Verantwortung in Bereichen erfolgreich übernimmt, die sich den regulativen Möglichkeiten der einzelnen Staaten entziehen, kann sich die effektive Steuerung durch die EU positiv auf die Legitimität der Mitgliedstaaten auswirken. Wenn aber EU-Vorgaben die Regulierungsfähigkeit der Mitgliedstaaten hemmen, wie im Fall der Maastricht-Vorgaben und der nationalen Wirtschaftspolitik, kann die Legitimität der Staaten dadurch gemindert werden. Ein theoretisches Modell, welches die Legitimität der

und ihres Bezugs zur Demokratie vgl. Vöneky, Silja; Neuman, Gerald L. (Hg.), Human rights, democracy, and legitimacy in a world of disorder. Cambridge: Cambridge University Press 2018.

222 Vgl. Beetham; Lord, Legitimacy and the EU, 15, bezugnehmend auf Wallace, William; Smith, Julie, Democracy or technocracy? European integration and the problem of popular consent, in: West European Politics, 18/3, 1995, 137-157.

223 Vgl. Beetham; Lord, Legitimacy and the EU, 16. 
EU von derjenigen der Staaten als einziger Quelle abhängig macht, scheint besonders vulnerabel zu sein, wenn diese einzige Quelle ihrerseits durch die EU-Politik unterminiert werden kann.

Das internationale Modell der Legitimität scheint also keine umfassende Grundlage für die Legitimität der EU zu liefern. Wie ich argumentieren werde, kann es jedoch als ein Teil eines weiter gefassten Legitimitätsmodells eine - wahrscheinlich abnehmende - Rolle spielen. ${ }^{224}$

\subsection{Technokratische Legitimation}

Ein weiteres alternatives Legitimitätsmodell, das als Evaluationsrahmen für die EU vorgeschlagen wurde, ist das technokratische. Nach diesem Modell ist eine legitime Ordnung diejenige, die von Experten gesetzt wird. Politik besteht nach dieser Konzeption in der Lösung von Problemen, und diese Lösung gelingt durch den Zugang zu einem spezialisierten Wissen. Expert_innen hätten einen privilegierten Zugang zu diesem Wissen und seien, anders als Politiker_innen, nicht der Instabilität der demokratischen Autorisierung ausgesetzt.

Dieses Modell der Legitimität dürfte in der ersten Phase der europäischen Integration eine Rolle gespielt haben, als noch der Eindruck entstehen konnte, dass die gemeinschaftlichen Entscheidungen nur technische und klar umgrenzte Bereiche betreffen würden. Das technokratische Modell der Legitimität scheint aber nicht zu einer Organisation zu passen, die, wie die EU und insbesondere in Bereichen wie dem RFSR, zunehmend politische Entscheidungen trifft. Politik impliziert die Wahl zwischen verschiedenen Konzeptionen des Guten und verschiedenen Formen des Zusammenlebens in einer Gesellschaft. Diese gründen sich auf evaluative Stellungnahmen anstatt auf eine technisch-wissenschaftliche Lösung. ${ }^{225}$

224 Für eine Darstellung dessen, wie dieses Element in der Überprüfung der EU-Sicherheitsmaßnahmen operationalisiert wird, vgl. unten Abschnitt 6.2.

225 Für eine ausführlichere Diskussion des technokratischen Modells vgl. Beetham; Lord, Legitimacy and the EU, 16-22. 


\subsection{Rechtfertigungsbasierte Legitimation}

Eine dritte alternative Konzeption der Legitimität für die EU wurde von Jürgen Neyer vorgeschlagen. ${ }^{226}$ Neyers Vorschlag ist im Kontext der vorliegenden Abhandlung besonders interessant. In Analogie zu dieser setzt Neyer nicht die verbreitete Annahme voraus, dass das demokratische Staatsmodell die passenden Maßstäbe für die Evaluation der Legitimität der EU liefert. 227

Neyer baut auf der Theorie des "deliberativen Supranationalismus" auf, welche eine „nichtutopische und trotzdem kritische“ Legitimationstheorie für die EU liefern soll.228 Nach diesem Ansatz seien weder das Demokratiedefizit noch das Fehlen eines europäischen Demos bzw. Volkes die Hauptprobleme für die Legitimität der EU. Vielmehr liege das gravierendste Problem bei den Nationalstaaten, die als solche nicht in der Lage seien, in ihren Entscheidungsprozessen „fremde“ Interessen zu berücksichtigen, weshalb sie hinter der wachsenden transnationalen Interdependenz zurückbleiben würden. Supranationale Legitimitätsformen

226 Vgl. Neyer, Jürgen, Europe's Justice Deficit: Justification and Legitimacy in the European Union, in: Neyer, Jürgen; Wiener, Antje (Hg.), Political Theory of the European Union. Oxford: Oxford University Press 2011, 169-186.

227 Ein zweiter Grund ist, dass Neyer seinen Ansatz eine „realistische normative Konzeption“ (ebd., 174, Übersetzung E.O.) nennt, ein Ausdruck, der eine Ähnlichkeit mit dem hier befürworteten Ansatz suggeriert. Der Realismus Neyers unterscheidet sich jedoch von dem Ansatz der vorliegenden Untersuchung. Der Grund, warum Neyer seinen Ansatz „realistisch“ nennt, ist, in Einklang mit dem späten Rawls (vgl. Rawls, John, Das Recht der Völker. Berlin: de Gruyter 2002), dass seine Gerechtigkeitsprinzipien in der Realität anwendbar sind. Dies, anders als der hier vertretene Ansatz, geht aber nicht über das Schema ideale/nicht ideale Theorien hinaus und priorisiert das Normative über das Reale. Wie im rawlsschen idealen Ansatz werden zuerst normative Prinzipien entwickelt, die später auf die Realität angewendet werden, wobei die Besonderheit darin besteht, dass für die normativen Prinzipien die Bedingung der Realisierbarkeit gilt. Neyers Ansatz ist also vorrangig normativ, soll aber gleichzeitig realitätstauglich sein. Mein Ansatz dagegen ist in einem anderen Sinn normativ, nämlich indem er von den real existierenden Phänomenen ausgeht, um die darin geltenden normativen Prinzipien herauszuarbeiten und einer immanenten Kritik zu unterziehen.

228 Vgl. Neyer, Europe's Justice Deficit: Justification and Legitimacy in the European Union, 169-170 und Joerges, Christian, Neyer, Jürgen, From Intergovernmental Bargaining to Deliberative Political Processes: The Constitutionalisation of Comitology, in: European Law Journal, 3/3, 1997, 273-299. Zum Verhältnis zwischen Neyers nicht utopischem, aber kritischem und meinem „kritisch-realistischen" Ansatz vgl. die vorige Fußnote. 
würden ein Korrektiv zu den Unzulänglichkeiten der Nationalstaaten bieten. Konsequenterweise, so Neyers Argument, dürfe der Maßstab für die Bewertung der Legitimität der EU nicht in der Erfüllung demokratischer Prinzipien liegen. Es sollte vielmehr eine Verschiebung des Fokus auf Fragen der Gerechtigkeit und insbesondere auf Gerechtigkeit als „Recht auf Rechtfertigung" stattfinden. ${ }^{229}$

Neyer greift hier Rainer Forsts Ansatz auf, nachdem alle Menschen einen basalen Anspruch haben, nämlich „das Recht, als moralische Person geachtet zu werden, die zumindest in dem Sinne autonom ist, dass sie nicht auf eine Weise behandelt werden darf, für die ihr nicht angemessene Gründe geliefert werden können“. ${ }^{230}$ Immer wenn unsere Freiheit durch andere Menschen oder Institutionen eingeschränkt wird, haben wir einen Anspruch darauf, nach einer Rechtfertigung zu verlangen. Die Legitimität der Freiheitseinschränkungen hängt nach dieser Konzeption von dieser Rechtfertigung ab: Die gelieferten Gründe müssen die Bedingungen der Reziprozität und der Universalität erfüllen. Reziprozität bedeutet, von niemandem etwas zu verlangen, das eine Person in Bezug auf sich selbst nicht auch zulassen würde. Universalität impliziert die Akzeptierbarkeit der Gründe und die Verbindlichkeit der Entscheidungen für alle. ${ }^{231}$

Meiner Meinung nach hebt Neyers Konzeption wichtige Komponenten der EU-Legitimität hervor. Jedoch sehe ich seinen Ansatz nicht als einen Ersatz der Evaluationen der EU, die auf demokratischen Standards basieren, sondern vielmehr als eine Ergänzung dazu. Dass Neyers Interpretation eine auf demokratischen Prinzipien fußende Bewertung der EU nicht ausschließt, wird auch dadurch bestätigt, dass seine Argumente gegen das demokratische Modell nicht vollständig überzeugen.

Das erste dieser Argumente besagt, dass die EU keine realistische Chance hat, eine demokratische Organisation zu werden. Demokratische Maßstäbe an die EU anzulegen, würde daher der Theorie jegliche empirische

229 Vgl. Neyer, Europe's Justice Deficit: Justification and Legitimacy in the European Union, 174-175.

230 Forst, Rainer, Das Recht auf Rechtfertigung. Elemente einer konstruktivistischen Theorie der Gerechtigkeit. Frankfurt am Main: Suhrkamp 2007, 300. Vgl. auch Forst, Rainer, Der Grund der Kritik. Zum Begriff der Menschenwürde in sozialen Rechtfertigungsordnungen, in: Jaeggi, Rahel; Wesche, Tilo (Hg.), Was ist Kritik? Frankfurt am Main: Suhrkamp 2009, 150-164.

231 Vgl. Neyer, Europe's Justice Deficit: Justification and Legitimacy in the European Union, 174-175. 
Relevanz entziehen. ${ }^{232}$ Die Charakteristika, welchen die EU seiner Meinung nach nie entsprechen wird, sind die Befugnis, Steuern zu erheben, Sanktionen durch Zwangsausübung durchzusetzen und externe Sicherheit zu gewährleisten. ${ }^{233}$ Jedoch gehören diese Fähigkeiten zu den Kernkompetenzen eines souveränen Staates, ungeachtet seines demokratischen Charakters. Indem er so argumentiert, liefert Neyer zwar Erklärungen, warum die EU kein souveräner Staat werden wird, nicht jedoch, warum sie nicht demokratisch sein kann. Es kann jedoch argumentiert werden, dass für die EU demokratische Standards sui generis gelten oder, anders gesagt, dass die EU demokratische Prinzipien erfüllen kann und soll, nicht aber notwendigerweise in der gleichen Form wie staatliche Institutionen. ${ }^{234}$

Ein zweiter Grund, warum seiner Auffassung nach die EU nicht demokratisch sein kann, ist für Neyer die strukturelle und absichtliche Ablehnung des fundamentalen demokratischen Prinzips der Gleichheit der Bürger_innen. Sowohl im EU-Parlament als auch im Rat seien die Entscheidungsmechanismen so konzipiert, dass die Stimme der Bürger_innen kleinerer Staaten mehr Gewicht habe als diejenige der Bürger_innen größerer Staaten. Die EU negiere dabei das Prinzip der Gleichheit der Bürger_innen zugunsten des Prinzips der Gleichheit der Staaten. Diesem Argument kann aber erwidert werden, dass es nicht ausschließlich und notwendigerweise bedeutet, nach der Repräsentativität des EU-Parlaments zu fragen, wenn die EU nach demokratischen Standards evaluiert wird. Vielmehr, wie beispielsweise in der vorliegenden Untersuchung, kann der demokratische Charakter der EU in Bezug auf multiple Formen der demokratischen Kontrolle überprüft werden. Diese schließen auch Mechanismen ein, die typisch für die mehrstufige Struktur der EU sind, wie die Einbeziehung der nationalen Parlamente und die Qualität von deren Kontrolle über die Entscheidungen, die auf europäischer Ebene getroffen werden. ${ }^{235}$

Neyers Ansatz schließt somit meiner Meinung nach eine Überprüfung der EU-Legitimität nach demokratischen Prinzipien nicht aus. Nichtdestotrotz liefert er eine wichtige Ergänzung, indem er ermöglicht, Formen der Kontrolle zu berücksichtigen, die eine enge demokratische Perspektive

232 Da Neyer seinen Ansatz als zugleich realistisch und normativ bezeichnet, hat eine solche seiner Meinung nach utopische Assimilation der EU mit dem Nationalstaat keinen Platz in seiner Theorie. Vgl. oben Fußnote 225.

233 Vgl. Neyer, Europe's Justice Deficit: Justification and Legitimacy in the European Union, 170.

234 Vgl. vertiefend unten Abschnitt 5.2.

235 Vgl. unten Abschnitt 5.2. 
nicht erfassen konnte, wie zum Beispiel die Pflicht der Kommission, dem Rat Rechtfertigungen für ihre Entscheidungen zu liefern. ${ }^{236}$ Wie diese Kriterien in die breitere Legitimitätskonzeption integriert werden können, wird unten gezeigt. ${ }^{237}$

\subsection{Demokratie und Rechtsstaatlichkeit als Grundsätze der normativen Ordnung der EU}

Wenn die diskutierten alternativen Konzeptionen der Legitimität keine umfassende, überzeugende Vorlage für die Bewertung der EU liefern, bleibt dann doch nur das Staatsmodell als Maßstab? Wie oben angedeutet, lautet meine These, dass das Paradigma des demokratischen Rechtsstaates die grundlegenden Legitimationsprinzipien der EU liefert, in dem doppelten Sinne, dass die EU in Bezug auf diese Prinzipien ihren Legitimitätsanspruch erhebt und dass sie überwiegend anhand demokratisch-rechtsstaatlicher Prinzipien als legitime Ordnung akzeptiert (oder kritisiert) wird. Jedoch ist die Kongruenz mit dem demokratisch-rechtsstaatlichen Modell nicht auf der Ebene der institutionellen Architektur zu suchen, sondern auf der Ebene der grundlegenden Prinzipien.

Dass der demokratische Rechtsstaat den Horizont des Legitimitätsanspruchs der EU darstellt, ist in den fundamentalen Dokumenten der EU, etwa in dem Vertrag über die EU (EUV) ${ }^{238}$ oder in der Charta der Grundrechte der EU, verdeutlicht. Der EUV weist in der Präambel auf Demokratie und Rechtsstaatlichkeit als grundlegende Werte Europas hin, und die Grundrechtecharta stellt fest:

236 Vgl. Neyer, Europe's Justice Deficit: Justification and Legitimacy in the European Union, 179.

237 Vgl. unten Abschnitt 6.2.

238 Vgl. Konsolidierte Fassungen des Vertrags über die Europäische Union und des Vertrags über die Arbeitsweise der Europäischen Union - Vertrag über die Europäische Union (konsolidierte Fassung) - Vertrag über die Arbeitsweise der Europäischen Union (konsolidierte Fassung) - Protokolle - Anhänge Erklärungen zur Schlussakte der Regierungskonferenz, die den am 13.12.2007 unterzeichneten Vertrag von Lissabon angenommen hat - Übereinstimmungstabellen, Amtsblatt Nr. C 326 vom 26.10.2012, 1-390. Über die Verpflichtung der EU zu demokratischen Prinzipien und ihre besondere Art, diese zu verkörpern vgl. Habermas, Jürgen, Zur Verfassung Europas: ein Essay. Berlin: Suhrkamp 2011, 63. 
In dem Bewusstsein ihres geistig-religiösen und sittlichen Erbes gründet sich die Union auf die unteilbaren und universellen Werte der Würde des Menschen, der Freiheit, der Gleichheit und der Solidarität. Sie berubt auf den Grundsätzen der Demokratie und der Rechtsstaatlichkeit. Sie stellt den Menschen in den Mittelpunkt ihres Handelns, indem sie die Unionsbürgerschaft und einen Raum der Freiheit, der Sicherheit und des Rechts begründet. ${ }^{239}$

Demokratie und Rechtsstaatlichkeit sind also die Grundsätze, auf welche die EU ihren Legitimitätsanspruch gründet. Die Erfüllung demokratischer und rechtsstaatlicher Kriterien ist nicht nur eine notwendige Bedingung für den Beitritt neuer Mitglieder, sondern die EU hat sich die Einhaltung dieser Kriterien auch selbst vorgeschrieben. In dem Vokabular des kritischen Realismus bedeutet dies, dass Demokratie und Rechtsstaatlichkeit die spezifische Antwort der EU auf die „erste politische Frage“ liefern. Die politische Ordnung der EU ist nach ihrer Selbstauffassung legitim, wenn sie in der Lage ist, demokratische und rechtstaatliche Prinzipien zu respektieren und zu fördern.

Wie bereits erwähnt, möchte ich aber nicht daraus folgern, dass die EU, um ihrem Anspruch gerecht zu werden, die institutionelle Struktur des demokratischen Rechtsstaates duplizieren sollte. Vielmehr sollte meines Erachtens die Konvergenz auf der Ebene der Grundprinzipien überprüft werden. Diese werden zwar vom Modell des demokratischen Rechtsstaates übernommen, können aber auf institutioneller Ebene durch Strukturen realisiert werden, die ursprünglich für die EU und ihre komplexe Architektur konzipiert wurden, und dabei zum Beispiel auch die auf nationaler Ebene existierenden Mechanismen miteinbeziehen.

In diesem Sinne grenzt sich die hier durchgeführte Analyse von der Demokratiedefizit-Debatte ab. In ihrer klassischen Form impliziert die Diagnose eines Demokratiedefizits der EU die Annahme, dass bei der Beurteilung der Legitimität der EU-Ordnung Maßstäbe des liberal-demokratischen Modells des Nationalstaates angewendet werden sollten. Die somit diagnostizierten Mängel fokussieren sich dabei auf die unzureichende Teilnahme der EU-Bürger_innen und des EU-Parlaments an den Prozessen der Entscheidungsfindung. ${ }^{240}$

239 Charta der Grundrechte der Europäischen Union, Amtsblatt der EU C 326/391 vom 26.12.2012, Präambel, Kursivsetzung E.O.

240 Für die Rekonstruktion der Debatte seit den 1970er Jahren vgl. exemplarisch Bellamy, Richard, The Challenge of European Union, in: Dryzek, John S.; Honig, Bonnie; Phillips, Anne (Hg.), The Oxford Handbook of Political Theory. 
Mit diesen Positionen teile ich die Überzeugung, dass die demokratischrechtsstaatliche Tradition im Enddefekt das Legitimationsmuster der EUPolitik und damit die Maßstäbe für eine kritische (im Sinne der immanenten Kritik) Bewertung der Legitimität der EU liefert. Jedoch, wie ich argumentieren werde, wird die Übereinstimmung zwischen den Legitimitätsprinzipien der EU und dem liberal-demokratischen Modell nicht auf der Ebene der institutionellen Architektur lokalisiert, sondern auf einer basaleren Ebene. Es sind nicht notwendigerweise die konkreten Mechanismen und Institutionen des demokratischen Rechtsstaates, die auf der EU-Ebene reproduziert werden sollten. Der Einklang, wie ich argumentieren werde, ist vielmehr auf der Ebene der Grundprinzipien zu verorten. Die Verwirklichung dieser Prinzipien kann in der rechtlich-politischen Ordnung der EU durch institutionelle Mechanismen stattfinden, die sich von den nationalen unterscheiden.

Eine interessante Wende in der Demokratiedefizit-Debatte wurde durch die Konzeptualisierung der EU als eine „Demoikratie“ angestoßen. Dieser Begriff bezeichnet die EU als eine Vereinigung von Völkern, die zwar zusammen regieren, dabei jedoch nicht zu einem Volk verschmelzen. ${ }^{241}$ In Anlehnung an diese Bezeichnung haben Richard Bellamy und Albert Wea-

Oxford: Oxford University Press 2006, 245-261, hier 252-257. Exemplarisch zu der Demokratiedefizit-Debatte vgl. auch Moravscik, Andrew, In Defence of the Democratic Deficit: Reassessing Legitimacy in the EU, in: Journal of Common Market Studies, 40/4, 2002, 603-624, Lord, Christopher, An indirect legitimacy argument for a directly elected European Parliament, in: European Journal of Political Research, 56/3, 2017, 512-528 und Hennette-Vauchez, Stéphanie et al., Für ein anderes Europa: Vertrag zur Demokratisierung der Eurozone. München: C.H. Beck 2017.

241 Vgl. Ronzoni, Miriam, The European Union as a demoicracy: Really a third way?, in: European Journal of Political Theory, 16/2, 2017, 210-234; Ronzoni übernimmt hier die Definition der "demoicracy“ von Kalypso Nicolaïdis, vgl. Nicolaïdis, Kalypso, European demoicracy and its crisis, in: Journal of Common Market Studies, 51/2, 2013, 351-369, hier 351. Der Ausdruck wurde durch Philippe Van Parijs geprägt und von Nicolaïdis weiterentwickelt, vgl. Van Parijs, Philippe, Should the European Union Become More Democratic?, in: Føllesdal, Andreas; Koslowski, Peter (Hg.), Democracy and the European Union. Berlin: Springer 1997, 287-301; Nicolaïdis, Kalypso, Our European Demoi-cracy: Is this Constitution a Third Way for Europe?, in: Nicolaidis, Kalypso; Weatherill, Stephen (Hg.), Whose Europe? National Models and the Constitution of the European Union. Oxford: Oxford University Press 2003, 137-152; Nicolaïdis, Kalypso, The New Constitution as European 'Demoi-Cracy'?, in: Critical Review of International Social and Political Philosophy, 7/1, 2004, 76-93; Cheneval, Francis; Schimmelfennig, Frank, The Case for Demoicracy in the European Union, in: JCMS: Journal of Common Market Studies, 51/2, 2013, 334-350. 
le kürzlich die These aufgestellt, wonach die EU nicht an einem demokratischen Defizit, sondern an einem „demoi-cratic disconnect“ leiden würde. Dieser bestünde in der defizitären Verbindung zwischen den Bürger_innen der jeweiligen Staaten und den Entscheidungen, welche ihre Repräsentant_innen auf multi- und supranationaler Ebene treffen. Während die Lösung des Demokratiedefizits in der Ermächtigung des EU-Parlaments liege, weise der „demoi-cratic disconnect“ auf die Notwendigkeit einer Ermächtigung der nationalen Parlamente im Entscheidungsverfahren auf supranationaler Ebene hin. ${ }^{242}$

Ich werde unten im neunten Kapitel mögliche Konvergenzen dieser Auffassung mit dem im Abschluss dieses Buches präsentierten Vorschlag besprechen. Trotz dieser möglichen Berührungspunkte unterscheidet sich die hier geführte Diskussion von dem erwähnten demoikratischen Ansatz dadurch, dass der Schwerpunkt der vorliegenden Ausführungen nicht in der Diskussion der Legitimität der EU als ganzer Ordnung besteht, sondern in der Überprüfung der Legitimität einzelner Maßnahmen gemäß den Legitimationsprinzipien, die für die EU als Ganze gelten. Ferner wird hier die Frage der Legitimität nicht nur in Bezug auf die Einhaltung demo- (oder demoi-)kratischer Standards bewertet. Vielmehr ist das der EU immanente Legitimitätsmodell ein multidimensionales Konzept, das neben demokratischer Repräsentation auch weitere Kriterien umfasst, wie beispielsweise Rechtfertigbarkeit der erlassenen Normen, einschließlich deren Effektivität und Verfahrenskonformität sowie Abschätzung der politischen und sozialen Auswirkungen der Maßnahmen.

242 Vgl. Bellamy, Richard; Weale, Albert, Political legitimacy and European monetary union: contracts, constitutionalism and the normative logic of two-level games, in: Journal of European Public Policy, 22/2, 2015, 257-274; Bellamy, Richard, A Republican Europe of States Cosmopolitanism, Intergovernmentalism and Democracy in the EU. Cambridge: Cambridge University Press 2019 und Bellamy, Richard, A European Association of Democratic States: Republican Intergovernmentalism, the Role of National Parliaments and the Democratic Constitution of the EU, in: Besselink, Leonard F. M. (Hg.), De Economische Constitutie. Beginselen van de Democratische Rechtsstaat tussen Globalisering en Europeanisering/The Economic Constitution. Principles of Constitutional Democracy between Globalisation and Europeanisation. Nijmegen: Wolf Legal Publishers 2020, 11-27. Die demoikratische Konzeption der EU wurde neuerdings auch aus realistischer Perspektive fruchtbar gemacht, um die Volksouveränität auf EU-Ebene zu stärken: vgl. Beetz, Jan Pieter; Rossi, Enzo, The EU's democratic deficit in a realist key: multilateral governance, popular sovereignty and critical responsiveness, in: Transnational Legal Theory, 8/1, 2017, 22-41. 
Um diese Kriterien herauszuarbeiten, werde ich versuchen, die tiefgreifenden Strukturen und Prinzipien zu skizzieren, die sich in den westlichen Gesellschaften als Legitimitätskriterien des demokratischen Rechtsstaates historisch herauskristallisiert haben. Da zwar Demokratie und Rechtsstaat eng miteinander verflochten sind, jedoch auf zwei unterschiedlichen philosophischen Kernen gründen, werde ich zuerst die Prinzipien des Rechtsstaates erörtern, um dann nach der Beziehung zwischen diesen und den demokratischen Grundsätzen zu fragen.

Die herauszuarbeitenden Prinzipien werden für die darauffolgende Analyse provisorisch für gültig gehalten. Dies schließt aber nicht aus, dass dieselben Prinzipien, die eine gültige Grundlage für die Überprüfung der Legitimität der EU-Sicherheitsmaßnahmen liefern, sich durch diese Kritik selbst als einer Transformation bedürftig erweisen können. Wie im ersten Kapitel dargestellt, ist es durchaus im Sinne einer immanenten Kritik, dass dieselben Prinzipien gleichzeitig als gültige Instrumente der Kritik gelten und selbst in die auf der Kritik fußende Transformation miteinbezogen werden.

\section{Grundsätze des demokratischen Rechtsstaates: Bausteine einer Genealogie}

\subsection{Historische Prämissen und philosophische Grundannahmen des Rechtsstaates}

Das Wort „Rechtsstaat“ bezieht sich zunächst auf eine bestimmte historische Entwicklung des deutschen Rechtssystems ab dem 19. Jahrhundert. ${ }^{243} \mathrm{Im}$ Kontext der hier untersuchten Legitimationsgrundlagen der EU wäre es jedoch irreführend, die Charakteristika eines solchen Modells in Bezug auf eine spezifische - obwohl an sich komplexe und alles andere als homogene - nationale Geschichte zu rekonstruieren. Dies allein schon deswegen, weil in den französischen und englischen Versionen der EU-Grundrechtecharta, in dem oben zitierten Auszug, ${ }^{244}$ Ausdrücke benutzt werden, die auf eigenständige historische Erfahrungen verweisen, wie "État de droit“" und „rule of law“. ${ }^{245}$ Die Bedeutung des Verweises auf die Rechtsstaatlichkeit als Grundsatz der EU muss also vielmehr auf

243 Vgl. Huster, Stefan, Rechtsstaat, in: Gosepath; Hinsch; Rössler (Hg.), Handbuch der politischen und Sozialphilosophie, 1092-1098.

244 Vgl. oben, Abschnitt 4.4 in diesem Kapitel.

245 Vgl. Huster, Rechtsstaat, 1092-1094. 
der Ebene der grundlegenden, allgemeinen Prinzipien gesucht werden, auf denen die verschiedenen historischen Erfahrungen beruhen.

In diesem allgemeinen Sinne kann der Rechtsstaat als eine Staatsform bezeichnet werden, in der „politische Herrschaft nur aufgrund und im Rahmen des Rechts ausgeübt wird“. ${ }^{246}$ Dabei ist der Grund für die Rechtsbindung der politischen Gewalt der Schutz der individuellen Rechte, der zudem als primäre Quelle der Legitimation des politischen Systems dient. $^{247}$

Der philosophische Hintergrund dieser Konzeption ist die moderne Idee des Individualismus. ${ }^{248}$ Die Theorie des Rechtsstaates ist eine durch die Jahrhunderte entwickelte Antwort auf ein spezifisch modernes Problem. Bekanntlich fand beim Übergang vom Mittelalter zur Neuzeit ein Umbruch statt, der unmittelbare und tiefgreifende Konsequenzen für die Legitimation der politischen Macht mit sich brachte. Sowohl die organizistische Konzeption des politischen Lebens als auch die religiöse Begründung der Herrschaft, welche die früheren Epochen charakterisierten, verloren zunehmend an Bedeutung. Nach dem ersten Modell stellt die Gesellschaft eine organische Einheit dar und genießt axiologische Priorität vor dem Individuum. Die politische Ordnung ist nach diesem Modell von Natur aus gegeben und bedarf daher keiner zusätzlichen Legitimation. Nach dem zweiten Modell ist der Herrscher selbst an das sakrale Recht göttlichen Ursprungs gebunden und legitimiert die Ausübung seiner Macht durch den Einklang mit diesem göttlichen, seiner Verfügung entzogenen Recht. ${ }^{249}$ Mit Beginn der Neuzeit werden beide Konzeptionen in zunehmendem Maße obsolet: Die politische Gemeinschaft ist weder natürlichen noch göttlichen Ursprungs, sondern eine künstliche, menschengemachte Ordnung. Damit gewinnt die Frage der Legitimität dieser Ordnung erneu-

246 Huster, Rechtsstaat, 1091, verweisend auf Grimm, Dieter, Die Zukunft der Verfassung. Frankfurt am Main: Suhrkamp 1991, 159.

247 Vgl. Zolo, Danilo, Teoria e critica dello Stato di diritto, in: Costa, Pietro; Zolo, Danilo (Hg.), Lo Stato di diritto. Storia, teoria, critica. Milano: Feltrinelli 2006, 17-88, engl. Übersetzung The Rule of Law. History, Theory and Criticism. Dordrecht: Springer 2007.

248 Vgl. Bobbio, Norberto, L'età dei diritti. Torino: Einaudi 1991, deutsche Übersetzung Bobbio, Das Zeitalter der Menschenrechte: ist Toleranz durchsetzbar?; vgl. auch Habermas, Jürgen, Zur Legitimation durch Menschenrechte, in: Habermas, Jürgen, Die postnationale Konstellation. Politische Essays. Frankfurt am Main: Suhrkamp 1998, 170-192, hier 171-172.

249 Vgl. zum einen Bobbio, L'età dei diritti, 45-65 und zum anderen Habermas, Wie ist Legitimität durch Legalität möglich? Dazu auch Özmen, Politische Philosophie zur Einfübrung, 43. 
te Brisanz: Wenn das politische System nicht mehr an ein ihm gegenüber transzendentes Wertesystem gebunden ist, wie kann dann gesichert werden, dass politische Macht nicht in reine Willkür mündet?250

Die politischen Philosoph_innen der Neuzeit antworten auf diese Herausforderung mit Verweis auf den Individualismus, der auch den philosophischen Kern der späteren Konzeption des Rechtsstaates ausmacht. Der Individualismus hat mit anderen Worten die Funktion übernommen, die Hans Blumenberg als typisch für Prozesse der Säkularisierung beschrieb: Die individualistische Theorie hat nämlich in Bezug auf die Legitimation der Herrschaft die „vakant gewordene[n] Positionen von Antworten“ umbesetzt, „deren zugehörige Fragen nicht eliminiert werden konnten“. ${ }^{251}$ Nach Norberto Bobbio glich diese Antwort einer kopernikanischen Revolution im kantischen Sinne: Das Politische wird nicht mehr aus der Perspektive des Herrschenden (ex parte principis), sondern aus derjenigen der Beherrschten (ex parte populi) betrachtet. Die zentrale deontische Grundstruktur ist demnach nicht mehr diejenige der Pflicht, sondern diejenige des subjektiven Rechts. ${ }^{252}$

Diese Wende wurde in der politischen Philosophie durch die Vertragstheoretiker_innen durchgesetzt: Schon bei Thomas Hobbes, obwohl seine Theorie sich durch die Legitimierung einer absolutistischen Herrschaftsform in einen "performativen Widerspruch“ ${ }^{\text {253 }}$ verwickelt, ist das Individuum der Ausgangspunkt für die Legitimation des politischen Systems. ${ }^{254}$ Die individualistische Perspektive der Vertragstheorien wird mit Locke in dieser Hinsicht konsistenter: Hier behalten die frei und gleich geborenen

250 Zur Verknüpfung der Frage der politischen Legitimität mit der Entstehung des modernen Staates vgl. Würtenberger, Legitimität, Legalität, 689-691, wobei im Zuge der anfänglichen Theoretisierung der Souveränität bei Jean Bodin das Naturrecht, das an die Stelle des religiösen Elements tritt, noch eine entscheidende Rolle bei der Legitimierung der Herrschaft spielt. Vgl. Bodin, Über den Staat.

251 Blumenberg, Die Legitimität der Neuzeit, 75. Zur Kontroverse zwischen Hans Blumenberg und Carl Schmitt in Bezug auf das Thema der politischen Legitimität vgl. Müller, Oliver, Beyond the political: Hans Blumenberg's criticism of Carl Schmitt, in: Minkov, Svetozar; Nowak, Piotr (Hg.), Man and his enemies. Essays on Carl Schmitt. Bialystok: University of Bialystok Press 2008, 237-253.

252 Vgl. Bobbio, L'età dei diritti, 55-56. Vgl. dazu auch Habermas, Zur Legitimation durch Menschenrechte, 172 und Baccelli, Luca; Bobbio, Norberto: An Age of Rights Without Foundations, in: IRIS - European Journal of Philosophy and Public Debate, 2/4, 2010, 401-422.

253 Habermas, Wie ist Legitimität durch Legalität möglich?, 7.

254 Vgl. Hobbes, Leviathan: oder Stoff, Form und Gewalt eines kirchlichen und bürgerlichen Staates. 
Individuen ihre Freiheit und Gleichheit auch im Staat, dessen Macht präzise Grenzen gesetzt werden. ${ }^{255}$ Individuelle Rechte werden nicht vom Souverän, gegebenenfalls temporär oder widerruflich, gewährt: Sie sind vielmehr die Bedingung der Legitimität seiner Herrschaft. Historisch wird die Idee der Priorität des Individuums gegenüber dem Staat in Art. 2 der Erklärung der Menschen- und Bürgerrechte exemplarisch proklamiert, wonach die Erhaltung der "natürlichen und unantastbaren Menschenrechte“ der "Zweck jeder politischen Vereinigung“ ist. ${ }^{256}$ Im 19. Jahrhundert entfaltete sich dann die Idee der Zentralität des Individuums in der Konzeption der subjektiven Rechte als Grundlage „privatautonomer Verfügungsbereiche" und in der Idee, dass der Zweck der Gesetze die Ermöglichung der subjektiven Entfaltung und die Förderung der Individuen ist. ${ }^{257}$

Der Individualismus ist also der Kern der Antwort der europäischen Neuzeit auf die Herausforderung, welche sich mit dem Ausfall der traditionellen Legitimationstheorien von Herrschaft stellte. Das bedeutet aber weder, dass den früheren Epochen die Idee der individuellen Rechte vollkommen fremd war, noch, dass die organizistische Konzeption des politischen Lebens verschwand. ${ }^{258}$ Als prominentes Beispiel einer organi-

255 Vgl. Locke, Zwei Abhandlungen über die Regierung. Auch bei Locke steht aber letztendlich die Legitimation der Herrschaft potenziell im Widerspruch zu den individualistischen Prämissen. Vgl. dazu und allgemein zur problematischen Verbindung zwischen politischem Gehorsam und Konsens Pateman, The Problem of Political Obligation. A Critical Analysis of Liberal Theory; Simmons, Justification and legitimacy: essays on rights and obligations und Pitkin, Hanna Fenichel, Obligation and Consent, in: The American Political Science Review, 59/4, 1965, 990-999.

256 Eine zentrale Frage, die sich in Bezug sowohl auf die Theorie als auch auf die Umsetzung der Menschenrechte stellt, ist, wie die Individuen definiert werden, die in den Genuss dieser als universell proklamierten Rechte kommen sollen. Vgl. hierzu Senger, Harro von, From the limited to the universal concept of human rights: two periods of human rights, in: Schluchter, Wolfgang (Hg.), Human rights and cultural diversity: Europe, Arabic-Islamic world, Africa, China. Goldbach: Keip 1993, 47-100; Orrù, Elisa, Olympe de Gouges on Slavery, in: Diacronìa, 2/2, 2020, 95-121 und Orrù, Elisa, Ein Gesellschaftsvertrag für alle. Die Universalität der Menschenrechte nach Olympe de Gouges, in: Allgemeine Zeitschrift für Philosophie, 46/2, 2021, 183-206.

257 Bobbio, L'età dei diritti, 60 und Habermas, Wie ist Legitimität durch Legalität möglich?, 8-9. Jedoch wurden für Habermas beide Ideen bald durch eine positivistische Umdeutung entleert - zudem betont Habermas in der historischen Rekonstruktion mehr die prozeduralen Aspekte als die inhaltlichen Prinzipien der Vertragstheorien.

258 Als vormoderne Beispiele verweist Zolo auf die franziskanische Theologie des 13. und 14. Jahrhunderts, in der die Wurzeln für die Idee der subjektiven 
zistischen Konzeption der Politik, die sich in der Neuzeit dem Individualismus widersetzte, sei Hegels politische Philosophie erwähnt. ${ }^{259}$ Auch die gegenwärtigen kommunitaristischen Theorien distanzieren sich von der typisch liberalen Konzeption des atomistischen Individuums und seiner normativen Priorität gegenüber der Gesellschaft. ${ }^{260}$ Jedoch kann behauptet werden, dass mit der Neuzeit der Individualismus zum ersten Mal das dominante Paradigma der Legitimation der politischen Macht wird. ${ }^{261}$

Wenn das Individuum und seine Rechte nunmehr die Quelle der politischen Legitimität sind, nimmt die politische Macht eine paradoxe Position ein: Sie soll gleichzeitig die individuellen Rechte schützen, stellt aber auch selbst die größte Gefahr für die individuellen Freiheiten dar. Politische Herrschaft ist gleichzeitig notwendig, um die gesellschaftliche Ordnung und die effektive Ausübung der individuellen Rechte zu garantieren, aber auch gefährlich. Dabei geht die Theorie des Rechtsstaates das erste politische Problem an, so wie Bernard Williams es zum Ausdruck gebracht hat: Das politische System soll die soziale Ordnung, den Schutz der Individuen, Sicherheit, Vertrauen und die Bedingungen der Kooperation aufrechterhalten, gleichzeitig aber darf „die Lösung nicht Teil des Problems werden“. ${ }^{262}$ Das politische System darf nicht die Übel, wie etwa Unsicherheit und Terror, wiederherstellen, gegen die es Schutz bieten soll.

Das Rechtssystem wird, in der Theorie des Rechtsstaates, mit der Lösung dieses Paradoxons beauftragt: Das Recht soll gleichzeitig zur Erhaltung der Ordnung beitragen, der Gefährlichkeit der Macht entgegenwirken und die subjektiven Rechte schützen. ${ }^{263}$ Hierin besteht auch die Spezifizität des Le-

Rechte und die Voraussetzungen für ihren Ausbau lägen. Vgl. Zolo, Teoria e critica dello Stato di diritto, 35.

259 Vgl. Hegel, Grundlinien der Philosophie des Rechts.

260 Vgl. beispielsweise Taylor, Charles, Quellen des Selbst: die Entstehung der neuzeitlichen Identität. Frankfurt am Main: Suhrkamp 1996 und Taylor, Charles, Negative Freiheit? Zur Kritik des neuzeitlichen Individualismus. Frankfurt am Main: Suhrkamp 1992.

261 Vgl. auch Özmen, Politische Philosophie zur Einführung, 44.

262 Williams, In the beginning was the deed, 4.

263 Habermas hat bekanntlich diese Funktion des Rechts als „Vermittlung zwischen Faktizität und Geltung“, zwischen der Positivität und der Legitimität des Rechts oder zwischen der Ausübung der organisierten Herrschaft und ihrer Bindung an legitimes Recht konzeptualisiert. Allerdings steht in der hiesigen Abhandlung die Kategorie der Macht im Mittelpunkt, während der Fokus von Habermas' Theorie auf der Kategorie des Rechts liegt. In beiden Fällen findet dann ein Übergang von der einen zur anderen Kategorie statt. So ist hier der Ausgangspunkt die gleichzeitige Notwendigkeit und Gefährlichkeit der Macht, die einer Hemmung durch das Rechtssystem bedarf. In Habermas' Theorie ist 
gitimitätsmodells des Rechtsstaates, die in zwei philosophischen Grundannahmen Ausdruck findet. Diese können als „Machtpessimismus“ einerseits und ,juristischer Optimismus“ andererseits bezeichnet werden. ${ }^{264} \mathrm{Nach}$ dem ersten Prinzip ist der Macht eine Neigung zur maßlosen Ausdehnung in andere Bereiche, zur Konzentration der erlangten Befugnisse und zur Willkür in der Ausübung inhärent. Nach dem zweiten Prinzip ist das Recht ein effektives Mittel, um die eigentümliche Gefährlichkeit der Macht einzudämmen.

Diese komplexe Aufgabe kann vom Rechtssystem durch das Operationalisieren zweier Prinzipien bewältigt werden: des Prinzips der Streuung der Macht und des Prinzips der Differenzierung der Macht. ${ }^{265}$ Ersteres bedeutet die Ermächtigung der Individuen, dadurch dass die öffentliche Gewalt eingeschränkt und gleichzeitig die Sphäre der individuellen Rechte erweitert wird. Sowohl die Einschränkung der öffentlichen Gewalt als auch die Erweiterung der individuellen Freiheiten werden durch das Rechtssystem definiert und sanktioniert.

Das Prinzip der Differenzierung der Macht richtet sich an die öffentliche Gewalt und bestimmt die Trennung des rechtlich-politischen Bereichs von dem ethisch-religiösen einerseits und von dem ökonomischen andererseits. ${ }^{266}$ Letztere Differenzierung drückt in Habermas' Worten die Trennung von Staat und Gesellschaft aus, die „verhindern soll, daß soziale Macht ungefiltert [...] in administrative Macht umgesetzt wird", und die darauf abzielt, soziale Ungleichheiten zu neutralisieren, bevor sie in den politischen Willensbildungsprozess einfließen. ${ }^{267}$ Darüber hinaus kon-

dagegen das Rechtssystem und seine immanente Spannung zwischen Positivität und Legitimität oder zwischen ,gewaltsam stabilisierter und vernünftig legitimierter Ordnung“ (Habermas, Faktizität und Geltung, 20) der Ausgangspunkt. Die Positivität des Rechts verlangt eine Durchsetzung durch organisierte Herrschaft, die aber wiederum in den Formen des legitimen Rechts ausgeübt werden muss. Vgl. Habermas, Faktizität und Geltung, insbesondere 15-60.

264 Zolo, Teoria e critica dello Stato di diritto, 35.

265 Vgl. ebd., 34.

266 Vertiefend dazu vgl. Luhmann, Niklas, Gesellschaftliche und politische Bedingungen des Rechtsstaates, in: Luhmann, Niklas, Politische Planung: Aufsätze zur Soziologie von Politik und Verwaltung. Wiesbaden: VS Verlag für Sozialwissenschaften, 2007, 53-65.

267 Habermas, Faktizität und Geltung, 215. Aus Habermas' Sicht ist jedoch die erste Differenzierung, nämlich zwischen Recht und Politik einerseits und zwischen Recht und Moral andererseits, nur bedingt zu verstehen. Für Habermas bedeutet diese Differenzierung keine absolute Entkopplung des Rechts und der Politik von der Moral. Eine Autonomisierung des Rechts und der Politik im Rechtsstaat ist vielmehr nur unter der Bedingung möglich, dass moralische 
kretisiert sich aber das Prinzip der Differenzierung der Macht auch in der Trennung, innerhalb der rechtlich-politischen Macht, zwischen den Funktionen der Rechtssetzung (legis latio) und der Rechtsanwendung (legis executio). ${ }^{268}$

Zusammenfassend kann also der Rechtsstaat als die moderne europäische Version vom Staat bezeichnet werden, die sich philosophisch auf individualistische Prämissen und auf die Grundannahmen des Machtpessimismus und des juristischen Optimismus stützt. In diesem System wird die Rechtsordnung mit der Aufgabe betraut, die individuellen Grundrechte zu schützen und die Macht in ihren Grenzen zu halten. Dafür werden zwei Arten von Verfahren eingesetzt, welche die Streuung der Macht einerseits und die Differenzierung der Macht andererseits garantieren sollen. ${ }^{269}$

\subsection{Das demokratische Prinzip}

Aus den oben skizzierten Charakteristika des Rechtsstaates lässt sich keine unmittelbare Verpflichtung zur Demokratie ableiten. Prinzipiell sind rechtsstaatliche Systeme ohne demokratische Struktur denkbar, so wie es auch möglich ist, dass demokratische Systeme einige rechtsstaatliche Prinzipien missachten. ${ }^{270}$ Anders formuliert: Ein Rechtsstaat setzt sich dem absolutistischen, dem totalitären und dem Polizeistaat eindeutig entgegen; nicht so aber den Formen oligarchischer oder technokratischer Herrschaft, die zwar nicht demokratisch sind, aber kompatibel mit den Prinzipien des Rechtsstaates zu sein scheinen. ${ }^{271}$

Andererseits scheinen Rechtsstaat und Demokratie sich gegenseitig unterstützende Systeme zu sein, sodass sie nur aneinander gekoppelt langfristig bestehen bleiben können. Zum einen sind die individuellen Freiheiten als Raum, der gegen Machteingriffe geschützt ist, eine wichtige Vorausset-

Prinzipien die Verfahrensrationalität des Rechtssystems bestimmen. Vgl. Habermas, Wie ist Legitimität durch Legalität möglich? und Habermas, Jürgen, Recht und Moral (Tanner Lectures 1986). Zur Idee des Rechtsstaats, in: Habermas, Faktizität und Geltung: Beiträge zur Diskurstheorie des Rechts und des demokratischen Rechtsstaats, 571-599.

268 Der Bereich der Rechtsanwendung kann weiterhin in die judikative und exekutive Funktion ausdifferenziert werden. Vgl. Zolo, Teoria e critica dello Stato di diritto, 34 .

269 Vgl. ebd., 45.

270 Vgl. Huster, Rechtsstaat, 1096-1097.

271 Vgl. Zolo, Teoria e critica dello Stato di diritto, 47. 
zung für die freie Meinungsbildung und -äußerung, die unverzichtbar für eine nicht nur formelle Teilnahme an der demokratischen Entscheidungsfindung sind. Zum anderen scheint demokratische Partizipation eine zusätzliche Garantie gegen Machtmissbrauch zu sein. Daher haben einige prominente Autor_innen, darunter bekanntlich Jürgen Habermas, für die Gleichursprünglichkeit des rechtsstaatlichen und demokratischen Prinzips argumentiert. ${ }^{272}$

$\mathrm{Ob}$ nun diese Gleichursprünglichkeit besteht oder nicht, ist aber in diesem Kontext zweitrangig, da die EU sich sowohl zum rechtsstaatlichen als auch zum demokratischen Prinzip verpflichtet hat. ${ }^{273}$ Die Verpflichtung zum demokratischen Prinzip bedeutet auf philosophischer Ebene, dass eine zusätzliche Bedingung der Legitimität zu den rechtsstaatlichen hinzukommt. Diese besteht in der Möglichkeit der Individuen, auf den öffentlichen Raum durch die Teilnahme an politischen Entscheidungen einzuwirken. ${ }^{274}$

So kann die Beziehung zwischen Rechtsstaatlichkeit und Demokratie im Kern als die Beziehung zwischen privater und öffentlicher Autonomie verstanden werden. Erstere stellt einen Raum dar, der vor dem Eindringen der Macht geschützt wird, während die zweite auf die Möglichkeit des Einwirkens der Individuen auf politische Entscheidungen hinweist. ${ }^{275}$

Die Idee vom Mitwirken der Bürger_innen bei politischen Entscheidungen ist bereits in der Antike bekannt; die griechische Polis liefert das prototypische Modell dieser Konzeption. Die moderne Idee der öffentlichen Autonomie unterscheidet sich aber wesentlich von der klassischen. Das hellenistische Ideal war durch die Auslosung der Amtsträger und die direkten Volksversammlungen gekennzeichnet. In der modernen Form der Demokratie werden dagegen die Ämter per Wahl statt per Los besetzt und die Volksversammlungen durch Repräsentativkörper ersetzt. Aus

272 Vgl. Habermas, Faktizität und Geltung, u. a. 493.

273 Vgl. oben Abschnitt 4.4 und die Präambel der Charta der Grundrechte der Europäischen Union.

274 Vgl. Habermas, Faktizität und Geltung, 153 und Richardson, Henry S., Demokratie, in: Gosepath; Hinsch; Rössler (Hg.), Handbuch der politischen Philosophie und Sozialphilosophie, 206-211, hier 206.

275 Diese Unterscheidung zwischen privater und öffentlicher Autonomie kann auch mit Benjamin Constant als Unterscheidung zwischen einem typisch modernen und einem typisch antiken Verständnis von Freiheit aufgefasst werden, jedoch mit dem unten kurz geschilderten Vorbehalt der Unterschiede zwischen dem antiken und dem modernen Demokratieverständnis. Vgl. Constant, Benjamin, Über die Freiheit. Klosterberg, Basel: Schwabe 1946 (zuerst veröffentlicht 1819) und Habermas, Zur Legitimation durch Menschenrechte, 173-174. 
einer „unmittelbaren“ wurde eine repräsentative Demokratiekonzeption, die in größeren Gesellschaften als einzig anwendbare angesehen wird. ${ }^{276}$ Das Volk nimmt nicht direkt an der Entscheidungsfindung teil, sondern die Entscheidungsbefugnisse werden durch Wahlen an Vertreter_innen übertragen.

Der philosophische Kern dieses Ideals wird von der Idee der Autonomie als Selbstgesetzgebung verkörpert, welche die Fähigkeit vernünftiger Wesen, sich selbst Gesetze zu geben, bezeichnet und im Mittelpunkt von Kants moral- und politischer Philosophie steht. ${ }^{277}$ Nach dieser Konzeption kann ein Subjekt legitimerweise nur an diejenigen Gesetze gebunden sein, denen es selbst hätte zustimmen können. Diese Idee der öffentlichen Autonomie mündet, wie erwähnt, nicht in der politischen Forderung, dass jedes Subjekt tatsächlich in den Entscheidungsprozess eingebunden werden sollte, sondern wird vielmehr in einer Art von rationalem Universalisierbarkeitstest konkretisiert. So besagt nach Habermas das Demokratieprinzip, dass „nur die juridischen Gesetze legitime Geltung beanspruchen dürfen, die in einem ihrerseits rechtlich verfaßten diskursiven Rechtsetzungsprozeß die Zustimmung aller Rechtsgenossen finden können“. ${ }^{278}$

In Habermas' Interpretation gewinnt zudem dieses moderne liberale Demokratieverständnis eine diskurstheoretische Dimension. Diese besteht

276 Vgl. Meier, Christian; Reimann, Hans Leo; Conze, Werner, Demokratie, in: Brunner, Otto; Conze, Werner; Koselleck, Reinhart (Hg.), Geschichtliche Grundbegriffe, Bd. 1. Heidelberg: Klett-Cotta 1972, 821-899, hier 872-873; Richardson, Demokratie, 207-208.

277 Vgl. Kant, Grundlegung zur Metaphysik der Sitten; Christman, John, Autonomie, in: Gosepath; Hinsch; Rössler (Hg.), Handbuch der politischen Philosophie und Sozialphilosophie, 96-102, hier 96.

278 Habermas, Faktizität und Geltung, 141. Dieser Nexus zwischen politischer Obligation und Konsens ist zugegeben problematisch. Vgl. oben Fußnote 253. Ebenfalls können aus einer realistischen und kritischen Perspektive heraus die Wirksamkeit und Bedeutung des demokratischen Ideals für die real existierenden politischen Organisationen infrage gestellt werden. Da aber hier das Ziel der Abhandlung ist, zunächst die internen Legitimitätsprinzipien herauszuarbeiten, wird das Appellieren der EU an demokratische Prinzipien ernst genommen und zunächst nicht infrage gestellt. Ich beschränke mich hier auf den Verweis auf die Literatur zum Thema, welche die Widersprüche und funktionellen Spannungen der Demokratietheorie aus einer kritischen und historischen Perspektive untersucht. Vgl. u. a.: Dunn, John, Democracy: the unfinished journey. 508 $B C$ to $A D$ 1993. Oxford: Oxford University Press 1992; Zolo, Die demokratische Fürstenherrschaft. Für eine realistische Theorie der Politik; Dunn, John, Capitalist democracy: elective affinity or beguiling illusion?, in: Daedalus, 136/3, 2007, $5-13$. 
in einer breiteren Öffentlichkeit, in der idealerweise alle Bürger_innen zu relevanten Themen Stellung nehmen können und die eine „informelle Meinungsbildung "279 ermöglicht. Durch Wahlentscheidungen und legislative Beschlüsse fließt die informelle Meinungsbildung in institutionalisierte Verfahren ein, wodurch sie die tatsächlichen Entscheidungen nicht unmittelbar trifft, sondern in „bestimmte Kanäle“280 lenkt.

Ähnlich wie im Fall des Rechtsstaates stellt das Ideal der repräsentativen Demokratie das dominante legitimierende Paradigma in der westlichen Welt und insbesondere in Europa dar, jedoch sind der europäischen Moderne konkurrierende Demokratieverständnisse nicht fremd. Prototypisch für diese modernen alternativen Konzeptionen ist Rousseaus Theorie, die nicht ohne Widerspruch zu seinen individualistischen Prämissen durch das Ideal der unmittelbar ausgeübten Demokratie geprägt ist. ${ }^{281}$ An Rousseaus Ideal knüpft Carole Patemans Modell der partizipatorischen Demokratie an, um nur ein Beispiel gegenwärtiger politisch-philosophischer Konzeptionen zu nennen. ${ }^{282}$

\section{Kriterien der Legitimität der EU-Normen}

In den vorigen Abschnitten habe ich die philosophischen Grundsätze beleuchtet, die den Horizont der Legitimität der EU-Politik darstellen. Die grundlegende Frage dieser Untersuchung ist aber nicht, ob die EU als politisches System legitim ist, sondern wie sich die spezifischen Maßnahmen im Rahmen des RFSR, die im zweiten Teil analysiert werden, in den EU-Legitimationshorizont einfügen und ob - und wenn ja, wie - sie auf diesen rückwirken.

279 Habermas, Jürgen, Drei normative Modelle der Demokratie, in: Habermas, Jürgen, Die Einbeziehung des Anderen. Studien zur politischen Theorie. Frankfurt am Main: Suhrkamp 1996, 277-293, hier 288; vgl. auch Habermas, Jürgen, Braucht Europa eine Verfassung? Eine Bemerkung zu Dieter Grimm, in: Habermas, Die Einbeziehung des Anderen. Frankfurt am Main: Suhrkamp 1996, 185-191.

280 Habermas, Drei normative Modelle der Demokratie, 288.

281 Vgl. Rousseau, Jean-Jacques, Vom Gesellschaftsvertrag oder Grundsätze des Staatsrechts, hg. v. Brockard, Hans. Stuttgart: Reclam 2008 (zuerst veröffentlicht 1762).

282 Vgl. Pateman, Carole, Participation and democratic theory. Cambridge: University Press 1970; Pateman, The Problem of Political Obligation. A Critical Analysis of Liberal Theory; vgl. dazu auch Zolo, Die demokratische Fürstenherrschaft, 90-94. 
Die Frage ist also, wie die oben erläuterten philosophischen Grundsätze operationalisiert werden können, um als Basis für die Evaluation der Legitimität einzelner Normen zu dienen. Ich schlage drei Kriterien vor, die aus den Grundannahmen des rechtsstaatlich-demokratischen Modells abgeleitet werden und als Grundlage einer kritischen Überprüfung der EU-Maßnahmen dienen können: Rechtfertigung und Effektivität, Verfahrenskonformität sowie Rückwirkung auf die normative Ordnung. ${ }^{283}$

\subsection{Rechtfertigung und Effektivität}

Die grundlegende Idee dieses Kriteriums ist, dass Maßnahmen, welche die individuellen Rechte einschränken oder die Befugnisse der politischen Macht erweitern, einer besonderen Rechtfertigung bedürfen. Das Kriterium entspringt direkt aus den individualistischen Prämissen des rechtsstaatlichen Paradigmas, nimmt die Idee der gleichzeitigen Notwendigkeit und Gefährlichkeit der politischen Macht ernst und operationalisiert den Mechanismus der Streuung der Macht auf grundlegende Art.

Erstens besteht die Verbindung mit den individualistischen Prämissen des Rechtsstaates darin, dass der Schutz der individuellen Rechte als erste Legitimationsquelle der politischen Macht angesehen wird. Für jede Einschränkung dieser Rechte besteht Rechtfertigungsbedarf. Die Maßnahmen, die diese Rechte einschränken, müssen dementsprechend einerseits

283 In der Politikwissenschaft ist die Einteilung der Legitimität in Input- und Output-Legitimität, zu der neuerdings als dritte Kategorie noch die Throughput-Legitimität hinzukommt, üblich. An dieser Stelle wird nicht diskutiert, inwiefern die hier vorgeschlagenen Kriterien sich mit der politikwissenschaftlichen Unterscheidung decken, sondern nur auf die Komplexität der Debatte in der Politikwissenschaft selbst hingewiesen. Diese deutet darauf hin, dass die Bedeutung der drei Begriffe umstritten ist. Vgl. für die Einführung der Einteilung in Inputund Output-Legitimität Scharpf, Fritz Wilhelm, Demokratietheorie zwischen Utopie und Anpassung. Konstanz: Universitätsverlag 1970. Zur aktuellen Diskussion vgl. Steffek, Jens, Die Output-Legitimität internationaler Organisationen und die Idee des globalen Gemeinwohls, in: Geis, Anna; Nullmeier, Frank; Daase, Christopher (Hg.), Der Aufstieg der Legitimitätspolitik. Baden-Baden: Nomos Verlagsgesellschaft 2012, 81-100; Scharpf, Fritz Wilhelm, De-constitutionalisation and majority rule: A democratic vision for Europe, in: European Law Journal, 23/5, 2017, 315-334; Schmidt, Vivien A., Democracy and Legitimacy in the European Union, in: Jones, Erik; Menon, Anan; Weatherill, Stephen (Hg.), The Oxford Handbook of the European Union. Oxford: Oxford University Press 2012, 661-675. 
notwendig sein und andererseits die Einschränkungen der subjektiven Rechte auf ein Minimum begrenzen. Zweitens findet hier der Machtpessimismus, oder die Idee der gleichzeitigen Notwendigkeit und Gefährlichkeit der Macht, Berücksichtigung. Denn nach diesem Prinzip ist jede Maßnahme, die Machtbefugnisse ausweitet, potenziell gefährlich. Zudem neigt sie dazu, wenn nicht sorgfältig eingeschränkt, zu weiteren Machtausweitungen zu führen. Dementsprechend dürfen solche Maßnahmen nur unter bestimmten Bedingungen und nach Überprüfung ihrer Berechtigung eingeführt werden. Drittens fließt hier schließlich der Mechanismus der Streuung der Macht in die Analyse ein. Das Rechtssystem muss nach diesem Prinzip sicherstellen, dass die öffentliche Macht eingeschränkt und die Sphäre der individuellen Rechte geschützt wird. Das Verlangen nach einer Rechtfertigung ist eine erste Schranke zur Verwirklichung dieses Prinzips.

Die verlangte Rechtfertigung soll plausibel machen, dass die eingeführten Maßnahmen einen legitimen Zweck verfolgen und dass sie zur Verwirklichung dieses Zwecks auf effektive und effiziente Weise beitragen.

Gemäß diesem Kriterium werde ich im zweiten Teil des vorliegenden Buches bei jeder analysierten Maßnahme besondere Aufmerksamkeit den Argumenten, welche deren Einführung gerechtfertigt haben, und den sich daran anschließenden Debatten schenken. Es wird zunächst gefragt, zu welchem Zweck die Maßnahmen eingeführt wurden und wie sie als Mittel zur Realisierung dieser Zwecke beitragen sollen. Dabei werden Pro- und Contra-Argumente in Betracht gezogen und falls alternative Lösungen zur Debatte standen, werden diese mit den tatsächlich eingeführten Maßnahmen verglichen. Wenn empirische Daten über die Effektivität (als Fähigkeit, die gesetzten Ziele zu erreichen) der Maßnahmen vorhanden sind, werden diese im Folgenden ebenfalls präsentiert und diskutiert. Wenn dagegen keine empirischen Daten zur Verfügung stehen, oder auch zusätzlich zu diesen, werden weitere theoretische Überlegungen über die zu erwartende Effektivität der Maßnahmen miteinbezogen. Auch die Effizienz dieser Maßnahmen, als Kosten-Nutzen-Verhältnis verstanden, wird eine Rolle bei ihrer Evaluation spielen, insbesondere indem die tatsächlich angefallenen oder geschätzten Kosten aufgeführt werden.

Das Kriterium der Rechtfertigung weist Ähnlichkeiten mit dem verfassungsrechtlichen Verhältnismäßigkeitsgrundsatz auf, welcher verlangt, dass „ein Grundrechtseingriff einem legitimen Zweck dient und als [legitimes] Mittel zu diesem Zweck geeignet, erforderlich und angemessen 
ist“. ${ }^{284}$ Das Kriterium der Rechtfertigung drückt meiner Meinung nach den gleichen philosophischen Kern wie dieser Grundsatz aus. Jedoch gehört zum Verhältnismäßigkeitsgrundsatz auch die Überprüfung der Angemessenheit der Maßnahmen, nämlich die Abwägung, ob der zu erwartende Grundrechtseingriff in einem adäquaten Verhältnis zu den rechtfertigenden Gründen steht. Eine solche Abwägung wird hier nicht als Teil des Rechtfertigungskriteriums durchgeführt. Vielmehr werden Fragen des Eingriffs in die Grundrechte und -freiheiten als Teil des dritten Kriteriums, nämlich der politischen Auswirkungen, in die Analyse einfließen.

Ich habe hier das Kriterium der Rechtfertigung im Rahmen eines realistischen Ansatzes, nämlich als immanentes Legitimationsmodell der analysierten Ordnung, herausgearbeitet. Ohne die universalistischen Implikationen der jeweiligen Theorien zu teilen, ist dieses Kriterium aber auch kompatibel sowohl mit Habermas' diskurstheoretischer Auffassung, wonach die Legitimität die „Begründbarkeit der jeweiligen Normen“ ist, ${ }^{285}$ als auch mit Forsts Idee, wonach jedes Individuum ein „Recht auf Rechtfertigung" der Entscheidungen hat, die ihn maßgeblich betreffen. ${ }^{286}$

\subsection{Verfahrenskonformität}

Dieses Kriterium verlangt, dass die gesetzten Normen durch rechtmäßige Verfahren zustande kommen und durch dafür kompetente Instanzen gesetzt werden. Dieses Prinzip baut auf den philosophischen Annahmen des Machtpessimismus einerseits und des juridischen Optimismus andererseits auf. Es setzt voraus, dass die Machtausübung rechtlich reguliert werden soll und dass die rechtlichen Mechanismen die zur Ausuferung neigende politische Macht effektiv eindämmen können. Dieses Prinzip konkretisiert

284 BVerfGE 19, 342, zitiert in Wienbracke, Mike, Der Verhältnismäßigkeitsgrundsatz, in: Zeitschrift für das Juristische Studium, 2, 2013, 148-155, hier 148. Zum Verhältnismäßigkeitsgrundsatz vgl. auch Jestaedt, Matthias; Lepsius, Oli$\operatorname{ver}$ (Hg.), Verhältnismäßigkeit. Zur Tragfähigkeit eines verfassungsrechtlichen Schlüsselkonzepts. Tübingen: Mohr Siebeck 2015.

285 Habermas, Faktizität und Geltung, 48.

286 Forst, Das Recht auf Rechtfertigung. Elemente einer konstruktivistischen Theorie der Gerechtigkeit. Wie im ersten Kapitel und in den vorigen Teilen dieses Kapitels argumentiert wurde, liefert das Modell des Rechtsstaates die Grundlage für eine kritische Überprüfung der EU-Maßnahmen im Sinne einer internen oder immanenten Kritik, die aber die Universalisierbarkeit dieser Maßstäbe nicht impliziert. An Habermas' Auffassung finde ich zudem die Rückkopplung an den hypothetischen Konsensus problematisch. Vgl. oben Fußnote 253. 
die Idee des Machtpessimismus und des juristischen Optimismus durch den Rekurs auf die Differenzierung der Macht, insbesondere durch die Trennung der Rechtssetzung von der Rechtsanwendung und innerhalb letzterer durch die Ausdifferenzierung zwischen judikativer und exekutiver Funktion. ${ }^{287}$

Im Kontext der hier durchgeführten Analyse operationalisiert das Kriterium der Verfahrenskonformität den Mechanismus der Machtdifferenzierung in einer Art und Weise, welche der Spezifizität der EU-Architektur und ihrem dynamischen Charakter Rechnung trägt. Einerseits berücksichtigt es, dass eine Differenzierung der Macht auf EU-Ebene nicht nur die Trennung der Rechtssetzung von der Rechtsanwendung bedeutet, sondern dass sie auch die vertikale Verteilung der Kompetenzen zwischen den nationalen und den europäischen Institutionen beinhaltet. Zudem richtet sich die Evaluation der Verfahrenskonformität nach den Kompetenzzuschreibungen, wie sie nach EU- und nationalem Recht zur Zeit der Bestimmung der jeweiligen Maßnahmen galten. Dabei respektiert dieses Kriterium die Eigenartigkeit der EU als politisches System, indem es keine starre Übertragung der nationalen Gewaltenteilung fördert. Es wird auch dem dynamischen Charakter der EU-Entwicklung gerecht, indem es die Kriterien anwendet, die zur Zeit der Erlassung der Maßnahmen galten. Schließlich findet hier auch das Modell der internationalen Legitimität, wonach die Legitimität internationaler Institutionen von der Zustimmung der Mitgliedstaaten abhängt, Berücksichtigung. ${ }^{288}$ Dieses Element spielte insbesondere in der früheren Phase der Entwicklung der EU-Sicherheitspolitik, wie ich schildern werde, eine wichtige Rolle, weil damals die Struktur der EU noch ausgeprägter intergouvernemental war.

Ein zweites Element der Legitimität, das durch dieses Kriterium überprüft wird, ist das demokratische Prinzip. Die Verbindung zu diesem

287 Dabei bleibt die andere wichtige Komponente des Prinzips der Machtdifferenzierung, nämlich die Trennung des Politischen von den religiösen und ökonomischen Bereichen, unbeachtet. Die Überprüfung dieses Aspektes könnte interessante Einsichten für die Frage nach der Legitimität der EU-Sicherheitspolitik bieten, ihre Durchführung würde aber den inhaltlichen und disziplinären Rahmen dieses Buches sprengen. Für einen Einstieg in die Thematik vgl. Bigo, Didier et al., Mapping the Field of the EU Internal Security Agencies, in: Bigo, Didier et al., The Field of the EU Internal Security Agencies. Paris: L'Harmattan 2008, 5-66 und Chris Jones, Market Forces: The Development of the EU Security-Industrial Complex, Report by the Transnational Institute and Statewatch, 2017.

288 Vgl. oben Abschnitt 4.1. 
Prinzip besteht in der Überprüfung der demokratischen Partizipation und Kontrolle in den Prozessen, die zur Einführung der EU-Sicherheitsmaßnahmen geführt haben. Auch in diesem Fall wird der speziellen Architektur der EU Rechnung getragen, indem die Einbeziehung der Parlamente sowohl auf EU- als auch auf nationaler Ebene überprüft wird.

Das Kriterium der Verfahrenskonformität nimmt an, dass die Verteilung der Kompetenzen zwischen den EU-Organen und zwischen diesen und den Institutionen der Mitgliedstaaten der Verteilung der Machtausübung und der gegenseitigen Kontrolle dient. Gleichwohl wird vorausgesetzt, dass die Befugnisse der nationalen und legislativen Parlamente gewissermaßen die demokratische Repräsentation der EU-Bürger_innen gewährleisten. Die Einhaltung der immanenten Kriterien wird mit anderen Worten als eine minimale Anforderung an die Legitimität der beschlossenen Maßnahmen angesehen. ${ }^{289}$

Gemäß dem Kriterium der Verfahrenskonformität werde ich für jede untersuchte Maßnahme fragen, wie sich die institutionellen Verhältnisse sowohl zwischen den EU-Organen als auch zwischen der nationalen und der supranationalen Ebene bei der Verabschiedung der Maßnahmen gestaltet haben.

\subsection{Rückwirkung auf die normative Ordnung}

Das Kriterium der Rückwirkung auf die normative Ordnung bezieht sich auf die sowohl inhaltlichen als auch prozeduralen Auswirkungen der verabschiedeten Maßnahmen auf die Herausbildung der dynamischen normativen Ordnung der EU. Dieses Kriterium bezieht sich noch einmal auf alle Grundprinzipien des demokratischen Rechtsstaates, aber sozusagen aus einer Ex-post-Perspektive. Es drückt die Idee aus, dass es - unabhängig von der Rechtfertigung einer Maßnahme und der Verfahrenskonformität ihrer Verabschiedung - wichtig für die Evaluation ihrer Legitimität ist, wie

289 Dieses Kriterium entspricht auch dem Legalitätsprinzip, nämlich der Idee, dass legitime Normen auf legale Weise (i. e. in Konformität mit den dafür vorgesehenen Verfahren) verabschiedet werden müssen. Dementsprechend wird Legalität als eine notwendige Voraussetzung der Legitimität angesehen, nicht aber als eine hinreichende, wie auch die Tatsache, dass weitere Kriterien der Legitimität herangezogen werden, zeigt. Für eine Kritik der Reduktion von Legitimität auf Legalität und eine Diskussion der Thesen Webers und Luhmanns vgl. Habermas, Legitimationsprobleme im Spätkapitalismus, 133-140 und Habermas, Wie ist Legitimität durch Legalität möglich? 
sich ihre Effekte zu den Legitimitätsvoraussetzungen (nämlich den rechtsstaatlichen und demokratischen Prinzipien und deren philosophischen Grundlagen) verhalten.

Die erste hierfür relevante Frage ist, wie die eingeführten Maßnahmen sich auf das Grundprinzip des Individualismus und auf die davon abgeleiteten Grundrechte und -freiheiten auswirken. Zweitens werde ich, gemäß dem Prinzip der Streuung der Macht, in die Analyse einfließen lassen, wie sich die Sphären der individuellen Freiheiten und der öffentlichen Macht zueinander verhalten und wie ihr Verhältnis durch die Sicherheitsmaßnahmen modifiziert wird. Drittens, und in Anlehnung an das Prinzip der Differenzierung der Macht, werde ich skizzieren, wie die eingeführten Maßnahmen das Verhältnis zwischen den Funktionen der Rechtssetzung sowie der exekutiven und justiziellen Rechtsanwendung neu gestalten. Schließlich werde ich verfolgen, welche Auswirkungen die eingeführten Maßnahmen auf die individuelle Autonomie als Kern des demokratischen Prinzips haben.

Konkret werde ich zum Beispiel die Rolle von Sicherheit als Wert und Begriff untersuchen und wie sich der Verweis auf Sicherheit auf die politische Macht der EU auswirkt. Darüber hinaus werde ich fragen, ob sich neue Formen des Regierens abzeichnen, etwa unter dem Stichwort „algorithmische Regulierung“. Sollte sich im Folgenden ergeben, dass sich auf EU-Ebene tatsächlich solche neuen Regulierungsformen abzeichnen, werde ich deren Charakteristika anschließend näher untersuchen und mit den Grundzügen des demokratischen und rechtsstaatlichen Modells kontrastieren. 


\section{Teil II Die Digitalisierung der EU-Sicherheitspolitik: Erhebung, Austausch und Auswertung von personenbezogenen Informationen - Fallstudien}

The assumption, amply justified by every page of political history, is that some agents of government will behave lawlessly and brutally in

small or big ways most of the time unless they are prevented from doing so. Judith N. Shklar, The Liberalism of Fear, 28 Given the ubiquity of algorithms, do they, in a sense, regulate us? And what would it mean to resist them? Solon Barocas, Sophie Hood, Malte Ziewitz, Governing Algorithms: A Provocation Piece, 9 


\section{Einführung zur Analyse der Fallbeispiele}

In diesem Teil werden anhand der theoretischen Grundlagen, die ich im ersten Teil dargestellt habe, zentrale Sicherheitsmaßnahmen in der EU analysiert.

Das erste Kapitel dieses Teils, Kapitel 3, hat einführenden Charakter und handelt vom europäischen Raum der Freiheit, der Sicherheit und des Rechts (RFSR). Unter diesem Oberbegriff werden alle Maßnahmen der EU gebündelt, die den Bereich Justiz und innere Sicherheit betreffen, also auch alle im vorliegenden Buch analysierten Fallbeispiele. In diesem Kapitel werde ich auf die historische Entwicklung des RFSR, auf seine Einbettung in den EU-Rechtsrahmen, auf seine Grundzüge sowie auf seine Kernbegriffe eingehen. Ich werde die Bedeutung von „Raum“, „Freiheit“, "Sicherheit“, „Recht" und „Grundrechte“ in diesem besonderen Kontext erörtern und die Beziehung zwischen den Elementen der Trias Freiheit Sicherheit - Recht durchleuchten.

Als Maßnahmen der polizeilichen und justiziellen Zusammenarbeit konzentrieren sich die Sicherheitsmaßnahmen im RFSR auf den Informationsaustausch zwischen den Mitgliedstaaten. Das bedeutet jedoch nicht, wie ich darstellen werde, dass die EU-Maßnahmen bloß den Austausch von bereits vorliegenden Informationen vereinfachen. Vielmehr sind die europäischen Maßnahmen eine treibende Kraft beim Ausbau der Datenerhebung und -verarbeitung sowie bei der Entwicklung neuer Ansätze in der europäischen Sicherheitspolitik.

Die Kapitel 4, 5 und 6 analysieren jeweils ein paradigmatisches Beispiel der europäischen Zusammenarbeit im Bereich Justiz und Inneres: das Schengener Informationssystem, die Prümer Regelungen und die Fluggastdatensätze-Richtlinie. Jedes Beispiel wird zunächst im Hinblick auf seine historische Entwicklung und auf den Normeninhalt präsentiert. Diese Einführung dient der Kontextualisierung der Fallbeispiele sowohl historisch in Bezug auf die Entwicklung der EU-Sicherheitspolitik als auch inhaltlich.

Für jedes Beispiel folgt dann die spezifische Analyse seiner Legitimität. Diese wird in drei Schritten durchgeführt, welchen die drei Kriterien der Legitimität, die ich im zweiten Kapitel identifiziert habe, entsprechen. Erstens werde ich jede analysierte Maßnahme anhand des Kriteriums der Rechtfertigung und der Effektivität diskutieren. In den jeweiligen Abschnitten werde ich die Rechtfertigungsargumente analysieren, welche die 
Einführung der Maßnahmen unterstützt haben. Ebenfalls werde ich die erwartete Effektivität dieser Maßnahmen mit deren tatsächlichem Einsatz und, falls Statistiken und Erfahrungsberichte zur Verfügung stehen, mit den erreichten Ergebnissen kontrastieren.

In einem zweiten Schritt werde ich anhand des Kriteriums der Verfahrenskonformität die institutionellen Verhältnisse untersuchen, welche die Durchsetzung dieser Maßnahmen ermöglicht haben. Insbesondere werde ich auf das Verhältnis zwischen Legislative, Exekutive und Judikative sowohl auf nationaler als auch auf europäischer Ebene, aber auch in der Dynamik zwischen Interstaatlichkeit und Supranationalität eingehen.

Schließlich folgt für jede analysierte Sicherheitsmaßnahme ein Teil, in dem ich die theoretischen und normativen Implikationen der analysierten Maßnahmen beleuchte. Dabei werde ich die besonderen Aspekte jeder Maßnahme im Hinblick auf die strukturellen und legitimierenden Charakteristika des verwirklichten Machtmodells diskutierten und fragen, ob diese eine Verschiebung des sicherheitspolitischen Modells implizieren.

Dieser Teil des Buches wird durch Kapitel 7 abgeschlossen, das die Analysen der einzelnen Sicherheitsmaßnahmen in Verbindung mit den Fluchtlinien der aktuellen Sicherheitspolitik im RFSR setzt. Besondere Aufmerksamkeit wird dabei den Plänen der EU für die Potenzierung der Informationssysteme sowie für die Intensivierung ihrer Interoperabilität gewidmet.

Die im zweiten Teil des Buches durchgeführten Analysen liefern die Grundlage für die theoretische und normative Diskussion, die ich im dritten und letzten Teil des Buches entwickeln werde. Diese wird auf die Fallanalysen zurückgreifen, um eine mögliche Transformation der Legitimitätsprinzipien vorzuschlagen, die diesen Entwicklungen Rechnung trägt. 


\section{Kapitel 3 Freiheit, Sicherheit und Recht im europäischen Raum: eine kurze Genealogie der "Sicherheitsunion"}

\section{Charakterisierung des RFSR: ein Raum obne Binnengrenzen}

Der Raum der Freiheit, der Sicherheit und des Rechts (RFSR) ist der Oberbegriff für die EU-Maßnahmen, die den Bereich Justiz und innere Sicherheit betreffen. Obwohl er etwa im Vergleich mit der gemeinsamen Wirtschaftspolitik zu den späteren Entwicklungen der EU gehört, hat er sich in den letzten zwei Jahrzehnten als ein zentraler und dynamischer Politikbereich der EU etabliert. ${ }^{290}$

Aktuell gelten als vertragliche Grundlage des RFSR der Vertrag über die EU (EUV) und der Vertrag über die Arbeitsweise der EU (AEUV) (gemeinsam auch „Die Verträge“), in den durch den Vertrag von Lissabon festgelegten Fassungen. ${ }^{291}$ In der Präambel des EUV wird der Aufbau eines RFSR als Ziel der Union festgelegt. Eine genaue Definition des RFSR ist weder in diesem Vertrag noch in anderen primärrechtlichen Quellen der EU vorhanden. Jedoch finden sich im EUV und im AEUV klare Hinweise auf die Natur dieses Raums und auf die Elemente, die ihn konstituieren. Zunächst verdeutlicht Art. 3 Abs. 2 EUV, dass der RFSR primär als ein Raum ohne Binnengrenzen und des freien Personenverkehrs zu verstehen ist:

Die Union bietet ihren Bürgerinnen und Bürgern einen Raum der Freiheit, der Sicherheit und des Rechts ohne Binnengrenzen, in dem -

290 Als Einführung in den RFSR vgl. u. a. Müller-Graff, Peter-Christian (Hg.), Der Raum der Freiheit, der Sicherheit und des Rechts. Baden-Baden: Nomos 2005; Fischer, Hans Georg; Keller, Matthias (Hg.), Justiz und innere Sicherheit im EU-Recht: die EU als Raum der Freiheit, der Sicherheit und des Rechts. Köln: Bundesanzeiger-Verlag 2014; Fletcher, Maria; Herlin-Karnell, Ester; Matera, Claudio (Hg.), The European Union as an Area of Freedom, Security and Justice. London; New York: Routledge 2017.

291 Vgl. Dok. 2016/C 202/1 „Konsolidierte Fassungen des Vertrags über die Europäische Union und des Vertrags über die Arbeitsweise der Europäischen Union", Amtsblatt der EU C 202 vom 07.06.2016. Der Vertrag von Lissabon ist 2009 in Kraft getreten. 
in Verbindung mit geeigneten Maßnahmen in Bezug auf die Kontrollen an den Außengrenzen, das Asyl, die Einwanderung sowie die Verhütung und Bekämpfung der Kriminalität - der freie Personenverkehr gewährleistet ist.

Dabei wird gleich klargestellt, dass diese Freiheit im Kontext von spezifischen und sie begleitenden Kontroll- und Sicherheitsmaßnahmen gewährt wird.

Darüber hinaus legt Art. 67 Abs. 1 AEUV fest, dass sowohl die Grundrechte als auch die nationalen Rechtssysteme im RFSR berücksichtigt und respektiert werden:

Die Union bildet einen Raum der Freiheit, der Sicherheit und des Rechts, in dem die Grundrechte und die verschiedenen Rechtsordnungen und -traditionen der Mitgliedstaaten geachtet werden.

Diese Erklärung über die Achtung des nationalen Rechts ist vor dem Hintergrund zu betrachten, dass der Politikbereich des RFSR traditionell sehr sensible Materien wie die polizeiliche und justizielle Zusammenarbeit umfasst, über welche die Mitgliedstaaten ihr jeweiliges Bestimmungsrecht besonders achtsam bewahren. Deswegen hat dieser Bereich bis zum Lissaboner Vertrag eine Sonderstellung im rechtlichen Rahmen der EU eingenommen, die insbesondere in den Handlungsformen, nämlich der Art und Weise, wie Entscheidungen der Union getroffen und die entsprechenden Rechtsakte erlassen werden, sichtbar war. Erst seit dem Lissaboner Vertrag, wie unten näher erläutert wird, sind diese Handlungsformen formell ähnlich geregelt wie die anderen Politikbereiche der Union.

Trotz dieser Erneuerung ist der RFSR de facto noch von einem intergouvernementalen Geist geprägt. Tatsächlich, wie auch aus der Analyse der in diesem Buch untersuchten Maßnahmen ersichtlich wird, basieren die institutionellen Methoden in diesem Bereich mehr auf minimalen Standards und gegenseitiger Anerkennung als auf Rechtsangleichung. ${ }^{292}$

In den nächsten Abschnitten werde ich zunächst die Entstehung des RFSR von der Gründung der Europäischen Gemeinschaften bis heute rekonstruieren (Abschnitt 2). Ferner werde ich nachzeichnen, wie die Grundbegriffe Freiheit, Sicherheit und Recht in diesem Raum ausgelegt werden (Abschnitt 3), und darstellen, wie deren Verhältnis zueinander

292 Vgl. de Waele, Henri, Entrenching the Area of Freedom, Security and Justice. Questions of institutional governance and judicial control, in: Fletcher, Maria; Herlin-Karnell, Ester; Matera, Claudio (Hg.), The European Union as an area of freedom, security and justice. London; New York: Routledge 2017, 485-508. 
sich im Laufe der Zeit herausgebildet und gewandelt hat (Abschnitt 4). Schließlich, im fünften Abschnitt, fasse ich die Bedeutung des RFSR im Kontext des gesamten EU-Projekts zusammen und zeichne nach, wie der RFSR progressiv den Weg zu einer „Sicherheitsunion“ geebnet hat.

\section{Die Entwicklung des RFSR von der Nachkriegszeit bis zur Gegenwart}

\subsection{Die Gründungsverträge}

Als in der Nachkriegszeit mit der 1952 erfolgten Gründung der Europäischen Gemeinschaft für Kohle und Stahl (EGKS) die europäische Integration offiziell begann, wurde sie vom Leitgedanken geführt, die „kriegerischen" Rohstoffe unter Kontrolle der Gemeinschaft zu bringen. Es war also ein gewisser Bezug zur Vergemeinschaftung der Sicherheitspolitik gegeben. Der Versuch, darüber hinaus auch eine Verteidigungsgemeinschaft zu bilden, scheiterte jedoch zugunsten der Übertragung der Verteidigungskompetenzen an die NATO. Damit verlagerte sich der Schwerpunkt der (west-)europäischen Zusammenarbeit für die kommenden Jahrzehnte auf die wirtschaftliche Integration. ${ }^{293}$ Dementsprechend sah der Gründungsvertrag der Europäischen Wirtschaftsgemeinschaft, der 1957 unterzeichnet wurde und am 1. Januar 1958 in Kraft trat, auch keine Kooperation weder im Bereich der äußeren noch dem der inneren Sicherheit vor. ${ }^{294}$

Formell fand der Begriff eines RFSR erst 1999 mit dem Vertrag von Amsterdam Eingang ins Primärrecht der EU. Eine Kooperation im Bereich Justiz und Inneres erfolgte aber schon davor, zunächst auf informeller Basis und ab dem Vertrag von Maastricht im Jahr 1992 auch innerhalb des rechtlichen und institutionellen Unionsrahmens.

293 Vgl. Holzhacker, Ronald L.; Luif, Paul, Introduction: Freedom, Security and Justice after Lisbon, in: Holzhacker, Ronald L.; Luif, Paul (Hg.), Freedom, security, and justice in the European Union: Internal and External Dimensions of Increased Cooperation after the Lisbon Treaty. New York; Heidelberg: Springer 2014, 1-12.

294 Vgl. Vertrag zur Gründung der Europäischen Wirtschaftsgemeinschaft (EWGVertrag), am 25.03.1957 geschlossen, ab 01.01.1958 in Kraft, Dok. 11957E/TXT. 


\subsection{Vor dem Vertrag von Maastricht: informelle Kooperation}

Die nicht formalisierte Kooperation der EG-Mitgliedstaaten im Bereich Justiz und Inneres begann 1976 mit dem ersten Treffen der TREVI („Terrorisme, radicalisme, et violence international“)-Gruppe, in der sich bis 1993 einmal jährlich die Innen- und Justizminister der Mitgliedstaaten versammelten. ${ }^{295}$ Die TREVI-Gruppe beschäftigte sich insbesondere mit Fragen der polizeilichen Zusammenarbeit, der Bekämpfung der organisierten Kriminalität und des Terrorismus sowie mit Fragen der Zuwanderung. Die beschlossenen Maßnahmen wurden durch die zuständigen Minister_innen, hohe Beamte und nationale Expert_innen vollzogen. ${ }^{296}$ Es handelte sich insofern um eine Kooperation, die nicht nur durch Intergouvernementalität als Gegenbegriff zur Supranationalität geprägt war, sondern auch durch die Präeminenz der jeweiligen nationalen Exekutiven gegenüber den nationalen Parlamenten. Die TREVI-Zusammenarbeit stellte die Grundlage für die im Vertrag von Maastricht geregelte polizeiliche und justizielle Zusammenarbeit dar und beeinflusste damit den Handlungsansatz in diesem Bereich nachhaltig.

Ein weiterer wichtiger Kern der polizeilichen und justiziellen Zusammenarbeit in dieser intergouvernementalen Phase besteht in den Schengener Abkommen. Um die erwünschte Realisierung des Binnenmarktes zu ermöglichen, schlug die Kommission im Jahr 1985 vor, die Personenkontrollen an den Binnengrenzen abzuschaffen und dafür kompensatorische Maßnahmen einzuführen. ${ }^{297}$ Da diese aber aufgrund der Opposition einiger Mitgliedstaaten nicht als Gemeinschaftsrecht eingeführt werden konnten, wurden sie außerhalb des EG-Rechtsrahmens geregelt, nämlich in zwischenstaatlichen Abkommen, die in Schengen 1985 (das Schengener Übereinkommen) und 1990 (das Schengener Durchführungsübereinkommen) unterzeichnet wurden. ${ }^{298}$ Insbesondere das Schengener Durch-

295 Vgl. Holzhacker; Luif, Introduction: Freedom, Security and Justice after Lisbon; Monar, Jörg, The Dynamics of Justice and Home Affairs: Laboratories, Driving Factors and Costs, in: JCMS: Journal of Common Market Studies, 39/4, 2001, 747-764.

296 Vgl. Fischer; Keller (Hg.), Justiz und innere Sicherheit im EU-Recht, Kapitel 2.

297 Vgl. Vollendung des Binnenmarktes: Weißbuch der Kommission an den Europäischen Rat, KOM (1985) 310 endgültig (Mailand, 28.06.-29.06.1985).

298 Übereinkommen zwischen den Regierungen der Staaten der Benelux-Wirtschaftsunion, der Bundesrepublik Deutschland und der Französischen Republik betreffend den schrittweisen Abbau der Kontrollen an den gemeinsamen Grenzen und Übereinkommen zur Durchführung des Übereinkommens von 
führungsübereinkommen liefert die Basis für die späteren gemeinsamen Außengrenzmaßnahmen im RFSR und, wie ich im vierten Kapitel schildern werde, für die Einführung des Schengener Informationssystems.

\subsection{Die Regelung des RFSR im EU-Primärrecht ab Maastricht: vom Intergouvernementalismus zur Supranationalität}

Der Vertrag über die Europäische Union (EUV), auch als Vertrag von Maastricht bekannt (1992 unterzeichnet, 1993 in Kraft getreten), ${ }^{299}$ gründete die Europäische Union. Damit wurden neben den bereits existierenden Europäischen Gemeinschaften die Gemeinsame Außen- und Sicherheitspolitik und die Zusammenarbeit im Bereich Justiz und Inneres als Bestandteil der EU neu eingeführt. 300

$\mathrm{Ab}$ diesem Moment ist die Materie des (noch nicht so genannten) RFSR offizieller Teil der EU-Kompetenzen. Seine Gestaltung wird nunmehr durch die Entwicklungen und Bestimmungen auf zwei Ebenen beeinflusst. Einerseits gestalten die Veränderungen auf primärrechtlicher Ebene (in primis durch die Reform der Gründungsverträge) die Entscheidungs- und Handlungsformen der EU im Bereich Justiz und Inneres neu. Andererseits liefern die vom Europäischen Rat im regulären zeitlichen Abstand verabschiedeten „Programme“ die politischen Richtlinien für die inhaltliche Gestaltung der Maßnahmen im RFSR. Erstere Erneuerungen werden in diesem, letztere im nächsten Abschnitt präsentiert.

Schengen vom 14.06.1985 zwischen den Regierungen der Staaten der BeneluxWirtschaftsunion, der Bundesrepublik Deutschland und der Französischen Republik betreffend den schrittweisen Abbau der Kontrollen an den gemeinsamen Grenzen, vgl. Amtsblatt der EU L 239/1 vom 22.09.2000. Der Inhalt der Schengener Abkommen wird im nächsten Kapitel näher erläutert. Vgl. auch Peers, Steve, The rise and fall of EU justice and home affairs law, in: Fletcher, Maria; Herlin-Karnell, Ester; Matera, Claudio (Hg.), The European Union as an area of freedom, security and justice. London; New York: Routledge 2017, 11-33.

299 Vertrag über die Europäische Union (EUV), unterzeichnet zu Maastricht am 07.02.1992, Dok. Nr. 92/C 191/0, Amtsblatt der EG C 191 vom 29.07.1992.

300 Vgl. Fischer; Keller (Hg.), Justiz und innere Sicherheit im EU-Recht, Kapitel 2. 


\subsubsection{Die Maastricht-Ära}

Der Vertrag von Maastricht führte das Drei-Säulen-Modell als Leitbild der neu gegründeten Europäischen Union ein. Nach diesem Modell bestand die EU aus drei Säulen, wobei die erste die in der Nachkriegszeit gegründeten EU-Gemeinschaften, die zweite die Gemeinsame Außen- und Sicherheitspolitik und die dritte die Zusammenarbeit im Bereich Justiz und Inneres umfasste. Während die erste Säule supranationalen Charakter hatte, waren die zweite und dritte Säule intergouvernemental geprägt. Art. B EUV in der alten Fassung (EUV a. F.) legte jedoch als Ziel der Union fest, eine enge Zusammenarbeit hinsichtlich der dritten Säule zu entwickeln. Das Hauptentscheidungsorgan für diese Zusammenarbeit war der Rat, in dem die nationalen Minister Entscheidungen nur per Einstimmigkeit treffen konnten. Das Parlament wurde nur zu den wichtigsten Aspekten angehört und der Europäische Gerichtshof (EuGH) durfte keine gerichtliche Kontrolle ausüben. ${ }^{301}$ Die Zusammenarbeit nach diesen Regeln wird, vor allem wegen des Vetorechts jedes Mitgliedstaates im Rat, zumeist als wenig effektiv bewertet. ${ }^{302}$

\subsubsection{Die Amsterdam-Ära}

Der Vertrag von Amsterdam (02.10.1997 unterzeichnet, 01.05.1999 in Kraft getreten $)^{303}$ führte wichtige Änderungen für die Zusammenarbeit im Bereich Justiz und Inneres ein. Wie bereits erwähnt, wurde die Union dort zum ersten Mal als ein „Raum der Freiheit, der Sicherheit und des Rechts" bezeichnet.

Gleichzeitig wurden wichtige Teile der dritten Säule in die erste Säule überführt und unterlagen nunmehr damit den supranationalen Entscheidungsstrukturen, die typisch für die wirtschaftspolitischen Bereiche waren. $\mathrm{Zu}$ diesen Teilen gehörten Außengrenzkontrolle, Einwanderung, Asyl, justizielle Zusammenarbeit in Zivilsachen und Zusammenarbeit im Zollwesen.

301 Vgl. Fischer; Keller (Hg.), Justiz und innere Sicherheit im EU-Recht, Kapitel 2.

302 Vgl. ebd.; Peers, The rise and fall of EU justice and home affairs law.

303 Vertrag von Amsterdam zur Änderung des Vertrags über die Europäische Union, der Verträge zur Gründung der Europäischen Gemeinschaften sowie einiger damit zusammenhängender Rechtsakte vom 02.10.1997. 
Die polizeiliche und justizielle Zusammenarbeit in Strafsachen blieb dagegen Bestandteil der dritten Säule und behielt damit den bisherigen intergouvernementalen Charakter. Diese Materie war im Titel VI EUV a.F. (Art. 29-42) geregelt. Der Rat und das Einstimmigkeitsprinzip machten weiterhin den Kern des Entscheidungsprozesses aus, es wurden jedoch einige Öffnungen zur sogenannten Gemeinschaftsmethode, die in der ersten Säule galt und supranational geprägt war, eingeführt. Mitgliedstaaten und Kommission teilten sich nunmehr das Initiativrecht, und das Parlament musste nun für nahezu jede Maßnahme angehört werden. ${ }^{304}$

Eine weitere wichtige Erneuerung des Amsterdamer Vertrags ist die Überführung des sogenannten Schengen-Besitzstands, bestehend aus den Schengener Abkommen und den Konventionen für deren Implementierung, in den EG-Rechtsrahmen. ${ }^{305}$

\subsubsection{Die Erneuerungen des Lissaboner Vertrags}

Wie erwähnt führte der Lissaboner Vertrag von 2007 eine grundlegende Veränderung der EU-Struktur ein, die mit seinem Inkrafttreten 2009 der Union ihre heutige Form verlieh.

Der Prozess, der zu dieser Erneuerung führte, fing aber schon lange vor der Ausarbeitung des Vertrags an. Zum einen spielten die Ratsprogramme, die im nächsten Abschnitt näher analysiert werden, im Vorfeld des Lissaboner Vertrags eine wichtige Rolle. Zum anderen sah bereits der Vertrag über eine Verfassung für Europa (unterzeichnet am 29.10.2004) auf primärrechtlicher Ebene die Auflösung des Drei-Säulen-Modells und die „Vergemeinschaftung“ der polizeilichen und justiziellen Zusammenarbeit vor. Da aber die Referenden über die geplante Verfassung in den Niederlanden und in Frankreich negativ ausgingen, wurde der Vertrag nie ratifiziert. Die dort beinhalteten grundlegenden Aspekte der EU-Reform wurden jedoch in den Lissaboner Vertrag aufgenommen.

Die erste grundlegende Veränderung des Vertrags von Lissabon besteht in der Erklärung der EU zur Rechtsnachfolgerin der EG, die seitdem

304 Vgl. Fischer; Keller (Hg.), Justiz und innere Sicherheit im EU-Recht; Müller-Graff, Peter-Christian, Der Raum der Freiheit, der Sicherheit und des Rechts - Der primarrechtliche Rahmen, in: Müller-Graff, Peter-Christian (Hg.), Der Raum der Freiheit, der Sicherheit und des Rechts. Baden-Baden: Nomos 2005, 11-27; Peers, The rise and fall of EU justice and home affairs law.

305 Vertiefend dazu vgl. Kapitel 4, Abschnitt 2.3. 
nicht mehr existiert (Art. 1 Abs. 3 EUV). Das Recht der EU besitzt nun supranationalen Charakter und gilt, gemäß der Auflösung der Drei-SäulenStruktur, einheitlich für alle Politikbereiche. ${ }^{306}$

Ferner wurde mit dem Lissaboner Vertrag die supranationale Gemeinschaftsmethode schrittweise auf den gesamten Bereich Justiz und Inneres ausgedehnt. Konkret bedeutet das, dass die Kommission das Initiativrecht hat, der Rat und das Parlament mit (jeweils qualifizierter und einfacher) Mehrheit über die Rechtsakte entscheiden ${ }^{307}$ und dass der EuGH über die Legalität der Akte entscheiden kann. Außerdem wurden den nationalen Parlamenten durch den Lissaboner Vertrag mehr Rechte eingeräumt, indem sie in einer frühen Phase des europäischen Entscheidungsprozesses sich zu der Einhaltung des Subsidiaritätsprinzips äußern und gegebenenfalls eine Überarbeitung des anvisierten Rechtsaktes bewirken können. Über Rechtsakte, die vor Lissabon verabschiedet wurden, sah der Vertrag jedoch eine 5-jährige Sperre der Zuständigkeit vom EuGH und der Möglichkeit für die Kommission, Vertragsverletzungsverfahren einzuleiten, vor. Beide Sperren liefen im Dezember 2014 aus. ${ }^{308}$

Gleichwohl gelten für den RFSR Sonderregelungen zur Anwendung der supranationalen Gemeinschaftsmethode.

Zunächst können für die justizielle Zusammenarbeit in Strafsachen und die polizeiliche Kooperation Rechtsakte auch auf Initiative eines Viertels der Mitgliedstaaten (anstatt wie sonst nur auf Initiative der Kommission) erlassen werden. In diesem Fall ist die notwendige Mehrheit der Stimmen im Rat anders definiert, nämlich mit höheren Zustimmungsanteilen (vgl. Art. 238 [3 b] AEUV). Für Richtlinien mit strafrechtlicher Relevanz ist auBerdem eine „Notbremse“ vorgesehen: Wenn ein Mitgliedstaat befürchtet, dass eine Richtlinie Grundaspekte seines Rechtssystems betrifft, kann er beantragen, dass die Entscheidung im Europäischen Rat stattfindet und damit dem Einstimmigkeitsprinzip unterworfen wird. Wenn der Europäische Rat sich nicht einigen kann, kann eine Gruppe von mindestens neun Staaten eine verstärkte Zusammenarbeit einleiten (Art. 82-83 AEUV). ${ }^{309}$ Die somit eingeführten Maßnahmen gelten zunächst nur für die Staaten, die das Verfahren angestoßen haben, und für diejenigen, die sich expli-

306 Vgl. Fischer; Keller (Hg.), Justiz und innere Sicherheit im EU-Recht.

307 Diese Methode wird auch als „ordentliches Gesetzgebungsverfahren“, früher "Mitentscheidungs-“ oder „Kodezisionsverfahren“, bezeichnet.

308 Vgl. Holzhacker; Luif, Introduction: Freedom, Security and Justice after Lisbon; Peers, The rise and fall of EU justice and home affairs law.

309 Holzhacker; Luif, Introduction: Freedom, Security and Justice after Lisbon. 
zit anschließen, obwohl sie mehr oder weniger unmittelbar einen Anpassungsdruck für alle Mitgliedstaaten schaffen.

Auch die Einführung des ordentlichen Gesetzgebungsverfahrens in die Materie der früheren dritten Säule hat ihre Wirkung noch nicht voll entfalten können. Prinzipiell bedeutet die Ausdehnung dieser Entscheidungsmethode eine Stärkung der Rolle des EU-Parlaments. Tatsächlich hat sie aber die Arbeit in den ersten Schritten der Entscheidungsfindung, die nach wie vor in den Arbeitsgruppen im Rat stattfinden, kaum geändert. Der Einfluss des Parlaments hat nur in den letzten Phasen des Gesetzgebungsverfahrens zugenommen. ${ }^{310}$

Die Sonderregelungen für den RSFR und das Fortbestehen alter Praxen führen dazu, dass alles in allem und trotz der Veränderungen durch den Lissaboner Vertrag der Rat und die nationalen Regierungen, im Vergleich mit anderen Politikbereichen der Union, trotz der institutionellen Erneuerungen ihre überragende Position im RFSR nicht verloren haben. ${ }^{311}$

\subsection{Die politischen Vorgaben des Europäischen Rates}

Seit 1999 hat der Europäische Rat regelmäßig Programme verabschiedet, welche die politischen Leitlinien der Entwicklung des RFSR in den nachfolgenden fünf Jahren enthalten. ${ }^{312}$ In diesem Abschnitt werden die Programme in ihren allgemeinen Zügen präsentiert, während im Abschnitt 4.2 unten auf den Inhalt der wirkungsstärksten Programme ausführlicher eingegangen wird. Wie aus der nachfolgenden Analyse deutlich wird, haben die Programme den Akzent stets unterschiedlich auf ein oder mehrere Elemente der Trias Freiheit - Sicherheit - Recht gesetzt und damit die Beziehung dieser Elemente untereinander mannigfaltig gestaltet.

Das Tampere-Programm von 1999 für die Jahre 1999-2004 basierte auf dem Vertrag von Amsterdam und lieferte den politischen Input für die Entwicklung des RFSR. Nach dem Programm sollte dieser "fest auf ein gemeinsames Bekenntnis zur Freiheit gegründet [sein], das sich auf

310 Vgl. Holzhacker; Luif, Introduction: Freedom, Security and Justice after Lisbon. 311 Vgl. ebd.

312 Vgl. Guild, Elspeth; Carrera, Sergio, The European Union's Area of Freedom, Security and Justice Ten Years on, in: Guild, Elspeth; Carrera, Sergio; Eggenschwiler, Alejandro (Hg.), The area of freedom, security and justice ten years on: successes and future challenges under the Stockholm Programme. Brüssel: CEPS 2010, $1-12$. 
die Menschenrechte, demokratische Institutionen und Rechtsstaatlichkeit stützt“. 313

Das Programm schreibt somit der Freiheit eine wichtige Rolle zu. Die Umsetzung dieses Konzepts durch die Kommission erwies sich aber als schwierig. Zudem schafften die Anschläge vom 11. September 2001 und 11. März 2004 ein politisches und gesellschaftliches Klima, das eine Priorisierung der Sicherheitsagenda und insbesondere der Terrorismusbekämpfung über Freiheit und Recht begünstigte. ${ }^{314}$ Die Präeminenz von Sicherheit über Freiheit und Recht wurde im Folgeprogramm, dem Haager Programm von 2004 ,zur Stärkung von Freiheit, Sicherheit und Recht in der Europäischen Union“, 315 sichtbar. Das Haager Programm war dafür konzipiert, die EU auf das Inkrafttreten des Verfassungsvertrags, inklusive der Auflösung des Drei-Säulen-Modells, vorzubereiten, seine Gültigkeit war aber nicht vom Inkrafttreten des Vertrags abhängig. ${ }^{316}$ Das Haager Programm führte die Metapher einer nötigen Balance zwischen Sicherheit und Freiheit, zwischen der Gewährleistung von Ordnung und Sicherheit und dem Schutz der Grundrechte, ein. ${ }^{317}$

Von dieser Balance ist im Folgeprogramm, dem Stockholmer Programm „Ein offenes und sicheres Europa im Dienste und zum Schutz der Bürger“318 von 2009, keine Rede mehr. Stattdessen hat die Idee eines „Europa der Rechte“ (Ziff. 2) als das Fundament jeder Sicherheitsmaßnahme Platz gefunden. Statt eine Balance zwischen Sicherheit und Freiheit anzustreben, wird im Programm festgelegt, dass Sicherheit und Schutz der Grundrechte sich gegenseitig stärken sollen. Nach Auffassung des

313 Tampere Europäischer Rat, 15. und 16.10.1999, Schlussfolgerungen des Vorsitzes, Ziff. 1. Vgl. auch Balzacq, Thierry; Carrera, Sergio, The Hague Programme: The Long Road to Freedom, Security and Justice, in: Balzacq, Thierry; Carrera, Sergio (Hg.), Security Versus Freedom? A Challenge for Europe's Future. London: Routledge 2006, 1-32.

314 Über die Wurzeln der sicherheitszentrierten Denkweise im Kontext der europäischen Integration vgl. Bigo, Didier, Liberty, whose Liberty? The Hague Programme and the Conception of Freedom, in: Balzacq, Thierry; Carrera, Sergio (Hg.), Security Versus Freedom? A Challenge for Europe's Future. London: Routledge 2006, 35-44, hier 37.

315 Haager Programm zur Stärkung von Freiheit, Sicherheit und Recht in der Europäischen Union, Dok. 2005/C 53/01, Amtsblatt der EU C 53/1 vom 03.03.2005.

316 Vgl. Fischer; Keller (Hg.), Justiz und innere Sicherheit im EU-Recht, Kapitel 2.

317 Vgl. Guild; Carrera, The European Union's Area of Freedom, Security and Justice Ten Years on.

318 Dok. Nr. 17024/09 vom 02.12.2009. 
Rates sollen „vorrangig die Interessen und Bedürfnisse der Bürger im Mittelpunkt stehen“ (Ziff. 1.1), wobei für die „Wahrung der Grundfreiheiten und der Integrität des Einzelnen und zugleich für Sicherheit in Europa“ Sorge zu tragen sei. ${ }^{319}$

Als Nachfolgeprogramm wurden 2014 die „strategic guidelines for legislative and operational planning“, auch als "Post-Stockholm-Programm“ bezeichnet, im belgischen Ypern verabschiedet. ${ }^{320} \mathrm{Im}$ Vergleich mit dem Stockholmer Programm sind diese deutlich kürzer und allgemeiner formuliert. Einerseits wurde dies damit gerechtfertigt, dass die Priorität des RFSR nicht mehr bei der Ausweitung der Themenfelder liegt, sondern bei der Konsolidierung und korrekten Anwendung der existierenden Maßnahmen. Andererseits wird kritisiert, dass die Richtlinien keine strategische Vision anbieten. ${ }^{321}$ Deutlich sichtbar ist, dass der Fokus dieses Dokuments sich erneut verschoben hat und, wie ich unten näher erläutern werde, Sicherheit wieder Zentralität gewonnen hat. ${ }^{322}$

Schließlich wurde im Juni 2019 die „Neue Strategische Agenda 20192024" vom Rat verabschiedet, welche die politischen Prioritäten der Union für den Zeitbereich festlegt. ${ }^{323}$ Diese betreffen die innere Sicherheit, die wirtschaftliche Entwicklung, Nachhaltigkeit und soziale Gerechtigkeit sowie die Außenpolitik, wobei der erste Bereich derjenige ist, der in diesem Kontext von Interesse ist. Da die strategischen Richtlinien für den RFSR, mit denen der Rat üblicherweise die Umsetzung der in der Agenda nur allgemein formulierten Ziele spezifiziert, aktuell noch ausstehen, ${ }^{324}$ wird im folgenden Paragrafen die Strategische Agenda selbst als Grundlage für die Diskussion dienen.

319 Vgl. Guild; Carrera, The European Union's Area of Freedom, Security and Justice Ten Years on.

320 European Council, Brussels, 27.06.2014, Dok Nr. EUCO 79/14.

321 Vgl. Léonard, Sarah; Kaunert, Christian, Searching for a strategy for the European Union's area of freedom, security and justice, in: European Politics and Society, 17/2, 2016, 143-149.

322 Vgl. Abschnitt 4.2 in diesem Kapitel.

323 Europäischer Rat, „Eine neue strategische Agenda. 2019-2024“, 20.06.2019, https://www.consilium.europa.eu/media/39963/a-new-strategic-agenda-2019 -2024-de.pdf (letzter Zugriff: 10.02.2021).

324 Stand: 10.02.2021. 


\section{Grundbegriffe des RFSR}

Die fünfjährigen Programme des Europäischen Rates, wie ich im vorigen Abschnitt dargelegt habe, setzen jeweils unterschiedliche Prioritäten, was das Verhältnis zwischen Freiheit, Sicherheit und Recht angeht.

In diesem Abschnitt werde ich die Bedeutung der grundlegenden Begriffe des RFSR, inklusive, aber nicht ausschließlich der drei Trias-Elemente, näher analysieren, so wie sie in den wichtigsten primär- und sekundärrechtlichen EU-Dokumenten gebildet werden. Im nächsten Abschnitt kehre ich dann zum Verhältnis zwischen Freiheit, Sicherheit und Recht zurück, um dieses tiefgreifender zu analysieren.

Entscheidend für die Bestimmung der Bedeutung des RFSR ist der bereits zitierte Art. 67 AEUV, ${ }^{325}$ der Titel V des Vertrags „Der Raum der Freiheit, der Sicherheit und des Rechts“ eröffnet. Art. 67 AEUV lautet wie folgt:

(1) Die Union bildet einen Raum der Freiheit, der Sicherheit und des Rechts, in dem die Grundrechte und die verschiedenen Rechtsordnungen und -traditionen der Mitgliedstaaten geachtet werden.

(2) Sie stellt sicher, dass Personen an den Binnengrenzen nicht kontrolliert werden, und entwickelt eine gemeinsame Politik in den Bereichen Asyl, Einwanderung und Kontrollen an den Außengrenzen, die sich auf die Solidarität der Mitgliedstaaten gründet und gegenüber Drittstaatsangehörigen angemessen ist. [...]

(3) Die Union wirkt darauf hin, durch Maßnahmen zur Verhütung und Bekämpfung von Kriminalität sowie von Rassismus und Fremdenfeindlichkeit, zur Koordinierung und Zusammenarbeit von Polizeibehörden und Organen der Strafrechtspflege und den anderen zuständigen Behörden sowie durch die gegenseitige Anerkennung strafrechtlicher Entscheidungen und erforderlichenfalls durch die Angleichung der strafrechtlichen Rechtsvorschriften ein hohes Maß an Sicherheit zu gewährleisten.

(4) Die Union erleichtert den Zugang zum Recht, insbesondere durch den Grundsatz der gegenseitigen Anerkennung gerichtlicher und auBergerichtlicher Entscheidungen in Zivilsachen.

Absatz 1 führt das Konzept des RFSR ein, wobei neben den Trias-Elementen der Freiheit, der Sicherheit und des Rechts auch die Begriffe „Raum“ und „Grundrechte“ eine zentrale Rolle spielen. Die Tripartition 
der darauffolgenden Absätze suggeriert, dass jeder Absatz der näheren Erläuterung eines der drei Elemente gewidmet ist, obwohl nur die Begriffe „Sicherheit“ und „Recht“ in den jeweiligen Absätzen (Abs. 3 bzw. 4) explizit genannt werden. „Freiheit“ wird dagegen im zweiten Absatz nicht explizit erwähnt.

\subsection{Raum}

Die Verwendung des Begriffs „Raum“weist auf die Vision eines einzelnen, alle Mitgliedstaaten umfassenden Territoriums hin. Dieses ist einerseits geografisch definiert, andererseits weist es auch auf eine symbolische, wertgeladene Komponente hin, weil eben der Raum einer ist, in dem Freiheit, Sicherheit und Recht verwirklicht werden sollen.

Im Kontext der europäischen Integration wird der Begriff des Raumes häufig in Verbindung mit Themenbereichen benutzt, die noch kein Gegenstand einer gemeinsamen europäischen Politik sind, gleichzeitig aber über eine bloße zwischenstaatliche Zusammenarbeit hinausgehen. Ein Beispiel dafür ist, neben dem RFSR, die Benutzung des Begriffes „Europäischer Strafrechtsraum“ im Jahr 1977 durch den damaligen Präsidenten Frankreichs Valéry Giscard d'Estaing. Der Begriff verwies auf das zunächst gescheiterte Projekt einer verstärkten strafrechtlichen Integration in den Mitgliedstaaten. ${ }^{326}$ Ein weiteres Beispiel ist die Verwendung des Ausdrucks „Europäischer Forschungsraum“, mit dem die EU den Kontext ihrer aktuellen Forschungsrahmenprogramme bezeichnet. ${ }^{327}$ Diese übliche Verwendung für noch unvollständig „vergemeinschaftete“ Materien macht die programmatische Komponente des Raumbegriffs nochmals deutlich.

Andererseits, und im Gegensatz zu der eben erwähnten Verwendung, wird auch der Binnenmarkt im AEUV als „Raum“ definiert, nämlich als ein

Raum ohne Binnengrenzen, in dem der freie Verkehr von Waren, Personen, Dienstleistungen und Kapital gemäß den Bestimmungen der Verträge gewährleistet ist. ${ }^{328}$

326 Vgl. Monar, Jörg, Die politische Konzeption des Raumes der Freiheit, der Sicherheit und des Rechts: Vom Amsterdamer Vertrag zum Verfassungsentwurf des Konvents, in: Müller-Graff, Peter-Christian (Hg.), Der Raum der Freiheit, der Sicherheit und des Rechts. Baden-Baden: Nomos 2005, 29-41.

327 Vgl. ebd.

328 Art. 26 Satz 2 AEUV, ex-Artikel 14 EGV. 
Zwischen dem Raum des Binnenmarktes und dem RFSR besteht, wie ich ausführen werde, eine enge Beziehung. ${ }^{329}$ Jedoch können die jeweiligen Bedeutungen dieser beiden Räume im Kontext der europäischen Integration nicht gleichgestellt werden.

Bereits auf Ebene ihrer theoretischen Grundlage erweisen sich die beiden Räume als unterschiedlich. Zum einen ist der europäische Binnenmarkt fest in einem klaren theoretischen Rahmen verankert, nämlich in der wirtschaftstheoretischen Lehre des komparativen Kostenvorteils. Nach dieser Theorie ist „der Freiverkehr von Produktionsfaktoren und Produkten in einem definierten Gebiet“ ${ }^{\text {*30 }}$ die „Voraussetzung für die Erzielung der gesamtwirtschaftlich besten Ergebnisse“. ${ }^{331}$ Zum anderen ist eine vergleichbare Theorie für die Errichtung des RFSR nicht vorhanden: Der RFSR scheint eher das Ergebnis von disparaten Praxen zu sein als die Verwirklichung eines kohärenten und theoriengeleiteten Projekts.

Demzufolge stellt sich die Frage, ob der RFSR als ein eigenständiger Bereich der EU-Politik oder vielmehr als ein Appendix des Binnenmarktes zu verstehen ist. $\mathrm{Zu}$ dieser Frage werde ich am Ende dieses Kapitels zurückkehren, nachdem die weiteren Begriffe des RFSR erörtert wurden.

\subsection{Freiheit}

Wie oben erwähnt, enthält Art. 67 AEUV eine Darstellung der Elemente, die konstitutiv für den RFSR sind. Dem einleitenden Abschnitt 1, in dem Freiheit, Sicherheit und Recht genannt werden, folgen drei weitere Absätze, die nach der oben vorgeschlagenen Interpretation jeweils die drei Begriffe näher erläutern.

Abschnitt 2 soll demnach der Spezifizierung des Begriffes „Freiheit“ gewidmet sein. Jedoch: Nicht nur wird das Wort „Freiheit“ in dem Abschnitt nicht verwendet, sondern es ist auch nur von Abwesenheit der Kontrollen an den Binnengrenzen und gemeinsamen Kontrollen an den Außengrenzen (begleitet von einer gemeinsamen Einwanderungs- und Asylpolitik) die Rede. Auf den ersten Blick mag ein solches Verständnis von Freiheit seltsam scheinen. Bei näherer Betrachtung erweist es sich aber als eine konsequente Konkretisierung der Konzeption der Freiheit als zunächst

329 Vgl. unten Abschnitt 4.1.

330 Müller-Graff, Der Raum der Freiheit, der Sicherheit und des Rechts - Der primärrechtliche Rahmen, 13.

331 Ebd. 
und wesentlich identisch mit „Freizügigkeit“, die den Politikbereich Justiz und Inneres prägt.

Bereits 1998, kurz nach dem Amsterdamer Vertrag, der den Begriff des RFSR ins Primärrecht der Union einführte, wurde diese Priorität der Freizügigkeit vor den anderen Dimensionen der Freiheit betont. Im Wiener „Aktionsplan des Rates und der Kommission zur bestmöglichen Umsetzung der Bestimmungen des Amsterdamer Vertrags über den Aufbau eines Raums der Freiheit, der Sicherheit und des Rechts" ${ }^{\text {"332 heißt es }}$ unter dem Titel „Ein umfassender Freiheitsbegriff“: „Freiheit im Sinne des freien Personenverkehrs innerhalb der Europäischen Union bleibt ein grundlegendes Ziel des Vertrags“ (Ziff. 6). Dabei wird hinzugefügt, dass auch der Schutz der Grundrechte, der Privatsphäre und der Daten den Freiheitsbegriff ergänzen soll (Ziff. 6 und 7).

Nach diesem Verständnis bedeutet Freiheit also wesentlich Bewegungsfreiheit von bestimmten Personengruppen (in primis Unionsbürger_innen) innerhalb eines bestimmten Gebietes. ${ }^{333}$ Dazu gehört zunächst die Abwesenheit von Kontrollen an den Binnengrenzen, weil solche Kontrollen ein Hindernis für die freie Personenzirkulation darstellen würden. Die Abwesenheit von Kontrollen innerhalb des Raumes erfordert aber nach Ansicht der Verfasser_innen der Verträge ausgleichende Maßnahmen. Diese konkretisieren sich in den gemeinsamen Aktionen im Bereich der Außengrenzkontrolle, der Migrations- und Asylpolitik und der Kriminalitätsbekämpfung, die ebenfalls im zweiten Abschnitt des Art. 67 AEUV neben der Bewegungsfreiheit Platz finden. ${ }^{334}$

\subsection{Sicherheit}

Art. 67 Abs. 3 AEUV führt die Maßnahmen auf, wodurch die EU „ein hohes Maß an Sicherheit“" zu erreichen sucht. Diese bestehen aus der Verhütung und Bekämpfung von Kriminalität, Rassismus und Fremdenfeindlichkeit, der Kooperation im strafrechtlichen Bereich sowie der Anerkennung und Angleichung der strafrechtlichen Entscheidungen bzw. Vorschriften.

Zunächst ist somit Sicherheit als innere, in Abgrenzung zu äußerer, Sicherheit gemeint. Die Gewährleistung der inneren Sicherheit, verstanden

332 Am 03.12.1998 vom Rat angenommen, Amtsblatt EG C 19/1 vom 23.01.1999.

333 Vgl. Fischer, Keller (Hg.), Justiz und innere Sicherheit im EU-Recht, Kapitel 1.

334 Dazu mehr im Kapitel 4 unten. 
als die Ausübung des öffentlichen Gewaltmonopols, ${ }^{335}$ ist jedoch in der EU immer noch hauptsächlich Aufgabe des Staates. Sicherheit im RFSR bezieht sich daher, genauso wie im Wesentlichen auch der Begriff der „Freiheit“, auf den freien Personenverkehr ohne Binnengrenzen und hat seinen logischen Ursprung in der Abwehr der Gefahren, die sich aus diesem ergeben. ${ }^{336}$

Dies scheint auch vom oben erwähnten Wiener Aktionsplan zur Umsetzung des Amsterdamer Vertrag bestätigt zu werden, ${ }^{337}$ in dem Sicherheit und Recht die Bezugskonzepte für "flankierende Maßnahmen“" zur Verwirklichung der Freiheit als freien Personenverkehrs darstellen. 338

\subsection{Recht}

Art. 67 Abs. 4 AEUV nennt als hauptsächliche Maßnahme zur Verwirklichung des „Rechts“ im RFSR die gegenseitige Anerkennung der zivilrechtlichen Entscheidungen.

Auch in diesem Fall ist der Bezug zum freien Personenverkehr deutlich, da das Instrument des Rechts dazu dient, die Herausforderungen zu bewältigen, die sich aus der Personenfreizügigkeit ergeben. ${ }^{339}$ Menschen, die in mehreren Ländern der EU leben, arbeiten oder ihre Tätigkeiten ausüben, sollen nicht aufgrund von zu aufwendigen Verfahren für die Anerkennung von nationalen Rechtsakten in den anderen Mitgliedstaaten behindert werden.

Verglichen mit der üblichen Bedeutung des Begriffes „Recht“ erweist sich seine Verwendung im RFSR somit als begrenzt. Die Selektivität, mit welcher der Rechtsbegriff hier verwendet wird, scheint noch bedeutender im Hinblick auf die Formulierung der englischen und französischen Versionen des Vertrags. Diese verwenden den Begriff „justice“, der am intuitivsten mit „Gerechtigkeit“ ins Deutsche übersetzt werden kann und auf

335 Vgl. Lange, Hans-Jürgen, Innere Sicherheit, in: Lange, Hans-Jürgen; Gasch, Matthias (Hg.), Wörterbuch zur Inneren Sicherheit. Wiesbaden: VS Verlag für Sozialwissenschaften 2006, 123-134.

336 Vgl. Fischer, Keller (Hg.), Justiz und innere Sicherheit im EU-Recht, Kapitel 1.

337 Vgl. Abschnitt 3.2 in diesem Kapitel.

338 „Aktionsplan des Rates und der Kommission zur bestmöglichen Umsetzung der Bestimmungen des Amsterdamer Vertrags über den Aufbau eines Raums der Freiheit, der Sicherheit und des Rechts“, Amtsblatt EG C 19/1 vom 23.01.1999, Ziff. 6.

339 Vgl. Fischer, Keller (Hg.), Justiz und innere Sicherheit im EU-Recht, Kapitel 1. 
weitere Dimensionen wie „Unparteilichkeit, Fairness oder Gleichbehandlung" hinweist. ${ }^{340}$

\subsection{Grundrechte}

Wie bereits geschildert, stellt Art. 67 AEUV fest, dass die Union ein RFSR ist, in dem die Grundrechte geachtet werden. Aus dem Text des Artikels wird allerdings nicht ersichtlich, welche Grundrechte damit gemeint werden: ob diese die auf nationaler, europäischer oder internationaler Ebene festgelegten Grund- und Menschenrechte sind.

Diese Frage kann aber mit Bezug auf eine langjährige Rechtsprechung des EuGH geklärt werden. In dieser hat der EuGH die im EU- (bzw. EG-) Primärrecht erwähnten Grundrechte in denjenigen der EG bzw. EU selbst identifiziert. Einerseits entspricht das der grundlegenden Einstellung des $\mathrm{EuGH}$, nach der das Gemeinschafts- (nun Unions-)recht vorrangig gegenüber dem nationalen Recht der Mitgliedstaaten, inklusive des Verfassungsrechts, ist. Demnach ist ausschließlicher Maßstab für die Gültigkeit des Gemeinschafts- bzw. Unionsrechts das Gemeinschafts- bzw. Unionsrecht selbst. ${ }^{341}$

Allerdings war diese Position insofern problematisch, als die Union vor dem Jahr 2000, in dem die Charta der Grundrechte der EU proklamiert wurde, noch keinen schriftlichen Grundrechtskatalog hatte. Denn die ur-

340 Hartmann, Martin; Offe, Claus (Hg.), Politische Theorie und Politische Philosophie. Ein Handbuch. München: C.H. Beck 2011, 198.

341 Vgl. Fischer, Keller (Hg.), Justiz und innere Sicherheit im EU-Recht, Kapitel 3, Abschn. B. Folge dieser Sichtweise ist auch, dass es nach Auffassung des EuGH nicht zulässig ist, EU-Vorschriften wegen Inkompatibilität mit dem nationalen (Verfassungs-)Recht für ungültig zu erklären. Vgl. Urteil des Gerichtshofs vom 15.07.1964, Flaminio Costa gegen E.N.E.L., Rechtssache 6/64, ECLI:EU:C:1964:66. Vgl. auch Urteil des Gerichtshofs vom 26.02.2013, Stefano Melloni gegen Miniserio Fiscal Rechtssache C 399/11, ECLI:EU:C:2013:107. Dazu auch de Waele, Entrenching the Area of Freedom, Security and Justice. Questions of institutional governance and judicial control. Anderer Meinung war das Bundesverfassungsgericht, vgl. BVerfGE 123, 267; vgl. Poscher, Ralf, Tendencies in Public Civil Security Law, in: European Journal for Security Research, 1/1, 2016, 59-76, hier 63-64; Jestaedt, Matthias, Warum in die Ferne schweifen, wenn der Maßstab liegt so nah? Verfassungshandwerkliche Anfragen an das Lissabon-Urteil des BVerfG, in: Der Staat, 48/4, 2009, 497-516 und Jestaedt, Matthias, Die Europäische Integration und das Grundgesetz: Die Rechtsprechung des BVerfG zwischen Integrationsbeförderung und Integrationsbegrenzung, in: Osaka University Law Review, 64/2, 2017, 43-110. 
sprünglichen Verträge der europäischen Gemeinschaften beinhalteten keine Grundrechteerklärung. Um die potenziell daraus resultierende Rechtslücke zu schließen, hat der EuGH in seiner Rechtsprechung seit 1969 die Theorie der Grundrechte der EU als ungeschriebenes Unionsrecht mit primärrechtlichem Rang entwickelt. ${ }^{342}$ Seine Quellen werden in der Europäischen Konvention zum Schutz der Menschenrechte und Grundfreiheiten (EMRK) und in den gemeinsamen Verfassungsüberlieferungen der Mitgliedstaaten festgelegt.

Erst im Jahr 2000 kam, wie erwähnt, die Charta der Grundrechte der EU als (geschriebene) Rechtsquelle für die Rechtsprechung des EuGH hinzu. Durch den Vertrag von Lissabon besitzt nun die Charta rechtsverbindlichen Charakter. ${ }^{343}$

\section{Die Wechselbeziehungen innerhalb der Trias Freiheit-Sicherheit-Recht}

\subsection{Die Darstellung nach dem EU-Primärrecht}

Wie aus der obigen Darstellung ersichtlich wurde, stehen die drei Begriffe der Trias Freiheit - Sicherheit - Recht in enger Beziehung mit dem Konzept der Freizügigkeit als Kernelement des europäischen Binnenmarktes. Zunächst wird Freiheit im RFSR im Wesentlichen als freier Personenverkehr betrachtet und dieser zusammen mit dem freien Verkehr von Waren, Dienstleistungen und Kapital als Voraussetzung für das Funktionieren des Binnenmarktes gesehen. ${ }^{344}$ Darüber hinaus werden die beiden Begriffe der Sicherheit und des Rechts als funktional für die Verwirklichung der Freiheit im Sinne der Freizügigkeit verstanden, indem sie eine Reihe von Maßnahmen vorsehen, die der Bewältigung der mit der Freizügigkeit einhergehenden Herausforderungen dienen.

In diesem Sinne können die im Vertrag zur Gründung der Europäischen Wirtschaftsgemeinschaft festgelegten Freiheiten des Gemeinsamen Marktes und insbesondere der freie Verkehr von Personen und Dienstleistungen als die „Keimzellen“ ${ }^{445}$ der späteren Zusammenarbeit im Bereich

342 Vgl. Urteil des Gerichtshofs vom 12.11.1969, Erich Stauder gegen Stadt Ulm Sozialamt., Rechtssache 29-69, ECLI:EU:C:1969:57, 419, Rn. 7.

343 Es ist zudem vorgesehen, dass die Union der EMRK beitritt. Vgl. Fischer, Keller (Hg.), Justiz und innere Sicherheit im EU-Recht, Kapitel 3, Abschn. B.

344 Vgl. unter anderem Art. 26 AEUV.

345 Fischer, Keller (Hg.), Justiz und innere Sicherheit im EU-Recht, 10. 
Justiz und Inneres angesehen werden. Ebenfalls haben in diesem Prozess die Schengener Übereinkommen, die den Abbau der Kontrolle an den Binnengrenzen eingeleitet haben, eine entscheidende Rolle gespielt. ${ }^{346}$

In diesem historischen Zusammenhang scheint also das Konzept der Freiheit im Sinne der Freizügigkeit der ursprünglichere Begriff zu sein, wovon sich Sicherheit und Recht ableiten lassen.

\subsection{Die Gestaltung der Wechselbeziehungen nach den Ratsprogrammen sowie in der Praxis}

Die konkrete Entwicklung der Maßnahmen, die im Rahmen des RFSR entstanden sind, zeigt dagegen ein anderes Bild. Faktisch haben nämlich die Maßnahmen, die der Sicherheit zuzuordnen sind, Priorität vor den anderen beiden Elementen der Trias gewonnen und in die jeweiligen Bereiche Eingang gefunden. ${ }^{347}$

Schon 1998, in dem mehrmals erwähnten Aktionsplan zur bestmöglichen Umsetzung der Bestimmungen des Amsterdamer Vertrags, ${ }^{348}$ nach dem wie gesehen Freiheit als zentraler Begriff dargestellt wird, wird seine Verwirklichung fest an Sicherheitsmaßnahmen gekoppelt. ${ }^{349}$ Dort heißt es nämlich, dass der Begriff der Freiheit auch

die Gewißheit [beinhaltet], daß die Behörden (auf nationaler Ebene, auf Ebene der Union und darüber hinaus) alles in ihrer individuellen und kollektiven Macht Stehende tun, um gegen diejenigen vorzugehen, die diese Freiheit nicht anerkennen oder sie mißbrauchen (Ziff. 6).

Etwas weiter unten wird zudem angemerkt, dass: „Die Vorteile eines Raums der Freiheit [...] in vollem Umfang nur in einem Umfeld genossen werden [können], in dem sich die Menschen völlig sicher fühlen“" (Ziff. 9).

Diese Rückkopplung der Freiheit an Sicherheit spiegelt sich in den im RFSR verabschiedeten Maßnahmen wider und wandelt sich in eine deutliche Priorisierung der Sicherheit über die beiden übrigen Konzepte.

346 Vgl. Fischer, Keller (Hg.), Justiz und innere Sicherheit im EU-Recht, Kapitel 2.

347 Die „Kontaminierung“ von Freiheit durch Sicherheit ist jedoch dem EU-Primärrecht nicht fremd, wie oben erwähnt. Vgl. oben Abschnitt 3.2.

348 Amtsblatt EG C 19/1 vom 23.01.1999.

349 Vgl. dazu Monar, Die politische Konzeption des Raumes der Freiheit, der Sicherheit und des Rechts: Vom Amsterdamer Vertrag zum Verfassungsentwurf des Konvents. 
Schon 2001 und 2002, als das wie gesehen eher ausgeglichene Programm von Tampere die Leitlinien der Politik im RFSR bestimmte, waren $80 \%$ der vom Rat angenommenen Maßnahmen im RFSR der Sicherheit zuzuordnen. 350

Im Haager Programm, dem Nachfolger des Programms von Tampere, wird die Fokussierung auf Sicherheit schon im Text des Programms deutlich.

Formell ist der Teil des Haager Programms, in dem spezifische Leitlinien enthalten sind, relativ gleichmäßig zwischen den drei Abschnitten „Stärkung der Freiheit“, „Stärkung der Sicherheit" und „Stärkung des Rechts" verteilt. Freiheit scheint sogar die größte Aufmerksamkeit zu bekommen, da dies der längste der drei Teile ist. Inhaltlich stellt sich das Bild aber anders dar. Tatsächlich wird das Thema Sicherheit auch in den anderen zwei Abschnitten behandelt, sodass viele Sicherheitsmaßnahmen in den Abschnitten "Stärkung der Freiheit" oder "Stärkung des Rechts“ untergebracht werden. In dem Teil, der formell der Freiheit gewidmet ist, finden etwa nach einem ersten Unterteil über die Unionsbürgerschaft nur die Asyl-, Migrations- und Grenzpolitik betreffende Themen Platz, inklusive der „Rückkehr- und Rückübernahmepolitik“, der „Grenzkontrolle und Bekämpfung der illegalen Einwanderung“ und der „Biometrie und Informationssysteme“. Unter den letzteren Maßnahmen werden Datenbanken wie das Schengener Informationssystem, VIS (Visa Information System) und Eurodac genannt. ${ }^{351}$

Auch im Teil „Stärkung des Rechts" werden, neben Themen wie der Beschleunigung der EuGH-Verfahren, dem Aufbau gegenseitigen Vertrauens und der Zusammenarbeit in Zivilsachen, Maßnahmen für die Verbesserung und Intensivierung der justiziellen Zusammenarbeit in Strafsachen erwähnt. Die Auswahl der Themen für diesen Abschnitt verdeutlicht, dass im Haager Programm das Thema „Recht“ vielmehr aus der Perspektive der Behörde betrachtet wird, anstatt aus der Perspektive des Einzelnen als effektiver Schutz der Grundrechte und Verbesserung des Zugangs zum Recht verstanden zu werden.

350 Vgl. Monar, Die politische Konzeption des Raumes der Freiheit, der Sicherheit und des Rechts: Vom Amsterdamer Vertrag zum Verfassungsentwurf des Konvents.

351 Vgl. Haager Programm, Ziff. 1.1 - 1.7; Bigo, Liberty, whose Liberty? The Hague Programme and the Conception of Freedom und Balzacq; Carrera, The Hague Programme: The Long Road to Freedom, Security and Justice. 
Das Stockholmer Programm, ${ }^{352}$ wie oben erwähnt,, ${ }^{353}$ stellt in dieser Hinsicht eine Zäsur dar. In diesem Programm wird der Förderung der Grundrechte, inklusive des Datenschutzes, der demokratischen Teilnahme und der Erleichterung des Zugangs zum Recht viel Platz eingeräumt. Diese Gegenstände werden auch inhaltlich getrennt von anderen Themen behandelt, wie der inneren Sicherheit, den Außengrenzkontrollen und der Migrations- und Asylpolitik, mit denen sich das Programm ebenfalls ausführlich auseinandersetzt.

Die Richtlinien von $2014^{354}$ stellen jedoch die früheren Verhältnisse zwischen Freiheit, Sicherheit und Recht wieder her. Von den 13 Punkten des kurzen Programmes scheinen nur zwei sich mit Fragen der Grundrechte und -freiheiten und des Rechts authentisch zu befassen. Diese sind Ziff. 4, unter der es um den Schutz personenbezogener Daten geht, und Ziff. 11, unter der es unter anderem um die Rationalisierung des EU-Rechts und den Zugang zu ihm sowie um die Angeklagten-, Kinderund Opferrechte geht, obwohl hier auch Maßnahmen der justiziellen $\mathrm{Zu}$ sammenarbeit genannt werden. Ziff. 12 erwähnt die Bewegungsfreiheit der EU-Bürger_innen als eine der Grundfreiheiten der EU, die geschützt werden muss. Allerdings wird als einzige Spezifizierung hinzugefügt, dass diese Freiheit „from misuse and fraudolent claim“ geschützt werden muss, sodass wieder eine Rückkopplung zur Sicherheit hergestellt wird. Alle anderen Punkte, die nicht wie Ziff. 1 und 2 einleitenden oder wie Ziff. 13 abschließenden Charakter haben, befassen sich mit der Intensivierung der behördlichen (inklusive polizeilichen) Zusammenarbeit, mit Fragen von Migration, Asyl und Grenzkontrollen.

Im darauffolgenden Jahr wurde die Zentralität der Sicherheit auch formell statuiert. Mit der „Europäischen Sicherheitsagenda“355 wurde der Grundstein für den Übergang von einem noch formell RFSR heißenden zu einem „europäischen Raum der Inneren Sicherheit“356 gelegt. Dabei sollte sichergestellt werden, dass die EU sich zu einer „wirksamen und echten Sicherheitsunion" entwickelt, wie es in den darauffolgenden regelmäßigen Berichten der Kommission über die ergriffenen Maßnahmen

352 „Ein offenes und sicheres Europa im Dienste und zum Schutz der Bürger“, Dok. Nr. 17024/09 vom 02.12.2009.

$353 \mathrm{Vgl}$. Abschnitt 2.4 in diesem Kapitel.

354 Dok. Nr. EUCO 79/14 vom 27.06.2014.

355 Mitteilung der Kommission an das Europäische Parlament, den Rat, den Europäischen Wirtschafts- und Sozialausschuss und den Ausschuss der Regionen „Die Europäische Sicherheitsagenda“, $\operatorname{COM(2015)~} 185$ final, 28.04.2015.

356 Ebd., 2. 
heißt. ${ }^{357}$ Diese sehen an erster Stelle die Stärkung des Informationsaustausches vor.

Die oben erwähnte „Neue Strategische Agenda 2019-2024“358 verwendet die auf eine Sicherheitsunion hindeutenden Ausdrücke nicht mehr, bleibt aber im Kern bei der Konzeption eines RFSR als eines überwiegend durch Sicherheitsmaßnahmen geprägten Politikfelds. Der erste Teil des Dokuments, der dem „Schutz der Bürgerinnen und Bürger und der Freiheiten" gewidmet ist, befasst sich in zwei einleitenden und abstrakt formulierten Paragrafen mit Grundwerten der EU, Freiheiten und dem Rechtsstaat. Der verbleibende Teil, der mehr als $70 \%$ des Textes ausmacht, ist einer Reihe von Sicherheitsmaßnahmen gewidmet, die nach Sicht des Rates die Prioritäten der EU-Politik im RFSR darstellen. Dabei werden prominent Außengrenzkontrollen, Migrations- und Asylpolitik genannt, gefolgt von dem Funktionieren des Schengen-Raums, dem Informationsaustausch zur Kriminalitäts- und Terrorismusbekämpfung sowie dem Schutz gegen Naturkatastrophen und Kriminalität.

Insgesamt lässt sich feststellen, dass in den Ratsprogrammen und in der darauffolgenden Praxis die Beziehung zwischen den drei Elementen der Trias durch ein Ungleichgewicht zugunsten der Sicherheit geprägt ist. Im RFSR sind in der Praxis sowohl der Begriff „Freiheit“ als auch der Begriff „Recht“ stark sicherheitsbezogen. Zum einem wird Freiheit als die Schaffung eines sicheren Raumes ohne Eindringlinge neu interpretiert und konkretisiert sich somit in einer Reihe von Überwachungsmaßnahmen, die in Widerspruch zur Stärkung der Grundrechte, insbesondere des Schutzes der Privatsphäre und personenbezogener Daten, steht. Zum anderen ist „Recht“ durch die Betonung der justiziellen Zusammenarbeit und der Bekämpfung der transnationalen Kriminalität teilweise durch Sicherheit definiert. ${ }^{359}$

357 Diese wurden seit 2016 zweimal jährlich erstellt. Für einen Überblick vgl. https://ec.europa.eu/home-affairs/what-we-do/policies/european-agenda-sec urity/legislative-documents_en (letzter Zugriff: 03.06.2019).

358 Siehe oben, Abschnitt 2.4 in diesem Kapitel.

359 Vgl. Monar, Die politische Konzeption des Raumes der Freiheit, der Sicherheit und des Rechts: Vom Amsterdamer Vertrag zum Verfassungsentwurf des Konvents; Bigo, Liberty, whose Liberty? The Hague Programme and the Conception of Freedom. 


\section{Aufdem Weg zu einer Sicherheitsunion}

Die in diesem Kapitel durchgeführte Untersuchung hat drei Hauptzüge des RFSR und seiner Entwicklung zu einem „Raum der Sicherheit“ erhellt.

Erstens hat sich dieses Politikfeld in den letzten vier Jahrzehnten von einem subsidiären zu einem zentralen Aktionsbereich der EU entwickelt. Noch Mitte der 1980er Jahre wurden die Initiativen in den Politikbereichen, die heute unter dem Begriff „RFSR“ zusammengefasst werden, als „Ausgleichsmaßnahmen“ zum Abbau der Kontrollen an den Binnengrenzen betrachtet. Nachdem sie im Vertrag von Maastricht als „Angelegenheiten von gemeinsamem Interesse" bezeichnet wurden, wurden sie schließlich mit dem Amsterdamer Vertrag unter dem Sammelbegriff des RFSR in den Status eines zentralen Politikbereichs der Union erhoben. ${ }^{360}$ Die politische Bedeutung dieser Wandlung wird in den nächsten Kapiteln mit Bezug auf konkrete Maßnahmen untersucht.

Zweitens hat die oben skizzierte Entwicklung des RFSR gezeigt, dass dieser Politikbereich durch die Präeminenz der nationalen Exekutive in zwei Hinsichten gekennzeichnet ist. Erstens ist die Kooperation im Bereich des RFSR, verglichen mit anderen EU-Politikbereichen, intergouvernemental geprägt. Obwohl die Zuständigkeiten und Rechte der EU-Institutionen progressiv und vor allem mit dem Vertrag von Lissabon ausgeweitet worden sind, gelten im RFSR immer noch Sonderregelungen, die einen vergleichsweise hohen Einfluss der nationalen Exekutive ermöglichen. ${ }^{361}$ Zweitens haben die nationalen Exekutiven auch gegenüber den nationalen Legislativen eine präeminente Rolle gespielt, wie der Ausbau des Politikbereichs Justiz und Inneres als Schöpfung informeller Treffen der nationalen Minister_innen zeigt.

Bedeutend in diesem Zusammenhang ist die Rolle des Europäischen Rates, der unter anderem durch die Erlassung der analysierten Ratsprogramme nach wie vor die politische Linie des RFSR bestimmt. Der Europäische Rat, in dem die nationalen Staats- und Regierungschef_innen vertreten sind, war bis 2009 keine offizielle EU-Institution. Seine Existenz im Rahmen der EU und seine Rolle wurden erst mit dem Vertrag von Lissabon formalisiert.

360 Vgl. Monar, Die politische Konzeption des Raumes der Freiheit, der Sicherheit und des Rechts: Vom Amsterdamer Vertrag zum Verfassungsentwurf des Konvents.

361 Vgl. oben Abschnitt 2.3.3. 
Drittens hat die durchgeführte Untersuchung die komplexe Wechselbeziehung zwischen den Elementen der Trias Freiheit - Sicherheit - Recht beleuchtet. Wie auch der Ursprung der Kooperation im Bereich Justiz und Inneres in den Schengener Abkommen darlegt, diente diese Zusammenarbeit anfänglich dem Ausbau des Binnenmarktes. Damit ein Markt nachhaltig funktioniert, muss er in der Gesellschaft fest verankert und in nicht ökonomischen Beziehungen verwurzelt sein. ${ }^{362}$ Dazu gehört zunächst der freie Verkehr von Personen und Dienstleistungen, so wie er im EU-Primärrecht festgelegt ist. Die Verwirklichung dieser Marktfreiheit wirkte sich aber auch auf die Dimensionen der Sicherheit und des Rechts aus. Als Eckstein der Realisierung der Bewegungsfreiheit wurde mit den Schengener Abkommen der Abbau der Kontrollen an den Binnengrenzen des Schengener Raums beschlossen. Dieser wurde aber, wie im nächsten Kapitel näher dargelegt wird, als ein Sicherheitsverlust empfunden, wofür Ausgleichsmaßnahmen auf supranationaler Ebene geschaffen werden mussten. ${ }^{363}$ Die Dimension des Rechts betreffend, durfte die transnationale Dimension des Marktes und des Personenverkehrs nicht dazu führen, dass die verschiedenen nationalen Rechtsordnungen ihre Gültigkeit verlieren. ${ }^{364}$ Andererseits durften sie für Unternehmer_innen, Arbeitnehmer_innen und Dienstleister_innen, die über nationale Grenzen hinaus tätig sind, keine zu großen Hürden darstellen. Dafür wurde eine gewisse Harmonisierung der nationalen Rechtsvorschriften für nötig gehalten.

In diesem Sinne hat also Freiheit als Freizügigkeit im konzeptuell-historischen Sinn Priorität vor den anderen beiden Elementen der Trias, nämlich Sicherheit und Recht. Alle drei Elemente sind aber derivativ gegenüber dem Binnenmarkt, weil sie als unterstützende Maßnahmen zur vollständigen Verwirklichung des freien europäischen Marktes eingeführt wurden.

Wie ihre Entwicklung zeigt, hat sich aber die Materie des RFSR progressiv von diesem Status der Begleitmaßnahmen emanzipiert und sich

362 Vgl. Fichera, Massimo, Sketches of a theory of Europe as an Area of Freedom, Security and Justice, in: Fletcher, Maria; Herlin-Karnell, Ester; Matera, Claudio (Hg.), The European Union as an area of freedom, security and justice. London; New York: Routledge 2017, 34-56; Lenaerts, Foreword.

363 Vgl. unten Kapitel 4.

364 Vgl. Fichera, Sketches of a theory of Europe as an Area of Freedom, Security and Justice. Für die Konzeption des Rechts als Förderung des Binnenmarktes vgl. Communication from the Commission - The EU Justice Agenda for 2020: Strengthening Trust, Mobility and Growth within the Union, 11 March 2014, $\operatorname{COM}(2014) 144$ final, Ziff. 3. 
als autonomer Politikbereich etabliert. Im Laufe dieses Prozesses und in seiner konkreten Durchführung hat sich auch die dem RFSR interne Grundkonstellation verändert: Die Hauptkomponente der Trias ist nicht mehr Freiheit als Freizügigkeit. Vielmehr hat die Sicherheit Priorität vor den anderen beiden Elementen gewonnen, sodass nunmehr der RFSR hauptsächlich ein „Raum der Sicherheit“ ist. 365

Dabei geht bereits aus diesen vorläufigen Ergebnissen hervor, dass die Entwicklung des RFSR Fragen aufwirft, die über den spezifischen Bereich Justiz und Inneres hinausgehen und das politische Projekt der EU-Verfassung als Ganzes betreffen.

Dem Präsidenten des EuGH, Koen Lenaerts, zufolge hat der Ausbau des RFSR die EU in ein neues konstitutionelles Paradigma versetzt:

The establishment and consolidation of the AFSJ [Area of Freedom, Security and Justice, Anm. d. Verf.] have given rise to important questions that are not only specific to that area but have also served to define key features of the EU legal order as a whole. Notably, those questions relate to the vertical and horizontal allocation of powers between the EU and its Member States, to the balance between collective security and individual freedom, and to the degree of mutual trust between national judiciaries. Those questions show that the establishment and consolidation of the AFSJ have shifted the EU into a new constitutional paradigm that goes beyond market integration. 366

Der Untersuchung dieser grundlegenden Fragen unter Bezug auf konkrete Fallstudien sind die nachfolgenden Kapitel gewidmet.

365 Jörg Monar hat dies die „Sekuritarisierung“ des RFSR genannt, vgl. Monar, Die politische Konzeption des Raumes der Freiheit, der Sicherheit und des Rechts: Vom Amsterdamer Vertrag zum Verfassungsentwurf des Konvents, 35.

366 Lenaerts, Foreword, xvi. 


\section{Kapitel 4 Grenzen und Kontrolle: der Ausbau der EU- Sicherheitspolitik nach Schengen}

\section{Das Schengener Informationssystem (SIS): die erste europäische Datenbank}

Das SIS ist die älteste europäische Datenbank. Sie ermöglicht den Behörden der Schengen-Mitgliedstaaten die automatisierte Fahndung nach Personen und Gegenständen. Ihr Aufbau wurde im Schengener Durchführungsübereinkommen (SDÜ) von 1990 als „Ausgleichsmaßnahme“ zum Abbau der Grenzkontrollen bestimmt. ${ }^{367}$ Das System enthält Daten von EU- und Drittstaatsangehörigen, die polizeilich gesucht oder vermisst werden, von Drittstaatsangehörigen, deren Einreise in oder Aufenthalt im Schengener Raum nicht erlaubt ist, und von gesuchten Gegenständen wie Fahrzeugen, Waffen, Urkunden etc.

Von 1995 bis 2013 war das System der ersten Generation SIS I in Betrieb, seit April 2013 wurde es durch das SIS II abgelöst, das die Speicherung und Verarbeitung nicht nur wie bisher von alphanumerischen Daten, sondern nun auch von Fingerabdrücken und biometrischen Lichtbildern sowie die Verknüpfung verschiedener Fahndungen miteinander ermöglicht. ${ }^{368}$ Ende 2019 enthielt die Datenbank 91 Millionen Einträge und wurde von 30 europäischen Ländern sowie von den europäischen Behörden Europol und Eurojust benutzt. ${ }^{369}$

Aktuell wird der Ausbau der Einsatzmöglichkeiten des SIS II, etwa durch Ausschreibung unbekannter Personen anhand ihrer Fingerabdrü-

367 Schengener Durchführungsübereinkommen, Titel IV, Art. 92-119, 1993/95. Krane, Christian, Schengener Informationssystem, in: Lange, Hans-Jürgen; Gasch, Matthias (Hg.), Wörterbuch zur Inneren Sicherheit. Wiesbaden: VS Verlag für Sozialwissenschaften 2006, 277-280.

368 Vgl. Report from the Commission to the European Parliament and the Council on the evaluation of the second generation Schengen Information System (SIS II) in accordance with art. 24 (5), 43 (3) and 50 (5) of Regulation (EC) No 1987/2006 and art. 59 (3) and 66 (5) of Decision 2007/533/JHA, COM(2016) 880 final, 21.12.2016, 6 .

369 Diese sind alle EU-Mitglieder außer Irland und Zypern und den vier Schengen-assoziierten Ländern Schweiz, Liechtenstein, Norwegen und Island, vgl. eu-LISA, SIS II - Statistics 2019, March 2020, 4, 8. 
cke, und die Verknüpfung des SIS II mit anderen europäischen Datenbanken unter dem Stichwort „Interoperabilität“ getestet bzw. geplant. ${ }^{370}$

\section{Die Entstehung des SIS: vom zwischenstaatlichen Abkommen zum EU-Recht}

\subsection{Die Errichtung des europäischen Binnenmarktes}

Der Aufbau eines europäischen Binnenmarktes war seit Mitte der 1970er Jahre ein zentrales Ziel der EU. Die Abschaffung der Grenzen innerhalb des EU-Raums wurde dabei als notwendig zur Realisierung dieses Ziels erachtet. Jedoch erwies sich dies als besonders schwierig umzusetzen. Allein die Kommission schlug zweimal - 1982 und 1985 - vergeblich Pläne vor, um die Lockerung der Kontrollen an den Binnengrenzen einzuleiten. Diese scheiterten am Widerstand einiger Staaten, der erst 1987 überwunden werden konnte, als im Rahmen der Einführung des Artikels 8 a EGV (später Art. 2 EUV) erstmals in einem bindenden EU-Vertrag das Ziel der Schaffung eines Raums ohne Binnengrenzen, in dem der freie Verkehr von Waren, Personen, Dienstleistungen und Kapital gewährleistet ist, festgelegt wurde. Es handelte sich jedoch immer noch lediglich um einen Programmartikel, ohne konkrete Umsetzungspflichten. Die tatsächliche Realisierung eines Raums ohne Binnengrenzen war somit noch nicht erreicht und verzögerte sich letztlich bis $1993 .{ }^{371}$

2.2 Die zwischenstaatlichen Bemühungen zum Abbau der Grenzkontrollen

Parallel zu den Bemühungen innerhalb der EG und als Ausweichmöglichkeit zum Widerstand mancher EG-Mitglieder fanden auch auf zwischenstaatlicher Ebene Initiativen statt, die das Ziel der Abschaffung der Grenzkontrollen verfolgten. Ein erstes Abkommen für die Abschaffung der Grenzkontrollen wurde am 13. Juli 1984 in Saarbrücken zwischen Frank-

370 Vgl. Mitteilung der Kommission das Europäische Parlament, den europäischen Rat und den Rat „Auf dem Weg zu einer wirksamen und echten Sicherheitsunion - Achtzehnter Fortschrittsbericht“, COM(2019) 145 final, 20.03.2019.

371 Vgl. Stämpfli, Sandra, Das Schengener Informationssystem und das Recht der informationellen Selbstbestimmung. Bern: Stämpfli 2009, Kapitel B. 
reich und Deutschland beschlossen. ${ }^{372}$ Dieser bilaterale Vertrag diente als Grundlage für die späteren in Schengen getroffenen Vereinbarungen. Diese wurden im Schengener Übereinkommen vom 14. Juni 1985 zwischen Frankreich, Deutschland und den Benelux-Staaten festgelegt, welches den Abbau der Grenzkontrollen zwischen jenen Staaten bestimmte. ${ }^{373}$

Das Schengener Übereinkommen enthielt zunächst politische Absichtserklärungen und wurde in Form eines Verwaltungsabkommens von den nationalen Exekutiven ohne Einbindung der Parlamente beschlossen. ${ }^{374}$ Es ist in zwei Teile unterteilt: Der erste beinhaltet kurzfristige Maßnahmen zur Erleichterung der Grenzkontrollen, während der zweite langfristige Maßnahmen zum Abbau der Grenzkontrollen vorsieht. Obwohl das Schengener Abkommen außerhalb des EG-Rechtsrahmens entstand, wurde dies von den Vertragsparteien als eine Übergangslösung gesehen, welche die Erweiterung des Raums ohne Binnengrenzen auf das ganze Gebiet der EG begünstigen soll. ${ }^{375}$

Die konkreten Maßnahmen zur Ausführung der im Schengener Übereinkommen festgelegten Absichtserklärungen wurden in dem Schengener Durchführungsübereinkommen vom 19. Juni 1990 geregelt. Der Akzent liegt hierbei auf den von den Vertragsparteien für notwendig gehaltenen Ausgleichsmaßnahmen. Diese sollen den empfundenen Sicherheitsverlust kompensieren, der infolge des Abbaus der Grenzkontrollen zu erwarten war. ${ }^{376}$ Anders als das Schengener Übereinkommen ist das Schengener Durchführungsübereinkommen ein völkerrechtlicher Vertrag, der von den nationalen Legislativen ratifiziert werden musste. Außerdem wurde für diesen Vertrag die außergewöhnliche Unterscheidung zwischen Inkrafttreten und Inkraftsetzen eingeführt: Letzteres wurde von einer Erklärung über die tatsächliche Durchführung der Kontrollen an den Außengrenzen sowie den weiteren Ausgleichsmaßnahmen abhängig gemacht. $\mathrm{Zu}$ diesen

372 Abkommen zwischen der Regierung der Bundesrepublik Deutschland und der Regierung der Französischen Republik über den schrittweisen Abbau der Kontrollen an der deutsch-französischen Grenze, Saarbrücken, 13.07.1984, vgl. Bekanntmachung vom 30.07.1984, BGBl. 1984 II, 767.

373 Vgl. Stämpfli, Das Schengener Informationssystem und das Recht der informationellen Selbstbestimmung, Kapitel B.

374 Ebd., Kapitel A. Detaillierter dazu vgl. auch Brouwer, Evelien, Digital borders and real rights. Effective remedies for third-country nationals in the Schengen Information System. Boston: Martinus Nijhoff Publishers 2008.

375 Vgl. Stämpfli, Das Schengener Informationssystem und das Recht der informationellen Selbstbestimmung, Kapitel B.

376 Der Abbau der Grenzkontrolle wurde im Art. 17 Satz 1 des Schengener Übereinkommens festgelegt. 
Bedingungen für das Inkraftsetzen des Schengener Durchführungsübereinkommens gehörte auch die Inbetriebnahme des Schengener Informationssystems, wodurch sich das Inkraftsetzen des SDÜ bis zum 26. März 1995 verzögerte. ${ }^{377}$

\subsection{Die Überführung in den EU-Rechtsrahmen}

Die Absicht der Schengen-Vertragsparteien, den Abbau der Binnengrenzen auf gesamteuropäischer Ebene zu erweitern, wurde 1997 verwirklicht, als mit dem Vertrag von Amsterdam die Schengen-Materie in das EURecht integriert wurde. Das Schengen-Protokoll oder „Protokoll zur Einbeziehung des Schengen-Besitzstands in den Rahmen der Europäischen Union“ ${ }^{\text {378 }}$ regelte die Überführung und wurde dem EG- und EU-Vertrag angefügt. Mit Inkrafttreten des Vertrags von Amsterdam wurde der Schengener Besitzstand verpflichtend für alle EU-Mitgliedstaaten. Damit war aber noch nicht die Personenkontrolle für alle Mitgliedstaaten abgeschafft: Für deren tatsächlichen Abbau war die Inbetriebnahme des SIS als conditio sine qua non festgelegt. ${ }^{379}$

Das Schengen-Protokoll (Art. 2 Abs. 1 Satz 2) beauftragte den Rat, für jede Bestimmung des Besitzstands eine Rechtsgrundlage im Rahmen des EG- oder EU-Rechts (das heißt in der ersten oder dritten Säule der EU) festzulegen. Dieser Prozess stellte erhebliche Herausforderungen dar, darunter zunächst die Feststellung der zum Schengener Besitzstand gehörenden Regelungen, die zahlreiche Sonder- und Übergangslösungen benötigte. 380

Mit dem Lissaboner Vertrag wurde schließlich die gesamte dritte Säule, und damit die Teile des Schengener Besitzstandes, die vom Rat als solche bestimmt wurden, dem ordentlichen Entscheidungsverfahren ${ }^{381}$ unterge-

377 Vgl. Stämpfli, Das Schengener Informationssystem und das Recht der informationellen Selbstbestimmung; Schindehütte, Das Schengener Informationssystem, Kapitel A.

378 Amtsblatt der EG C 340/1997, vom 10.11.1997, 93-102.

379 Vgl. Stämpfli, Das Schengener Informationssystem und das Recht der informationellen Selbstbestimmung, Kapitel B; Schindehütte, Das Schengener Informationssystem, Kapitel A.

380 Dazu ausführlicher Stämpfli, Das Schengener Informationssystem und das Recht der informationellen Selbstbestimmung, 26-28.

381 Dieses sieht die Mitentscheidung des Rates und des Parlaments vor. Für weitere Details vgl. Kapitel 3 dieses Buches. 
ordnet und im Wesentlichen unter den Schirm des „Raums der Freiheit, der Sicherheit und des Rechts“ gebracht.

\subsection{Der Übergang zum SIS der zweiten Generation}

Parallel zu der Überführung des Schengener Besitzstandes in den EURechtsrahmen fand der Beschluss zum Übergang zum System der zweiten Generation SIS II statt.

Das Schengener Informationssystem der ersten Generation, abgekürzt „SIS I“, war wie gesehen das Herzstück der Ausgleichsmaßnahmen, die im Schengener Durchführungsübereinkommen bestimmt wurden. Es wurde zunächst 1995 zwischen den fünf ursprünglichen Schengen-Vertragsparteien in Betrieb genommen. Schrittweise wurden mehr und mehr Staaten an das System angeschlossen, 2001 etwa wurde das SIS bereits von 13 Staaten genutzt. ${ }^{382}$ An das SIS I konnten allerdings maximal 18 Staaten angeschlossen werden, was in Anbetracht der geplanten EU-Erweiterung, die 2004 zehn neue EU-Mitglieder bringen sollte, problematisch schien. ${ }^{383}$

In diesem Zusammenhang entschied der Rat den Übergang zum Schengener Informationssystem der zweiten Generation, abgekürzt „SIS II“. Im Jahr 2001 betraute der Rat die Kommission damit, das Projekt für die Entwicklung des SIS II zu vergeben und zu beaufsichtigen. Für die Vollendung des Projekts wurden zunächst fünf Jahre veranschlagt. Die Realisierung des Projekts stellte sich aber komplexer als geplant heraus, sodass die Kommission ihr Mandat mehrmals verlängern ließ. Das hatte vor allem für die neuen EU-Mitgliedstaaten negative Konsequenzen, da sie ohne Anschluss an das SIS auch nicht von der Freizügigkeit profitieren konnten. Im Jahr 2006 schlug daher die portugiesische Präsidentschaft eine Übergangslösung vor: das SISone4all, eine Anpassung des SIS, die den Anschluss der neuen EU-Mitglieder ermöglichte. Der Rat bewilligte das Projekt, blieb aber der Überzeugung, dass die Einführung des SIS II Priorität behielt, obwohl dessen Entwicklung weiterhin Probleme bereitete und die Inbetriebnahme sich verzögerte. ${ }^{384}$

382 Vgl. Verordnung 2424/2001, Ziff. 2.

383 Vgl. Stämpfli, Das Schengener Informationssystem und das Recht der informationellen Selbstbestimmung, Kapitel B.

384 Vgl. Stämpfli, Das Schengener Informationssystem und das Recht der informationellen Selbstbestimmung; mehr dazu unten Abschnitt 4.4. 
Tatsächlich wurden neun neue Mitgliedstaaten am 21. Dezember 2007 an das SISone4all angeschlossen. Das SIS II wurde erst im Jahr 2013 in Betrieb genommen. ${ }^{385}$

\section{Normeninhalt: Fahndung nach Personen und Gegenständen}

Die aktuell gültige Rechtsgrundlage für den Betrieb und die Nutzung des SIS II wird durch die Verordnung des EU-Parlaments und des Rates 1987/2006 vom 20. Dezember 2006 und den Ratsbeschluss 2007/533/JI vom 12. Juni 2007 geliefert. ${ }^{386}$ Erstere bietet die Grundlage für die Nutzung des SIS II im Zusammenhang mit Angelegenheiten, die zur Zeit des Erlasses der Verordnung unter die Zuständigkeit der Europäischen Gemeinschaft fielen, während der Ratsbeschluss die Themenbereiche abdeckt, die damals Kompetenz der EU waren. Zusammen ersetzen die beiden Dokumente die Vorschriften für das SIS, die ursprünglich im Schengener Durchführungsübereinkommen von 1990 festgelegt wurden. Mit dem Erlass dreier Verordnungen im Jahr 2018, die bis Ende 2021 vollständig umgesetzt werden sollen, hat die EU-Kommission zudem eine umfangreiche Erweiterung der Funktionalitäten und der zugriffsberechtigten

385 Vgl. Stämpfli, Das Schengener Informationssystem und das Recht der informationellen Selbstbestimmung; Schindehütte, Das Schengener Informationssystem, Kapitel A.

386 Verordnung (EG) Nr. 1987/2006 des Europäischen Parlaments und des Rates vom 20.12.2006 über die Einrichtung, den Betrieb und die Nutzung des Schengener Informationssystems der zweiten Generation (SIS II), Amtsblatt der EU L 381/4 vom 28.12.2006 und Beschluss 2007/533/JI des Rates vom 12.06.2007 über die Einrichtung, den Betrieb und die Nutzung des Schengener Informationssystems der zweiten Generation (SIS II), Amtsblatt der EU L 205/63 vom 07.08.2007. 
Behörden bestimmt. ${ }^{387}$ Dieser weitere Ausbau des SIS wird als Übergang zum „SIS 3.0“ bezeichnet. ${ }^{388}$

\subsection{Ziele des SIS}

In den beiden neuen Dokumenten wird das SIS II als „Ausgleichsmaßnahme“ präsentiert, deren Ziel die "Wahrung eines hohen Maßes an Sicherheit in dem Raum der Freiheit, der Sicherheit und des Rechts der Europäischen Union" ist. ${ }^{389}$ Dieses Ziel wird dadurch verfolgt, dass das SIS II die Durchführung der im Schengen-Besitzstand festgelegten Maßnahmen bezüglich des Personenverkehrs bzw. die Zusammenarbeit zwischen den nationalen Polizei- und Justizbehörden erleichtert. ${ }^{390}$ Ersterer Bereich wird durch die Verordnung 1987/2006 gedeckt. Diese regelt den Austausch der Informationen, die der Verweigerung der Einreise in den oder des Aufenthalts im Schengen-Raum dienen. Der Ratsbeschluss 2007/533/JI dagegen bestimmt die Bedingungen des Austauschs der Informationen im zweiten Bereich, nämlich die Intensivierung der Zusammenarbeit in Strafsachen. ${ }^{391}$

387 Verordnung (EU) 2018/1860 des Europäischen Parlaments und des Rates vom 28.11.2018 über die Nutzung des Schengener Informationssystems für die Rückkehr illegal aufhältiger Drittstaatsangehöriger, Amtsblatt der Europäischen Union L 312/1 vom 07.12.2018; Verordnung (EU) 2018/1861 des Europäischen Parlaments und des Rates vom 28.11.2018 über die Einrichtung, den Betrieb und die Nutzung des Schengener Informationssystems (SIS) im Bereich der Grenzkontrollen, zur Änderung des Übereinkommens zur Durchführung des Übereinkommens von Schengen und zur Änderung und Aufhebung der Verordnung (EG) Nr. 1987/2006, Amtsblatt der Europäischen Union L 312/14 vom 07.12.2018 und Verordnung (EU) 2018/1862 des Europäischen Parlaments und des Rates vom 28.11.2018 über die Einrichtung, den Betrieb und die Nutzung des Schengener Informationssystems (SIS) im Bereich der polizeilichen Zusammenarbeit und der justiziellen Zusammenarbeit in Strafsachen, zur Änderung und Aufhebung des Beschlusses 2007/533/JI des Rates und zur Aufhebung der Verordnung (EG) Nr. 1986/2006 des Europäischen Parlaments und des Rates und des Beschlusses 2010/261/EU der Kommission, Amtsblatt der Europäischen Union L 312/56 vom 07.12.2018. Näheres dazu im Kapitel 7, Abschnitt 4.1 unten.

388 Bundesministerium des Innern, für Bau und Heimat, Moderne Kriminalitätsbekämpfung, Das polizeiliche Informationswesen, 2020.

389 Ziff. 5 der Verordnung 1987/2006 bzw. des Ratsbeschlusses 2007/533/JI.

390 Vgl. Verordnung 1987/2006 und Ratsbeschluss 2007/533/JI.

391 Vgl. Art. 2 der Verordnung 1987/2006 bzw. des Ratsbeschlusses 2007/533/JI. 


\subsection{Systemarchitektur und Zuständigkeiten}

Das SIS II, wie auch früher das SIS der ersten Generation, besteht aus drei Elementen: einem zentralen System, den nationalen Systemen der Mitgliedstaaten und einer Kommunikationsinfrastruktur für die Verbindung zwischen den beiden Systemteilen und für den sonstigen Informationsaustausch zwischen den nationalen Büros. ${ }^{392}$ Das zentrale System beinhaltet eine Datenbank (die SIS-II-Datenbank) und eine einheitliche nationale Schnittstelle. Die nationalen Systeme enthalten die eigenen Datenbestände und gegebenenfalls eine Teil- oder vollständige Kopie der SIS-II-Datenbank, die für die Abfrage benutzt wird. Die nationalen Datenbestände der anderen Mitgliedstaaten dürfen nicht direkt abgefragt werden. Die zentrale Agentur, zuständig für den technischen Betrieb der zentralen SISEinheit, befand sich zunächst in Straßburg; mit Inbetriebnahme des SIS II im Jahr 2013 wurde die Kompetenz an die eu-LISA ${ }^{393}$ mit Sitz im estländischen Tallin weitergegeben. ${ }^{394}$ Die eu-LISA ist auch für die Verwaltung anderer europäischer Datensysteme, wie das VIS und Eurodac, zuständig.

Jeder Staat pflegt die eigene Datenbank und trägt die Kosten dafür. Die zentrale Infrastruktur dagegen wird aus dem Haushalt der EU finanziert. Konkret werden die Fahndungen durch die zugriffberechtigten nationalen Behörden eingeleitet. Die Anfragen können manuell oder automatisiert erfolgen. Im Fall eines Treffers erfolgt innerhalb von Sekunden eine positive Rückmeldung an die abfragende Behörde. Im Anschluss können weitere Informationen aufgerufen und über die nationale Kontaktstelle die ausländischen Behörden um weitere Informationen ersucht werden. ${ }^{395}$ Die Mitgliedstaaten bestimmen sowohl die nationale Behörde, die für das nationale SIS Verantwortung trägt, als auch diejenige Behörde, die für den Austausch zusätzlicher Informationen zuständig ist. Letztere Behörden werden in allen Mitgliedstaaten SIRENE (Supplementary Information

392 Für die Systemarchitektur des SIS II vgl. Art. 4 der Verordnung 1987/2006 bzw. des Ratsbeschlusses 2007/533/JI.

393 „European Agency for the operational management of large-scale IT systems in the area of freedom, security and justice."

394 In Straßburg ist jedoch zunächst der Großteil der Mitarbeiter_innen und der physischen Infrastruktur geblieben. Vgl. Töpfer, Eric, Die Trias digitaler Grenzen: Eurodac, SIS II und VIS, CILIP 109, 05.04.2016.

395 Vgl. Schindehütte, Das Schengener Informationssystem, 24-25. 
Request at National Entry)-Büros genannt. ${ }^{396}$ In Deutschland ist das SIRENE-Büro beim BKA angesiedelt.

\subsection{Daten- und Ausschreibungskategorien}

Die Daten über Personen, die zur Fahndung ausgeschrieben sind, enthalten wie schon im früheren SIS der ersten Generation den Namen, besondere und unveränderbare physische Merkmale, Geburtsort und -datum, Geschlecht, Staatsangehörigkeit, Informationen darüber, ob die Person gewalttätig, bewaffnet oder geflohen ist, sowie Informationen, die im Zusammenhang mit der Fahndung stehen, wie etwa den Grund der Ausschreibung und die zu ergreifenden Maßnahmen. Neu im SIS II ist die Möglichkeit, biometrische Daten wie Lichtbilder und Fingerabdrücke im System zu speichern und abzurufen sowie verschiedene Ausschreibungen miteinander zu verknüpfen. ${ }^{397}$ Zunächst werden biometrische Daten nicht für die Suche nach Personen verwendet, sondern nur, um die Identität einer Person zu prüfen, die durch eine alphanumerische Abfrage (etwa nach Namen und Geburtsdatum) im SIS II aufgefunden wird. Die Verordnung 1987/2006 und der Ratsbeschluss 2007/533/JI sahen schon die Möglichkeit vor, sobald dies technisch realisierbar sein wird, Fingerabdrücke für die Fahndung zu verwenden. ${ }^{398}$ Diese technischen Möglichkeiten sind dank dem Subsystem AFIS („Automated Fingerprint Identification System“) seit 2018 vorhanden, sodass die Suche anhand von daktyloskopischen Daten nun möglich ist. Die Abfrage anhand von daktyloskopischen Daten ist nun sogar für alle Staaten verpflichtend, wenn keine anderen Mittel für die Feststellung der Identität einer Person zur Verfügung stehen. ${ }^{399}$ Dabei war im Schengener Durchführungsübereinkommen explizit

396 Vgl. Art. 6 und 7 der Verordnung 1987/2006 bzw. des Ratsbeschlusses 2007/533/JI.

397 Vgl. Art. 20 der Verordnung 1987/2006 bzw. des Ratsbeschlusses 2007/533/JI.

398 Vgl. Art. 22 der Verordnung 1987/2006 bzw. des Ratsbeschlusses 2007/533/JI. Im April 2016 kündigte die Kommission an, diese neue Funktionalität 2017 in das SIS II einzuführen. Vgl. Mitteilung der Kommission an das Europäische Parlament und den Rat "Solidere und intelligentere Informationssysteme für das Grenzmanagement und mehr Sicherheit", $\operatorname{COM(2016)~} 205$ final, 06.04.2016, 8-9.

399 Vgl. Art. 43(2) der Verordnung (EU) 2018/1862 und unten, Kapitel 7, Abschnitt 4. Diese Pflicht besteht seit Dezember 2020 für alle an das SIS II angebundene Staaten, vgl. Monroy, Matthias, Schengener Informationssystem - 
verboten, andere Datenkategorien als die dort aufgelisteten im SIS zu erfassen, und Fingerabdrücke gehörten nicht zu den vorgesehenen Datenkategorien. ${ }^{400}$ Die EU-Kommission plant zudem die Einführung weiterer neuer Funktionalitäten, wofür allerdings eine Revision der rechtlichen Grundlagen des SIS II notwendig ist. Diese umfassen beispielsweise die Verwendung von Gesichtsbildern für die biometrische Identifikation, die automatische Übermittlung von Informationen nach einem Treffer sowie die Speicherung von DNA-Profilen für die Identifikation vermisster Personen. 401

Die Personenkategorien, die im SIS gesucht werden können, haben sich im Vergleich mit dem früheren System der ersten Generation nicht wesentlich verändert. Nur sind die Personenkategorien statt in einem einzigen Dokument (früher: das SDÜ) nun in zwei verschiedenen aufgelistet. Die Verordnung 1987/2006 enthält nämlich nur die Kategorie der Drittstaatsangehörigen, die zur Einreise- oder Aufenthaltsverweigerung ausgeschrieben sind, weil dies die einzige Kategorie ist, die den Personenverkehrsmaßnahmen zugeordnet ist. ${ }^{402}$ Indessen enthält der Ratsbeschluss 2007/533/JI die Personenkategorien, die im Rahmen der polizeilichen und justiziellen Zusammenarbeit gesucht werden. Diese sind zunächst Personen, die zum Zwecke der Übergabe- oder Auslieferungshaft (aufgrund eines europäischen bzw. internationalen Haftbefehls) gesucht werden, ${ }^{403}$ Vermisste ${ }^{404}$ und Personen, die im Zusammenhang mit ihrer Teilnahme an einem Gerichtsverfahren (etwa als Zeuge oder als Beschuldigte und Verurteilte) auffindbar gemacht werden sollen. Hinzu kommt die Kategorie der Personen und Sachen, die zur verdeckten oder gezielten Kontrolle ausgeschrieben werden. 405 Diese Art der Ausschreibung soll der Strafverfolgung und der Abwehr von Gefahren für die öffentliche Sicherheit dienen. Voraussetzung für eine solche Ausschreibung ist, dass entweder kon-

Abgleich von Fingerabdrücken jetzt EU-weit verpflichtend, in: Netzpolitik.org, 27.01.2021.

400 Vgl. Art. 94 Schengener Durchführungsübereinkommen.

401 Vgl. Mitteilung der Kommission an das Europäische Parlament und den Rat „Solidere und intelligentere Informationssysteme für das Grenzmanagement und mehr Sicherheit“, $\operatorname{COM(2016)~} 205$ final, 06.04.2016, 8-9 und eu-LISA, SIS II - Statistics 2019, March 2020, 4. Die Themen des Ausbaus und der Integration der EU-Datenbanken werden in Kapitel 7 wieder aufgegriffen und ausführlicher diskutiert.

402 Vgl. Art. 24 Verordnung 1987/2006.

403 Vgl. Art. 26 des Ratsbeschlusses 2007/533/JI.

404 Vgl. Art. 32 des Ratsbeschlusses 2007/533/JI.

405 Vgl. Art. 36 des Ratsbeschlusses 2007/533/JI. 
krete Anhaltspunkte vorliegen oder die Gesamtbeurteilung einer Person erwarten lässt, dass diese Person eine schwere Straftat plant oder begeht bzw. in Zukunft wieder schwere Straftaten begehen wird. Außerdem ist eine Ausschreibung zum Zwecke der verdeckten oder gezielten Kontrolle vorgesehen, wenn die Informationen, die damit gewonnen werden sollen, erforderlich für die Abwehr erheblicher Gefahren für die innere oder äußere Sicherheit sind. Diese Informationen umfassen unter anderem Ort und Zeit der Kontrolle, Reiseweg und Reiseziel sowie eventuelle Begleitpersonen und werden als Zusatzinformationen (also als Informationen, die nicht im SIS gespeichert werden) zwischen den SIRENE-Büros ausgetauscht. ${ }^{406}$ Schließlich sieht der Ratsbeschluss Sachfahndungsausschreibungen zum Zweck der Sicherstellung oder Beweissicherung in Strafverfahren vor. Darunter fallen Gegenstände wie Fahrzeuge, Schusswaffen, gestohlene oder abhandengekommene Dokumente, Urkunden, Wertpapiere, Zahlungsmittel und Banknoten. ${ }^{407}$

Sowohl im Rahmen der Maßnahmen bezüglich des Personenverkehrs wie auch im Rahmen der polizeilichen und justiziellen Kooperation ist es möglich, verschiedene Ausschreibungen im SIS II miteinander zu verknüpfen. ${ }^{408}$

\subsection{Zugriffsberechtigte}

Zugriffsberechtigte für beide Bereiche des Personenverkehrs sowie der polizeilichen und justiziellen Zusammenarbeit sind diejenigen Behörden, die zuständig für Grenzkontrollen und sonstige polizeiliche oder zollrechtliche Überprüfungen sind sowie die nationalen Justizbehörden. ${ }^{409}$ Laut Verordnung 1987/2006 haben außerdem Zugang zum SIS-II-Datenbestand unter anderem die Behörden und Stellen, die für die Prüfung der Visumsanträge, die Erteilung von Visa und Aufenthaltstiteln und die Anwendung anderer Rechtsvorschriften über den Personenverkehr zuständig sind. ${ }^{410}$ Der Ratsbeschluss 2007/533/JI erlaubt zusätzlich den Zugriff durch Euro-

406 Vgl. Art. 36-37 des Ratsbeschlusses 2007/533/JI.

407 Vgl. Art. 38 des Ratsbeschlusses 2007/533/JI.

408 Vgl. Art. 37 der Verordnung 1987/2006 und Art.52 des Ratsbeschlusses 2007/533/JI.

409 Vgl. Art. 27 der Verordnung 1987/2006 und Art. 40 des Ratsbeschlusses 2007/533/JI.

410 Vgl. Art. 27 Verordnung 1987/2006. 
pol und Eurojust, jedoch beschränkt auf bestimmte Datenkategorien. ${ }^{411}$ Prinzipiell dürfen die im SIS II gespeicherten Daten nicht mit Drittstaaten oder internationalen Organisationen ausgetauscht oder diesen zur Verfügung gestellt werden. ${ }^{412}$ Der Ratsbeschluss 2007/533/JI räumt jedoch eine Ausnahme ein, die den Austausch von Informationen über „gestohlene, unterschlagene, abhanden gekommene oder für ungültig erklärte Pässe“ mit der weltweiten Agentur Interpol durch eine Verbindung zwischen dem SIS II und der Interpol-Datenbank erlaubt. ${ }^{413}$

Mit dem Erlass dreier Verordnungen im Jahr 2018 hat die EU den Kreis der Behörden, die Zugriff auf das SIS haben, deutlich erweitert. ${ }^{414}$ Die Verordnungen, die bis Ende 2021 umgesetzt werden müssen, bedeuten zum Beispiel für Deutschland eine Erweiterung der Zugriffsberechtigten auf Zulassungsstellen für Luft- und Wasserfahrzeuge und Botschaften. ${ }^{415}$ Zudem wurden die Datenkategorien, auf die Eurojust und Europol Zugriff haben, erweitert und Frontex als weitere zugriffberechtigte Agentur benannt.

Mittelfristig wird von der EU-Kommission geplant, das SIS II mit anderen europäischen Systemen zu verbinden, wie zum Beispiel mit dem VIS, dem zukünftigen EES (Einreise-/Ausreisesystem, englisch: Entry/Exit System ${ }^{416}$ oder mit Eurodac, sodass diese Systeme direkt miteinander kommunizieren und Daten von den anderen Systemen abfragen können. Langfristig ist die Entstehung einer europäischen zentralisierten Datenbank geplant, die alle europäischen Informationssysteme miteinander verbinden

411 Vgl. Art. 41-42 des Ratsbeschlusses 2007/533/JI.

412 Vgl. Art. 39 der Verordnung 1987/2006 und Art. 54 des Ratsbeschlusses 2007/533/JI.

413 Art. 55 des Ratsbeschlusses 2007/533/JI. Dabei war im Schengener Durchführungsübereinkommen kein Zugriff durch nationale Justizbehörden vorgesehen. Da es weder die Agenturen Europol und Eurojust noch die Interpol-Datenbank verlorener und gestohlener Reisedokumente gab, war der Zugriff durch erstere und die Verbindung mit letzterer im SDÜ ebenfalls nicht vorgesehen. Vgl. Art. 101 SDÜ.

414 Verordnung (EU) 2018/1860, Verordnung (EU) 2018/1861 und Verordnung (EU) 2018/1862.

415 Vgl. Deutscher Bundestag, Antwort der Bundesregierung auf die Kleine Anfrage der Abgeordneten Andrej Hunko, Heike Hänsel, Christine Buchholz, weiterer Abgeordneter und der Fraktion DIE LINKE - Drucksache 19/23251, Drucksache 19/23614 vom 23.10.2020.

416 Das EES wird die Grenzübertritte von visumspflichtigen und visumsbefreiten Drittausländer_innen erfassen, die für kurze Aufenthalte in den Schengener Raum einreisen. Vgl. ausführlicher dazu das Kapitel 7 dieses Buches. 
soll und durch ein zentralisiertes System für den Abgleich biometrischer Daten verschiedener Datenbanken unterstützt werden soll. 417

Auch im Bereich der Zugriffsberechtigungen stellt die neue Rechtslage im Vergleich mit den ursprünglichen Regelungen des SDÜ eine Erweiterung dar. Zum Beispiel sah das SDÜ keinen Zugriff weder durch die nationalen Justizbehörden noch durch die EU-Agenturen Europol und Eurojust oder durch Interpol vor. ${ }^{418}$

\section{Rechtfertigungsargumente und Effektivität des SIS}

Bei der Frage nach der Legitimation des Schengener Informationssystems soll zwischen den Gründen für die Entstehung und den Weiterbetrieb des SIS und denjenigen für die Umwandlung zum SIS II unterschieden werden.

\subsection{Entstehung des SIS - Legitimation}

\subsubsection{Der Wortlaut der Dokumente}

Was den ersten Schritt angeht, nämlich die Herausbildung und das Bestehen des Schengener Informationssystems überhaupt, wird das Hauptlegitimationsargument im Schengener Übereinkommen und im SDÜ festgehalten. Ersteres legt im Artikel 17 fest, dass die Vertragsparteien vor der tatsächlichen Abschaffung der Grenzkontrolle

ergänzende Maßnahmen zum Schutz der inneren Sicherheit sowie zur Verhinderung der unerlaubten Einreise von Personen, die nicht Angehörige von Mitgliedstaaten der Europäischen Gemeinschaften sind,

417 Vgl. Mitteilung der Kommission an das Europäische Parlament und den Rat "Solidere und intelligentere Informationssysteme für das Grenzmanagement und mehr Sicherheit“, $\operatorname{COM(2016)~} 205$ final, 06.04.2016, 20-21.

418 Diese Erneuerungen wurden teilweise bereits in das SIS I eingeführt mit der Verordnung (EG) Nr. 871/2004 des Rates vom 29.04.2004 „über die Einführung neuer Funktionen für das Schengener Informationssystem, auch im Hinblick auf die Terrorismusbekämpfung", Amtsblatt L 162/29 vom 30.04.2004 und dem Beschluss 2005/211/JI des Rates vom 24.02.2005 „über die Einführung neuer Funktionen für das Schengener Informationssystem, auch im Hinblick auf die Terrorismusbekämpfung“, Amtsblatt L 68/44 vom 15.03.2005. 
ergreifen müssen. Wie erwähnt wurden diese Maßnahmen im SDÜ konkretisiert; Herzstück davon ist das Schengener Informationssystem. Artikel 93 SDÜ stellt als Ziel des Informationssystems die Gewährleistung der öffentlichen Sicherheit und Ordnung sowie der „Anwendung der Bestimmungen dieses Übereinkommens im Bereich des Personenverkehrs“ fest. Das Schengener Informationssystem erfüllt damit eine doppelte Funktion: Zum einen dient es der Aufrechterhaltung der inneren Sicherheit der Mitgliedstaaten, zum anderen der Durchsetzung von deren Einwanderungsund Asylpolitik. Diese Funktionen sind mit dem Übergang zum SIS II unverändert geblieben. In der Verordnung 1987/2006, welche die Nutzung des SIS II im Rahmen des Personenverkehrs regelt, wird jedoch die zweite Funktion der ersten untergeordnet:

Das SIS II sollte als Ausgleichsmaßnahme zur Wahrung eines hohen Maßes an Sicherheit in dem Raum der Freiheit, der Sicherheit und des Rechts der Europäischen Union beitragen, indem es die Umsetzung der Maßnahmen im Zusammenhang mit dem den Personenverkehr betreffenden Teil des Schengen-Besitzstands, der in den Dritten Teil Titel IV des Vertrags aufgenommen wurde, erleichtert.

Anders als vom Wortlaut des SDÜ suggeriert, wird hier die Durchsetzung der Personenverkehrspolitik (nämlich die Einwanderungs- und Asylpolitik) nicht als eigenständiges Ziel verstanden, sondern als Instrument zur Gewährleistung der inneren Sicherheit auf dem Gebiet der Vertragsstaaten.

\subsubsection{Die polizeiliche Position}

Die Funktion des SIS als Sicherheitsinstrument spielte tatsächlich während der Entstehungsphase des SIS die Hauptrolle für die Rechtfertigung des Systems.

Dieses Rechtfertigungsargument basiert auf der Annahme, dass der Wegfall der Grenzkontrollen ein Sicherheitsdefizit mit sich bringe, das durch die Errichtung eines Fahndungssystems wie des SIS zu kompensieren sei.

Diese Position wurde besonders während der Schengen-Verhandlungen zwischen Mitte und Ende der 1980er Jahre, aber auch noch Anfang der 1990er Jahre vor allem im polizeilichen Umfeld stark vertreten. Reinhard Rupprecht, späterer Schengen-Delegierter des Bundesministeriums des Innern, ist einer der Hauptvertreter dieser Position. Der Grenzkontrolle wird 
durch ihn zunächst eine Filterfunktion zugeschrieben: Die Grenze und die dort durchgeführten Kontrollen fungieren als ein Raster zur Aufdeckung von Kriminalität. ${ }^{419}$ Vor allem die professionelle Kriminalität würde dadurch zu aufwendigen Manövern gezwungen, um das Aufdeckungsrisiko zu umgehen. ${ }^{420}$ Zudem wäre die Effektivität der Grenze als Raster durch Statistiken belegbar, die auf hohe Aufgriffsquoten bei den Grenzkontrollen hinweisen. ${ }^{421} 1988$ etwa wurden durch die westdeutsche Grenzpolizei und den Zoll 103000 Aufgriffe gemeldet.

Die positive Wirkung der Grenzkontrollen wird aber nicht durch diese Aufdeckungsfunktion ausgeschöpft. Dieser Auffassung nach kommt noch eine präventiv-abschreckende Funktion der Grenzkontrolle hinzu: Allein das Risiko, durch Grenzkontrollen ergriffen zu werden, würde Kriminelle davon abhalten, transnational tätig zu werden. ${ }^{422}$ Schließlich würde aber die „abstrakte Beschreibung der Sicherheitsfunktion der Grenze“423 das entscheidende Argument liefern, das einen Sicherheitsverlust als Folge des Abbaus der Grenzkontrollen erwarten lässt. Die Grenze bilde eine

419 Vgl. Rupprecht, Reinhard; Hellenthal, Markus, Programm für eine Europäische Gemeinschaft der Inneren Sicherheit, in: Rupprecht, Reinhard; Hellenthal, Markus (Hg.), Innere Sicherheit im Europäischen Binnenmarkt. Eine Veröffentlichung der Bertelsmann Stiftung. Gütersloh: Verlag Bertelsmann Stiftung 1992, 23-318, hier 42; Schreiber, Manfred, Abschaffung der Grenzkontrollen in Europa? Tendenzen - mögliche Auswirkung und Auffangmaßnahmen, in: Die Neue Polizei, 3, 1985, 56-60, 58 und Walter, Bernd, Europäischer Enthusiasmus. Grenzüberschreitende Kriminalität im Spannungsfeld zwischen Kontrolle und Liberalisierung des Grenzverkehrs, in: Kriminalistik, 2, 1989, 66-71, hier 69.

420 Vgl. Schreiber, Abschaffung der Grenzkontrollen in Europa? Tendenzen - mögliche Auswirkung und Auffangmaßnahmen.

421 Vgl. Rupprecht, Reinhard, Wettlauf der Schnecken. Probleme und Konsequenzen des Abbaus von Grenzkontrollen, in: Kriminalistik, 5, 1989, 263-270; Gröbl, Harald, 1992: Offene Grenzen und was dann?, in: Die Neue Polizei, 2, 1989, 81-87 und Rupprecht; Hellenthal, Programm für eine Europäische Gemeinschaft der Inneren Sicherheit, 133-134.

422 Vgl. Rupprecht; Hellenthal, Programm für eine Europäische Gemeinschaft der Inneren Sicherheit, 42 und 133; Schreiber, Abschaffung der Grenzkontrollen in Europa? Tendenzen - mögliche Auswirkung und Auffangmaßnahmen; Rupprecht, Wettlauf der Schnecken. Probleme und Konsequenzen des Abbaus von Grenzkontrollen; Gröbl, 1992: Offene Grenzen und was dann?; Walter, Europäischer Enthusiasmus. Grenzüberschreitende Kriminalität im Spannungsfeld zwischen Kontrolle und Liberalisierung des Grenzverkehrs.

423 Schreiber, Abschaffung der Grenzkontrollen in Europa? Tendenzen - mögliche Auswirkung und Auffangmaßnahmen, 58; wortwörtlich gleich Rupprecht, Wettlauf der Schnecken. Probleme und Konsequenzen des Abbaus von Grenzkontrollen, 44 . 
„natürliche strategische Linie“424 für die polizeiliche Arbeit, weil es an den Grenzen und nur dort möglich sei, Kontrollen auch ohne Vorliegen von Verdachts- oder Gefährdungsgründen durchzuführen. Aufgrund aller dieser Erwägungen sei zu erwarten, dass der Wegfall der Grenzkontrollen Sicherheitsverluste mit sich bringen würde und dass die transnationale Kriminalität in Bereichen wie u. a. Rauschgifthandel, Waffenschmuggel, Vernetzung zwischen Mitgliedern terroristischer Organisationen, Diebstahl, Raubüberfällen und Menschenhandel zunehmen würde. ${ }^{425}$

Schon Mitte der 1990er Jahre aber, als die Schaffung des SIS bereits beschlossen war, jedoch seine Inbetriebnahme und damit der Wegfall der Grenzkontrollen noch nicht konkretisiert wurden, wird auch unter den Verfechter_innen des Sicherheitsdefizit-Arguments an der Effektivität des SIS als Ausgleichsmaßnahme gezweifelt. Das SIS würde nicht nur einen Mehraufwand für die Polizei bedeuten, es würde auch keine bedeutenden zusätzlichen Möglichkeiten erschließen als diejenigen, die bereits im Rahmen von Europol existierten. Dennoch verlieren die Schengener Regelungen nicht an Bedeutung: Trotz aller Unzulänglichkeiten des SIS bleiben sie ein wichtiger „Schrittmacher“ für die Europäisierung der Inneren Sicherheit. 426

\subsubsection{Die Ansicht der EU-Kommission und Positionen in der Politik}

Die entgegengesetzte Position, die einen Sicherheitsverlust infolge des Wegfalls der Grenzkontrollen verneint oder mindestens relativiert, wurde ebenfalls schon zur Zeit der Schengen-Verhandlungen vertreten. $\mathrm{Zu}$ den prominentesten Verfechtern dieser Position gehörten die EG-Kommission wie auch der damalige deutsche Bundeskanzler Helmut Kohl. In ihrem

424 Schreiber, Abschaffung der Grenzkontrollen in Europa? Tendenzen - mögliche Auswirkung und Auffangmaßnahmen, 58; Rupprecht, Wettlauf der Schnecken. Probleme und Konsequenzen des Abbaus von Grenzkontrollen, 263.

425 Vgl. Schreiber, Abschaffung der Grenzkontrollen in Europa? Tendenzen - mögliche Auswirkung und Auffangmaßnahmen; Rupprecht, Wettlauf der Schnecken. Probleme und Konsequenzen des Abbaus von Grenzkontrollen; Walter, Europäischer Enthusiasmus. Grenzüberschreitende Kriminalität im Spannungsfeld zwischen Kontrolle und Liberalisierung des Grenzverkehrs und Rupprecht; Hellenthal, Programm für eine Europäische Gemeinschaft der Inneren Sicherheit, 100-102.

426 Vgl. Krüger, Ralf, Innere Sicherheit für Europa. Schengen und Maastricht Stationen der Polizei auf dem Weg nach Europa, in: Kriminalistik, 12, 1994, 773-779. 
Bericht über die Abschaffung der Personenkontrollen ${ }^{427}$ aus dem Jahr 1989 behauptete die Kommission, dass es jedem, der mit der Materie vertraut sei, bekannt wäre, dass „die derzeit an den Grenzen vorgenommenen Kontrollen ineffizient sind“. ${ }^{428}$ Infolge des Wegfalls der Grenzkontrollen sei zudem keine Zunahme des Terrorismus und der schweren Kriminalität zu erwarten. Insgesamt vertritt die Kommission die Position, dass durch die Öffnung der Grenzen sich vielmehr ein Sicherheitsgewinn ergebe, weil dadurch ein Druck zur Rechtsangleichung und Kooperation entstünde, der ohnehin sinnvoll und als Fortschritt zu betrachten wäre. Die von ihr vorgeschlagenen Maßnahmen, wie etwa die Angleichung zahlreicher Rechtsvorschriften, werden nicht als „Ausgleichs-“, sondern als „flankierende Maßnahmen“ zum Abbau der Grenzkontrollen präsentiert. Der Wert dieser Maßnahmen wird zudem als weiterer Schritt zur Vervollständigung des EG-Binnenraums hervorgehoben. Andere Maßnahmen, wie etwa die Intensivierung der strafrechtlichen Kooperation zwischen den Justizbehörden, werden von der Kommission „für die Abschaffung der innergemeinschaftlichen Grenzen nicht unbedingt für erforderlich" gehalten. ${ }^{429}$ Lediglich die Verstärkung und Vereinheitlichung der Kontrollen an den Außengrenzen werden von der Kommission als sinnvolle Maßnahmen zur Kompensierung eines von der Abschaffung der Grenzkontrollen verursachten Sicherheitsverlusts angesehen. Die Kommission begründet jedoch ihre Position, insbesondere die Aussage über die Ineffektivität von Grenzkontrollen, nicht weiter.

Wie oben erwähnt hatte die deutsche Regierung bei der Öffnung der Grenzen zu den Nachbarländern eine Vorreiterfunktion besessen. ${ }^{430}$ Schon vor dem ersten Schengener Abkommen mit Frankreich und den Benelux-Staaten hatte Deutschland im Alleingang am 13.07.1984 ein Abkommen über den schrittweisen Abbau der Grenzkontrollen mit Frankreich geschlossen. Kurz darauf folgte ein ähnliches Abkommen mit dem damaligen Nicht-EG-Staat Österreich. ${ }^{431}$ Bundeskanzler Kohl war auf deutscher

427 Bericht der Kommission über die Abschaffung der Personenkontrollen an den Innergemeinschaftlichen Grenzen, COM(88) 640 final, 16.01.1989.

428 S. 2 des Berichtes, zitiert in Kühne, Hans-Heiner, Kriminalitätsbekämpfung durch innereuropäische Grenzkontrollen? Auswirkungen der Schengener Abkommen auf die innere Sicherheit. Berlin: Duncker \& Humblot 1991 (Schriften zum europäischen Recht), 12.

429 S. 25 des Kommissionsberichtes, zitiert in ebd., 13.

430 Vgl. oben, Abschnitt 2.2 in diesem Kapitel.

431 Vgl. Schreiber, Abschaffung der Grenzkontrollen in Europa? Tendenzen - mögliche Auswirkung und Auffangmaßnahmen. 
Seite der Hauptakteur der Grenzöffnungen. Kohls Entscheidung fand nicht nur außerhalb des EG-Rahmens statt, sondern auch „ohne Rücksprache mit den Polizei-Experten im Innenministerium und den Zoll-Spezialisten im Finanzressort“". ${ }^{432}$ Vorwürfe, die Öffnung der Grenze würde ein Sicherheitsdefizit mit sich bringen, wurden seitens des Kanzleramtes zurückgewiesen. Als 1984 die Zahl der Festnahmen an den deutschen Grenzen laut Statistiken stark anstieg, unterstellte Kohl den Grenzbeamten eine interessierte Eifrigkeit, die darauf abzielen würde, die Unabdingbarkeit der Grenzkontrollen zu belegen. ${ }^{433}$ Wolfgang Schäuble, damaliger Parlamentarischer Geschäftsführer der Unionsfraktion, verneinte ebenfalls die Gefahr von gravierenden Sicherheitsdefiziten im Zusammenhang mit dem Abbau der Grenzkontrollen. ${ }^{43}$ Später, in seinem Einführungsvortrag als Bundesinnenminister beim BKA im Jahr 1989, bekräftigte Schäuble nochmals diese Position:

Die Erfahrung zeigt, daß das Instrument der Grenzkontrolle gegenüber organisierter Kriminalität nur eingeschränkt wirksam ist. Gezielte Ermittlung und Fahndung sind erfolgreicher als die routinemäßige, auf Stichproben reduzierte Ausweiskontrolle und Fahndungsabfrage. Der Schlagbaum ist kein besonders intelligentes Fahndungsinstrument. Im Drogenhandel, dem klassischen Betätigungsfeld der organisierten Kriminalität, haben die Kartelle sich schon längst auf die Grenzkontrollen eingestellt. Schon lange ist uns dort kein Financier, kein Hintermann mehr ins Netz gegangen. ${ }^{435}$

Seitens der Polizeibehörden und der Politik wurden somit zwei gegensätzliche Positionen vertreten. So sehr unterschiedlich diese Positionen inhalt-

432 Vgl. Der Spiegel, Big Brother ersetzt den Zöllner, in: Der Spiegel, 1989, 27-28, hier 28.

433 „Die Zahl der Festnahmen an den Grenzen sei stark gestiegen, weil sich die Beamten nach unserer Ankündigung mächtig ins Zeug legen um nachzuweisen, daß der Fortfall der Grenzkontrollen unmöglich ist“, Frankfurter Rundschau, 09.07.1984. „An den Grenzen endet die Macht von Kohl und Mitterrand“, zitiert in Baumann, Mechthild, Der Einfluss des Bundeskanzleramts und des Bundesministeriums des Innern auf die Entwicklung einer europäischen Grenzpolitik, in: Hunger, Uwe et al. (Hg.), Migrations- und Integrationsprozesse in Europa. Wiesbaden: VS Verlag für Sozialwissenschaften 2008, 17-33, hier 25.

434 Der Spiegel, Big Brother ersetzt den Zöllner.

435 Zitiert in: Busch, Heiner, Grenzenlose Polizei? Neue Grenzen und polizeiliche Zusammenarbeit in Europa. Münster: Westfälisches Dampfboot 1995, 72. Originalquelle: Pressedienst des BMI - Der Bundesinnenminister teilt mit, 26.06.1989, 5 . 
lich sind, so sehr sind sie sich aber darin einig, dass sie eine spezifische Interpretation des nationalen Interesses sowie die Interessen der eigenen Institutionen zum Ausdruck bringen. Einerseits wird das nationale Interesse eher „sicherheitspolitisch“, andererseits „gesamtgesellschaftlich“ interpretiert. ${ }^{436}$ In beiden Fällen geht es aber auch darum, die Existenz der eigenen Institution sowie den Erhalt bzw. Ausbau der eigenen Macht zu sichern. Zudem sind die beiden Positionen dadurch vereint, dass sie die vorliegenden Statistiken entweder durch einen allgemeinen Hinweis auf die Praxis und die Erfahrung der Spezialist_innen ersetzen (wie etwa die Kommission oder Schäuble in dem obigen Zitat) oder nur oberflächlich zitieren, ohne auf die Bedeutung der Zahlen näher einzugehen (wie die Vertreter_innen der polizeilichen Position). ${ }^{437}$

\subsubsection{Rechts- und politikwissenschaftliche Studien und Einschätzung des BKA}

Studien, die sich ausführlich mit den Tätigkeitsberichten der Grenzbehörden auseinandergesetzt haben, zeigen ein gegenüber den beiden soeben dargestellten Positionen differenzierteres Bild. Im Ergebnis relativieren diese die Effektivität von Grenzkontrollen als Filter gegen (schwere) Kriminalität und damit die Grundannahme des Ausgleichsarguments.

Der deutsche Rechtswissenschaftler und Kriminologe Hans-Heiner Kühne fertigte im Auftrag des rheinland-pfälzischen Innenministeriums ein Gutachten an, dessen Ergebnisse 1991 veröffentlicht wurden. ${ }^{438}$ Das Gutachten basiert auf den Statistiken der Grenzschutzdirektion Koblenz vom Jahr 1980 bis zum ersten Halbjahr 1989.

Kühne differenziert zunächst zwischen allgemeiner und „grenzgemachter“439 Kriminalität. Zur grenzgemachten Kriminalität gehören Delikte, die nur deswegen begangen werden können, weil Grenzen und Grenzkontrollen existieren, wie illegale Einreise und Urkundenfälschung. Diese De-

436 Ausführlicher dazu vgl. Baumann, Der Einfluss des Bundeskanzleramts und des Bundesministeriums des Innern auf die Entwicklung einer europäischen Grenzpolitik, 17. Über die innerdeutsche Debatte hinaus vgl. Den Boer, Monica, The Quest for European Policing: Rethoric and Justification in a Desorderly Debate, in: Anderson, Malcolm; Den Boer, Monica (Hg.), Policing across national boundaries. London: Pinter 1994, 174-196.

437 Vgl. Kühne, Kriminalitätsbekämpfung durch innereuropäische Grenzkontrollen?, 41.

438 Ebd.

439 Ebd., 43. 
likte stellen keine unmittelbare Gefahr für die Grundrechte der Bürger_innen dar. Das, was durch deren strafrechtliche Verfolgung geschützt wird, sind vielmehr „ordnungspolitische Konzepte des Staates“. ${ }^{440}$ Diese habe aber der Staat offenbar mit der Erweiterung der Binnengrenze durch u. a. Schengen revidiert und neu definiert, ${ }^{441}$ sodass es widersprüchlich wäre, die Zahlen der "grenzgemachten Kriminalität“ in einer Berechnung des möglichen Sicherheitsverlusts zu berücksichtigen.

Für die Beantwortung der Frage nach einem möglichen Sicherheitsverlust durch Wegfall der Grenzkontrollen sind nur diejenigen Delikte relevant, die die Rechte der Bürger_innen beeinträchtigen und/oder verletzen sowie ein Problem für die innere Sicherheit darstellen. Diese Kriminalität besteht etwa aus Delikten wider das Leben, wider das Eigentum und Vermögen, Delikten im Bereich des illegalen Besitzes oder illegaler Verwendung von Waffen und Sprengstoff sowie Betäubungsmitteldelikten. Was diese Kategorien angeht, ergibt sich aus den von Kühne untersuchten Daten, dass Grenzkontrollen nur von geringer Aufklärungseffektivität sind. Was die Art der Delikte, die durch Grenzkontrollen aufgedeckt werden, angeht, schlussfolgert Kühne, dass:

bei allen Grenzen der quantitative Aufgriffsschwerpunkt bei den hier sogenannten grenzgemachten Delikten liegt und daß die Kontrollerleichterungen nur diese, nicht aber die Aufgriffshäufigkeit der allgemeinen Kriminalität beeinträchtigen. ${ }^{442}$

Kühne führt zudem eine weitere für die Interpretation der Daten wichtige Unterscheidung zwischen Fahndungs- und Initiativaufgriffen ein. Erstere finden aufgrund einer Ausschreibung im Fahndungssystem statt, letztere lediglich auf Initiative der Grenzbeamten. Initiativaufgriffe sind für die Messung der Effektivität der Grenzkontrollen am relevantesten, weil die Existenz der Grenze und die Möglichkeit, dort Kontrollen durchzuführen, notwendige Bedingung dafür sind, dass der Aufgriff stattfinden kann. Was die Relevanz der Fahndungsaufgriffe angeht, ist eine weitere Unterscheidung nötig. Wenn die vorhandenen Informationen ausführlich genug sind, um den Aufgriff auch anderswo als an der Grenze zu ermöglichen,

440 Kühne, Kriminalitätsbekämpfung durch innereuropäische Grenzkontrollen?, 43.

441 Zum Beispiel stellte früher die Einreise eines niederländischen Bürgers mit falschem Pass einen ordnungspolitischen Verstoß dar, nunmehr benötigen niederländische Bürger_innen aber keinen Pass mehr, um nach Deutschland zu reisen.

442 Kühne, Kriminalitätsbekämpfung durch innereuropäische Grenzkontrollen?, 45. 
dann sind die durchgeführten Aufgriffe für die Feststellung der Effektivität der Grenzkontrollen nicht relevant. Anders verhält es sich hingegen, wenn die gesuchte und zur Fahndung ausgeschriebene Person oder der gesuchte und zur Fahndung ausgeschriebene Gegenstand erst durch die Grenzkontrolle gefunden werden. In diesem Fall sind Grenzkontrollen wie bei den Initiativaufgriffen eine notwendige Voraussetzung für die Durchführung der Aufgriffe und damit bedeutsam für die Messung der Effektivität von Grenzkontrollen für die Bewahrung der inneren Sicherheit. Aus den von Kühne analysierten Daten wird ersichtlich, dass die Initiativaufgriffe im Rahmen der allgemeinen Kriminalität eher eine geringe Rolle spielen. Die Qualität der Daten ermöglicht jedoch keine ausführlichere Analyse, zum Beispiel über den Anteil der relevanten Fahndungsaufgriffe.

Im Ergebnis stellt Kühne Folgendes fest:

Der Beitrag der Grenzen zum Erhalt der inneren Sicherheit ist gemessen an den Grenzschutzstatistiken sowohl qualitativ als auch quantitativ äußerst gering. [...] Der völlige Kontrollabbau würde die Tätigkeit der Strafverfolgungsbehörden nicht merklich beeinträchtigen. ${ }^{443}$

Die obigen Überlegungen betreffen die repressive Funktion der Grenzkontrollen, jedoch nicht die andere - präventive - Funktion, welche die Verfechter_innen des Sicherheitsdefizit-Arguments den Grenzkontrollen zuschreiben. Diesbezüglich kann Kühne nur das bekräftigen, was die Vertreter_innen der polizeilichen Position bereits einräumen:

Die präventive Wirkung verbleibender Grenzkontrollen ist nicht empirisch erfaßbar. Es kann nur vermutet werden, daß sie den schlecht organisierten Gelegenheitsdelinquenten, keinesfalls aber den überlegt und planerisch vorgehenden Kriminellen beeindruckt. ${ }^{444}$

Auch der Publizist und Politikwissenschaftler Heiner Busch befasste sich mit der Frage nach der tatsächlichen Effektivität der Grenzkontrollen zur Bewahrung der inneren Sicherheit und führte zu ihrer Beantwortung eine eingehende Analyse vorhandener Daten durch. Seine Analyse stützt sich hauptsächlich auf die grenzpolizeilichen Tätigkeitsberichte für die Jahre 1980-1991, berücksichtigt aber auch ältere Datenbestände und die Statistiken der Kriminalämter.

443 Kühne, Kriminalitätsbekämpfung durch innereuropäische Grenzkontrollen?, 49.

444 Ebd. Kritisch zu den Schlussfolgerungen Kühnes vgl. Rupprecht; Hellenthal, Programm für eine Europäische Gemeinschaft der Inneren Sicherheit, 129-131. 
Auch Busch, wie schon Kühne, weist auf die Undifferenziertheit hin, mit der Daten und Statistiken von den Vertreter_innen des Sicherheitsdefizit-Arguments zitiert werden. Die Art und Weise, wie diese erwähnt werden, kann leicht zu dem Missverständnis führen, dass die zitierten Aufgriffszahlen mit der Zahl der tatsächlichen Festnahmen übereinstimmen würden. Aufgriffe bestehen jedoch vielmehr in der „Feststellung einer Person oder einer Sache im Rahmen polizeilicher Kontrolle oder Überprüfungen" 445 und führen nicht notwendigerweise zu einer Festnahme: Tatsächlich lag in den Jahren 1980-1991 der Anteil der Aufgriffe, die zu einer Festnahme führten, stets zwischen 13 und $17 \%$. In allen anderen Fällen handelte es sich entweder um keine Straftaten oder um leichte Kriminalitätsformen, die keine Festnahme erforderten.

Busch untersucht außerdem die vorhandenen Daten in Verbindung mit der Art der Kriminalität, die diese Aufgriffe bekämpfen sollten, und unterscheidet dabei zwischen Aufgriffen gegen Diebstahldelikte, gegen Drogendelikte und zum Ziel des Staatsschutzes. Die Analyse führt zu der Schlussfolgerung, dass die Effektivität der Grenzkontrollen sich auf Alltagskriminalität und Kleinschmuggel beschränkt. Die Idee, Grenzen wären wichtig, um schwere oder organisierte Kriminalität zu bekämpfen, beruhe auf einem Denkfehler: Tatsächlich werden große Drogenlieferungen über die Grenze ins Inland gebracht, so wie Terrorist_innen ins Ausland flüchten und Diebstahlbanden die Beute ins Ausland verschleppen. Das bedeutet aber nicht, dass diese Kriminalität auch an der Grenze erkannt werden kann. Vielmehr sind die Grenzkontrollen ein „,grobmaschiges Netz', in dem sich im Wesentlichen alltägliche, sichtbare Kriminalität verfängt “ ${ }^{.}{ }^{4} 6$

1996 veröffentlichte auch das BKA eine Studie, die sich mit den Auswirkungen des Binnenmarktes auf die Kriminalitätsentwicklung befasste. ${ }^{447}$ Die Studie entstand aus einem Forschungsprojekt im Zeitraum 19931995; sie reichte also gerade bis zur Inbetriebnahme des SIS, die im März 1995 erfolgte. Die Studie schätzt die Effektivität des SIS positiv ein und empfiehlt eine Intensivierung der Schengener Kooperation als eine von zahlreichen Maßnahmen auf nationaler und internationaler Ebene, die dem erwarteten Kriminalitätsanstieg entgegenwirken sollen. Jedoch

445 Rupprecht, Reinhard; Altmann, Robert, Polizei-Lexikon. Heidelberg: Kriminalistik-Verlag 1986, 33, zitiert in Busch, Grenzenlose Polizei?, 39.

446 Busch, Grenzenlose Polizei?, 73.

447 Wittkämper, Gerhard W.; Krevert, Peter; Kohl, Andreas, Europa und die innere Sicherheit: Auswirkungen des EG-Binnenmarktes auf die Kriminalitätsentwicklung und Schlußfolgerungen für die polizeiliche Kriminalitätsbekämpfung. Wiesbaden: Bundeskriminalamt 1996, 420. 
prognostiziert die Studie, trotz Inbetriebnahme des SIS, einen Anstieg der Kriminalität bis zum Jahr 2000 infolge der Errichtung und Ausweitung des europäischen Binnenmarktes. ${ }^{448}$ Die erwartete Steigerung der Kriminalität betrifft Bereiche wie Wirtschaftskriminalität, organisierte Kriminalität, Diebstahl, Betrug, Computerkriminalität und Umweltkriminalität. Interessant an der Studie ist, dass, anders als die Hauptannahme des Sicherheitsdefizit-Arguments, nicht speziell der Wegfall der Grenzkontrollen verantwortlich für einen Anstieg der Kriminalität sei. Vielmehr ist nach dem theoretischen Ansatz der Studie der Kriminalitätsanstieg mit der Errichtung des Binnenmarktes als solcher in Verbindung zu bringen. Nach diesem Ansatz hat der Binnenmarkt sich verstärkend auf die Bildung und den Aufbau von „Strömen von Gütern, Dienstleistungen, Personen, Geld/Kapital und Zahlungen" 449 ausgewirkt, welche von der Kriminalität gefolgt werden, um von den Güter-, Geld- und Personenbewegungen zu profitieren. In diesem Zusammenhang sind nicht der Wegfall der Grenzkontrollen bzw. der freie Personenverkehr die wichtigsten Faktoren, die den Anstieg der Kriminalität begünstigen, sondern „die Freiheiten des Warenund des Geld/Kapitalverkehrs“. ${ }^{450}$

\subsection{Die Effektivität des SIS I}

Bisher wurden die Argumente untersucht, die zur Zeit der Einführung des SIS oder kurz danach seine Nützlichkeit, sogar Notwendigkeit, hervorhoben, sowie Gegenargumente und die davon angestoßene kritische Diskussion. Was lässt sich aber über die tatsächliche Anwendung des SIS nach seiner Inbetriebnahme und über seine Resultate feststellen?

Im Jahr 2010 veröffentlichte der Rat einen kurzen Bericht über die Nutzung des SIS zwischen 1997 und 2009.451 In dem Zeitraum vervierfachte sich die Zahl der im SIS jährlich erzielten Treffer von 21280 auf 85 569. Die Distribution der Treffer zwischen den verschiedenen Ausschreibungskategorien zeigt, dass über den gesamten Zeitraum $41,4 \%$ der

448 Wittkämper; Krevert; Kohl, Europa und die innere Sicherheit, 308.

449 Ebd., 404. Eine andere wichtige Grundlage des Erklärungsansatzes wird vom sog. Diskrepanztheorem geliefert, nach dem die gesellschaftliche Stellung und Akzeptanz von Wohlstand als Wert und die Verfügbarkeit von legalen respektive illegalen Wegen, um den Wohlstand zu erreichen, ebenfalls Einfluss auf die Entwicklung der Kriminalität haben.

450 Wittkämper; Krevert; Kohl, Europa und die innere Sicherheit, 415.

451 Rat der Europäischen Union, Dok. 14934/1/10 REV 1 vom 19.10.2010. 
Treffer Drittstaatsausländer zur Einreise- oder Aufenthaltsverweigerung betrafen. ${ }^{452}$ Weitere $31,7 \%$ der Treffer erzielten Sachfahndungsanfragen. ${ }^{453}$ Lediglich $5 \%$ der Treffer betrafen Ausschreibungen zum Zwecke der Festnahme von Personen, die aufgrund eines europäischen bzw. internationalen Haftbefehls gesucht wurden. ${ }^{454}$ Aus den Statistiken ist nicht ersichtlich, für welche Art von Straftaten diese Personen gesucht wurden. Weitere 11,7\% der Treffer erfolgten für „strafrechtliche Zwecke“, wie es im Bericht heißt, wobei hier anzumerken ist, dass die gesuchten Personen nicht unbedingt als Beschuldigte oder Verurteilte gesucht wurden, sondern auch als Zeugen. ${ }^{455} 7 \%$ der Treffer fielen auf Personen oder Sachen, die zur verdeckten oder gezielten Kontrolle ausgeschrieben wurden. ${ }^{456}$ Schließlich betrafen 3,3\% der erzielten Treffer vermisste Personen. ${ }^{457}$

Aus diesen Daten ergibt sich, dass die größte tatsächliche Bedeutung des SIS darin bestand, Drittausländer_innen die Einreise oder den Aufenthalt im Schengen-Raum zu verweigern. Die Sachfahndung hatte in dieser Phase die zweitgrößte Bedeutung in den Aktivitäten des SIS. Dagegen machte die Fahndung zum Zwecke der Festnahme, wofür das SicherheitsdefizitArgument im Rahmen der Einführung des SIS die stärksten Argumente lieferte, nur einen minimalen Anteil der Treffer aus.

\subsection{Die Funktion des SIS I}

In Anbetracht sowohl der Studien, die sich ausführlich mit den Statistiken über die Aktivität der Grenzbehörde vor dem Wegfall der Grenzkontrollen befasst haben, als auch der Statistiken über die Nutzung des SIS in den Jahren 1997-2009 scheint das Hauptargument für die Einführung des SIS, nämlich der Ausgleich eines aus dem Wegfall der Grenzkontrollen resultierenden Sicherheitsdefizits, diskussionswürdig zu sein.

452 Ausschreibungen nach Art. 96 SDÜ bzw. Art. 24 Verordnung 1987/2006.

453 Ausschreibungen nach Art. 100 SDÜ bzw. Art. 38 des Ratsbeschlusses 2007/533/JI.

454 Ausschreibungen nach Art.95 SDÜ bzw. Art. 26 des Ratsbeschlusses 2007/533/JI.

455 Ausschreibungen nach Art.98 SDÜ bzw. Art. 34 des Ratsbeschlusses 2007/533/JI.

456 Ausschreibungen nach Art. 99 SDÜ bzw. Art.36 des Ratsbeschlusses 2007/533/JI.

457 Ausschreibungen nach Art.97 SDÜ bzw. Art. 32 des Ratsbeschlusses 2007/533/JI. 
Vielmehr scheint die tatsächliche Wirkung der Einführung des SIS in dieser ersten Betriebsphase an anderer Stelle zu liegen. Einerseits, wie seine tatsächliche Nutzung beweist, diente das SIS in dieser ersten Phase vor allem dem Aufbau "migrationsfester" europäischer Außengrenzen. ${ }^{458}$ Andererseits drückt die Errichtung des SIS ein polizeiliches Interesse an der Intensivierung der europäischen Kooperation aus, die an sich zwar als sinnvoll angesehen werden kann, aber unabhängig von dem Wegfall der Grenzkontrollen zu sein scheint. 459

Wie ich geschildert habe, bestand schon seit Mitte der 1970er Jahre Interesse an einer solchen Zusammenarbeit. ${ }^{460}$ Obwohl ein Wegfall der Grenzkontrollen noch nicht in Sicht war, wurde damals die polizeiliche Kooperation zunächst durch den Kampf gegen den Terrorismus legitimiert. In den 1980er Jahren gewann dann die Bekämpfung des internationalen Drogenhandels an Wichtigkeit für die Legitimation der Europäisierung und Internationalisierung der inneren Sicherheit. Erst Ende der 1980er Jahre wurde der Fokus auf die organisierte Kriminalität verlegt, obwohl damit hauptsachlich immer noch der Drogenhandel gemeint war. ${ }^{461}$ In diesem Kontext bot der Wegfall der Grenzkontrollen lediglich „eine Gelegenheit, sachlichen und zeitlichen Druck für die Durchsetzung“ des Wunsches nach intensiverer polizeilicher Kooperation „zu entfalten“. ${ }^{462}$

Diese Interpretation wird indirekt auch durch die zitierte BKA-Studie von 1996 bestätigt: Die Ursachen des prognostizierten Kriminalitätsanstiegs sind nicht speziell in dem Wegfall der Grenzkontrollen zu suchen. Sie reichen viel tiefer und hängen vielmehr mit der Schaffung des Binnen-

458 Nelles, Ursula, Europäisierung des Strafverfahrens - Strafprozeßrecht für Europa?, in: Zeitschrift für die gesamte Strafrechtswissenschaft, 109/4, 1997, 727755, hier 736.

459 Vgl. ebd.

460 Vgl. oben, Kap. 3, Abschnitt 2.2.

$461 \mathrm{Zu}$ den Legitimationsfiguren der Europäisierung der inneren Sicherheit vgl. Aden, Hartmut; Busch, Heiner, Europäisierung des Rechts der Inneren Sicherheit, in: Roggan, Fredrik; Kutscha, Martin (Hg.), Handbuch zum Recht der Inneren Sicherheit. Berlin: Berliner Wissenschafts-Verlag 2006, 513-582. Immer wieder war auch die Migrationskontrolle die Hauptlegitimation der Europäisierung der inneren Sicherheit. Nach dem 11. September 2001 rückte erneut die Terrorismusbekämpfung in den Mittelpunkt.

462 Busch, Heiner, Europa - ein „Mekka der Kriminalität“? EG-Grenzöffnung und internationale Polizeikooperation, in: Kritische Justiz, 23/1, 1990, 1-13, hier 2. Vgl. auch Taschner, Hans Claudius, Schengen: die Übereinkommen zum Abbau der Personenkontrollen an den Binnengrenzen von EU-Staaten. Baden-Baden: Nomos 1997, 42; Schindehütte, Das Schengener Informationssystem, 14-16. 
marktes an sich, mit dem freien Verkehr der Waren und des Kapitals und mit der gesamten wirtschaftlichen und sozialen Verfasstheit des betroffenen Raums zusammen. ${ }^{463}$

In diesem Sinne scheint das SIS kein Ausgleich für den Wegfall der Grenzkontrollen zu sein, sondern eine davon unabhängige Ausweitung der polizeilichen Kooperation. Auch die Vertreter des Ausgleichsarguments weisen schließlich darauf hin, dass die Kernbedeutung der Grenze als „strategische Linie“, nämlich die Fähigkeit, die Durchführung von Kontrollen unabhängig von einem bestehenden Verdacht oder einer Gefahr zu ermöglichen, nicht durch das SIS zu kompensieren sei. ${ }^{464}$

\section{4 Übergang zum SIS II - Legitimation}

Technisch wurde das SIS I als zwischenstaatliches Projekt unter Leitung Frankreichs entwickelt. 1996, ein Jahr nach seiner Inbetriebnahme, beschlossen die Schengen-Staaten, das SIS durch ein System der zweiten Generation zu ersetzen. ${ }^{465}$ Der Plan konnte aber erst 2001 konkretisiert werden, als der Schengener Besitzstand bereits in den EU-Rechtsrahmen

463 Vgl. Wittkämper; Krevert; Kohl, Europa und die innere Sicherheit. Ähnlich auch Rupprecht; Hellenthal, Programm für eine Europäische Gemeinschaft der Inneren Sicherheit, 46-49.

464 Vgl. Busch, Grenzenlose Polizei?, 73 und oben Abschnitt 4.1.2. Interessant ist, dass zur Zeit der Einführung des SIS selbst die Verfechter_innen der polizeilichen Position es für nicht realistisch hielten, Ausgleichsmaßnahmen einzuführen, die den Wegfall dieser Funktion der Grenze kompensieren konnten, weil sie nicht mit dem geltenden Strafverfolgungs- und Polizeirecht zu vereinbaren waren. Diese Möglichkeit erhielten aber die bayrischen Polizeibeamten schon Ende 1994 mit der sogenannten Schleierfahndung, die später auf zahlreiche andere Bundesländer ausgeweitet wurde und seit 1998 auch der Bundespolizei gesetzlich ermöglicht wird. Vgl. Schreiber, Abschaffung der Grenzkontrollen in Europa? Tendenzen - mögliche Auswirkung und Auffangmaßnahmen, 59; Rupprecht, Wettlauf der Schnecken. Probleme und Konsequenzen des Abbaus von Grenzkontrollen, 264; Krüger, Innere Sicherheit für Europa. Schengen und Maastricht - Stationen der Polizei auf dem Weg nach Europa, 775; Rupprecht; Hellenthal, Programm für eine Europäische Gemeinschaft der Inneren Sicherheit, 135-136 und Krane, Christian, Schleierfahndung, in: Lange, Hans-Jürgen; Gasch, Matthias (Hg.), Wörterbuch zur Inneren Sicherheit. Wiesbaden: VS Verlag für Sozialwissenschaften 2006, 283-287.

465 Vgl. Europäischer Rechnungshof, Erkenntnisse aus der Entwicklung des Schengener Informationssystems der zweiten Generation (SIS II) durch die Europäische Kommission, Sonderbericht 03/2014, 8. 
übertragen wurde und der Rat die Europäische Kommission beauftragte, die Entwicklung des Systems der zweiten Generation, das sog. SIS II, zu beaufsichtigen. ${ }^{466}$

\subsubsection{Wortlaut der Dokumente}

Als Hauptgrund für die Bereitstellung eines neuen Systems führte der Rat an, dass das SIS I in der ursprünglichen Form nicht mehr als 18 Teilnehmer aufnehmen und verwalten konnte. In Anbetracht der EU-Osterweiterung, die tatsächlich 2004 mit der Aufnahme zehn neuer Mitgliedstaaten erfolgte, war es daher nötig, die Teilnahme einer höheren Mitgliederanzahl zu ermöglichen. ${ }^{467}$ Zudem ermöglichte die Entwicklung des neuen Systems eine Anpassung an den neuesten Stand der Informationstechnik und eine Ergänzung um neue Funktionen. ${ }^{468}$

Der Rat veranschlagte zunächst einen Zeitraum von fünf Jahren für die Entwicklung des SIS II, sodass das System Ende 2006 bereitgestellt werden sollte. ${ }^{469}$ Damit hätte das SIS II bei der Erweiterung des Schengener Raums um die zehn neuen EU-Mitglieder, die für 2007 geplant war, einsatzfähig sein sollen.

\subsubsection{Veränderte Zielsetzung während der Entwicklung des SIS II}

Die Inbetriebnahme des SIS II erfolgte wie erwähnt 2013, mit über sechs Jahren Verspätung gegenüber dem ursprünglichen Plan. Zudem, wie eine Untersuchung des Europäischen Rechnungshofs ergab, erhöhten sich im Laufe der Zeit die Kosten des neuen Systems um das Achtfache. Weiterhin

466 Vgl. Verordnung des Rates 2424/2001 vom 06.12.2001 über die Entwicklung des Schengener Informationssystems der zweiten Generation (SIS II), Amtsblatt der EG L 328 vom 13.12.2001, 4 und Beschluss des Rates 2001/886/JI vom 06.12.2001 über die Entwicklung des Schengener Informationssystems der zweiten Generation (SIS II), Amtsblatt der EG L 328 vom 13.12.2001, 1.

467 Vgl. $\$ 2-3$ und Art. 1 der Verordnung des Rates 2424/2001 und des Ratsbeschlusses 2001/886/JI.

468 Vgl. $\$ 3$ der Verordnung des Rates 2424/2001 und des Ratsbeschlusses 2001/886/JI.

469 Vgl. Europäischer Rechnungshof, Erkenntnisse aus der Entwicklung des Schengener Informationssystems, 8. 
ging aus der Untersuchung hervor, dass die ursprüngliche Zielsetzung an Bedeutsamkeit verloren hatte. ${ }^{470}$

Für die Bereitstellung des neuen Systems verlängerte der Rat die Frist mehrmals, zunächst bis Dezember 2008, dann bis Juni 2010 und schließlich bis März 2013.471

470 Vgl. Europäischer Rechnungshof, Erkenntnisse aus der Entwicklung des Schengener Informationssystems, 6-7.

471 Vgl. Verordnung 1988/2006 des Rates vom 21.12.2006 zur Änderung der Verordnung 2424/2001 über die Entwicklung des Schengener Informationssystems der zweiten Generation (SIS II), Amtsblatt L 411 vom 30.12.2006, 1; Beschluss 2006/1007/JI des Rates vom 21.12.2006 zur Änderung des Beschlusses 2001/886/JI über die Entwicklung des Schengener Informationssystems der zweiten Generation (SIS II), Amtsblatt L 411 vom 30.12.2006, 78; Verordnung 1104/2008 des Rates vom 24.10.2008 über die Migration vom Schengener Informationssystem (SIS 1+) zum Schengener Informationssystem der zweiten Generation (SIS II), Amtsblatt L 299 vom 08.11.2008, 43; Verordnung 541/2010 des Rates vom 03.06.2010 zur Änderung der Verordnung 1104/2008 über die Migration vom Schengener Informationssystem (SIS 1+) zum Schengener Informationssystem der zweiten Generation (SIS II), Amtsblatt L 155 vom 22.06.2010, 19 und Verordnung 542/2010 des Rates vom 03.06.2010 zur Änderung des Beschlusses 2008/839/JI über die Migration vom Schengener Informationssystem (SIS 1+) zum Schengener Informationssystem der zweiten Generation (SIS II), Amtsblatt L 155 vom 22.06.2010, 23. Die Ursachen für die Zeitverschiebungen sind vielfältig. Zunächst wurde das Projekt aufgrund einer Klage durch einen Bieter, der den Auftrag für die Entwicklung des SIS nicht bekommen hatte, für knapp drei Monate angehalten. Nach Entscheidung des EuGH konnte das Projekt weitergeführt werden, das entwickelte System erwies sich aber als mangelhaft und bestand 2008 den Betriebstest nicht. Die Verantwortung für die Verspätungen liegt aber auch, wie eine Untersuchung durch den Europäischen Rechnungshof belegt, in der fehlerhaften Planung und Missmanagement durch die Kommission. Vgl. Europäischer Rechnungshof, Erkenntnisse aus der Entwicklung des Schengener Informationssystems. In dem Bericht stellt der Rechnungshof etwa fest, dass die Kommission eines der Angebote als kostengünstigstes bewertete, obwohl dieses teurer als die alternative Option war. Das war unter anderem Anlass für die Klage durch den erfolglosen Bieter (vgl. ebd., 16). Der ursprüngliche Zeitplan war zudem nicht realistisch, und obwohl die Kommission teilweise Schwierigkeiten bei der Einhaltung der Frist einräumte, aktualisierte sie den Zeitplan nur mit erheblicher Verzögerung (vgl. ebd., 12). Schließlich war die Kommission in den ersten Phasen des Projekts nicht mit ausreichender Expertise ausgestattet und die Mechanismen der Entscheidungsfindung waren selbst für die Beteiligten teilweise nicht nachvollziehbar. „Es war nicht allen SIS-II-Akteuren klar, wer in der Praxis zentrale Entscheidungen traf. Wenngleich über die Sitzungen des SIS/VIS-Ausschusses Protokoll geführt wurde, gab es doch kein Entscheidungsprotokoll, das ermöglicht hätte, die 
Neben der Zeitverzögerung entwickelten sich auch die endgültigen Kosten des Projekts anders als ursprünglich geschätzt. Die Gesamtkosten des Projekts erhöhten sich von den anfänglich geschätzten 23 Mio. € um das Achtfache auf insgesamt 189 Mio. $€{ }^{472}$

Während sich die Bereitstellung des SIS II verzögerte und die Kosten für seine Entwicklung stiegen, wurden verschiedene Zwischenlösungen realisiert. Im Dezember 2007 wurde zum Beispiel das System „SISone4all“ in Betrieb genommen. Dieses System wurde von Portugal zur Verfügung gestellt, basierte auf einer Erweiterung des portugiesischen nationalen Systems und erlaubte neun neuen EU-Mitgliedstaaten den Anschluss an das System. Mit dem SIS 1+R und dem SIS 1+R2 wurden parallel dazu Folgeversionen des SIS entwickelt, die neue Leistungen ermöglichten. ${ }^{473}$

Dies hatte wichtige Auswirkungen auf die Legitimationsgrundlage des SIS II. Die Existenz alternativer Systeme, welche die Ziele des SIS II bereits vor dessen Fertig- bzw. Bereitstellung erfüllten, führte dazu, dass die ursprünglichen Gründe für die Entwicklung des SIS II an Bedeutung verloren. Entsprechend stellte der Rechnungshof fest:

Während die Kosten für das SIS II stiegen, verlor der wichtigste erwartete Nutzen (der Anschluss einer gestiegenen Zahl von Mitgliedsländern nach der Erweiterung) mit der Einführung des SISone4all im Jahr 2007 an Bedeutung. [...] Weitere Gründe für die Entwicklung des SIS II wurden am Ende des Projekts ebenfalls anders gewichtet als zu Beginn. Beispielsweise waren die Vermeidung eines Reputationsschadens für die EU und der Schutz der bereits getätigten Investitionen am Ende des Projekts wichtig. Die zu Beginn des Projekts zweitwichtigste Begründung für das SIS II (Bereitstellung neuer Funktionen)

Grundlage sämtlicher wichtiger Entscheidungen leicht nachzuvollziehen.“ (vgl. ebd., 22).

472 Obwohl das Konsortium aus den Unternehmen Hewlett-Packard und Steria, das mit der Entwicklung des SIS beauftragt wurde, zunächst ein mangelhaftes System bereitstellte, erhöhte die Kommission den Wert des Auftrags für diesen Anbieter von den ursprünglichen 20 auf $82 \mathrm{Mio}$. €. Auch in dieser Hinsicht stellte der Europäische Rechnungshof Mängel beim Vorgehen der Kommission fest. $\mathrm{Zu}$ den Kosten der Errichtung des zentralen Systems kommen noch geschätzte 300 Mio. $€$ für die nationalen Systeme hinzu, sodass die Entwicklung des SIS II insgesamt knapp eine halbe Mrd. € gekostet hat. Vgl. Töpfer, Die Trias digitaler Grenzen.

473 Laut Angaben von zwei an dem Prozess teilnehmenden Mitgliedstaaten besaß zudem das SIS 1+R2 vergleichbare Fähigkeiten wie das SIS II. Vgl. Europäischer Rechnungshof, Erkenntnisse aus der Entwicklung des Schengener Informationssystems, 35 . 
hatte zum Projektende die größte Bedeutung erlangt. Das SIS II bietet den Endnutzern neue Funktionen, darunter neue Ausschreibungskategorien [...], ein System zur Verknüpfung von Ausschreibungen (etwa eine Ausschreibung in Bezug auf eine Person und ein Fahrzeug) und die Möglichkeit der Speicherung von Dokumenten (z. B. Europäischer Haftbefehl) einschließlich biometrischer Informationen. ${ }^{474}$

Doch verzichtete die Kommission in dieser Zeit darauf, eine aktualisierte Untersuchung durchzuführen, um Kosten, Nutzen und Alternativen des SIS erneut gründlich zu prüfen und darzustellen. ${ }^{475}$ Dazu schreibt der Rechnungshof:

Der Nutzen des SIS II aufgrund seines Beitrags zur Verbrechensbekämpfung und zur Stärkung der Außengrenzen wurde nicht aufgeführt. Die Probleme, für deren Bekämpfung das SIS II konzipiert wurde, wurden nicht genannt; ebenso wenig wurde dargelegt, wie sein Erfolg gemessen werden sollte. ${ }^{476}$

Vielmehr hielten Rat und Kommission an der Weiterführung des SIS IIProjekts fest, bis dieses schließlich im April 2013 in Betrieb genommen wurde.

\subsection{Effektivität des SIS II}

Wie sieht nun die Bilanz über die Aktivität des SIS II einige Jahre nach seiner Inbetriebnahme aus?

Die Europäische Kommission sieht im SIS II einen eindeutigen Erfolg. Das SIS ist ihrer Ansicht nach „derzeit in Europa das wichtigste und am meisten genutzte Instrument zum Austausch von Informationen“. 477

Die Statistiken der Agentur eu-LISA, die für die Verwaltung des SIS und anderer großer Datenbanken der EU zuständig ist, bestätigen die breite

474 Europäischer Rechnungshof, Erkenntnisse aus der Entwicklung des Schengener Informationssystems, 33-34.

475 Vgl. ebd., 31.

476 Ebd., 32.

477 Bericht der Kommission an das Europäische Parlament und den Rat über die Evaluierung des Schengener Informationssystems der zweiten Generation (SIS II) nach den Art. 24 Abs. 5, Art. 43 Abs. 3 und Art. 50 Abs. 5 der Verordnung (EG) Nr. 1987/2006 in Verbindung mit den Art. 59 Abs. 3, Art. 66 Abs. 5 und Art. 66 Abs. 5 des Beschlusses 2007/533/JI vom 21.12.2016 COM(2016) 880 final, 18. 
Verwendung des SIS II. ${ }^{478}$ So wurden etwa im Jahr 2019 über 6,6 Millionen Zugriffe auf das SIS II seitens der zuständigen nationalen Behörden registriert. Am 31. Dezember 2019 enthielt das SIS II über 91 Millionen Ausschreibungen. Davon betrafen 1,08 \% - also ca. 983000 Ausschreibungen - Personen, alle anderen enthielten Daten über Gegenstände und dienten damit der Sachfahndung. ${ }^{479}$

Von den Personenausschreibungen entfielen $54 \%$ auf Drittstaatsangehörige, mit dem Ziel, diesen die Einreise oder den Aufenthalt im Schengener Raum zu verweigern. Die zweitgrößte Kategorie, die noch 2016 aus Personen bestand, die im Zusammenhang mit deren Teilnahme an einem Strafverfahren gesucht wurden, besteht seit 2017 aus Ausschreibungen zum Zwecke der verdeckten oder gezielten Kontrolle. ${ }^{480}$

Im SIS II wurden 2019 mehr als 200000 Treffer erzielt. Obwohl die Personenfahndung wie erwähnt nur einen minimalen Bruchteil der Ausschreibungen ausmachte, wurden vier Fünftel $(80,6 \%)$ der erzielten Treffer in Verbindung mit Personenausschreibungen erzielt. Von diesen betrafen die meisten (34,7\% der Gesamttreffer) Ausschreibungen zum Zwecke der verdeckten oder gezielten Kontrolle. Die zweitgrößte Kategorie innerhalb der Treffer in Bezug auf Personenausschreibungen (20,5\% der Gesamttreffer) wurde durch Ausschreibungen im Hinblick auf die Teilnahme an einem Strafverfahren gebildet. 19,3\% der Gesamttreffer betrafen Sachfahndungen. $18 \%$ der Gesamttreffer bezogen sich auf die Verweigerung der Einreise oder des Aufenthalts im Schengener Raum. 4,2\% der Gesamttreffer wurden in Verbindung mit Ausschreibungen zum Zwecke der Übergabe- oder Auslieferungshaft erzielt. Die kleinste Kategorie formten schließlich mit 3,3\% der Gesamttreffer Ausschreibungen vermisster Personen. ${ }^{481}$

Die folgende Tabelle präsentiert und vergleicht die Zahlen der Treffer pro Ausschreibungskategorie für die Jahre 2014-2019.482

478 Die Statistiken und andere Berichte werden auf der Webseite der Agentur veröffentlicht: http://www.eulisa.europa.eu/Pages/default.aspx (letzter Zugriff: 11.02.2021).

479 Vgl. eu-LISA, SIS II - 2019 Statistics, March 2020, 8.

480 Vgl. eu-LISA, SIS II - 2017 Statistics, February 2018, 10; eu-LISA, SIS II 2018 Statistics, February 2019, 7 und eu-LISA, SIS II - 2019 Statistics, March $2020,8$.

481 Vgl. eu-LISA, SIS II - 2019 Statistics, March 2020, 10-11.

482 Für das Jahr 2013 deckt die eu-LISA-Statistik nur den Zeitraum vom 9. April (Datum der Inbetriebnahme des SIS II) bis zum 31. Dezember ab. Diese Daten 
Tabelle 1: Treffer im SIS II (2014-2019)

\begin{tabular}{|c|c|c|c|c|c|c|}
\hline $\begin{array}{l}\text { Art der } \\
\text { Ausschreibung }\end{array}$ & 2014 & 2015 & 2016 & 2017 & 2018 & 2019 \\
\hline $\begin{array}{l}\text { Art. } 24 \text { Richtlinie } \\
1987 / 2006 \\
\text { (Verweigerung Ein- } \\
\text { reise/Aufenthalt) }\end{array}$ & $20,6 \%$ & $19,5 \%$ & $14,8 \%$ & $15,6 \%$ & $17,9 \%$ & $18 \%$ \\
\hline
\end{tabular}

$\begin{array}{lcccccc}\begin{array}{l}\text { Art. } 26 \text { Beschluss } \\ \begin{array}{l}2007 / 533 / J I \\ \text { (Haftbefehl) }\end{array}\end{array} & 6,8 \% & 7,1 \% & 6 \% & 4,8 \% & 4,7 \% & 4,2 \% \\ \begin{array}{l}\text { Art. } 32 \text { Beschluss } \\ \begin{array}{l}\text { 2007/533/JI } \\ \text { (Vermisste) }\end{array}\end{array} & 3 \% & 3,6 \% & 3,8 \% & 3,5 \% & 3,6 \% & 3,3 \% \\ & & & & & & \end{array}$

\begin{tabular}{|c|c|c|c|c|c|c|}
\hline $\begin{array}{l}\text { Art. } 34 \text { Beschluss } \\
\text { 2007/533/JI } \\
\text { (Teilnahme Strafver- } \\
\text { fahren) }\end{array}$ & $24,3 \%$ & $22 \%$ & $23,9 \%$ & $23,7 \%$ & $20,6 \%$ & $20,5 \%$ \\
\hline $\begin{array}{l}\text { Art. } 36 \text { Beschluss } \\
\text { 2007/533/JI } \\
\text { (verdeckte/gezielte } \\
\text { Kontrolle) }\end{array}$ & $18,6 \%$ & $21,9 \%$ & $30,3 \%$ & $32,8 \%$ & $33,6 \%$ & $34,7 \%$ \\
\hline
\end{tabular}

\begin{tabular}{|c|c|c|c|c|c|c|}
\hline $\begin{array}{l}\text { Art. } 38 \text { Beschluss } \\
\text { 2007/533/JI } \\
\text { (Sachfahndung) }\end{array}$ & $26,7 \%$ & $25,9 \%$ & $21,2 \%$ & $19,6 \%$ & $19,6 \%$ & $19,3 \%$ \\
\hline Treffer insgesam & 128598 & 156447 & 200778 & 243,818 & 267,239 & 283,713 \\
\hline
\end{tabular}

Quelle: eu-LISA-Statistiken für die Jahre 2014-2019: http://www.eulisa.europa.eu/P ages/default.aspx

\subsection{Die Funktion des SIS II}

Wie schon im SIS I bleiben Drittausländer_innen diejenige Personenkategorie, für welche die meisten Ausschreibungen im SIS II eingetragen sind. Während jedoch für die Anfangsjahre des SIS I Drittausländer_innen auch die Kategorie waren, in Bezug auf welche die meisten Treffer erzielt wurden, ${ }^{483}$ haben sich die Verhältnisse bei der Nutzung des SIS II geändert.

wurden daher nicht in der Tabelle dargestellt. Vgl. eu-LISA, SIS II - Statistics 2013, June 2014.

483 Vgl. oben Abschnitt 4.2. 
Tabelle 2 vergleicht die Distribution der Treffer im SIS I für den Zeitraum 1997-2009 mit den Treffern im SIS II zwischen 2014 und 2019.484

Tabelle 2: Treffer im SIS I (1997-2009) und SIS II (2014-2019) im Vergleich

$\begin{array}{lll}\begin{array}{l}\text { Art der } \\ \text { Ausschreibung }\end{array} & \begin{array}{l}\text { SIS I } \\ (\mathbf{1 9 9 7 - 2 0 0 9 )}\end{array} & \begin{array}{l}\text { SIS II } \\ (\mathbf{2 0 1 4 - 2 0 1 9 )}\end{array} \\ \begin{array}{l}\text { Art. 96 SDÜ/24 Richtlinie 1987/2006 } \\ \text { (Verweigerung Einreise/Aufenthalt) }\end{array} & 41,4 \% & 17,7 \% \\ \begin{array}{l}\text { Art. 95 SDÜ/26 Beschluss 2007/533/JI } \\ \text { (Haftbefehl) }\end{array} & 5 \% & 5,6 \% \\ \begin{array}{l}\text { Art. 97 SDÜ/32 Beschluss 2007/533/JI } \\ \text { (Vermisste) }\end{array} & 3,3 \% & 3,5 \% \\ \begin{array}{l}\text { Art. 98 SDÜ/34 Beschluss 2007/533/JI } \\ \text { (Teilnahme Strafverfahren) }\end{array} & 11,7 \% & 23 \% \\ \begin{array}{l}\text { Art. 99 SDÜ/36 Beschluss 2007/533/JI } \\ \text { (verdeckte/gezielte Kontrolle) }\end{array} & 7 \% & 28,6 \% \\ \begin{array}{l}\text { Art. 100 SDÜ/38 Beschluss 2007/533/JI } \\ \text { (Sachfahndung) }\end{array} & 31,7 \% & 22 \%\end{array}$

Quelle: Ratsdokument Nr.14934/1/10 REV 1 vom 19.10.2010, http://data.consiliu m.europa.eu/doc/document/ST-14934-2010-REV-1/en/pdf und eu-LISA-Statistiken für die Jahre 2014-2019: http://www.eulisa.europa.eu/Pages/default.aspx

Aus den dargestellten Daten wird ersichtlich, dass sich der Fokus des SIS in den letzten Jahren von der Verweigerung der Einreise oder des Aufenthalts von Drittstaatsangehörigen auf die Fahndung nach Personen im Hinblick auf deren Teilnahme in einem Strafverfahren und auf die verdeckte/gezielte Kontrolle verschoben hat. Insbesondere diese letzte Kategorie hat in den letzten Jahren eine erhebliche Zunahme verzeichnet (von 18,6 \% der erzielten Treffer im Jahr 2014 auf 34,7 \% im Jahr 2019). ${ }^{485}$

Die für die Schaffung des SIS wichtigste Ausschreibungskategorie, nämlich die von Personen, die zum Zwecke der Übergabe- oder Auslieferungshaft gesucht werden, weist dagegen seit Einrichtung des SIS einen nur minimalen Anstieg der Treffer auf und macht mit 4,2\% der erzielten

484 Für die Jahre 2010-2012 geben die Berichte des EU-Rates nur Auskunft über die Zahl der im SIS eingetragenen Ausschreibungen, nicht aber über die Trefferquoten, vgl. Ratsdokumente Nr.6434/2/11 vom 16.03.2011; 8281/12 vom 28.03.2012 und 7389/13 vom 13.03.2013. Für das Jahr 2013 berichten die Statistiken der eu-LISA nur ab Inbetriebnahme des SIS II im April, deswegen werden die Daten für dieses Jahr hier nicht berücksichtigt.

485 Vgl. oben Tabelle 1. Treffer im SIS II 2014-2019. 
Treffer im Jahr 2019 die zweitkleinste Kategorie der Treffer im SIS II aus. Wie auch schon die früheren Statistiken über den Betrieb des SIS I, liefern die neuen SIS II-Statistiken keine Informationen über die Art der Delikte, in Bezug auf welche diese Treffer erzielt wurden.

Das SIS II zeichnet sich im Vergleich zum Vorgängersystem auch durch die Ausweitung der technischen Funktionen aus. Wie oben dargelegt, hatte die ursprüngliche Motivation für die Umstellung auf das SIS II, nämlich die Möglichkeit des Anschlusses neuer EU-Mitgliedstaaten, zur Zeit der Bereitstellung des SIS II nur noch eine minimale Bedeutung, da dieses Ziel bereits durch Modifikationen des SIS I erreicht werden konnte. Der tatsächliche Mehrwert des SIS II im Vergleich mit dem vorigen System besteht in der Möglichkeit, auch biometrische Daten wie daktyloskopische Daten und Lichtbilder zu speichern und verschiedene Fahndungen miteinander zu verknüpfen. Bislang werden die biometrischen Daten nur für die Prüfung der Identität gesuchter Personen verwendet. Zukünftig sollen sie aber auch für die Ermittlung der Identität verwendet werden. ${ }^{486}$ Die Agentur eu-LISA wurde in diesem Zusammenhang beauftragt, ein System zu erarbeiten, das die Suche nach Personen anhand ihrer daktyloskopischen Daten ermöglichen soll. ${ }^{487}$ Ebenfalls ist geplant, die Speicherung der DNA-Profile für die Identifizierung von vermissten Personen im SIS II einzuführen. ${ }^{488}$

Sowohl mit der Möglichkeit zur Verknüpfung verschiedener Fahndungen als auch mit der Suche anhand biometrischer statt nur alphanumerischer Daten findet ein Funktionswechsel des SIS statt. Ursprünglich war das SIS ein reines Informationssystem, wobei die ausgetauschten Informationen der Identifizierung von Personen und Gegenständen dienten und den Behörden ermöglichten, die Gründe der Ausschreibungen und die empfohlenen Maßnahmen festzustellen. Dabei bestand die Rückmeldung auf eine Abfrage im SIS zunächst aus einem Treffer bzw. keinem Treffer, wodurch die Behörden erfuhren, ob die bereits identifizierten Personen oder Gegenstände schon im System gespeichert waren.

Doch durch die Verknüpfung verschiedener Datensätze (wie etwa Namen/Bild, Person/Person) erlauben die neuen Funktionalitäten neben der

486 Vgl. Mitteilung der Kommission an das Europäische Parlament und den Rat, Solidere und intelligentere Informationssysteme für das Grenzmanagement und mehr Sicherheit, COM(2016) 205 final, 06.04.2016.

487 Vgl. Ratsdokument 14260/16 „Detaillierte Beschreibung jüngster und geplanter Maßnahmen zur Bekämpfung von Terrorismus und gewalttätigem Extremismus" vom 20.12.2016, 11.

488 Vgl. eu-LISA, SIS II - 2019 Statistics, March 2020, 4. 
Prüfung auch die Ermittlung der Identität einer Person. Dem SIS kommen damit Eigenschaften eines Fahndungs- oder Ermittlungssystems zu. ${ }^{489}$ Die Konsequenzen dieser Verschiebung werden in Abschnitt 6 unten erörtert.

\section{Die institutionellen Verhältnisse bei der Entscheidungsfindung im Falle des SIS}

\subsection{Von der Interstaatlichkeit zur Supranationalität}

Die oben dargestellte geschichtliche Entwicklung der Schengener Maßnahmen zeichnet eine klare Linie von der Interstaatlichkeit zur Supranationalität ab. Das Schengener Übereinkommen von 1985 war ein rein intergouvernementales Abkommen zwischen Deutschland, Frankreich und den Benelux-Staaten. Von Anfang an war aber von den Initiatoren beabsichtigt, die Wirkung der Schengener Maßnahmen auf das ganze Gebiet der EG auszuweiten. Einige weitere Staaten, sowohl EG- als auch Nicht-EG-Mitglieder, traten dem Abkommen auf zwischenstaatlicher Basis bei. ${ }^{490}$ 1997, mit dem Vertrag von Amsterdam, wurden schließlich die gesamten Schengener Regelungen in den rechtlichen Rahmen der EU überführt. Damit wurde der sogenannte Schengener Besitzstand für alle EU-Mitgliedstaaten verpflichtend. Zudem wird ab diesem Zeitpunkt die Schengener Materie den europäischen Entscheidungsverfahren untergeordnet. Mit dem Lissaboner Vertrag von 2007 wurde dann die gesamte Schengen-Materie endgültig dem „Raum der Freiheit, der Sicherheit und des Rechts“ zugeteilt. ${ }^{491}$ Die maßgebende Entscheidungsmethode wurde ab diesem Zeitpunkt das sogenannte ordentliche Entscheidungsverfahren, das die Mitentscheidung von Rat und Parlament vorsieht.

489 Vgl. Brouwer, Digital borders and real rights. Effective remedies for third-country nationals in the Schengen Information System, 104-106. Vgl. auch die Mitteilung der Kommission an den Rat und das Europäische Parlament „Die Entwicklung des Informationssystems Schengen II“ vom 18.12.2001, COM(2001) 720 final.

490 Dazu gehören Italien, Portugal, Spanien, Griechenland, Österreich, Dänemark, Finnland, Island und Norwegen.

491 Vgl. Kapitel 3, Abschnitt 2.3.3 dieses Buches. 


\subsection{Die Präeminenz der Exekutive}

Die Einbeziehung des EU-Parlaments in die Entscheidungsverfahren erfolgte somit relativ spät. Aber auch die nationalen Parlamente spielten zumindest in der Anfangszeit gegenüber den Exekutiven eine deutlich untergeordnete Rolle.

Wie oben bereits erwähnt, wurde das Schengener Übereinkommen von den nationalen Exekutiven als bloße Absichtserklärung eingestuft, wofür keine Einbindung der Parlamente nötig war.

Das SDÜ dagegen musste von den nationalen Legislativen ratifiziert werden. Dies allein konnte aber noch keine demokratische Kontrolle garantieren, da die größte Bedeutung in der Entscheidungsfindung vor der Überführung in den EU-Rechtsrahmen der Schengener Exekutivausschuss besaß. Die Entstehung dieses Ausschusses wurde im SDÜ selbst festgelegt (Art. 131 SDÜ). Jede Vertragspartei besaß einen Sitz, der mit Vertretern des Justiz- oder Innenministeriums besetzt wurde. Alle Entscheidungen mussten einstimmig getroffen werden (Art. 132 SDÜ). Damit erhielt der Exekutivausschuss gesetzgeberische Kompetenzen, wurde aber durch keine internationale legislative Instanz kontrolliert, und auch auf nationaler Ebene beschränkte sich die Einbindung der Parlamente meist auf eine Ex-post-Billigung. ${ }^{492}$

In dieser Hinsicht spiegeln sowohl die schrittweise Supranationalisierung der Materie wie auch die Präeminenz der Exekutive über die Legislative im Schengener Kontext jeweils diejenige im RFSR insgesamt wider. ${ }^{493}$

Die Schengener Vorgehensweise, nach der eine kleine Gruppe von Staaten unter mangelnder parlamentarischer Kontrolle Maßnahmen ausarbeitet und beschließt, um diese dann auf alle EG-/EU-Mitgliedstaaten

492 Ausnahmen waren die Niederlande, wo das Parlament über ein Vetorecht über die Entscheidungen verfügte, und Italien und Belgien, wo die Parlamente ähnliche Rechte besaßen. Der Deutsche Bundestag hingegen besaß keinen Zustimmungsvorbehalt und hatte nur das Recht, informiert zu werden, wenn die getroffenen Beschlüsse in seinen Kompetenzbereich fielen. Vgl. Kietz, Daniela; Maurer, Andreas, Fragmentierung und Entdemokratisierung der europäischen Justiz- und Innenpolitik? Folgen der Prümer Vertragsavantgarde, in: Möllers, Martin H. W.; van Ooyen, Robert Chr. (Hg.), Jahrbuch Öffentliche Sicherheit 2006/2007. Frankfurt am Main: Verlag für Polizeiwissenschaft 2007, 439-452, hier 444-445, und Baumann, Der Einfluss des Bundeskanzleramts und des Bundesministeriums des Innern auf die Entwicklung einer europäischen Grenzpolitik. Anderer Meinung, wonach die Beteiligung des Deutschen Bundestag ausreichend war, ist Schindehütte, Das Schengener Informationssystem, Teil 3.

493 Vgl. Kapitel 3 dieses Buches. 
auszuweiten, prägte ferner einen Verhandlungsstil, der sich nachhaltig auf europäischer Ebene auswirkte. ${ }^{494}$ Das wird besonders sichtbar im Rahmen der Prümer Verhandlungen, die im Fokus des nächsten Kapitels stehen.

\section{Sicherheitstheoretische und normative Implikationen des SIS: Flexibilität und Erweiterung der Machtbefugnisse}

Die Legitimation für die Herausbildung des SIS stützt sich, wie ich geschildert habe, im Wesentlichen auf die Annahme, dass durch den Wegfall der Grenzkontrollen ein Sicherheitsdefizit entstünde, das durch entsprechende Maßnahmen zu kompensieren sei. Das SIS wurde als Herzstück dieser Ausgleichsmaßnahmen konzipiert.

Aus diesem Argument ist zu entnehmen: Erstens, dass das SIS einen wesentlichen Beitrag zur Gewährleistung der inneren Sicherheit leisten soll, und zweitens, dass es eine kompensatorische Maßnahme sei, welche dazu beitragen soll, den Sicherheits-Status-quo zu erhalten.

Die in diesem Kapitel durchgeführte Analyse scheint aber diese Annahmen nicht zu rechtfertigen. Sowohl der Beitrag des SIS zur Erhaltung der inneren Sicherheit als auch sein kompensatorischer Charakter wurden durch die Analyse relativiert. ${ }^{495}$

\subsection{Das SIS: ein „flexibles Instrument“4496}

Was die Funktion des SIS als Instrument der Sicherheitsgewährung angeht, hat sich das System vielmehr als ein „flexibles Instrument“497 erwiesen, das zunächst schwerpunktmäßig als Instrument der Migrationskontrolle eingesetzt wurde und neuerdings immer mehr zum Zwecke der gezielten oder verdeckten Kontrolle benutzt wird. Im ersteren Fall ist der Bezug zur Sicherheit nicht unbedingt gegeben: Es ist keine notwendige Bedingung für die Ausschreibung von Drittausländer_innen im SIS, dass

494 Vgl. Baumann, Der Einfluss des Bundeskanzleramts und des Bundesministeriums des Innern auf die Entwicklung einer europäischen Grenzpolitik.

495 Vgl. oben Abschnitt 4.

496 Ratsdokument 9808/03 vom 26.05.2003, 4.

497 Ratsdokument 9808/03 vom 26.05.2003, 4. Vgl. dazu Brouwer, Digital borders and real rights. Effective remedies for third-country nationals in the Schengen Information System, 144-145. 
diese tatsächlich eine Gefahr darstellen. ${ }^{498}$ Im zweiten Fall besteht die Verbindung zur Gefährlichkeit der ausgeschriebenen Personen in einer polizeilichen Prognose, und die Effektivität der Maßnahmen ist schwierig, wenn nicht unmöglich zu erfassen. ${ }^{499}$ Außerdem ist diese Art der Kontrolle im Vergleich mit den Zwecken der anderen SIS-Fahndungskategorien besonders problematisch, insbesondere weil während der Kontrolle auch Daten von Unbeteiligten erfasst werden können und weil der geheime Charakter der Maßnahmen potenziell ein Klima der diffusen Überwachung erzeugen kann. ${ }^{500}$ Die einzige Ausschreibungskategorie, von der eindeutig ein Beitrag zur Erhaltung der inneren Sicherheit zu erwarten wäre, d. h. die Festnahme von Personen, gegen die ein Haftbefehl erlassen wurde, hat seit Entstehung des SIS, wie oben ausgeführt, nur eine geringe Rolle gespielt. Die Quote der Treffer, die in Verbindung mit dieser Ausschreibungsart erzielt wurden, bewegte sich stets zwischen 4 und $7 \%$ der gesamten Treffer. ${ }^{501}$

Die Statistiken über die tatsächliche Nutzung des SIS ließen einige Autor_innen an seiner Legitimation zweifeln. So hat sich etwa für Hartmut Aden und Heiner Busch „die Anstrengung, die mit der Einrichtung des Systems verbunden war, nie gerechtfertigt“". ${ }^{502}$ Selbst wenn die seit Einführung des SIS II stark angestiegenen Ausschreibungen im Hinblick auf

498 Ursprünglich unterschied das SDÜ explizit zwischen zwei Zielen des SIS (Gewährleistung der Sicherheit und Sicherung der Grenze). Sowohl in der damaligen Diskussion bei der Einführung des SIS als auch später in der neuen Rechtsgrundlage des SIS II gewann aber die Sicherheitsfunktion Priorität und wurde die Hauptrechtfertigungsgrundlage des SIS, wozu die Grenzsicherung als funktional dargestellt wurde. Vgl. oben Abschnitte 4.1.1 und 4.4.2.

499 Vgl. ausführlicher dazu Schindehütte, Das Schengener Informationssystem, 154155. Schindehütte weist unter anderem auf den Mangel empirischer Daten hin und darauf, dass eine Bewertung der Effektivität der verdeckten Kontrollen nur aufgrund abstrakter Erwägungen erfolgen könne. Nach einer solchen Abschätzung kommt sie zum Schluss, dass der Nutzen der verdeckten Kontrollen eher gering sei. Dazu, wie die Effektivität der „prognostischen“ Sicherheitsansätze empirisch erforscht werden kann, vgl. Ostermeier, Lars, Der Staat in der prognostischen Sicherheitsgesellschaft, in: Puschke, Jens; Singelnstein, Tobias (Hg.), Der Staat und die Sicherheitsgesellschaft. Wiesbaden: Springer Fachmedien Wiesbaden 2018, 101-121.

500 Vgl. ebd., 153-156.

501 Vgl. oben Abschnitt 4.6 in diesem Kapitel.

502 Aden; Busch, Europäisierung des Rechts der Inneren Sicherheit, 553. 
die Teilnahme an einem Strafverfahren miteinbezogen werden, ${ }^{503}$ machen die Treffer, die eine direkte Verbindung mit einem Strafverfahren haben, insgesamt gerade einmal knapp $29 \%$ der Treffer im SIS II aus. ${ }^{504}$

\subsection{Die Legitimierungskraft des Sicherheits- und Ausgleichsarguments}

Auch in Bezug auf die Annahme, das SIS würde lediglich einen Mangel kompensieren, der durch den Wegfall der Grenzkontrollen zu erwarten sei, hat die hier durchgeführte Analyse Zweifel entstehen lassen. Vielmehr scheint das SIS dem Bestreben zu einer intensiveren polizeilichen Zusammenarbeit nachzukommen, das unabhängig von und bereits vor dem geplanten Wegfall der Grenzkontrollen bestand.

Daraus lässt sich schlussfolgern, dass das SIS auch einen Beitrag zur Erhaltung der inneren Sicherheit leistet, seine Funktion und seine Ziele sich jedoch nicht darin erschöpfen. Dabei wird an seiner Herausbildung und Erhaltung auch unabhängig von seiner Fähigkeit, diese Ziele effektiv zu erreichen, festgehalten. Einmal eingeleitet, hat das Verfahren zum Aufund Ausbau des SIS eine eigene Dynamik entfaltet, in der die ursprüngliche Motivation und Rechtfertigung keine bindende Kraft mehr besaßen. Dies wurde beim Transfer des SIS I in das SIS II besonders deutlich, als der Hauptgrund für die Schaffung eines neuen Systems (d. h. die Möglichkeit, die Zahl der angeschlossenen Staaten zu erhöhen) weggefallen war, das Projekt aber trotz steigender Kosten und erheblicher Verzögerungen weiterverfolgt wurde.

Die ursprünglichen Rechtfertigungsgrundlagen spielen nichtdestotrotz eine zentrale Rolle bei der Legitimierung des SIS. Die Vorstellung eines drohenden Sicherheitsdefizits verlieh dem SIS den Anschein der Notwendigkeit und Dringlichkeit. Parallel dazu suggeriert die Ausgleichsrhetorik, dass das SIS keine an sich neuen Möglichkeiten für die polizeiliche Arbeit eröffnet, sondern nur zur (wenn auch nicht vollständigen) Erhaltung des Status quo beiträgt. Damit geht auch einher, dass das SIS als reiner Ausgleich keine erheblichen Risiken im Hinblick auf die Grund-

503 Ausschreibungen nach Art. 34 Beschluss 2007/533/JI, die sich jedoch nicht unbedingt auf Beschuldigte/Verdächtige oder Verurteilte beziehen, sondern auch etwa auf Zeuginnen und Zeugen. Vgl. oben Tabelle 2.

504 Die Daten beziehen sich auf den Zeitraum 2014-2019, begrenzt auf 2019 sinkt die Quote der Treffer, die eine Verbindung mit Strafverfahren haben, auf 25\% der Gesamttreffer. Vgl. oben Tabelle 1. 
rechte und -freiheiten mit sich bringt. Die Kombination dieser beiden Rechtfertigungsgrundlagen (Sicherheits- und Ausgleichsargument) schaffte somit eine Grundlage, die eine kritische Betrachtung des Vorhabens erschwerte. Wäre das SIS von Anfang an als ein Instrument mit - wenn nicht offenen - zumindest flexiblen Zielen dargestellt worden, welches die bestehenden polizeilichen Fahndungsmöglichkeiten ausweitet, wären möglicherweise die Grenzen des SIS klarer und strikter definiert und die Kontroll- und Rechtsschutzmechanismen effektiver gewesen.

\subsection{Die Erweiterung der Ermittlungsmöglichkeiten durch das SIS}

Dass das SIS eine Ausweitung der Fahndungsmöglichkeiten bedeutet und keinen reinen Ausgleich für den Wegfall der Grenzkontrollen darstellt, ergibt sich zunächst aus der oben geführten Diskussion. ${ }^{505}$ Diese verdeutlichte, dass die vom SIS eröffneten neuen Fahndungswege nicht einfach eine Reaktion auf ein neues Problem darstellten. Das SIS ermöglichte zum Beispiel den nationalen Behörden, auf automatisierte Weise Informationen über Personen abzufragen, die im Ausland zur Fahndung ausgeschrieben wurden - eine Möglichkeit, die allererst mit dem SIS entstanden ist, obwohl die Fähigkeit von Kriminellen, sich international zu bewegen, nicht erst mit dem Wegfall der Grenzkontrollen entstanden ist. Ebenfalls erlaubte es zunächst das SIS, nationale Fahndungsausschreibungen auch im Ausland abzurufen sowie Bewegungen der eigenen Bürger_innen durch verdeckte oder gezielte Kontrollen auch im Ausland verfolgen zu lassen. Dabei wurden vor dem Wegfall der Grenzkontrollen bei Weitem nicht alle national zur Fahndung ausgeschriebenen Personen bei Grenzübertritt aufgegriffen. ${ }^{506}$

Das SIS stellt aber auch aus einer anderen Perspektive eine Erweiterung der Ermittlungsinstrumente dar. Wie Ursula Nelles hervorhob, erhielten die Ermittlungsbehörden durch das SIS die Möglichkeit, die strafprozessualen Grenzen der eigenen Befugnisse zu umgehen, indem sie von eventuell permissiveren Befugnissen der ausländischen Kolleg_innen Gebrauch machen können. ${ }^{507}$ Telefonüberwachungsmaßnahmen etwa unterliegen

505 Vgl. den Abschnitt 4 dieses Kapitels und insbesondere den Unterteil 4.3.

506 Außerdem ist auch gegenwärtig, wo Grenzkontrollen immer häufiger mehr oder weniger vorübergehend wieder eingeführt werden, vom Verzicht auf das SIS keine Rede mehr.

507 Vgl. Nelles, Europäisierung des Strafverfahrens - Strafprozeßrecht für Europa? 
in verschiedenen europäischen Ländern unterschiedlich strikten Voraussetzungen.

Über ihre jeweiligen Ermittlungsergebnisse - und dies ist zugleich eine sachliche Ausweitung der Befugnisse - dürfen sich die Polizeibeamten im Wege der sogenannten Spontanauskunft gegenseitig unterrichten (Art. 46 [SDÜ]). Es reicht dann ein Aktenvermerk über die Erkenntnisse der Nachbarbehörden, damit die Staatsanwaltschaften oder die Gerichte formal unangreifbar im Wege der Rechtshilfe um die „Übermittlung von Beweisstücken, Akten oder Schriftstücken“ ersuchen können. ${ }^{508}$

Es besteht damit die Möglichkeit eines „Befugnis-Shoppings“,509 das gleichzeitig aber die Gewährleistung der individuellen strafprozessualen Garantien erschwert, weil damit die im nationalen System vorgesehenen Sicherungen der Individualrechte unterlaufen werden können und weil es im Falle einer Verletzung der Rechte der Beschuldigten deutlich schwieriger wird, den richtigen Rechtsweg zu beschreiten, um diese einzuklagen.

Trotz dieser de-facto-Erweiterung der Ermittlungsmöglichkeiten durch das SIS hat bei seiner Einführung kein Ausgleich des damit entstandenen Rechtsschutzdefizits stattgefunden. ${ }^{510}$ Lediglich datenschutzrechtliche Überlegungen haben, wenn auch in begrenztem Umfang, eine Rolle gespielt und erst im Jahr 2016 durch eine umfangreiche Datenschutzreform zu effektiven und zeitgemäßen Schutzmechanismen geführt. ${ }^{511}$

508 Nelles, Europäisierung des Strafverfahrens - Strafprozeßrecht für Europa?, 737738.

509 Ebd., 738.

510 Vgl. ebd.

511 Über den anfänglichen Ausschuss der nationalen Datenschutzkommissionen vgl. Der Spiegel, Big Brother ersetzt den Zöllner, 28. Über die spätere Arbeit der Gemeinsamen Kontrollinstanz für das Schengener Informationssystem vgl. Schriever-Steinberg, Angelika, Kontrolle des Schengener Informationssystems, in: DuD Datenschutz und Datensicherheit, 31/8, 2007, 571-574. Die Datenschutzreform fand durch die Verabschiedung der Datenschutzgrundverordnung und der Datenschutzrichtlinie im Bereich Polizei und Justiz statt. Vgl. Verordnung (EU) 2016/679 des Europäischen Parlaments und des Rates vom 27.04.2016 zum Schutz natürlicher Personen bei der Verarbeitung personenbezogener Daten, zum freien Datenverkehr und zur Aufhebung der Richtlinie 95/46/EG (Datenschutz-Grundverordnung), Amtsblatt der Europäischen Union L 119/1 vom 04.05.2016 und Richtlinie (EU) 2016/680 des Europäischen Parlaments und des Rates vom 27.04.2016 zum Schutz natürlicher Personen bei der Verarbeitung personenbezogener Daten durch die zuständigen Behörden zum Zwecke der Verhütung, Ermittlung, Aufdeckung oder Verfolgung von 
Schließlich hat seit Einführung des SIS eine Ausweitung seiner technischen Möglichkeiten stattgefunden, die potenziell weitere Risiken für die Individualrechte mit sich bringt. Mit der Umwandlung zum SIS II wurde das Informationssystem um die Möglichkeit, biometrische Datenkategorien zu erfassen und Fahndungen miteinander zu verknüpfen, erweitert. Wie erwähnt hat sich dadurch die Natur des SIS schleichend verändert, indem es nun nicht mehr nur ein reines Fahndungsinstrument ist, sondern auch Züge eines Ermittlungsinstruments erhalten hat. Die geplante (und teilweise bereits umgesetzte) Verwendung der biometrischen Daten auch als Suchinstrumente (anstatt nur für Identifikationszwecke) und die Absicht, das SIS mit anderen europäischen Datenbanken zu verbinden, zeigen, dass sich die Erweiterung der Funktionalitäten und des Anwendungsbereichs des SIS auch in Zukunft fortsetzen wird. ${ }^{512}$ Diese Entwicklung spiegelt die Sichtweise des Rates wider, dass das SIS II ein flexibles Instrument sein soll, das mit geringem Aufwand an neue Umstände und Anforderungen angepasst werden kann. ${ }^{513}$ Die Kehrseite dieser Flexibilität ist, dass die gesammelten Informationen für Zwecke genutzt werden, die ursprünglich nicht vorgesehen waren. Das macht es im Endeffekt unmöglich, die Risiken solcher Anwendungen einzuschätzen und dadurch effektive Schutzmaßnahmen zu entwickeln. ${ }^{514}$

Straftaten oder der Strafvollstreckung sowie zum freien Datenverkehr und zur Aufhebung des Rahmenbeschlusses 2008/977/JI des Rates, Amtsblatt der Europäischen Union L 119/89 vom 04.05.2016; beide Verordnungen werden seit Mai 2018 umgesetzt.

512 Vgl. oben Abschnitt 3.3 und 3.4. Teilweise müssen dafür noch die Rechtsgrundlagen geschaffen werden, sodass die Frage offenbleibt, ob diese auch ausreichende Rechtschutzmechanismen vorsehen werden.

513 Vgl. Ratsdokument 9808/03 vom 26.05.2003, 4.

514 Vgl. Schriever-Steinberg, Kontrolle des Schengener Informationssystems. 


\section{Kapitel 5 Erhebung und Austausch biometrischer Daten zu kriminalistischen Zwecken: der Fall von Prüm}

\section{Die Prümer Regelungen: Austausch biometrischer Daten}

Die Prümer Regelungen sind ein Instrument des Informationsaustauschs zwischen den Staaten im Bereich der Kriminalitätsbekämpfung. Sie wurden zunächst durch einen Vertrag zwischen sieben europäischen Staaten eingeführt und später in den Rechtsrahmen der Europäischen Union übertragen. Als EU-Normen konzentrieren sie sich auf den Austausch von DNA-Profilen, daktyloskopischen Daten und Fahrzeugregisterdaten sowie auf die Regelung gemeinsamer Einsätze zur Gefahrenabwehr. Für die Zukunft ist eine Erweiterung der Datenkategorien auf Gesichtsbilder geplant. $^{515}$

Auf den nächsten Seiten werde ich die Entstehung der Prümer Regelungen als interstaatlicher Vertrag bis zu ihrer Überführung ins EU-Recht nachverfolgen (Abschnitt 2). Im darauffolgenden Abschnitt werde ich den Inhalt der Prümer Regelungen darstellen, mit besonderem Fokus auf deren Zielen und den Austausch von daktyloskopischen und DNA-Daten. Im vierten Abschnitt werde ich auf die Rechtfertigungsargumente eingehen, durch welche die Einführung der Prümer Regelungen begründet wurde, und diese mit der bisherigen Effektivität der darauf aufbauenden Maßnahmen konfrontieren. Darüber hinaus wird Prüm aus institutionellrechtlicher Sicht analysiert, insbesondere in Bezug auf das Kriterium der Verfahrenskonformität und die Frage, wie die Mechanismen, durch welche die Prümer Regelungen eingeführt wurden, sich in die institutionellen Verfahren der Entscheidungsfindung auf EU-Ebene eingefügt haben (Abschnitt 5). Schließlich untersuche ich im sechsten Abschnitt die Rolle der Sicherheit als Katalysator der Machtausweitung im RFSR.

515 Siehe unten, Abschnitt 2.2 in diesem Kapitel. 


\section{Entstehung der Prümer Regelungen: ein SIS III?}

\subsection{Der Prümer Vertrag als völkerrechtliches Abkommen}

Der Prümer Vertrag „,̈̈ber die Vertiefung der grenzüberschreitenden $\mathrm{Zu}$ sammenarbeit, insbesondere zur Bekämpfung des Terrorismus, der grenzüberschreitenden Kriminalität und der illegalen Migration" 516 wurde am 27. Mai 2005 in der rheinland-pfälzischen Stadt Prüm geschlossen. Obwohl die sieben Vertragsparteien, nämlich Belgien, Deutschland, Spanien, Frankreich, Luxemburg, Niederlande und Österreich, zu der Zeit alle EU-Mitglieder waren, ist der Prümer Vertrag ursprünglich außerhalb des EU-Rechtsrahmens entstanden. Er ist somit ein völkerrechtlicher Vertrag und kein Rechtsakt der EU. ${ }^{517}$

Die Initiative für die Schließung des Vertrags kam aus Deutschland. $\mathrm{Zu}$ Beginn der Verhandlungen setzte die Bundesrepublik das Thema „Rasterfahndung" als Priorität, dieses verlor jedoch im Laufe der Verhandlungen an Bedeutung und fand im Endvertrag keine Erwähnung mehr. Die Verhandlungen wurden je nach Vertragspartei entweder durch das Justiz- oder Innenministerium geleitet. Für Deutschland war auch ein Vertreter der Länder eingeladen. Die EU-Kommission wurde über die Aushandlungen regelmäßig informiert. 518

Der Prümer Vertrag diente als Vorbild für ähnliche internationale Abkommen, die auf Initiative der USA zwischen verschiedenen europäischen Ländern und den USA geschlossen wurden. So wurden schon 2008 Prüm-ähnliche bilaterale Verträge zwischen den USA und jeweils Estland, Deutschland und der Tschechischen Republik ausgehandelt. Es folgten unter anderen die Niederlande, Finnland, Spanien, Griechenland, Österreich

516 Vertrag zwischen dem Königreich Belgien, der Bundesrepublik Deutschland, dem Königreich Spanien, der Französischen Republik, dem Großherzogtum Luxemburg, dem Königreich der Niederlande und der Republik Österreich über die Vertiefung der grenzüberschreitenden Zusammenarbeit, insb. zur Bekämpfung des Terrorismus, der grenzüberschreitenden Kriminalität und der illegalen Migration, BGBl. 2006 II, 626.

517 Vgl. Pörschke, Der Grundsatz der Verfügbarkeit von Informationen am Beispiel des Prümer Modells, 110-111.

518 Mutschler, Stefanie, Der Prümer Vertrag: neue Wege der Kriminalitätsbekämpfung auf europäischer Ebene. Stuttgart: Boorberg 2010, 62-63. 
und Belgien. ${ }^{519}$ Das Abkommen zwischen Deutschland und den USA ist 2011 in Kraft getreten. ${ }^{520}$

\subsection{Die Überführung in den EU-Rechtsrahmen und geplante Erweiterungen}

Obwohl der Prümer Vertrag kein EU-Rechtsakt ist, betrifft er Rechtsgebiete, die relevant für das Recht der EU sind und die bereits durch EU-Normen reguliert waren, wie die polizeiliche und justizielle Zusammenarbeit und die Migrationskontrolle. Eine Überführung der Regelungen des Prümer Vertrags in den Rechtsrahmen der EU war von Anfang an vorgesehen und ist explizit im Art. 1 Nr. 4 des Vertrags erwähnt. Laut Prümer Vertrag hätte die Initiative zur Überführung in den Rechtsrahmen der EU spätestens drei Jahre nach Inkrafttreten des Vertrags gestartet werden und auf der Bewertung der Erfahrungen bei der Durchführung des Vertrags basieren sollen. ${ }^{521}$

Bereits im Dezember 2006 hatte der damalige deutsche Innenminister Wolfgang Schäuble angekündigt, während der deutschen Präsidentschaft des Rates im Jahr 2007 die Überführung realisieren zu wollen, obwohl zu der Zeit noch keine Erfahrungsberichte vorlagen. ${ }^{522}$ Tatsächlich wurde die Überführung 2007 unter der deutschen Präsidentschaft begonnen und 2008 durch den Erlass zweier Beschlüsse vervollständigt. ${ }^{523}$ Seitdem

519 Luif, Paul; Trauner, Florian, The Prüm Process: The Effects of Enhanced Cooperation within Europe and with the United States in Combating Serious Crime, in: Holzhacker, Ronald L.; Luif, Paul (Hg.), Freedom, security, and justice in the European Union: internal and external dimensions of increased cooperation after the Lisbon treaty. New York; Heidelberg: Springer 2014, 101-117.

520 Vgl. Pörschke, Der Grundsatz der Verfügbarkeit von Informationen am Beispiel des Prümer Modells, 160.

521 Vgl. Art. 1 Nr. 4 Prümer Vertrag.

522 Vgl. Bundesministerium des Innern (2006), Living Europe Safely. Work Programme for the German EU Presidency in the First Half of 2007, 5; Mutschler, Der Prümer Vertrag, 67 und Luif; Trauner, The Prüm Process: The Effects of Enhanced Cooperation within Europe and with the United States in Combating Serious Crime, 109.

523 Beschluss 2008/615/JI zur Vertiefung der grenzüberschreitenden Zusammenarbeit, insbesondere zur Bekämpfung des Terrorismus und der grenzüberschreitenden Kriminalität und Beschluss 2008/616/JI zur Durchführung des Beschlusses 2008/615/JI zur Vertiefung der grenzüberschreitenden Zusammenarbeit, insbesondere zur Bekämpfung des Terrorismus und der grenzüberschreitenden 
sind die Prümer Regelungen Teil des sekundären EU-Rechts (insbesondere der damaligen dritten Säule) und verpflichten alle EU-Mitgliedstaaten, bis 2011 die enthaltenen Regelungen umzusetzen. Island, Norwegen und die Schweiz wurden auf eigenen Wunsch assoziiert, ein ähnliches Assoziierungsabkommen ist auch für Liechtenstein in Sicht. ${ }^{524}$

Einige Regelungen des Prümer Vertrags wurden von der Übertragung in den Rechtsrahmen der Union ausgeschlossen, weil sie Materien der ersten Säule betrafen. Eine Übertragung hätte einen Verstoß gegen das EU-Recht bedeuten können, weil in der ersten Säule die EU-Kommission über ein Initiativmonopol verfügte. ${ }^{525}$ Von der Übertragung blieben insbesondere die Normen über die Flugsicherheitsbegleiter_innen (Art. 17-19 Prümer Vertrag) und die Maßnahmen zur Bekämpfung illegaler Migration (Kapitel 4 Prümer Vertrag) ausgeschlossen.

Im Juli 2018, zehn Jahre nach dem Erlass der Prümer Beschlüsse, hat der Rat der EU ein Dokument veröffentlicht, in dem er die Erweiterung der Datenkategorien auf Gesichtsbilder und die verstärkte Nutzung des Netzwerkes zur Verhütung der Kriminalität angestoßen hat. ${ }^{526}$

\section{Inhalt der Prümer Beschlüsse}

In diesem Abschnitt wird der Inhalt der Prümer Regelungen dargestellt, so wie sie heute für die Mitgliedstaaten der EU verpflichtend sind. Es wird daher auf die Normen Bezug genommen, die Teil des EU-Rechts sind, und

Kriminalität, beide vom 23.06.2008, Amtsblatt der EU L 210 vom 06.08.2008, 111 und 12-72. Über den Inhalt der Beschlüsse vgl. unten Abschnitt 3.

524 Vgl. Europäische Kommission, Commission Staff Working Document, Comprehensive Assessment of EU Security Policy, $\operatorname{SWD}(2017) 278$ final, 26.07.2017, 124 und https://www.eda.admin.ch/dea/de/home/verhandlunge n-offene-themen/verhandlun (letzter Zugriff: 03.06.2019).

525 Vgl. Guild, Elspeth, Merging Security from the Two Level Game: Inserting the Treaty of Prüm into EU Law? CEPS (Centre for European Policy Studies) Policy paper Nr. 124, 2007, 2.

526 Vgl. Rat der Europäischen Union, Schlussfolgerungen des Rates zur Umsetzung der „Prümer Beschlüsse“ zehn Jahre nach ihrer Annahme, 11227/18, 18.07.2018, 5. Infolgedessen haben sich verschiedene Arbeitsgruppen gegründet, welche die Entwicklung eines „Prüm der nächsten Generation“ vorantreiben sollen. Spezifisch zur Gesichtserkennung vgl. Council of the European Union, Next generation Prüm (Prüm.ng) - Reports from focus groups/Report on face recognition, 13356/19, 30.10.2019. 
nicht auf die Regelungen des Prümer Vertrags, der ursprünglich zwischen den sieben „Vorreiter"-Staaten geschlossen wurde.

Die Überführung der Prümer Regelungen in den EU-Rechtsrahmen erfolgte wie erwähnt am 23. Juni 2008 mit dem Erlass zweier Ratsbeschlüsse: des Beschlusses 2008/615/JI „zur Vertiefung der grenzüberschreitenden Zusammenarbeit, insbesondere zur Bekämpfung des Terrorismus und der grenzüberschreitenden Kriminalität“ (PB) und des Beschlusses 2008/616/JI „zur Durchführung des Beschlusses 2008/615/JI zur Vertiefung der grenzüberschreitenden Zusammenarbeit, insbesondere zur Bekämpfung des Terrorismus und der grenzüberschreitenden Kriminalität“ (PDB) (im Folgenden gemeinsam als „Prümer Beschlüsse“ bzw. abgekürzt als „PB“ bezeichnet). 527

Der erste Beschluss überträgt die wesentlichen Bestimmungen des Prümer Vertrags in den EU-Rechtsrahmen, insbesondere die Regelungen, die den Datenaustausch und den gemeinsamen Einsatz der Polizeikräfte regeln. Ausgeschlossen von der Übertragung blieben wie erwähnt die Regelungen des Prümer Vertrags, die den Einsatz von Flugsicherheitsbegleiter_innen und die Migrationspolitik betreffen. Der zweite Beschluss legt die Verwaltungs- und technischen Vorschriften für die Umsetzung des ersten Beschlusses fest.

\subsection{Ziel des Datenaustausches: Vertiefung der Zusammenarbeit}

Das Hauptziel der PB ist es, die Zusammenarbeit der Mitgliedstaaten zur Verhinderung und Verfolgung von Straftaten zu vertiefen, insbesondere durch den Austausch von Informationen (Art. 1 PB). In diesem Bereich sollten die bisherigen Verfahren beschleunigt und „neue Ermittlungsansätze“ (Präambel PB, Nr. 12) erschlossen werden.

\subsection{Datenkategorien und Formen des Datenaustausches}

Im Mittelpunkt des Beschlusses stehen drei Kategorien von Daten: DNA-, daktyloskopische und Fahrzeugdaten. Für die ersten zwei Kategorien basiert der Austausch auf einem Treffer/Kein-Treffer-System, dementsprechend der ersuchende Staat zunächst die Information bekommt, ob ein

527 Vgl. Fußnote 523 in diesem Kapitel oben. 
Treffer vorliegt oder nicht. ${ }^{528}$ Der anschließende Austausch erfolgt wie ein „konventionelles“ Rechtshilfeverfahren gemäß den geltenden europarechtlichen und völkerrechtlichen Normen. Für die dritte Kategorie erlauben die Staaten einen direkten Zugriff auf ihre Fahrzeugregister. Für den Datenaustausch werden keine neuen europäischen Datenbanken eingerichtet, sondern es wurde eine Vernetzung der nationalen Datenbanken realisiert.

Für jede Datenkategorie spezifizieren die PB, wie der Zugriff und das Folgeersuchen erfolgen sollen.

\subsubsection{DNA-Daten}

Das Prümer Modell des Datenaustauschs setzt die Existenz nationaler DNA-Analyse-Dateien voraus. Sind diese nicht vorhanden, verpflichten die PB die Mitgliedstaaten zu deren Einrichtung (Art. 2 Nr. 1 PB). Die nationalen Dateien sollen „Fundstellendatensätze“ enthalten, die aus einem DNA-Profil und einer Kennung bestehen (Art. 2 lit. e PDB). Ein DNA-Profil ist ein Code aus Buchstaben bzw. Nummern, der den nicht codierenden $^{529}$ Teil einer DNA-Probe abbildet (Art. 2 lit. e PDB). Die dazugehörige Kennung enthält einen Code, der den Abruf von personenbezogenen Daten des DNA-Profils ermöglichen soll, einen Staatencode, der die Herkunft des Profils bezeichnet, sowie einen Code, der auf die Art des DNA-Profils hinweist. Die Fundstellendatensätze dürfen keine unmittelbare Identifizierung der Personen, zu denen sie gehören, ermöglichen. „Offene Spuren“, d. h. Fundstellendatensätze, die niemandem zugeordnet werden können, müssen als solche erkennbar sein (Art. 2.2).

Die Fundstellendatensätze werden den anderen Mitgliedstaaten nur zum Zweck der Verfolgung von Straftaten zur Verfügung gestellt. ${ }^{530}$ Die DNA-Profile werden automatisiert abgerufen: Die nationalen Kontaktstellen ermöglichen den anderen Staaten den Vergleich mit den nationalen Fundstellendatensätzen, ohne die Anfrage im Voraus zu prüfen. Die Ver-

528 Wie ich weiter unten näher erläutern werde, bedeutet dies allerdings nicht, dass der ersuchende Staat nur die Information bezüglich des (Nicht-)Vorliegens eines Treffers bekommt. Im Fall eines Treffers werden schon in diesem Stadium pseudonymisierte DNA-Profile oder daktyloskopische Daten ausgetauscht. Vgl. unten Abschnitt 3.4.

529 Nicht codierende Teile der DNA sind laut Art. 2 lit. d PDB „die Chromosomenbereiche, die keine genetische Information, d. h. keine Hinweise auf funktionale Eigenschaften eines Organismus, enthalten“.

530 Das könnte sich in Zukunft ändern, vgl. oben Fußnote 524 in diesem Kapitel. 
gleiche dürfen nur in Einzelfällen erfolgen; Massenabgleiche sind ausgeschlossen. Die Anfragen müssen nach dem nationalen Recht des abrufenden Staates erfolgen. Wird eine Übereinstimmung festgestellt, bekommt der ersuchende Staat die Fundstellendatensätze (also DNA-Profil und Kennung), anhand derer die Übereinstimmung festgestellt wurde. Wird keine Übereistimmung festgestellt, bekommt der ersuchende Staat eine entsprechende Nachricht (Art. 3 PB).

Neben dem Abruf von DNA-Profilen ermöglichen die PB auch den automatisierten Abgleich der offenen Spuren eines Staates mit allen DNAProfilen eines anderen Staates. Die Anfragen müssen nach nationalem Recht des abrufenden Staates erfolgen. Die Übermittlung der übereinstimmenden Fundstellendatensätze erfolgt in diesem Fall nicht automatisch (Art. 4 PB).

Im Fall eines Treffers, als Ergebnis sowohl eines Abruf- als auch Abgleichverfahrens, erfolgt die Übermittlung weiterer Daten und Informationen nicht automatisiert. Stattdessen wird ein traditionelles Rechtshilfeverfahren eingeleitet, das sich nach dem Recht des ersuchten Staates richtet und über nationale Kontaktstellen, die für die Datenübermittlung benannt werden (Art. 6 PB), erfolgt.

Im Kontext eines laufenden Ermittlungs- oder Strafverfahrens sind außerdem die Mitgliedstaaten verpflichtet, sich gegenseitig bei der Gewinnung von DNA-Profilen von Personen, die sich in ihrem Hoheitsgebiet befinden, zu unterstützen (Art. 7 PB).

\subsubsection{Daktyloskopische Daten}

Die PB verpflichten die Mitgliedstaaten zur Gewährleistung, dass daktyloskopische Datenbanken für den Informationsaustausch vorhanden sind. Diese dürfen nur daktyloskopische Daten und eine Kennung erhalten und dürfen nicht zu einer unmittelbaren Identifizierung der Betroffenen führen. Wie auch im Fall der DNA-Profile müssen offene Spuren als solche identifizierbar sein (Art. 8 PB).

Anders als DNA-Profile werden daktyloskopische Daten nicht nur für die Verfolgung, sondern auch für die Verhinderung von Straftaten zur Verfügung gestellt. Der Abruf und das anschließende Verfahren verlaufen nach dem gleichen Muster wie für DNA-Informationen. Nur EinzelfallAbfragen sind gestattet, diese richten sich nach dem Recht des abrufenden Mitgliedstaates. Im Fall eines möglichen Treffers bekommt der ersuchende Staat automatisiert die infrage kommenden Fundstellendatensätze des er- 
suchten Staates (Art.9). Das weitere Prozedere und die Übermittlung weiterer Informationen folgen den nationalen Normen des ersuchten Staates (Art. 10). Für die Übermittlung der Informationen werden nationale Kontaktstellen benannt, deren Arbeit sich nach dem innerstaatlichen Recht des jeweiligen Staates richtet (Art.11). Da es möglich ist, dass mehrere Fundstellendatensätze als Treffer in Betracht kommen, ${ }^{531}$ spezifizieren die $\mathrm{PB}$, dass die endgültige Zuordnung der daktyloskopischen Daten zu einem Fundstellendatensatz durch den abrufenden Mitgliedstaat erfolgt (Art. 9 Nr. 2).

\subsubsection{Daten aus Fahrzeugregistern}

Der Bereich der Angelegenheiten, für die Fahrzeugregisterdaten ausgetauscht werden können, wird im Vergleich mit den DNA- und daktyloskopischen Daten ausgeweitet. Der Informationsaustausch erfolgt nämlich in diesem Fall zur Verhinderung und Verfolgung von Straftaten und „zur Verfolgung solcher Verstöße, die bei dem abrufenden Mitgliedstaat in die Zuständigkeit der Gerichte oder Staatsanwaltschaften fallen, und zur Abwehr von Gefahren für die öffentliche Sicherheit" (Art. 12 Nr. 1 PB). Da dieser Bereich ziemlich umfassend ist, sehen die PB vor, dass die Staaten der Bekämpfung schwerer Straftaten Priorität einräumen können (Präambel PB, Nr. 15).

In diesem Fall hat der ersuchende Staat direkten Zugriff auf Daten des nationalen Fahrzeugregisters des ersuchten Staates und insbesondere auf Eigentümer- oder Halterdaten sowie Fahrzeugdaten. Dies bedeutet, dass der ersuchende Staat in diesem Fall auch direkten Zugriff auf personenbezogene Daten hat. Auch für den Austausch der Fahrzeugregisterdaten werden nationale Kontaktstellen ernannt, deren Befugnisse sich nach nationalem Recht richten (Art. 12 PB).

\subsection{Weitere Normen betreffend den Informationsaustausch}

Die PB sehen die Möglichkeit für Mitgliedstaaten vor, sowohl auf Ersuchen der Behörden anderer Mitgliedstaaten als auch auf eigene Initiative Informationen in einer nicht automatisierten Form auszutauschen. So

531 Vgl. Schaar, Peter, Datenaustausch und Datenschutz im Vertrag von Prüm, in: DuD - Datenschutz und Datensicherheit, 30/11, 2006, 691-693, hier 693. 
werden zum Beispiel „zur Verhinderung von Straftaten und zur Abwehr einer Gefahr für die öffentliche Sicherheit und Ordnung bei Großveranstaltungen mit grenzüberschreitender Dimension" (Art. 13 PB), wie etwa Sportveranstaltungen oder Tagungen des EU-Rates, Daten über Personen ausgetauscht, die entweder schon verurteilt wurden oder von denen angenommen wird, dass sie eine Gefahr darstellen (Art. 14). Außerdem können die Mitgliedstaaten auch zur Verhinderung terroristischer Straftaten Daten über Individuen austauschen, bei denen aufgrund von Tatsachen angenommen werden kann, dass sie eine terroristische Straftat begehen werden (Art. 16 PB). Auch diese Formen des Datenaustauschs laufen über nationale Kontaktstellen.

Neben dem Datenaustausch regeln die Prümer Beschlüsse auch andere Formen der Zusammenarbeit, insbesondere gemeinsame Einsatzformen, bei denen Beamte eines Staates im Hoheitsgebiet eines anderen Staates mitwirken (Art. 17 PB), sowie Hilfeleistungen bei Massenveranstaltungen, Katastrophen und schweren Unglücksfällen (Art. 18 PB).

Zudem enthalten die Prümer Beschlüsse Datenschutzregelungen, die sowohl auf existierende Normen verweisen als auch spezielle Bestimmungen festlegen, die unter anderem eine nachträgliche Kontrolle des erfolgten Datenaustauschs gestatten. Zudem gelten nunmehr für polizeiliche und justizielle Maßnahmen die Bestimmungen der EU-Richtlinie zum Schutz personenbezogener Daten in diesen Bereichen. ${ }^{332}$

\subsection{Weitere Schritte des Austausches von DNA-Informationen}

Wie oben erwähnt, wurde für den Datenaustausch nach den Prümer Beschlüssen keine neue zentrale Datenbank auf EU-Ebene errichtet. Das unterscheidet das Prümer Modell etwa vom Informationsaustausch im Rahmen des SIS, der über eine zentralisierte europäische Datenbank erfolgt.

532 Richtlinie (EU) 2016/680 des Europäischen Parlaments und des Rates vom 27.04.2016 zum Schutz natürlicher Personen bei der Verarbeitung personenbezogener Daten durch die zuständigen Behörden zum Zwecke der Verhütung, Ermittlung, Aufdeckung oder Verfolgung von Straftaten oder der Strafvollstreckung sowie zum freien Datenverkehr und zur Aufhebung des Rahmenbeschlusses 2008/977/JI des Rates, Amtsblatt der Europäischen Union L 119/89 vom 04.05.2016. 
Nach dem Prümer Modell werden dagegen die nationalen Datenbanken miteinander verknüpft. 533

In allem Übrigen folgt aber der automatisierte Datenaustausch nach den Prümer Beschlüssen zwei verschiedenen Modellen, je nachdem ob sich die zu tauschenden Daten auf DNA- und daktyloskopische Informationen beziehen oder Fahrzeugregisterdaten betreffen. Während für den Austausch von DNA-Profilen und daktyloskopischen Daten der ersuchende Staat zunächst Zugang ausschließlich zu den pseudonymisierten ${ }^{534}$ Fundstellendatensätzen des ersuchten Staates zum Zwecke des Vergleichs hat, wird auf die Fahrzeugregisterdaten des ersuchten Staates direkter Zugriff gewährleistet.

Im Folgenden wird der Informationsaustausch nach dem automatisierten Abruf von DNA-Profilen und daktyloskopischen Daten näher analysiert. Dieser folgt einem zweistufigen Verfahren: Im ersten Schritt bekommt der ersuchende Staat auf automatisierte Weise entweder eine negative Meldung oder, im Fall eines (möglichen) Treffers, die Fundstellendatensätze des anderen Staates, die als Treffer infrage kommen. Im zweiten Schritt wird ein „traditionelles“, nach geltendem EU- oder Völkerrecht gerichtetes Rechtshilfeersuchenverfahren eingeleitet. Erst in diesem Schritt

533 Die Kommunikation zwischen den Staaten erfolgt über das Kommunikationssystem TESTA (Trans European System for Telematics between Administrators, nun in der Version „new generation“, oder „TESTA-ng“). Das ist ein privates, von der EU finanziertes und durch die Kommission verwaltetes Netzwerk, das auch für die Kommunikation und den Abgleich von Daten, die in EU-zentralisierten Datenbanken gespeichert sind, wie z. B. Eurodac, VIS und SIS II, verwendet wird. Auch die Kommunikation innerhalb des Europol-Informationssystems wird über TESTA abgewickelt. Vgl. Art. 4 PDB, Pörschke, Der Grundsatz der Verfügbarkeit von Informationen am Beispiel des Prümer Modells, 132; Mutschler, Der Prümer Vertrag, 120 und eu-LISA, eu-LISA Strategy 2018-2022, 2017.

534 Pseudonymisierung wird definiert als „das Ersetzen des Namens und anderer Identifikationsmerkmale durch ein Kennzeichen zu dem Zweck, die Bestimmung des Betroffenen auszuschließen oder wesentlich zu erschweren“ ( $\$ 3$ Abs. 6 a BDSG), während Anonymisierung folgendes Verfahren bezeichnet: „das Verändern personenbezogener Daten derart, dass die Einzelangaben über persönliche oder sachliche Verhältnisse nicht mehr oder nur mit einem unverhältnismäßig großen Aufwand an Zeit, Kosten und Arbeitskraft einer bestimmten oder bestimmbaren natürlichen Person zugeordnet werden können" ( $\mathbb{3}$ Abs. 6 BDSG). Da nach den PB die Kennung der Fundstellendatensätze einen Code beinhaltet, der in einem weiteren Schritt den Abruf von personenbezogenen Daten ermöglicht, sind die DNA-Profile und daktyloskopischen Daten in den Fundstellendatensätzen nach dem Prümer Modell „pseudonymisiert“. 
werden die zu den Fundstellendatensätzen gehörenden personenbezogenen (und eventuell auch weiteren) Informationen übermittelt. Wenn statt eines Abrufs der DNA-Profile oder daktyloskopischen Daten ein Abgleich der offenen DNA-Spuren erfolgt, folgt das Austauschverfahren ebenfalls einem zweistufigen Modell, nur werden dann die übereinstimmenden Fundstellendatensätze nicht automatisiert übermittelt (Art. 4 PB).

Das Verfahren, insbesondere mit Bezug auf den ersten Schritt, wird in den PB selbst und in der Literatur als „Treffer/Kein-Treffer"-System (auf Englisch „hit/no-hit“) bezeichnet. ${ }^{535}$ Jedoch ist diese Bezeichnung irreführend, da sie suggeriert, dass zunächst nur die Information übermittelt wird, ob ein Treffer vorliegt oder nicht. Wie oben dargestellt, ist dies aber nicht der Fall: Wenn der automatisierte Abruf der DNA-Profile oder daktyloskopischen Daten einen Treffer ergibt, werden unmittelbar und automatisiert (d. h. ohne vorherige Prüfung des übermittelnden Staates) auch die (möglicherweise) übereinstimmenden Fundstellendatensätze übermittelt. Diese bestehen aus einer Kennung und den pseudonymisierten DNAProfilen oder daktyloskopischen Daten.

Zur Verwirrung trägt ebenfalls bei, dass im Prümer Vertrag vorgesehen ist, dass im Fall eines Treffers beim Abgleich von DNA-Profilen nur die Kennung des passenden Fundstellendatensatzes übermittelt wird (Art. 3 Prümer Vertrag). In den PB wurde dies aber dahingehend geändert, dass nunmehr auch die pseudonymisierten DNA-Profile übermittelt werden. Der Grund dafür könnte sein, dass sich nach Abschluss des Prümer Vertrags herausgestellt hat, dass mehrere ähnliche DNA-Profile als mögliche Treffer infrage kommen können. Das Problem war zur Zeit der Prümer Verhandlungen bereits hinsichtlich der daktyloskopischen Daten bekannt, weshalb sowohl der Prümer Vertrag als auch die PB explizit die Möglichkeit erwähnen, bei einem Treffer mehrere potenziell übereinstimmende Fundstellendatensätze zu übermitteln, deren endgültige Zuordnung beim ersuchenden Staat erfolgt. ${ }^{536}$ Das bedeutet auch, dass die übermittelten Daten nicht unbedingt bereits bei dem ersuchenden Staat vorhanden sind oder, anders gesagt, dass die Daten, die automatisch übermittelt werden, nicht unbedingt die Person betreffen, um die es sich bei der Anfrage handelt.

Die Weitergabe dieser Daten kann aus datenschutzrechtlicher Perspektive problematische Folgen haben. Die übermittelten Daten ermöglichen

535 Präambel PB, Nr. 10; Pörschke, Der Grundsatz der Verfügbarkeit von Informationen am Beispiel des Prümer Modells, 108; Mutschler, Der Prümer Vertrag, 80, 108.

536 Vgl. Schaar, Datenaustausch und Datenschutz im Vertrag von Prüm. 
zwar keine unmittelbare Identifizierung der Betroffenen. Da eine persönliche Zuordnung jedoch noch möglich (und im Fall eines Treffers sogar vorgesehen) ist, gelten diese immer noch als "personenbezogene“ Daten. ${ }^{537}$ Außerdem ist es technisch möglich, aus den übermittelten pseudonymisierten DNA-Profilen eine Reihe von Informationen zu gewinnen, selbst wenn die DNA-Profile aus dem nicht codierenden Teil der DNA stammen. Diese Informationen ermöglichen etwa die Feststellung des Geschlechts oder eine statistische Prognose über die ethnische Zugehörigkeit und über Krankheiten, die auf chromosomalen Unregelmäßigkeiten beruhen. ${ }^{538}$

\section{Rechtfertigungargumente und Effektivität der Prümer Regelungen für die Bekämpfung von Terrorismus und grenzüberschreitender Kriminalität}

In Kontinuität zum SIS wird auch die Einführung der Prümer Regelungen unter Bezugnahme auf ein Sicherheitsdefizit gerechtfertigt, das durch den Abbau der Grenzkontrollen nach Schengen entstanden sein soll. In diesem Zusammenhang wird normalerweise auf schwere Kriminalität wie Terrorismus, Drogenhandel und organisierte Kriminalität wie auch auf illegale Migration hingewiesen. Wie oben erwähnt, nannten die ursprünglichen Prümer Regelungen, so wie sie im Prümer Vertrag formuliert wurden, auch im Titel den Kampf gegen Terrorismus und organisierte Kriminalität sowie die Bekämpfung der illegalen Migration als Ziele der Maßnahmen. Der Bezug auf Migration und die damit verbundenen Normen wurden aber nicht in die Prümer Beschlüsse übernommen. Wie erwähnt, hätte deren Überführung einen Konflikt mit dem EU-Recht impliziert, da zur Zeit der Übertragung die Migrationspolitik schon Teil der ersten Säule geworden war. In den Prümer Beschlüssen ist somit nur noch die Bekämpfung des Terrorismus und der grenzüberschreitenden Kriminalität als Ziel erwähnt. 539

537 Vgl. Polenz, Sven, Datenschutz. Rechtsquellen und Grundbegriffe des allgemeinen Datenschutzes, in: Kilian, Wolfgang; Heussen, Benno (Hg.), ComputerrechtsHandbuch. Informationstechnologie in der Rechts- und Wirtschaftspraxis. München: Beck 2017, Kapitel 131, hier Rn. 79-82. Vgl. auch die Definition nach Art. 4, Ziff. 1 der Datenschutzgrundverordnung.

538 Vgl. Feuerlein, Monika; Potthof, Christof, Codierend-nicht-codierend. Interview mit Peter Schneider, in: Gen-ethischer Informationsdienst, 170, 2005, 1419.

539 Vgl. Mutschler, Der Prümer Vertrag, 267-268. 
„Grenzüberschreitend“ impliziert an sich keine Einschränkung, was die Schwere der Straftaten angeht, das heißt, ob es sich um gravierende Verbrechen handeln muss. Die Anwendung der Prümer Regelungen wird jedoch oft mit Bezug auf spektakuläre und schwere Straftaten gerechtfertigt. So steht etwa in einem Bericht der Kommission von 2017, dass Prüm „eines der Instrumente“ war, „die den französischen Ermittlern nach den Terroranschlägen von Paris im November 2015 halfen“. .540

Die von der EU veröffentlichten Statistiken über die Ergebnisse von Prüm geben keinerlei Auskunft darüber, für welche Art von Straftaten der Datenaustausch erfolgte. Solche Informationen liegen nur für die „zwischenstaatliche" Phase der Prümer Maßnahmen vor, also als sie noch aufgrund des Prümer Vertrags angewendet wurden. Diese Ergebnisse zeigen, dass die größte Bedeutung der Prümer Maßnahmen, zumindest aus quantitativer Sicht, in der Aufklärung von Eigentumsdelikten und anderen nicht schweren Straftaten liegt. So bezogen sich etwa 3005 der von den bis September 2009 insgesamt 3135 erzielten Treffer des Datenaustauschs zwischen Deutschland und Österreich auf „sonstige“ Straftaten, zu denen keine gemeingefährlichen Straftaten, Straftaten gegen die persönliche Freiheit, Sexualdelikte oder Straftaten gegen das Leben gehören. Was den Austausch daktyloskopischer Informationen angeht, bestanden 223 der 325 von Deutschland erzielten Treffer aus Eigentumsdelikten und Verstößen gegen das Aufenthaltsgesetz oder Betäubungsmittelgesetz. ${ }^{541}$

Nach der ersten zwischenstaatlichen Phase ist die Anwendung von Prüm auf europaweiter Ebene nur langsam vorangeschritten. Die Anwendung der Prümer Regelungen konnte die eigenen zeitlichen Vorgaben nicht einhalten und ist aktuell immer noch unvollständig. Nach den Prümer Beschlüssen hätten die Mitgliedstaaten bis August 2011 die Normen vollständig in nationales Recht umsetzen müssen. ${ }^{542}$ Aber auch sechs Jahre

540 Europäische Kommission, Mitteilung der Kommission an das Europäische Parlament, den Europäischen Rat und den Rat. Auf dem Weg zu einer wirksamen und echten Sicherheitsunion - Fünfter Fortschrittsbericht, $\operatorname{COM}(2017) 203$ final, 02.03.2017, 6 .

541 Vgl. Deutscher Bundestag, Antwort der Bundesregierung auf die Kleine Anfrage der Abgeordneten Ulla Jelpke, Inge Höger, Jan Korte, weiterer Abgeordneter und der Fraktion DIE LINKE - Drucksache 16/14150 - 22.10.2009 und Bundesministerium des Innern, Vertrag von Prüm. Auswertung DNA-Datenabgleich zwischen Deutschland und Österreich. Stand 18.03.2007.

542 Vgl. Art. 36 PB und Europäische Kommission, Commission Staff Working Document, Comprehensive Assessment of EU Security Policy, SWD(2017) 278 final, 26.07.2017, 122. 
später waren verschiedene EU-Länder, wie Kroatien, Griechenland, Irland, Italien und Portugal, immer noch nicht dazu bereit, die Prümer Regelungen umzusetzen. Die EU-Kommission hat deswegen 2017 gegen diese Länder das erste Vertragsverletzungsverfahren eingeleitet, das einen Rechtsakt der einstmaligen dritten Säule betrifft. ${ }^{543} 2019$ betrug die Anzahl der Staaten, die operationell an das Prümer Netzwerk angebunden sind, zwischen 24 und 26, je nach Kategorie der Daten (DNA, Fingerabdrücke oder Kennzeichen). ${ }^{544}$ Im Dezember 2020 liefen nur noch Vertragsverletzungsverfahren gegen zwei Staaten. ${ }^{545}$

Zwischen den Staaten, die an das Prümer System angebunden sind, zeigen die EU-Statistiken einen intensiven und steigenden Datenaustausch. ${ }^{546}$

543 Vgl. Europäische Kommission, Mitteilung der Kommission an das Europäische Parlament, den Europäischen Rat und den Rat. Auf dem Weg zu einer wirksamen und echten Sicherheitsunion - Erster Fortschrittsbericht, COM(2016) 670 final, 12.10.2016, 7; Europäische Kommission, Mitteilung der Kommission an das Europäische Parlament, den Europäischen Rat und den Rat. Auf dem Weg zu einer wirksamen und echten Sicherheitsunion - Fünfter Fortschrittsbericht, $\operatorname{COM(2017)} 203$ final, 02.03.2017 und Pörschke, Der Grundsatz der Verfügbarkeit von Informationen am Beispiel des Prümer Modells, 151-152. Für die neuesten Entwicklungen vgl. Mitteilung der Kommission an das Europäische Parlament, den europäischen Rat und den Rat „Auf dem Weg zu einer wirksamen und echten Sicherheitsunion - Zwanzigster Fortschrittsbericht", $\operatorname{COM(2019)} 552$ final, 30.10.2019. Nach einer Umfrage aus dem Jahr 2011 sollen die Gründe für die verspätete nationale Umsetzung der Prümer Beschlüsse weniger rechtliche Bedenken als vielmehr technische, administrative und ökonomische Probleme sein. Vgl. Pörschke, Der Grundsatz der Verfügbarkeit von Informationen am Beispiel des Prümer Modells, 152-153. In manchen Staaten, wie zum Beispiel Italien, Griechenland, Irland oder Malta, existierten zur Zeit des Beitritts zu den Prümer Regelungen keine zentralisierten DNA-Datenbanken; diese mussten erst aufgrund der Prümer Verpflichtungen errichtet werden. Vgl. Töpfer, Eric, Prüm und das europäische DNA-Datennetz \& Transatlantischer DNA-Freihandel? in: Gen-ethisches Netzwerk e. V. (Hg.), Identität auf Vorrat. Zur Kritik der DNA-Sammelwut. Berlin; Hamburg: Assoziation A 2017, 79-87.

544 Vgl. European Commission, Study on the feasibility of improving information exchange under the Prüm decisions. Final Report, May 2020, 7.

545 Vgl. Europäische Kommission, Mitteilung der Kommission an das Europäische Parlament und den Rat. Erster Fortschrittsbericht zur EU-Strategie für die Sicherheitsunion, COM/2020/797 final, 09.12.2020, Anhang.

546 Anzumerken ist, dass die an das Prümer System angeschlossenen Staaten nicht automatisch alle Typen von Daten mit allen anderen Staaten tauschen. 2014 etwa tauschte Belgien nur mit Frankreich und den Niederlanden DNA-Daten, während die Niederlande DNA-Daten mit 20 und daktyloskopische Daten mit 12 anderen Staaten austauschten. Die deutschen Datenbanken waren mit denen von 15 anderen Staaten für den DNA-Austausch und mit 13 für den Austausch 
Deutschland allein hat im Jahr 2014 knapp eine Million (989 418) DNA-Profile mit anderen Prüm-Ländern ausgetauscht. ${ }^{547}$ Zwischen 2011 und 2015 wuchs die Anzahl der erzielten Treffer von 2568 auf 5826 bzw. von 20686 auf $37313 \mathrm{im}$ Rahmen des daktyloskopischen bzw. DNA-Datenaustauschs; im selben Zeitraum stieg die Anzahl der erhaltenen Antworten im Bereich des Austauschs von KFZ-Daten von 260253 auf über zwei Millionen. ${ }^{548} 2019$ standen im Prümer Netzwerk über 9,2 Millionen DNA-Profile zur Verfügung und es wurden mehr als 2,2 Millionen DNASuchen eingeleitet. Im selben Jahr fanden über 400000 Fingerabdruckabfragen statt, von denen ca. 10000 zu verifizierten Treffern führten. ${ }^{549}$ Die EU-Statistik unterscheidet außerdem die Zahl der Treffer in Spur-SpurTreffer, Spur-Person-Treffer und Person-Person-Treffer. Allerdings sagen die veröffentlichten Daten, wie erwähnt, weder auf welche Art von Delikten sich die Treffer beziehen, noch wie hoch die Fehlerquote ist, das heißt, wie viele von den erzielten Treffern „Zufallstreffer“ waren. Dadurch dass diese Daten fehlen, ist es auch unmöglich, zu errechnen, wie viele von den erzielten Treffern tatsächlich für Ermittlungen genutzt werden konnten. Die Mitgliedstaaten haben sich mehrheitlich für dieses Rechnungsmodell entschieden, und trotz Hinweisen auf seine Unzulänglichkeit wurde die Diskussion über eine mögliche Inklusion der Fehlerquoten vertagt. 550

daktyloskopischer Informationen verbunden. Das Prümer System ermöglicht nämlich nicht, anders als das bereits existierende Interpol-System „Gateway“ für den Austausch von DNA-Profilen, Treffer zwischen mehr als zwei Ländern zu vergleichen oder Fingerabdrücke mit DNA-Profilen zu verbinden. Dadurch ist das Prümer Modell gleichzeitig teurer, weil unter anderem mehrere Datenbanken durchsucht werden müssen. Vgl. McCartney, Carole I.; Wilson, Tim J.; Williams, Robin, Transnational Exchange of Forensic DNA: Viability, Legitimacy, and Acceptability, in: European Journal on Criminal Policy and Research, 17/4, 2011, 305-322.

547 Vgl. Council of the European Union, Doc. 5503/2/15 REV 2 vom 16.03.2015.

548 Vgl. Europäische Kommission, Commission Staff Working Document, Comprehensive Assessment of EU Security Policy, SWD(2017) 278 final, 26.07.2017, 122.

549 Vgl. European Commission, Study on the feasibility of improving information exchange under the Prüm decisions. Final Report, May 2020, 7.

550 Vgl. Council of the European Union, Doc. 5503/2/15 REV 2 vom 16.03.2015, 6; Toom, Victor; Granja, Rafaela; Ludwig, Anika, The Prüm Decisions as an Aspirational regime: Reviewing a Decade of Cross-Border Exchange and Comparison of Forensic DNA Data, in: Forensic Science International: Genetics, 41, 2019, 50-57. Auf diesen Mangel wurde schon im Zusammenhang mit den ersten Evaluationen über den Datenaustausch nach dem Prümer Vertrag hingewiesen, vgl. Deutscher Bundestag, „Antwort der Bundesregierung auf die 
Die Aussagekraft der Trefferzahl wird auch dadurch relativiert, dass das Folgeverfahren nach einem Treffer, das erst zur Identifikation der gesuchten Personen führen kann, sich als besonders schwierig erwiesen hat. ${ }^{551}$

Was die Kosten für den Anschluss an das Prümer System betrifft, gehen die Schätzungen auseinander: Während die deutsche Bundesregierung knapp eine Mio. € angab, schätzte eine belgische Studie zwei Mio. € für Staaten mit bereits vorhandenen nationalen Datenbanken und noch höhere Kosten für Staaten, die erst eine nationale DNA-Datenbank errichten müssen. Andere Schätzungen divergieren noch erheblicher: Für die Umsetzung der Prümer Regelungen schätzte etwa Großbritannien die national anfallenden Kosten auf 46 Mio. $€ .{ }^{552} \mathrm{Da}$ anders als üblich Deutschland beim Ergreifen der Überführungsinitiative keinen Kostenplan vorlegte, existieren dazu keine durch die EU anerkannten Schätzungen.

\section{Die Prümer Regelungen im Kontext des institutionellen und rechtlichen Rabmens der EU}

5.1 Eine „verstärkte Zusammenarbeit“ außerhalb der EU: Schengen als Vorbild?

Bei der Einführung der Prümer Regelungen haben sich die sieben Initiatoren für eine Art „verstärkte Zusammenarbeit“, jedoch außerhalb des rechtlichen und institutionellen Rahmens der EU, entschieden. Zur Zeit der Schließung des Prümer Vertrags war die polizeiliche und justizielle Zusammenarbeit, wie schon erwähnt, Teil der dritten Säule der EU: 553 Entscheidungen in diesem Politikbereich würden damit nach regulärem Verfahren Einstimmigkeit im Rat erfordern, um beschlossen zu werden. Vorstöße, die polizeiliche Kooperation auszuweiten, die vor allem aus Deutschland kamen, scheiterten aufgrund des Widerstands anderer Staa-

Kleine Anfrage der Abgeordneten Ulla Jelpke ...“, Antwort auf die Frage 9 und Pörschke, Der Grundsatz der Verfügbarkeit von Informationen am Beispiel des Prümer Modells, 151-152.

551 Vgl. ebd., 152.

552 Vgl. Prainsack, Barbara; Toom, Victor, Performing the Union: The Prüm Decision and the European dream, in: Studies in History and Philosophy of Biological and Biomedical Sciences, 44/1, 2013, 71-79; Mutschler, Der Prümer Vertrag, 272-273.

553 Vgl. Abschnitt 2.2 in diesem Kapitel. 
ten, insbesondere Großbritanniens. ${ }^{554}$ Das EU-Primärrecht ${ }^{555}$ sieht aber auch die Möglichkeit der verstärkten Zusammenarbeit vor, um Entscheidungsblockaden in jenen Politikbereichen zu vermeiden, in denen, wie in der polizeilichen und justiziellen Zusammenarbeit, die Konsensfindung sich als besonders schwierig erweisen kann. Nach dem EU-Primärrecht kann sich somit eine kleine „Avantgarde“ von mindestens acht Staaten zusammenschließen, um Maßnahmen zu beschließen, die zunächst nur zwischen den teilnehmenden Staaten gelten. Dafür sind eine Kompatibilitätsprüfung durch die Kommission und die Zustimmung des Rates mit qualifizierter Mehrheit und nach Anhörung des Parlaments nötig. ${ }^{556}$

Die sieben Staaten, die den Prümer Vertrag schlossen, nahmen aber diese Möglichkeit bewusst nicht in Anspruch und entschieden sich für eine zwischenstaatliche Kooperation außerhalb des EU-Rahmens. Dabei waren alle sieben Vertragsparteien EU-Mitglieder und verfolgten ein Ziel, das im EU-Primärrecht festgelegt ist, nämlich die Intensivierung der polizeilichen Zusammenarbeit. Um die Bedingungen zur Anwendung der verstärkten Zusammenarbeit zu erfüllen, hätte zwar die Teilnahme eines Staates gefehlt. Angesichts der vielseitigen Überschneidungen mit dem EU-Kompetenzbereich scheint jedoch die Entscheidung, die Prümer Regelungen außerhalb der EU zu beschließen, alles andere als selbstverständlich. Zudem, wie schon erwähnt, war die Überführung der Prümer Regelungen in den EU-Rechtsrahmen von Anfang an vorgesehen und sogar im Prümer Vertrag beschlossen.

554 Vgl. Hummer, Waldemar, Der Vertrag von Prüm - „Schengen III“?, in: Europarecht, 42/4, 2007, 517-530, hier 518; Kietz; Maurer, Fragmentierung und Entdemokratisierung der europäischen Justiz- und Innenpolitik? Folgen der Prümer Vertragsavantgarde und Luif; Trauner, The Prüm Process: The Effects of Enhanced Cooperation within Europe and with the United States in Combating Serious Crime.

555 Vgl. Art. 40-45 EUV, Konsolidierte Fassungen des Vertrags über die Europäische Union und des Vertrags zur Gründung der Europäischen Gemeinschaft, Amtsblatt der Europäischen Gemeinschaften C 325/01, 24.12.2002, für die zur Zeit der Schließung des Prümer Vertrags geltende Fassung.

556 Vgl. Hummer, Der Vertrag von Prüm - „Schengen III“?; Guild, Elspeth; Geyer, Florian, Getting Local: Schengen, Prüm and the Dancing Procession of Echternach. Three Paces Forward and two Back for EU Police and Judicial Cooperation in Criminal Matters, in: Journal of European Criminal Law, 1/3, 2007, 61-66 und Luif; Trauner, The Prüm Process: The Effects of Enhanced Cooperation within Europe and with the United States in Combating Serious Crime. 
Die Vertragsparteien selbst stellten ihre Vorgehensweise als eine Wiederholung des „Schengener Wegs“ dar, im Zuge dessen sich eine Avantgarde von Mitgliedstaaten unabhängig von den anderen auf eine Vertiefung der Integration verständigt hatte, die dann auf alle anderen Staaten angewendet wurde. Die Avantgarde hätte demnach also als Katalysator der europäischen Integration fungiert.

Diese Darstellung vernachlässigt aber die Tatsache, dass zwischen Schengen (1985) und Prüm (2005) zwanzig Jahre vergingen, in denen die europäische Integration sich wesentlich verstärkt hat. In diesem Zeitraum haben sich die Bedingungen der polizeilichen und justiziellen Zusammenarbeit in der EU vielfältig und tiefgreifend geändert. Die wichtigsten Erneuerungen führte der Vertrag von Amsterdam 1999 ein, der die Schaffung eines Raums der Freiheit, der Sicherheit und des Rechts zum Ziel der Union erklärte, den Schengen-Acquis in den Rechtsrahmen der Union überführte und die schrittweise Überführung der meisten Teile der justiziellen und innenpolitischen Kooperation von der intergouvernementalen dritten Säule in die supranationale erste Säule festlegte. Obwohl zur Zeit der Schließung des Prümer Vertrags die polizeiliche und justizielle Zusammenarbeit noch Materie der dritten Säule war, konnten auch in diesem Bereich bedeutsame Projekte verwirklicht werden, wie z. B. der Aufbau von Europol, die Schaffung von Eurojust und des Europäischen Haftbefehls. ${ }^{557}$

Außerdem steht die Behauptung, dass Schengen als Vorbild für die EUIntegration im Bereich Justiz und Inneres gelten kann, im Widerspruch zur Tatsache, dass die Übertragung der Schengener Regelungen in den EU-Rechtsrahmen alles andere als komplikationslos erfolgte. Als etwa das Schengen-Acquis Teil des EU-Rechts wurde, erwies es sich als besonders schwierig, die Schengener Regelungen mit dem bestehenden EU-Recht in Einklang zu bringen. Außerdem beanspruchten viele Mitgliedstaaten Ausnahmen für sich als Bedingung für ihre Teilnahme. ${ }^{558}$

557 Vgl. Kietz; Maurer, Fragmentierung und Entdemokratisierung der europäischen Justiz- und Innenpolitik? Folgen der Prümer Vertragsavantgarde.

558 Vgl. ebd.; Guild; Geyer, Getting Local: Schengen, Prüm and the Dancing Procession of Echternach. Three Paces Forward and two Back for EU Police and Judicial Cooperation in Criminal Matters. 


\subsection{Vergleich mit konkurrierenden Projekten im RSFR}

Die Entscheidung der sieben Prümer Vertragsparteien, die Maßnahmen außerhalb der EU zu beschließen, scheint auch deswegen rechtfertigungsbedürftig, weil die im Prümer Vertrag regulierte Materie Gegenstand damaliger Regulierungsbestrebungen der EU war. ${ }^{559}$

Die Verbesserung des Informationsaustauschs wurde konkret 2004 im Haager Programm als Maßnahme für die Schaffung des RFSR vereinbart. ${ }^{560}$ Das Haager Programm nennt als Leitprinzip dazu den Grundsatz der Verfügbarkeit von Informationen, die für die Verfolgung von Straftaten benötigt werden (vgl. Punkt 2.1 des Haager Programms). Nach dem Prinzip der Verfügbarkeit sollen anderen Mitgliedstaaten alle strafverfolgungsrelevanten Informationen zur Verfügung stehen, die innerstaatlich vorhanden sind. Grundsätzlich sollten dafür nationale oder bereits existierende europäische Datenbanken genutzt werden; zentralisierte Datenbanken sollten nur dann entwickelt werden, wenn sie nachweislich einen Zusatznutzen erbringen würden. Das Haager Programm lädt die Kommission ein, bis Ende 2005 einen Vorschlag für die Implementierung des Prinzips der Verfügbarkeit vorzulegen. Dieser Aufforderung kommt der Kommissionsvorschlag „für einen Rahmenbeschluss des Rates über den Austausch von Informationen nach dem Grundsatz der Verfügbarkeit“ nach. ${ }^{561}$

Der Vorschlag der Kommission und die Prümer Regelungen weisen Gemeinsamkeiten und Unterschiede auf. Sowohl nach dem Prümer Modell als auch nach dem Kommissionsvorschlag erfolgt die Suche nach Informationen zunächst automatisiert und liefert in einem ersten Schritt nur anonymisierte Fundstellendatensätze. Der anschließende Datenaustausch erfolgt dann aber, so der Kommissionsvorschlag, gemäß EU-Recht, welches festlegt, dass grundsätzlich alle weiteren Informationen zur Verfügung gestellt werden müssen, und welches die Ausnahmen zu dieser Pflicht klar eingrenzt. Dagegen sehen die Prümer Regelungen wie erwähnt vor, dass

559 Für einen Überblick über die Maßnahmen innerhalb des EU-Rechtsrahmens, deren Inhalt sich von den Prümer Regelungen überscheidet, vgl. Kietz; Maurer, Fragmentierung und Entdemokratisierung der europäischen Justiz- und Innenpolitik? Folgen der Prümer Vertragsavantgarde, 451.

560 Vgl. Mitteilung der Kommission an den Rat und das Europäische Parlament vom 10.05.2005 - Das Haager Programm: Zehn Prioritäten für die nächsten fünf Jahre. Die Partnerschaft zur Erneuerung Europas im Bereich der Freiheit, der Sicherheit und des Rechts, COM(2005) 184 final, Amtsblatt C 236 vom 24.09.2005.

561 Kommissionsvorschlag vom 12.10.2005, COM(2005) 490 final. 
sich der Datenaustausch im zweiten Schritt nach nationalem Recht des ersuchten Staates richtet, womit diesem zugleich die Entscheidungsfreiheit gewährt wird, ob und welche Daten weitergegeben werden. ${ }^{562}$ Im Unterschied zu den Prümer Regelungen sieht der Kommissionsvorschlag außerdem vor, dass auch Europol-Bedienstete Zugang zu den Informationen haben sollen (Art. 6).

Dadurch, dass die Verweigerungsmöglichkeiten des ersuchten Staates und auch Europol miteinbezogen werden, stellt der Vorschlag der Kommission, auch nach eigener Auffassung, eine vollständigere Umsetzung des Grundsatzes der Verfügbarkeit von Informationen dar. ${ }^{563}$ Insoweit liegt der Kommissionsvorschlag näher an den Prinzipien des Haager Programms als die Prümer Regelungen. Trotzdem wurden letztlich die Prümer Regelungen in den EU-Rechtsrahmen überführt, anstatt den Kommissionsvorschlag zu verwirklichen. Aus Anlass des Inkrafttretens des Lissaboner Vertrags im Jahr 2009 und der darin enthaltenen Auflösung des Drei-Säulen-Modells hat dann die Kommission ihren Vorschlag offiziell wieder zurückgezogen. ${ }^{564}$

5.3 Die Konsequenzen des Ausweichens in den intergouvernementalen Raum im Fall von Prüm

Zur Zeit der Schließung des Prümer Vertrags war der Politikbereich der polizeilichen und justiziellen Zusammenarbeit stärker als heutzutage durch Intergouvernementalität geprägt. Für eine Entscheidung gemäß dem regulären Verfahren hätten die Prümer Maßnahmen die Einstimmigkeit des Rates benötigt, um beschlossen zu werden. Außerdem hätten auch die anderen EU-Institutionen eine Rolle im Entscheidungsprozess gespielt. Die Kommission teilte sich damals das Initiativrecht mit den Mitgliedstaaten, und die Kontrollrechte des EuGH, obwohl immer noch begrenzt, hatten im Vergleich etwa mit der Zeit des Schengen-Vertrags zugenommen. Auch das EU-Parlament war in den Entscheidungsprozess

562 Vgl. Kietz; Maurer, Fragmentierung und Entdemokratisierung der europäischen Justiz- und Innenpolitik? Folgen der Prümer Vertragsavantgarde, 450.

563 Vgl. Mutschler, Der Prümer Vertrag, 284.

564 Vgl. Pörschke, Der Grundsatz der Verfügbarkeit von Informationen am Beispiel des Prümer Modells, 82-83; vgl. auch Mitteilung der Kommission an das Europäische Parlament und den Rat, Auswirkungen des Inkrafttretens des Vertrags von Lissabon auf die laufenden interinstitutionellen Beschlussfassungsverfahren, $\operatorname{COM}(2009) 665$ final. 
stärker als früher miteinbezogen und verfügte in diesem Bereich über Konsultationsrechte und Haushaltsbefugnisse. ${ }^{565}$

Wie oben erwähnt, hätte auch ein Verfahren gemäß dem EU-Instrument der verstärkten Zusammenarbeit die Beteiligung der EU-Institutionen impliziert. Die Kommission hätte dabei eine Kompatibilitätsprüfung durchführen, der Rat mit qualifizierter Mehrheit den Maßnahmen zustimmen und das Parlament angehört werden müssen. ${ }^{566}$

Da aber die sieben Vertragsparteien sich für den zwischenstaatlichen Weg entschieden, wurden diese institutionellen Verfahren in Gänze umgangen. Das bedeutet zunächst, dass die Kompromissfindung im Rat umgangen wurde, sodass die anderen EU-Mitgliedstaaten keine Möglichkeit hatten, die Prümer Regelungen mitzugestalten und diese nachträglich bei der Überführung in den EU-Rahmen als fait accompli akzeptieren mussten. Desgleichen gilt für die EU-Institutionen: Infolge der Überführung in den EU-Rahmen wurden dann diese, und insbesondere das Parlament und der EuGH, mit Normen konfrontiert, bei deren Entstehung sie ihre Kontrollrechte nicht ausüben konnten. ${ }^{567}$ Mit anderen Worten:

Wären die Prümer Maßnahmen zur Vertiefung der Polizeikooperation innerhalb des institutionellen Rahmens der dritten Säule erlassen worden, wäre das Europäische Parlament zu jedem Rechtsakt zumindest konsultiert worden, hätte seine Haushaltsrechte ebenso wie der EuGH seine Kontrollrechte und die Kommission ihr Initiativrecht geltend machen können. ${ }^{568}$

565 Vgl. Kietz; Maurer, Fragmentierung und Entdemokratisierung der europäischen Justiz- und Innenpolitik? Folgen der Prümer Vertragsavantgarde.

566 Vgl. Hummer, Der Vertrag von Prüm - „Schengen III“?

567 Vgl. Kietz; Maurer, Fragmentierung und Entdemokratisierung der europäischen Justiz- und Innenpolitik? Folgen der Prümer Vertragsavantgarde.

568 Ebd., 446. Wie Elspeth Guild und Florian Geyer anmerkten, wurde die fehlende Kontrolle des EU-Parlaments nicht von einer eingehenderen Prüfung durch die nationalen Parlamente kompensiert. Im Gegenteil ist die Kontrolle der nationalen Parlamente über zwischenstaatliche Abkommen erfahrungsgemäß eher gering. In Deutschland wurde der Vertrag beispielsweise im Mai 2005 unterschrieben, aber der Ratifizierungsentwurf wurde erst im April 2006 fertiggestellt, kurz vor der Fußball-Weltmeisterschaft, die als ein großes Risiko für die innere Sicherheit angesehen wurde. Der Entwurf wurde also als „dringend“ eingestuft und ließ wenig Zeit (weniger als zwei Monate) für die parlamentarische Prüfung. Für die Debatte und die Abstimmung im Plenum wurden nur 30 Minuten vorgesehen. Die meisten Abgeordneten reichten ihre Kommentare schriftlich ein, nur drei Abgeordnete von der Opposition ergriffen das Wort und dann auch eher mit der Intention, die Vorgehensweise insgesamt zu kriti- 
Diese Einschränkung der Kontrollrechte der EU-Institutionen wirkte sich auch auf die Zeit nach der Überführung der Maßnahmen in den EURechtsrahmen aus. In der Tat galten bis zu fünf Jahre nach Inkrafttreten des Vertrags von Lissabon (also bis zum 1. Dezember 2014) Einschränkungen zu den Durchsetzungsbefugnissen der Kommission und den Kontrollrechten des EuGH. ${ }^{569}$

Das Ausweichen in den zwischenstaatlichen Raum wurde als ein Versuch gerechtfertigt, die polizeiliche Kooperation auf europäischer Ebene schneller voranzutreiben und eine mögliche Blockade durch die mühsamen Entscheidungsverfahren der EU zu vermeiden. ${ }^{570}$

Doch weiteren Bemühungen, auch die polizeiliche und justizielle $\mathrm{Zu}$ sammenarbeit in den Gemeinschaftsrahmen zu überführen, womit dann die mühsame Entscheidungsfindung durch den Übergang zum Mehrheitsprinzip hätte beendet werden können, stand der Widerstand einiger Staaten entgegen, darunter besonders heftig der Widerstand des Hauptinitiators der Prümer Initiative, nämlich Deutschlands. ${ }^{571}$

Einige Beteiligte und Beobachter_innen, darunter die britische Regierung, der EU-Datenschutzbeauftragte und einige Kommentator_innen, haben diese Vorgehensweise als einen potenziellen Bruch der Normen und Bestimmungen über die Kooperation in der EU oder gar als einen tatsächlichen Bruch, wenn auch nicht ihres Wortlauts, so doch zumindest ihres Sinns, bezeichnet. ${ }^{572}$ Einige haben daraus die Schlussfolgerung gezogen,

sieren, als zum Inhalt Stellung zu nehmen. Vgl. Guild; Geyer, Getting Local: Schengen, Prüm and the Dancing Procession of Echternach. Three Paces Forward and two Back for EU Police and Judicial Cooperation in Criminal Matters.

569 Vgl. Europäische Kommission, Commission Staff Working Document, Comprehensive Assessment of EU Security Policy, SWD(2017) 278 final, 26.07.2017, 123.

570 Vgl. Hummer, Der Vertrag von Prüm - „Schengen III“?; Mutschler, Der Prümer Vertrag, 61.

571 Vgl. Kietz; Maurer, Fragmentierung und Entdemokratisierung der europäischen Justiz- und Innenpolitik? Folgen der Prümer Vertragsavantgarde; Hummer, Der Vertrag von Prüm - „Schengen III“? Die offizielle Rechtfertigung der Bundesregierung lautete, dass diese Regelungen auch Teil des Verfassungsvertrags waren und dass eine vorzeitige Zustimmung der Bundesregierung zur Verringerung der Verhandlungsmasse bei den Verhandlungen zum Verfassungsvertrag geführt hätte. Daniela Kietz und Andreas Maurer weisen aber darauf hin, dass der Grund hierfür vielmehr in grundsätzlichen Bedenken hinsichtlich des Verlusts von Souveränitätsrechten liegen könnte, die eine durch das Mehrheitsprinzip geprägte Entscheidungsstruktur auf EU-Ebene mit sich bringen würde.

572 Vgl. House of Lords, European Union Committee, Prüm: an effective weapon

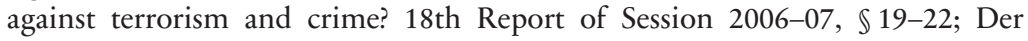


dass der Grund für das Ausweichen in den zwischenstaatlichen Raum in dem Wunsch bestand, die Mitspracherechte der anderen EU-Mitglieder und der EU-Institutionen zu umgehen und somit die Kooperation nach eigenen Vorstellungen und Interessen zu gestalten. Denn obwohl die Vertiefung der polizeilichen und justiziellen Zusammenarbeit im EU-Primärrecht klar als Ziel definiert ist, sind die sekundärrechtlichen Maßnahmen zu ihrer Konkretisierung oft kontrovers. ${ }^{573}$ Prüm wird also als ein Manöver kritisiert, mit dem es die sieben Vertragspartner vermieden haben, einen Konsens über kontroverse Aspekte zu suchen, um ihre eigene präferierte Position durchzusetzen und diese dann den anderen Staaten als nicht veränderbares Gesamtpaket zu präsentieren. ${ }^{574}$

Europäische Datenschutzbeauftragte, Stellungnahme zur Initiative des Königreichs Belgien, der Republik Bulgarien, der Bundesrepublik Deutschland, des Königreichs Spanien, der Französischen Republik, des Großherzogtums Luxemburg, des Königreichs der Niederlande, der Republik Österreich, der Republik Slowenien, der Slowakischen Republik, der Italienischen Republik, der Republik Finnland, der Portugiesischen Republik, Rumäniens und des Königreichs Schweden zum Erlass eines Beschlusses des Rates zur Vertiefung der grenzüberschreitenden Zusammenarbeit, insbesondere zur Bekämpfung des Terrorismus und der grenzüberschreitenden Kriminalität, in: Amtsblatt der Europäischen Union C 169, vom 21.07.2007, 2-14; Der Europäische Datenschutzbeauftragte, Stellungnahme zur Initiative der Bundesrepublik Deutschland im Hinblick auf den Erlass eines Beschlusses des Rates zur Durchführung des Beschlusses 2007/.../JI zur Vertiefung der grenzüberschreitenden Zusammenarbeit, insbesondere zur Bekämpfung des Terrorismus und der grenzüberschreitenden Kriminalität, in: Amtsblatt der Europäischen Union C 89, vom 10.04.2008, 1-7; Kietz; Maurer, Fragmentierung und Entdemokratisierung der europäischen Justiz- und Innenpolitik? Folgen der Prümer Vertragsavantgarde, 450; Guild; Geyer, Getting Local: Schengen, Prüm and the Dancing Procession of Echternach. Three Paces Forward and two Back for EU Police and Judicial Cooperation in Criminal Matters; McCartney; Wilson; Williams, Transnational Exchange of Forensic DNA.

573 Vgl. Kietz; Maurer, Fragmentierung und Entdemokratisierung der europäischen Justiz- und Innenpolitik? Folgen der Prümer Vertragsavantgarde.

574 Vgl. McCartney; Wilson; Williams, Transnational Exchange of Forensic DNA; Der Europäische Datenschutzbeauftragte, Stellungnahme zur Initiative des Königreichs Belgien [...] zur Vertiefung der grenzüberschreitenden Zusammenarbeit, insbesondere zur Bekämpfung des Terrorismus und der grenzüberschreitenden Kriminalität. 
5.4 Die Art der Überführung in den EU-Rechtsrahmen und insbesondere die Rolle des EU-Parlaments

Auch in dem Verfahren, mit dem die Prümer Regelungen in den EURechtsrahmen überführt wurden, wurden die vorhandenen Möglichkeiten der institutionellen und insbesondere parlamentarischen Kontrolle nicht ausgeschöpft. Die Überführung wurde zu einem Zeitpunkt realisiert, zu dem der Lissaboner Vertrag schon unterzeichnet war und in absehbarer Zeit in Kraft treten sollte. Dieser Vertrag schreibt dem EU-Parlament die Rolle „eines vollwertigen Mitgesetzgebers“ ${ }^{\text {" } 75}$ zu und stärkt damit seine Stellung in den Entscheidungsmechanismen der EU. In diesem Kontext ließ die Art und Weise, wie die Prümer Regelungen in den EU-Rechtsrahmen überführt wurden, dem Parlament und den anderen EU-Institutionen nur einen begrenzten Handlungsspielraum.

Im Rahmen der Überführung musste nach Art. 39 EUV 576 eine Anhörung des EU-Parlaments stattfinden. Diese wurde am 7. Mai 2007 durchgeführt. In seinem Bericht über die Initiative zur Überführung bedauerte das Parlament, dass der Rat es aufgefordert hatte, so schnell wie möglich eine Stellungnahme abzugeben, ohne ihm einen angemessenen Zeitraum zur Verfügung zu stellen, um den Vertrag von Prüm sorgfältig prüfen zu können. Außerdem kritisierte das Parlament, dass zu der Zeit der Stellungnahme sowohl Erfahrungsberichte über die bisherige Anwendung des Prümer Vertrags als auch eine allgemeine Datenschutzregelung für Maßnahmen im Rahmen der polizeilichen und justiziellen Zusammenarbeit fehlten. ${ }^{577}$ Darüber hinaus empfiehlt das Parlament in seiner Stellungnahme, einen Rahmenbeschluss als Handlungsinstrument zu benutzen, während die EU-Staaten, welche die Überführungsinitiative unterstützten, sich für das Instrument des Beschlusses entschieden. Während Rahmenbeschlüsse nur für die Zielsetzung verpflichtend sind und den Staaten die Wahlfreiheit

575 Der Europäische Datenschutzbeauftragte, Stellungnahme zur Initiative der Bundesrepublik Deutschland im Hinblick auf den Erlass eines Beschlusses des Rates zur Durchführung des Beschlusses 2007/.../JI zur Vertiefung der grenzüberschreitenden Zusammenarbeit, insbesondere zur Bekämpfung des Terrorismus und der grenzüberschreitenden Kriminalität, 2.

576 Konsolidierte Fassungen des Vertrags über die Europäische Union und des Vertrags zur Gründung der Europäischen Gemeinschaft, Amtsblatt der Europäischen Gemeinschaften C 325/01 vom 24.12.2002.

577 Vgl. „Entwurf einer Legislativen Entschliessung des Europäischen Parlaments“ in Bericht des EU-Parlaments (Berichterstatter: Fausto Correia) endgültig A60207/2007, 6 . 
hinsichtlich der Form und der Mittel überlassen, sind Beschlüsse auch bezüglich der letzteren beiden Aspekte verpflichtend. Außerdem sind laut EU-Verträgen Rahmenbeschlüsse als Rechtsinstrument zu wählen, wenn die enthaltenen Normen der Rechtsangleichung oder -harmonisierung dienen (Art. 34 Abs. 2 Buchstaben b und c EUV). Das Parlament hielt den Rahmenbeschluss als geeigneteres Instrument für die Überführung der Prümer Regelungen, weil die Initiative die Angleichung der Rechts- und Verwaltungsvorschriften der Mitgliedstaaten zum Ziel hatte. ${ }^{578}$ Ein aus Sicht des Parlaments bedeutender Unterschied zwischen den beiden Rechtsakten war ferner, dass die Maßnahmen, die für die Durchführung eines Beschlusses notwendig sind, vom Rat mit qualifizierter Mehrheit und ohne Anhörung des Parlaments entschieden werden können. ${ }^{579}$ Die vom Rat getroffene Wahl des Beschlusses als Rechtsinstrument für die Überführung implizierte somit, dass das Parlament nicht angehört werden musste, um Durchführungsmaßnahmen der Prümer Beschlüsse zu entscheiden.

Schließlich wurde bei der Initiative zur Überführung von dem die Initiative ergreifenden Staat kein Memorandum, wie sonst üblich, vorgelegt, in dem die Hintergründe der Maßnahmen, die zu erwartenden Kosten und Resultate sowie eine Evaluationsstrategie dargelegt werden. ${ }^{580}$

\section{Sicherheitstheoretische und normative Implikationen der Prümer Regelungen: Sicherheit als Machtkatalysator}

Die Prümer Regelungen greifen aus grund- und menschenrechtlicher Sicht in sehr bedeutende Bereiche ein: Wie der Deutsche Bundestag und der Deutsche Bundesrat feststellten, schränken die Prümer Regelungen das Grundrecht auf Leben und körperliche Unversehrtheit sowie die Grundrechte der Freiheit der Person, der Freiheit der Versammlung, des

578 Vgl. „Stellungnahme des Rechtsausschusses zur Rechtsgrundlage“ im Bericht des EU-Parlaments (Berichterstatter: Fausto Correia) endgültig A6-0207/2007, 48.

579 Vgl. ebd., 45.

580 Vgl. Der Europäische Datenschutzbeauftragte, Stellungnahme zur Initiative der Bundesrepublik Deutschland im Hinblick auf den Erlass eines Beschlusses des Rates zur Durchführung des Beschlusses 2007/.../JI zur Vertiefung der grenzüberschreitenden Zusammenarbeit, insbesondere zur Bekämpfung des Terrorismus und der grenzüberschreitenden Kriminalität; Prainsack; Toom, Performing the Union. 
Brief-, Post- und Fernmeldegeheimnisses und der Unverletzlichkeit der Wohnung ein. ${ }^{581}$

Der Datenaustausch im Prümer System ermöglicht die Übermittlung hochsensibler personenbezogener Daten, wie (pseudonymisierter, jedoch nicht anonymisierter) DNA-Profile, an einen anderen Staat. Da die Übermittlung der DNA-Profile im Fall eines Treffers automatisiert erfolgt, wird die Übermittlung der Profile keiner Prüfung durch den Staat, der die Daten erhoben und gespeichert hat, unterzogen. Im Regelfall sollte der ersuchende Staat nur DNA-Profile von Menschen bekommen, die sich schon in seinen nationalen Datenbanken befinden, weil die Übermittlung nur dann erfolgt, wenn ein Treffer (d. h. eine Übereinstimmung der Profile) erzielt wurde. Jedoch ist mit Zunahme der angeschlossenen Staaten und der vorhandenen Daten die Wahrscheinlichkeit der Zufallstreffer gestiegen; dadurch ist es häufiger möglich, dass die übermittelten Profile Menschen betreffen, die nicht diejenigen sind, die gesucht werden und deren DNA-Profile nicht bereits beim ersuchenden Staat vorhanden sind.

Wie auch schon im Fall des SIS, wurden diese Maßnahmen als strategische Antwort auf ein Sicherheitsdefizit konzipiert, wobei nicht dargelegt wurde, inwiefern die Prümer Maßnahmen eine effektive Gegenmaßnahme darstellen. Die Bezugnahme auf den Wegfall der Grenzkontrollen als Legitimationsfigur, obwohl auf den ersten Blick plausibel, erweist sich bei näherer Betrachtung als fragil. Einerseits wird das Prümer System vor allem als Instrument zur Identifizierung (insbesondere tatverdächtiger Personen) betrachtet. ${ }^{582}$ Tatsächlich helfen Grenzkontrollen, Tatverdächtige festzunehmen, wenn diese bereits im Vorfeld identifiziert wurden und gesucht werden. Anderenfalls können sie auch trotz stattfindender Kontrollen ungehindert die Grenzen passieren. ${ }^{583}$ In diesem Sinne hat der Wegfall der Grenzkontrollen nichts an der Nützlichkeit von Identifizierungsmaßnahmen, wozu das Prümer System gehört, geändert.

Dadurch dass die von der EU zur Verfügung gestellten Statistiken keine Auskunft über die Art der Delikte, die Zufallstreffer und die Weiterverwendung der während der Ermittlungen ausgetauschten Daten geben, ist die Effektivität der Prümer Maßnahmen auch nicht verifizierbar. Wir wis-

581 Vgl. Kietz; Maurer, Fragmentierung und Entdemokratisierung der europäischen Justiz- und Innenpolitik? Folgen der Prümer Vertragsavantgarde, 440.

582 Vgl. Europäische Kommission, Commission Staff Working Document, Comprehensive Assessment of EU Security Policy, SWD(2017) 278 final, 26.07.2017, 123.

583 Vgl. Mutschler, Der Prümer Vertrag, 265. 
sen zwar, dass daktyloskopische, DNA- und KFZ-Daten mit zunehmender Intensität ausgetauscht werden, wir können aber nicht verifizieren, für welche Zwecke dies getan wird.

Frühere Statistiken zur Anwendung der Prümer Maßnahmen als zwischenstaatliche Normen zeigten, wie bereits erwähnt, dass der Datenaustausch vor allem im Rahmen der Bekämpfung von leichteren Kriminalitätsformen erfolgte. Manche Autor_innen haben zudem darauf hingewiesen, dass dieser Fokus auf bestimmte Delikte der Prümer Logik immanent sei. Schwere Straftaten, wie etwa Kindesmissbrauch, Menschenhandel oder Wirtschafts- und Finanzstraftaten, bei denen typischerweise keine biologischen Spuren am Tatort hinterlassen werden, werden zwangsläufig von den Erfassungsmöglichkeiten des Prümer Systems ausgeschlossen. Dagegen werden Straftaten wie Diebstahl und Raub bevorzugt durch die Prümer Maßnahmen verfolgt. ${ }^{584}$

Das Ausmaß des für legitim und zweckmäßig gehaltenen Eingriffs in die von den Prümer Maßnahmen eingeschränkten Grundrechte hängt natürlich auch von der Schwere der Straftaten, gegen welche die Maßnahmen eingesetzt werden, und von der Effektivität dieser Maßnahmen ab. In diesem Sinne wären Informationen über die Art der verfolgten Straftaten und die Quote der Treffer, die tatsächlich in den Ermittlungen verwendet werden und/oder zu Festnahmen führen, von entscheidender Bedeutung, um die Legitimität der Prümer Maßnahmen zu bewerten.

Dass die Prümer Maßnahmen nicht einfach einen Ausgleich der ausgefallenen Grenzkontrollen darstellen, wird mittelbar auch durch die PB bestätigt, wonach wie erwähnt die Prümer Regelungen „neue Ermittlungsansätze erschließen" sollen. ${ }^{585}$ In dieser Hinsicht existiert tatsächlich eine Kontinuität mit der Einführung des SIS. Denn in beiden Fällen wird eine de-facto-Erweiterung der Machtbefugnisse als eine Kompensierung früher existierender, aber nun weggefallener Sicherheitsmaßnahmen präsentiert.

Dabei wurden im Fall von Prüm auch die theoretisch möglichen, obwohl begrenzten, Kontrollmöglichkeiten durch die EU-Kommission, das EU-Parlament und den EuGH umgangen, genauso wie auch eine Debatte und Kompromissfindung zwischen den Mitgliedstaaten im Rat.

584 Vgl. Pörschke, Der Grundsatz der Verfügbarkeit von Informationen am Beispiel des Prümer Modells, 157-158 und Prainsack, Barbara; Toom, Victor, The Prüm Regime: Situated Dis/Empowerment in Transnational DNA Profile Exchange, in: The British Journal of Criminology, 50/6, 2010, 1117-1135.

585 PB, Präambel, Ziff. 12, vgl. auch oben Abschnitt 3.1. 
Die Bezugnahme auf die Sicherheitsproblematik hat in diesem Fall als stärkender Faktor des politischen Willens einer kleinen Gruppe von Staaten (darunter besonders stark Deutschland) gedient, um die eigenen Interessen und Wünsche bezüglich der europäischen Kooperation im strafrechtlichen Bereich durchzusetzen. Diese Vorgehensweise hat zunächst die Intensivierung der polizeilichen und justiziellen Zusammenarbeit in der EU bzw. die Supranationalisierung der EU geschwächt. Die Intensivierung der Zusammenarbeit in der polizeilichen und justiziellen Zusammenarbeit wurde geschwächt, weil die Prümer Maßnahmen zurückhaltender sind als ähnliche, konkurrierende Initiativen, die aufgrund der Durchsetzung der Prümer Maßnahmen nicht weiterverfolgt wurden, insbesondere der Kommissionsvorschlag für den Austausch von Informationen nach dem Prinzip der Verfügbarkeit. Der Vorschlag der Kommission hätte vor allem den nicht automatisierten Informationsaustausch nach einem Treffer erleichtert, weil dies aufgrund europarechtlicher Normen anstatt nationalen Rechts erfolgt wäre. Außerdem hätte der Vorschlag der Kommission auch Europol den Zugriff auf die Datenbanken ermöglicht. Die Art, wie die Prümer Maßnahmen eingeführt wurden, hat zudem den Prozess der Supranationalisierung der EU zunächst geschwächt, weil die EU-Institutionen nicht in den Entscheidungsprozess miteinbezogen wurden.

Obwohl der Datenaustausch auf europäischer Ebene noch weitreichender hätte sein können, verfügen die EU-Mitgliedstaaten nun tatsächlich über ein effektiveres System für den Datenaustausch als früher. In diesem Sinne hat Prüm letztendlich der Intensivierung der Zusammenarbeit im RFSR gedient und damit den Prozess der Supranationalisierung der EU gestärkt.

Die EU-Mitgliedstaaten müssen nun aufgrund von EU-Normen sehr sensible Daten erheben, speichern und miteinander austauschen. In den Ländern, die erst aufgrund von Prüm nationale DNA-Datenbanken errichten mussten, bedeutet das auch eine Ausweitung der Befugnisse bezüglich der Erhebung und Speicherung von Daten, und nicht nur ihres Austauschs. Kommen sie diesen neuen Pflichten gegenüber der EU, die gleichzeitig auch eine Ausweitung der Machtbefugnisse gegenüber den eigenen Bürger_innen darstellen, nicht nach, kann die EU-Kommission ein Vertragsverletzungsverfahren gegen sie einleiten. Die EU-Kommission hat also gegenüber den Mitgliedstaaten das Recht, die Umsetzung der Prümer Maßnahmen zu erzwingen.

Diese Ausweitung der staatlichen und europäischen Machtbefugnisse ist durch ein Verfahren entstanden, bei dem die demokratischen und juristischen Kontrollen, die im Rahmen der Einführung von Normen durch ein 
nationales oder europäisches Verfahren gewirkt hätten, umgangen worden sind.

Angesichts der erforderlichen Legitimation dieser Maßnahmen ist das ein schwerwiegendes Problem, vor allem in Bezug auf das im zweiten Kapitel dieses Buches eingeführte Kriterium der Verfahrenskonformität. Wie auch schon im Falle des SIS sind die institutionellen und rechtlichen Vorgaben im Namen der Sicherheit forciert worden. Dabei hat sich eine kleine Gruppe von Staaten des „Machtkatalysators Sicherheit“ bedient, wodurch letztendlich die Machtbefugnisse der EU und ihr supranationaler Charakter gestärkt wurden. 


\section{Kapitel 6 Mobilität und Sicherheit: Passagierdaten als Risikoindikatoren nach der PNR-Richtlinie}

\section{Die Fluggastdatensätze-Richtlinie (PNR-Richtlinie): zentralisierte Speicherung von Fluggastdaten auf nationaler Ebene}

Die EU-Richtlinie von 2016 über die Verwendung von Fluggastdatensätzen $^{586}$ schreibt die Übermittlung, Speicherung und Verarbeitung von Informationen über Fluggäste vor, die in die oder aus der EU fliegen. ${ }^{587}$ Diese Daten werden in den Mitgliedstaaten zentralisiert gespeichert und verarbeitet und sowohl präventiv als auch reaktiv zur Bekämpfung terroristischer Straftaten und schwerer Kriminalität verwendet. Die Richtlinie schreibt nicht vor, ein zentralisiertes Informationssystem auf EU-Ebene aufzubauen; ihr Ziel ist es vielmehr, dafür zu sorgen, dass die Speicherung von Daten auf nationaler Ebene zentralisiert erfolgt und, durch die Verwendung einheitlicher Datenformate und gemeinsamer Protokolle, dass der Informationsaustausch zwischen den Staaten und mit Europol erleichtert wird. Dafür müssen die Mitgliedstaaten Zentralstellen einrichten, die bei einer Sicherheitsbehörde angesiedelt sein sollen. Nach Angaben der Kommission hatten im Mai 2020 insgesamt 24 von 26 Mitgliedstaaten die PNR-Richtlinie vollständig umgesetzt. 588

Fluggastdatensätze sind Informationen, die Fluggesellschaften bei der Buchung erheben und die unter anderem Name, Anschrift, Zahlungsinformationen, Reiseverlauf, Gepäckinformationen, Mitreisende, Sitzplatzinformationen sowie andere allgemeine Hinweise enthalten. Nach der Richtlinie müssen die Fluggesellschaften diese Informationen über alle Reisen-

586 Richtlinie (EU) 2016/681 des Europäischen Parlaments und des Rates vom 27.04.2016 über die Verwendung von Fluggastdatensätzen (PNR-Daten) zur Verhütung, Aufdeckung, Ermittlung und Verfolgung von terroristischen Straftaten und schwerer Kriminalität, Amtsblatt der EU L 119/132 vom 27.04.2016.

587 Optional können auch Daten über Passagier_innen von Flügen innerhalb der EU gespeichert und verarbeitet werden, vgl. Abschnitt 3 unten.

588 Bericht der Kommission an das Europäische Parlament und den Rat über die Überprüfung der Richtlinie (EU) 2016/681 über die Verwendung von Fluggastdatensätzen (PNR-Daten) zur Verhütung, Aufdeckung, Ermittlung und Verfolgung von terroristischen Straftaten und schwerer Kriminalität, COM(2020) 305 final, 24.07.2020, 5 . 
den von Flügen, die zwischen Mitgliedstaaten und Drittstaaten fliegen, im Voraus (d. h. vor dem Abflug) an die Zentralstelle im Abflugs- oder Zielmitgliedstaat übermitteln. Die Daten werden von den Zentralstellen mit anderen Datenbanken, aber auch mit von der Zentralstelle selbst entwickelten Mustern abgeglichen.

Während der Abgleich mit anderen Datenbanken dazu dienen soll, gesuchte Personen zu identifizieren, zielt der Abgleich mit Mustern darauf $\mathrm{ab}$, potenzielle und davor unbekannte Verdächtige zu identifizieren. Mit dieser Möglichkeit der Profilherstellung wird eine neue Dimension in die Landschaft des europäischen Datenaustauschs eingeführt. Aufgrund der möglichen Inkompatibilität einer solchen Datenverwendung mit der Charta der Grundrechte der EU und mit dem primären EU-Recht haben 2019 und 2020 verschiedene Gerichte aus EU-Mitgliedstaaten ein Vorabentscheidungsersuchen an den EuGH vorgelegt. ${ }^{589}$ Eine negative Entscheidung des EuGH könnte, wie schon im Fall der Richtlinie zur Vorratsdatenspeicherung, zu einer Annullierung der PNR-Richtlinie führen. ${ }^{590}$

Im Folgenden werde ich die zeitliche Entwicklung der Maßnahmen im Kontext der weltweiten Verschärfung von Normen zur Terrorismusbekämpfung rekonstruieren (Abschnitt 2). Im dritten Abschnitt werde ich dann den konkreten Inhalt der PNR-Richtlinie präsentieren. Im darauffolgenden Abschnitt 4 werde ich die Rechtfertigungsargumente sowie die erwartete Effektivität der Maßnahmen präsentieren und diskutieren. Im fünften Unterteil werde ich dann verdeutlichen, wie die Verabschiedung der Richtlinie sich im institutionellen EU-Rahmen integriert hat und wie die verschiedenen europäischen und nationalen Organe der Legislative, Exekutive und Judikative mitgewirkt haben. Schließlich diskutiere ich im sechsten Abschnitt einige problematische Aspekte, die aus der Verwendung von Mobilitätsdaten für kriminalistische Zwecke entstehen. Dieser

589 Bei den ersuchenden Gerichten handelt es sich um den belgischen Verfassungsgerichtshof, das Amtsgericht Köln, das Verwaltungsgericht Wiesbaden und das Verfassungsgericht der Republik Slowenien. Vgl. respektive Rechtssache C-817/19, verbundene Rechtssachen C-148/20 bis C-150/20, C-215/20 und C-222/20 und schließlich C-486/20.

590 Richtlinie 2006/24/EG des Europäischen Parlaments und des Rates vom 15.03.2006 über die Vorratsspeicherung von Daten, die bei der Bereitstellung öffentlich zugänglicher elektronischer Kommunikationsdienste oder öffentlicher Kommunikationsnetze erzeugt oder verarbeitet werden, und zur Änderung der Richtlinie 2002/58/EG, Amtsblatt der Europäischen Union L 105/54 vom 13.04.2006 und Urteil des Gerichtshofs (Große Kammer) vom 08.04.2014, Digital Rights Ireland Ltd, verbundene Rechtssachen C-293/12 und C-594/12. 
Unterteil, vervollständigt durch einen Exkurs zum Begriff der algorithmischen Regulierung, verdeutlicht zudem, welche weiteren Fragestellungen die Anwendung von künstlicher Intelligenz für die Auswertung der Daten aufwerfen könnte.

\section{Im Schatten der Terrorismusbekämpfung: die Entstehung der EU-Normen und der internationalen PNR-Abkommen}

Der erste Vorschlag für die Einführung einer Regelung auf EU-Ebene für die Speicherung und Verwendung von Fluggastdatensätzen geht auf das Jahr 2007 zurück. Damals erließ die Kommission einen Vorschlag für einen Rahmenbeschluss des Rates „über die Verwendung von Fluggastdatensätzen (PNR-Daten) zu Strafverfolgungszwecken“. ${ }^{591}$ Mit der Veränderung des EU-Gesetzgebungsverfahrens, die das Inkrafttreten des Vertrags von Lissabon im Jahr 2009 mit sich brachte, verfiel der Vorschlag der Kommission. Im Stockholmer Programm ${ }^{592}$ forderte der Europäische Rat die Kommission auf, einen erneuten Vorschlag gemäß der neuen Rechtslage vorzulegen. Daraufhin verwandelte die Kommission 2011 ihren ersten Vorschlag in einen Richtlinienvorschlag, der auch inhaltliche Änderungen beinhaltete. ${ }^{593}$ Wie schon der vorherige Vorschlag wurde auch dieser mit Kritik seitens des EU-Parlaments und anderer institutioneller Vertreter der EU konfrontiert. Dementsprechend lehnte das Parlament den Vorschlag im Jahr $2013 \mathrm{ab}$, sodass das Gesetzgebungsverfahren auf Eis gelegt wurde. 594

Unmittelbar nach den terroristischen Anschlägen von Paris im Januar 2015 wurde der Vorschlag wieder aufgegriffen, und das neue politische

$591 \operatorname{COM}(2007) 654$ final, 06.11.2007.

592 „Ein offenes und sicheres Europa im Dienste und zum Schutz der Bürger“, Dok. Nr. 17024/09 vom 02.12.2009; vgl. auch Kapitel 3.

593 Vorschlag für eine Richtlinie des Europäischen Parlaments und des Rates über die Verwendung von Fluggastdatensätzen zu Zwecken der Verhütung, Aufdeckung, Aufklärung und strafrechtlichen Verfolgung von terroristischen Straftaten und schwerer Kriminalität, $\operatorname{COM(2011)~} 32$ final, 02.02.2011.

594 Vgl. Bericht des Europäischen Parlaments vom 09.04.2013 über den Vorschlag für eine Richtlinie des Europäischen Parlaments und des Rates über die Verwendung von Fluggastdatensätzen zu Zwecken der Verhütung, Aufdeckung, Aufklärung und strafrechtlichen Verfolgung von terroristischen Straftaten und schwerer Kriminalität, COM(2011)0032 - C7-0039/2011 - 2011/0023(COD), Dok. A7-0150/2013, Ausschuss für bürgerliche Freiheiten, Justiz und Inneres, Berichterstatter: Timothy Kirkhope. 
Klima ebnete den Weg für die Wiederaufnahme der Verhandlungen und schließlich für die Verabschiedung der Fluggastdatensätze-Richtlinie im April 2016.595

Die Richtlinie ist seit Mai 2016 in Kraft und verpflichtet die Mitgliedstaaten, die notwendigen Vorschriften zu erlassen, damit die von der Richtlinie vorgesehenen Maßnahmen bis zum 25. Mai 2018 realisiert werden können. Deutschland hat bereits im Juni 2017 ein entsprechendes Gesetz verabschiedet. ${ }^{596}$ Zwei Jahre nach Ablauf der Frist hatten wie erwähnt insgesamt 24 Mitgliedstaaten die PNR-Richtlinie vollständig umgesetzt. 597

Zusätzlich zu den eigenen Regelungen hat die EU bereits 2004 auf Initiative der USA mit diesen ein Abkommen über die Übermittlung von PNR-Daten geschlossen. Nach dem dieses vom EuGH aufgrund der falschen rechtlichen Grundlage für nichtig erklärt wurde, schloss die EU 2007 und 2011 zwei neue Abkommen mit den USA. Die EU-USA-Verträge regeln zwar die Übermittlung der Daten von Passagieren, die aus der EU in die USA reisen, an die USA-Behörde, aber nicht umgekehrt. Behörden der EU-Länder, die Zugriff auf die Daten haben wollen, müssen einen Antrag bei der zuständigen US-amerikanischen Behörde stellen. ${ }^{598}$

Auch mit Australien und Kanada hat die EU Abkommen für die Übermittlung von Fluggastdatensätzen unterschrieben. Das Abkommen mit Kanada ist aber nie in Kraft getreten, weil das EU-Parlament im Jahr 2014 entschied, ein Gutachten des EuGH über die Vereinbarkeit des Abkommens mit der Grundrechte-Charta der EU einzuholen. Der EuGH stellte infolgedessen 2017 fest, dass das Abkommen nicht geschlossen werden darf, was auch Konsequenzen für die bestehenden Abkommen mit den

595 Über die zahlreichen Initiativen, die unmittelbar nach den Anschlägen von Paris vom Januar 2015 unternommen wurden, vgl. Bigo, Didier et al., The EU Counter-Terrorism Policy Responses to the Attacks in Paris: Towards an EU Security and Liberty Agenda, CEPS Papers in Liberty and Security in Europe, Nr. 81, 2015.

596 Gesetz über die Verarbeitung von Fluggastdaten zur Umsetzung der Richtlinie (EU) 2016/681 (Fluggastdatengesetz - FlugDaG) vom 06.06.2017 (BGBl. I S. 1484).

597 Bericht der Kommission an das Europäische Parlament und den Rat über die Überprüfung der Richtlinie (EU) 2016/681, COM(2020) 305 final, 24.07.2020, 5 .

598 Vgl. Blasi Casagran, Cristina, The Future EU PNR System: Will Passenger Data Be Protected?, in: European Journal of Crime, Criminal Law and Criminal Justice, 23, 2015, 241-257. 
USA und Australien haben könnte. ${ }^{599} 2015$ wurden Verhandlungen mit Mexiko für ein mögliches PNR-Abkommen aufgenommen, während 2020 die Kommission vom Rat ermächtigt wurde, Verhandlungen mit Japan aufzunehmen. ${ }^{600}$

Unabhängig von der PNR-Richtlinie und den internationalen Abkommen besteht seit 2004 für die Grenzschutzbehörden der EU-Mitgliedstaaten die Möglichkeit, Daten über Passagiere zu erhalten, die über die Schengen-Außengrenzen in die EU fliegen. Diese Daten (auch API, „Advance Passenger Information “, genannt) werden ebenfalls von den Fluggesellschaften übermittelt und erfassen neben Namen, Geburtsdatum und Staatsangehörigkeit auch Informationen über Reisedokumente, Angaben zur Reiseroute und Anzahl der Mitreisenden. Sie werden aber nicht immer, sondern nur auf Anfrage der Grenzbehörden übermittelt und müssen, wenn nicht für weitere Zwecke wie z. B. die Verwendung in Strafverfahren benötigt, 24 Stunden nach der Einreise gelöscht werden. ${ }^{601}$

\section{Inhalt der PNR-Richtlinie: Übermittlung, Speicherung und Überarbeitung von Fluggastinformationen zu kriminalistischen Zwecken}

Wie bei EU-Richtlinien üblich, richtet sich auch die FluggastdatensätzeRichtlinie an die Mitgliedstaaten. Diese müssen die notwendigen nationalen Rechtsvorschriften erlassen, um die in der Richtlinie vorgesehenen Maßnahmen umzusetzen.

599 Vgl. Eintrag „Passenger Name Record (PNR)“ auf der Webseite der EU-Kommission und Gerichtshof der Europäischen Union, Pressemitteilung Nr. 84/17, Gutachten 1/15, vom 26.07.2017. Für beide PNR-Abkommen wurde 2019 eine Überprüfung eingeleitet, welche deren Implementierung, Effektivität und Notwendigkeit bewerten soll. Vgl. European Commission, Commission Staff Working Document Accompanying the Document Report from the Commission to the European Parliament and the Council on the Review of Directive 2016/681 on the use of passenger name record (PNR) data for the prevention, detection, investigation and prosecution of terrorist offences and, $\operatorname{SWD}(2020)$ 128 final, 24.07.2020, 4.

600 Vgl. Bericht der Kommission an das Europäische Parlament und den Rat über die Überprüfung der Richtlinie (EU) 2016/681, COM(2020) 305 final, 24.07.2020, 3.

601 Vgl. Richtlinie 2004/82/EG des Rates vom 29.04.2004 über die Verpflichtung von Beförderungsunternehmen, Angaben über die beförderten Personen zu übermitteln, Amtsblatt der Europäischen Union L 261/24 vom 06.08.2004. 
Ziel der Fluggastdatensätze-Richtlinie ist es, einen Beitrag zur Gewährleistung der inneren Sicherheit zu leisten, indem sie eine neue Herangehensweise zur Bekämpfung von Terrorismus und schwerer Kriminalität auf EU-Ebene etabliert. Die Verwendung von PNR-Daten soll erlauben, Personen zu ermitteln, die potenziell mit terroristischen oder anderen schweren Straftaten in Verbindung stehen, die aber vor der Datenauswertung nicht als Verdächtigte bekannt waren ${ }^{602}$ Gleichzeitig zielt die Richtlinie darauf ab, „einen Rechtsrahmen für den Schutz von PNR-Daten im Bezug auf deren Verarbeitung durch die zuständigen Behörden zu schaffen". .03

Die Fluggastdatensätze-Richtlinie schreibt vor, dass Mitgliedstaaten Fluggesellschaften, die Drittstaatsflüge betreiben, verpflichten, die von ihnen gesammelten Daten einer nationalen Zentralstelle zu übermitteln. Darüber hinaus regelt die Richtlinie die Verarbeitung von diesen Daten durch die nationale Zentralstelle und den Datenaustausch zwischen den Mitgliedstaaten sowie den mit Europol und Drittstaaten. Schließlich begrenzt die Richtlinie die Zwecke der Datenverarbeitung auf die Verhütung, Aufdeckung, Ermittlung und Verfolgung von Terrorismus und schwerer Kriminalität. ${ }^{604}$

Die Verpflichtung zur Datenübermittlung gilt nur für „Drittstaatsflüge“, d. h. für Flüge, die zwischen einem Drittstaat und einem Mitgliedstaat stattfinden. Bei Umsetzung der Richtlinie dürfen jedoch die Mitgliedstaaten darüber entscheiden, diese Verpflichtung eventuell auch auf Flüge innerhalb der EU auszuweiten. ${ }^{605}$ Alle außer einem der zum Zeitpunkt des ersten Kommissionsberichts teilnehmenden 24 Staaten haben sich für die Erweiterung auf EU-Binnenflüge entschieden, darunter auch Deutschland. ${ }^{606}$

Um die zentralisierte Speicherung und Verarbeitung der Fluggastdaten zu ermöglichen, müssen die Mitgliedstaaten Zentralstellen einrichten. Die-

602 Vgl. Richtlinie (EU) 2016/681, Ziff. 5 und 7.

603 Ebd., Ziff. 5.

604 Vgl. ebd., Art. 1.

605 Vgl. ebd., Art. 2.

606 Vgl. Bericht der Kommission an das Europäische Parlament und den Rat über die Überprüfung der Richtlinie (EU) 2016/681, 11. Spezifisch für Deutschland vgl. Gesetz über die Verarbeitung von Fluggastdaten zur Umsetzung der Richtlinie (EU) 2016/681 (Fluggastdatengesetz - FlugDaG) vom 06.06.2017 (BGBl. I S. 1484), $\$ 2$ Abs. 3 . 
se müssen bei einer Behörde angesiedelt sein, die für die Bekämpfung von terroristischen Straftaten und schwerer Kriminalität verantwortlich ist. ${ }^{607}$

An diese Zentralstelle müssen Fluggesellschaften die Daten weiterleiten, die sie zwar im Rahmen ihres üblichen Geschäfts bereits erhoben, bisher aber nur für betriebliche Zwecke genutzt haben. Diese Daten werden 24 bis 48 Stunden vor dem geplanten Abflug und direkt, nachdem alle Fluggäste an Bord des Flugzeugs gegangen sind, übermittelt. ${ }^{608}$

Die von der nationalen Zentralstelle erhobenen Daten werden für die Überprüfung der Fluggäste verwendet. Einerseits werden diese Daten mit dem Bestand anderer Datenbanken, die für die Bekämpfung von Terrorismus und schwerer Kriminalität betrieben werden (wie etwa das SIS), abgeglichen. Andererseits werden sie anhand von Kriterien bewertet, welche die Zentralstelle selbst entwickelt und die dazu dienen sollen, potenzielle Verdächtige zu ermitteln, die in terroristische Straftaten oder schwere Kriminalität involviert sein könnten. Die Treffer, die so erzielt werden, müssen individuell und auf nicht automatisierte Weise geprüft werden, bevor konkrete Maßnahmen gegen die Betroffenen eingeleitet werden. Die übermittelten Datensätze werden zudem analysiert, um die Abgleichmuster weiterzuentwickeln und zu modifizieren. ${ }^{609}$

Alle „relevanten und erforderlichen“610 Daten oder Ergebnisse der Datenverarbeitung werden von dem erhebenden Staat an die anderen Mitgliedstaaten übermittelt. Nach Abfrage können diese Informationen auch an Europol und unter besonderen Bedingungen auch an Drittstaaten weitergegeben werden. ${ }^{611}$

Die erhobenen Daten werden bei der Zentralstelle fünf Jahre lang gespeichert. Nach sechs Monaten erfolgt eine Depersonalisierung der Daten: Elemente, die eine unmittelbare Identifizierung der Fluggäste ermöglichen, werden unkenntlich gemacht. Die Identifizierung der Fluggäste bleibt aber möglich und kann nach Genehmigung einer Justizbehörde oder einer anderen zuständigen Behörde erfolgen. ${ }^{612}$

Zugang zu den Daten haben Behörden, die zuständig für die „Verhütung, Aufdeckung, Ermittlung oder Verfolgung von terroristischen Strafta-

607 Vgl. Richtlinie (EU) 2016/681, Art. 3. In Deutschland ist die Zentralstelle beim BKA angesiedelt.

608 Vgl. Richtlinie (EU) 2016/681, Art. 8.

609 Vgl. ebd., Art. 6.

610 Ebd., Art. 9, Ziff. 1.

611 Vgl. ebd., Art. 10-11.

612 Vgl. ebd., Art. 12. 
ten oder schwerer Kriminalität"613 sind. Welche Behörden dies in jedem Staat sind, wird von jedem Staat in einer Liste, die der Kommission mitgeteilt wird, festgelegt. Die Informationen dürfen ausschließlich für die Bekämpfung terroristischer Straftaten und schwerer Kriminalität verwendet werden. Falls jedoch durch die Verarbeitung der Daten für diese Zwecke andere Straftaten festgestellt oder vermutet werden, dürfen die Informationen auch für die Verfolgung anderer Arten von Straftaten benutzt werden. ${ }^{614}$

Die Kosten für den Betrieb der Zentralstelle, die Speicherung, Verarbeitung und den Austausch der Daten werden von den Mitgliedstaaten getragen. ${ }^{615}$

\section{Rechtfertigungsargumente und Effektivität der PNR-Richtlinie zur Bekämpfung von Terrorismus und schwerer Kriminalität}

\subsection{Die Ansicht der Kommission}

In der Begründung zum Richtlinienvorschlag von $2011^{616}$ erwähnt die Kommission verschiedene Gründe, die aus ihrer Sicht die Umsetzung der Richtlinie unerlässlich machen. Diese können unter vier Themenbereiche subsumiert werden.

Die erste Begründung bezieht sich auf den grenzüberschreitenden Charakter des Terrorismus und der organisierten Kriminalität. Beide Verbrechensformen sind mit Reisen in andere Länder verbunden, im ersten Fall vor allem für den Besuch terroristischer Ausbildungslager außerhalb der EU, im zweiten Fall meistens, um Menschen, Drogen oder Waffen in die EU einzuschleusen bzw. zu schmuggeln.

Zweitens weist die Kommission auf Lücken in den bereits existierenden Informationssystemen hin. Sowohl das SIS II als auch das VIS haben sich aus Sicht der Kommission als erfolgreich erwiesen. Wie auch das (damals erst geplante) Einreise-/Ausreisesystem ermöglichten sie jedoch zu der Zeit nur die Identifizierung von bereits bekannten Verdächtigen. ${ }^{617}$

613 Richtlinie (EU) 2016/681, Art. 7, Ziff. 1 und 2.

614 Vgl. Richtlinie (EU) 2016/681, Art. 7, Ziff. 4 und 5.

615 Vgl. ebd., Ziff. 14.

$616 \operatorname{COM}(2011) 32$ final, 02.02.2011.

$617 \mathrm{Zu}$ den Möglichkeiten der Suche anhand von biometrischen Daten im SIS, vgl. Kapitel 4 oben, Abschnitte 3.3 und 6.3. 
Die Verwendung von PNR-Daten ergänzt die Strategien zur Bekämpfung der oben genannten Kriminalitätsformen um einen neuen Ansatz, indem sie auch die Ermittlung von „bisher unbekannten Verdächtigen“618 ermöglicht. Die Kommission nennt hierzu zwei Fälle aus den EU-Mitgliedstaaten, die offenbar damals bereits PNR-Systeme betrieben. In diesen zwei Fällen konnten vorher nicht verdächtigte Straftäter durch die Verwendung von PNR-Daten identifiziert werden. ${ }^{619}$ Über die Effektivität der Auswertung der Fluggastdatensätze für Strafverfolgungszwecke im Allgemeinen zitiert die Kommission Daten aus Belgien, Schweden und Großbritannien, demnach die meisten Drogensicherstellungen ,ausschließlich oder maßgeblich" aufgrund der Verwendung von PNR-Daten erfolgten (nach Angaben der Kommission war dies in Belgien im Jahr 2009 für $95 \%$ aller Drogensicherstellungen der Fall). ${ }^{620}$

Drittens besteht für die Kommission ein weiterer Vorteil der Verwendung der PNR-Daten darin, dass das Risiko von diskriminierenden Kontrollen durch Grenzschutz-, Zoll- und Strafverfolgungsbeamt_innen verringert wird. Personen, die näher überprüft werden sollten, werden nicht mehr aufgrund von Hautfarbe oder Staatsangehörigkeit ausgewählt, sondern aufgrund von „objektiven Prüfkriterien“621 und der bisherigen Erfahrung.

Schließlich strebt die Kommission durch ihren Vorschlag eine Harmonisierung der Rechtslage auf europäischer Ebene an. Insbesondere möchte die Kommission verhindern, dass sich in der Europäischen Union 27 unterschiedliche Regelungen für die Benutzung der Fluggastdatensätze entwickeln.

Der Kommissionsvorschlag enthält zudem eine kurze Folgenabschätzung verschiedener Szenarien, die unter anderem auch die Beibehaltung des Status quo einerseits und die Ausweitung der Datensammlung und -verwendung im Schiffs- und Bahnverkehr andererseits vorsieht. ${ }^{622}$ Aus der Analyse ergibt sich laut Kommission, dass die im Vorschlag vorgestellte Option die beste Alternative darstellt.

$618 \operatorname{COM}(2011) 32$ final, 02.02.2011, 4.

619 Vgl. ebd., 5-6. In der Begründung wird jedoch nicht spezifiziert, um welche Mitgliedstaaten es geht.

620 Ebd., 6.

621 Ebd., 6.

622 Letztere Option wurde in Belgien implementiert, wo auch der Schiffs-, Bahnund Busverkehr erfasst werden. Vgl. Loi du 25 décembre 2016 relative au traitement des données des passagers, Moniteur Belge, 25.01.2017, 12905-12918. 


\section{2 Überprüfung der Rechtfertigungsargumente und Ergebnisse der ersten Umsetzungsevaluation}

In diesem Abschnitt werde ich die Begründungen der Kommission überprüfen und fragen, ob sie in der Lage sind, die in ihrem Vorschlag enthaltenen Maßnahmen zu rechtfertigen.

Bezüglich der Effektivität der Verwendung von PNR-Daten zur Kriminalitätsbekämpfung haben die von der Kommission zitierten konkreten Beispiele - die oben erwähnten beiden Fälle aus den Mitgliedstaaten anekdotischen Charakter. Die statistischen Ergebnisse, die die Kommission ebenfalls aufführt, etwa über die Drogenbeschlagnahmungen, werden gebracht, ohne wirklich erklärt zu werden. Die niederländische Juristin Evelien Brouwer weist zudem auf den Widerspruch hin, dass die Kommission Daten aus Belgien zitiert, obwohl Belgien zu der Zeit kein System für die Nutzung der PNR-Daten hatte. ${ }^{623}$

Zudem beziehen sich die von der Kommission präsentierten Daten nur auf die Drogenkriminalität und sagen nichts über die Effektivität der Analyse der Fluggastdatensätze für die Bekämpfung anderer Formen schwerer Kriminalität oder des Terrorismus aus. ${ }^{624}$ Tatsächlich fehlen bislang allgemein Studien zur Effektivität der Verwendung von Fluggastdaten für die Kriminalitätsbekämpfung, trotz deren langjähriger Verwendung in anderen Staaten, wie den USA, Großbritannien oder Australien. ${ }^{625}$ Aus Anlass der Anhörung zum deutschen Gesetzentwurf konnte auch der Präsident des BKA nur allgemein auf positive Erfahrungen anderer Länder hinweisen, ohne jedoch konkrete Studien zu zitieren. ${ }^{626}$ Zur Effektivität der Verwendung von Passagierdaten bei der Terrorismusbekämpfung be-

623 Vgl. Brouwer, Evelien, Ignoring Dissent and Legality. The EU's proposal to share the personal information of all passengers, CEPS Paper in Liberty and Security in Europe, June 2011, 2-3.

624 Vgl. dazu auch die Stellungnahme der Digitalen Gesellschaft e.V. vom 20.04.2017 zum Entwurf eines Gesetzes über die Verarbeitung von Fluggastdaten zur Umsetzung der Richtlinie (EU) 2016/681 (Fluggastdatengesetz - FlugDaG), Drucksache 18/11501, Ausschussdrucksache 18(4)869 B vom 24.04.2017.

625 Vgl. Rademacher, Timo, Predictive Policing im deutschen Polizeirecht, in: Archiv des öffentlichen Rechts (AöR), 142/3, 2017, 366-416, hier 372.

626 Vgl. Bundeskriminalamt, Anhörung des Präsidenten des Bundeskriminalamtes Holger Münch vor dem Innenausschuss des Bundestages am 24.04.2017 zum Entwurf eines Fluggastdatengesetzes (FlugDaG), Drucksache 18/11501, Ausschussdrucksache 18(4)869 D vom 24.04.2017, 2. 
stehen zudem prinzipielle Zweifel, die in der technischen Funktionalität des Systems gründen. ${ }^{627}$

Der Mangel an messbaren statistischen Ergebnissen setzt sich auch in dem ersten Überprüfungsbericht fort, den die Kommission im Juli 2020 vorgelegt hat und der sich auf die ersten zwei Jahre der Anwendung der PNR-Richtlinie bezieht. ${ }^{628}$ Obwohl dort die Kommission betont, dass nach Angaben der Mitgliedstaaten die Verwendung der PNR-Daten ein effektives Mittel in der Bekämpfung der Kriminalität darstellt, werden keine Zahlen, etwa über den erfolgreich abgeschlossenen Ermittlungen oder erfolgten Festnahmen, genannt. ${ }^{629}$ Dabei haben die Mitgliedstaaten nach Art. 20 der Richtlinie die Pflicht, Statistiken über die Implementierung der PNR-Richtlinie zu führen und an die Kommission mitzuteilen. Diese Statistiken standen der Kommission zur Zeit der Verfassung des Berichts bereits zur Verfügung, sodass es möglich gewesen wäre, sie zu verwenden. Stattdessen relativiert die Kommission die eigenen Angaben über die Nützlichkeit der PNR-Daten, indem sie schreibt, die Statistiken der einzelnen Staaten könnten keine "harte quantitative Analyse"630 ermöglichen, da sie sehr heterogen seien. Zudem sei es oft unmöglich, festzustellen, welche kriminalistischen Erfolge allein auf die Verwendung von PNR-Daten zurückzuführen seien. ${ }^{631}$ Letztendlich weist die Kommission zur Bekräftigung ihrer Erfolgseinschätzung wieder auf Einzelfälle und Anekdoten hin. ${ }^{632}$

Bezüglich des zweiten Arguments der Kommission, nämlich der Verringerung des Diskriminierungsrisikos, kann Folgendes angemerkt werden. Zunächst bleiben Grenzkontrollen durch Beamt_innen und damit das von der Kommission eingeräumte Risiko von diskriminierenden Kontrollen erhalten, da die Verwendung von PNR-Daten die Grenzkontrolle durch Beamt_innen nicht ersetzt. Zweitens, auch wenn die Anzahl der Kontrol-

627 Vgl. Pelzer, Robert, Policing of Terrorism Using Data from Social Media, in: European Journal for Security Research, 3/2, 2018, 163-179; ausführlicher dazu unten Abschnitt 6.3.1.

628 Bericht der Kommission an das Europäische Parlament und den Rat über die Überprüfung der Richtlinie (EU) 2016/681.

629 Ebd., 8.

630 Bericht der Kommission an das Europäische Parlament und den Rat über die Überprüfung der Richtlinie (EU) 2016/681, 11.

631 Ebd.

632 Ebd., Fußnote 18, welche auf das Commission Staff Working Document Accompanying the Document Report from the Commission, SWD(2020) 128 final, 29-30 und 32-33, verweist. 
len durch Beamt_innen durch die Verwendung der PNR-Daten abnehmen würde, werden potenzielle Diskriminierungen lediglich in Raum und Zeit verschoben, nämlich von den Grenzkontrollen zur Aktivität der Zentralstellen, sie verschwinden jedoch nicht. Denn auch die Datenverwendung durch die nationalen Zentralstellen führt ebenfalls zu Entscheidungen über Individuen (Verweigerung der Einreise oder Fortsetzung der Ermittlungen), auch aufgrund von Musterabgleichen alias Profiling. ${ }^{633}$

Zwar bekräftigt die Kommission in ihrem ersten Überprüfungsbericht, dass die PNR-Daten nicht zur „individualisierten Profilherstellung“ verwendet werden, sondern zur Erstellung von „abstrakten Profilen““.634 Jedoch wird weder in dem Bericht noch in dem zugrunde liegenden Arbeitspapier erklärt, wo der Unterschied zwischen den beiden liegt und inwiefern die Einstufung der Passagiere in verschiedene Risikokategorien und die Identifizierung von „Fluggästen mit hohem Risiko“635 sowie die Integration von Daten über Route, Zahlungsart und Gepäck eines bzw. einer Reisenden sich von einer „individualisierten Profilerstellung“ unterscheidet.

Wie sich aus einer Stellungnahme aus Deutschland ergibt, die dem EuGH vorgelegt wurde, ${ }^{636}$ werden in der Praxis Muster verwendet, die das Verbot der Erhebung sensibler Daten de facto vereiteln und zu diskriminierenden Praxen führen können. So wurde zum Beispiel von den deutschen Behördenvertreter_innen als verwendetes vorbestimmtes Kriterium für die Ermittlung von „foreign fighters“ das Fliegen in die Türkei erwähnt. Da aus Deutschland hauptsächlich Menschen mit Migrationshintergrund in die Türkei fliegen, werden durch solche Kriterien Menschen mit Migrationshintergrund, so die Stellungnahme, häufiger der Gefahr einer eingehenderen Prüfung durch die Behörden als Menschen ohne Migrationshintergrund ausgesetzt. ${ }^{637}$

633 Vgl. Brouwer, Ignoring Dissent and Legality. The EU's proposal to share the personal information of all passengers, 9-10. Mehr dazu in diesem Kapitel, Abschnitt 6.4.2.

634 Bericht der Kommission an das Europäische Parlament und den Rat über die Überprüfung der Richtlinie (EU) 2016/681, 9-10.

635 Bericht der Kommission an das Europäische Parlament und den Rat über die Überprüfung der Richtlinie (EU) 2016/681, 11.

636 Vgl. Stellungnahme zu den verbundenen Ersuchen um Vorabentscheidung C-148/20 bis C-150/20, Deutsche Lufthansa u. a. (vorlegendes Gericht: Amtsgericht Köln - Deutschland) vom 26.08.2020.

637 Ebd., 16. 
Schließlich hält auch das Argument, die Kommission strebe die Harmonisierung der nationalen Rechtslagen an, nicht stand. Zur Zeit des Kommissionsvorschlags hatten nur drei Mitgliedstaaten Rechtsvorschriften für die Verwendung von Fluggastdatensätzen, nämlich Dänemark, Frankreich und Großbritannien. ${ }^{638}$ Vielmehr bedeutete die Verabschiedung der Richtlinie für die Mehrheit der Mitgliedstaaten eine neue Verpflichtung, solche Rechtsvorschriften und die Verwendung von PNR-Daten einzuführen. Dass die Kommission in dieser Hinsicht eine treibende - nicht einfach harmonisierende - Rolle spielte, wird auch dadurch veranschaulicht, dass sie schon 2012 eine Ausschreibung für die Finanzierung der Errichtung der Zentralstellen in den Mitgliedstaaten veröffentlichte. Davon profitierten 14 EU-Länder, die 2013 eine Finanzierung in Höhe von insgesamt 50 Mio. $€$ erhielten. ${ }^{639} 2017$ folgten zusätzliche 70 Mio. $€$ für die Implementierung der PNR-Richtlinie und weitere mehr als 8 Mio. $€$ für die Finanzierung von vier Projekten, die es den nationalen Kontaktstellen ermöglichen sollen, die notwendigen operativen Fähigkeiten für den Austausch der PNR-Daten zu entwickeln. ${ }^{640}$

Die treibende Rolle der Kommission wird auch durch die Verletzungsverfahren bestätigt, welche die Kommission 2018 gegen 14 Mitgliedstaaten eröffnet hat, die der Kommission noch nicht die volle Umsetzung der PNR-Richtlinie mitgeteilt hatten. ${ }^{641} 2020$ hat zudem die Kommission eine Klage wegen der nicht erfolgten Implementierung der PNR-Richtlinie gegen Spanien vor dem EuGH erhoben. ${ }^{642}$

Zudem hat die PNR-Richtlinie auch eine große Wirkung außerhalb der EU gehabt. Die Anfragen seitens der EU wegen der Übermittlung von PNR-Daten aus Drittstaaten führten zu einer erhöhten Nachfrage vonseiten der Drittstaaten nach der Übermittlung von PNR-Daten aus der EU. Die Anfragen aus der EU haben zu einer Art Reziprozitätserwartung geführt und zu entsprechenden Vergeltungsmaßnahmen, als EU-Fluggesellschaften sich geweigert haben, PNR-Daten an Drittstaaten zu übermitteln. Die Aufnahme der Verhandlungen für ein PNR-Abkommen mit Japan

638 Vgl. Brouwer, Ignoring Dissent and Legality. The EU's proposal to share the personal information of all passengers, 4.

639 Vgl. Bakowski, Piotr; Voronova, Sofija, The proposed EU passenger name records (PNR) directive. Revived in the new security context, April 2015 Briefing, 7.

640 Vgl. Commission Staff Working Document Accompanying the Document Report from the Commission, $\operatorname{SWD}(2020) 128$ final, 7-8.

641 Vgl. ebd, 9.

642 Vgl. ebd. 
scheinen eine Folge dieser Situation zu sein. ${ }^{643}$ Die Kommission gibt keine Auskunft darüber, von welchen anderen Staaten die erhöhten Anfragen ausgingen. Würde es sich um autoritäre Staaten handeln oder um Staaten mit unzureichenden Datenschutzgarantien, wären die Implikationen für Grundrechte und -freiheiten bedeutend. Auf globaler Ebene hat der Sicherheitsrat der Vereinten Nationen zwei Resolutionen erlassen, welche eine Verpflichtung zur Sammlung, Speicherung und Übermittlung von PNR-Daten enthalten. ${ }^{644}$ Zunächst als Pflicht zum Zweck der Terrorismusbekämpfung eingeführt, wurde dann die Pflicht auf die Bekämpfung der organisierten Kriminalität ausgeweitet. Darauffolgend hat die ICAO (International Civil Aviation Organisation) im Jahr 2020 Standards für die Erhebung und Verwendung der PNR-Daten entwickelt und angenommen, die international bindenden Charakter haben. ${ }^{645}$

Schließlich erwähnt die Kommission in dem ersten Evaluationsbericht die Aspekte, welche die Effektivität der PNR-Richtlinie bisher gehemmt haben und die dementsprechend korrigiert oder ergänzt werden sollen. Erstes Desiderat ist die Ausweitung der Pflicht zur Datenübermittlung von den nationalen Zentralstellen auf die Reisebüros. Aktuell unterliegen nur Fluggesellschaften einer solchen Pflicht, ein bedeutender Anteil der Flugreservierungen wurde jedoch von Reisebüros getätigt. Diese geben oft nur die notwendigen Daten an die Fluggesellschaften weiter, nicht aber etwa die Zahlungsmodalitäten oder die Kontaktdetails. ${ }^{646}$ Des Weiteren wird die Ausweitung der Erhebung von Passagierdaten auf andere Reisemodalitäten, wie Bahn-, Fähr- und Busverkehr, erwähnt. Einige Mitgliedstaaten haben eine solche Ausweitung bereits realisiert. Auch der Rat der EU hat sich mit dieser Möglichkeit befasst und der Kommission empfohlen, diesbezüglich eine umfangreiche Folgenabschätzung durchzuführen. ${ }^{647}$ Auch die Verwendung der PNR-Daten für die Nachverfolgung

643 Vgl. Commission Staff Working Document Accompanying the Document Report from the Commission, SWD(2020) 128 final, 49.

644 Es handelt sich dabei um die UN Security Council Resolution 2396 (2017) und 2482 (2019), vgl. Commission Staff Working Document Accompanying the Document Report from the Commission, $\operatorname{SWD}(2020) 128$ final, 6-7.

645 Vgl. ebd.

646 Vgl. Bericht der Kommission an das Europäische Parlament und den Rat über die Überprüfung der Richtlinie (EU) 2016/681, 12 und Commission Staff Working Document Accompanying the Document Report from the Commission, $\operatorname{SWD}(2020) 128$ final, 38-39.

647 Vgl. ebd. und Rat der EU, Schlussfolgerungen des Rates zur Ausweitung des Umfangs der Nutzung von PNR-Daten auf andere Beförderungsformen als den Luftverkehr-vom 2. Dezember 2019, Dok. Nr. 14746/19. 
von Infektionsketten, wie zum Beispiel im Fall der COVID-19-Pandemie, wird von einigen Mitgliedstaaten als weitere Verwendung der PNR-Daten erwünscht. Schließlich wird die Einführung des Geburtsdatums als weitere verpflichtende Datenkategorie, die durch die Fluggesellschaften zu erheben und übermitteln wäre, genannt. Die Nicht-Erfassung des Geburtsdatums hat bisher bei dem Abgleich mit existierenden kriminalistischen Datenbanken zu Fehlergebnissen geführt. ${ }^{648}$ Die Kommission hat sich in all diesen Punkte zunächst dafür entschieden, von Änderungsvorschlägen der PNR-Richtlinie abzusehen und weitere Entwicklungen, insbesondere die Entscheidung des EuGH zur Vereinbarkeit mit den Grundrechten der EU, abzuwarten. ${ }^{649}$

\subsection{Kosten und Umfang der Datenübermittlung und -verarbeitung}

Dem Richtlinienvorschlag von 2011 legte die Kommission eine Folgenabschätzung bei, die auch eine Kostenkalkulation enthält. Für den Aufbau des Systems schätzt die Kommission einen Aufwand von über 614 Mio. $€$ für alle Mitgliedstaaten zusammen. Hinzu kommen nach Schätzung der Kommission jährlich 11 Mio. $€$ für Personal und 61 Mio. $€$ für die Aufrechterhaltung des Systems. Zusätzliche Kosten entstehen den Staaten für den Aufbau und den Unterhalt des Systems für den Informationsaustausch. Auch für die europäischen Fluggesellschaften werden aufgrund der Anwendung der Richtlinie mehrere hundert Mio. $€$ insgesamt fällig. ${ }^{650}$

Was die Kosten für die einzelnen Staaten angeht, wird beispielsweise für Deutschland mit Kosten in Höhe von 78 Mio. $€$ für den Aufbau der Flug-

648 Vgl. Bericht der Kommission an das Europäische Parlament und den Rat über die Überprüfung der Richtlinie (EU) 2016/681, 13. Die Fehlerquoten betreffen vor allem EU-Binnenflüge, weil für diese Flüge keine API-Daten, welche das Geburtsdatum beinhalten, erhoben werden. Eine alternative Lösung bestünde nach der Kommission in der Ausweitung der Erhebung und Übermittlung der API-Daten auf EU-Binnenflüge. Vgl. Commission Staff Working Document Accompanying the Document Report from the Commission, SWD(2020) 128 final, 43.

649 Vgl. Bericht der Kommission an das Europäische Parlament und den Rat über die Überprüfung der Richtlinie (EU) 2016/681, 14.

650 Vgl. Commission Staff Working Paper. Impact Assessment Accompanying document to the Proposal for a European Parliament and Council Directive on the use of Passenger Name Record data for the prevention, detection, investigation and prosecution of terrorist offences and serious crime, $(\mathrm{COM}(2011) 32$ final, SEC (2011) 133 final), SEC(2011) 132 final vom 02.02.2011, 39. 
gastdatenzentralstelle und jährlich 65 Mio. € für den Betrieb gerechnet. ${ }^{651}$ Es werden ca. 600 neue Stellen in der öffentlichen Verwaltung benötigt, davon bemerkenswerterweise nur zwei Stellen für die Unterstützung des Bundesdatenschutzbeauftragten. ${ }^{652}$

Einer Einschätzung des deutschen Bundesbeauftragten für Datenschutz aus dem Jahr 2017 nach beträgt die Zahl der Passagiere, deren Daten in Deutschland aufgrund des deutschen Übertragungsgesetzes jährlich gesammelt und gespeichert werden, über 170 Millionen. Darunter sind Daten von 68 Millionen Passagieren, die entweder aus Deutschland ins außereuropäische Ausland oder aus diesem nach Deutschland fliegen, während die restlichen 102 Millionen Passagiere innerhalb Europas fliegen. ${ }^{653}$

Der erste Überprüfungsbericht der Kommission enthält keine Zahlen darüber, wie viele Passagierdaten tatsächlich in den ersten zwei Jahren aufgrund der PNR-Richtlinie verarbeitet wurden. Ebenso fehlen Daten über die Quote der Falsch-Positiven, nämlich derjenigen Fluggäste, die fälschlich als „Hochrisiko-Passagiere“ eingestuft wurden. Die Quote der Falsch-Positiven ist eine Schlüsselkriterium, um die Effektivität einer Maßnahme zu evaluieren. Bemerkenswert ist, dass Art. 20 der PNR-Richtlinie,

651 Vgl. Entwurf eines Gesetzes über die Verarbeitung von Fluggastdaten zur Umsetzung der Richtlinie (EU) 2016/681 (Fluggastdatengesetz - FlugDaG), Deutscher Bundestag, Drucksache 18/11501 vom 13.03.2017, 3. Um ein Gespür für die Größenordnung zu bekommen, können die Kosten mit den geplanten Ausgaben nach dem Bundeshaushalt für das Jahr 2019 verglichen werden. So betragen etwa die jährlichen Kosten für den Betrieb der Fluggastdatenzentralstelle mehr als die geplanten Ausgaben für das Bundesverfassungsgericht und für die Bundesbeauftragte für den Datenschutz und die Informationsfreiheit zusammen (jeweils 34,34 und 25,22 Mio. €). Quelle: Bundesministerium der Finanzen, „Eckdaten und wesentliche Kennziffern zum Regierungsentwurf“, 06.07.2018.

652 Vgl. Ulbricht, Lena, When Big Data Meet Securitization. Algorithmic Regulation with Passenger Name Records, in: European Journal for Security Research, 3/2, 2018, 139-161; Arzt, Clemens, Stellungnahme zur Anhörung des Innenausschusses des Deutschen Bundestages am 26.04.2017 zum Entwurf eines Gesetzes über die Verarbeitung von Fluggastdaten zur Umsetzung der Richtlinie (EU) 2016/681 (Fluggastdatengesetz - FlugDaG) BT-Drs. 18/11501, Ausschussdrucksache 14(4)869 F, 39.

653 Vgl. Voßhoff, Andrea, Stellungnahme der Bundesbeauftragten für den Datenschutz und die Informationsfreiheit zur öffentlichen Anhörung des Innenausschusses am 24.04.2017 zum Entwurf eines Gesetzes über die Verarbeitung von Fluggastdaten zur Umsetzung der Richtlinie (EU) 2016/681 (Fluggastdatengesetz - FlugDaG) BT-Drs. 18/11501, Ausschussdrucksache 14(4)869 A vom 13.04.2017, 4. 
die den Mitgliedstaaten die Führung von Statistiken vorschreibt, keine Pflicht zur Erhebung dieses kritischen Parameters enthält. ${ }^{654}$

Der Bericht der Kommission gibt lediglich Auskunft über den Anteil der Fluggäste, für welche ein automatisierter Treffer erfolgte und die infolgedessen einer manuellen Überprüfung durch PNR-Zentralstellen unterzogen wurden. Dieser betrug 2019 0,59\% der Fluggäste. Der Anteil der Passagiere, deren Daten nach der manuellen Überprüfung von den PNR-Zentralstellen an andere Behörden weitergeleitet wurden, beträgt $0,11 \% .{ }^{655}$

\section{Die institutionellen Verhältnisse in der EU und der Einfluss der USA}

Wie ich geschildert habe, war die Kommission der Hauptakteur, der das Projekt einer Fluggastdatensätze-Richtlinie vorangetrieben hat.

Für die meisten Mitgliedstaaten, die kein PNR-System hatten und auch nicht planten, ein solches in der nahen Zukunft einzuführen, bedeutet die Verabschiedung der Richtlinie eine Auferlegung neuer (Überwachungs-) Pflichten. Diese weiten die Eingriffsmöglichkeiten der Behörden in die Grundrechte aus, insbesondere, wie der EuGH bezüglich des Abkommens mit Kanada festgestellt hat, in das Grundrecht auf Achtung des Privatlebens und in das Grundrecht auf Schutz personenbezogener Daten. ${ }^{656} \mathrm{Zu}$ -

654 Stellungnahme zu den verbundenen Ersuchen um Vorabentscheidung C-148/20 bis C-150/20, 9.

655 Vgl. Commission Staff Working Document Accompanying the Document Report from the Commission, SWD(2020) 128 final, 28. Schätzungsweise, ausgehend von einer wahrscheinlich stark unterschätzten Gesamtzahl der erfassten Passagier_innen von 100 Millionen, würden die Zahlen bedeuten, dass 590000 Fluggäste einer weiteren Überprüfung unterzogen wurden und dass die Daten von 110000 Passagier_innen an andere Behörden weitergegeben wurden. Vgl. Stellungnahme zu den verbundenen Ersuchen um Vorabentscheidung C-148/20 bis C-150/20. Die absolute Zahl der durch das BKA überprüften Fluggäste liegt für Deutschland vor, nicht aber wie erwähnt die Gesamtzahl der erfassten Passagier_innen. Die vorliegenden Daten weisen auf hohe Fehlerquoten (teilweise bis 99,6\%) hin. Vgl. die Antwort des Bundesministeriums des Innern, für Bau und Heimat auf die schriftliche Frage des Abgeordneten Thomas Nord vom 25.01.2021, 1. Februar 2021, Arbeitsnummer 1/428; die Antwort des Staatssekretärs Hans-Georg Engelke vom 4. August 2020, Deutscher Bundestag, Drucksache 19/21517, 07.08.2020, 32 und Stellungnahme zu den verbundenen Ersuchen um Vorabentscheidung C-148/20 bis C-150/20, 10.

656 Vgl. Gerichtshof der Europäischen Union, Pressemitteilung Nr. 84/17, Gutachten $1 / 15$. 
dem eröffnen sie, wie ich argumentieren werde, ${ }^{657}$ ein neues Kapitel der Regulierung im Bereich der inneren Sicherheit.

Bezüglich des Verhältnisses zu den anderen EU-Institutionen, insbesondere dem EU-Parlament und dem EuGH, wurde die Beharrlichkeit der Kommission in der Verfolgung der Richtlinie als ein Akt des Widerstandes interpretiert, der sich gegen die Reorganisierung der institutionellen EUArchitektur durch den Vertrag von Lissabon richtete. Dieser erweiterte die Bestimmungsrechte des Parlaments und stärkte die Kontrollmöglichkeiten des EuGH, wie in Kapitel 3 dargestellt. ${ }^{658}$ Das EU-Parlament hatte sich bereits zum ersten Entwurf der Kommission kritisch geäußert; seine Opposition zur Einführung der Richtlinie konnte nur unter dem Druck, der infolge der terroristischen Anschläge von Paris im Januar 2015 entstand, überwunden werden. ${ }^{659}$ Zudem stand zum Zeitpunkt der Verabschiedung der Richtlinie noch die Entscheidung des EuGH zum PNR-Abkommen mit Kanada aus. Diese fiel dann 2017 wegen Unvereinbarkeit mit der EU-Grundrechtecharta negativ aus, was nun auch Konsequenzen für die Geltung der PNR-Richtlinie haben könnte. ${ }^{660}$ Passender zur gestärkten Rolle des EuGH wäre es gewesen, wenn die Kommission für die Verabschiedung der Richtlinie auf das Gutachten des Gerichtshofes gewartet und den Richtlinienvorschlag entsprechend angepasst hätte.

Schließlich offenbart die Geschichte der PNR-Richtlinie den Einfluss der USA nicht nur auf die Verhältnisse der EU mit anderen Staaten, sondern auch auf die innere Gestaltung der EU-Sicherheitspolitik. Denn die Abkommen mit den USA waren ein Katalysator nicht nur der Abkommen mit Kanada und Australien, sondern auch für die Verabschiedung der EU-Richtlinie. ${ }^{661}$ Hätte es kein Abkommen mit den USA gegeben, hätte die Kommission die Einführung der PNR-Richtlinie nicht angestoßen. ${ }^{662}$ Auch inhaltlich ist die PNR-Richtlinie ursprünglich stark vom bestehenden Abkommen mit den USA geprägt worden, zum Beispiel in Bezug auf

657 Vgl. unten Abschnitt 6.2.

658 Vgl. Bigo et al., The EU Counter-Terrorism Policy Responses to the Attacks in Paris: Towards an EU Security and Liberty Agenda, 13.

659 Vgl. oben Abschnitt 2.

660 Vgl. ebd.

661 Vgl. Bigo et al., The EU Counter-Terrorism Policy Responses to the Attacks in Paris: Towards an EU Security and Liberty Agenda; Casagran, The Future EU PNR System und Argomaniz, Javier, When the EU is the „Norm-taker“: The Passenger Name Records Agreement and the EU's Internalization of US Border Security Norms, in: Journal of European Integration, 31/1, 2009, 119-136.

662 Vgl. Casagran, The Future EU PNR System. 
die Art der Daten, die übermittelt, gespeichert und verarbeitet werden, und auf die Ziele der Maßnahmen. ${ }^{663}$

\section{Sicherheitstheoretische und normative Implikationen der PNR-Richtlinie: Mobilitätsdaten als Indizien für Straftaten}

Die PNR-Daten, wie oben bereits kurz erwähnt, werden von den nationalen Zentralstellen vielfältig verarbeitet. Die Fluggastdatensätze-Richtlinie unterscheidet zunächst drei Zwecke der Datenverarbeitung: die Überprüfung von Fluggästen; den Datenaustausch mit ausländischen Behörden und mit Europol; die Aktualisierung der Kriterien oder die Aufstellung neuer Kriterien bzw. Muster. ${ }^{64}$ Für die Verfolgung des ersten Zweckes, nämlich der Überprüfung von Fluggästen, sieht die Richtlinie zwei Verfahren vor: den Abgleich mit anderen Datenbanken, die der Strafverfolgung dienen, und den Abgleich mit Mustern, die im Voraus festgelegt werden. Die Treffer, die aus den Abgleichen resultieren, müssen individuell geprüft werden, bevor die betroffenen Individuen weiteren Maßnahmen unterzogen werden. ${ }^{665}$

Mit der partiellen Ausnahme des Abgleichs mit strafrechtlichen Datenbanken haben alle genannten Formen der Datenverarbeitung gemeinsam, dass sie keine kriminell relevanten Daten für strafrechtliche Zwecke benutzen. Erstens stammen diese Daten undifferenziert von allen Passagieren der betreffenden Flüge, unabhängig davon, ob sie schon den Sicherheitsbehörden bekannt sind und ob sie sich in der Vergangenheit an Straftaten beteiligt haben. Zweitens bestehen die erhobenen Daten aus Informationen zur Mobilität: Deren Verwendung für kriminalistische Zwecke basiert somit auf der Annahme, dass diese Daten, ohne an sich schon strafrechtliche Anhaltspunkte aufzuweisen, dennoch auf Kriminelle hinweisen können. ${ }^{666}$ In dieser Hinsicht unterscheiden sie sich erheblich von anderen Systemen der Kriminalitätsbekämpfung, die bereits in Verwendung sind, wie die in den vorigen Kapiteln diskutierten SIS- und Prüm-Modelle.

663 Vgl. Boehm, EU PNR: European Flight Passengers Under General Suspicion The Envisaged European Model of Analyzing Flight Passenger Data.

664 Vgl. Richtlinie (EU) 2016/681, Art. 6 (2).

665 Vgl. ebd, Art. 6 (3) und (5).

666 Vgl. dazu Ulbricht, When Big Data Meet Securitization. Algorithmic Regulation with Passenger Name Records. 
6.1 Datensammlung, -übermittlung und -speicherung: Zweckbindung, Datenminimierung und andere datenschutzrechtliche Erwägungen

Die folgenden ersten Erwägungen betreffen die Sammlung, Übermittlung und Speicherung der PNR-Daten unabhängig von der Art der Verarbeitung. Sie beziehen sich daher auf die Anwendung der PNR-Richtlinie allgemein, also für alle drei Zwecke der Datenverarbeitung. Zweck dieser Erwägungen ist nicht, eine eingehende rechtliche Analyse anzubieten. Diese liegt außerhalb der Reichweite der vorliegenden Abhandlung. Vielmehr dienen die folgenden Ausführungen dazu, einen Überblick über die zahlreichen Fragen zu bieten, welche die Verwendung von Mobilitätsdaten für kriminalistische Zwecke aufwirft.

Erstens gibt es eine grundsätzliche Spannung mit dem Prinzip der Zweckbindung, nach dem Daten nur für die Zwecke verarbeitet werden dürfen, wofür sie erhoben wurden. Denn es handelt sich um Daten, die für geschäftliche Zwecke erhoben wurden, welche aber dann für Sicherheitszwecke verwendet werden. ${ }^{667}$ Zwar erlaubt die einschlägige Richtlinie für den Datenschutz in den Bereichen Polizei und Justiz Ausnahmen zu dem Grundsatz der Zweckbindung, diese Ausnahmen müssen aber „erforderlich und verhältnismäßig sein“. ${ }^{668}$ Ob diese Bedingungen im Fall der Fluggastdatensätze-Richtlinie erfüllt sind, kann hier nicht definitiv entschieden werden. Bis eine gerichtliche Entscheidung durch den EuGH vorliegt, kann nur auf die laufende Debatte und die zahlreichen skeptischen Positionen hingewiesen werden. ${ }^{669}$

667 Vgl. Vermeulen, Mathias; Bellanova, Rocco, European 'smart' surveillance: What's at stake for data protection, privacy and non-discrimination?, in: Security and Human Rights, 23, 2013, 297-311, hier 307.

668 Richtlinie (EU) 2016/680 des Europäischen Parlaments und des Rates vom 27.04.2016 zum Schutz natürlicher Personen bei der Verarbeitung personenbezogener Daten durch die zuständigen Behörden zum Zwecke der Verhütung, Ermittlung, Aufdeckung oder Verfolgung von Straftaten oder der Strafvollstreckung sowie zum freien Datenverkehr und zur Aufhebung des Rahmenbeschlusses 2008/977/JI des Rates, Amtsblatt der Europäischen Union L 119/89 vom 04.05.2016, Art. 4, Abs. 1, lit. b und Art. 4, Abs. 2.

669 Vgl. Art. 29 Data Protection Working Party, Opinion 10/2011, 5; Arzt, Stellungnahme zur Anhörung des Innenausschusses des Deutschen Bundestages am 26.04.2017; Voßhoff, Stellungnahme der Bundesbeauftragten für den Datenschutz, 2-3; Stellungnahme der Digitale Gesellschaft e. V., 3 und Stellungnahme zu den verbundenen Ersuchen um Vorabentscheidung C-148/20 bis C-150/20, 8-11. 
Zweitens ist die Art von Datenerhebung „by default and design“670 massiv. Solche Daten enthalten Informationen unter anderem über Bewegungen (Reiseverlauf), soziale Beziehungen (Daten der Mitreisenden) und Kaufverhalten (Zahlungsart, Reisebüro). Zudem sieht die Richtlinie vor, im „Freitextfeld“ weitere Informationen als „allgemeine Hinweise“ einzufügen, wobei nicht eingegrenzt wird, um welche Art von Informationen es sich handeln darf oder welchen Inhalt sie haben dürfen. Die verarbeiteten PNR-Daten können somit ein ziemlich detailliertes Profil über die Passagiere erzeugen, und das bezüglich aller Passagiere, die einen Flug von oder zu einem Mitgliedstaat buchen. ${ }^{671}$ Jedoch ist es genau die Reichhaltigkeit an Informationen, die in diesen Daten zu finden sind, was sie so interessant für die Kommission und Behörden macht. Deswegen kann Datenminimierung nach einer solchen Logik gerade nicht verfolgt werden, weil sie den Zielen der Maßnahmen widerspricht. ${ }^{672}$ Zwar ist in dieser Hinsicht die EU-Richtlinie zum Schutz der personenbezogenen Daten in den Bereichen Polizei und Justiz etwas permissiver als die EU-Datenschutz-Grundverordnung (EU-DSGV), die für die Datenverarbeitung in den übrigen Bereichen gilt. Letztere verlangt, dass die Daten „dem Zweck angemessen und erheblich sowie auf das für die Zwecke der Verarbeitung notwendige Maß beschränkt sein" 673 müssen, während die Richtlinie im Bereich Polizei und Justiz „nur“ verlangt, dass die verwendeten Daten „dem Verarbeitungszweck entsprechen, maßgeblich und in Bezug auf die Zwecke, für die sie verarbeitet werden, nicht übermäßig sind““.674 Obwohl also der Grundsatz der Datenminimierung für den Bereich der polizeili-

670 Vermeulen; Bellanova, European 'smart' surveillance, 307.

671 Vgl. Ulbricht, When Big Data Meet Securitization. Algorithmic Regulation with Passenger Name Records. Zu den Bedenken in dieser Hinsicht bezüglich des deutschen Gesetzes vgl. Arzt, Stellungnahme zur Anhörung des Innenausschusses des Deutschen Bundestages am 26.04.2017 und Voßhoff, Stellungnahme der Bundesbeauftragten für den Datenschutz und die Informationsfreiheit zur öffentlichen Anhörung des Innenausschusses am 24.04.2017. Dabei ist nach der PNR-Richtlinie nur verpflichtend, die Daten der Fluggäste zu verarbeiten, die von der EU in außereuropäische Länder oder von diesen in die EU buchen. Wie oben dargestellt, haben sich aber alle Mitgliedstaaten bis auf einen dafür entschieden, auch die Daten der Passagiere von EU-Binnenflügen zu erfassen.

672 Vgl. Vermeulen; Bellanova, European 'smart' surveillance, 307.

673 Verordnung (EU) 2016/679 des Europäischen Parlaments und des Rates vom 27.04.2016 zum Schutz natürlicher Personen bei der Verarbeitung personenbezogener Daten, zum freien Datenverkehr und zur Aufhebung der Richtlinie 95/46/EG (Datenschutz-Grundverordnung), Amtsblatt der Europäischen Union L 119/1 vom 04.05.2016, Art. 5, Abs. 1, lit. c.

674 Richtlinie (EU) 2016/680, Art. 4, Abs. 1, lit. c, Kursivierung E.O. 
chen und justiziellen Maßnahmen weniger stringent zu sein scheint, muss trotzdem eine gewisse Sparsamkeit im Umgang mit den Daten eingehalten werden. Auch in diesem Fall kann hier nur auf die bestehende Spannung zwischen der Logik der Datensammlung nach der PNR-Richtlinie und dem Prinzip der Datenminimierung hingewiesen werden. Eine genaue Überprüfung, ob diese Spannung im vorliegenden Fall einem nach datenschutzrechtlichen Standards annehmbaren Verhältnis entspricht, liegt außerhalb der Reichweite dieser Abhandlung. ${ }^{675}$

Drittens gibt es für die überwiegende Mehrheit der Passagier_innen, deren Daten erhoben werden, keinen Anlass, sie als „verdächtig“ anzusehen. ${ }^{676}$ Und trotzdem werden ihre Daten von den Fluggesellschaften an die Sicherheitsbehörden weitergegeben und von diesen verarbeitet. Alle Passagier_innen der relevanten Flüge werden profiliert, alle werden in Risikokategorien eingeteilt (und sei es nur, weil sie als „Niedrigrisiko-Fluggäste" eingestuft werden), unabhängig davon, ob sie sich in der Vergangenheit an Straftaten beteiligt haben. ${ }^{677}$ Auch diese diffuse Erfassung von Daten ist keine Zufallscharakteristik, sondern in der Logik der PNR-Richtlinie als prädiktives System eingebaut. Um darauf trainiert zu werden, nach „abweichendem“ Verhalten zu suchen, brauchen die Systemalgorithmen große Datenmengen, die "normales“ Verhalten abbilden. Es ist also dieser Logik immanent und für das Funktionieren des Systems notwendig, den Kreis der erfassten Menschen erheblich über den tatsächlich „gefährlichen" hinaus auszuweiten. ${ }^{678}$ Dies geht für manche Autor_innen deutlich über die üblichen Befugnisse der deutschen Polizeibehörde, etwa im Kontext der Gefahrenabwehr, hinaus. ${ }^{679}$ Auch die Entscheidung des Bundesverfassungsgerichts zur Rasterfahndung von 2006, wenn an Formen des personenbezogenen predictive policing übertragen, deutet auf deren Unzu-

675 Der EuGH hat diese Aspekte bezüglich des PNR-Abkommens mit Kanada kritisch bewertet. Vgl. Gerichtshof der Europäischen Union, Pressemitteilung Nr. 84/17, Gutachten 1/15, 2-3.

676 Nach Angaben der Kommission betrug 2019 der Anteil der Passagiere, für die ein Treffer erzeugt wurde, 0,59\%. Siehe oben, Abschnitt 4.3 dieses Kapitels.

677 Vgl. Ulbricht, When Big Data Meet Securitization. Algorithmic Regulation with Passenger Name Records.

678 Vgl. Degeling, Martin; Berendt, Bettina, What is wrong about Robocops as consultants? A technology-centric critique of predictive policing, in: AI \& SOCIETY, 33/3, 2017, 347-356, hier 355.

679 Vgl. Arzt, Stellungnahme zur Anhörung des Innenausschusses des Deutschen Bundestages am 26.04.2017. 
lässigkeit hin. ${ }^{600}$ Denn dort hat das Bundesverfassungsgericht festgelegt, dass die Verwendung von Mustern zur Gefahrenabwehr nur dann zulässig ist, wenn die Schwelle der konkreten Gefahr überschritten wird. Jedoch setzen predictive policing allgemein und die Fluggastdatenrichtlinie insbesondere per definitionem einen Schritt früher an, nämlich wenn potenzielle Gefahren noch unbekannt sind - denn genau diese noch unbekannten Gefahren sollen aufgedeckt werden. ${ }^{681}$

Schließlich sind sowohl die Zeit, in der die Daten in nicht depersonalisierter Form gespeichert werden (6 Monate), und der Zeitraum der Speicherung insgesamt (5 Jahre) besonders lang. Ähnliche Speicherzeiten waren in dem EU-Abkommen mit Kanada festgelegt und wurden vom EuGH kritisiert. ${ }^{62}$

\subsection{Datenverarbeitung zur Risikobewertung}

Die obigen Ausführungen beziehen sich auf die Datenerhebung im Rahmen der PNR-Richtlinie im Allgemeinen. Die erhobenen Daten werden, wie oben erwähnt, für den Abgleich mit anderen Datenbanken, für den Austausch mit europäischen Behörden, für den Abgleich mit Mustern und für die Aktualisierung der existierenden oder die Herstellung neuer Muster verwendet. Während der Abgleich mit kriminalistischen Datenbanken und der Datenaustausch mit europäischen Behörden, rein verfahrenstechnisch gesehen (d.h. unabhängig von der Art der Daten, die abgeglichen oder ausgetauscht werden), bereits auf EU-Ebene praktiziert werden, ${ }^{683}$ unterscheiden sich die anderen beiden Verfahren wesentlich von weiteren Formen der Datenverarbeitung, die bisher auf europäischer Ebene genutzt wurden. Die PNR-Richtlinie eröffnet damit einen neuen Ansatz in der EUSicherheitspolitik, der sich von einer regelbasierten Sicherheitskonzeption distanziert und in eine risikobasierte Sicherheitslogik übergeht.

680 Vgl. BVerfGE 115, 320/360, vgl. Rademacher, Predictive Policing im deutschen Polizeirecht, 393.

681 Vgl. Rademacher, Predictive Policing im deutschen Polizeirecht, 393. Zur Gefahrenabwehr in der deutschen Verfassungsrechtsprechung vgl. Poscher, Ralf, Eingriffsschwellen im Recht der inneren Sicherheit. Ihr System im Licht der neueren Verfassungsrechtsprechung, in: Die Verwaltung, 41/3, 2008.

682 Vgl. Gerichtshof der Europäischen Union, Pressemitteilung Nr. 84/17, Gutachten $1 / 15,1$.

683 Zum Beispiel im Rahmen des SIS und der Prümer Regelungen, die in den vorigen Kapiteln dieses Buches untersucht wurden. 
Der Abgleich mit vorgegebenen Mustern verwirklicht einen risikobasierten Ansatz, dessen Zweck nicht die Identifizierung von Personen ist, die in einem Zusammenhang mit einer Straftat stehen, sondern die Aufstellung von Wahrscheinlichkeiten, die für Verhaltensprognosen und -einschätzungen verwendet werden. Im ersten Fall werden Menschen ermittelt, die unter Verdacht stehen, eine Straftat begangen zu haben oder mindestens eine solche zu planen. Dafür sollen konkrete Anhaltspunkte im Verhalten dieser Menschen bestehen. Im zweiten Fall geht es darum, die Individuen einer großen Bevölkerungsmenge im Hinblick auf ihr Risikopotenzial zu klassifizieren und diejenigen Individuen hervorzuheben, die das größte Risikopotenzial darstellen. ${ }^{684}$

Wie unten näher erörtert wird, werden die Risikokriterien, die der Bewertung zugrunde gelegt werden, weitestgehend geheim gehalten. ${ }^{685}$ Die wenigen Beispielen, die öffentlich gemacht wurden, verhelfen jedoch zu interessanten Einblicken in die Verhaltensweisen, die zu einer erhöhten "Gefährlichkeitsprognose“ beitragen können. Diese sind in allen bekannten Fällen sehr alltägliche und harmlose Verhaltensweisen, bei denen kein notwendiger Zusammenhang zu einer Straftat besteht. Als Kriterien, die zur Erzeugung eines hohen Risikoprofils führen können, wurden zum Beispiel Barzahlung oder „last-minute-booking“ genannt, die Unverhältnismäßigkeit zwischen Schwere des Gepäcks und der Reisedauer sowie das bereits erwähnte Kriterium des Flugziels „Türkei““.686 Diese Beispiele verdeutlichen einerseits, wie wenig die Risikokriterien mit kriminellem Verhalten zusammenhängen, und andererseits, wie weit "Gefährlichkeit" gefasst wird. Zudem wird deutlich, wie solche Prognosen dazu führen, dass Menschen, die nicht diffusen und dominanten Vorstellungen von „Ungefährlichkeit“ oder „Normalität“ entsprechen, viel häufiger ins Visier der Behörden geraten. Etwa keine Kreditkarte zur Verfügung zu haben oder (etwa wegen hoher Gebühren) verwenden zu wollen, gern spontan zu verreisen, bei einem kurzen Familien- oder Freundesbesuch reichlich Geschenke einzupacken oder einen Migrationshintergrund aus der Türkei zu haben: All diese Eigenschaften können nach den erwähnten Kriterien

684 Vgl. Ulbricht, When Big Data Meet Securitization. Algorithmic Regulation with Passenger Name Records.

685 Vgl. unten, Abschnitt 3.2.3 im Kapitel 3.

686 Vgl. Commission Staff Working Document Accompanying the Document Report from the Commission, SWD(2020) 128 final, 28 und 24, sowie Stellungnahme zu den verbundenen Ersuchen um Vorabentscheidung C-148/20 bis C-150/20, 15-16. 
zur Klassifizierung als Passagier_innen, die eine erhöhte „Auffälligkeit“ und daher "Gefährlichkeit" aufweisen, beitragen.

Dieser risikobasierte Ansatz zielt zudem nicht darauf ab, die Ursachen zu bekämpfen oder alle möglichen Rechtsverletzungen zu vermeiden, sondern vielmehr die vorhandenen Ressourcen auf die bedeutendsten Bedrohungen zu konzentrieren, um die Verwirklichung von potenziellen Rechtsverletzungen in den priorisierten Fällen zu verhindern. ${ }^{687}$

\subsection{Datenverarbeitung zur Aktualisierung und Herstellung der Risikokriterien}

Wie oben kurz eingeführt, sieht die Richtlinie neben der Verwendung der Fluggastdaten für den Abgleich mit kriminalistischen Datenbanken und mit im Vorfeld festgelegten Mustern vor, die Daten für die Aktualisierung der Kriterien oder die Aufstellung neuer Muster zu verwenden.

Weder die Richtlinie noch das deutsche Gesetz spezifizieren, wie genau dies geschehen soll. Vorstellbar ist, dass die Polizeibehörden die Muster punktuell aktualisieren, indem sie die gesammelten Daten von Passagier_innen, die sich als straftatverdächtig erwiesen haben, nachträglich manuell durchforschen und für die Aktualisierung oder Herstellung der Muster verwenden. Ebenfalls wahrscheinlich ist, dass für diesen Zweck auch künstliche Intelligenz zum Einsatz kommt. Denn gerade auf EU-Ebene werden seit einigen Jahre erhebliche Ressourcen in die Entwicklung von Technologien für das behavioural profiling für Sicherheitszwecke investiert, insbesondere auch unter Einsatz von maschinellen Lernverfahren, u. a. im Bereich der Grenzkontrolle. ${ }^{68}$ Außerdem verspricht die Verwendung von maschinellem Lernen, wie ich im nächsten Abschnitt näher erörtern

687 Vgl. Commission Staff Working Document Accompanying the Document Report from the Commission, $\operatorname{SWD}(2020) 128$ final, 28 und 24, sowie Stellungnahme zu den verbundenen Ersuchen um Vorabentscheidung C-148/20 bis C-150/20, 15-16.

688 Siehe zum Beispiel das im Rahmen des siebten Forschungsrahmenprogramms der EU finanzierte Projekt INDECT (Intelligent information system supporting observation, searching and detection for security of citizens in urban environment, http://www.indect-project.eu/) oder die im Rahmen des Horizont-2020Programms finanzierten Projekte iBorderCtrl (Intelligent Portable Control System, https://www.iborderctrl.eu/) und TRESSPASS (robusT Risk basEd Screening and alert System for PASSengers and luggage https://www.tresspass.eu/ [letzter Zugriff (alle): 03.06.2019]). 
werde, das prädiktive Potenzial großer, disparater Datensammlungen wie der Fluggastdaten nach der PNR-Richtlinie am besten zu entfalten.

Unabhängig von der konkreten aktuellen Anwendung stellt daher die PNR eine Art Trojanisches Pferd dar, indem die Möglichkeit des Einsatzes maschinellen Lernens und anderer KI-Techniken für risikobasierte Sicherheitsmaßnahmen auf EU-Ebene eingeführt wird. Obwohl also nach aktuellem Kenntnisstand maschinelle Lernverfahren noch nicht auf gesamteuropäischer Ebene zu Sicherheitszwecken genutzt werden, ist es sinnvoll, sich mit dieser Möglichkeit auseinanderzusetzen, da alles dafürspricht, dass sie bald Realität werden könnte. Die folgenden Überlegungen sollen dazu dienen, die Bedeutung des Einsatzes von maschinellem Lernen im Sicherheitsbereich zu erforschen. Zuvor ist aber eine kurze Einführung in die sogenannte algorithmische Regulierung nötig.

\subsection{Exkurs: algorithmische Regulierung zwischen Mythos und Realität}

Debatten über das Potenzial von automatisierten, datengestützten Verfahren, insbesondere im Bereich der öffentlichen Regulierung, finden häufig in Verbindung mit mächtigen Assoziationen statt. Diese zeigen sowohl im Positiven wie auch im Negativen Szenarien auf, die vielmehr auf tief verwurzelten Hoffnungen und Ängsten basieren als auf einer möglichst nüchternen Betrachtung der Tatsachen. Beispiele ersterer Neigungen wurden vom weißrussischen Publizisten Evgeny Morozov unter dem Stichwort "Solutionismus“ („solutionism“) als die Überzeugung bezeichnet, dass Digitalisierung und technologische Innovation per se soziale Probleme lösen können. ${ }^{689}$ Dabei wecken Algorithmen Assoziationen mit immerwährenden Narrativen der Entstehung von Ordnung:

[T]he drama of the powerful yet inscrutable algorithm bears some resemblance to long-standing mythologies, such as Adam Smith's "invisible hand" or Charles Darwin's natural selection" [...]. Algorithms,

689 Morozov, Evgeny, Why the internet of things could destroy the welfare state, in: The Observer, 20.06.2014. Als Beispiel einer enthusiastischen Darstellung der Möglichkeiten, die durch big data und maschinelles Lernen eröffnet werden, vgl. Mayer-Schönberger, Viktor; Cukier, Kenneth, Big Data: Die Revolution, die unser Leben verändern wird. München: Redline Verlag 2013. 
it seems, fit in seamlessly with this line of stubbornly seductive stories about the origins of order. 690

Auf der anderen Seite wird die Verwendung von algorithmischen Verfahren im Regulierungsbereich schnell mit dystopischen Science-Fiction-Szenarien verglichen, wie sie in das kollektive Gedächtnis durch Filme wie Steven Spielbergs Minority Report eingeprägt wurden. Diese Situation wird auch dadurch begünstigt, dass der Einsatz von künstlicher Intelligenz durch eine (nicht komplett unbegründete, wie ich ausführen werde) Aura von Unergründlichkeit umgegeben ist. Es ist daher sehr wichtig, zunächst so weit wie möglich Einblick in das Funktionieren dieser Technologien sowie in deren tatsächliche bisherige Anwendung im Sicherheitsbereich zu gewinnen.

Algorithmische Regulierung kann als eine Form von Regulierung definiert werden, die Systeme für algorithmische Wissensproduktion einsetzt, um Entscheidungen durchzuführen oder Entscheidungsempfehlungen zu formulieren. ${ }^{691}$ Dabei wird „Regulierung“ als Versuch definiert, mit Risiko umzugehen oder menschliches Verhalten zu steuern, um vorgegebene Zwecke zu erreichen. ${ }^{692}$ Es handelt sich also um automatisierte Systeme, die aufgrund von Risikoanalysen Entscheidungen selbstständig treffen (zum Beispiel: die Verweigerung der Autorisierung, mit Kreditkarte zu bezahlen) oder eine Empfehlung formulieren, an der sich die Entscheidung orientieren soll. ${ }^{693}$ Die vom System erarbeiteten Entscheidungen oder Entscheidungsempfehlungen basieren zudem auf Wissen - und das ist entscheidend -, das durch die Datenverarbeitung selbst produziert wird. Dies erfolgt nach maschinellen Lernverfahren. Im Folgenden wird skizziert, wie diese Verfahren funktionieren und wie sie sich von traditionellen sta-

690 Ziewitz, Malte, Governing Algorithms. Myth, Mess, and Methods, in: Science, Technology, \& Human Values, 41/1, 2016, 3-16, hier 7.

691 "Algorithmic decisionmaking refers to the use of algorithmically generated knowledge systems to execute or inform decisions, which can vary widely in simplicity and sophistication. Algorithmic regulation refers to regulatory governance systems that utilize algorithmic decisionmaking“, Yeung, Karen, Algorithmic regulation: A critical interrogation, in: Regulation \& Governance, 2017, 3.

692 Vgl. Yeung, Algorithmic regulation, 3.

693 Diese zweite Option scheint diejenige zu sein, die durch die Fluggastdatensätze-Richtlinie eingeführt wird: Der automatisierte Abgleich mit Mustern soll diejenigen Individuen aussortieren, die mit hoher Wahrscheinlichkeit ein Risiko darstellen, um diese einer weiteren von Menschen durchgeführten Überprüfung zu unterziehen. 
tistischen Verfahren sowie von anderen Techniken künstlicher Intelligenz unterscheiden.

Bei maschinellen Lernverfahren werden aus großen Datenmengen Muster und Modelle automatisch entwickelt. Dabei wird ein übergeordneter Zweck, aber keine Spezifizierung der Beziehungen zwischen den Daten oder zwischen den eingegebenen Daten (Input) und den erwünschten Ergebnissen (Output) vorgegeben. Vielmehr erkennen Algorithmen in diesen großen, häufig unstrukturierten Datenmengen Korrelationen, die durch menschlichen Verstand allein nicht erkennbar wären. Aufgrund dieser Korrelationen werden Modelle entwickelt, welche die Input-Daten mit bestimmten Ergebnissen korrelieren. Die unstrukturierten Daten werden somit in (neu) strukturiertes Wissen verwandelt. ${ }^{694}$ Diese Generierung von Mustern kann menschlich überwacht werden (supervised learning) oder selbstständig funktionieren (unsupervised learning). Im ersten Fall werden dem System „korrekte“ oder gewünschte Input-Output-Paare gezeigt, damit das System die richtigen Assoziationen lernt und daraus die Funktionen für die Verbindung von Input und Output erstellt. Im unüberwachten maschinellen Lernen werden dagegen die Assoziationen und Muster vollständig vom System erstellt, ohne menschlichen Eingriff. ${ }^{695}$

Maschinelles Lernen unterscheidet sich sowohl von statistischen Methoden wie auch von traditionelleren Einsätzen künstlicher Intelligenz. In statistischen Verfahren wird die mathematische Funktion für die Verbindung zwischen den Input- und den Output-Variablen im Voraus definiert. ${ }^{696}$ Das vordefinierte mathematische Modell ist entscheidend, um die erzielten Ergebnisse zu kalkulieren. Ähnliches gilt für traditionelle künstliche Intelligenz, so wie sie etwa in Programmen für das automatische Schachspielen eingesetzt wird. In diesen Fällen wird die Funktionalität des Systems durch Algorithmen definiert, welche durch die Formalisierung des vorhandenen Wissens (Konzepte, semantische Beziehungen und Inferenzregeln) von den Programmierer_innen festgelegt wurden. Dagegen wird in maschinellen Lernverfahren die Funktionalität der Systeme nicht durch vorgegebene Regeln und Algorithmen definiert, sondern durch das Lernverfahren

694 Vgl. Yeung, Algorithmic regulation.

695 Für Beispiele, wie unüberwachtes maschinelles Lernen funktioniert, vgl. Domingues, Rémi et al., A comparative evaluation of outlier detection algorithms: Experiments and analyses, in: Pattern Recognition, 74, 2018, 406-421.

696 Vgl. Yeung, Algorithmic regulation, 2. 
des Systems selbst. ${ }^{697}$ Im Falle künstlicher neuronaler Netze etwa - eine mögliche Anwendung des maschinellen Lernens - wird die spezifische Funktionalität des Netzes nicht von vorgegebenen Algorithmen generiert, sondern durch die Adaptierung der eigenen Struktur, die das Netz selbst aufgrund der analysierten Daten vollzieht. ${ }^{698}$ Dieser Unterschied zwischen traditioneller künstlicher Intelligenz und maschinellem Lernen wurde von der niederländischen Juristin und Philosophin Mireille Hildebrandt als Gegensatz zwischen „code-driven“- und „data-driven“-Ansätzen definiert: Erstere implementieren vorgegebene „wenn ... dann“-Regeln, während im zweiten Fall die entscheidenden Kriterien aus den vorhandenen Daten herausgearbeitet werden. ${ }^{699}$

Der Unterschied zwischen den beiden Modellen hat kritische Konsequenzen für die Nachvollzierbarkeit der Korrelationen zwischen Inputund Outputdaten. Denn im Falle statistischer Verfahren oder traditioneller künstlicher Intelligenz wissen die Programmierer_innen prinzipiell, welche Regeln und Funktionen vom System genutzt werden, sodass die Verbindung zwischen Ausgangsdaten und Resultaten generell nachvollziehbar und erklärbar ist. Dagegen sind die Korrelationen, die maschinelle Lernsysteme zwischen den Eingangs- und Ausgangsdaten herstellen, undurchschaubar. ${ }^{700}$ Vielmehr: Die aufgestellten Korrelationen sind nicht unbedingt kausaler Natur und können auch auf reinen Häufigkeitsbeobachtungen basieren. Die Attraktivität des Einsatzes von maschinellem Lernen liegt genau darin: Diese Verfahren sollen zu Resultaten führen, die Menschen allein nicht erreichen könnten, weil sie die relevanten Korrelationen nicht erkennen können. ${ }^{701}$

Die möglichen Anwendungen von maschinellen Lernverfahren sind so vielfältig wie die Bereiche, die durch Digitalisierung geprägt sind - sie umfassen also virtuell alle Lebensbereiche. Dementsprechend wurden auch im Bereich der Sicherheitspolitik Ansätze für den Einsatz maschinellen

697 Für eine sehr anschauliche Darstellung des Unterschieds zwischen den beiden Ansätzen vgl. Schubbach, Arno, Judging machines: philosophical aspects of deep learning, in: Synthese, 198, 2019, 1807-1827.

698 Das Entscheidende hierbei sind nämlich die Gewichtungen, die das System den einzelnen neuronalen Verbindungen zuweist, vgl. Schubbach, Judging machines, 1815.

699 Hildebrandt, Mireille, Algorithmic regulation and the rule of law, in: Philosophical Transactions of the Royal Society A. Mathematical, Physical and Engineering Sciences, 376/2128, 2018, 1-11, hier 2-3.

700 Vgl. Schubbach, Judging machines.

701 Vgl. Mayer-Schönberger; Cukier, Big Data. 
Lernens entwickelt. ${ }^{702}$ Die bekanntesten Beispiele sind unter dem Namen "predictive policing" bekannt und können in zwei Kategorien unterteilt werden. Einerseits gibt es ortsbezogene Formen von predictive policing, die darauf abzielen, im Voraus die Orte zu identifizieren, an denen am wahrscheinlichsten die nächsten Straftaten einer Serie (typischerweise Wohnungseinbrüche) stattfinden werden. Ziel dieser Anwendungen ist es, durch erhöhte Polizeipräsenz vor Ort die Durchführung der Straftaten zu verhindern. Solche Systeme werden derzeit auch in Deutschland, vor allem in Pilotprojekten, eingesetzt. ${ }^{703}$ Sie unterscheiden sich von den für unsere Diskussion relevanten Fällen aber dadurch, dass sie nicht personenbezogen sind: Ihr Ziel ist es, mögliche Tatorte zu identifizieren anstatt möglicher Täter_innen. Die Suche nach „Hochrisiko“-Individuen verkörpert dagegen eine zweite Form von predictive policing, die auch als „personenbezogen" bezeichnet wird. ${ }^{704}$ Diese Form von predictive policing involviert, wie die Analyse der Fluggastdaten im Rahmen der PNR-Richtlinie auch, Formen der Verhaltensprofilierung. Einige Beispiele dieser Form von predictive policing werden in der Literatur aus den USA und Großbritannien erwähnt. ${ }^{705}$ Auch das deutsche BKA verwendet seit 2017 ein Programm zur „Risikobewertung von potentiellen Gewaltstraftätern“ namens RADAR-iTE. ${ }^{706}$ Solche Instrumente werden zum Beispiel eingesetzt für die Einschätzung der Rückfälligkeitswahrscheinlichkeit bei bereits verurteilten Straftäter_innen oder für die Identifizierung von Personen, die in terroristische Aktivitäten verwickelt sein könnten. Zum Beispiel wertete das Programm Skynet, das durch die Snowden-Enthüllungen über die NSA-Über-

702 Für einen Überblick über frühere Ansätze vgl. die Berichte aus dem von der EU finanzierten Projekt INDECT, insbesondere D9.9. Report on current state-ofthe-art of machine learning methods for behavioural profiling, 2011, www.indect-project.eu (letzter Zugriff: 03.06.2019).

703 Vgl. Rademacher, Predictive Policing im deutschen Polizeirecht, 366-416.

704 Für eine Klassifizierung der Formen von predictive policing vgl. Degeling; Berendt, What is wrong about Robocops as consultants? und Rademacher, Predictive Policing im deutschen Polizeirecht, 366-416.

705 Vgl. Pelzer, Policing of Terrorism Using Data from Social Media; Zweig, Katharina A.; Wenzelburger, Georg; Krafft, Tobias D., On Chances and Risks of Security Related Algorithmic Decision Making Systems, in: European Journal for Security Research, 3/2, 2018, 181-203.

706 Bundeskriminalamt, Presseinformation: Neues Instrument zur Risikobewertung von potentiellen Gewaltstraftätern, 02.02.2017. Einen aktuellen Überblick über die im deutschen Sprachraum verwendeten predictive-policing-Instrumente gibt der Band Bode, Felix; Seidensticker, Kai, Predictive Policing. Eine Bestandsaufnahme für den deutschsprachigen Raum. Frankfurt am Main: Verlag für Polizeiwissenschaft, 2020. 
wachungsaktivitäten bekannt wurde, Smartphone-Daten aus, um terroristische Kuriere zu identifizieren. Obwohl durch dieses Programm mehr als 55 Millionen Datensätze ausgewertet wurden, war Skynet ziemlich ineffektiv für die Identifizierung von Verdächtigen. Ein Problem war, dass die Zahl der tatsächlichen „Terrorist_innen“ zu klein war, um das Programm trainieren zu können. Das ist ein allgemeines Problem, das gegen den Einsatz von maschinellen Lernverfahren zur Terrorismusbekämpfung also auch im Fall der PNR-Richtlinie - spricht. ${ }^{707}$

Die mögliche Anwendung von maschinellem Lernen im Fall der Fluggastdatensätze-Richtlinie wäre ein weiteres Beispiel der zweiten Form von predictive policing, die auf Verhaltensprofilierung basiert. Denn die Muster dienen dem Herausfiltern von Personen, die aufgrund ihres Mobilitätsverhaltens eine erhöhte Bedrohungswahrscheinlichkeit aufweisen sollen.

707 Vgl. Pelzer, Policing of Terrorism Using Data from Social Media, 176. 


\section{Kapitel 7 Fluchtlinien der EU-Sicherheitspolitik: Ausbau der Datenbanken und gesteigerte Interoperabilität}

\section{Von den spezifischen Analysen zum Gesamtbild des Informationsaustausches im RFSR}

Dieses Kapitel bettet die detaillierten Analysen der vorigen Kapitel dieses Teiles in den Kontext des gesamten europäischen Informationsaustausches im RFSR ein. Zu diesem Zweck wird zunächst ein Überblick über weitere Systeme des Informationsaustauschs in der EU geboten. Danach werden die Pläne der EU für die Potenzierung der Informationssysteme sowie für die Intensivierung ihrer Interoperabilität präsentiert. Die durch diese Perspektive gewonnenen Einblicke ermöglichen eine Betrachtung der Sicherheitsmaßnahmen im RFSR, die sowohl die Entwicklungsrichtung zu einem allumfassenden Informationssystem als auch die Paradoxa der Unionspolitik in diesem Bereich veranschaulicht. ${ }^{708}$

\section{Der Informationsaustausch in der EU: Überblick}

Zum Zwecke der Klassifizierung kann zwischen zentralisierten und dezentralen europäischen Datenbanken unterschieden werden. Bei zentralisierten EU-Datenbanken werden die Daten in einem zentralen System gespeichert. Bei dezentralisierten Datenbanken dagegen werden die Daten in nationalen Systemen gespeichert und durch eine gemeinsame Infrastruktur miteinander vernetzt.

Neben dem SIS sind die wichtigsten zentralen europäischen Datenbanken das Visa-Informationssystem VIS und Eurodac. Das VIS dient dem Austausch von Informationen über Visumsanträge und die damit verbundenen Personen, während im Eurodac die Fingerabdrücke von Asylbewerber_innen und Drittstaatsangehörigen, die bei der illegalen Einreise im Schengener Raum aufgegriffen wurden, gespeichert sind. Weitere Syste-

708 Für einen Überblick über die europäischen Informationssysteme auch außerhalb des RFSR vgl. Schneider, Jens-Peter, Informationssysteme als Bausteine des Europäischen Verwaltungsverbunds, in: Neue Zeitschrift für Verwaltungsrecht, 2, 2012, 65-70. 
me des Informationsaustauschs sind das Advance Passenger Information System (APIS) für die Erfassung der Daten von Passagier_innen, bevor diese in die EU fliegen, und das Europol-Informationssystem (EIS), in das Nationalstaaten Informationen über schwere Straftaten und Terrorismus eingeben und auch mit Dritten, die ein entsprechendes Abkommen mit Europol geschlossen haben, austauschen können. $\mathrm{Zu}$ den zentralisierten EU-Datenbanken gehört darüber hinaus auch das neu eingerichtete Einreise/Ausreise-System (EES, „Entry/Exit System“).709 Schließlich ist in diesem Kontext die Datenbank für gestohlene und verlorene Reisedokumente (SLTD) der weltweiten Agentur Interpol zu nennen, da sie, obwohl selbst kein EU-Informationssystem, mit europäischen Datenbanken vernetzt ist. ${ }^{710}$

$\mathrm{Zu}$ den dezentralisierten EU-Datenbanken gehört neben dem Prümund dem PNR-System das Europäische Strafregisterinformationssystem (ECRIS). Dieses ermöglicht den Austausch von Daten über Verurteilte aus den verschiedenen nationalen Strafregistern. ${ }^{711}$

Im Folgenden wird auf die wichtigsten existierenden Datenbanken, die nicht bereits in den vorigen Kapiteln analysiert wurden, sowie auf die Pläne der Kommission für die nähere Zukunft eingegangen.

Letztere reichen vom Ausbau der bereits bestehenden Informationssysteme über die Errichtung neuer Systeme bis hin zur Vernetzung verschiedener Datenbanken miteinander. ${ }^{712}$

709 Vgl. Verordnung (EU) 2017/2226 des Europäischen Parlaments und des Rates vom 30.11.2017 über ein Einreise-/Ausreisesystem (EES) zur Erfassung der Einund Ausreisedaten sowie der Einreiseverweigerungsdaten von Drittstaatsangehörigen an den Außengrenzen der Mitgliedstaaten und zur Festlegung der Bedingungen für den Zugang zum EES zu Gefahrenabwehr- und Strafverfolgungszwecken und zur Änderung des Übereinkommens zur Durchführung des Übereinkommens von Schengen sowie der Verordnungen (EG) Nr. 767/2008 und (EU) Nr. 1077/2011, Amtsblatt der Europäischen Union L 327/20 vom 09.12.2017 und unten, Abschnitt 4.2 in diesem Kapitel.

710 Für einen Überblick über diese Datenbanken vgl. Mitteilung der Kommission an das Europäische Parlament und den Rat „Solidere und intelligentere Informationssysteme für das Grenzmanagement und mehr Sicherheit“, $\operatorname{COM(2016)}$ 205 final, 06.04.2016.

711 Vgl. ebd.

712 Vgl. ebd. und die zweimal jährlich erscheinenden Fortschrittsberichte der Kommission bis zuletzt Mitteilung der Kommission an das Europäische Parlament, den europäischen Rat und den Rat „Auf dem Weg zu einer wirksamen und echten Sicherheitsunion - Zwanzigster Fortschrittsbericht“, $\operatorname{COM}(2019) 552$ final, 30.10.2019. 


\section{Aktuell betriebene Informationssysteme}

\subsection{Das VIS}

Mit der Entscheidung 2004/512/EG vom 8. Juni 2004 beschloss der Rat der EU, ein System für den Austausch von Visa-Daten einzurichten. ${ }^{713}$ Erst mit der Verordnung (EG) Nr. 767/2008 des Europäischen Parlaments und des Rates vom 9. Juli 2008 wurden jedoch die konkreten Eigenschaften des Visa-Informationssystems (VIS) im Detail festgelegt. ${ }^{714}$

Das VIS ist seit dem 11. Oktober 2011 in Betrieb. Es wurde zuerst bei den europäischen Konsulaten in der nordafrikanischen Region in Betrieb genommen und progressiv ausgeweitet, sodass das VIS nun von den europäischen Konsulaten weltweit sowie an den (Außen-)Grenzübertrittstellen der EU-Mitgliedstaaten genutzt wird. ${ }^{715}$

Das VIS soll dabei helfen, die gemeinsame Visumspolitik der EU umzusetzen, das Verfahren für die Entscheidung über die Erteilung eines Visums zu erleichtern, Betrug und „Visa-Shopping“ zu verhindern und zu bekämpfen sowie Kontrollen in den Mitgliedstaaten und an den Außengrenzen zu erleichtern. Außerdem soll das VIS auch die Identifizierung von Personen vereinfachen, die keinen gültigen Aufenthaltstitel (mehr) besitzen, die Entscheidung über die Zuständigkeit der Mitgliedstaaten für die Bearbeitung der Asylanträge erleichtern und schließlich „zur Verhütung von Gefahren für die innere Sicherheit der einzelnen Mitgliedstaaten beitragen“.716 Dabei wurde von Anfang an der Zugriff zum VIS nicht nur für Konsulate und andere Stellen, die für die Migrationskontrolle zuständig sind, vorgesehen, sondern auch für Polizeibehörden und Europol. Laut Art. 3 der Verordnung (EG) Nr.767/2008 dürfen diese Behörden nur in Einzelfällen und nach erfolgreicher Antragstellung Zugang zu den VIS-Daten bekommen, wobei in dringenden „Ausnahmefällen“ die Prüfung der Zugangsvoraussetzungen auch nachträglich stattfinden kann.

713 Entscheidung des Rates Nr. 2004/512/EG vom 08.06.2004 zur Einrichtung des Visa-Informationssystems (VIS), Amtsblatt L 213/5 vom 15.06.2004.

714 Verordnung (EG) Nr.767/2008 des Europäischen Parlaments und des Rates vom 09.07.2008 über das Visa-Informationssystem (VIS) und den Datenaustausch zwischen den Mitgliedstaaten über Visa für einen kurzfristigen Aufenthalt (VIS-Verordnung), Amtsblatt L 218/60 vom 13.08.2008.

715 Vgl. eu-LISA, VIS Report pursuant to Article 50(3) of Regulation (EC) No 767/2008 and VIS Report pursuant to Article 17(3) of Council Decision 2008/633/JHA, July 2016, 6-7.

716 Verordnung (EG) Nr. 767/2008, Ziff. 5. 
Im VIS wird eine Reihe von Daten gespeichert, die nicht nur die Personen, die den Visumsantrag stellen, betreffen. Neben Namen, Geschlecht, Geburtsdatum und -ort, Nationalität sowie Daten des Visums und des Reisedokuments werden auch die Daten der Personen, die für die Kosten des Aufenthalts sorgen sollen, oder der Arbeitgeber_innen samt Anschrift gespeichert. Außerdem werden im VIS ein Foto der Antragesteller_innen und die Abdrücke aller Finger gespeichert. Wird das Visum als Teil einer mitreisenden Gruppe oder Familie beantragt, werden die Datensätze der verschiedenen Anträge miteinander verknüpft. ${ }^{717}$ Diese Daten werden ab einem bestimmten Datum, zum Beispiel dem Ablauftag eines erteilten Visums, fünf Jahre lang im VIS gespeichert. ${ }^{718}$

Ähnlich wie das SIS besteht das VIS aus einer zentralen Einheit, einer Kommunikationsinfrastruktur, einer nationalen Schnittstelle in jedem Mitgliedstaat und den nationalen Systemen, für deren Betrieb die jeweiligen Mitgliedstaaten zuständig sind. Für den Betrieb des zentralen Systems war zunächst die Kommission zuständig. Am 1. Dezember 2012 wurde die Verantwortung an die eu-LISA weitergegeben, die nun für den Betrieb des SIS II, des VIS und von Eurodac zuständig ist. Die zentrale Einheit enthält ein Subsystem namens „AFIS“, das die biometrischen Verfahren durchführt. ${ }^{719} \mathrm{Um}$ die Suche anhand von biometrischen Daten auch zwischen verschiedenen Systemen zu ermöglichen, wurde das AFIS auch in das SIS eingebaut. ${ }^{720}$

Ende 2019 waren im VIS ca. 66 Millionen Visumsanträge und 69 Millionen Fingerabdruckdatensätze gespeichert. ${ }^{721}$

717 Vgl. Art. 5, 8 und 9 der Verordnung (EG) Nr. 767/2008.

718 Vgl. Art. 23 der Verordnung (EG) Nr. 767/2008.

719 Vgl. eu-LISA, VIS Report pursuant to Article 50(3) of Regulation (EC) No 767/2008, 5 und 7.

720 Vgl. oben, Abschnitt 3.3 im Kapitel 4 und unten, Abschnitt 4.3 in diesem Kapitel.

721 Vgl. eu-LISA, Report on the technical functioning of the Visa Information System (VIS), August 2020, 6-7. Noch im September 2017 waren im VIS ca. 49 Millionen Visumsanträge und 42 Millionen Fingerabdruckdatensätze gespeichert, im September 2015 waren im VIS 17 Millionen Visumsanträge gespeichert. Vgl. eu-LISA, Technical reports on the functioning of VIS as per Article 50(3) of the VIS Regulation and Article 17(3) of the VIS Decision, May 2018, 4 und eu-LISA, VIS Report pursuant to Article 50(3) of Regulation (EC) No 767/2008, 16. 


\subsection{Eurodac}

Die europäische Datenbank Eurodac (eine Zusammensetzung aus den Wörtern „European“ und „dactyloscopy“) dient der Speicherung und dem Vergleich der Fingerabdrücke von Asylbewerber_innen und bei illegaler Einreise aufgegriffenen Drittausländer_innen. ${ }^{722}$ Sie wurde mit der Ratsverordnung Nr. 2725/2000 vom 11. Dezember $2000^{723}$ eingerichtet und ist als erstes System zur biometrischen Identifizierung, das supranational betrieben wird, seit 15. Januar 2003 in Betrieb. ${ }^{724}$ Ziel der Errichtung war es, eine effektivere Umsetzung des Dubliner Übereinkommens vom 15. Juni $1990^{725}$ zu ermöglichen, welches die Zuständigkeiten der Mitgliedstaaten bei der Prüfung von Asylanträgen bestimmt. ${ }^{726}$ Durch den Vergleich mit den in der Datenbank gespeicherten Daten soll geklärt werden, ob eine Person bereits einen Asylantrag in einem Mitgliedstaat gestellt hat, und damit vermieden werden, dass Asylbewerber_innen parallel oder sukzessive Anträge in verschiedenen Ländern stellen.

Die Eurodac-Verordnung verpflichtet die Mitgliedstaaten, von Asylbewerber_innen, die mindestens 14 Jahre alt sind, die Fingerabdrücke aller zehn Finger zu nehmen und diese unverzüglich an die durch die EU

722 Über die Datenbank Eurodac vgl. Schröder, Birgit, Das Fingerabdruckvergleichssystem EURODAC, in: Zeitschrift für Ausländerrecht und Ausländerpolitik, 2, 2001, 71-76; Brouwer, Evelien, Eurodac: Its Limitations and Temptations, in: European Journal of Migration and Law, 4/2, 2002, 231-247 und Brouwer, Digital borders and real rights. Effective remedies for third-country nationals in the Schengen Information System.

723 Verordnung (EG) Nr. 2725/2000 des Rates vom 11.12.2000 über die Einrichtung von „Eurodac“ für den Vergleich von Fingerabdrücken zum Zwecke der effektiven Anwendung des Dubliner Übereinkommens, Amtsblatt L 316/1 vom 15.12.2000.

724 Vgl. Aus, Jonathan P., Eurodac: a solution looking for a problem?/EURODAC: ein Lösungskonzept für ein Problem?, in: European Integration online Papers, 10, 2006.

725 Übereinkommen über die Bestimmung des zuständigen Staates für die Prüfung eines in einem Mitgliedstaat der Europäischen Gemeinschaften gestellten Asylantrags, Amtsblatt C 254/1 vom 19.08.1997; später durch die Verordnung (Eu) Nr. 604/2013 des Europäischen Parlaments und des Rates vom 26.06.2013 zur Festlegung der Kriterien und Verfahren zur Bestimmung des Mitgliedstaats, der für die Prüfung eines von einem Drittstaatsangehörigen oder Staatenlosen in einem Mitgliedstaat gestellten Antrags auf internationalen Schutz zuständig ist (Neufassung), Amtsblatt Nr. L 180/31 vom 29.06.2013 ersetzt.

726 Für eine kritische Auseinandersetzung mit der Annahme, Eurodac sei als Antwort auf ein konkretes Problem eingerichtet worden, vgl. Aus, Eurodac. 
verwaltete Zentraleinheit zu übermitteln. ${ }^{727}$ Dort werden die Fingerabdrücke mit dem Bestand verglichen. Das Ergebnis wird dem Staat automatisch mitgeteilt. Die übermittelten Fingerabdrücke werden außerdem in der Zentraleinheit gespeichert. Die Fingerabdrücke werden in Zusammenhang mit einer Kennnummer, der Eingabe des Staates, der sie abgenommen hat, Platz und Ort des Asylantrags, Geschlecht sowie dem Datum der Abnahme und der Übermittlung an die Zentraleinheit gespeichert. Anders als das SIS und das VIS, enthält Eurodac weder Name noch Adresse der Person; diese Daten werden stattdessen in den nationalen Datenbanken aufbewahrt. Die Daten werden in der Regel für einen Zeitraum von zehn Jahren im System gespeichert.

Neben Asylbewerber_innen müssen die Mitgliedstaaten auch die Fingerabdrücke von Drittausländer_innen nehmen und übermitteln, die mindestens 14 Jahre alt sind und bei illegalem Grenzübertritt aufgegriffen werden. Die Fingerabdrücke von Personen, die bei der illegalen Einreise angetroffen werden, werden zur zentralen Datenbank übermittelt und dort für den zukünftigen Vergleich mit den Fingerabdrücken von Asylbewerber_innen gespeichert. Sie dürfen aber nicht mit den schon gespeicherten Fingerabdrücken oder mit den Fingerabdrücken von illegal Einreisenden, die in Zukunft übermittelt werden, verglichen werden. Die Fingerabdruckdaten werden zusammen mit einer Kennnummer, dem Datum und Ort des Aufgriffs, der Information, welcher Staat die Daten erhoben hat, sowie dem Zeitpunkt der Abnahme und der Übermittlung gespeichert. Die Daten werden zwei Jahre lang aufbewahrt und dann automatisch gelöscht.

Optional können die Mitgliedstaaten in Eurodac auch Fingerabdrücke von Personen eingeben, die sich ohne gültigen Aufenthaltstitel auf ihrem Territorium aufhalten. Diese werden ebenfalls mit den bereits gespeicherten Fingerabdrücken von Asylbewerber_inneagstetrn verglichen, um festzustellen, ob die Person bereits einen Asylantrag gestellt hat; sie werden aber nach Übermittlung der Ergebnisse automatisch gelöscht.

Die Zentraleinheit steht unter der Obhut der EU-Kommission und saß bis zum Jahr 2015 in Luxemburg. Mit Inkrafttreten der Verordnung

727 Über den konkreten Verlauf und die zuständige Behörde in Deutschland vgl. Giegerich, Thomas; Schmitt, Desirée; Kreß, Sabihat, Gutachten zu Rechtsfragen betreffend die Erhebung, Speicherung und Verarbeitung personenbezogener Daten von Flüchtlingen, Saar Expert Papers, 1/2006. 
603/2013 ${ }^{728}$ wurde die Zuständigkeit für den Betrieb der Zentraleinheit an die eu-LISA weitergegeben, die wie erwähnt ebenfalls für den Betrieb des SIS II und des VIS zuständig ist.

Die Verordnung 603/2013 enthält aber auch eine weitreichende, drastische Veränderung von Eurodac: Sie erlaubt nämlich die Nutzung der Datenbank für Gefahrenabwehr- und Strafverfolgungszwecke. ${ }^{729}$ Damit erhalten nationale Strafverfolgungsbehörden wie auch Europol die Berechtigung, den Abgleich von Fingerabdrücken mit dem Eurodac-Datenbestand zu beantragen, wenn dies zur „Verhütung, Aufdeckung und Untersuchung terroristischer und sonstiger schwerer Straftaten " erforderlich ist. ${ }^{730}$

Derzeit sind die EU-Mitgliedstaaten, Europol und vier Schengen-assoziierte Länder, nämlich Island, Liechtenstein, Norwegen und die Schweiz an das System angeschlossen. ${ }^{731}$ Ende 2019 enthielt die Datenbank 5,69 Millionen Datensätze. ${ }^{732}$

728 Verordnung (EU) Nr. 603/2013 des Europäischen Parlaments und des Rates vom 26.06.2013 über die Einrichtung von Eurodac für den Abgleich von Fingerabdruckdaten zum Zwecke der effektiven Anwendung der Verordnung (EU) Nr. 604/2013 zur Festlegung der Kriterien und Verfahren zur Bestimmung des Mitgliedstaats, der für die Prüfung eines von einem Drittstaatsangehörigen oder Staatenlosen in einem Mitgliedstaat gestellten Antrags auf internationalen Schutz zuständig ist und über der Gefahrenabwehr und Strafverfolgung dienende Anträge der Gefahrenabwehr- und Strafverfolgungsbehörden der Mitgliedstaaten und Europols auf den Abgleich mit Eurodac-Daten sowie zur Änderung der Verordnung (EU) Nr. 1077/2011 zur Errichtung einer Europäischen Agentur für das Betriebsmanagement von IT-Großsystemen im Raum der Freiheit, der Sicherheit und des Rechts (Neufassung), Amtsblatt L 180/1 vom 29.06.2013.

729 Vgl. Roots, Lethe, The New EURODAC Regulation: Fingerprints as a Source of Informal Discrimination, in: Baltic Journal of European Studies, 5/2, 2015, $108-129$.

730 Art. 20, Abs. 1 Lit. a und Art. 21, Abs. 1 Lit. a der Verordnung 603/2013.

731 Vgl. eu-LISA, Eurodac - 2019 Annual Report, July 2020, 5.

732 Vgl. ebd., 4. 


\section{Der Ausbau der Datenbanken und ihrer Interoperabilität: kürzlich eingeführte und geplante Maßnahmen}

\subsection{Potenzierung existierender Datenbanken}

Mit der Mitteilung „Solidere und intelligentere Informationssysteme für das Grenzmanagement und mehr Sicherheit" vom 6. April $2016^{733}$ hat die Kommission die Absicht angekündigt, eine Reihe von Vorschlägen vorzubereiten, um unter anderem die Funktionalitäten und Einsatzmöglichkeiten der existierenden Informationssysteme auszuweiten.

Was das SIS angeht, wurden auf Basis der von der Kommission eingereichten Vorschläge 2018 drei Verordnungen erlassen, welche die rechtliche Basis für die Ausweitung darstellen. ${ }^{734}$ Die Verordnungen führen neue

733 Mitteilung der Kommission an das Europäische Parlament und den Rat $\operatorname{COM}(2016) 205$ final. Vgl. auch konkretisierend den „Vorschlag für eine Verordnung des Europäischen Parlaments und des Rates zur Errichtung eines Rahmens für die Interoperabilität zwischen EU-Informationssystemen (polizeiliche und justizielle Zusammenarbeit, Asyl und Migration)" $\operatorname{COM(2017)~} 794$ final, 12.12.2017. Vgl. auch die Fortschrittberichte der Kommission, insbesondere den siebten und achtzehnten, jeweils $\operatorname{COM}(2017) 261$ final, 16.05.2017 und $\operatorname{COM}(2019) 145$ final, 20.03.2019.

734 Verordnung (EU) 2018/1860 des Europäischen Parlaments und des Rates vom 28.11.2018 über die Nutzung des Schengener Informationssystems für die Rückkehr illegal aufhältiger Drittstaatsangehöriger, Amtsblatt der Europäischen Union L 312/1 vom 07.12.2018; Verordnung (EU) 2018/1861 des Europäischen Parlaments und des Rates vom 28.11.2018 über die Einrichtung, den Betrieb und die Nutzung des Schengener Informationssystems (SIS) im Bereich der Grenzkontrollen, zur Änderung des Übereinkommens zur Durchführung des Übereinkommens von Schengen und zur Änderung und Aufhebung der Verordnung (EG) Nr. 1987/2006, Amtsblatt der Europäischen Union L 312/14 vom 07.12.2018 und Verordnung (EU) 2018/1862 des Europäischen Parlaments und des Rates vom 28.11.2018 über die Einrichtung, den Betrieb und die Nutzung des Schengener Informationssystems (SIS) im Bereich der polizeilichen Zusammenarbeit und der justiziellen Zusammenarbeit in Strafsachen, zur Änderung und Aufhebung des Beschlusses 2007/533/JI des Rates und zur Aufhebung der Verordnung (EG) Nr. 1986/2006 des Europäischen Parlaments und des Rates und des Beschlusses 2010/261/EU der Kommission, Amtsblatt der Europäischen Union L 312/56 vom 07.12.2018. Im Folgenden wird vor allem auf die dritte Verordnung Bezug genommen, weil sie die einschlägige für den Bereich der polizeilichen Kooperation ist. Vgl. außerdem die Mitteilung der Kommission an das Europäische Parlament und den Rat "Schengen bewahren und stärken“ $\operatorname{COM}(2017) 570$ final, 27.09.2017. 
Funktionen, neue Ausschreibungskategorien, neue Zugriffsberechtigte sowie neue Datenkategorien ein.

Die neuen Funktionen bestehen in der Möglichkeit, Abfragen auch ausgehend von Licht- und Gesichtsbildern, Handabdrücken und DNA-Profilen einzuleiten. Licht- und Gesichtsbilder wurden vor diesen Neuerungen im SIS II bereits gespeichert, sie wurden jedoch nur benutzt, um die Identität derjenigen Person zu bestätigen, für die es einen Treffer gegeben hat. Die neuen Verordnungen erlauben es, an den regulären Grenzübertrittstellen eine Person anhand ihres Gesichtsbildes im System zu suchen. ${ }^{735}$

Zusätzlich zu Fingerabdrücken werden in den Verordnungen Handabdrücke als im SIS verwendbare daktyloskopische Daten eingeführt. Wie bereits Fingerabdrücke, dürfen diese gemäß den Verordnungen sowohl für die Bestätigung der Identität einer Person als auch für die Suche nach unbekannten Personen benutzt werden, wenn keine anderen Mittel für die Feststellung der Identität einer Person zur Verfügung stehen. In diesem Fall ist nach den Verordnungen die Suche anhand daktyloskopischer Daten nicht mehr nur, wie früher bei Abfragen von Fingerabdrücken, möglich, sondern explizit vorgeschrieben. ${ }^{736}$

DNA-Profile wurden vor der Verabschiedung der Verordnungen nicht im SIS II gespeichert. Nunmehr dagegen sollen DNA-Profile in Ausschreibungen von Vermissten, die unter Schutz oder Gewahrsam genommen werden müssen, hinzugefügt werden, wenn keine Licht- bzw. Gesichtsbilder oder daktyloskopischen Daten für die Identifizierung zur Verfügung stehen. Die DNA-Profile dürfen nur für die Überprüfung der Identität benutzt werden und nicht, um Abfragen einzuleiten. ${ }^{737}$

$\mathrm{Zu}$ den neuen Ausschreibungskategorien gehört die für die Mitgliedstaaten verpflichtende Ausschreibung von Personen, denen ein Einreiseverbot nach der Richtlinie 2008/115/EG über die Abschiebung von Drittstaatsangehörigen erteilt wurde. ${ }^{738}$ Zudem wurde die Ausschreibungskategorie „unbekannte gesuchte Personen“ aufgrund daktyloskopischer Daten eingeführt. Nach dieser Kategorie sollen dringend Tatverdächtige auf schwere oder terroristische Straftaten ausgeschrieben werden, wofür nur Finger-

735 Vgl. Art. 43 Verordnung (EU) 2018/1862.

736 Vgl. ebd., Art. 43 (2).

737 Vgl. Art. 43 (1) und (2) Verordnung (EU) 2018/1862.

738 Richtlinie 2008/115/EG des Europäischen Parlaments und des Rates „über gemeinsame Normen und Verfahren in den Mitgliedstaaten zur Rückführung illegal aufhältiger Drittstaatsangehöriger" vom 16.12.2008, Amtsblatt L 348/98 vom 24.12.2008, vgl. Art. 24 (3) Dok. COM(2016) 882 final. Für diese Kategorie wurde die Verordnung (EU) 2018/1860 vom 07.12.2018 erlassen. 
oder Handabdrücke zur Verfügung stehen und die durch die Abfrage anderer nationaler und supranationaler Datenbanken nicht identifiziert werden konnten. ${ }^{739}$

Die größte Neuerung in puncto Zugriffsberechtigte ist die Erteilung des Zugriffrechts auf das SIS II an die EU-Agentur für die Grenz- und Küstenwache (Frontex). ${ }^{740}$

$\mathrm{Zu}$ den neuen Datenkategorien, die im SIS II gespeichert werden können, gehören, neben den bereits erwähnten Handabdrücken und DNAProfilen, Angaben zu Ausweis- und Reisedokumenten der ausgeschriebenen Personen sowie Farbkopien dieser Dokumente. ${ }^{741}$ Weitere Datenkategorien sind für Fälle des Identitätsmissbrauchs vorgesehen. ${ }^{742}$

Die maximale reguläre Speicherzeit für die im SIS II eingegebenen Daten wurde zudem für einige Ausschreibungskategorien von drei auf fünf Jahre erhöht. ${ }^{73}$

Die Kommission hat zudem Änderungen für das VIS vorgeschlagen. Diese sehen unter anderem vor, den Abgleich biometrischer Daten und die Verwendung biometrischer Daten von Visumsantragsteller_innen für die Suche im SIS zu ermöglichen sowie die Altersgrenze für die Erfassung von Fingerabdrücken bei Kindern auf sechs Jahre abzusenken. Zudem beabsichtigt die Kommission, den rechtlichen Rahmen für den Zugang zum VIS durch die Strafverfolgungsbehörden zu überprüfen und eventuell zu ändern. ${ }^{74}$

Was Eurodac betrifft, soll das System in Zukunft ermöglichen, nicht mehr nur Asylbewerber_innen zu identifizieren, sondern auch „Sekundärbewegungen illegaler Migranten zwischen den Mitgliedstaaten zu überwachen“, um dadurch die Abschiebungsverfahren zu vereinfachen und

739 Vgl. Art. 40 Verordnung (EU) 2018/1862.

740 Vgl. ebd., Art. 50.

741 Vgl. ebd., Art. 20.

742 Vgl. ebd., Art. 62.

743 Vgl. Art. 53 Verordnung (EU) 2018/1862.

744 Vgl. $\operatorname{COM(2016)~} 205$ final, 10. Vgl. als Folgemaßnahme den Vorschlag für eine Verordnung des Europäischen Parlaments und des Rates zur Änderung der Verordnung (EG) Nr. 767/2008, der Verordnung (EG) Nr. 810/2009, der Verordnung (EU) 2017/2226, der Verordnung (EU) 2016/399, der Verordnung (EU) 2018/XX [Interoperabilitäts-Verordnung] und der Entscheidung 2004/512/EG sowie zur Aufhebung des Beschlusses 2008/633/JI des Rates, COM/2018/302 final, 16.05.2018. 
zu beschleunigen. ${ }^{745}$ Ebenfalls wird beabsichtigt, die Fingerabdrücke von Kindern ab sechs Jahren zu erfassen. ${ }^{76}$

\subsection{Einführung zusätzlicher Informationssysteme}

Wie erwähnt hat die Kommission bereits 2016 das Ziel angekündigt, neue Informationssysteme zu schaffen und die Vernetzung zwischen bestehenden Informationssystemen und mit zukünftigen zu intensivieren. Ziel dieser Maßnahmen ist es, eine lückenlose Abdeckung der Strafverfolgungsund Grenzmanagementdaten zu ermöglichen. ${ }^{77}$

Tatsächlich wurde 2017 neben der Errichtung des PNR-Systems ${ }^{748}$ auch die Errichtung eines Einreise/Ausreise-Systems (EES) verabschiedet. ${ }^{749}$ Letzteres System wird derzeit von der Agentur eu-LISA entwickelt und soll die Grenzübertritte von visumspflichtigen und visumsbefreiten Drittausländer_innen erfassen, die den Schengener Raum für einen Kurzaufenthalt betreten. Durch die Erfassung der Ausreisedaten sollen Fälle aufgedeckt werden, in denen legal eingereiste Drittausländer_innen sich über die zugelassene Dauer hinaus im Schengener Raum aufhalten. Das Informationssystem soll als zentralisierte europäische Datenbank errichtet und von der EU-Agentur eu-LISA betrieben werden. Es wird alphanumerische und biometrische Daten enthalten und sowohl für Behörden zugänglich sein, die für die Visa-Erteilung und andere Aufenthaltsfragen zuständig sind, als auch für Strafverfolgungsbehörden. ${ }^{750}$

$745 \operatorname{COM}(2016) 205$ final, 10-11.

746 Vgl. Vorschlag für eine Verordnung des Europäischen Parlaments und des Rates über die Einrichtung von Eurodac für den Abgleich von Fingerabdruckdaten zum Zwecke der effektiven Anwendung der [Verordnung (EU) Nr. 604/2013 zur Festlegung der Kriterien und Verfahren zur Bestimmung des Mitgliedstaats, der für die Prüfung eines von einem Drittstaatsangehörigen oder Staatenlosen in einem Mitgliedstaat gestellten Antrags auf internationalen Schutz zuständig ist], für die Feststellung der Identität illegal aufhältiger Drittstaatsangehöriger oder Staatenloser und über der Gefahrenabwehr und Strafverfolgung dienende Anträge der Gefahrenabwehr- und Strafverfolgungsbehörden der Mitgliedstaaten und Europols auf den Abgleich mit Eurodac-Daten (Neufassung), COM/ 2016/0272 final, 04.05.2016, 4 und 15.

$747 \mathrm{Vgl.} \operatorname{COM}(2016) 205$ final, 14.

748 Vgl. Kapitel 6.

749 Verordnung (EU) 2017/2226 vom 30.11.2017.

750 Vgl. $\operatorname{COM}(2016) 205$ final, 14 und Verordnung (EU) 2017/2226, Art. 5-7 und $23-35$. 
In Bezug auf visumsbefreite Drittausländer_innen würde allerdings eine solche Datenerfassung nur für Reisende möglich sein, die auf dem Luftoder Seeweg einreisen, nicht aber für diejenigen, die auf dem Landweg in den Schengener Raum eintreten. Für diese Fälle hat die Kommission die Einrichtung eines EU-Reiseinformations- und Genehmigungssystems (ETIAS) vorgeschlagen. ${ }^{751}$ Diese wurde 2018 beschlossen, sodass nun die Agentur eu-LISA mit der Errichtung des Systems beauftragt wurde. ${ }^{752}$ Das System basiert auf den Angaben, welche die Reisenden vor Beginn der Reise in ein Online-Formular selbst eingeben, und soll eine Risikoabschätzung liefern, anhand derer die Einreisegenehmigung erteilt oder verweigert wird.

Ebenfalls wird die Machtbarkeit eines Europäischen Polizeiregisterinformationssystems (EPRIS) geprüft, das die direkte Abfrage nationaler Polizeiregister durch die Behörden anderer Staaten erlauben soll. ${ }^{753}$

\subsection{Interoperabilität der Informationssysteme: der Aufbau einer zentralen EU-Superdatenbank}

Neben der Errichtung neuer Systeme soll nach Ansicht der Kommission die Interoperabilität der verschiedenen europäischen Datenbanken ausgebaut werden. Die Kommission unterscheidet zu diesem Zweck zwischen vier Aspekten der Interoperabilität. Diese reichen von der Abfrage verschiedener Systeme durch eine zentralisierte Schnittstelle bis hin zur Errichtung eines gemeinsamen Datenspeichers, der die Kerndaten aller Informationssysteme enthalten soll. ${ }^{754}$

Die erste Stufe der Interoperabilität, nämlich die gleichzeitige Abfrage verschiedener Datenbanken durch eine zentrale Schnittstelle, wird bereits in etlichen Mitgliedsländern praktiziert. Die Kommission zielt darauf ab, in Zusammenarbeit mit der eu-LISA eine standardisierte Lösung für die zentralisierte Abfrage der Informationssysteme zu entwickeln und diese in allen Mitgliedstaaten einzuführen.

751 Vgl. COM(2016) 205 final, 15-16. Vgl. auch COM (2016) 272 final, 04.05.2016.

752 Vgl. Verordnung (EU) 2018/1240 des Europäischen Parlaments und des Rates vom 12.09.2018 über die Einrichtung eines Europäischen Reiseinformationsund -genehmigungssystems (ETIAS) und zur Änderung der Verordnungen (EU) Nr. 1077/2011, (EU) Nr. 515/2014, (EU) 2016/399, (EU) 2016/1624 und (EU) 2017/2226, Amtsblatt der Europäischen Union L 236/1 vom 19.09.2018.

753 Vgl. Verordnung (EU) 2018/1240 vom 12.09.2018, 16.

754 Vgl. ebd., 17. 
Die zweite von der EU angestrebte Stufe der Interoperabilität besteht in der Vernetzung der Informationssysteme. Dadurch soll es möglich werden, die in einer Datenbank gespeicherten Informationen automatisch und zentral durch ein anderes System abzufragen. Eine solche Möglichkeit soll im geplanten EES eingebaut sein, wodurch das System mit dem VIS vernetzt werden kann. Die Kommission wird zudem prüfen, ob auch das SIS mit den beiden Systemen sowie Eurodac mit dem SIS verbunden werden können..$^{755}$

Der dritte Aspekt der Interoperabilität besteht im Abgleich biometrischer Daten, die in verschiedenen Systemen gespeichert sind. Die Kommission will die Machtbarkeit eines gemeinsamen Dienstes für den Abgleich biometrischer Daten prüfen, die im SIS, EES, VIS und in der Eurodac-Datenbank gespeichert sind. ${ }^{756} 2019$ schrieb die EU-Kommission einen Auftrag für die Entwicklung eines „BMS“ (Biometric Matching System) aus, das die gleichzeitige Suche anhand von Gesichtsbildern und daktyloskopischen Daten in verschiedenen EU-Datenbanken ermöglichen soll. ${ }^{757}$

Schließlich sieht die Kommission als langfristiges Ziel der Interoperabilität die Errichtung eines zentralen EU-Datenspeichers vor, der die Kerndaten aller europäischen Informationssysteme enthält, wie etwa alphanumerische und biometrische Daten. Zusatzinformationen, die datenbankspezifisch sind, wie etwa Visumsdaten, sollen in besonderen Modulen gespeichert und nach gezielter Abfrage abgerufen werden können. ${ }^{758}$

Der Plan der Kommission wurde 2018 durch einen Verordnungsvorschlag konkretisiert, welcher vier Komponenten der Interoperabilität der Informationssysteme beinhaltet. ${ }^{759}$ Diese sind erstens das Europäische Suchportal (ESP) für die gleichzeitige Abfrage mehrerer Systeme anhand

755 Vgl. Verordnung (EU) 2018/1240 vom 12.09.2018, 19-20.

756 Vgl. ebd., 20-21.

757 Vgl. Estonia-Tallinn: Framework Contract for Implementation and Maintenance in Working Order of the Biometrics Part of the Entry Exit System and Future Shared Biometrics Matching System2019/S 092-221106, OJ/S S92 vom 14.05.2019, Dok. 221106-2019-EN und Monroy, Matthias, Projekt Interoperabilität - EU zahlt 300 Millionen Euro für Erkennung von Gesichtern und Fingerabdrücken, in: Netzpolitik.org, 05.06.2020.

758 Vgl. ebd., 21-22.

759 Vgl. Geänderter Vorschlag für eine Verordnung des Europäischen Parlaments und des Rates zur Errichtung eines Rahmens für die Interoperabilität zwischen EU-Informationssystemen (polizeiliche und justizielle Zusammenarbeit, Asyl und Migration) und zur Änderung der [Verordnung (EU) 2018/XX [EurodacVerordnung], der Verordnung (EU) 2018/XX [Verordnung über das SIS im Bereich der Strafverfolgung], der Verordnung (EU) 2018/XX [ECRIS-TCN-Verord- 
biografischer und biometrischer Identitätsdaten. Zweitens würde es der gemeinsame Dienst für den Abgleich biometrischer Daten (gemeinsamer BMS) ermöglichen, biometrische Daten aus mehreren EU-Zentralsystemen abzufragen und abzugleichen. Drittens würde der gemeinsame Speicher Identitätsdaten (CIR) von Drittstaatsangehörigen beinhalten, die in anderen EU-Systemen gespeichert sind. Schließlich würde der Detektor für Mehrfachidentitäten überprüfen, ob bestimmte Identitätsdaten in mehr als einem System gespeichert sind. Die jetzigen Pläne der Kommission betreffen die zentralen EU-Systeme, es ist aber bereits die Möglichkeit vorgesehen, zu einem späteren Zeitpunkt auch die dezentralisierten Datenbanken (wie diejenigen nach der PNR-Richtlinie) mit den Interoperabilitätskomponenten zu verknüpfen. ${ }^{760}$

Die Grafik unten bildet den geplanten Dienst für den Abgleich biometrischer Daten bzw. den zentralen Datenspeicher nach Darstellung der Kommission ab. ${ }^{761}$

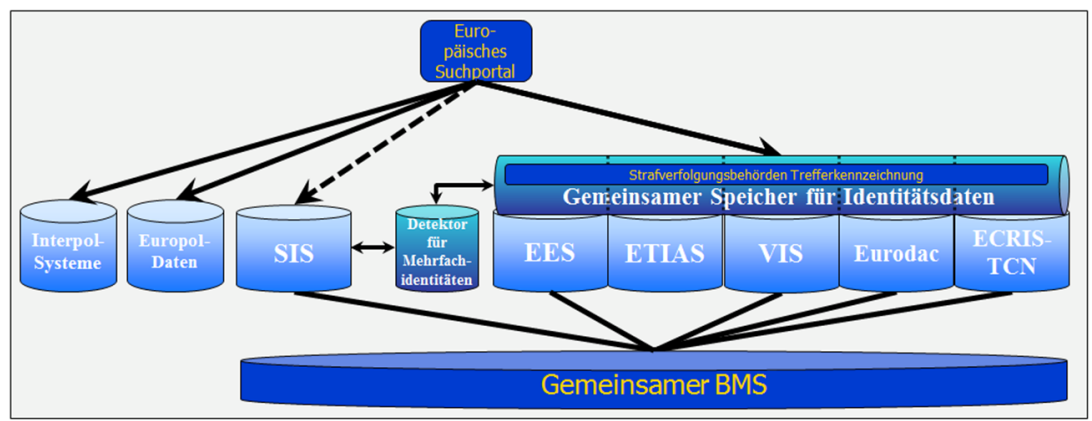

Abbildung 1: Geplante Komponenten für die Interoperabilität der EU-Informationssysteme (Quelle: EU-Kommission 2018)

nung] und der Verordnung (EU) 2018/XX [eu-LISA-Verordnung], COM(2018) 480 final, 13.06.2018.

760 Vgl. ebd., 6.

761 Vgl. ebd., 7. 


\section{Teil III Sicherheit als Präemption, Autonomie als Infragestellung. Theoretische und normative Anregungen}

The story is sometimes told of the man who was lost somewhere in Scotland, and asked a farmer if he could tell him which was the way to Edinburgh. 'Oh sir,' the farmer replied, 'if I were you, I shouldn't start from here!'

H. Bull, The Anarchical Society, 295

Recognizing what we say, what we do, what we feel, who we are, can mean giving up some dreams of change as impossible; but it can also be a foundation - perhaps the only effective foundation - for genuine change. H. F. Pitkin, Wittgenstein and Justice, 338 


\section{Kapitel 8 Ein neuer sicherheitspolitischer Ansatz: Grundeigenschaften und Herausforderungen für die normative Ordnung}

\section{Die Logik der EU-Sicherheitspolitik im RFSR}

In diesem Kapitel werde ich die Argumentationsfäden, die sich vom dritten bis zum siebten Kapitel des Buches erstrecken, zusammenziehen und dabei versuchen, die Haupttendenzen der EU-Sicherheitspolitik im RFSR zu fixieren. Die Analyse der Fallbeispiele hat gezeigt, dass sich das Sicherheitskonzept im Laufe des Aus- und Aufbaus des RFSR verändert hat. ${ }^{762}$ Nicht nur hat Sicherheit Priorität vor den anderen beiden Konzepten der Trias und dabei auch vor Freiheit als logischem Kernelement gewonnen. Sicherheit droht am Ende auch diese ursprüngliche Idee der Freiheit als Freizügigkeit wieder einzuschränken. Dabei hat Sicherheit vor allem eine präemptive Komponente hinzugewonnen, die sie sowohl von präventiven als auch von reaktiven Modellen der Sicherheit unterscheidet. ${ }^{763}$

Daher können meines Erachtens die zwei bedeutendsten Eigenschaften der aktuellen EU-Sicherheitspolitik als Zirkularität und Präemption zusammengefasst werden. In welchem Sinn der sicherheitspolitische Ansatz der EU als zirkulär bezeichnet werden kann, wird im nächsten Abschnitt verdeutlicht. Dabei werde ich auf die Entwicklung des RFSR im Allgemeinen, die ich insbesondere in den Kapiteln 3 und 7 nachverfolgt habe,

762 Für eine Kontextualisierung des Wandels von Sicherheitskonzeptionen in der Moderne vgl. den zweiten Teil von Zoche; Kaufmann; Haverkamp (Hg.), Zivile Sicherheit. Gesellschaftliche Dimensionen gegenwärtiger Sicherheitspolitiken und insbesondere die Beiträge von Wolfgang Bonß, Hans-Jörg Albrecht, Rudolf Egg und Christopher Daase.

763 Eine unterschiedliche Kategorisierung wird von Ulrich Bröckling vorgeschlagen, wonach nicht scharf zwischen Prävention und Präemption unterschieden wird und präemptive Strategien zum allgemeinen Modell der Prävention gehören. Jedoch differenziert Bröckling innerhalb der Prävention zwischen drei „Vorbeugungsregimen": Hygiene als Verhütung von Infektionskrankheiten, Immunisierung und Vorsorgeprinzip. Dieses letzte Prinzip, insbesondere in der von Bröckling beschriebenen zweiten, post-9/11-Variante, stimmt meiner Meinung nach in groben Linien mit dem von mir im Folgenden skizzierten Modell der präemptiven Sicherheit überein. Vgl. Bröckling, Ulrich, Gute Hirten führen sanft. Über Menschenregierungskünste. Berlin: Suhrkamp 2017, 73-112. 
Bezug nehmen. Im dritten Abschnitt dieses Kapitels arbeite ich die Rationalität der Sicherheitsmaßnahmen aus, die sich mehr und mehr als kennzeichnend für den sicherheitspolitischen Ansatz der EU erweist: das präemptive Sicherheitsmodell. Dabei werde ich mich zunächst auf die Analysen der drei Fallbeispiele, insbesondere der PNR-Richtlinie, stützen, die ich in den Kapiteln 4, 5 und 6 durchgeführt habe.

\section{Zirkuläre Sicherheit}

\subsection{Von der Unterstützung des Marktes zum selbstständigen Zweck}

Im siebten Kapitel dieses Buches habe ich die Analysen der speziellen Maßnahmen mit der allgemeinen Entwicklung der Sicherheitspolitik im RFSR in Verbindung gebracht.

Das ursprüngliche Phänomen, das die Maßnahmen im RFSR hervorgebracht hat, ist der europäische freie Markt mit seinen Grundfreiheiten. Diese Grundfreiheiten beziehen sich auf die freie Zirkulation der Waren, Personen, Dienstleistungen und des Kapitals. Es ist also ein sehr spezifisches Konzept von Freiheit, das hier realisiert werden soll, nämlich Freiheit als Freizügigkeit. Individuen sollen sich frei bewegen können, und die Hindernisse dazu müssen abgebaut werden. Staaten müssen also auf ihre Grenzkontrollen womöglich verzichten. Das bedeutet nur auf den ersten Blick eine Zurückhaltung der öffentlichen Gewalt, denn um zu garantieren, dass das Potenzial des freien Marktes sich voll entfalten kann und die Bedingungen der freien Zirkulation erhalten bleiben, bedarf es aktiver, öffentlicher Interventionen. Der Impuls für den Ausbau der Sicherheitsmaßnahmen ergibt sich aus dieser Logik: Es soll gesichert werden, dass die freie Zirkulation von Menschen, Waren, Dienstleistungen und Kapital reibungslos funktioniert. Der europäische freie Markt ist also das ursprüngliche Phänomen, das den Impuls für die Schaffung des RFSR gab. In diesem Raum ist Freiheit als Freizügigkeit der ursprüngliche Begriff und Wert: Die anderen beiden Begriffe, nämlich Sicherheit und Recht, sind gegenüber dem Freiheitsbegriff funktional.

In dem Prozess, im Rahmen dessen die Sicherheitsmaßnahmen im RFSR realisiert werden, findet jedoch ein Umbruch statt. Die ergriffenen Sicherheitsmaßnahmen sind keine Antwort auf ein konkretes Sicherheitsproblem und scheinen bald eine eigene, von den Herausforderungen des freien Marktes losgelöste Logik zu entfalten. Tatsächlich wurde durch die Implementierung des freien Marktes ein erwarteter Anstieg der Krimi- 
nalität, etwa durch Studien des BKA, belegt. Dessen Ursachen wurden aber vor allem in der freien Zirkulation der Waren und des Kapitals ausgemacht und hätten eine gestiegene Kontrolle dieser erfordert. Der Ausbau der Kontrolle fokussiert sich aber im RFSR auf Personen und wird als eine Kompensation des Wegfalls der Grenzkontrollen gerechtfertigt. Die Verbindung zwischen Abbau der Personenkontrolle an den Grenzen und dem Anstieg der Kriminalität wurde dabei jedoch weder im Vorfeld plausibilisiert noch im Nachhinein überprüft. Nichtsdestotrotz findet eine doppelte Verschiebung statt: von der Grenzkontrolle zur Sicherheit durch grenzunabhängige Personenkontrolle und von Waren und Kapital auf Personen.

Die Sicherheitsmaßnahmen des RFSR sind also im Kern eine Form der Personenkontrolle, die sich von der ursprünglichen Logik der Kompensation als Pendant des freien Marktes losgelöst und sich über seine Grenzen hinaus verbreitet hat. Das Sicherheitsargument hat als Machtkatalysator funktioniert, der die für gültig gehaltene Legitimitätsschwelle absinken ließ. Denn je ernster das Sicherheitsproblem, auf das eine Antwort gegeben werden soll, desto niedriger sind die Standards, die eingehalten werden müssen, damit „die Lösung nicht Teil des Problems“ wird. Folgerichtig ist nunmehr die Kraft, die den Machtausbau im RFSR vorantreibt, nicht mehr vom ursprünglichen Bereich des Marktes bestimmt, sondern entspringt aus einer Eigenlogik. Es ist die Logik der Lückenschließung, wonach durch die Abdeckung bestimmter Phänomene diejenigen sichtbar werden, die durch Kontrolle noch nicht abgedeckt werden und die damit neue Maßnahmen hervorrufen. Dabei ist Sicherheit durch grenzunabhängige Personenkontrolle ein Zweck an sich geworden, der sich unabhängig von den Herausforderungen des freien Marktes rechtfertigen lässt.

\subsection{Die „Logik der Lückenschließung“ des EU-Informationsaustauschs und seine Paradoxa}

Im Zuge dieses Ausbaus, wie im siebten Kapitel dargestellt, haben die europäischen Datenbanken des RFSR im letzten Jahrzehnt eine signifikante Ausdehnung erlebt. Diese ist auf verschiedenen Ebenen erfolgt.

Erstens ist die Verflechtung zwischen Sicherheitsgewährleistung sowie Grenz- und Migrationspolitik verstärkt worden. Während das SIS und das VIS von Anfang an als Systeme mit dieser doppelten Funktion gedacht waren, ist der Einsatz von Eurodac für Strafverfolgungs- und Gefahrenabwehrzwecke erst nachträglich im Jahr 2013 eingeführt worden. Auch 
die geplante zunehmende Vernetzung dieser Systeme untereinander läuft einer Trennung dieser Zwecke zuwider.

Zweitens ist eine Ausdehnung hinsichtlich der Nutzung biometrischer Daten erfolgt. Wie erwähnt, ist es seit 2017 erlaubt, verschiedene Arten biometrischer Daten im SIS nicht nur wie bisher für die Identitätsfeststellung, sondern auch für die Suche im System zu benutzen. ${ }^{764}$ Eine solche Funktion ist im VIS bereits eingebaut und wird entsprechend genutzt. ${ }^{765}$ Zudem ist es nun im SIS möglich, Ausschreibungen von Unbekannten anhand von deren Fingerabdrücken einzugeben. DNA-Profile, eine Datenkategorie, die bisher nicht im SIS vertreten war, werden nun für die Identitätsbestätigung von Vermissten eingeführt. Schließlich ist die geplante Intensivierung der Vernetzung der Datenbanken auch hinsichtlich der Nutzung biometrischer Daten bedeutsam, da wie erwähnt derzeit die technischen Voraussetzungen geschaffen werden, um die verschiedenen Informationssysteme anhand von Gesichtsbildern, Fingerabdrücken und anderen daktyloskopischen Daten zentralisiert abzufragen. ${ }^{766}$

Drittens deuten verschiedene andere Maßnahmen, wie die beschlossene Erhöhung der Speicherzeit oder die Erweiterung des Kreises der Zugriffsberechtigten im SIS, ebenfalls auf eine Ausdehnung der Möglichkeiten der europäischen Datenbanken hin.

Schließlich scheinen die Entwicklungen auf EU-Ebene paradigmatisch für die Tendenzen zu sein, die Ralf Poscher als kennzeichnend für das gesamte Feld der zivilen Sicherheit identifiziert hat. ${ }^{767}$ Dazu gehören die Internationalisierung der Sicherheitsmaßnahmen, deren Zentralisierung, die Verschmelzung von Repression und Prävention sowie von Polizei und Geheimdiensten einerseits und Polizei und Militär andererseits. Insbesondere scheint die Stärkung der Interoperabilität der europäischen Informationssysteme die Dynamiken der Internationalisierung und der Zentralisierung zu verschmelzen und auf eine neue Ebene zu heben. Denn Zentralisierung findet hier unmittelbar auf supranationaler Ebene statt und zeigt in Richtung eines gesamten und zentralisierten europäischen Meta-Informationssystems. Was die Verschmelzung von Repression und

764 Wie erwähnt (vgl. Kapitel 4 oben) war eine solche Nutzung von Fingerabdrücken bereits vor 2017 rechtlich erlaubt, aber technisch noch nicht möglich. Für andere Arten biometrischer Daten, wie Lichtbilder und DNA-Profile, ist die rechtliche Grundlage für die Recherchefunktion erst 2017 geschaffen worden.

765 Vgl. eu-LISA, Report on the technical functioning of the Visa Information System (VIS), August 2020, 4.

766 Vgl. oben, Kapitel 7, Abschnitt 4.3.

767 Vgl. Poscher, Tendencies in Public Civil Security Law. 
Prävention angeht, scheint diese sich auf EU-Ebene durch eine Verschiebung zu einem dritten Ansatz zu manifestieren, wie ich im nächsten Abschnitt anhand des Paradigmas der präemptiven Sicherheit argumentieren werde. Die letzte Tendenz, die Poscher erwähnt, nämlich die in zwei Bereichen stattfindende Verschmelzung der Kompetenzen verschiedener Behörden (von Polizei und Geheimdiensten einerseits und von Polizei und Militär andererseits), scheint mir im Fall der EU-Informationssysteme vor allem durch die Zunahme der Verwendung der Informationssysteme für verdeckte Kontrollen und als Verschmelzung zwischen Sicherheits- und Grenzmanagementmaßnahmen stattzufinden.

Diese Verschiebungen und Ausweitungen bedeuten nicht nur einen quantitativen Sprung, sondern auch eine qualitative Veränderung. Wie schon in Bezug auf das SIS erwähnt, verändert allein die Möglichkeit, aufgrund von biometrischen Daten Suchen einzuleiten, die Natur des Systems. Waren bisher das SIS und das VIS Systeme, die spezifische Fragen für einen bestimmten Zweck beantworten sollten (etwa „Ist diese Person schon verurteilt worden?“ oder „Hat diese Person ein gültiges Visum?"), werden sie nun aufgrund der neuen Funktionen zu Systemen, die bisher unbekannte Verbindungen herstellen können (etwa zwischen zwei daktyloskopischen Spuren, die niemandem zugeordnet werden können). Die bereits existierenden und geplanten Verbindungen zwischen den Informationssystemen potenzieren diese Fähigkeit, neue Verbindungen herzustellen. Die parallele Abfrage verschiedener Systeme und die Vernetzung dieser miteinander erlauben es, umfangreiche Personenprofile zu erzeugen. Zum Beispiel kann eine Suche in mehreren Datenbanken gleichzeitig Auskunft darüber geben, ob eine Person etwa als Zeuge in einem gerichtlichen Verfahren gesucht wird (SIS), über Name und Adresse der Arbeitgeberin eines Ausländers während seines früheren visumspflichtigen Aufenthalts (VIS) und möglicherweise, durch eine zukünftige Verbindung mit dem PNR-System, über frühere Reiseziele der Arbeitgeberin. Damit entsteht ein umfassendes Bild der Person, inklusive der Kontakte zu Unbeteiligten, ohne dass im Vorfeld entschieden werden muss, welche Informationen relevant sein können.

Die Logik, die dieser Erweiterung unterliegt, ist eine der „Lückenschließung“. Die existierenden Informationssysteme werden von der EUKommission als Erfolgsmaßnahmen beschrieben; jedoch werden regelmäßig nach den Erfolgen die noch bevorstehenden Herausforderungen und die noch nicht durch die Datenerfassung abgedeckten Bereiche erwähnt. 
Folgende Schlussfolgerungen zieht zum Beispiel die Kommission 2016 aus einem Evaluationsbericht über das SIS:

Das SIS II wird vor dem Hintergrund größter Besorgnisse bezüglich der inneren Sicherheit, grenzüberschreitenden Kriminalität und irregulären Migration betrieben - einige der schwerwiegendsten Herausforderungen weltweit. Die Gesamtevaluierung bestätigt den herausragenden operativen und technischen Erfolg dieses Systems. Offenkundig können kein operatives System und keine diesbezügliche Rechtsgrundlage jemals vollkommen sein; deshalb hat die Kommission für die Zwecke der kontinuierlichen Verbesserung des SIS II [...] Möglichkeiten zur weiteren Steigerung von Wirksamkeit, Effizienz, Bedeutung und Kohärenz sowie zur Förderung des EU-weiten Mehrwerts des SIS II identifiziert [...]..$^{768}$

Analog führt die Kommission zur Begründung des Vorschlags zur Einführung neuer Datenbanken Folgendes aus:

Die bestehenden Informationssysteme decken ein sehr breites Spektrum von Daten ab, die für das Grenzmanagement und die Strafverfolgung benötigt werden. Dennoch gibt es noch große Lücken. Die Kommission hat, um einige dieser Lücken zu beseitigen, Legislativvorschläge zur Schaffung eines Einreise-/Ausreisesystems sowie für eine EU-weite Erfassung von Fluggastdatensätzen vorgelegt. Bei anderen erkannten Lücken gilt es sorgfältig zu prüfen, ob zusätzliche EU-Instrumente erforderlich sind. ${ }^{769}$

Wie im sechsten Kapitel erwähnt, spielen gegenwärtig ähnliche Überlegungen bei der Definition der zukünftigen Gestaltung der PNR-Maßnahmen eine Rolle, die sich auf nicht kriminalistische Datenbanken erstrecken. Die Entscheidung, nicht kriminalistische Daten für Zwecke der Kriminalitätsbekämpfung zu verwenden, führt zu einer Art Spirale der Verifizierung. Da die PNR-Daten aktuell etwa nicht das Geburtsdatum erfassen, führt der Abgleich mit behördlichen Datenbanken zu Fehltreffern. Um die Genauigkeit der PNR-Maßnahmen zu erhöhen, wäre es daher

768 Bericht der Kommission an das Europäische Parlament und den Rat über die Evaluierung des Schengener Informationssystems der zweiten Generation (SIS II) nach den Art. 24 Abs. 5, Art. 43 Abs. 3 und Art. 50 Abs. 5 der Verordnung (EG) Nr. 1987/2006 in Verbindung mit den Art. 59 Abs. 3, Art. 66 Abs. 5 und Art. 66 Abs. 5 des Beschlusses 2007/533/JI vom 21.12.2016 COM(2016) 880 final, 18.

$769 \operatorname{COM}(2016) 205$ final, 14. 
nach Ansicht der Kommission sinnvoll, den Fluggesellschaften (und eventuell auch den Reisebüros) vorzuschreiben, bei der Buchung auch das Geburtsdatum zu erfassen und dieses den Behörden zu übermitteln. Je mehr nicht kriminalistische (d. h. nicht verifizierte) Daten für Behördenzwecke verwendet werden, desto stärker könnte diese Verifizierungs- oder Identifizierungsspirale auch in nicht behördlichen Kontexten werden. ${ }^{770}$

Durch diese Logik entsteht das Paradoxon, das unter dem Begriff der „Sicherheitsspirale“ bekannt ist: Das Versprechen nach Sicherheit ruft Erwartungen hervor, an denen die Ergebnisse zwar gemessen werden, die aber nie vollständig erfüllt werden können. Stattdessen werden neue Sicherheitslücken identifiziert, wofür ein erhöhter Ressourceneinsatz benötigt wird, der aber wiederum nicht genügen wird, um dem Versprechen einer umfassenden Sicherheit gerecht zu werden. ${ }^{771}$

Zudem verweist das Sicherheitsparadoxon auf die Eigenlogik der Sicherheitsmaßnahmen: Einmal eingeleitet zielen sie auf Selbststeigerung aus eigenem Antrieb, statt auf erhöhte äußere Bedrohungen oder Gefahren zu reagieren. Und das, selbst wenn ihnen wie im Falle der analysierten EU-Maßnahmen eine Widersprüchlichkeit mit den grundlegenden Zielen der EU innewohnt, wie etwa die Auswertung der Mobilitätsdaten aller

770 Neuerdings wurde etwa vom deutschen Bundesinnenministerium gefordert, eine Ausweisepflicht für Nutzer_inenn von Online-Diensten wie E-Mails und Messenger einzuführen, damit diese Daten für Strafverfolgungen zur Verfügung gestellt werden können. Vgl. Reuter, Markus, TKG-Novelle. Seehofer will Personalausweis-Pflicht für E-Mail und Messenger einführen, in: Netzpolitik.org, 03.03.2021.

771 Vgl. auch Münkler, Herfried, Strategien der Sicherung: Welten der Sicherheit und Kulturen des Risikos. Theoretische Perspektiven, in: Münkler, Herfried; Bohlender, Matthias; Meurer, Sabine (Hg.), Sicherheit und Risiko. Über den Umgang mit Gefahr im 21. Jahrhundert. Bielefeld: Transcript 2010, 11-34, hier 12-13 und Gander, Hans-Helmuth, Das Verlangen nach Sicherheit. Anthropologische Befunde, in: Heckmann, Dirk; Schenke, Ralf P.; Sydow, Gernot (Hg.), Verfassungsstaatlichkeit im Wandel. Festschrift für Thomas Würtenberger zum 70. Geburtstag. Berlin: Duncker \& Humblot 2013, 983-993. Über das Verhältnis zwischen der individuellen und der gesellschaftlichen Dimension von Sicherheit vgl. Kaufmann, Franz-Xaver, Sicherheit als soziologisches und sozialpolitisches Problem: Untersuchungen zu einer Wertidee hochdifferenzierter Gesellschaften. Münster; Berlin: Ferdinand Enke Verlag 1973, 24-28 und über die Verflechtung zwischen Sicherheit und Unsicherheit Kaufmann, Stefan, Security Through Technology? Logic, Ambivalence and Paradoxes of Technologised Security, in: European Journal for Security Research, 1/1, 2016, 77-95. 
Fluggäste (mit möglichen Mobilitätseinschränkungen als Folge) oder die Idee, Reisegenehmigungen für visumsbefreite Reisende einzuführen. ${ }^{772}$

In diesen Fällen überrollt die Eigendynamik der EU-Sicherheitsmaßnahmen ebenjene Ziele, für deren Unterstützung sie hätten dienen sollen. Wie in Kapitel 3 geschildert, wurden die Sicherheitsmaßnahmen im RFSR anfänglich als Ausgleich zur Realisierung des freien Personenverkehrs eingeführt. Im Nachhinein haben sie jedoch diesen unterstützenden Charakter verloren und sich zu einem eigenständigen Bereich entwickelt.

In diesem Zusammenhang hat der Sicherheitsaspekt zunehmend eine das ursprünglich primäre Element der Freiheit überragende Bedeutung gewonnen. Nun haben die Sicherheitsmaßnahmen ein Ausmaß erreicht, das nicht nur andere Grundrechte, wie das Recht auf Privatleben und auf Schutz der personenbezogenen Daten, sondern auch den Kern der EU-Freiheiten, nämlich die Bewegungsfreiheit, einschränkt. Das gilt außerdem nicht nur für diejenigen, die von Anfang an von ihrem Genuss ausgeschlossen waren, sondern auch für diejenigen, die als EU-Bürger_innen oder durch die Befreiung von der Visumspflicht eigentlich Adressat_innen der erweiterten Bewegungsfreiheit wären.

\section{Sicherheit als Präemption}

3.1 Die Durchsetzung der präemptiven Logik als richtungsweisend für die EU-Sicherheitspolitik

In diesem Abschnitt wird eine weitere Tendenz der EU-Sicherheitspolitik im RFSR herausgearbeitet: nämlich ihre präemptive Ausrichtung. Im RFSR, wie auch die drei Fallbeispiele zeigen, koexistieren reaktive und präemptive Modelle nebeneinander. Der präemptive Ansatz scheint aber sowohl der grundlegenden Logik der Entwicklung der Sicherheitsmaßnahmen im RFSR zu entsprechen als auch das Modell zu sein, das sich mehr und mehr durchsetzt. Im Fall des SIS und der Prümer Regelungen, die an sich eher ein reaktiv-repressives Sicherheitsmodell verkörpern, ist die präemptive Logik später hinzugekommen, ${ }^{773}$ wobei sie bei der Fluggastda-

772 Das ist jeweils der Fall bei der PNR-Richtlinie und beim ETIAS.

773 Beim SIS ist die präemptive Logik vor allem in dem zunehmenden Einsatz des Systems zum Zwecke der gezielten oder verdeckten Kontrolle sichtbar. Vgl. Kapitel 4, Abschnitt 6.1. Im Fall der Prümer Regelungen ist diese Logik ansatzweise vorhanden, zum Beispiel im Hinblick auf den automatisierten Aus- 
tensätze-Richtlinie, der neuesten unten den analysierten Maßnahmen, am ausgeprägtesten ist. ${ }^{774}$

Daher werde ich im Folgenden die Tendenz der EU-Sicherheitspolitik hin zu einem präemptiven Ansatz insbesondere mit Bezug auf die PNRRichtlinie illustrieren. Die PNR-Maßnahmen stellen allerdings eine Entwicklung dar, die richtungsweisend für den zukünftigen Ausbau der EUSicherheitspolitik im Allgemeinen sein könnten, wie etwa die Übernahme des risikobasierten Ansatzes beim ETIAS verdeutlicht. Dementsprechend sind die folgenden Erwägungen für den RFSR generell von Bedeutung.

\subsection{Der präemptive Ansatz unter besonderer Berücksichtigung der PNR- Maßnahmen}

Die im sechsten Kapitel hervorgehobenen zentralen Merkmale der PNRRichtlinie weisen auf einige Tendenzen des sicherheitspolitischen Ansatzes hin, die ich auf den folgenden Seiten beleuchten möchte.

\subsubsection{Effektvermeidung statt Ursachenbekämpfung}

Der risikobasierte Ansatz der Fluggastdatensätze-Richtlinie wird auch als „proaktiv“ beschrieben. ${ }^{775}$ Dabei wird „proaktiv“ dem Begriff „reaktiv“

tausch der daktyloskopischen Daten zur Verhinderung von Straftaten oder auf den nicht automatisierten Informationsaustausch zur Straftatenverhinderung und zur Gefahrenabwehr. Vgl. Kapitel 5, Abschnitte 3.2 und 3.3. Dagegen wird im SIS und im Prümer System eine reaktive Logik von den Maßnahmen verkörpert, die auf die Identifizierung von bereits bekannten Personen, etwa Verurteilten oder Angeklagten, abzielen.

774 Stark geprägt durch ein präemptives Sicherheitsverständnis war ebenfalls die EU-Richtlinie zur Vorratsdatenspeicherung von 2006, die 2014 vom EuGH für nichtig erklärt wurde. Vgl. Richtlinie 2006/24/EG des Europäischen Parlaments und des Rates vom 15.03.2006 über die Vorratsspeicherung von Daten, die bei der Bereitstellung öffentlich zugänglicher elektronischer Kommunikationsdienste oder öffentlicher Kommunikationsnetze erzeugt oder verarbeitet werden, und zur Änderung der Richtlinie 2002/58/EG, Amtsblatt der Europäischen Union L 105/54 vom 13.04.2006 und Urteil des Gerichtshofs (Große Kammer) vom 08.04.2014, Digital Rights Ireland Ltd, verbundenen Rechtssachen C-293/12 und C-594/12.

775 Vgl. zum Beispiel den Vorschlag der Kommission $\operatorname{COM}(2011) 32$ final, 02.02.2011 und Vermeulen; Bellanova, European 'smart' surveillance. 
entgegengesetzt. Reaktive Maßnahmen werden ergriffen, nachdem ein bestimmtes Ereignis geschehen ist. Dieser reaktive Ansatz ist ebenfalls in der PNR-Richtlinie vertreten, und zwar dort, wo sie den Abgleich der Fluggastdaten mit vorhandenen Datenbanken ermöglicht, nachdem eine Straftat begangen wurde. Dagegen werden die PNR-Daten proaktiv eingesetzt, wenn sie vor der Begehung einer Straftat verwendet werden, um diese zu verhindern.

Diese Art von Proaktivität adressiert das bekämpfte Phänomen (Terrorismus bzw. schwere Kriminalität) in einer besonderen Art und Weise. Sie zielt nicht darauf $\mathrm{ab}$, dieses zu beseitigen, indem es seine Ursachen bekämpft, was typisch für eine präventive Vorgehensweise wäre. Vielmehr werden die Existenz und das Weiterbestehen dieses Phänomens angenommen. Was vermieden werden soll, sind einzelne Erscheinungen dieses Phänomens, nämlich die Begehung einer begrenzten Zahl von Straftaten, deren Täter_innen als „gefährlichste“ eingestuft wurden. Dabei wird eingeräumt, dass die Behörden nicht alle möglichen Schäden vermeiden können. Genauer: Nach dem risikobasierten Ansatz der algorithmischen Regulierung sollten sie es auch nicht tun. Vielmehr sollen sich die Behörden auf die Kontrolle der Bedrohungen konzentrieren, die nach einer Ex-ante-Evaluierung als potenziell am gefährlichsten eingestuft wurden. ${ }^{776}$

Dieser effektzentrierte und risikobasierte Ansatz ist keine absolute Neuigkeit. Eine ähnliche Wendung im strafrechtlichen Bereich wurde etwa bereits in den 1990er Jahren beobachtet. ${ }^{777}$ Der italienische Philosoph Giorgio Agamben sieht in der Fokussierung auf die Effekte sogar ein kennzeichnendes Merkmal der modernen Regierungskunst. ${ }^{778}$ Anstatt die Ursachen zu regieren, würde diese darauf abzielen, die Effekte zu kontrollieren. Dabei hebt Agamben hervor, dass diese Verschiebung von den Ursachen auf die Effekte eine Zunahme an Kontrolle mit sich bringt: „Causes demand to be known, while effects can only be checked and con-

776 Vgl. Beaussier, Anne-Laure et al., Accounting for failure: risk-based regulation and the problems of ensuring healthcare quality in the NHS, in: Health, Risk \& Society, 18/3-4, 2016, 205-224, hier 206; Yeung, Algorithmic regulation; Ulbricht, When Big Data Meet Securitization. Algorithmic Regulation with Passenger Name Records.

777 Vgl. Feely, Malcom M.; Simon, Jonathan, The new penology: notes on the emerging strategy of corrections and its implications, in: Criminology, 30/4, 1992, 449-474.

778 Vgl. Agamben, Giorgio, For a Theory of Destituent Power. Lecture Transcript, Athens, 16.11.2013. 
trolled." "779 Wenn auch die Fokussierung auf Effekte und die dazugehörige Ausweitung der Überwachung und der Kontrolle keine absolute Neuheit sind, haben zunächst die Digitalisierung und die rasch steigenden Rechenkapazitäten die idealen Rahmenbedingungen geschaffen, damit sich diese Tendenzen verstärkt entfalten konnten. Die Möglichkeiten, die der Einsatz von KI-Methoden eröffnet, stellen eine weitere Steigerungsmöglichkeit dieser Tendenzen dar.

Im Kontext der gegenwärtigen Sicherheitspolitik der EU steht das proaktive Modell der PNR-Richtlinie im Widerspruch zur „Logik der Lückenschließung", an der sich die Entwicklung der EU-Politik im Raum der Freiheit, der Sicherheit und des Rechts orientiert und die auch für die Einführung der PNR-Richtlinie eine Rolle gespielt hat. ${ }^{780}$ Wie oben erläutert, besteht diese Logik darin, progressiv die Sicherheitslücken zu schließen, die durch die bestehenden Maßnahmen nicht abgedeckt werden. Das zugrunde liegende Ideal dabei ist der Zustand absoluter Sicherheit, der auf die Beseitigung aller möglichen Bedrohungen abzielt. Dies wird aber im Fall der PNR-Richtlinie durch Maßnahmen verwirklicht, die prinzipiell nicht die Vermeidung aller Schäden vorsehen, wie es etwa zumindest ansatzweise der Fall bei einem Modell wäre, das auf Ursachenbekämpfung basiert.

\subsubsection{Profile und die Erstellung von Gefährlichkeitsprognosen}

Die Identifizierung der möglichen Effekte, die in Zukunft eintreten könnten und vermieden werden sollen, erfolgt aufgrund von Prognosen, die sich auf die Gefährlichkeit der einzelnen Individuen bezieht. Um diese Prognosen zu erstellen, stützen sich die PNR-Maßnahmen auf Kategorisierungen der Reisenden in verschiedene Risikokategorien.

Automatisierte Verfahren werden häufig als objektiver und neutraler als menschliche angesehen. Wie oben erwähnt hat auch die Kommission die Einführung der PNR-Richtlinie als eine Alternative zu möglicherweise diskriminierenden Kontrollen durch Beamte gerechtfertigt. ${ }^{781}$ Menschen wer-

779 Agamben, For a Theory of Destituent Power, vgl. auch Morozov, Why the internet of things could destroy the welfare state.

780 Vgl. oben Abschnitt 2.2 in diesem Kapitel.

781 Vgl. Kapitel 6, Abschnitt 4.1. 
den nun aufgrund von „objektiven Prüfkriterien“782 auseinandersortiert, und nicht aufgrund subjektiver Einschätzungen.

Bei näherer Betrachtung erweist sich aber die Neutralität und Objektivität algorithmischer Verfahren als illusorisch. Algorithmen und Datenbanken sind menschliche Produkte, die genauso wie alle anderen Artefakte von menschlichen Vorstellungen geprägt werden.

Das kann auf verschiedenen Ebenen der automatisierten Verarbeitung von Daten beobachtet werden. Erstens können die Ausgangsdaten an sich, die für die Erarbeitung der Gefährlichkeitskriterien benutzt werden, bereits durch diskriminierende Praktiken geprägt sein. Wenn zum Beispiel bestimmte Personengruppen häufiger in den Kriminalstatistiken auftauchen, weil sie aufgrund ihrer äußerlichen Erscheinung besonders häufig kontrolliert werden, wird diese Häufigkeit in die Datenbank aufgenommen und möglicherweise von den Algorithmen als „Muster“ identifiziert. ${ }^{783}$ Der Mechanismus an sich ist nicht neu, jedoch wäre es irreführend, zu denken, dass solche Mechanismen durch die Automatisierung der Filterungsverfahren verschwinden würden.

Zweitens sind Systeme, die Personen durch automatisierte Analyseverfahren sortieren und klassifizieren, auch auf eine spezielle, für sie spezifische, Art und Weise diskriminierend. Profile, die durch solche Analysen erzeugt werden, beziehen sich per definitionem auf relationale oder vergleichende statt individuelle Identitäten. ${ }^{784}$ Entscheidungen über Individuen (etwa ob sie aufgrund ihrer "Gefährlichkeit" weiteren Überprüfungen unterzogen werden sollen) werden nicht nur aufgrund ihrer Charakteristika getroffen, sondern auch basierend auf Annahmen und Hypothesen über die Kategorie, der sie zugeordnet wurden. Wenn zum Beispiel ein Fluggast sein Flugticket von Berlin nach Istanbul mit nur geringem zeitlichen Vorlauf kauft, dieses in bar bezahlt und womöglich noch einen $30 \mathrm{~kg}$ schwe-

$782 \operatorname{COM}(2011) 32$ final, 02.02.2011, 6.

783 Für weitere Beispiele, wie algorithmische Systeme in den verschiedenen Phasen der Programmierung und Anwendung diskriminierend geprägt sein oder wirken können, vgl. Barocas, Solon; Selbst, Andrew D., Big Data’s Disparate Impact, in: California Law Review, 104, 2016, 671-732; Orrù, Elisa, Minimum Harm by Design. Reworking Privacy by Design to mitigate the risks of surveillance, in: Leenes, Ronald et al. (Hg.), Computers, Privacy and Data Protection: Invisibilities \& Infrastructures. Dordrecht: Springer 2017, 107-137.

784 Vgl. Gandy, Oscar H., Data Mining, Surveillance, and Discrimination in the Post-9/11 Environment, in: Haggerty, Kevin D.; Ericson, Richard V. (Hg.), The new politics of surveillance and visibility. Toronto: University of Toronto Press 2007, 363-384, hier 370. 
ren Rucksack eincheckt, obwohl der Rückflug bereits drei Tage nach dem Hinflug stattfindet, wird er eventuell als „Hochrisiko-Passagier“ eingestuft. Diese Gefährlichkeitsprognose wird aber aufgrund von Annahmen über die Kategorie von Menschen, die die erwähnten Kriterien mit ihm teilen, und womöglich von anderen Individuen, die mit ihrem vergangenen Verhalten diesen Kriterien entsprachen, getroffen, nicht aber aufgrund seines eigenen vergangenen Verhaltens. Anders gesagt: Der Fluggast wird als "gefährlich" eingestuft, nicht weil er selbst sich in der Vergangenheit in einem Camp für "foreign fighters“ in Syrien aufhielt oder weil in seinem vergangenen Verhalten Anhaltspunkte dafür zu finden wären. Vielmehr erfolgt diese Einstufung, weil beobachtet wurde bzw. angenommen wird, dass eine Anzahl von anderen Menschen, die von Deutschland nach Syrien in solche Camps gereist sind, kurzfristig einen Flug in die Türkei gebucht, das Ticket in bar bezahlt und einen Scheinruckflug gebucht haben, wobei sie zudem Gepäck für einen längeren Aufenthalt mit sich geführt haben. In die Gefährlichkeitsprognose über den Fluggast fließen damit Bewertungen ein, die nicht ihn individuell betreffen, sondern Menschen, die in die gleiche Kategorie wie er eingeteilt wurden. Selbst wenn die Programmierer_innen sich dessen nicht bewusst sind oder dies nicht intendieren, kann die Art, wie die verschiedenen Kategorien definiert werden, bereits diskriminierende Muster reproduzieren.

Die Fluggastdatensätze-Richtlinie schließt explizit aus, dass Entscheidungen über die Gefährlichkeit von Individuen „aufgrund der rassischen oder ethnischen Herkunft, der politischen Meinungen, der religiösen oder weltanschaulichen Überzeugungen, der Mitgliedschaft in einer Gewerkschaft, des Gesundheitszustands, des Sexuallebens oder der sexuellen Orientierung einer Person getroffen" werden. ${ }^{785}$ Werden solche Daten an die nationale Zentralstelle übermittelt, darf diese sie nicht verarbeiten und muss sie löschen. ${ }^{786}$

Gerade bei der automatisierten Analyse von großen Datenmengen können aber Rückschlüsse über solche sensiblen Merkmale aus scheinbar nicht sensiblen Daten hervorgehen. ${ }^{787}$ Die Postleitzahl könnte zum Bei-

785 Richtlinie (EU) 2016/681, Art. 7 (6).

786 Vgl. ebd., Art. 13 (4).

787 Vgl. Orrù, Minimum Harm by Design. Reworking Privacy by Design to mitigate the risks of surveillance, 129; Kamiran, Faisal; Calders, Toon; Pechenizkiy, Mykola, Techniques for Discrimination-Free Predictive Models, in: Custers, Bart et al. (Hg.), Discrimination and privacy in the information society: data mining and profiling in large databases. Berlin; Heidelberg: Springer 2013, 223-241. Vgl. auch Hardt, Moritz, Occupy Algorithms: Will Algorithms Serve the 99\%? 
spiel Hinweise auf Ethnizität, Herkunft oder Migrationshintergrund liefern, oder Angaben über Mitreisende können die Beziehung zu den Passagier_innen, mit dem sie reisen, und damit potenziell Informationen über deren Sexualleben, offenbaren. Wie oben dargelegt, können durch maschinelles Lernen sogar Korrelationen erstellt werden, die ohne maschinelle Unterstützung (also durch menschliche Beobachtung allein) nicht erkannt werden können. Da diese Verbindungen durch die Verarbeitung der Daten selbst erzeugt werden und nicht im Voraus fixiert sind, ist es auch unmöglich, auszuschließen, dass solche potenziell sensiblen Assoziationen zum Einsatz kommen. Außerdem deutet die bisher nur sparsam vorhandene öffentlich zugängliche Literatur über den Einsatz von maschinellem Lernen für Verhaltensprofilierung darauf hin, dass Informationen wie Geschlecht, Alter, Aussehen und vor allem die im Freitextfeld eingegebenen Informationen besonders wertvoll für Profilierungszwecke sein könnten. ${ }^{788}$

Im Widerspruch zu den Erklärungen der Kommission über die Objektivität der automatisierten Datenverarbeitung führt die FluggastdatensätzeRichtlinie selbst eine menschliche Überprüfung der Ergebnisse der automatisierten Auswertung ein. In der Richtlinie heißt es:

Die zuständigen Behörden treffen Entscheidungen, aus denen sich eine nachteilige Rechtsfolge oder ein sonstiger schwerwiegender Nachteil für die betroffene Person ergibt, unter keinen Umständen allein auf der Grundlage der automatisierten Verarbeitung der PNR-Daten. ${ }^{789}$

Menschliche Beurteilungen wurden also zunächst als vorurteilsbeladen ausgeschlossen und durch „objektive“ und „neutrale“ maschinelle Verfahren ersetzt, um dann aber am Ende des Prozesses wieder eingeführt zu werden, um dadurch wiederum mögliche maschinelle Fehler zu beseitigen und zu garantieren, dass die Entscheidungen gerecht sind. ${ }^{790}$

Response Paper presented at the Governing Algorithms Conferenz, New York, 17.03.2013, wonach das Ableiten von Merkmalen aus sogenannten proxies (in diesem Fall: der Ethnizität aus der Postleitzahl) genau das ist, was Algorithmen besonders gut können.

788 Vgl. INDECT D9.9. Report on current state-of-the-art of machine learning methods for behavioural profiling, 2011, www.indect-project.eu (letzter Zugriff: 03.06.2019), das sogar die „ethnic appearance of the offender" als wertvolle Information erwähnt (S. 13).

789 Richtlinie (EU) 2016/681, Art. 7 (6).

790 Vgl. Vermeulen; Bellanova, European 'smart' surveillance. 
Sobald maschinelles Lernen hinzukommt, wird aus diesem Widerspruch eine Unmöglichkeit, weil die Überprüfbarkeit der Entscheidungen nicht mehr möglich sein wird. Wie unten näher ausgeführt wird, ${ }^{791}$ werden die maschinell erzeugten Entscheidungen für Menschen nicht mehr nachvollziehbar sein. Da die Strukturen und Funktionen, die zu der Entscheidung geführt haben, keine im Voraus fixierte Funktion durchführen, sondern vom System selbst erzeugt werden und für Menschen nicht nachvollziehbar sind, wird es für Menschen unmöglich sein, sie kritisch und gründlich zu überprüfen. Tatsächlich werden sich die Kontrolleur_innen in diesen Fällen auf die mitgelieferte Übersetzung des automatisierten Verfahrens in Risikokategorien verlassen müssen. ${ }^{792}$

Zudem ist fraglich, ob solche Ergebnisse, die auf Wahrscheinlichkeiten hinweisen, überhaupt überprüfbar sein können. Die Ergebnisse der PNRProfilierung werden Prognosen darüber enthalten, wie wahrscheinlich es ist, dass ein Mensch eine Bedrohung darstellen wird. Eine Aussage wie „Mensch X weist eine 95-prozentige Wahrscheinlichkeit auf, in Zukunft eine terroristische Straftat zu begehen" kann durchaus korrekt sein und trotzdem zu ungerechten Folgen führen. Denn die Wahrscheinlichkeit kann (nach welchen Kriterien auch immer) „korrekt“ ermittelt worden sein, und damit kann es korrekt sein, zu sagen, dass dieser Mensch mit hoher Wahrscheinlichkeit eine terroristische Straftat begehen könnte. Die Aussage würde weiterhin korrekt sein, auch wenn dieser Mensch nach den verbleibenden $5 \%$ nie eine terroristische Straftat begehen wird. Jedoch wäre es ungerecht, etwa diesem Menschen aufgrund seines Gefährlichkeitsprofils ein Flugverbot zu erteilen. Anders als Entscheidungen, die sich auf in der Vergangenheit begangene Taten beziehen, wäre die Gerechtigkeit einer solchen Entscheidung nur in Zukunft überprüfbar, wenn von jeglichen Interventionen abgesehen werden würde. ${ }^{793}$ Solche Interventionen als proaktive Maßnahmen sind aber genau das, worauf die Gefährlichkeitsprognosen abzielen. Dieses Phänomen, auch als „asym-

791 Vgl. unten, Abschnitt 3.2.3 in diesem Kapitel.

792 Vgl. Leese, Matthias, The new profiling: Algorithms, black boxes, and the failure of anti-discriminatory safeguards in the European Union, in: Security Dialogue, 45/5, 2014, 494-511.

793 Die Kontrastierung mit Urteilen, die auf vergangenen Taten basieren, bedeutet nicht, dass diese immer korrekt wären oder immer auf sicherer Basis gesprochen werden können. Vielmehr bedeutet sie, dass in diesen Urteilen wenigstens im Prinzip überprüfbar ist, ob die Voraussetzungen für die Entscheidung (die bereits erfolgte Begehung einer Straftat) erfüllt sind. 
metrisches Feedback “794 bekannt, ist nicht spezifisch für Prognosen, die durch maschinelles Lernen erzeugt werden. Doch hat es für diese Art der Prognose gravierende Konsequenzen, da maschinelle Lernsysteme auf Feedback angewiesen sind, um die gewünschten Funktionalitäten zu entwickeln und zu verbessern und um deren spezifisches Potenzial, wie etwa die Analyse großer Datenmengen und die Anpassung an neue Situationen, zu entfalten.

\subsubsection{Opazität der Bewertungskriterien}

Die automatisierte Analyse der Fluggastdaten zum Zweck der Profilierung wird nach der PNR-Richtlinie benutzt, um Entscheidungsempfehlungen zu formulieren. Entsprechend werden Verhaltensnormen („Fluggast X soll näher überprüft werden“) formuliert, an denen sich menschliches Handeln orientieren soll. Die Formulierung von diesen Entscheidungsempfehlungen ist durch verschiedene Varianten von Opazität gekennzeichnet. Diese Opazität ist besonders ausgeprägt, wenn die Profilierung der Passagier_innen durch den Einsatz maschinellen Lernens erfolgt bzw. erfolgen würde, gilt aber unter bestimmten Bedingungen auch dann, wenn die Muster von Personen vorgegeben werden.

Die erste Form von Opazität betrifft die mangelnde Begründbarkeit der Kriterien, wodurch bestimmte Individuen als gefährlich eingestuft werden. Diese Form von Opazität ist unvermeidbar, wenn die Kriterien durch maschinelles Lernen zustande kommen: Durch maschinelles Lernen werden in (unstrukturierten) großen Datenmengen Regelmäßigkeiten aufgespürt. Diese sind umso interessanter, als sie zuvor unbekannt waren und nicht durch menschliche Verstandesleistung allein erkannt werden konnten. ${ }^{795}$ Aufgrund dieser Regelmäßigkeiten werden Verbindungen zwischen Merkmalen erstellt, etwa zwischen dem Vorhandensein einer bestimmten Eigenschaft A und dem errechneten Bedrohungspotenzial einer Person B. $\mathrm{Ob}$ nun $\mathrm{A}$ und $\mathrm{B}$ in einem kausalen Zusammenhang stehen, ob beide durch einen dritten Faktor $C$ verursacht wurden oder ob es reiner Zufall ist, dass sie zusammen auftreten, ist für die Erstellung der Korrelation unbedeutend. Zum Beispiel: Wenn sich etwa aus der Datenanalyse ergibt,

794 Zweig; Wenzelburger; Krafft, On Chances and Risks of Security Related Algorithmic Decision Making Systems, 13, Übersetzung E.O.

795 Genau deswegen, um „neue“ Korrelationen herauszufinden, wird maschinelles Lernen eingesetzt. Vgl. Yeung, Algorithmic regulation. 
dass eine bestimmte Bezahlungsart häufig genug gekoppelt mit einem „abweichenden“ Verhalten auftritt (d.h., nach dem Check-in den Flug nicht anzutreten), wird daraus eine Assoziation erstellt, ohne dass es eine logische Erklärung dafür geben muss. Warum nun genau diese Korrelation aufgestellt wird und nicht eine andere, oder warum das System zu einem bestimmten Ergebnis kommt und nicht zu einem anderen, kann nicht erklärt werden. Anders formuliert: Die relevanten Assoziationen werden sozusagen unmittelbar aus „Beobachtungen“ erstellt, nicht aus logischen (kausalen) Zusammenhängen, und im Nachhinein ist es nicht möglich, die Wege zu rekonstruieren, die das System zu dem jeweiligen Ergebnis geführt haben. ${ }^{796}$ Diese Unerklärbarkeit der Muster, die - wenn sie durch maschinelles Lernen erzeugt werden - prinzipiell ist, kann auch die von den Behörden vorgegebenen Muster betreffen, wenn diese aufgrund von Häufigkeitsbeobachtungen erstellt wurden und nicht plausibel erklärt werden können.

Dass eine solche Situation ein Problem in Bezug auf das Kriterium der Rechtfertigung darstellt, kann auf verschiedenen Ebenen verdeutlicht werden. Im deutschen Polizeirecht wird bisher zum Beispiel verlangt, dass die Gründe für die vertiefte Kontrolle („Gefahrerforschungseingriff“) plausibilisierbar sein müssen. Dafür reicht es nicht, dass das eingesetzte System erfahrungsgemäß funktioniert, sondern es muss auch erklärbar sein, warum es das tut. ${ }^{797}$ Der Grund dafür liegt in der Idee, dass Beamte die Maßnahme verantworten können müssen und dass dies nur dann möglich ist, wenn sie auch verstehen können, wie es zu der Prognose, welche die Maßnahme veranlasst hat, gekommen ist. ${ }^{798}$ Auch auf europäischer Ebene werden benachteiligende Maßnahmen aufgrund von automatisierter Profilierung nur dann zugelassen, wenn bestimmte Grundrechte garantiert sind. Dazu zählt zwingend das Recht, das Einschreiten einer Person zu erwirken, um den eigenen Standpunkt darlegen zu können, die Gründe der Entscheidung erläutert zu bekommen und die Entscheidung anfechten zu können. ${ }^{799}$ Wenn maschinelles Lernen zum Einsatz kommt, sind aber diese Voraussetzungen, wie ich geschildert habe, nicht gegeben.

Ansätze, die unter dem Begriff „explainable artificial intelligence“ („erklärbare künstliche Intelligenz") bekannt sind, versuchen dieses Problem

796 Vgl. Schubbach, Judging machines; Rademacher, Predictive Policing im deutschen Polizeirecht, 377.

797 Vgl. Rademacher, Predictive Policing im deutschen Polizeirecht, 386-391.

798 Vgl. ebd., 387.

799 Vgl. Richtlinie (EU) 2016/680 vom 04.05.2016, Art. 11 und Präambel, Ziff. 38. 
zu umgehen. Was diese Ansätze leisten können, ist zwar, zu rechtfertigen, warum ein durch maschinelles Lernen erzeugtes Ergebnis richtig ist, nicht aber, wie es dazu gekommen ist. Diese Ansätze könnten also eine Rechtfertigung liefern, die nicht - wie die bisherigen gesetzlich verlangten Rechtfertigungen - auf Erklärung basiert. ${ }^{800}$ Solche Ansätze können einen signifikanten Beitrag zur Akzeptanz von künstlicher Intelligenz leisten. Da sowohl das deutsche als auch das europäische Recht, wie oben ausgeführt, auf Erklärbarkeit bestehen, scheint jedoch eine solche Rechtfertigung nach dem jetzigen Stand unterhalb der rechtlichen Standards zu bleiben.

Zusammenfassend: Wenn Entscheidungen aufgrund nicht erklärbarer Bewertungen getroffen werden, fällt eine wichtige Voraussetzung dafür, dass sie gerechtfertigt und kritisiert werden können, fort: nämlich deren Begründbarkeit. Begründbarkeit als Lieferung plausibler Erklärungen scheint bisher eine nötige Voraussetzung für die Rechtfertigung behördlicher Maßnahmen, die benachteiligend für die Betroffenen sind.

\subsubsection{Opazität der Überprüfungsmaßnahmen}

Die zweite Variante der Opazität der Maßnahmen nach der Fluggastdatensätze-Richtlinie betrifft den weiteren Schritt der PNR-Maßnahmen. Die oben beschriebene erste Form der Opazität bezieht sich auf die Nicht-Erklärbarkeit der Gründe, die zu einer Gefährlichkeitsprognose geführt haben. Die zweite Variante der Opazität betrifft die genaueren Überprüfungen, welche den Bewertungen folgen, und ist unabhängig von der Art und Weise, wie diese Bewertungen generiert wurden. Sie betrifft somit sowohl Fälle, in denen die Muster vorgegeben sind, als auch Fälle, in denen sie automatisch produziert werden.

Die genaueren Überprüfungen, die der Profilierung folgen, sind durch Opazität gekennzeichnet, weil die Betroffenen zunächst nichts davon erfahren. Sie erfahren nämlich weder, dass sie vom System als „HochrisikoPassagier_innen“ eingestuft wurden, noch, dass sie weiteren menschlichen

800 Vgl. Schubbach, Judging machines. Für weitere Ansätze zur Überwachung von algorithmischen Entscheidungen, die keine Transparenz der Systeme voraussetzen vgl. Zweig, Katharina, Algorithmische Entscheidungen: Transparenz und Kontrolle, in: Analysen und Argumente aus der Konrad-Adenauer-Stiftung, 2019. 
Überprüfungen unterzogen werden. ${ }^{801}$ In beiden Fällen werden sie nicht benachrichtigt, die Richtlinie sieht lediglich vor,

dass eine betroffene Person das Recht hat, den Datenschutzbeauftragten als zentrale Kontaktstelle im Zusammenhang mit allen Fragen bezüglich der Verarbeitung der PNR-Daten der betroffenen Person zu kontaktieren. ${ }^{802}$

Dabei wird aber nicht sichergestellt, dass alle Betroffenen informiert werden und damit tatsächlich von ihrem Auskunftsrecht Gebrauch machen können. ${ }^{803}$ Erst wenn die genaueren Überprüfungen zu weiteren konkreten Folgen führen, wie etwa die Verweigerung des Flugantritts, können die Betroffenen davon erfahren.

Zwei Aspekte sind hier besonders relevant. Erstens: Wenn die genauere menschliche Überprüfung, die der automatisierten Risikoprofilierung folgt, bereits eine „nachteilige rechtliche Wirkung“ darstellt, dann sind die oben erwähnten Garantien des Rechts auf Darstellung der eigenen Position, auf Erläuterung der Entscheidung und auf Anfechtbarkeit der Entscheidung nicht gegeben. Die offene Frage zu beantworten, ob dies der Fall ist, ist Aufgabe der gerichtlichen Kontrolle und geht über die Ziele vorliegender Untersuchung hinaus. Wenigstens im Sinne des deutschen Rechts auf informationelle Selbstbestimmung, wonach jeder behördliche Umgang mit personenbezogenen Daten eine erhebliche rechtliche Belastung und damit einen Eingriff darstellt, ${ }^{804}$ scheint jedoch die Frage positiv beantwortbar zu sein.

801 Das bedeutet auch einen Unterschied zu anderen Formen der Passagierkontrolle, zum Beispiel einer Abtastung am Flughafen, nachdem der Metalldetektor Alarm geschlagen hat. Abgesehen von anderen möglichen Unterscheidungen in Bezug auf die Punktualität der Kontrolle, die Erhebung personenbezogener Daten etc., ist in diesem Zusammenhang relevant, dass im Fall der Passagierkontrollen an Flughäfen die Betroffenen jedoch ohne Weiteres sowohl den Alarm durch den Metalldetektor als auch die menschliche Kontrolle, die daraufhin folgt, erfahren. Damit ist auch die Gelegenheit gegeben, nach den Gründen der Abtastung zu fragen und die eigene Position zu klären („ich habe vergessen, meinen Schlüsselbund aus der Tasche zu nehmen“) sowie auch die Maßnahme zu kritisieren.

802 Richtlinie (EU) 2016/681, Art. 5 (3).

803 Noch weniger wird in der Richtlinie spezifiziert, welche Informationen die betroffene Person erhalten muss oder dass die Datenschutzbeauftragten überhaupt verpflichtet sind, den Betroffenen irgendeine Auskunft zu geben.

804 Vgl. Rademacher, Predictive Policing im deutschen Polizeirecht, 391. 
Zweitens: Die Nicht-Erfahrbarkeit der Überprüfungen, die im Hintergrund stattfinden, scheint eine schleichende Gefahr für die Demokratie darzustellen. Diese Gefahr kann in Anlehnung an die von der deutschen Juristin Indra Spiecker genannt Döhmann nachgewiesene Wechselbeziehung zwischen Demokratie und Fragmentierung verdeutlicht werden. ${ }^{805}$

Fragmentierung wird von Spiecker als Neugestaltung der Beziehungen zwischen Einzelheiten (den Individuen) und dem Gesamtsystem (dem demokratischen System) verstanden. Eine wichtige Stärke demokratischer Gesellschaften liegt darin, neu entstandene Fragmentierungen aufzugreifen und sie positiv zur Anpassung an den Wandel zu nutzen. Dafür sind aber „offene - physische, virtuelle und vor allem diskursive - Treffräume [eine zentrale Voraussetzung], in denen unterschiedliche Fragmentierungen aufeinandertreffen", 806 wodurch sie verhandelt, diskutiert und demokratisch verarbeitet werden können.

Obwohl Spiecker damit auf die Gefahren von Digitalisierungs- und Vernetzungsprozessen in anderen Bereichen als in der Sicherheitspolitik hinweisen will, können ihre Überlegungen auch für die FluggastdatensätzeRichtlinie fruchtbar sein. Denn durch die Klassifizierung der Passagier_innen in Risikokategorien werden Fragmentierungen erzeugt, die nicht in eine öffentliche Diskussion überführt, kritisiert und infrage gestellt werden können, weil sie nicht wahrgenommen werden können. Die Risikokategorien als neue Fragmentierungen greifen auf eine flächendeckende Art und Weise zu: Sie teilen alle Passagier_innen in verschiedene Kategorien ein, die womöglich unterschiedlich behandelt werden. Die Passagier_innen bekommen damit eine auf sie zugeschnittene Behandlung, ohne zu erfahren, dass sich diese überhaupt von der Behandlung anderer Fluggäste unterscheidet, und folglich ohne diese hinterfragen zu können.

805 Vgl. Spiecker Döhmann, Indra, Kontexte der Demokratie: Partei, Medien und Sozialstrukturen, in: Spiecker Döhmann et al. (Hg.), Fragmentierungen, Bd. 77. Berlin: de Gruyter 2018, 9-66. Für eine Reflexion über algorithmische Regulierung und Demokratie vgl. Zweig; Wenzelburger; Krafft, On Chances and Risks of Security Related Algorithmic Decision Making Systems. Kritisch über die Auswirkungen des Einsatzes von big-data-Technologien und Demokratie im Allgemeinen vgl. O'Neil, Cathy, Weapons of math destruction: how big data increases inequality and threatens democracy. London: Penguin Books 2017; Pasquale, Frank, The Black Box Society: the secret algorithms that control money and information. Cambridge: Harvard University Press 2015.

806 Spiecker Döhmann, Kontexte der Demokratie, 35. 


\subsubsection{Opazität der Verhaltensnormen}

Die dritte Variante der Opazität der Fluggastdatensätze-Richtlinie wird durch die Definition der Gefährlichkeitskriterien verwirklicht. Die Kriterien, die auf die Gefährlichkeit mancher Individuen hinweisen sollen, sind nicht in Bezug auf verbotene Handlungen definiert. Sie werden auch nicht aus kriminalistisch relevanten Daten abgeleitet, sondern aus Daten, die sich auf Tätigkeiten beziehen, die durchaus erlaubt und sogar für die Buchung und Durchführung der Reisen nötig sind.

Nehmen wir zum Beispiel die Daten zur Art der Bezahlung. Die relevante Frage hierbei ist nicht, ob das Flugticket etwa mit gefälschten Scheinen bezahlt wurde - was eine illegale Tätigkeit wäre. Denn die gesammelten Fluggastdaten enthalten in der Regel solche Informationen nicht. ${ }^{807} \mathrm{Was}$ die gesammelten Daten jedoch liefern, ist die Information über das Medium der Bezahlung, wobei eine Barbezahlung (an sich eine vollständig legale Form der Bezahlung) möglicherweise als „gefährlicher“ als die Bezahlung mit Kreditkarte eingestuft wird. Wie dann dieses Kriterium (in Verbindung mit anderen) in einer bestimmten Situation gewichtet wird, hängt nicht von seinem Bezug zu einer externen Norm, die eine klare, binäre Unterscheidung zwischen verbotenem und erlaubtem Verhalten bietet, ab. Ob die Barzahlung nun in Verbindung mit anderen Kriterien dazu führt, dass eine Person herausgefiltert wird, verdankt sich vielmehr der statistischen Verteilung der Kriterien zwischen allen anderen Passagier_innen. ${ }^{808}$ Denn was durch die Analyse der Daten gesucht wird, sind Anomalien oder Spitzenwerte. Die Analyse ist nur dann sinnvoll, wenn eine zahlenmäßig kleinere Gruppe von Fluggäste herausgefiltert werden kann. Wenn etwa an einem besonderen Tag oder auf einer bestimmten Route die Mehrheit der Passagier_innen bar bezahlt, dann hat das Kriterium der Barzahlung keine Aussagekraft. Wenn aber in einer anderen Situation 99\% der Passagier_innen mit Kreditkarte bezahlen, dann kann es durchaus attraktiv sein, die Barzahler genauer zu überprüfen. Es wäre, als ob die Geschwindigkeit, die auf einer Bundesstraße als verboten bzw. gefährlich gilt, nicht rechtlich festgelegt wurde, sondern aus der Analyse der Verkehrsdaten entstehen würde, etwa als die Geschwindigkeitsgrenze, die von $95 \%$ der Fahrer nicht überschritten wird. Wer diese Grenze über-

807 Denn die Daten werden von Fluggesellschaften übermittelt und stammen nicht aus behördlichen Datenbanken.

808 Vgl. auch Leese, The new profiling: Algorithms, black boxes, and the failure of anti-discriminatory safeguards in the European Union. 
schreitet, wird behördlichen Maßnahmen unterzogen, nicht weil sein bzw. ihr Verhalten verboten ist, sondern weil sein bzw. ihr Verhalten von dem der anderen Fahrer_innen erheblich abweicht. ${ }^{809}$

Das hat interessante Konsequenzen für die Art der Normativität, die durch solche Verfahren erzeugt wird. Denn Werturteile (was als „gefährlich“ gilt) werden dabei nicht in Bezug auf ein normatives System definiert, das relativ stabil und relativ unabhängig von den empirischen Informationen über die Gegebenheiten, die es "normieren“ soll, ist. ${ }^{810}$ Werturteile werden vielmehr aus einem Pool empirischer Daten abgeleitet, die dasselbe empirische Verhalten beschreiben, das bewertet werden soll. Diese Form von Normativität kann als „empirische Normativität“ bezeichnet werden: Gefährlichkeit wird nicht unter Bezug auf eine übergeordnete rechtliche Norm definiert, die gegenüber den vorhandenen Daten „extern“ ist. Die Norm wird vielmehr aus den Daten selbst erarbeitet, ist sozusagen den empirischen Daten immanent. Nun wurde im ersten Kapitel argumentiert, dass eine externe, objektive, aus unserer Erfahrung losgelöste Normativität nicht erreichbar ist. Konsequenterweise könnte nun schlussfolgert werden, dass die empirische Ableitung der Kriterien im Fall der PNRRichtlinie nur das übliche Vorgehen darstellt. Jedoch: Das Versprechen und die Funktion der rechtsstaatlichen Mechanismen, wie sie im zweiten Kapitel dieses Buches dargestellt wurden, liegt darin, dieser Befangenheit entgegenzuwirken und durch die rechtliche Fixierung der Normen (des verbotenen und erlaubten Verhaltens) Stabilität und Transparenz zu bieten. Die durch die PNR-Richtlinie eingeschlagene Richtung scheint diesen rechtsstaatlichen Anspruch infrage zu stellen. Die Konsequenz ist, dass niemand im Voraus mit Gewissheit vorhersehen kann, welche Tätigkeiten die Aufmerksamkeit der Behörden auf ihn oder sie lenken werden.

809 Um das Beispiel noch weiter zu verdeutlichen: Das Kriterium „schnell fahren“ ist in beiden Fällen als ein entscheidendes Merkmal vorgegeben. Nur im ersten Fall ist klar definiert, was als „zu schnell“ (und deswegen verboten) gilt im zweiten Fall hingegen nicht, denn hier wird die Schwelle relational zum Verhalten anderer definiert und verschiebt sich ständig.

810 Natürlich spielen die empirischen Gegebenheiten auch für die Festlegung rechtlicher Normen eine Rolle, wie etwa, dass es Straßen und Kraftfahrzeuge gibt, die bestimmte technische Eigenschaften haben und eine bestimmte Geschwindigkeit erreichen können. Aber die Norm, etwa dass auf Bundesstraßen die maximal erlaubte Geschwindigkeit $100 \mathrm{~km} / \mathrm{h}$ beträgt, gilt unabhängig vom allgemeinen Fahrverhalten an einem bestimmten Tag, etwa wie viele Fahrzeuge tatsächlich die Geschwindigkeitsgrenze überschreiten oder ob die durchschnittliche Geschwindigkeit der Fahrzeuge an dem Tag 80 oder $90 \mathrm{~km} / \mathrm{h}$ ist. 
Diese Mobilität der Gefährlichkeitsschwelle ist charakteristisch für die Logik der PNR-Richtlinie, unabhängig davon, ob die Kriterien von den Behörden vorgegeben werden oder durch maschinelles Lernen hergestellt werden. Die Instabilität spitzt sich aber zu, wenn maschinelles Lernen, insbesondere in den nicht durch Menschen überwachten Formen, zum Einsatz kommt. Denn dann entscheidet die statistische Verteilung der Merkmale nicht nur über die Gewichtung der vorgegebenen Kriterien, sondern Anomalien an sich werden zu Hauptkriterien der Klassifizierung. Die Mobilität der Kriterien wird ferner dadurch forciert, dass die Verarbeitung der Fluggastdaten dazu dienen soll, die Kriterien selbst kontinuierlich zu adaptieren. 811

Schließlich wird diese Form der Opazität der PNR-Normen dadurch erschwert, dass die Gefährlichkeitskriterien und die Kalkulationsregeln nicht offengelegt werden. Dies wird von den Behörden dadurch gerechtfertigt, dass, wenn die Kriterien öffentlich wären, potenzielle Kriminelle oder Terrorist_innen ihr Verhalten anpassen könnten, um Kontrollen auszuweichen. ${ }^{812}$ Jedoch scheint dieses Argument nicht vollständig zu überzeugen, da die aktuelle Forschung auf die Möglichkeit hinweist, die Kriterien offenzulegen, ohne diese der Manipulationsgefahr auszusetzen und ohne die Effektivität der Maßnahmen zu mindern. ${ }^{813}$

\subsection{Das Modell der präemptiven Sicherheit}

In diesem Abschnitt werde ich die Grundcharakteristika des präemptiven Sicherheitsmodells auf allgemeine Art und Weise darstellen. Die im vorigen Abschnitt hervorgehobenen Züge werden zu einem gemeinsamen Bild zusammengefügt und durch die Kontrastierung mit reaktiven und präventiven Ansätzen verdeutlicht.

Grundsätzlich kann ein risikobasierter, proaktiver Ansatz als ein effektzentriertes Modell verstanden werden, in dem es um die Vermeidung von den (schlimmsten) Effekten eines Phänomens anstatt um die Bekämpfung

811 Vgl. Kapitel 6, Abschnitt 6.3 und Yeung, Algorithmic regulation.

812 Vgl. Ulbricht, When Big Data Meet Securitization. Algorithmic Regulation with Passenger Name Records und Entwurf eines Gesetzes über die Verarbeitung von Fluggastdaten zur Umsetzung der Richtlinie (EU) 2016/681 (Fluggastdatengesetz - FlugDaG), 30.

813 Vgl. aus technischer Perspektive Hardt, Occupy Algorithms: Will Algorithms Serve the 99\%? und aus rechtlicher Perspektive Poscher, Tendencies in Public Civil Security Law, 70. 
seiner Ursachen geht. ${ }^{814}$ Präemptive Sicherheitsmodelle zielen darauf ab, die schwerwiegendsten negativen Effekte eines Phänomens vorauszusagen und sie dadurch zu verhindern.

Präemptive Modelle stehen daher in einem besonderen Verhältnis zum zeitlichen Geschehen, das sich von der zeitlichen Ausrichtung von sowohl reaktiven als auch präventiven Modellen unterscheidet. Reaktive Sicherheitsmodelle etwa basieren auf Ereignissen in der Vergangenheit und stellen eine Reaktion auf diese dar. Dagegen sind präemptive Modelle, wie präventive auch, zukunftsorientiert, weil sie darauf abzielen, bestimmte zukünftige Ereignisse zu vermeiden. ${ }^{815}$ Dafür agieren beide Modelle in der Gegenwart.

Präemptive und präventive Sicherheitsmodelle teilen somit miteinander eine Art Projektion der zu erreichenden Ziele in die Zukunft, die aber durch eine Intervention in der Gegenwart erreicht werden sollen. Die epistemischen Strategien, um mit dieser Projektion in die Zukunft umzugehen, sind aber unterschiedlich. Während präventive Modelle auf Ursachen fokussieren und im Hinblick auf diese agieren wollen, suchen präemptive Modelle nach Anzeichen. Präventive Modelle wollen Ursachen erkennen, präemptive Modellen wollen Anzeichen interpretieren. ${ }^{816}$ Dementsprechend gründen präemptive Modelle auf Korrelationen, während präventive Modelle auf Kausalität setzen. Letztere brauchen Theorien, die den Zusammenhang zwischen Ursachen und Effekten herstellen und verdeutlichen. Dagegen brauchen präemptive Modelle Beobachtungen, in denen verschiedene Elemente zueinander in Korrelation gebracht werden können. Erstere wollen das Dass erfassen, letztere fragen nach dem Warum eines bestimmten Phänomens. ${ }^{817}$

Ferner: In Bezug auf den Zustand, auf den sie einwirken wollen, stellen präventive Modelle eine Diagnose. Die Diagnose fokussiert auf ein bereits

814 Vgl. dazu auch Yeung, Algorithmic regulation und Morozov, Evgeny, Smarte neue Welt: digitale Technik und die Freibeit des Menschen. München: Blessing 2013.

815 Über das Verhältnis zwischen Sicherheit und Unwissen vgl. Burgess, J. Peter, Sicherheit als Ethik, in: Zoche, Peter; Kaufmann, Stefan; Arnold, Harald (Hg.), Sichere Zeiten? Gesellschaftliche Dimensionen der Sicherheitsforschung. Berlin Münster: LIT Verlag 2015, 33-42.

816 Am deutlichsten im Kontext der in den vorigen Kapiteln analysierten Maßnahmen zeigt sich das bei der PNR-Richtlinie, wonach Daten über Mobilität Hinweise auf die Gefährlichkeit der Flugpassagiere liefern sollen.

817 Auch in Bezug auf diese Aspekte stellt die PNR-Richtlinie die eindeutigste Illustration dar, vgl. oben Abschnitt 3.2 dieses Kapitels. 
existierendes Problem, will dieses durch die Darstellung des Erscheinungsbildes und die Nennung der Ursachen verdeutlichen und womöglich eine Therapie aufzeigen, die zur Bewältigung des Problems führen soll. Präemptive Ansätze stellen dagegen eine Prognose. Die Frage ist nicht, ob ein Problem hier und jetzt besteht, sondern ob es in Zukunft bestehen wird. Die Prognose wird aufgrund von Indikatoren gestellt: Zeichen, die hier und jetzt präsent sind und an sich nicht problematisch sein müssen, sondern auf eine zukünftige problematische Situation hinweisen sollen. ${ }^{818}$

In beiden Fällen sollen Maßnahmen unternommen werden. Doch während sie im ersten Fall auf die Beseitigung der Ursachen und dabei idealerweise auf die Ausrottung des Problems zielen, wollen präemptive Maßnahmen punktuell und auf die noch nicht eingetretenen Effekte reagieren. Sicherheitsmaßnahmen, die von einer präventiven Logik gesteuert werden, adressieren die Ursachen eines bestimmten Kriminalitätsphänomens und sollen, wenigstens idealiter, das Phänomen beseitigen. Präemptive Sicherheitsmaßnahmen dagegen wollen punktuellen, besonders schwerwiegenden Ereignissen zuvorkommen. Für präemptive Modelle ist es irrelevant, wodurch bestimmte Ereignisse verursacht werden und warum es dazu kommt. Das adressierte (Kriminalitäts-)Phänomen wird nicht im Ganzen bekämpft: Ziel präemptiver Maßnahmen ist vielmehr, wie erwähnt, eine Realisierung der schwerwiegendsten Effekte zu vermeiden. ${ }^{819}$

\subsection{Die normativen Implikationen des präemptiven Sicherheitsmodells}

Die normativen Implikationen des präemptiven Sicherheitsmodells sind vielfach. Erstens ist diesem Modell eine allumfassende Tendenz immanent. Denn es wird nicht nach etwas gesucht, das im Vorfeld, etwa durch eine Theorie oder - wie im Fall eines repressiven Sicherheitsmodells - vergangene Ereignisse identifiziert wurde. Vielmehr sollen die Ergebnisse der Informationsanalyse selbst die Richtung vorgeben, in der es gesucht werden muss. Das bedeutet, dass die Selektion der relevanten und zu beobachtenden Gegenstände nicht im Vorfeld stattfinden kann. Deswegen neigen präemptive Modelle dazu, möglichst viele Informationen über möglichst

818 Vgl. in dieser Hinsicht die Maßnahmen der verdeckten Kontrolle im SIS (Kapitel 4, Abschnitte 4.6 und 6.1) und den gesamten Ansatz der PNR-Richtlinie (Kapitel 6, Abschnitt 6).

819 Vgl. am deutlichsten den risikobasierten Ansatz der Fluggastdatensätze-Richtlinie (Kapitel 6, Abschnitt 6.2). 
viele Individuen oder Ereignisse zu sammeln und zu analysieren. Hier wird die Affinität zur Digitalisierung besonders sichtbar. Obwohl präemptive Systeme auch in einer analogen Welt denkbar sind, bieten Big Data und künstliche Intelligenz ideale Entfaltungsmöglichkeiten für präemptive Modelle. Sie ermöglichen es, die Quantität der erfassten Daten exponentiell zu steigern. Die Antiselektivität der präemptiven Ansätze stößt durch den Einsatz analoger Mittel an faktische Grenzen. In einer digitalen Welt entfallen diese Grenzen. ${ }^{820}$

Zweitens, da im Vorfeld nicht bekannt ist, was genau herausgefunden werden soll, müssen die Systeme offen und flexibel bleiben. Um effektiv zu sein, dürfen sie nicht im Vorfeld übermäßig eingeschränkt werden - sie müssen auf neue Erkenntnisse adaptierbar bleiben. Dieses Merkmal kann als Offenheit des präemptiven Sicherheitsmodells aufgefasst werden. ${ }^{821}$

Drittens ist schließlich ein präemptives Sicherheitsmodell durch Opazität gekennzeichnet: Die Korrelationen, auf denen die Prognosen basieren, müssen nicht erklärbar sein. Anders als kausale Zusammenhänge brauchen sie keine rationale Erklärung, warum sie bestehen. Sie können nur dadurch gerechtfertigt werden, indem ex post gezeigt wird, dass sie funktionieren, d. h., dass sie zu den richtigen Prognosen führen. Diese nicht erklärbaren Korrelationen können im besten Fall offengelegt werden, worauf aber häufig aus strategischen Gründen verzichtet wird, da ihre Offenlegung die Korrelationen zur Manipulierbarkeit exponieren könnte.

Hiermit wird ein weiterer Aspekt der Opazität präemptiver Sicherheitsmodelle deutlich. Denn es wird behauptet, dass Transparenz die Effektivität der Prognose schwächen könnte. Es soll nicht im Vorfeld bekannt gemacht werden, welches Verhalten zu welcher Prognose führt. Verhaltensoptionen werden nicht durch die binäre Trennung zwischen Erlaubtem und Verbotenem unterschieden. Potenziell alles, nicht nur verbotene Handlungen, könnte als Indiz für eine gewisse Prognose interpretiert

820 Besonders illustrativ für diese Tendenz ist die Sammlung nicht sicherheitsbezogener Daten aller Passagiere aufgrund der Fluggastdatensätze-Richtlinie, vgl. Kapitel 6.

821 Besonders deutlich wird dieser Aspekt durch die Bezeichnung des SIS als „flexibles Instrument" (Kapitel 4, Abschnitt 6.1), die Adaptierbarkeit der Kriterien nach der PNR-Richtlinie (Kapitel 6, Abschnitt 6.3) und, obwohl weniger spezifisch, durch die flexible Verwendung der Prümer Instrumente für die im Vorfeld nicht als prioritär angesehenen Kategorien von Straftaten (Kapitel 5, Abschnitt 4). Offenheit und Flexibilität sind auch die grundlegenden Merkmale der Pläne für die Steigerung der Interoperabilität der europäischen Datenbanken, vgl. Kapitel 7, Abschnitt 4.3. 
werden. Damit die Anzeichen richtig interpretiert werden können, soll zudem alles möglichst ungestört und ungesteuert weiterlaufen. In Bezug auf menschliches Handeln, das leicht beinflussbar und steuerbar ist, bedeutet das, dass sich Menschen weiter so verhalten müssen, als ob es keine Kontrollen gäbe. Dafür müssen diese Kontrollen und die zugrunde liegenden Kriterien möglichst verborgen bleiben. ${ }^{822}$

Dies alles ist normativ relevant, weil es grundlegende Mechanismen, die zum Schutz der individuellen Rechte dienen, infrage stellt. Kontrolle wird inhärent anlasslos und tendenziell allumfassend, im Vorfeld kann ihre Logik nicht von den Adressate_innen erkannt und ihre Effektivität nicht demonstriert werden. Die rechtsstaatlichen Grundmechanismen, die im zweiten Kapitel dieses Buches rekonstruiert wurden, sind nach wie vor wichtig, um diese neue Ausrichtung der Sicherheitspolitik kritisch zu überprüfen. Wie ich geschildert habe, reichen sie aber nicht, um die ausufernde Tendenz der präemptiven Sicherheitsmaßnahmen effektiv einzugrenzen. Wie Ralf Poscher gezeigt hat, können fundamentale rechtsstaatliche Prinzipien wie das Verhältnismäßigkeitsprinzip gegen die Logik der präemptiven Sicherheitsmaßnahmen kaum Widerstand leisten. Denn wenn es darum geht, schwere terroristische Angriffe zu vermeiden, können alle Maßnahmen verhältnismäßig scheinen. ${ }^{823}$

Die These, die ich im folgenden Kapitel aufstellen möchte, ist, dass es dafür ein Verständnis von Autonomie braucht, dessen philosophische Prämissen eher auf einem kontroversialistischen als auf einem konsensualistischen Ideal fußen.

822 Vgl. am prominentesten die PNR-Richtlinie (Abschnitt 3.2.3 in diesem Kapitel), aber auch die wachsende Bedeutung der verdeckten Kontrolle im SIS (Kapitel 4, Abschnitte 4.6 und 6.1).

823 Vgl. Poscher, Tendencies in Public Civil Security Law, 71. 
Kapitel 9 Autonomie als Möglichkeit der Infragestellung

\section{Von der Kritik zur Transformation}

In den vorigen Kapiteln habe ich die Frage nach der Legitimität der EU-Sicherheitsmaßnahmen im RFSR ergründet. Diese Frage stellt sich dringend, da die rekonstruierten Entwicklungen im europäischen RFSR ein bahnbrechendes und folgenreiches Machtphänomen darstellen. Denn die EU hat in den letzten Jahrzehnten in diesem Politikbereich progressiv Kompetenzen übernommen, die den Kern dessen ausmachen, was seit der Neuzeit als die zentrale Aufgabe des Staates gilt: die Gewährleistung der Sicherheit. ${ }^{824}$ Dabei haben die Entwicklungen im RFSR einen Wandel angestoßen, der als paradigmatisch für die Überführung der EU in eine neue Integrationsphase gilt. ${ }^{825}$

In den vorigen Teilen des Buches habe ich gefragt, nach welchem Legitimationsmodell die EU-Sicherheitsmaßnahmen legitimiert wurden, um dann die Maßnahmen anhand dieses Modells kritisch zu überprüfen. Ich werde nun die Ergebnisse dieser Untersuchung fruchtbar machen, um die grundlegende Frage dieser Abhandlung zu beantworten. Diese Frage lautet, ob das gültige Legitimitätsmodell der EU in der Lage ist, die Ausübung der Macht in diesem Bereich effektiv einzugrenzen, oder ob aus den Defiziten des bestehenden Verständnisses von Legitimität ein neues Modell herausgearbeitet werden soll.

Auf den folgenden Seiten werde ich daher zunächst die Hauptergebnisse der vorigen Kapitel rekapitulieren (Abschnitt 2 unten). In diesem Abschnitt werde ich an den im ersten Teil des Buches präsentierten theoretischen Ansatz anknüpfen und zeigen, inwieweit er operationalisiert wurde. Dabei werde ich die Hauptzüge der Legitimitätskonzeption, die für die EU gilt, noch einmal überblicksartig darstellen. Anhand dieser werde ich schließlich die Hauptergebnisse der Analyse der Legitimität der EU-Sicherheitsmaßnahmen, die ich im zweiten Teil durchgeführt habe, vor Augen führen.

824 Vgl. dazu Gander, Hans-Helmuth, Sicherheitsethik - ein Desiderat? Mögliche Vorüberlegungen, in: Gander, Hans-Helmuth et al. (Hg.), Resilienz in der offenen Gesellschaft, 85-94.

825 Vgl. oben Kapitel 3, Abschnitt 5. 
Die Abschnitte 3 und 4 bauen auf diese Ergebnisse auf, um eine Transformation des Legitimationsmodells der EU vorzuschlagen, die mir anhand der Entwicklungen im RFSR nötig scheint. Diese Entwicklungen fordern die existierenden Mechanismen zur Eingrenzung der Macht heraus, die in Konformität mit dem Legitimationsmodell des demokratischen Rechtsstaates im RFSR nur teilweise erfolgreich eingesetzt werden (Abschnitt 4.1). Meine These ist, dass es, um diese Herausforderungen erfolgreich zu bewältigen, einer Transformation des Autonomiekonzepts bedarf, das als Grundlage der demokratischen Komponente des EU-Legitimationsmodells gilt. Im Abschnitt 4.2 unten elaboriere ich dementsprechend ein Verständnis von Autonomie, das den Akzent vom notwendigen Konsens zur möglichen Infragestellung verschiebt. Dabei verdeutliche ich, warum ein solches Modell einerseits besonders affin zum realistischen Ansatz dieser Abhandlung und andererseits mir besonders geeignet scheint, die Herausforderungen des präemptiven Sicherheitsmodells zu adressieren (Abschnitt 4.3). Darüber hinaus skizziere ich die konkreten Mechanismen der Teilnahme und der Kontrolle, die ein solches Verständnis der Autonomie impliziert (Abschnitt 4.4).

Schließlich gehe ich im Abschnitt 5 der Frage nach, ob das vorgeschlagene Autonomieverständnis nur für den RFSR oder auch für die EU als politisches Projekt insgesamt ein angesichts der gegenwärtigen Herausforderungen angemessenes Legitimationsgerüst liefern könnte.

\section{Eine provisorisch für gültig gehaltene Legitimität}

Die Beantwortung der grundlegenden Frage dieser Untersuchung, nämlich der Frage nach der Legitimität der EU-Maßnahmen im RFSR, bedurfte im Vorfeld der Klärung anderer Fragen. Notwendige Klärungen bezogen sich zunächst auf den Begriff der Legitimität selbst: Was kann darunter verstanden werden? Aus welcher Perspektive kann die Legitimität der EU-Maßnahmen überprüft werden?

Im ersten Kapitel des Buches bin ich diesen beiden Teilfragen nachgegangen. Dort habe ich für eine realistische Perspektive im Sinne des gegenwärtigen Realismus als Strömung der politischen Philosophie plädiert. Nach diesem Ansatz soll die Beantwortung der politischen Fragen ihren Ausgangspunkt im politischen Bereich nehmen. Dieser soll zudem die Betrachtung von politischen Fakten anstatt die von Idealen privilegieren und bewusst machen, dass Werte und Prinzipien ihre normative Bedeutung nur im Kontext entfalten können. Eine solche realistische Perspektive ist 
keineswegs eine Perspektive, welche die Normativität scheut. Im Gegenteil: Sie erkennt die normative Dimension der Politik und die Zentralität der Legitimität als politische Kategorie an.

Nach dem gegenwärtigen Realismus ist die erste politische Frage diejenige nach der Gewährleistung von Ordnung, Sicherheit und der Erhaltung der Bedingungen der Kooperation. Das unterscheidet eine politische Organisation von einem anarchischen Zustand, aber noch nicht von anderen Formen der organisierten Gewalt wie einer Terrorherrschaft. Dafür bedarf es einer weiteren Bedingung: Eine politische Ordnung ist eine, die auch garantieren kann, dass „die Lösung nicht Teil des Problems wird“, ${ }^{826}$ nämlich dass die Ausübung von Gewalt Ordnung und Sicherheit gewährleistet und nicht die gleichen Probleme (Unsicherheit, Gewalt etc.) reproduziert, die sie eigentlich beseitigen sollte. Beide dieser Bedingungen sind aus einer realistischen Perspektive konstitutiv für die politische Macht: Die Gewährleistung der Ordnung kann nicht politisch gedacht werden, ohne gleichzeitig auch die Bedingungen der Einschränkung der Macht zu berücksichtigen. Mit anderen Worten ist eine politische Macht eine Form von Machtausübung, die einen Legitimitätsanspruch in dieser Form erhebt: Sie existiert, um Ordnung und Sicherheit zu garantieren und tut es in einer Art und Weise, die keine Unordnung und Unsicherheit ihrerseits reproduziert. Eine politische Machtorganisation ist also etwas, das sich stets durch diese beiden Bedingungen legitimiert: Effektivität und Einschränkung der Macht, wobei beide Bedingungen gleichzeitig erfüllt werden müssen.

Wie diese beiden Bedingungen konkret verstanden werden, ist für jeden Kontext spezifisch. Wo die Grenze zwischen Legitimsein und Nicht-Legitimsein verläuft, kann nach einer realistischen Auffassung nicht nur ein einziges Mal für alle Situationen in Bezug auf abstrakte Prinzipien entschieden werden, sondern muss in der Auseinandersetzung mit den konkreten politischen Realitäten und Kontexten herausgearbeitet werden. Das reduziert aber die jeweiligen Konzeptionen der Legitimität nicht auf oberflächliche und kontingente Überzeugungen, die etwa durch Meinungsumfragen abgefragt werden könnten. Vielmehr drücken die jeweiligen Konzeptionen der Legitimität Prinzipien aus, die sich historisch in einer Gesellschaft sedimentiert haben und in dieser tief verankert sind. ${ }^{827}$

Dies führt uns also zu einer zentralen Herausforderung einer politischen Philosophie, die realistisch sein, aber nicht auf jegliche Normativität ver-

826 Williams, In the beginning was the deed, 4, Übersetzung E.O.

827 Vgl. Kapitel 2, Abschnitt 5. 
zichten will. Diese Herausforderung besteht darin, die einem Kontext immanenten Legitimitätsmaßstäbe für eine kritische Überprüfung des gleichen Kontextes zu verwenden. Sie entsteht aus dem scheinbaren Paradoxon, von einem normativen System auszugehen und dieses System gleichzeitig infrage zu stellen. Diese Herausforderung kann, so habe ich im ersten Kapitel argumentiert, mit Rekurs auf die Konzeption eines Denksystems als „Lebenselement der Argumente“ 828 überwunden werden. Diese Figur verdeutlicht, wie es möglich ist, Teile eines Überzeugungssystems provisorisch als gültig anzusehen und als Grundlage für die Kritik anderer Teile des Systems zu nutzen, ohne die provisorisch für gültig gehaltenen Vorstellungen als letztbegründet, notwendig, objektiv oder universell anzusehen. Vielmehr können in einem zweiten Moment auch diese Überzeugungen kritisch hinterfragt werden. Es scheint somit plausibel, das Legitimitätsmodell der EU ernst zu nehmen und als Grundlage der Kritik zu verwenden, ohne es dabei - konsequent mit unseren realistischen Prämissen - für universell gültig, notwendig, letztbegründbar und nicht selbst hinterfragbar zu halten.

Damit eröffnet sich also die Möglichkeit einer nichttranszendentalen Kritik, die aus unserem partikulären Standpunkt erfolgen kann, ohne diesen vorbehaltlos akzeptieren zu müssen. Mit Michel Foucault gesagt, erlaubt uns diese Form der Kritik, ,an der Grenze zu sein“, 829 die Möglichkeit einer Transformation unserer Gegebenheiten in den Blick zu nehmen, ohne diese transzendieren zu müssen. Auf dieser Grundlage fußt auch die Möglichkeit, die EU-Sicherheitspolitik einer immanenten Kritik im Sinne Rahel Jaeggis zu unterziehen. Durch diese Form der Kritik deckt die Konfrontation der Praktiken mit ihren eigenen Idealen Widersprüche auf, die auf die Notwendigkeit einer Transformation sowohl der Praktiken als auch der Ideale hinweisen. ${ }^{830}$ Dabei können die geltenden Ideale der Legitimation der EU-Politik zunächst als Maßstäbe für die Kritik verwendet werden, ohne dass sie notwendigerweise auch als Leitbild der daran anknüpfenden Transformation gelten müssen. Eine Argumentationslinie, nach der die Legitimationsdefizite durch eine bessere Angleichung der Realität bzw. der Institutionen an die Ideale überwunden werden können,

828 Wittgenstein Über Gewißheit, $\mathbb{\$} 105$ und das Kapitel 1 dieses Buches, Abschnitt 3.1.

829 Foucault, Was ist Aufklärung?, 48. Vgl. auch das Kapitel 1 dieses Buches, Abschnitt 3.2.

830 Vgl. Jaeggi, Was ist Ideologiekritik?, und das Kapitel 1 dieses Buches, Abschnitte 3.3 und 3.4. 
würde sich in einer internen Kritik erschöpfen. Wie im ersten Kapitel dargestellt, ${ }^{831}$ bleibt aber diese Form der Kritik in der geltenden Normativität befangen, währenddessen es die Ambition einer immanenten Kritik ist, einen genuin normativen Beitrag zu leisten, der auch die geltenden Werte kritisch hinterfragt und möglicherweise Vorschläge für deren Transformation formuliert.

Im zweiten Kapitel habe ich eine Brücke geschlagen zwischen dem theoretischen Ansatz und dem spezifischen Kontext, der in diesem Buch analysiert wurde, nämlich demjenigen der EU-Sicherheitspolitik. Zunächst war es nötig, die Legitimitätskriterien herauszuarbeiten, die für die EU spezifisch sind.

Zu diesem Zweck habe ich geschildert, wie das Legitimitätsmodell der EU in der individualistischen Wende der Neuzeit wurzelt und sich durch die Jahrhunderte in dem Modell des demokratischen Rechtsstaates kristallisiert hat. Dieses basiert auf zwei philosophischen Grundannahmen: dem Machtpessimismus und dem juristischen Optimismus. Nach dem ersten ist Macht gleichzeitig notwendig, um die Sicherung der Ordnung zu garantieren, und gefährlich, weil ihr eine konstitutive Neigung zur Ausdehnung innewohnt. Mit dem Umgang mit dieser Spannung wird das Rechtssystem beauftragt: Es soll garantieren, dass die Macht in ihren Grenzen bleibt, wofür es aber wiederum eine Absicherung durch Gewalt braucht. Um diese paradoxe Funktion zu erfüllen, hat das Modell des Rechtsstaates zwei Mechanismen entwickelt: die Streuung der Macht und die Differenzierung der Macht. Ersteres Prinzip impliziert die Ermächtigung der Individuen, vor allem durch die Anerkennung individueller Rechte und die Eingrenzung der Macht; zweiteres Prinzip führt zur Trennung der politischen von der religiösen und ökonomischen Macht einerseits und andererseits bestimmt es die Trennung der Funktionen der Rechtssetzung und Rechtsanwendung innerhalb der Staatsgewalt. ${ }^{832}$ Diesen genuin rechtsstaatlichen Aspekten kommt im Legitimitätsmodell der EU ein weiteres Element hinzu: das Demokratieprinzip. Der philosophische Kern dieses Prinzips ist die kantische Idee der Autonomie des Menschen als Selbstgesetzgebung, wonach jedes Individuum nur an diejenigen Gesetze gebunden sein darf, denen es seine Zustimmung hätte geben können. ${ }^{833}$

In einem weiteren Schritt habe ich die identifizierten Legitimitätsprinzipien operationalisiert, um die EU-Sicherheitsmaßnahmen zu überprüfen.

831 Vgl. das Kapitel 1 dieses Buches, Abschnitt 3.4.

832 Vgl. Kapitel 2, Abschnitt 5.1.

833 Vgl. Kant, Grundlegung zur Metaphysik der Sitten und Kapitel 2, Abschnitt 5.2. 
Dementsprechend habe ich diese grundlegenden Legitimitätsprinzipien, die in der EU gelten und sich an dem Modell des demokratischen Rechtsstaates orientieren, in drei Kriterien übertragen: nämlich Rechtfertigung, Verfahrenskonformität und Rückwirkung auf die normative Ordnung. Nach dem Kriterium der Rechtfertigung habe ich gefragt, wie die Maßnahmen legitimiert wurden, insbesondere in Bezug auf deren Zweck und auf deren Effektivität, den vorgegebenen Zweck zu erreichen. Nach dem zweiten Kriterium (Verfahrenskonformität) habe ich untersucht, ob die Maßnahmen gemäß den auf EU-Ebene gültigen Verfahren bestimmt und eingeführt wurden. Schließlich habe ich nach dem dritten Kriterium untersucht, wie die eingeführten Sicherheitsmaßnahmen auf die rechtlich-politische Ordnung der EU zurückwirken. Anhand dieser Prinzipien und des methodologischen Ansatzes, der im ersten Kapitel dargestellt wurde, habe ich dann in den Kapiteln 3 bis 7 die EU-Sicherheitspolitik im RFSR analysiert.

Dabei habe ich das EU-Legitimitätsmodell für provisorisch gültig gehalten. Vor diesem Hintergrund habe ich mit Foucault gefragt, wie bestimmte Phänomene zu Sicherheitsproblemen geworden sind und wie diese Problematisierung eine Reihe von Wissens- und Machtmechanismen hervorgebracht hat, die sich mit ihrer Lösung beschäftigt haben. Bezogen auf den RFSR bedeutet dies, zu fragen, zu welchem Ordnungsproblem die Sicherheitsmaßnahmen eine Antwort geben, wie es überhaupt zu diesem Problem gekommen ist und welche Rationalität die darauf reagierenden Sicherheitsmaßnahmen verkörpern. Mit Jaeggi habe ich schließlich gefragt, welche Widersprüche sich aus der Konfrontation der Sicherheitsmaßnahmen im RFSR mit den gültigen EU-Legitimitätsprinzipien ergeben und ob diese die Richtung einer möglichen Transformation aufzeigen. Diese Transformation erschöpft sich nicht in der Angleichung der Maßnahmen an die für provisorisch gültig gehaltenen Legitimitätsprinzipien, sondern zieht in den Wandel auch die Ideale mit ein.

\section{Die defizitäre Legitimität der Sicherheitsmaßnahmen im RFSR}

Die Ergebnisse der Analyse der Legitimität der EU-Sicherheitspolitik gemäß dem provisorisch für gültig gehaltenen Legitimitätsmodell können in den folgenden drei Punkten zusammengefasst werden. In jedem Punkt fasse ich die Hauptthesen zusammen, die sich aus der Analyse anhand der drei Kriterien der Rechtfertigung, der Verfahrenskonformität und der Rückwirkung auf die normative Ordnung ergeben haben. 
Erstens hat die Untersuchung gezeigt, dass das Phänomen, auf das die Sicherheitsmaßnahmen der EU reagieren, der in Schengen 1985 beschlossene Abbau der Grenzkontrollen und die damit begünstigte, freie Zirkulation von Waren, Kapital und Menschen ist. Nun aber ist dieses Phänomen keine spezifische Sicherheitsherausforderung. Vielmehr wurde es als ein Kontrollverlust interpretiert und als Sicherheitsbedrohung dargestellt, obwohl empirische Studien keinen tatsächlichen Anstieg der Kriminalität im Zusammenhang mit dem Abbau der Grenzkontrollen beweisen konnten. Nichtsdestotrotz lieferte der in Schengen beschlossene Abbau der Grenzkontrollen den Impuls, um die Kooperation auf EU-Ebene, die zuvor nur informell existierte, unter einem gemeinsamen Dach zusammenzuführen und auszubauen. Das verdeutlicht zudem den ersten Widerspruch dieser Maßnahmen, der sich auf der Ebene der Rechtfertigung offenbart: Die Sicherheitsmaßnahmen sind eine Antwort auf ein Problem, dessen Sicherheitsrelevanz mehr postuliert als bewiesen wurde. Sie wurde zudem nicht ex post effektiv überprüft und ist in Bezug auf einige Maßnahmen auch prinzipiell nicht überprüfbar. Die Hauptrechtfertigung für den Auf- und Ausbau des RFSR scheint sich also nicht mit dem effektiven Einsatz der Maßnahmen zu decken.

Zweitens wurde festgestellt, dass die Einführung dieser Maßnahmen eine systematische Forcierung der geltenden institutionellen Verfahren bedeutet hat. Insbesondere die Mechanismen der Differenzierung der Macht wurden de facto umgangen, und die institutionellen Verfahren waren durch die Präeminenz der Exekutive über die Legislative und Judikative sowohl auf nationalen als auch auf europäischen Ebenen gekennzeichnet. Trotz der formell durch den Vertrag von Lissabon statuierten Erweiterung der Kompetenzen des EU-Parlaments und des EuGH ist der RFSR heute immer noch durch einen intergouvernementalen Stil und die überragende Rolle der Exekutivorgane geprägt. Das verdeutlicht einen zweiten Widerspruch, der zwischen dem rechtsstaatlichen Ideal der EU-Legitimität und der Realität der EU-Sicherheitsmaßnahmen besteht.

Drittens wurden durch diese Maßnahmen die individuelle Autonomie und die individuellen Rechte, die als philosophische Grundlage des Legitimitätsmodells der EU dienen, eingeschränkt. Hiermit manifestiert sich ein Zirkel zwischen Freiheit, Recht und Sicherheit, in dem sich die drei Elemente und insbesondere Freiheit und Sicherheit transformieren und rückwirkend gegenseitig beeinflussen. Von dem Vorrang der Freiheit, verstanden als Freizügigkeit, hat sich das Verhältnis zwischen diesen drei Elementen hin zur Präeminenz der Sicherheit entwickelt. 
Aufgrund dieser drei Ergebnisse, kann die Antwort auf die erste, grundlegende Frage dieser Untersuchung festgehalten werden: In Bezug auf die Kriterien der Normativität, die konstitutiv für die Legitimität in der EU sind, haben sich die EU-Maßnahmen im RFSR als defizitär erwiesen. Meine Überzeugung ist aber, dass die normative Konsequenz, die daraus zu ziehen ist, sich nicht in der Aufforderung zur Angleichung der Maßnahmen an die Ideale erschöpft. Vielmehr bedarf es einer zusätzlichen Transformation der Ideale selbst, wie ich im Folgenden ausführen werde.

\section{Ein Vorschlag für die Transformation der Legitimationsprinzipien}

\subsection{Stärken und Schwächen der geltenden Legitimationsmechanismen}

Im zweiten Kapitel habe ich dargelegt, dass die grundlegenden philosophischen Prinzipien, auf denen das Legitimationsmodell der EU fußt, der Machtpessimismus, der juristische Optimismus und die Idee der individuellen Autonomie sind. Die ersten beiden begründen die rechtsstaatlichen Prämissen des Legitimationsmodells, während das dritte die demokratische Komponente darstellt. ${ }^{834}$ Die rechtsstaatlichen Prinzipien begründen den Rekurs auf Mechanismen der Streuung und der Differenzierung von Macht, um die innere Neigung der Macht, sich über die eigenen Grenzen hinaus auszudehnen, zu kontrastieren. Das demokratische Prinzip der Autonomie verlangt die Partizipation der Individuen an politischen Entscheidungsprozessen.

Nun konnten aber diese Prinzipien und die damit verbundenen Mechanismen im Fall der EU-Sicherheitspolitik nur partiell die gewünschte zähmende Wirkung ausüben. Die Legitimität politischer Maßnahmen, wie ich im ersten Kapitel argumentiert habe, setzt einerseits voraus, dass diese effektiv zur Erhaltung der Ordnung beitragen, und andererseits, dass sie nicht selbst eine Bedrohung für grundlegende Grundrechte darstellen. Nun scheint aufgrund der durchgeführten Analyse die Legitimität der Sicherheitsmaßnahmen sowohl in Bezug auf das Effektivitätskriterium als auch in Bezug auf das Eingrenzungskriterium defizitär zu sein. In Bezug auf Effektivität konnte nicht überzeugend plausibilisiert werden, dass die eingeführten Maßnahmen tatsächlich zur Erhaltung der Sicherheit beitragen. In Bezug auf die Eingrenzung wurde aus der Analyse ersichtlich, dass die geltenden Kriterien der Machtkontrolle systematisch forciert wurden.

834 Vgl. Kapitel 2, Abschnitt 5. 
Es ist damit zu einer Situation gekommen, in der die Sphäre der individuellen Rechte eingeschränkt und diejenige der öffentlichen Macht erweitert wurde. Die Frage ist nun, wo die bestehenden Mechanismen wenigstens teilweise erfolgreich ihre Eingrenzungsfunktion ausüben konnten und wo dagegen Defizite bestehen.

Meiner Meinung nach haben die bestehenden Kontrollmechanismen in zwei Hinsichten effektiv auf die neue Herausforderung reagiert. Erstens stellt die Stärkung der Mitbestimmungsrechte des EU-Parlaments und der nationalen Parlamente sowie der Kontrollrechte des EuGH, die mit dem Vertrag von Lissabon beschlossen wurde, eine nötige und wichtige Operationalisierung des Prinzips der Differenzierung der Macht dar. ${ }^{835}$ Diese Mechanismen wurden zwar mit Verspätung eingeführt, sodass die Auswirkungen der Präeminenz der Exekutive, die lange die polizeiliche und justizielle Kooperation in der EU geprägt hat, immer noch spürbar sind. ${ }^{836}$ Jedoch stellen sie eine wichtige Entwicklung dar, die nun konsolidiert werden sollte.

Zweitens hat die Reform des Datenschutzrechts, die neben der Erlassung der Datenschutzgrundverordnung auch im Bereich der justiziellen und polizeilichen Zusammenarbeit stattfand, effektiv auf die Herausforderungen der Digitalisierung reagiert. ${ }^{837}$ Diese Erneuerungen sind zweifelsohne eine wichtige Verstärkung des Prinzips der Streuung der Macht hinsichtlich der individuellen Rechte auf Schutz der Privatsphäre und der personenbezogenen Daten. Das Bestehen dieser Sphäre ist nicht nur per se, sondern auch für eine effektive demokratische Teilnahme wichtig, weil sie als nötige Voraussetzung für die Entwicklung einer mündigen

835 Vgl. vertiefend Kapitel 3, Abschnitt 2.3.3.

836 Ebd.

837 Vgl. Verordnung (EU) 2016/679 des Europäischen Parlaments und des Rates vom 27.04.2016 zum Schutz natürlicher Personen bei der Verarbeitung personenbezogener Daten, zum freien Datenverkehr und zur Aufhebung der Richtlinie 95/46/EG (Datenschutz-Grundverordnung), Amtsblatt der Europäischen Union L 119/1 vom 04.05.2016 und Richtlinie (EU) 2016/680 des Europäischen Parlaments und des Rates vom 27.04.2016 zum Schutz natürlicher Personen bei der Verarbeitung personenbezogener Daten durch die zuständigen Behörden zum Zwecke der Verhütung, Ermittlung, Aufdeckung oder Verfolgung von Straftaten oder der Strafvollstreckung sowie zum freien Datenverkehr und zur Aufhebung des Rahmenbeschlusses 2008/977/JI des Rates, Amtsblatt der Europäischen Union L 119/89 vom 04.05.2016. 
Bürgerschaft gilt. ${ }^{838}$ Die Bedeutung der Datenschutzrechtsreform darf also auch aus demokratischer Perspektive nicht geleugnet werden.

Jedoch konnten beide Reformen (die Stärkung der Differenzierung der Macht durch den Lissaboner Vertrag und die Stärkung der Streuung der Macht durch die Datenschutzreform) kein ausreichendes Korrektiv für die Gefahr bieten, welche die präemptive Ausrichtung der Sicherheitspolitik im RFSR darstellt, wie ich im zweiten Teil dieses Buches geschildert habe.

Meine These ist, dass diese Unzulänglichkeit nicht nur institutionellen Mängeln geschuldet ist. Zwar sind die beiden erwähnten institutionellen Reformen zu einem Zeitpunkt erfolgt, als die meisten Maßnahmen bereits beschlossen wurden. Das gilt jedoch in Bezug auf die PNR-Richtlinie nicht. Einerseits war der Vertrag von Lissabon bereits lange in Kraft, als die Richtlinie 2016 beschlossen wurde. Andererseits wurde die Datenschutzreform am gleichen Tag wie die PNR-Richtlinie verabschiedet und trat wie auch die PNR-Richtlinie 2018 in Kraft. Daher sind meines Erachtens nicht nur (zum Teil bereits erfolgte) institutionelle Reformen notwendig, sondern auch eine Transformation auf der Ebene der Wertekonzeption, und zwar spezifisch bezüglich der öffentlichen Komponente der individuellen Autonomie.

Wie ich im zweiten Kapitel dieses Buches dargestellt habe, kann der konzeptuelle Kern des modernen westlichen demokratischen Ideals (das auch einen wichtigen Teil des EU-Legitimationsgerüsts darstellt) in der Konzeption der Autonomie als Selbstgesetzgebung identifiziert werden. Dieser Auffassung von Autonomie, wie ich im nächsten Abschnitt ausfüh-

838 Für eine Diskussion der Beziehung zwischen Schutz der Privatheit und Stärkung der Demokratie vgl. Orrù, Minimum Harm by Design. Reworking Privacy by Design to mitigate the risks of surveillance; über den Bezug zu anderen Grundrechten vgl. Poscher, Ralf, Die Zukunft der informellen Selbstbestimmung als Recht auf Abwehr von Grundrechtsgefährdungen, in: Gander, HansHelmuth et al. (Hg.), Resilienz in der offenen Gesellschaft, Baden-Baden: Nomos 2012, 167-190 und Poscher, Ralf, The Right to Data Protection: A No-Right Thesis, in: Miller, Russell A. (Hg.), Privacy and power. A transatlantic dialogue in the shadow of the NSA-Affair. Cambridge: Cambridge University Press 2017, 129-141. Über die institutionelle und abwehrrechtliche Dimension des Datenschutzgrundrechts aus Perspektive der Rechtsdogmatik vgl. Marsch, Nikolaus, Das europäische Datenschutzgrundrecht. Grundlagen, Dimensionen, Verflechtungen. Tübingen: Mohr Siebeck 2018. Über die Entwicklung des europäischen Datenschutzrechts zur Zeit der Verabschiedung der Datenschutzgrundverordnung vgl. Schneider, Jens-Peter, Developments in European Data Protection Law in the Shadow of the NSA-Affair, in: Miller, Russell A. (Hg.), Privacy and power. A transatlantic dialogue in the shadow of the NSA-Affair. Cambridge: Cambridge University Press 2017, 539-563. 
ren werde, wohnt eine Tendenz inne, die effektive Partizipation und Kontrolle durch die Bürger_innen hemmen kann. Eine Verschiebung des Akzentes von der Selbstgesetzgebung zur Infragestellung, so mein Vorschlag, könnte dazu beitragen, die Risiken der präemptiven Ausrichtung der EUSicherheitspolitik effektiver einzudämmen.

\section{2 Öffentliche Autonomie als Möglichkeit der Infragestellung}

Bekanntlich wurde die Konzeption der Autonomie als Selbstgesetzgebung durch Immanuel Kants Moralphilosophie geprägt und lieferte seitdem das Paradigma liberaler politisch-philosophischer Ansätze. ${ }^{839}$ Von Jürgen Habermas bis John Rawls, um nur die prominentesten Vertreter dieser Tradition zu nennen, wird Autonomie so interpretiert, dass die legitim bindenden, oder gerechten, Handlungsnormen diejenigen sind, zu denen eine jede Person ihre Zustimmung hätte geben können. Emblematisch dafür sind Habermas' Diskursprinzip und Rawls' Urzustand. Ersteres wird in der Formel kondensiert: „Gültig sind genau die Handlungsnormen, denen alle möglicherweise Betroffenen als Teilnehmer an rationalen Diskursen zustimmen könnten. “840 Nach Rawls soll auf ähnliche Weise der „Gedanke des Urzustands [...] zu einem fairen Verfahren führen, demgemäß eine Übereinkunft über Grundsätze nur zu gerechten Grundsätzen führen kann “. ${ }^{841}$ Sowohl Habermas' Diskursprinzip als auch Rawls' Urzustand verbinden dabei Autonomie mit Konsens und interpretieren letzteren als bypothetischen Konsens. Dass der entscheidende Konsens hypothetisch ist, wird in der Formel des Diskursprinzips durch die Verwendung des Konjunktivs „könnten“ und in Rawls' Theorie durch den fiktiven Charakter des Urzustandes verdeutlicht.

839 Vgl. Kant, Grundlegung zur Metaphysik der Sitten und Kant, Immanuel, Über den Gemeinspruch: Das mag in der Theorie richtig sein, taugt aber nicht für die Praxis, hg. v. Ebbinghaus, Julius. Frankfurt am Main: Klostermann 1982 (zuerst veröffentlicht 1793). Vgl. auch oben Kapitel 2, Abschnitt 5.2.

840 Habermas, Faktizität und Geltung, 138. Vgl. auch für Habermas' Interpretation des Autonomieverständnisses von Kant und dessen Implikationen für die Legitimität der Handlungsnormen ebd., 122.

841 Rawls, Eine Theorie der Gerechtigkeit, 159. In diesem Zustand befinden sich die Parteien unter einem "Schleier des Nichtwissens“, wodurch sie nicht wissen, „wie sich die verschiedenen Möglichkeiten auf ihre Interessen auswirken würden, und müssen Grundsätze allein unter allgemeinen Gesichtspunkten beurteilen“. 
Es würde den Rahmen dieser Untersuchung sprengen, alle möglichen Interpretationen und Weiterentwicklungen der Theorien von Habermas und Rawls nachzuverfolgen. Ich möchte hier in erster Linie hervorheben, dass eine konsensualistische Konzeption der Autonomie, wie sie bei diesen Autoren zum Ausdruck kommt, eine Tendenz in sich hat, Autonomie und Gehorsam letztendlich miteinander zu verschränken und damit die Möglichkeit einer genuinen Kritik einzuschränken. Damit meine ich keinesfalls, dass eine solche Verschränkung notwendig ist, noch dass keine Weiterentwicklungen dieser Theorien möglich sind, die dieser Neigung entgehen. ${ }^{842}$ Meines Erachtens kann aber eine Autonomiekonzeption, die dezidierter auf die Möglichkeiten der Infragestellung anstatt auf Konsensus setzt, effektivere Partizipations- und Kontrollmechanismen begünstigen. ${ }^{843}$

Wie ich gleich in Anlehnung an Carole Pateman schildern werde, neigen konsensbasierte Theorien der Autonomie dazu, sich in einen Wider-

842 Beispielhaft seien hier Rainer Forsts Recht auf Rechtfertigung und die Erweiterung des rawlsschen Gedankenexperiment auf die familiären Verhältnisse durch Susan Moller Okin genannt. Vgl. Forst, Das Recht auf Rechtfertigung. Elemente einer konstruktivistischen Theorie der Gerechtigkeit und Okin, Susan Moller, Justice, Gender, and the Family. New York: Basic Books 1989.

843 Eine interessante Forschungsfrage, die sich an dieser Stelle stellt, ist, ob eine solche Verschiebung in der Autonomiekonzeption Parallelen zu der republikanischen Verschiebung des Freiheitsbegriffes von Nicht-Einmischung (,non-interference“) zu Nicht-Beherrschung (,non-domination“) aufweist. Vgl. paradigmatisch Skinner, Quentin, Liberty before Liberalism. Cambridge: Cambridge University Press 1998 und Pettit, Philip, Republicanism. A theory of freedom and government. Oxford: Oxford University Press 1999. Sicherlich hat die Konzeption der Autonomie als Kritisierbarkeit und die Ablehnung des Konsenses als Basis der politischen Verpflichtung breite Überschneidungen mit Philip Pettits Modell der „bestreitbaren Demokratie“ und der Freiheit als Nichtbeherrschung. Auch für Pettit gilt: „what is required for non-arbitrariness in the exercise of a certain power is not actual consent to that sort of power but the permanent possibility of effectively contesting it." Pettit, Republicanism. A theory of freedom and government, 63. Pettits Argument gegen Konsens als Legitimitätskriterium von politischen Entscheidungen folgt jedoch einer anderen Argumentationslinie als die hier verfolgte, vgl. ebd., 184. Da ein eingehenderer Vergleich den Rahmen dieses Buches sprengen würde, werde ich mich im Folgenden darauf beschränken, bestehende mögliche Konvergenzen mit institutionellen Reformvorschlägen seitens der Vertreter_innen des gegenwärtigen Republikanismus, insbesondere Pettit, Richard Bellamy und John McCormick, hervorzuheben. 
spruch zu verwickeln, der letztendlich Autonomie und Gehorsam miteinander verschränkt. ${ }^{844}$

Diese Verquickung nimmt ihren Ausgangspunkt in der Qualifizierung des Konsenses als hypothetisch. Der nötige Konsens, der bindende Gesetze legitimiert, kann nicht empirisch als die tatsächliche Zustimmung jedes Individuums verstanden werden. Denn erstens würde die tatsächliche Befragung jedes Individuums die Theorie unvermeidbar mit dem diffizilen Problem der Nichtzustimmung Vieler konfrontieren. Zweitens würde ein empirisches Verständnis des Konsenses eine Form direkter Demokratie implizieren, die als nicht geeignet für moderne Großstaaten gilt. ${ }^{845} \mathrm{Kon}$ sens wird also als hypothetischer Konsens interpretiert: Legitime Gesetze sind diejenigen, denen aus einem rationalen, vernünftigen, objektiven und universellen Standpunkt zuzustimmen ist. Wie Carole Pateman überzeugend dargestellt hat, kann jedoch durch dieses Verständnis von Konsens das ursprüngliche Ideal der Autonomie leicht in notwendigen Gehorsam münden. Denn wenn plausibel dargestellt werden kann, dass die Gesetze rational (objektiv, universell, vernünftig usw.) sind, dann kann daraus geschlussfolgert werden, dass sie befolgt werden müssen. Einmal die Vernünftigkeit der Handlungsnormen festgelegt, kann die Möglichkeit einer späteren Kontestation leicht ausgeschlossen werden. Konsens als hypothetischer Konsens wird dabei in Pflicht zu Gehorsam transformiert. ${ }^{846}$

An dieser Verbindung zwischen hypothetischer Zustimmung und Gehorsamspflicht setzt die Idee der öffentlichen Autonomie an, die ich hier stark machen will. Diese Idee hält an der Rationalität verbindlicher Gesetze als Grundlage von deren Legitimität fest. Rationalität der Gesetze bedeutet nach diesem Verständnis von Autonomie nur die Voraussetzung

844 Vgl. vertiefend Pateman, The Problem of Political Obligation. A Critical Analysis of Liberal Theory. Pateman verdeutlicht zudem die Mechanismen der Universalisierung einer partikulären Perspektive, die bei diesen Theorien am Werk sind. Insbesondere hebt Pateman hervor, dass durch die Universalisierung des konkreten Standpunkts, von dem die Theorien aufgebaut werden (etwa demjenigen des possessiven männlichen Individuums oder des rationalen Egoisten), von konkreten sozialen Fakten abstrahiert wird, in dem Sinne, dass diese Fakten gleichzeitig vorausgesetzt und verschleiert werden.

845 Vgl. Meier, Christian; Reimann, Hans Leo; Conze, Werner, Demokratie, in: Brunner, Otto; Conze, Werner; Koselleck, Reinhart (Hg.), Geschichtliche Grundbegriffe, Bd. 1. Heidelberg: Klett-Cotta 1972, 821-899, hier 863-872.

846 Vgl. Pateman, The Problem of Political Obligation. A Critical Analysis of Liberal Theory, 11-23 und, spezifisch zu Rawls, ebd., 103-133. Über die Verbindung zwischen Legitimität und Gehorsam vgl. auch Tully, Public Philosophy in a New Key (Ideas in Context), 114-115. 
für die Ausübung der Autonomie, nicht aber ihre Eingrenzung. Die Rationalität der Gesetze, anstatt den Weg zu einer notwendigen Akzeptanz durch vernünftige Wesen zu ebnen, ist überhaupt die Voraussetzung dafür, dass diese Wesen Kritik ausüben können. Rationalität bietet dabei die Angriffsfläche, auf der Kritik haften kann.

Autonomie ausüben bedeutet dann nicht, das, was rational ist, zu akzeptieren, sondern dies zunächst kritisch betrachten zu können. Nach diesem Verständnis von öffentlicher Autonomie wird aus Konsens mögliche Kritik, statt Neigung zum Gehorsam entfaltet sich aus Rationalität die Möglichkeit einer kritischen Überprüfung der Handlungsnormen. Legitime Handlungsnormen sind diesem Modell entsprechend nicht diejenigen, die rational begründbar sind und universell gerechtfertigt werden können, sondern diejenigen, die sich zusätzlich noch durch Kritik und Kontestation in einem bestimmten Kontext als tatsächlich akzeptabel erweisen. Die damit erhaltene Legitimität wird nicht einmal für immer festgelegt, sondern lediglich provisorisch bis zur nächsten Herausforderung durch Kritik festgehalten. Autonomie kann also nach dieser Auffassung auch als Möglichkeit der permanenten Kritik verstanden werden. ${ }^{847}$

Diese Verschiebung ähnelt dem Perspektivenwechsel, für den Foucault in Bezug auf das, was er als Ethos der Aufklärung bezeichnet, plädiert. Nach Foucault soll die kritische Haltung der Aufklärung so neu interpretiert werden, dass Kritik von einer Aktivität der Setzung oder Bestätigung notwendiger Grenzen in eine Infragestellung der nun als kontingent gesehenen Grenzen transformiert wird. ${ }^{848}$ In Anlehnung an Foucault besteht Autonomie nach dem von mir vorgeschlagenen Verständnis nicht in der Akzeptanz vernünftiger Handlungsnormen, sondern in der Möglichkeit, diese Normen samt ihren Voraussetzungen infrage stellen zu können.

\subsection{Ein modifiziertes Legitimitätsmodell}

In Bezug auf das Legitimationsmodell des Rechtsstaates, das im zweiten Kapitel dieses Buches dargestellt wurde, soll der philosophische Kern der demokratischen Komponente von der Idee der Autonomie als Selbstgesetz-

847 Auch Pateman betont die Zentralität der Möglichkeit, die eigene Zustimmung zu revidieren, für eine genuin demokratische Konzeption der Politik. Vgl. Pateman, The Problem of Political Obligation. A Critical Analysis of Liberal Theory, 162.

848 Vgl. Foucault, Was ist Aufklärung?; Tully, Public Philosophy in a New Key (Ideas in Context), 18, 39-70. 
gebung und das damit verbundene Konsensprinzip auf Autonomie als Kritisierbarkeit verschoben werden. Neben dieser demokratischen Komponente bleiben die rechtsstaatlichen Elemente der Legitimität, so wie im zweiten Kapitel dargestellt, erhalten. Wie Habermas betont, bedingen sich Demokratie und Rechtsstaatlichkeit gegenseitig. ${ }^{849}$ Damit die rechtsstaatliche Komponente aber ihre machteinschränkende Wirkung voll entfalten kann, muss sie durch eine revidierte Form der Autonomie gestützt werden, nämlich von Autonomie als Möglichkeit der Infragestellung.

Diese vorgeschlagene Modifizierung des Legitimationsmodells korreliert mit dem realistischen Ansatz, der im ersten Kapitel dargestellt wurde und die grundlegende Ausrichtung dieser Analyse darstellt. Denn die Verschiebung von Konsens auf Kritik stimmt mit der realistischen Grundkonzeption des Politischen als eines Feldes überein, das mehr durch Konflikt als durch Konsens gekennzeichnet ist. ${ }^{850}$ Gleichzeitig aber ermöglicht die Fokussierung auf Kritisierbarkeit, an Begründbarkeit und Rationalität als Grundbedingungen der politischen Legitimität festzuhalten. Nach dieser realistischen Konzeption der Legitimität wird das Politische nicht auf ein Konfliktfeld reduziert, in dem nur irrationale Kräfte eine Rolle spielen. Vielmehr ist rationale Begründbarkeit ein wichtiges Instrument, um mit grundlegenden Interessen- und Meinungsverschiedenheiten umzugehen und dabei Konflikte zu entschärfen. Rationalität stellt in diesem Kontext die Grundbedingung der Legitimität dar und ermöglicht erst den demokratischen Entscheidungsprozess.

Die Betonung der Kritisierbarkeit als Kern der Autonomie bedeutet darüber hinaus, auf Universalität als Charakteristik von (gerechten) politischen Entscheidungen zu verzichten. Es wird anerkannt, dass die Möglichkeit eines universellen Konsenses illusorisch ist und dass die hypothetische Zustimmung aller, die nach einem konsensualistischen Modell die Legitimität politischer Entscheidungen rechtfertigt, eine Universalisierung partikularer Positionen darstellt. ${ }^{851}$

Anstatt dessen soll nach dem vorgeschlagenen Modell die Akzeptierbarkeit politischer Entscheidungen immer als provisorisch erachtet werden und für Kontestation offen bleiben. Denn nur so können sich politische Entscheidungen in der Praxis als legitim oder legitimierbar bewähren. Eine rationale Rechtfertigung politischer Maßnahmen ist, mit anderen

849 Vgl. Habermas, Faktizität und Geltung, 112.

850 Vgl. Kapitel 1, Abschnitt 1.

851 Vertiefend dazu vgl. Kapitel 1, Abschnitt 2.5 und oben Fußnote 844 dieses Kapitels. 
Worten, eine notwendige, aber nicht hinreichende Bedingung der Legitimität. Die Rechtfertigung muss sich zusätzlich in der Praxis bewähren und ihre Robustheit gegenüber der Kontestation beweisen oder der Kontestation Rechnung tragen und die getroffenen Entscheidungen entsprechend revidieren. Auch das ist kongruent mit der realistischen Überzeugung, dass die normative Geltung von politischen Entscheidungen nicht rational-abstrakt, sondern nur konkret und in Bezug auf den jeweiligen Kontext bestimmt werden kann. Schließlich ist diese Konzeption der Legitimität auch deswegen für einen realistischen Ansatz besonders geeignet, weil sie die Möglichkeit einer Transformation verdeutlicht, die von innerhalb eines politischen Systems ausgeht. Denn Transformation findet in einem solchen Modell ihre Motivation nicht in der angestrebten Angleichung an ein äußeres, ideales Modell, sondern in den Kontestationen, die in der Praxis innerhalb des politischen Systems durchgeführt werden.

Die vorgeschlagene Konzeption der Legitimität, die um Autonomie als Infragestellung ergänzt wird, ist zudem besonders geeignet, die Herausforderungen der sich im RFSR durchsetzenden Konzeption der präemptiven Sicherheit zu adressieren. Wie ich gleich argumentieren werde, kann sie effektive Mechanismen bieten, um die expansive Neigung des präemptiven Sicherheitsmodells einzugrenzen, zeigt aber auch gleichzeitig, dass die Intransparenz dieses Modells schlichtweg unvereinbar mit demokratischen und rechtsstaatlichen Prinzipien ist.

Wie ich oben ausgeführt habe, ${ }^{852}$ zählen zu den grundlegenden Charakteristika dieses Modells seine innere Neigung zur Ausdehnung und seine Offenheit, was Mittel und Zwecke angeht. Um ein solches Modell effektiv einzugrenzen, sind Bestimmungen im Vorfeld zwar notwendig, aber nicht hinreichend. Denn, wie ich dargestellt habe, können Versuche, das Anwendungsfeld der Maßnahmen einzugrenzen, leicht durch Sicherheitserwägungen beseitigt werden. Präemptive Logik bedeutet, den Fokus so breit wie möglich zu setzen, damit möglichst viele potenzielle Bedrohungen identifiziert werden können. Aufforderungen, den Fokus begrenzt zu halten, können dementsprechend nach dieser Logik leicht als die Effektivität der Maßnahmen hemmend abgelehnt werden. Das bedeutet nicht, dass diese Eingrenzungsversuche aufgegeben werden sollten. Da sie aber durch die präemptive Sicherheitslogik geschwächt werden, müssen sie von anderen Mechanismen flankiert werden. Die präemptive Logik impliziert zudem, wie ich argumentiert habe, eine Offenheit der Sicherheitssysteme, die im Hinblick auf die neuen, teilweise selbst produzierten Ergebnisse

852 Vgl. oben Kapitel 8, Abschnitt 3.3. 
adaptierbar bleiben sollen. ${ }^{853}$ Auch diese Eigenschaft erschwert die Durchsetzbarkeit von Ex-ante-Kontrollmechanismen. Denn gegen deren Einsatz kann leicht argumentiert werden, dass sie dem Sinn der präemptiven Maßnahmen widersprechen und deren Effektivität beeinträchtigen. Wie ich gezeigt habe, ist Sicherheit ein wirkungsvolles Argument, um die Grenzen der erforderlichen Legitimitätsbedingungen nach hinten zu verschieben.

Gegenüber diesen beiden Charakteristika kann eine Konzeption der Legitimität als Kritisierbarkeit ein mögliches Korrektiv darstellen, denn sie impliziert, dass eine Ex-ante-Rechtfertigung nicht genügt und dass die Legitimitätsbedingungen immer wieder und auch in ihren konkreten Realisierungen überprüft werden müssen. Im Vergleich zu einer konsensbasierten hat diese kritikbasierte Konzeption der Legitimität den Vorteil, dass sie eine konkrete Überprüfung ermöglicht, ob die Bedingungen der Legitimität erfüllt sind. Denn bei einer konsensbasierten Konzeption der Autonomie können die Bedingungen des hypothetischen Konsenses (nämlich die Rationalität, Objektivität und Universalisierbarkeit der Handlungsnormen) nur abstrakt, etwa durch Rekurs auf ein Gedankenexperiment oder einen Universalisierbarkeitstest, überprüft werden. Dagegen können die Bedingungen der Kritisierbarkeit nur durch konkrete Mechanismen der Einflussnahme auf Entscheidungsprozesse und der Kontrolle realisiert werden, deren Bestehen oder Nicht-Bestehen empirisch überprüft werden kann.

Schließlich ist das präemptive Modell der Sicherheit nicht nur durch Breite des Fokus und Offenheit der Ziele gekennzeichnet, sondern auch durch Opazität. Wenn die ersten beiden Charakteristika eine Herausforderung für die Legitimation der Maßnahmen darstellen, scheint diese dritte Eigenschaft mit ihr schlichtweg unvereinbar. Denn um für Kritik offen zu bleiben, müssen politische Entscheidungen sowie die darauffolgenden Maßnahmen transparent sein. ${ }^{854}$ Die Rechtfertigung der Entscheidungen muss nachvollziehbar und kritisierbar sein, dabei müssen insbesondere die Zwecke der Maßnahmen und deren Fähigkeit, diese effektiv umzusetzen, kritisch überprüfbar sein, und zwar, wie sich aus der obigen Diskussion ergibt, nicht nur ex ante, sondern auf kontinuierlicher Basis.

853 Kapitel 8, Abschnitt 3.3.

854 Vgl. auch Poscher, Tendencies in Public Civil Security Law, 68-70. Für die Unterstreichung der Transparenz als notwendige Eigenschaft der europäischen Sicherheitspolitik vgl. Hildebrandt, Algorithmic regulation and the rule of law; Bellanova, Rocco; De Hert, Paul, Transatlantic Cooperation on Travelers' Data Processing: From Sorting Countries to Sorting Individuals. Washington: Migration Politicy Institute 2011. 
4.4 Mechanismen der Teilnahme und der Kontrolle nach dem vorgeschlagenen Autonomieverständnis

Wie sich nun Kontroll- und Einschränkungsmechanismen, die sich an der vorgeschlagenen Konzeption orientieren, von den derzeit geltenden konkret unterscheiden könnten, werde ich im Folgenden verdeutlichen. Dabei geht es mir nicht darum, die institutionellen Formen detailliert zu beschreiben, sondern die grundlegenden Funktionen zu skizzieren, die durch diese Mechanismen ausgeführt werden können.

Die spezifischen Eigenschaften des vorgeschlagenen Autonomiemodells wirken sich sowohl auf Ebene der Einflussnahme auf politische Entscheidungen als auch auf Ebene von deren Kontrolle aus. Auf ersterer Ebene impliziert das Konzept der öffentlichen Autonomie als Kritisierbarkeit eine genuin europäische öffentliche Sphäre, welche die gesellschaftlichen Kontestationen aufnimmt und wirksam für die Transformation von politischen Entscheidungen einsetzt. Dabei werden Mechanismen benötigt, die ohne die Mediation nationaler Strukturen informelle Öffentlichkeit in institutionelle Meinungen übertragen. In einem Modell der repräsentativen Demokratie (also ohne notwendigerweise dieses durch ein System der direkten Demokratie ersetzen zu müssen) würde dies zwei Hauptveränderungen implizieren. Erstens bedürfte es auch Öffentlichkeitskanälen, die genuin europäisch sind, wie etwa europäische öffentlich-rechtliche Medien, Gewerkschaften, Nichtregierungs- und andere zivilgesellschaftliche Organisationen. Diese würden neben den nationalen bestehen bleiben, aber Möglichkeiten der Diskussion und der Kritik darstellen, die nicht durch den Filter und die Organisationsformen der nationalen Öffentlichkeiten gehen müssten. Ebenfalls bedürfte es genuin europäischer Parteien, die Meinungsorientierungen autonom, statt durch das Medium der nationalen Parteien organisieren würden. Diese transnationalen Parteien wären in der Lage, Konsens und Konflikt nicht territorial, sondern thematisch in Bezug auf Kernfragen der EU-Politik zu strukturieren. ${ }^{85}$

855 Wenngleich vor einem anderen Hintergrund, hat Habermas dieses Problem wie folgt prägnant beschrieben: „Was innerhalb eines Nationalstaates als eine Gemeinwohlorientierung zählt, verwandelt sich auf der europäischen Ebene in eine partikulare, auf das eigene Volk beschränkte Interessenverallgemeinerung, die mit jener europaweiten, in ihrer Rolle als Unionsbürger erwarteten Interessenverallgemeinerung in Konflikt geraten kann." Habermas, Zur Verfassung Europas: ein Essay, 68. Vgl. mit einem ähnlichen Argument, aber in Bezug auf eine globale politische Ordnung Nullmeier; Geis; Daase, Der Aufstieg der Legi- 
Die Schaffung einer europäischen Öffentlichkeit scheint gemäß einer Konzeption der öffentlichen Autonomie als Möglichkeit der Infragestellung aus den folgenden Gründen nötig. Erstens bedeutet der Filter der nationalen Öffentlichkeiten und Parteien eine doppelstufige Repräsentation. Diese Form der Repräsentation bleibt durch ein intergouvernementales Modell geprägt, das angesichts der Ausweitung der EU-Kompetenzen in politischen Kernbereichen überholt scheint. Das doppelstufige Modell ermöglicht darüber hinaus den nationalen Repräsentante_innen, sich ihrer Verantwortung für Entscheidungen zu entziehen. Unpopuläre Entscheidungen, die auf nationaler Ebene nicht getroffen werden oder bei den nächsten Wahlen bestraft werden könnten, können gefahrlos auf europäischer Ebene durchgesetzt werden, weil dort die Zuordnung zu einer spezifischen nationalen politischen Strömung aufgrund der komplexeren Entscheidungsmechanismen viel schwieriger ist. Da es schließlich kaum genuin europäische Parteien gibt, die direkt gewählt werden und für Entscheidungen auf europäischer Ebene eindeutig verantwortlich gemacht werden können, bleibt auch die Möglichkeit, durch Wahlen wenigstens die politische Ausrichtung der EU-Politik zu beeinflussen, so gut wie ausgeschlossen. ${ }^{856}$

Das aktuelle, doppelstufige Modell der Repräsentation auf EU-Ebene ist meiner Meinung nach affiner zum Konsensmodell als zu dem von mir vorgeschlagenen Modell der öffentlichen Autonomie als Möglichkeit der Infragestellung. Denn, wie ich oben ausgeführt habe, neigt das konsensualistische Modell dazu, Zustimmung aus der Vernünftigkeit und Verallgemeinerbarkeit der Rechtfertigungen abzuleiten. Werden diese einmal

timitätspolitik. Rechtfertigung und Kritik politisch-ökonomischer Ordnungen, 17.

856 Richard Bellamys Vorschlag, die EU-Politik zu „domestizieren“, verfolgt ein ähnliches Ziel, nämlich den Meinungsbildungsprozess über EU-Entscheidungen den Bürger_innen näherzubringen und in genuin politische Debatten einzubetten, die über eine starre Einteilung in Pro- und Anti-EU-Argumente hinausgehen und sich an die Diskussion der konkreten Entscheidungen richten. Die Mittel, die Bellamy zu diesem Zweck vorsieht, unterscheiden sich jedoch von meinem Vorschlag. Er setzt nämlich auf eine erhöhte Teilnahme der $n a$ tionalen Parlamente und der nationalen Parteien an den EU-Entscheidungsfindungsprozessen. Vgl. Bellamy, A European Association of Democratic States: Republican Intergovernmentalism, the Role of National Parliaments and the Democratic Constitution of the EU, 16. Meines Erachtens schließen sich die beiden Entwicklungen, nämlich die Herausbildung einer europäischen Öffentlichkeit und die Domestizierung der EU-Politik, nicht aus. Im Gegenteil, sie würden sich sogar gegenseitig ergänzen und verstärken. 
plausibilisiert, kann der weitere Entscheidungsfindungsprozess delegiert werden. Konkrete Einflussnahme der Betroffenen und die Möglichkeit der Kontestation spielen dabei eine zweitrangige Rolle. Ein Verständnis von Autonomie als Kritisierbarkeit verlangt dagegen, dass Möglichkeiten zur Einflussnahme und Kritik offen bleiben und permanent reaktiviert werden können.

Die zweite Ebene, auf der die Konzeption der öffentlichen Autonomie als Kritisierbarkeit ihre Wirkung entfaltet, ist die Ebene der Kontrolle. Nach diesem Modell bedarf es ständiger und unabhängiger Kontrollgremien, welche für die Evaluierung der durchgeführten Entscheidungen zuständig sind und über weitgehende Rechte verfügen, inklusive der Möglichkeit, bestimmte Entscheidungen rückgängig zu machen. ${ }^{857}$ Diese Kontrollgremien sollen eine mögliche Form der Institutionalisierung der informellen Öffentlichkeit darstellen, in dem Sinne, dass sie Ausdruck der Meinungen und Interessen der Individuen sein sollen. Andererseits sollen sie unabhängige Organe sein: Denn, wie Philip Pettit dargelegt hat, können sicherheitspolitische Themen leicht Gegenstand von Skandalisierungen und dabei einer sachlichen Diskussion entzogen werden. ${ }^{858}$ Im RFSR haben wir ähnliche Skandalisierungen beobachtet, etwa als Maßnahmen, die lange nicht konsensfähig waren, nach einem terroristischen Anschlag plötzlich umgesetzt werden konnten.

Gemäß einem Verständnis von Autonomie als Infragestellung könnte diesem Phänomen entgegengewirkt werden. Denn die eingeführten Maßnahmen könnten immer wieder überprüft werden, und diese permanenten Kontrollen würden es ermöglichen, die Maßnahmen nüchtern und anhand ihrer Effektivität zu evaluieren, nachdem der politische Druck

857 Die Wichtigkeit von Kontrollorganen unterstreichend vgl. auch Poscher, Tendencies in Public Civil Security Law, 70. Details wie etwa die spezifische Zusammensetzung der Gremien oder deren Verhältnis zu parlamentarischen Kontrollgremien möchte ich an dieser Stelle offenlassen, da sie einerseits über die Ziele dieses Buches hinausgehen und es mir andererseits wichtiger ist, die Funktion der Gremien zu skizzieren statt deren Zusammensetzung oder institutionelle Zuordnung. Für eine anregende Diskussion der Rolle und Risiken etwa der Ethikkommissionen vgl. Siep, Ludwig, Sinn und Grenzen von Ethik-Kommissionen aus philosophischer Sicht, in: Vöneky, Silja et al. (Hg.), Ethik und Recht - Die Ethisierung des Rechts/Ethics and Law - The Ethicalization of Law. Berlin; Heidelberg: Springer 2013, 423-432 und Poscher, Ralf, Was Juristen besser können als Ethiker: Ein interdisziplinäres Argument für die gerichtliche Kontrolle von Ethikkommissionen, in: Vöneky, Silja et al. (Hg.), Ethik und Recht, 433-441.

858 Vgl. Pettit, Republicanism. A theory of freedom and government, 197. 
nachgelassen hat, und sie eventuell zu revozieren. ${ }^{859}$ Unabhängige Kontrollgremien würden dabei ein Korrektiv für die Unbestimmtheit der präemptiven Maßnahmen darstellen, indem sie die Kontrollfunktionen, die nicht ex ante ausgeübt werden können, ex post erfüllen würden.

Mechanismen der nachträglichen Kontrolle existieren freilich bereits auch auf EU-Ebene. Die hier vorgeschlagenen Gremien unterscheiden sich jedoch von den bestehenden wie folgt: Einerseits fokussieren sich die im RFSR existierenden Kontrollgremien, wie etwa die Koordinierungsgruppe des SIS II, auf einzelne Aspekte, etwa auf die Überprüfung der datenschutzrechtlichen Konformität der eingeführten Maßnahmen. Zudem besitzen solche Gremien in der Regel keine effektive Sanktionsmacht, sondern nur beratenden Charakter. ${ }^{860}$ Die vorgeschlagenen Kontrollinstanzen sollen vielmehr nicht nur datenschutzrechtliche Aspekte prüfen, sondern auch die Auswirkungen auf andere Grundrechte und die Effektivität der Maßnahmen evaluieren.

Darüber hinaus müsste es effektive Mechanismen geben, die aufgrund einer negativen Evaluation die Weiterführung der Maßnahmen revozieren oder zu einer grundlegenden Revision führen könnten. Bestehende Überprüfungsmechanismen haben sich in Bezug auf die analysierten Sicher-

859 In diesem Sinne sind auch die drei Voraussetzungen der Bestreitbarkeit, die Pettit identifiziert. Die erste Voraussetzung ist nach Pettit, dass die Art und Weise, wie Entscheidungen getroffen werden, eine Basis für Kontestation bietet, was seinerseits Transparenz der Entscheidungen erfordert. Zweitens sind für Pettit Kanäle notwendig, über die Kontestation ausgedrückt werden kann. Schließlich bilden eine weitere Voraussetzung Foren, in denen diese Kontestationen gehört und passende Antworten formuliert werden. Ebd., 186-200. Zu der Frage, ob diese Foren demokratischer ausgerichtet werden können, als Pettit fordert, verweise ich auf die interessanten Überlegungen John McCormicks, vgl. McCormick, John P., Republicanism and Democracy, in: Niederberger, Andreas; Schink, Philipp (Hg.), Republican Democracy: Liberty, Law and Politics. Edinburgh: Edinburgh University Press 2013, 89-127. Nach der Auffassung McCormicks spielt die Zusammensetzung dieser Gremien eine wichtige Rolle. Insbesondere schlägt McCormick eine Besetzung durch Repräsentant_innen der populären Klassen vor als Alternative zu der elitären Ausrichtung des pettitschen Vorschlags.

860 Die rechtliche Basis für die Kontrollgruppe liefert Art. 46 der Verordnung (EG) Nr. 1987/2006 des Europäischen Parlaments und des Rates vom 20.12.2006 über die Einrichtung, den Betrieb und die Nutzung des Schengener Informationssystems der zweiten Generation (SIS II), Amtsblatt der Europäischen Union L 381/4 vom 28.12.2006 und Art. 62 des Beschlusses 2007/533/JI des Rates vom 12.06.2007 über die Einrichtung, den Betrieb und die Nutzung des Schengener Informationssystems der zweiten Generation (SIS II), Amtsblatt der Europäischen Union L 205/63 vom 07.08.2007. 
heitsmaßnahmen als defizitär erwiesen. Neuerdings bei der Implementierung der PNR-Richtlinie etwa, hat die EU-Kommission in ihrem ersten Überprüfungsbericht keine Angaben etwa zur Quote der falschpositiven Treffer, die durch die Auswertung der PNR-Daten erzeugt werden, gemacht. ${ }^{861}$ Dies und andere Defizite in der Offenlegung der Informationen zur Implementierung der PNR-Richtlinie erschweren eine unabhängige Evaluation der Effektivität und Notwendigkeit der PNR-Maßnahmen. Außerdem ist mit der Berichterstattung der Kommission zwar die Möglichkeit eines Änderungsvorschlags, aber keine Revisionspflicht der PNR-Richtlinie verknüpft, sollte sich diese als ineffektiv oder unverhältnismäßig erweisen. ${ }^{862}$ Die Einführung von stärkeren Revisionsrechten und -pflichten würde aus den hier vorgeschlagenen Mechanismen womöglich ein Korrektiv zu der sogenannten Sicherheitsspirale machen, welche die kontinuierliche Ausweitung der EU-Sicherheitspolitik vorantreibt. ${ }^{863}$

Andererseits würde sich diese Form der Kontrolle von der gerichtlichen unterscheiden, die zwar ein breites Kompetenzfeld hat, aber nur reaktiv und unter bestimmten Voraussetzungen aktiviert werden kann. Der EuGH war bisher tatsächlich eine wirkungsvolle Kontrollinstanz, die in einigen Fällen bereits beschlossene Sicherheitsmaßnahmen wieder rückgängig machen konnte, wie im Fall der Richtlinie zur Vorratsdatenspeicherung. ${ }^{864}$ Seine Aktivierung ist aber an hohe rechtliche Hürden gebunden und kann entsprechend nur in bestimmten Fällen ausgeübt werden. ${ }^{865}$ Die vorgeschlagenen Kontrollinstanzen würden dagegen grundsätzlich und routinemäßig alle Maßnahmen überprüfen, nicht nur diejenigen, gegen die geklagt wird.

861 Vgl. Kap. 6, Abschnitt 4.2. Bezugnehmend auf das SIS und die Prümer Regelungen vgl. jeweils Kap. 4, Abschnnitt 4 und Kapitel 5, Abschnitt 4.

862 Vgl. Art. 19 (4) Richtlinie (EU) 2016/681 vom 27.04.2016.

863 Vgl. Kapitel 8, Abschnitt 2.

864 Richtlinie 2006/24/EG vom 15.03.2006 und Urteil des Gerichtshofs der Europäischen Union vom 08.04.2014, Digital Rights Ireland Ltd. Zur Richtlinie über die Vorratsdatenspeicherung vgl. Schneider, Jens-Peter, Rechtsstaatliche Sicherheit in der europäischen Informationsgesellschaft am Beispiel der Vorratsdatenspeicherung, in: Buck, Henning (Hg.), Neue Fragen an den Rechtsstaat: wie begegnen Politik, Recht und Exekutive aktuellen Friedensgefährdungen?, Bd. 16. Göttingen: V \& R Unipress 2009, 179-192.

865 Vgl. Art. 19 des Vertrags über die EU (EUV) und Art. 251-281 des Vertrags über die Arbeitsweise der EU (AEUV), Dok. 2016/C 202/1, Amtsblatt der EU C 202 vom 07.06.2016. 


\section{Die Reaktivierung der Vision von einem Europa als Raum des Woblstands und des Friedens}

Die Konzeption der Autonomie als Kritisierbarkeit wurde in Bezug auf die Sicherheitspolitik im RFSR erarbeitet. Meiner Meinung nach könnte sie aber auch einen fruchtbaren Ansatz darstellen für eine Reform der Entscheidungsprozesse auf gesamter EU-Ebene. Denn ich teile die Ansicht Koen Lenaerts, des derzeitigen Präsidenten des EuGH, nach dem die Etablierung und der Ausbau des RFSR die EU in ein neues konstitutionelles Modell überführt haben. Der RFSR gilt als emblematisch für die neue Ausrichtung der EU-Politik, die sich nunmehr über die wirtschaftliche Integration hinaus erstreckt. ${ }^{866}$

Die Operationalisierung dieses Konzepts der Autonomie würde meiner Meinung nach die Entscheidungsfähigkeit Europas stärken. Denn die aktuelle Undurchlässigkeit zwischen zivilgesellschaftlicher Ebene und europäischer Politik sowie die aus der mangelnden Möglichkeit an Einflussnahme resultierende Frustration führen zu den gegenwärtigen eklatanten Erschütterungen des europäischen Projekts, die es als Ganzes infrage stellen. Denn wenn es unmöglich scheint, auf konstruktive Weise zur Transformation der EU-Politik beizutragen, dann bleiben nur zwei Alternativen. Die eine ist die Stärkung der nationalen Identitäten, in der Hoffnung, dass wenigstens die eigenen Interessen der Angehörigen einer nationalen Gemeinschaft von den nationalen Repräsentant_innen vertreten werden. Die zweite Option, die häufig mit der ersten kombiniert wird, besteht in einer destruktiven antieuropäischen Haltung, nach dem Motto: Wenn innerhalb Europas keine Transformation möglich ist, dann können die gewünschten Änderungen nur ohne oder gegen Europa durchgesetzt werden. Beide Alternativen deuten in eine nationalistische Richtung, die das Projekt Europa grundsätzlich bedroht.

Die Konzeption der öffentlichen Autonomie als Kritisierbarkeit und ihre doppelte Auswirkung auf Mechanismen der Einflussnahme und der Kontrolle könnten in diesem allgemeineren Kontext die Möglichkeit bieten, auch grundsätzliche politische Fragestellungen zu erörtern. Eine solche Fragestellung, die sich zwar besonders dringend in Bezug auf den RFSR stellt, aber auch eine allgemeinere Bedeutung besitzt, wäre etwa, wie weit die Sicherung des freien Marktes gehen und wie viel in ihrem Namen preisgegeben werden darf. Dass dies Kernwerte des europäischen Projekts infrage stellen könnte, darf uns nicht davon abhalten, diese und

866 Vgl. Lenaerts, Foreword, xvi. 
ähnliche Fragen zu stellen. Denn das Prinzip der Freiheit des Marktes, das den Impuls für die Sicherheitsmaßnahmen im RFSR gegeben hat, steht nun immer mehr in Konflikt zu anderen Grundwerten der EU, wie zum Beispiel dem Schutz der Grundrechte und -freiheiten, inklusive der für das EU-Projekt so zentralen Bewegungsfreiheit. Dieses Prinzip scheint nunmehr zudem auch dem ursprünglichen Versprechen der EU, Wohlstand zu sichern, entgegenzustehen. Ich glaube daher, dass das gegenwärtige europäische Projekt, wenn es nicht scheitern soll, sich grundsätzlich transformieren muss. Die Infragestellung einiger ihrer Selbstverständlichkeiten und ihrer grundsätzlichen Zielrichtung gehört zu diesem Projekt der Rettung Europas als Versprechen von Wohlstand und Frieden. 


\section{Schlussbetrachtung}

Hauptanliegen dieses Buches war es, die aktuelle dynamische und folgenreiche Entwicklung der europäischen Sicherheitspolitik im Kontext der Digitalisierung zu ergründen. Zu diesem Zweck habe ich als emblematische Sicherheitsmaßnahmen der EU das Schengener Informationssystem SIS, die Prümer Regelungen und die Fluggastdatensätze-Richtlinie als Untersuchungsgegenstände gewählt.

Mit der Untersuchung wurden weiter drei Unterziele verfolgt. Erstens habe ich das Ziel verfolgt, die strukturellen Charakteristika des sicherheitspolitischen Ansatzes der EU herauszuarbeiten. Zweitens war mein Anliegen, die Legitimität der Sicherheitsmaßnahmen der EU kritisch zu überprüfen und, drittens, Perspektiven zur Überwindung von deren problematischen Aspekten aufzuzeigen.

Die Hauptergebnisse des Buches können wie folgt zusammengefasst werden. Erstens hat die Analyse gezeigt, dass das Sicherheitsmodell der EU im RFSR sich zu einem präemptiven Verständnis von Sicherheit verschiebt und dass diese Entwicklung der EU-Sicherheitspolitik in einem grundlegenden Spannungsverhältnis zu den Legitimitätsprinzipien steht, die in Europa seit der Neuzeit als machteinschränkende Mechanismen eingesetzt werden. ${ }^{867}$ Darauf aufbauend habe ich eine Transformation der Legitimitätsprinzipien zur Diskussion gestellt, durch welche effektiv auf diese Verschiebungen reagiert werden könnte. Mein Vorschlag hat sich in einer Autonomiekonzeption konkretisiert, die sich auf die Möglichkeit der Infragestellung statt auf die Idee eines hypothetischen Konsensus gründet. ${ }^{868}$ Diese Konzeption impliziert, dass eine Ex-ante-Rechtfertigung nicht genügt und dass die Legitimitätsbedingungen immerfort und in ihren konkreten Umsetzungen überprüft werden müssen.

Durch diesen Forschungsertrag stellt das Buch einen spezifisch philosophischen Beitrag zum interdisziplinären Feld der zivilen Sicherheitsforschung dar, weil es die Charakteristika von neuen Sicherheitstechnologien, -verständnissen und -ansätzen aus der disziplinären Perspektive der Philosophie untersucht und problematisiert.

867 Vgl. insbesondere Kapitel 8.

868 Vgl. Kapitel 9. 
Die beiden begrifflichen Pole, die den Rahmen dieser Untersuchung definieren, nämlich Macht und Legitimität, sind gleichzeitig die zwei Grundkategorien einer realistischen, jedoch normativen politischen Philosophie. ${ }^{869}$ In diesem disziplinären Kontext hat die vorliegende Untersuchung ein Metaziel verfolgt, das über die inhaltliche Dimension hinausgeht. Dieses besteht in dem Vorhaben, zur Weiterentwicklung des kritisch-realistischen Ansatzes in der politischen Philosophie beizutragen. Die Verfolgung dieses Ziels habe ich in der Untersuchung durch zwei methodologische Aspekte konkretisiert. Erstens habe ich präzise, sachliche und tiefgreifende Untersuchungen der Aufstellung umfangreicher theoretischer Systeme vorgezogen. ${ }^{870}$ Die erarbeiteten theoretischen Befunde basieren auf konkreten Analysen, statt aus übergeordneten Theoriesystemen abgeleitet zu werden. Ebenfalls habe ich normative Vorschläge als Lösungsansätze zu den durch die Untersuchung identifizierten konkreten Problemen geboten, statt sie aus einem Kern von abstrakt festgelegten Prinzipien und Idealen zu folgern. Dieses Buch wurde dabei nicht nur als theoretischer Beitrag, sondern auch als konkrete Umsetzung einer politischen Philosophie konzipiert, die in der Realität gründet und nichtsdestoweniger auf Theorie und Normativität besteht.

Schließlich war ein allgemeines Anliegen dieses Buches, durch die spezifische Analyse der EU-Sicherheitsmaßnahmen im RFSR Licht auf umfassendere Dynamiken der EU-Entwicklungen zu werfen. Denn die sich im RFSR abzeichnenden Tendenzen können als paradigmatisch für den Übergang der EU zu einer neuen Integrationsphase gelten, in der weitere Kernbereiche der staatlichen Souveränität auf supranationale Ebene übertragen werden. Die sich dadurch abzeichnenden Tendenzen weisen auf eine Erweiterung der Machtbefugnisse der EU auf Kosten der individuellen Rechte hin. Es gibt aber auch Gegentendenzen, die vor allem in der Stärkung der demokratischen und gerichtlichen Kontrolle durch den Vertrag von Lissabon, in der neuesten EU-Datenschutzreform und in der effektiv durch den EuGH ausgeübten Kontrolle bestehen. Vor dem Hintergrund dieser gegensätzlichen Tendenzen bleibt die weitere Entwicklung somit offen. Dabei steht nichts weniger als die „kopernikanische Wende“ der Neuzeit auf dem Spiel, mit der in Europa das Individuum und der Schutz seiner Grundrechte ins Zentrum der politischen Legitimation gerückt sind.

869 Vgl. Kapitel 1, Abschnitt 2.1.

870 Vgl. dazu insbesondere die Kapitel 3-7 des Buches. 


\section{Literaturverzeichnis}

Aden, Hartmut; Busch, Heiner, Europäisierung des Rechts der Inneren Sicherheit, in: Roggan, Fredrik; Kutscha, Martin (Hg.), Handbuch zum Recht der Inneren Sicherheit. Berlin: Berliner Wissenschafts-Verlag 2006, 513-582.

Adorno, Theodor W., Beitrag zur Ideologienlehre, Gesammelte Schriften, Bd. 8: Soziologische Schriften I. Frankfurt am Main: Suhrkamp 1972, 457-477.

Allen, Jonathan, The Place of Negative Morality in Political Theory, in: Political Theory, 29/3, 2001, 337-363.

Angehrn, Emil (Hg.), Dialektischer Negativismus: Michael Theunissen zum 60. Geburtstag. Frankfurt am Main: Suhrkamp 1992.

Arendt, Hannah, A Reply, in: The Review of Politics, 15/1, 1953, 76-84.

Argomaniz, Javier, When the EU is the „Norm-taker“: The Passenger Name Records Agreement and the EU's Internalization of US Border Security Norms, in: Journal of European Integration, 31/1, 2009, 119-136.

Augustinus, Der Gottesstaat, hg. V. Perl, Carl Johann. Paderborn: Ferdinand Schöningh 1979.

Baccelli, Luca, Norberto Bobbio: An Age of Rights Without Foundations, in: IRIS - European Journal of Philosophy and Public Debate, 2/4, 2010, 401-422.

Bader, Veit-Michael, Max Webers Begriff der Legitimität. Versuch einer systematisch-kritischen Rekonstruktion, in: Weiss, Johannes (Hg.), Max Weber heute: Erträge und Probleme der Forschung. Frankfurt am Main: Suhrkamp 1989, 296334.

Bajohr, Hannes, „Am Leben zu sein heißt Furcht zu haben.“Judith Shklars negative Anthropologie des Liberalismus, in: Shklar, Judith N., Der Liberalismus der Furcht. Berlin: Matthes \& Seitz 2013, 131-167.

Balzacq, Thierry; Carrera, Sergio, The Hague Programme: The Long Road to Freedom, Security and Justice, in: Balzacq, Thierry; Carrera, Sergio (Hg.), Security Versus Freedom? A Challenge for Europe's Future. London: Routledge 2006, 1-32.

Barocas, Solon; Selbst, Andrew D., Big Data's Disparate Impact, in: California Law Review, 104, 2016, 671-732.

Baumann, Mechthild, Der Einfluss des Bundeskanzleramts und des Bundesministeriums des Innern auf die Entwicklung einer europäischen Grenzpolitik, in: Hunger, Uwe et al. (Hg.), Migrations- und Integrationsprozesse in Europa. Wiesbaden: VS Verlag für Sozialwissenschaften 2008, 17-33.

Beaussier, Anne-Laure et al., Accounting for failure: risk-based regulation and the problems of ensuring healthcare quality in the NHS, in: Health, Risk \& Society, 18/3-4, 2016, 205-224.

Beetham, David, The legitimation of power. Basingstoke: Macmillan 1991. 
Beetham, David; Lord, Christopher, Legitimacy and the EU. London; New York: Routledge 2013.

Beetz, Jan Pieter; Rossi, Enzo, The EU's democratic deficit in a realist key: multilateral governance, popular sovereignty and critical responsiveness, in: Transnational Legal Theory, 8/1, 2017, 22-41.

Bellamy, Richard, A European Association of Democratic States: Republican Intergovernmentalism, the Role of National Parliaments and the Democratic Constitution of the EU, in: Besselink, Leonard F. M. (Hg.), De Economische Constitutie. Beginselen van de Democratische Rechtsstaat tussen Globalisering en Europeanisering/The Economic Constitution. Principles of Constitutional Democracy between Globalisation and Europeanisation. Nijmegen: aolf Legal Publishers 2020, 11-27.

---, A Republican Europe of States Cosmopolitanism, Intergovernmentalism and Democracy in the EU. Cambridge: Cambridge University Press 2019.

--, The Challenge of European Union, in: Dryzek, John S.; Honig, Bonnie; Phillips, Anne (Hg.), The Oxford Handbook of Political Theory. Oxford: Oxford University Press 2006, 245-261.

Bellamy, Richard; Castiglione, Dario, Legitimizing the Euro-'polity' and its 'Regime': The Normative Turn in EU Studies, in: European Journal of Political Theory, 2/1, 2003, 7-34.

Bellamy, Richard; Weale, Albert, Political legitimacy and European monetary union: contracts, constitutionalism and the normative logic of two-level games, in: Journal of European Public Policy, 22/2, 2015, 257-274.

Bigo, Didier, Liberty, whose Liberty? The Hague Programme and the Conception of Freedom, in: Balzacq, Thierry; Carrera, Sergio (Hg.), Security Versus Freedom? A Challenge for Europe's Future. London: Routledge 2006, 35-44.

---, et al., Mapping the Field of the EU Internal Security Agencies, in: Bigo, Didier et al., The Field of the EU Internal Security Agencies. Paris: L'Harmattan 2008, 5-66.

Blasi Casagran, Cristina, The Future EU PNR System: Will Passenger Data Be Protected?, in: European Journal of Crime, Criminal Law and Criminal Justice, 23, 2015, 241-257.

Blumenberg, Hans, Die Legitimität der Neuzeit. Frankfurt am Main: Suhrkamp 1996.

Bobbio, Norberto, L'età dei diritti. Torino: Einaudi 1991.

---, Democracy and dictatorship. The nature and limits of state power. Cambridge: Polity Press 1997.

---, Das Zeitalter der Menschenrechte: ist Toleranz durchsetzbar? Berlin: Wagenbach 1998.

Bode, Felix; Seidensticker, Kai, Predictive Policing. Eine Bestandsaufnahme für den deutschsprachigen Raum. Frankfurt am Main: Verlag für Polizeiwissenschaft, Prof. Dr. Clemens Lorei 2020.

Bodin, Jean, Über den Staat, hg. v. Niedhart, Gottfried. Stuttgart: Reclam 2005. 
Boehm, Franziska, EU PNR: European Flight Passengers Under General Suspicion - The Envisaged European Model of Analyzing Flight Passenger Data, in: Gutwirth, Serge; Poullet, Yves; De Hert, Paul; Leenes, Ronald (Hg.), Computers, Privacy and Data Protection: an Element of Choice. Dordrecht: Springer 2011, 171199.

Bröckling, Ulrich, Gute Hirten führen sanft. Über Menschenregierungskünste. Berlin: Suhrkamp 2017.

Brouwer, Evelien, Eurodac: Its Limitations and Temptations, in: European Journal of Migration and Law, 4/2, 2002, 231-247.

---, Digital borders and real rights. Effective remedies for third-country nationals in the Schengen Information System. Boston: Martinus Nijhoff Publishers 2008.

Buchstein, Hubertus; Jörke, Dirk, Das Unbehagen an der Demokratietheorie, in: Leviathan, 31/4, 2003, 470-495.

Burgess, J. Peter, Sicherheit als Ethik, in: Zoche, Peter; Kaufmann, Stefan; Arnold, Harald (Hg.), Sichere Zeiten? Gesellschaftliche Dimensionen der Sicherheitsforschung. Berlin; Münster: LIT Verlag 2015, 33-42.

Busch, Heiner, Europa - ein „Mekka der Kriminalität“? EG-Grenzöffnung und internationale Polizeikooperation, in: Kritische Justiz, 23/1, 1990, 1-13.

---, Grenzenlose Polizei? Neue Grenzen und polizeiliche Zusammenarbeit in Europa. Münster: Westfälisches Dampfboot 1995.

Butler, Judith, Was ist Kritik?, in: Deutsche Zeitschrift für Philosophie, 50/2, 2002, 249-266.

Celikates, Robin; Gosepath, Stefan, Grundkurs Philosophie. Politische Philosophie. Stuttgart: Reclam 2013.

Cheneval, Francis; Schimmelfennig, Frank, The Case for Demoicracy in the European Union, in: JCMS: Journal of Common Market Studies, 51/2, 2013, 334350.

Christman, John, Autonomie, in: Gosepath, Stefan; Hinsch, Wilfried; Rössler, Beate (Hg.), Handbuch der politischen Philosophie und Sozialphilosophie. Berlin: de Gruyter 2008, 96-102.

Constant, Benjamin, Über die Freiheit. Klosterberg; Basel: Schwabe 1946.

Degeling, Martin; Berendt, Bettina, What is wrong about Robocops as consultants? A technology-centric critique of predictive policing, in: AI \& SOCIETY, 33/3, 2017, 347-356.

Den Boer, Monica, The Quest for European Policing: Rethoric and Justification in a Desorderly Debate, in: Anderson, Malcolm; Den Boer, Monica (Hg.), Policing across national boundaries. London: Pinter 1994, 174-196.

Der Spiegel, Big Brother ersetzt den Zöllner, 28/1989, 27-28.

Domingues, Rémi et al., A comparative evaluation of outlier detection algorithms: Experiments and analyses, in: Pattern Recognition, 74, 2018, 406-421.

Dunn, John, Democracy: the unfinished journey. 508 BC to AD 1993. Oxford: Oxford University Press 1992.

---, The cunning of unreason: making sense of politics. New York: Basic Books 2003. 
---, Capitalist democracy: elective affinity or beguiling illusion?, in: Daedalus, 136/3, 2007, 5-13.

Emerson, Ralph Waldo, Essays \& lectures, hg. v. Porte, Joel. New York: Literary Classics of the United States 1983.

Feely, Malcom M.; Simon, Jonathan, The new penology: notes on the emerging strategy of corrections and its implications, in: Criminology, 30/4, 1992, 449474.

Feuerlein, Monika; Potthof, Christof, Codierend-nicht-codierend. Interview mit Peter Schneider, in: Gen-ethischer Informationsdienst, 170, 2005, 14-19.

Fichera, Massimo, Sketches of a theory of Europe as an Area of Freedom, Security and Justice, in: Fletcher, Maria; Herlin-Karnell, Ester; Matera, Claudio (Hg.), The European Union as an area of freedom, security and justice. London; New York: Routledge 2017, 34-56.

Fischer, Hans Georg; Keller, Matthias (Hg.), Justiz und innere Sicherheit im EU-Recht: die EU als Raum der Freiheit, der Sicherheit und des Rechts. Köln: BundesanzeigerVerlag 2014.

Flathman, Richard, In and out of the ethical: The realist liberalism of Bernard Williams, in: Contemporary Political Theory, 9/1, 2010, 77-98.

Fletcher, Maria; Herlin-Karnell, Ester; Matera, Claudio (Hg.), The European Union as an Area of Freedom, Security and Justice. London; New York: Routledge 2017.

Forrester, Katrina, Hope and Memory in the Thought of Judith Shklar, in: Modern Intellectual History, 8/3, 2011, 591-620.

---, Judith Shklar, Bernard Williams and political realism, in: European Journal of Political Theory, 11/3, 2012, 247-272.

Forst, Rainer, Das Recht auf Rechtfertigung. Elemente einer konstruktivistischen Theorie der Gerechtigkeit. Frankfurt am Main: Suhrkamp 2007.

---, Der Grund der Kritik. Zum Begriff der Menschenwürde in sozialen Rechtfertigungsordnungen, in: Jaeggi, Rahel; Wesche, Tilo (Hg.), Was ist Kritik? Frankfurt am Main: Suhrkamp 2009, 150-164.

Foucault, Michel, Was ist Aufklärung?, in: Erdmann, Eva; Forst, Rainer; Honneth, Axel (Hg.), Ethos der Moderne. Foucaults Kritik der Aufklärung. Frankfurt am Main: Campus 1990, 35-54.

---, Was ist Kritik? Berlin: Merve 1992.

---, Polemics, Politics and Problematizations: An interview conducted by Paul Rabinow in May 1984, in: Rabinow, Paul (Hg.), Essential Works of Foucault, Bd. 1 “Ethics”. New York: The New Press 1998, 381-390.

Freyenhagen, Fabian; Schaub, Jörg, Hat hier jemand gesagt, der Kaiser sei nackt? Eine Verteidigung der Geussschen Kritik an Rawls' idealtheoretischem Ansatz, in: Deutsche Zeitschrift für Philosophie, 58/3, 2010, 457-477.

Gadamer, Hans-Georg, Lob der Theorie: Reden u. Aufsätze. Frankfurt am Main: Suhrkamp 1983.

---, Wabrheit und Methode. Grundzüge einer philosophischen Hermeneutik. Tübingen: Mohr Siebeck 2010. 
Galston, William A., Realism in political theory, in: European Journal of Political Theory, 9/4, 2010, 385-411.

Gander, Hans-Helmuth, Sicherheitsethik - ein Desiderat? Mögliche Vorüberlegungen, in: Gander, Hans-Helmuth et al. (Hg.), Resilienz in der offenen Gesellschaft: Symposium des Centre for Security and Society. Baden-Baden: Nomos 2012, 85-94.

---, Das Verlangen nach Sicherheit. Anthropologische Befunde, in: Heckmann, Dirk; Schenke, Ralf P.; Sydow, Gernot (Hg.), Verfassungsstaatlichkeit im Wandel. Festschrift für Thomas Würtenberger zum 70. Geburtstag. Berlin: Duncker \& Humblot 2013, 983-993.

Gander, Hans-Helmuth et. al (Hg.), Resilienz in der offenen Gesellschaft: Symposium des Centre for Security and Society. Baden-Baden: Nomos 2012.

Gander, Hans-Helmuth; Riescher, Gisela (Hg.), Sicherheit und offene Gesellschaft: Herausforderungen, Methoden und Praxis einer gesellschaftspolitischen Sicherheitsforschung. Baden-Baden: Nomos 2014.

Gandy, Oscar H., Data Mining, Surveillance, and Discrimination in the Post-9/11 Environment, in: Haggerty, Kevin D.; Ericson, Richard V. (Hg.), The new politics of surveillance and visibility. Toronto: University of Toronto Press 2007, 363-384.

Geuss, Raymond, Die Idee einer kritischen Theorie. Königstein: Hain 1983.

---, Kritik, Aufklärung, Genealogie, in: Deutsche Zeitschrift für Philosophie, 50/2, 2002, 273-282.

---, Outside Ethics. Princeton: Princeton University Press 2009.

---, Realismus, Wunschdenken, Utopie, in: Deutsche Zeitschrift für Philosophie, 58/3, 2010, 419-429.

---, Kritik der politischen Philosophie: eine Streitschrift. Hamburg: Hamburger Edition 2011.

Grimm, Dieter, Die Zukunft der Verfassung. Frankfurt am Main: Suhrkamp 1991.

Gröbl, Harald, 1992: Offene Grenzen und was dann?, in: Die Neue Polizei, 2/1989, 81-87.

Guild, Elspeth; Carrera, Sergio, The European Union's Area of Freedom, Security and Justice Ten Years on, in: Guild, Elspeth; Carrera, Sergio; Eggenschwiler, Alejandro (Hg.), The area of freedom, security and justice ten years on: successes and future challenges under the Stockholm Programme. Brüssel: CEPS 2010, 1-12.

Guild, Elspeth; Geyer, Florian, Getting Local: Schengen, Prüm and the Dancing Procession of Echternach. Three Paces Forward and two Back for EU Police and Judicial Cooperation in Criminal Matters, in: Journal of European Criminal Law, 1/3, 2007, 61-66.

Habermas, Jürgen, Legitimationsprobleme im Spätkapitalismus. Frankfurt am Main: Suhrkamp 1977.

---, Wie ist Legitimität durch Legalität möglich?, in: Kritische Justiz, 1/1987, 1-16.

---, Braucht Europa eine Verfassung? Eine Bemerkung zu Dieter Grimm, in: Habermas, Jürgen, Die Einbeziehung des Anderen. Studien zur politischen Theorie. Frankfurt am Main: Suhrkamp 1996, 185-191. 
---, Drei normative Modelle der Demokratie, in: Habermas, Jürgen, Die Einbeziebung des Anderen. Studien zur politischen Theorie. Frankfurt am Main: Suhrkamp 1996, 277-293.

---, Faktizität und Geltung: Beiträge zur Diskurstheorie des Rechts und des demokratischen Rechtsstaats. Frankfurt am Main: Suhrkamp 1998.

---, Recht und Moral (Tanner Lectures 1986). Zur Idee des Rechtsstaats, in: Habermas, Jürgen, Faktizität und Geltung: Beiträge zur Diskurstheorie des Rechts und des demokratischen Rechtsstaats. Frankfurt am Main: Suhrkamp 1998, 571-599.

---, Zur Legitimation durch Menschenrechte, in: Habermas, Jürgen, Die postnationale Konstellation. Politische Essays. Frankfurt am Main: Suhrkamp 1998, 170-192.

---, Zur Verfassung Europas: ein Essay. Berlin: Suhrkamp 2011.

Hall, Edward, Bernard Williams and the Basic Legitimation Demand: A Defence, in: Political Studies, 63/2, 2015, 466-480.

Hartmann, Martin; Offe, Claus (Hg.), Politische Theorie und Politische Philosophie. Ein Handbuch. München: C.H. Beck 2011.

Hawthorn, Geoffrey, Introduction, in: Williams, Bernard Arthur Owen, In the beginning was the deed: realism and moralism in political argument. Princeton: Princeton University Press 2005, xi-xx.

Hegel, Georg Wilhelm Friedrich, Werke. Band 5: Wissenschaft der Logik. Teil 1: Die objektive Logik, hg. v. Moldenhauer, Eva. Frankfurt am Main: Suhrkamp 1990.

---, Grundlinien der Philosophie des Rechts, hg. v. Grotsch, Klaus. Hamburg: Felix Meiner Verlag 2015.

Hennette-Vauchez, Stéphanie et al., Für ein anderes Europa: Vertrag zur Demokratisierung der Eurozone. München: C.H. Beck 2017.

Hildebrandt, Mireille, Algorithmic regulation and the rule of law, in: Philosophical Transactions of the Royal Society A. Mathematical, Physical and Engineering Sciences, 376/2128, 2018, 1-11.

Hinsch, Wilfried, Legitimität, in: Gosepath, Stefan; Hinsch, Wilfried; Rössler, Beate (Hg.), Handbuch der politischen Philosophie und Sozialphilosophie. Berlin: de Gruyter 2008, 704-712.

Hobbes, Thomas, Leviathan: oder Stoff, Form und Gewalt eines kirchlichen und bürgerlichen Staates, hg. v. Fetscher, Iring. Frankfurt am Main: Suhrkamp 1994.

Hoffmann, Thomas S., Idealismus, in: Hartmann, Martin; Offe, Claus (Hg.), Politische Theorie und Politische Philosophie. Ein Handbuch. München: C.H. Beck 2011, 26-30.

Holzhacker, Ronald L.; Luif, Paul, Introduction: Freedom, Security and Justice after Lisbon, in: Holzhacker, Ronald L.; Luif, Paul (Hg.), Freedom, security, and justice in the European Union: Internal and External Dimensions of Increased Cooperation after the Lisbon Treaty. New York; Heidelberg: Springer 2014, 1-12.

Honig, Bonnie; Stears, Marc, The new realism: From modus vivendi to justice, in: Floyd, Jonathan (Hg.), Political philosophy versus history? Contextualism and real politics in contemporary political thought. Cambridge: Cambridge University Press 2011, 177-205. 
---, James Tully's Agonistic Realism, in: Tully, James, On Global Citizenship. London; New York: Bloomsbury Academic 2014, 131-153.

Honneth, Axel, Rekonstruktive Gesellschaftskritik unter genealogischem Vorbehalt. Zur Idee der „Kritik“ in der Frankfurter Schule, in: Deutsche Zeitschrift für Philosophie, 48/5, 2000, 729-737.

---, Vorwort, in: Shklar, Judith N., Der Liberalismus der Furcht. Berlin: Matthes \& Seitz 2013, 7-25.

Horton, John, Realism, liberal moralism and a political theory of modus vivendi, in: European Journal of Political Theory, 9/4, 2010, 431-448.

House of Lords, European Union Committee, Prüm: an effective weapon against terrorism and crime? 18th Report of Session 2006-07.

Hume, David, Ein Traktat über die menschliche Natur, hg. v. Brandt, Horst D. Hamburg: Felix Meiner Verlag 2013.

Hummer, Waldemar, Der Vertrag von Prüm - „Schengen III“?, in: Europarecht, 42/4, 2007, 517-530.

Huster, Stefan, Rechtsstaat, in: Gosepath, Stefan; Hinsch, Wilfried; Rössler, Beate (Hg.), Handbuch der politischen und Sozialphilosophie. Berlin: de Gruyter 2008, 1092-1098.

Jaeggi, Rahel, Was ist Ideologiekritik?, in: Jaeggi, Rahel; Wesche, Tilo (Hg.), Was ist Kritik? Frankfurt am Main: Suhrkamp 2009, 266-295.

Jestaedt, Matthias, Das mag in der Theorie richtig sein ... vom Nutzen der Rechtstheorie für die Rechtspraxis. Tübingen: Mohr Siebeck 2006.

---, Warum in die Ferne schweifen, wenn der Maßstab liegt so nah? Verfassungshandwerkliche Anfragen an das Lissabon-Urteil des BVerfG, in: Der Staat, 48/4, 2009, 497-516.

---, Die Europäische Integration und das Grundgesetz: Die Rechtsprechung des BVerfG zwischen Integrationsbeförderung und Integrationsbegrenzung, in: Osaka University Law Review, 64/2, 2017, 43-110.

Jestaedt, Matthias; Lepsius, Oliver (Hg.), Verbältnismäßigkeit. Zur Tragfäbigkeit eines verfassungsrechtlichen Schlüsselkonzepts. Tübingen: Mohr Siebeck 2015.

Joerges, Christian; Neyer, Jürgen, From Intergovernmental Bargaining to Deliberative Political Processes: The Constitutionalisation of Comitology, in: European Law Journal, 3/3, 1997, 273-299.

Jubb, Robert, Playing Kant at the Court of King Arthur, in: Political Studies, 63/4, 2015, 919-934.

Kamiran, Faisal; Calders, Toon; Pechenizkiy, Mykola, Techniques for Discrimination-Free Predictive Models, in: Custers, Bart et al. (Hg.), Discrimination and privacy in the information society: data mining and profiling in large databases. Berlin; Heidelberg: Springer 2013, 223-241.

Kant, Immanuel, Über den Gemeinspruch: Das mag in der Theorie richtig sein, taugt aber nicht für die Praxis, hg. v. Ebbinghaus, Julius. Frankfurt am Main: Klostermann 1982. 
---, Grundlegung zur Metaphysik der Sitten, hg. v. Kraft, Bernd; Schönecker, Dieter. Hamburg: Felix Meiner Verlag 2016.

Kateb, George, Foreword, in: Shklar, Judith N., Political thought and political thinkers, hg. v. Hoffmann, Stanley. Chicago: University of Chicago Press 1998, vii$\mathrm{xx}$.

Kaufmann, Franz-Xaver, Sicherheit als soziologisches und sozialpolitisches Problem: Untersuchungen zu einer Wertidee hochdifferenzierter Gesellschaften. Münster; Berlin: Ferdinand Enke Verlag 2012.

Kaufmann, Stefan, Security Through Technology? Logic, Ambivalence and Paradoxes of Technologised Security, in: European Journal for Security Research, 1/1, 2016, 77-95.

Kelsen, Hans, Reine Rechtslehre. Einleitung in die rechtswissenschaftliche Problematik, hg. v. Jestaedt, Matthias. Studienausg. der 1. Aufl. 1934. Tübingen: Mohr Siebeck 2008.

---, Was ist juristischer Positivismus?, in: Juristenzeitung, 20/15/16, 1965, 465-468.

Kietz, Daniela; Maurer, Andreas, Fragmentierung und Entdemokratisierung der europäischen Justiz- und Innenpolitik? Folgen der Prümer Vertragsavantgarde, in: Möllers, Martin H. W.; van Ooyen, Robert Chr. (Hg.), Jabrbuch Öffentliche Sicherheit 2006/2007. Frankfurt am Main: Verlag für Polizeiwissenschaft 2007, 439-452.

Krane, Christian, Schengener Informationssystem, in: Lange, Hans-Jürgen; Gasch, Matthias (Hg.), Wörterbuch zur Inneren Sicherheit. Wiesbaden: VS Verlag für Sozialwissenschaften 2006, 277-280.

---, Schleierfahndung, in: Lange, Hans-Jürgen; Gasch, Matthias (Hg.), Wörterbuch zur Inneren Sicherheit. Wiesbaden: VS Verlag für Sozialwissenschaften 2006, 283287.

Krüger, Ralf, Innere Sicherheit für Europa. Schengen und Maastricht - Stationen der Polizei auf dem Weg nach Europa, in: Kriminalistik, 12, 1994, 773-779.

Kühne, Hans-Heiner, Kriminalitätsbekämpfung durch innereuropäische Grenzkontrollen? Auswirkungen der Schengener Abkommen auf die innere Sicherheit. Berlin: Duncker \& Humblot 1991.

Lange, Hans-Jürgen, Innere Sicherheit, in: Lange, Hans-Jürgen; Gasch, Matthias (Hg.), Wörterbuch zur Inneren Sicherheit. Wiesbaden: VS Verlag für Sozialwissenschaften 2006, 123-134.

Leese, Matthias, The new profiling: Algorithms, black boxes, and the failure of anti-discriminatory safeguards in the European Union, in: Security Dialogue, 45/5, 2014, 494-511.

Lenaerts, Koen, Foreword, in: Fletcher, Maria; Herlin-Karnell, Ester; Matera, Claudio (Hg.), The European Union as an Area of Freedom, Security and Justice. London; New York: Routledge 2017, xv-xvii.

Léonard, Sarah; Kaunert, Christian (Hg.), Searching for a strategy for the European Union's area of freedom, security and justice. London; New York: Routledge 2017. 
Léonard, Sarah; Kaunert, Christian, Searching for a strategy for the European Union's area of freedom, security and justice, in: European Politics and Society, 17/2, 2016, 143-149.

Liebsch, Burkhard; Bajohr, Hannes, Geschichte, Negativismus und Skepsis als Herausforderungen politischer Theorie: Judith N. Shklar, in: Deutsche Zeitschrift für Philosophie, 62/4, 2014, 633-659.

Locke, John, Zwei Abhandlungen über die Regierung, hg. v. Euchner, Walter. Frankfurt am Main: Suhrkamp 2006.

Loh, Wulf, Konsens und Autonomie - Zur Legitimität völkerrechtlicher Normen, in: Rechtsphilosophie - Zeitschrift für Grundlagen des Rechts, 1, 2018, 58-77.

Lord, Christopher, An indirect legitimacy argument for a directly elected European Parliament, in: European Journal of Political Research, 56/3, 2017, 512-528.

Luhmann, Niklas, Gesellschaftliche und politische Bedingungen des Rechtsstaates, in: Luhmann, Niklas, Politische Planung: Aufsätze zur Soziologie von Politik und Verwaltung. Wiesbaden: VS Verlag für Sozialwissenschaften 2007, 53-65.

---, Vertrauen: ein Mechanismus der Reduktion sozialer Komplexität. Stuttgart: Lucius \& Lucius 2009.

Luif, Paul; Trauner, Florian, The Prüm Process: The Effects of Enhanced Cooperation within Europe and with the United States in Combating Serious Crime, in: Holzhacker, Ronald L.; Luif, Paul (Hg.), Freedom, security, and justice in the European Union: internal and external dimensions of increased cooperation after the Lisbon treaty. New York; Heidelberg: Springer 2014, 101-117.

Machiavelli, Niccolò, Discorsi. Gedanken über Politik und Staatsführung, hg. v. Zorn, Rudolf. Stuttgart: Kröner 1977.

---, Der Fürst, hg. v. Rudolph, Enno. Hamburg: Felix Meiner Verlag 2019.

Marsch, Nikolaus, Das europäische Datenschutzgrundrecht. Grundlagen, Dimensionen, Verflechtungen. Tübingen: Mohr Siebeck 2018.

Mayer-Schönberger, Viktor; Cukier, Kenneth, Big Data: Die Revolution, die unser Leben verändern wird. München: Redline Verlag 2013.

McCartney, Carole I.; Wilson, Tim J.; Williams, Robin, Transnational Exchange of Forensic DNA: Viability, Legitimacy, and Acceptability, in: European Journal on Criminal Policy and Research, 17/4, 2011, 305-322.

McCormick, John P., Republicanism and Democracy, in: Niederberger, Andreas; Schink, Philipp (Hg.), Republican Democracy: Liberty, Law and Politics. Edinburgh: Edinburgh University Press 2013, 89-127.

Meier, Christian; Reimann, Hans Leo; Conze, Werner, Demokratie, in: Brunner, Otto; Conze, Werner; Koselleck, Reinhart (Hg.), Geschichtliche Grundbegriffe, Bd. 1. Heidelberg: Klett-Cotta 1972, 821-899.

Menke, Christoph, Weder Rawls noch Adorno? Raymond Geuss' Programm einer realistischen Philosophie, in: Deutsche Zeitschrift für Philosophie, 58/3, 2010, 445-455.

Monar, Jörg, The Dynamics of Justice and Home Affairs: Laboratories, Driving Factors and Costs, in: JCMS: Journal of Common Market Studies, 39/4, 2001, $747-764$. 
---, Die politische Konzeption des Raumes der Freiheit, der Sicherheit und des Rechts: Vom Amsterdamer Vertrag zum Verfassungsentwurf des Konvents, in: Müller-Graff, Peter-Christian (Hg.), Der Raum der Freiheit, der Sicherheit und des Rechts. Baden-Baden: Nomos 2005, 29-41.

Moravscik, Andrew, In Defence of the Democratic Deficit: Reassessing Legitimacy in the EU, in: Journal of Common Market Studies, 40/4, 2002, 603-624.

Morozov, Evgeny, Smarte neue Welt: digitale Technik und die Freiheit des Menschen. München: Blessing 2013.

Müller, Oliver, Beyond the political: Hans Blumenberg's criticism of Carl Schmitt, in: Minkov, Svetozar; Nowak, Piotr (Hg.), Man and his enemies. Essays on Carl Schmitt. Bialystok: University of Bialystok Press 2008, 237-253.

Müller-Graff, Peter-Christian (Hg.), Der Raum der Freiheit, der Sicherheit und des Rechts. Baden-Baden: Nomos 2005.

---, Der Raum der Freiheit, der Sicherheit und des Rechts - Der primarrechtliche Rahmen, in: Müller-Graff, Peter-Christian (Hg.), Der Raum der Freiheit, der Sicherheit und des Rechts. Baden-Baden: Nomos 2005, 11-27.

Münkler, Herfried, Strategien der Sicherung: Welten der Sicherheit und Kulturen des Risikos. Theoretische Perspektiven, in: Münkler, Herfried; Bohlender, Matthias; Meurer, Sabine (Hg.), Sicherheit und Risiko. Über den Umgang mit Gefahr im 21. Jahrbundert. Bielefeld: Transcript 2010, 11-34.

Mutschler, Stefanie, Der Prümer Vertrag: neue Wege der Kriminalitätsbekämpfung auf europäischer Ebene. Stuttgart: Boorberg 2010.

Nelles, Ursula, Europäisierung des Strafverfahrens - Strafprozeßrecht für Europa?, in: Zeitschrift für die gesamte Strafrechtswissenschaft, 109/4, 1997, 727-755.

Neyer, Jürgen, Europe's Justice Deficit: Justification and Legitimacy in the European Union, in: Neyer, Jürgen; Wiener, Antje (Hg.), Political Theory of the European Union. Oxford: Oxford University Press 2011, 169-186.

Neyer, Jürgen; Wiener, Antje (Hg.), Political Theory of the European Union. Oxford: Oxford University Press 2011.

Nicolaidis, Kalypso, Our European Demoi-cracy: Is this Constitution a Third Way for Europe?, in: Nicolaïdis, Kalypso; Weatherill, Stephen (Hg.), Whose Europe? National Models and the Constitution of the European Union. Oxford: Oxford University Press 2003, 137-152.

---, The New Constitution as European 'Demoi-Cracy'?, in: Critical Review of International Social and Political Philosophy, 7/1, 2004, 76-93.

---, European demoicracy and its crisis, in: Journal of Common Market Studies, 51/2, 2013, 351-369.

Nullmeier, Frank; Geis, Anna; Daase, Christopher, Der Aufstieg der Legitimitätspolitik. Rechtfertigung und Kritik politisch-ökonomischer Ordnungen, in: Geis, Anna; Nullmeier, Frank; Daase, Christopher (Hg.), Der Aufstieg der Legitimitätspolitik. Baden-Baden: Nomos 2012, 11-38.

Okin, Susan Moller, Justice, Gender, and the Family. New York: Basic Books 1989.

O'Neil, Cathy, Weapons of math destruction: how big data increases inequality and threatens democracy. London: Penguin Books, 2017. 
Orrù, Elisa, Minimum Harm by Design. Reworking Privacy by Design to mitigate the risks of surveillance, in: Leenes, Ronald et al. (Hg.), Computers, Privacy and Data Protection: Invisibilities \& Infrastructures. Dordrecht: Springer 2017, 107137.

---, Sorveglianza e potere nella Unione Europea, in: Filosofia Politica, 29/3, 2015, 459-474.

---, The Schengen Information System and Data Retention. On Surveillance, Security and Legitimacy in the European Union, in: Orrù, Elisa; Porcedda, Maria Grazia; Weydner-Volkmann, Sebastian (Hg.), Rethinking Surveillance and Control. Beyond the "Security vs. Privacy" Debate. Baden-Baden: Nomos 2017, 115136.

---, Olympe de Gouges on Slavery, in: Diacronìa, 2/2, 2020, 95-121.

---, Ein Gesellschaftsvertrag für alle. Die Universalität der Menschenrechte nach Olympe de Gouges, in: Allgemeine Zeitschrift für Philosophie, 46/2, 2021, 183-206.

Osborne, Thomas, Machiavelli and the liberalism of fear, in: History of the Human Sciences, 30/5, 2017, 68-85.

Ostermeier, Lars, Der Staat in der prognostischen Sicherheitsgesellschaft, in: Puschke, Jens; Singelnstein, Tobias (Hg.), Der Staat und die Sicherheitsgesellschaft. Wiesbaden: Springer Fachmedien 2018, 101-121.

Özmen, Elif, Politische Philosophie zur Einführung. Hamburg: Junius-Verlag 2013.

Pasquale, Frank, The Black Box Society: the secret algorithms that control money and information. Cambridge: Harvard University Press 2015.

Pateman, Carole, Participation and democratic theory. Cambridge: University Press 1970.

---, The Problem of Political Obligation. A Critical Analysis of Liberal Theory. Chichester: John Wiley \& Sons 1979.

Peers, Steve, The rise and fall of EU justice and home affairs law, in: Fletcher, Maria; Herlin-Karnell, Ester; Matera, Claudio (Hg.), The European Union as an area of freedom, security and justice. London; New York: Routledge 2017, 11-33.

Pelzer, Robert, Policing of Terrorism Using Data from Social Media, in: European Journal for Security Research, 3/2, 2018, 163-179.

Pettit, Philip, Republicanism. A theory of freedom and government. Oxford: Oxford University Press 1999.

Philp, Mark, Political Conduct. Harvard: Harvard University Press 2007.

Pitkin, Hanna Fenichel, Obligation and Consent, in: The American Political Science Review, 59/4, 1965, 990-999.

---, Wittgenstein and justice: on the significance of Ludwig Wittgenstein for social and political thought. Berkeley: University of California Press 1972.

Plato, Der Staat, hg. v. Szlezák, Thomas Alexander. Berlin: de Gruyter 2014. 
Polenz, Sven, Datenschutz. Rechtsquellen und Grundbegriffe des allgemeinen Datenschutzes, in: Kilian, Wolfgang; Heussen, Benno (Hg.), Computerrechts-Handbuch. Informationstechnologie in der Rechts- und Wirtschaftspraxis. München: C.H. Beck 2017, Kap. 131.

Pörschke, Julia Victoria, Der Grundsatz der Verfügbarkeit von Informationen am Beispiel des Prümer Modells. Berlin: Duncker \& Humblot 2014.

Portinaro, Pier Paolo, Il realismo politico. Roma-Bari: Laterza 1999.

---, Grundsätzliches oder Selbstverständliches zum Politischen Realismus, in: Brodocz, André et al. (Hg.), Die Verfassung des Politischen. Festschrift für Hans Vorländer. Wiesbaden: Springer 2014, 351-362.

Poscher, Ralf, Eingriffsschwellen im Recht der inneren Sicherheit. Ihr System im Licht der neueren Verfassungsrechtsprechung, in: Die Verwaltung, 41/3, 2008.

---, Die Zukunft der informellen Selbstbestimmung als Recht auf Abwehr von Grundrechtsgefährdungen, in: Gander, Hans-Helmuth et al. (Hg.), Resilienz in der offenen Gesellschaft. Symposium des Centre for Security and Society. Baden-Baden: Nomos 2012, 167-190.

---, Was Juristen besser können als Ethiker: Ein interdisziplinäres Argument für die gerichtliche Kontrolle von Ethikkommissionen, in: Vöneky, Silja et al. (Hg.), Ethik und Recht - Die Ethisierung des Rechts/Ethics and Law - The Ethicalization of Law. Berlin, Heidelberg: Springer 2013, 433-441.

---, Tendencies in Public Civil Security Law, in: European Journal for Security Research, 1/1, 2016, 59-76.

---, The Right to Data Protection: A No-Right Thesis, in: Miller, Russell A. (Hg.), Privacy and power. A transatlantic dialogue in the shadow of the NSA-Affair. Cambridge: Cambridge University Press 2017, 129-141.

Prainsack, Barbara; Toom, Victor, The Prüm Regime: Situated Dis/Empowerment in Transnational DNA Profile Exchange, in: The British Journal of Criminology, 50/6, 2010, 1117-1135.

---, Performing the Union: The Prüm Decision and the European dream, in: Studies in History and Philosophy of Biological and Biomedical Sciences, 44/1, 2013, 71-79.

Rademacher, Timo, Predictive Policing im deutschen Polizeirecht, in: Archiv des öffentlichen Rechts (AöR), 142/3, 2017, 366-416.

Rawls, John, Das Recht der Völker. Berlin: de Gruyter 2002.

---, Eine Theorie der Gerechtigkeit. Frankfurt am Main: Suhrkamp 2012.

Richardson, Henry S., Demokratie, in: Gosepath, Stefan; Hinsch, Wilfried; Rössler, Beate (Hg.), Handbuch der politischen Philosophie und Sozialphilosophie. Berlin: de Gruyter 2008, 206-211.

Ritter, Gerhard, Die Dämonie der Macht. Betrachtungen über Geschichte und Wesen des Machtproblems im politischen Denken der Neuzeit. München: Leibniz-Verlag 1948.

Ronzoni, Miriam, The European Union as a demoicracy: Really a third way?, in: European Journal of Political Theory, 16/2, 2017, 210-234. 
Roots, Lethe, The New EURODAC Regulation: Fingerprints as a Source of Informal Discrimination, in: Baltic Journal of European Studies, 5/2, 2015, 108-129.

Rossi, Enzo, Consensus, compromise, justice and legitimacy, in: Critical Review of International Social and Political Philosophy, 16/4, 2013, 557-572.

--, Can Realism Move Beyond a Methodenstreit?, in: Political Theory, 44/3, 2016, 410-420.

---, Being realistic and demanding the impossible, in: Constellations, 26/4, 2019, 638-652.

Rossi, Enzo; Sleat, Matt, Realism in Normative Political Theory, in: Philosophy Compass, 9/10, 2014, 689-701.

Rousseau, Jean-Jacques, Vom Gesellschaftsvertrag oder Grundsätze des Staatsrechts, hg. v. Brockard, Hans. Stuttgart: Reclam 2008.

Runciman, David, What Is Realistic Political Philosophy?, in: Metaphilosophy, 43/1/2, 2012, 58-70.

---, Political Theory and Real Politics in the Age of the Internet, in: Journal of Political Philosophy, 25/1, 2017, 3-21.

Rupprecht, Reinhard, Wettlauf der Schnecken. Probleme und Konsequenzen des Abbaus von Grenzkontrollen, in: Kriminalistik, 5, 1989, 263-270.

Rupprecht, Reinhard; Altmann, Robert, Polizei-Lexikon. Heidelberg: KriminalistikVerlag 1986.

Rupprecht, Reinhard; Hellenthal, Markus, Programm für eine Europäische Gemeinschaft der Inneren Sicherheit, in: Rupprecht, Reinhard; Hellenthal, Markus (Hg.), Innere Sicherheit im Europäischen Binnenmarkt. Eine Veröffentlichung der Bertelsmann Stiftung. Gütersloh: Verlag Bertelsmann Stiftung 1992.

Sagar, Paul, From Scepticism to Liberalism? Bernard Williams, the Foundations of Liberalism and Political Realism, in: Political Studies, 64/2, 2016, 368-384.

Schaal, Gary S., Zwischenbetrachtung. Totgesagte leben länger. Über die Vitalität politischer Theorie und Philosophie in den USA nach 1945: Institutionelle und theoriegeschichtliche Aspekte, in: Brodocz, André; Schaal, Gary S. (Hg.), Politische Theorien der Gegenwart I. Opladen: Leske und Budrich 2002, 503-538.

Schaar, Peter, Datenaustausch und Datenschutz im Vertrag von Prüm, in: DuD Datenschutz und Datensicherheit, 30/11, 2006, 691-693.

Scharpf, Fritz W., Demokratietheorie zwischen Utopie und Anpassung. Konstanz: Universitätsverlag 1970.

---, De-constitutionalisation and majority rule: A democratic vision for Europe, in: European Law Journal, 23/5, 2017, 315-334.

Schaub, Jörg, Ideale und/oder nicht-ideale Theorie - oder weder noch? Ein Literaturbericht zum neuesten Methodenstreit in der politischen Philosophie, in: Zeitschrift für philosophische Forschung, 64/3, 2010, 393-409.

---, Politische Theorie als angewandte Moralphilosophie? Die realistische Kritik, in: Zeitschrift für politische Theorie, 1, 2012, 8-24.

Scheuerman, William E., The realist revival in political philosophy. Or: Why new is not always improved, in: International Politics, 50/6, 2013, 798-814. 


\section{Literaturverzeichnis}

Schneider, Jens-Peter, Rechtsstaatliche Sicherheit in der europäischen Informationsgesellschaft am Beispiel der Vorratsdatenspeicherung, in: Buck, Henning (Hg.), Neue Fragen an den Rechtsstaat: wie begegnen Politik, Recht und Exekutive aktuellen Friedensgefährdungen?, Bd. 16. Göttingen: V \& R Unipress 2009, 179192.

---, Informationssysteme als Bausteine des Europäischen Verwaltungsverbunds, in: Neue Zeitschrift für Verwaltungsrecht, 2, 2012, 65-70.

---, Developments in European Data Protection Law in the Shadow of the NSA-Affair, in: Miller, Russell A. (Hg.), Privacy and power. A transatlantic dialogue in the shadow of the NSA-Affair. Cambridge: Cambridge University Press 2017, 539 563.

Schmelzle, Cord, Politische Legitimität und zerfallene Staatlichkeit. Frankfurt am Main: Campus-Verlag 2015.

Schmidt, Vivien A., Democracy and Legitimacy in the European Union, in: Jones, Erik; Menon, Anan; Weatherill, Stephen (Hg.), The Oxford Handbook of the European Union. Oxford: Oxford University Press 2012, 661-675.

Schmitt, Carl, Legalität und Legitimität. Berlin: Duncker \& Humblot 1988.

Schreiber, Manfred, Abschaffung der Grenzkontrollen in Europa? Tendenzen mögliche Auswirkung und Auffangmaßnahmen, in: Die Neue Polizei, 3, 1985, 56-60.

Schriever-Steinberg, Angelika, Kontrolle des Schengener Informationssystems, in: DuD Datenschutz und Datensicherheit, 31/8, 2007, 571-574.

Schröder, Birgit, Das Fingerabdruckvergleichssystem EURODAC, in: Zeitschrift für Ausländerrecht und Ausländerpolitik, 2, 2001, 71-76.

Schubbach, Arno, Judging machines: philosophical aspects of deep learning, in: Synthese, 198, 2019, 1807-1827.

Schwerpunkt: Judith N. Shklars politische Philosophie, in: Deutsche Zeitschrift für Philosophie, 62/4, 2014.

Schwerpunkt: Die politische Theorie von Judith N. Shklar, in: Zeitschrift für Politische Theorie, 9/2, 2018.

Senger, Harro von, From the limited to the universal concept of human rights: two periods of human rights, in: Schluchter, Wolfgang (Hg.), Human rights and cultural diversity: Europe, Arabic-Islamic world, Africa, China. Goldbach: Keip 1993, 47-100.

Shklar, Judith N., Der Liberalismus der Furcht. Berlin: Matthes \& Seitz 2013.

--, Ganz normale Laster. Berlin: Matthes \& Seitz 2014.

Siep, Ludwig, Sinn und Grenzen von Ethik-Kommissionen aus philosophischer Sicht, in: Vöneky, Silja et al. (Hg.), Ethik und Recht - Die Ethisierung des Rechts/ Ethics and Law - The Ethicalization of Law. Berlin; Heidelberg: Springer 2013, 423-432.

Simmons, Alan John, Justification and legitimacy: essays on rights and obligations. Cambridge: Cambridge University Press 2001. 
Skinner, Quentin, Liberty before Liberalism. Cambridge: Cambridge University Press 1998.

Sleat, Matt, Bernard Williams and the possibility of a realist political theory, in: European Journal of Political Theory, 9/4, 2010, 485-503.

---, Realism, Liberalism and Non-ideal Theory. Or, Are there Two Ways to do Realistic Political Theory?, in: Political Studies, 64/1, 2016, 27-41.

Spiecker Döhmann, Indra, Kontexte der Demokratie: Partei, Medien und Sozialstrukturen, in: Spiecker Döhmann et al. (Hg.), Fragmentierungen, Bd. 77. Berlin: de Gruyter 2018, 9-66.

Stämpfli, Sandra, Das Schengener Informationssystem und das Recht der informationellen Selbstbestimmung. Bern: Stämpfli 2009.

Steffek, Jens, Die Output-Legitimität internationaler Organisationen und die Idee des globalen Gemeinwohls, in: Geis, Anna; Nullmeier, Frank; Daase, Christopher (Hg.), Der Aufstieg der Legitimitätspolitik. Baden-Baden: Nomos Verlagsgesellschaft 2012, 81-100.

Strauß, Leo, What Is Political Philosophy?, in: Strauß, Leo, What Is Political Philosophy? And other studies. New York: The Free Press 1968, 9-55.

Stullerova, Kamila, The knowledge of suffering: On Judith Shklar's 'Putting Cruelty First', in: Contemporary Political Theory, 13/1, 2014, 23-45.

Taschner, Hans Claudius, Schengen: die Übereinkommen zum Abbau der Personenkontrollen an den Binnengrenzen von EU-Staaten. Baden-Baden: Nomos 1997.

Taylor, Charles, Negative Freiheit? Zur Kritik des neuzeitlichen Individualismus. Frankfurt am Main: Suhrkamp 1992.

---, Quellen des Selbst: die Entstehung der neuzeitlichen Identität. Frankfurt am Main: Suhrkamp 1996.

Thaler, Mathias, Hope Abjuring Hope: On the Place of Utopia in Realist Political Theory, in: Political Theory, 46/5, 2018, 671-697.

Theunissen, Michael, Das Selbst auf dem Grund der Verzweiflung. Kierkegaards negativistische Methode. Frankfurt am Main: Hain 1991.

---, Der Begriff Verzweiflung: Korrekturen an Kierkegaard. Frankfurt am Main: Suhrkamp 1993.

Thomas, Alan, Rawls and political realism: Realistic utopianism or judgement in bad faith?, in: European Journal of Political Theory, 16/3, 2017, 304-324.

Toom, Victor; Granja, Rafaela; Ludwig, Anika, The Prüm Decisions as an Aspirational regime: Reviewing a Decade of Cross-Border Exchange and Comparison of Forensic DNA Data, in: Forensic Science International: Genetics, 41, 2019, $50-57$.

Töpfer, Eric, Prüm und das europäische DNA-Datennetz \& Transatlantischer DNA-Freihandel?, in: Gen-ethisches Netzwerk e. V. (Hg.), Identität auf Vorrat. Zur Kritik der DNA-Sammelwut. Berlin; Hamburg: Assoziation A 2017, 79-87.

Tully, James, Public Philosophy in a New Key (Ideas in Context). Cambridge: Cambridge University Press 2008. 
Ulbricht, Lena, When Big Data Meet Securitization. Algorithmic Regulation with Passenger Name Records, in: European Journal for Security Research, 3/2, 2018, 139-161.

Van Parijs, Philippe, Should the European Union Become More Democratic?, in: Føllesdal, Andreas; Koslowski, Peter (Hg.), Democracy and the European Union. Berlin: Springer 1997, 287-301.

Vermeulen, Mathias; Bellanova, Rocco, European 'smart' surveillance: What's at stake for data protection, privacy and non-discrimination?, in: Security and Human Rights, 23, 2013, 297-311.

Vöneky, Silja; Neuman, Gerald L. (Hg.), Human rights, democracy, and legitimacy in a world of disorder. Cambridge: Cambridge University Press 2018.

de Waele, Henri, Entrenching the Area of Freedom, Security and Justice. Questions of institutional governance and judicial control, in: Fletcher, Maria; Herlin-Karnell, Ester; Matera, Claudio (Hg.), The European Union as an area of freedom, security and justice. London; New York: Routledge 2017, 485-508.

Waldenfels, Bernhard, Einführung in die Phänomenologie. München: Fink 1992.

Wallace, Helen, Deepening and Widening: Problems of legitimacy for the EC, in: García, Soledad (Hg.), European Identity and the Search for Legitimacy. London: Pinter 1993, 95-105.

Wallace, William; Smith, Julie, Democracy or technocracy? European integration and the problem of popular consent, in: West European Politics, 18/3, 1995, $137-157$.

Walter, Bernd, Europäischer Enthusiasmus. Grenzüberschreitende Kriminalität im Spannungsfeld zwischen Kontrolle und Liberalisierung des Grenzverkehrs, in: Kriminalistik, 2, 1989, 66-71.

Weber, Max, Gesammelte Aufsätze zur Religionssoziologie, Bd. 1. Tübingen: Mohr 1986.

---, Wirtschaft und Gesellschaft: Grundriss der verstehenden Soziologie. Frankfurt am Main: Zweitausendeins 2010.

Wesche, Tilo, Dialectical negativism: Michael Theunissen, 1932-2015, in: Radical Philosophy, 192, 2015, 66-68.

Wienbracke, Mike, Der Verhältnismäßigkeitsgrundsatz, in: Zeitschrift für das Juristische Studium, 2, 2013, 148-155.

Williams, Bernard Arthur Owen, Scham, Schuld und Notwendigkeit: eine Wiederbelebung antiker Begriffe der Moral. Berlin: Akademie-Verlag 2000.

---, In the beginning was the deed: realism and moralism in political argument. Princeton: Princeton University Press 2005.

Wittgenstein, Ludwig, Philosophische Untersuchungen. Frankfurt am Main: Suhrkamp 2017.

---, Über Gewißheit. Frankfurt am Main: Suhrkamp 2018. 
Wittkämper, Gerhard W.; Krevert, Peter; Kohl, Andreas, Europa und die innere Sicherheit: Auswirkungen des EG-Binnenmarktes auf die Kriminalitätsentwicklung und Schlußfolgerungen für die polizeiliche Kriminalitätsbekämpfung. Wiesbaden: Bundeskriminalamt 1996.

Würtenberger, Thomas, Legitimität, Legalität, in: Brunner, Otto; Conze, Werner; Koselleck, Reinhart (Hg.), Geschichtliche Grundbegriffe, Bd. 3. Heidelberg: KlettCotta 1982, 677-740.

Ziewitz, Malte, Governing Algorithms. Myth, Mess, and Methods, in: Science, Technology, \& Human Values, 41/1, 2016, 3-16.

Zoche, Peter; Kaufmann, Stefan; Haverkamp, Rita (Hg.), Zivile Sicherheit. Gesellschaftliche Dimensionen gegenwärtiger Sicherheitspolitiken. Bielefeld: transcript Verlag 2011.

Zolo, Danilo, Die demokratische Fürstenherrschaft. Für eine realistische Theorie der Politik. Göttingen: Steidl 1997.

---, Teoria e critica dello Stato di diritto, in: Costa, Pietro; Zolo, Danilo (Hg.), Lo Stato di diritto. Storia, teoria, critica. Milano: Feltrinelli 2006, 17-88.

Zürn, Michael, Autorität und Legitimität in der postnationalen Konstellation, in: Geis, Anna; Nullmeier, Frank; Daase, Christopher (Hg.), Der Aufstieg der Legitimitätspolitik. Baden-Baden: Nomos 2012, 41-62.

Zweig, Katharina A.; Wenzelburger, Georg; Krafft, Tobias D., On Chances and Risks of Security Related Algorithmic Decision Making Systems, in: European Journal for Security Research, 3/2, 2018, 181-203. 


\section{Verzeichnis der Internetquellen}

Agamben, Giorgio, For a Theory of Destituent Power. Lecture Transcript, Athens, 16.11.2013, http://criticallegalthinking.com/2014/02/05/theory-destituent-power/ (letzter Zugriff 28.4.2021).

Aus, Jonathan P., Eurodac: a solution looking for a problem? / EURODAC: ein Lösungskonzept für ein Problem?, in: European Integration online Papers, 10, 2006, http://eiop.or.at/eiop/pdf/2006-006.pdf (letzter Zugriff 28.4.2021).

Bakowski, Piotr; Voronova, Sofija: The proposed EU passenger name records (PNR) directive. Revived in the new security context. EU Parlament Briefing April 2015, http://www.europarl.europa.eu/EPRS/EPRS-Briefing-554215-The-EU -PNR-Proposal-FINAL.pdf (letzter Zugriff 18.2.2021).

Bellanova, Rocco; De Hert, Paul, Transatlantic Cooperation on Travelers' Data Processing: From Sorting Countries to Sorting Individuals, 2011, https://www. migrationpolicy.org/research/transatlantic-cooperation-travelers-data-processing (letzter Zugriff 28.4.2021).

Bigo, Didier et al., The EU Counter-Terrorism Policy Responses to the Attacks in Paris: Towards an EU Security and Liberty Agenda. CEPS (Centre for European Policy Studies) Papers in Liberty and Security in Europe, Nr. 81, 2015, https://w ww.ceps.eu/wp-content/uploads/2015/03/LSE81Counterterrorism.pdf (letzter Zugriff 28.4.2021).

Brouwer, Evelien, Ignoring Dissent and Legality. The EU's proposal to share the personal information of all passengers. CEPS (Centre for European Policy Studies) Papers in Liberty and Security in Europe, 2011, https://www.ceps.eu/wp-con tent/uploads/2011/06/No\%2040\%20Brouwer\%20on\%20PNR\%20Directive.pdf, (letzter Zugriff 28.4.2021).

Bundeskriminalamt, Presseinformation: Neues Instrument zur Risikobewertung von potentiellen Gewaltstraftätern, 2.2.2017, https:/www.bka.de/DE/Presse/List enseite_Pressemitteilungen/2017/Presse2017/170202_Radar.html (letzter Zugriff 2.2.2021).

Bundesministerium der Finanzen: Eckdaten und wesentliche Kennziffern zum Regierungsentwurf, 6.7.2018, https://www.bundesfinanzministerium.de/Conten t/DE/Downloads/Gesetze/2018-07-06-Entw-HH2019.pdf?_blob=publicationFile $\& v=1$ (letzter Zugriff: 28.4.2021).

Bundesministerium des Innern: Living Europe Safely. Work Programme for the German EU Presidency in the First Half of 2007, 2006, https://eucpn.org/docum ent/living-europe-safely (letzter Zugriff 28.4.2021).

---, Vertrag von Prüm. Auswertung DNA-Datenabgleich zwischen Deutschland und Österreich. Stand 18. März 2007, http://www.bmi.bund.de/cae/servlet/contentb lob/128692/publicationFile/14035/Vertrag_Pruem_DNA_Echtabgleich_de.pdf (letzter Zugriff 24.7.2017). 
Bundesministerium des Innern, für Bau und Heimat, Moderne Kriminalitätsbekämpfung: Das polizeiliche Informationswesen, 2020, http:/www.bmi.bund.de/ $\mathrm{DE} /$ themen/sicherheit/nationale-und-internationale-zusammenarbeit/polizeilich es-informationswesen/polizeiliches-informationswesen-artikel.html?nn=9391764 (letzter Zugriff 15.2.2021)

---, Antwort auf die Schriftliche Frage des Abgeordneten Thomas Nord vom 25.1.2021, 1. Februar 2021, Arbeitsnummer 1/428, https://thomas-nord.de/wp -content/uploads/2021/02/SF428.pdf (letzter Zugriff 18.2.2021)

Correia, Fausto, Entwurf einer legislativen Entschliessung des Europäischen Parlaments, in: Bericht des EU-Parlaments endgültig A6-0207/2007, 2007, http://www .europarl.europa.eu/RegData/seance_pleniere/textes_deposes/rapports/2007/020 7/P6_A(2007)0207_DE.doc (letzter Zugriff 28.4.2021).

---, Stellungnahme des Rechtsausschusses zur Rechtsgrundlage, in: Bericht des EU-Parlaments endgültig A6-0207/2007, 2007, http://www.europarl.europa.e u/RegData/seance_pleniere/textes_deposes/rapports/2007/0207/P6_A(2007 0207_DE.doc (letzter Zugriff 28.4.2021).

Council of the EU, Development of SIS II Ratsdokument 9808/03, vom 26.5.2003, https://data.consilium.europa.eu/doc/document/ST-9808-2003-INIT/en/pdf (letzter Zugriff 28.4.2021).

---, The Provision of SIS and SIRENE hit statistics to Council, Dokument Nr. 14934/1/10 REV 1, http://data.consilium.europa.eu/doc/document/ST-14 934-2010-REV-1/en/pdf (letzter Zugriff 28.4.2021).

---, Schengen information system database statistics dd. 01/01/2011, Ratsdokument Nr. 6434/2/11, vom 16.3.2011, http://data.consilium.europa.eu/doc/document/S T-6434-2011-REV-2/en/pdf (letzter Zugriff 28.4.2021).

---, Schengen information system database statistics 01/01/2012, Ratsdokument Nr. 8281/12, vom 28.3.2012, http://data.consilium.europa.eu/doc/document/ ST-8281-2012-INIT/en/pdf (letzter Zugriff 28.4.2021).

---, Schengen information system database statistics 01/01/2013, Ratsdokument Nr. 7389/13, vom 13.3.2013, http://data.consilium.europa.eu/doc/document/ ST-7389-2013-INIT/en/pdf (letzter Zugriff 28.4.2021).

---, Council Decision 2008/615/JHA of 23 June 2008 on the stepping up of crossborder cooperation, particularly in combating terrorism and cross-border-crime, Council Decision 2008/616/JHA of 23 June 2008 on theimplementation of Council Decision 2008/615/JHA of 23 June 2008 on thestepping up of crossborder cooperation, particularly in combating terrorism and cross-border-crime ("Prüm Decisions") - statistics and reports on automated data exchange for 2014, Dokument Nr. 5503/2/15 REV 2, vom 16.3.2015, https://data.consilium.eu ropa.eu/doc/document/ST-5503-2015-REV-2/en/pdf (letzter Zugriff 28.4.2021).

---, Next generation Prüm (Prüm.ng) - Reports from focus groups/Report on face recognition, Dokument Nr. 13356/19 vom 30.10.2019 https:/www.statewatch.o $\mathrm{rg} /$ media/documents/news/2020/mar/eu-council-prum-facial-recognition-13356 -19.pdf (letzter Zugriff 12.2.2021). 
EG-Kommission, Die Vollendung des Binnenmarktes. Weißbuch der Kommission an den Europäischen Rat, COM (85) 310 endgültig, vom 14.6.1985, http://eur opa.eu/documents/comm/white_papers/pdf/com1985_0310_f_de.pdf (letzter Zugriff 28.4.2021).

---, Mitteilung der Kommission an den Rat und das Europäische Parlament „Die Entwicklung des Informationssystems Schengen II“, COM (2001) 720 final, 18.12.2001, http://eur-lex.europa.eu/legal-content/DE/TXT/PDF/?uri=CELEX:52 001DC0720\&qid=1512633320530\&from=EN (letzter Zugriff 28.4.2021).

---, Vorschlag für einen Rahmenbeschluss des Rates über den Austausch von Informationen nach dem Grundsatz der Verfügbarkeit, $\{\mathrm{SEK}(2005) 1270\} / *$ KOM/ 2005/0490 endg. - CNS 2005/0207\%/, COM (2005) 490 final, 12.10.2005, http://e ur-lex.europa.eu/legal-content/DE/TXT/HTML/?uri=CELEX:52005PC0490\&qid $=1525768867672 \&$ from $=$ DE (letzter Zugriff 28.4.2021).

---, Vorschlag für einen Rahmenbeschluss des Rates über die Verwendung von Fluggastdatensätzen (PNR-Daten) zu Strafverfolgungszwecken, \{SEK(2007) $1422\}\{$ SEK(2007) 1453\} COM (2007) 654 final, 6.11.2007, https://eur-lex.europ a.eu/legal-content/DE/TXT/?qid=1560168494282\&uri=CELEX:52007PC0654 (letzter Zugriff 28.4.2021).

EU-Commission, Commission Staff Working Paper. Impact Assessment Accompanying document to the Proposal for a European Parliament and Council Directive on the use of Passenger Name Record data for the prevention, detection, investigation and prosecution of terrorist offences and serious crime (COM (2011) 32 final, SEC (2011) 133 final), SEC (2011) 132 final, 2.2.2011, http://ec.e uropa.eu/smart-regulation/impact/ia_carried_out/docs/ia_2011/sec_2011_0132_e n.pdf (letzter Zugriff 28.4.2021).

---, Communication from the Commission to the European Parliament, the Council, the European Economic and Social Committee and the Committee of Regions. The EU Justice Agenda for 2020. Strengthening Trust, Mobility and Growth within the Union, COM (2014) 144 final, https://eur-lex.europa.eu/lega l-content/EN/TXT/PDF/?uri=CELEX:52014DC0144\&from=EN (letzter Zugriff 28.4.2021).

---, Proposal for a Regulation of the European Parliament and of the Council on the establishment, operation and use of the Schengen Information System (SIS) in the field of border checks, amending Regulation (EU) No 515/2014 and repealing Regulation (EC) No 1987/2006, COM (2016) 882 final, http://www.eu roparl.europa.eu/RegData/docs_autres_institutions/commission_europeenne/co m/2016/0882/COM_COM(2016)0882_EN.pdf (letzter Zugriff 28.4.2021).

---, Commission Staff Working Document, Comprehensive Assessment of EU Security Policy, SWD (2017) 278 final, 26.7.2017, https://ec.europa.eu/home-affairs/si tes/homeaffairs/files/what-we-do/policies/european-agenda-security/20170726_n inth_progress_report_towards_an_effective_and_genuine_security_union_swd part2_en.pdf (letzter Zugriff 28.4.2021). 
---, Study on the feasibility of improving information exchange under the Prüm decisions. Final Report, May 2020, https://op.europa.eu/en/publication-detail/-/p ublication/6c877a2a-9ef7-11ea-9d2d-01aa75ed71a1/language-en/format-PDF/sou rce-130489216 (letzter Zugriff 12.2.2021).

---, Commission Staff Working Document Accompanying the Document Report from the Commission to the European Parliament and the Council on the Review of Directive 2016/681 on the use of passenger name record (PNR) data for the prevention, detection, investigation and proesecution of terrorist offences and, SWD(2020) 128 final vom 24.7.2020, https://ec.europa.eu/home-affairs/sites /homeaffairs/files/what-we-do/policies/european-agenda-security/20200724_swd -2020-128_en.pdf (letzter Zugriff 16.2.2021).

---, Website-Eintrag „Passenger Name Record (PNR)“, https://ec.europa.eu/home -affairs/what-we-do/policies/police-cooperation/information-exchange/pnr_en (letzter Zugriff 28.4.2021).

EU-Kommission, Mitteilung der Kommission an das Europäische Parlament und den Rat, Auswirkungen des Inkrafttretens des Vertrags von Lissabon auf die laufenden interinstitutionellen Beschlussfassungsverfahren, COM (2009) 665 final, 2.12.2009, http://eur-lex.europa.eu/legal-content/DE/TXT/HTML/?uri=CELEX:5 2009DC0665\&qid=1525769096564\&from=DE (letzter Zugriff 28.4.2021).

---, Vorschlag für eine Richtlinie des Europäischen Parlaments und des Rates über die Verwendung von Fluggastdatensätzen zu Zwecken der Verhütung, Aufdeckung, Aufklärung und strafrechtlichen Verfolgung von terroristischen Straftaten und schwerer Kriminalität, COM (2011) 32 final, 2.2.2011, http://ww w.europarl.europa.eu/meetdocs/2014_2019/documents/com/com_com\%282011 \%290032_/com_com\%282011\%290032_de.pdf (letzter Zugriff 28.4.2021).

---, Mitteilung der Kommission an das Europäische Parlament, den Rat, den Europäischen Wirtschafts- und Sozialausschuss und den Ausschuss der Regionen „Die Europäische Sicherheitsagenda“, COM (2015) 185 final, 28.4.2015, https://ec.europa.eu/home-affairs/sites/homeaffairs/files/e-library/documents/basi c-documents/docs/eu_agenda_on_security_de.pdf (letzter Zugriff 28.4.2021).

---, Mitteilung der Kommission an das Europäische Parlament und den Rat „Solidere und intelligentere Informationssysteme für das Grenzmanagement und mehr Sicherheit“, COM (2016) 205 final, 6.4.2016, https://www.parlament.gv.at/PA KT/EU/XXV/EU/10/21/EU_102143/imfname_10626607.pdf (letzter Zugriff 11.2.2021). 
---, Vorschlag für eine Verordnung des Europäischen Parlaments und des Rates über die Einrichtung von Eurodac für den Abgleich von Fingerabdruckdaten zum Zwecke der effektiven Anwendung der [Verordnung (EU) Nr. 604/2013 zur Festlegung der Kriterien und Verfahren zur Bestimmung des Mitgliedstaats, der für die Prüfung eines von einem Drittstaatsangehörigen oder Staatenlosen in einem Mitgliedstaat gestellten Antrags auf internationalen Schutz zuständig ist], für die Feststellung der Identität illegal aufhältiger Drittstaatsangehöriger oder Staatenloser und über der Gefahrenabwehr und Strafverfolgung dienende Anträge der Gefahrenabwehr- und Strafverfolgungsbehörden der Mitgliedstaaten und Europols auf den Abgleich mit Eurodac-Daten (Neufassung), COM (2016) 0272 final, 4.5.2016, https://eur-lex.europa.eu/legal-content/DE/TXT/?qid =1560168916280\&uri=CELEX:52016PC0272 (letzter Zugriff 28.4.2021).

---, Mitteilung der Kommission an das Europäische Parlament, den Europäischen Rat und den Rat. Auf dem Weg zu einer wirksamen und echten Sicherheitsunion - Erster Fortschrittsbericht, COM (2016) 670 final, 12.10.2016, https://db.eur ocrim.org/db/de/doc/2654.pdf (letzter Zugriff 28.4.2021).

---, Bericht der Kommission an das Europäische Parlament und den Rat über die Evaluierung des Schengener Informationssystems der zweiten Generation (SIS II) nach den Art. 24 Abs. 5, Art. 43 Abs. 3 und Art. 50 Abs. 5 der Verordnung (EG) Nr. 1987/2006 in Verbindung mit den Art. 59 Abs. 3, Art. 66 Abs. 5 und Art. 66 Abs. 5 des Beschlusses 2007/533/JI, COM (2016) 880 final, 21.12.2016, http://eur-lex.europa.eu/legal-content/DE/TXT/PDF/?uri=CELEX:52 016DC0880\&qid=1512475052084\&from=EN (letzter Zugriff 28.4.2021).

---, Mitteilung der Kommission an das Europäische Parlament, den Europäischen Rat und den Rat. Auf dem Weg zu einer wirksamen und echten Sicherheitsunion - Fünfter Fortschrittsbericht, COM (2017) 203 final, 2.3.2017, https://db.eur ocrim.org/db/de/doc/2770.pdf (letzter Zugriff 28.4.2021).

---, Mitteilung der Kommission an das Europäische Parlament, den Europäischen Rat und den Rat. Auf dem Weg zu einer wirksamen und echten Sicherheitsunion - Siebter Fortschrittsbericht, COM (2017) 261 final, 16.5.2017, https://ec.eur opa.eu/transparency/regdoc/rep/1/2017/DE/COM-2017-261-F1-DE-MAIN-PART -1.PDF (letzter Zugriff 28.4.2021).

---, Mitteilung der Kommission an das Europäische Parlament und den Rat „Schengen bewahren und stärken“, COM (2017) 570 final, 27.9.2017, https://eur-lex.e uropa.eu/legal-content/DE/TXT/HTML/?uri=CELEX:52017DC0570\&from=EN (letzter Zugriff 28.4.2021).

---, Vorschlag für eine Verordnung des Europäischen Parlaments und des Rates zur Errichtung eines Rahmens für die Interoperabilität zwischen EU-Informationssystemen (polizeiliche und justizielle Zusammenarbeit, Asyl und Migration), COM (2017) 794 final, 12.12.2017, https://ec.europa.eu/transparency/regdo c/rep/1/2017/DE/COM-2017-794-F1-DE-MAIN-PART-1.PDF (letzter Zugriff 28.4.2021). 
---, Vorschlag für eine Verordnung des Europäischen Parlaments und des Rates zur Änderung der Verordnung (EG) Nr.767/2008, der Verordnung (EG) Nr. 810/2009, der Verordnung (EU) 2017/2226, der Verordnung (EU) 2016/399, der Verordnung (EU) 2018/XX [Interoperabilitäts-Verordnung] und der Entscheidung 2004/512/EG sowie zur Aufhebung des Beschlusses 2008/633/JI des Rates, COM (2018) 302 final, 16.5.2018, https://eur-lex.europa.eu/legal-cont ent/DE/TXT/HTML/?uri=CELEX:52018PC0302\&from=EN (letzter Zugriff 28.4.2021).

---, Geänderter Vorschlag für eine Verordnung des Europäischen Parlaments und des Rates zur Errichtung eines Rahmens für die Interoperabilität zwischen EUInformationssystemen (polizeiliche und justizielle Zusammenarbeit, Asyl und Migration) und zur Änderung der [Verordnung (EU) 2018/XX [Eurodac-Verordnung], der Verordnung (EU) 2018/XX [Verordnung über das SIS im Bereich der Strafverfolgung], der Verordnung (EU) 2018/XX [ECRIS-TCN-Verordnung] und der Verordnung (EU) 2018/XX [eu-LISA-Verordnung], \{SWD(2017) 473 final $\}\{$ SWD(2017) 474 final $\}$ COM (2018) 480 final, 13.6.2018, https://eur-lex.eur opa.eu/legal-content/DE/TXT/HTML/?uri=CELEX:52018PC0480\&qid=1560169 357677\&from=DE (letzter Zugriff 28.4.2021).

---, Mitteilung der Kommission das Europäische Parlament, den europäischen Rat und den Rat „Auf dem Weg zu einer wirksamen und echten Sicherheitsunion Achtzehnter Fortschrittsbericht“, COM (2019) 145 final, 20.3.2019, https://eur-le x.europa.eu/legal-content/DE/TXT/HTML/?uri=CELEX:52019DC0145\&from=D E (letzter Zugriff 28.4.2021).

---, Mitteilung der Kommission an das Europäische Parlament, den europäischen Rat und den Rat „Auf dem Weg zu einer wirksamen und echten Sicherheitsunion - Zwanzigster Fortschrittsbericht“, $\operatorname{COM(2019)~} 552$ final, 30.10.2019, https:// eur-lex.europa.eu/legal-content/DE/TXT/HTML/?uri=CELEX:52019DC0552\&qi $\mathrm{d}=1626676686667 \&$ from=EN (letzter Zugriff 19.07.2021).

---, Bericht der Kommission an das Europäische Parlament und den Rat über die Überprüfung der Richtlinie (EU) 2016/681 über die Verwendung von Fluggastdatensätzen (PNR-Daten) zur Verhütung, Aufdeckung, Ermittlung und Verfolgung von terroristischen Straftaten und schwerer Kriminalität, COM (2020) 305 final, 24.7.2020, https://op.europa.eu/en/publication-detail/-/publication/4bfd0d e3-cda3-11ea-adf7-01aa75ed71a1/language-de (letzter Zugriff 16.2.2021).

---, Mitteilung der Kommission an das Europäische Parlament den Rat. Erster Fortschrittsbericht zur EU-Strategie für die Sicherheitsunion, COM (2020) 797 final, 9.12.2020, https://eur-lex.europa.eu/legal-content/DE/TXT/HTML/?uri=CE LEX:52020DC0797\&from=EN (letzter Zugriff 12.2.2021).

eu-LISA, SIS II - 2013 Statistics, 2014, http://www.eulisa.europa.eu/Publication s/Reports/eu-LISA_SIS\%20II\%20-\%20Statistics\%202013.pdf (letzter Zugriff 28.4.2021).

---, VIS Report pursuant to Article 50(3) of Regulation (EC) No 767/2008 and VIS Report pursuant to Article 17(3) of Council Decision 2008/633/JHA, 2016, http://www.eulisa.europa.eu/Publications/Reports/VIS\%20Reports\%20on\%20th e\%20technical\%20functioning\%202015.pdf (letzter Zugriff 28.4.2021). 
---, SIS II - 2016 Statistics, 2017, http://www.eulisa.europa.eu/Publications/Reports/ SIS\%20II\%20-\%20Statistics\%202016.pdf (letzter Zugriff 28.4.2021).

---, eu-LISA Strategy 2018-2022, 2017, https:/www.eulisa.europa.eu/Publications/C orporate/eu-LISA\%20Strategy\%202018-2022.pdf (letzter Zugriff 28.4.2021).

---, SIS II - 2017 Statistics, February 2018, https://www.eulisa.europa.eu/Publication s/Reports/2017\%20SIS\%20II\%20Statistics.pdf (letzter Zugriff 11.2.2021).

---, Technical reports on the functioning of VIS as per Article 50(3) of the VIS Regulation and Article 17(3) of the VIS Decision, 2018, https://www.eulisa.eur opa.eu/Publications/Reports/2018\%20VIS\%20reports.pdf\#search=vis\%202018 (letzter Zugriff 28.4.2021).

---, SIS II - 2018 Statistics, February 2019, https://www.eulisa.europa.eu/Publication s/Reports/SIS\%202018\%20statistics.pdf (letzter Zugriff 11.2.2021).

---, SIS II - Statistics 2019, March 2020, https://www.eulisa.europa.eu/Publicat ions/Reports/SIS\%20II\%20-\%202019\%20-\%20Statistics.pdf (letzter Zugriff 11.2.2021).

---, Eurodac - 2019 Annual Report, July 2020, https://www.eulisa.europa.eu/Publica tions/Reports/Eurodac - 2019 Annual Report.pdf (letzter Zugriff: 23.2.2021).

---, Report on the technical functioning of the Visa Information System (VIS), August 2020, https://www.eulisa.europa.eu/Publications/Reports/2019\%20VIS\% 20Report.pdf (letzter Zugriff: 23.2.2021).

Europäischer Rat, Tampere Europäischer Rat 15. und 16. Oktober 1999, Schlussfolgerungen des Vorsitzes, 1999, http://www.europarl.europa.eu/summits/tam_de. htm (letzter Zugriff 28.4.2021).

---, „Eine neue strategische Agenda. 2019-2024“, 20.6.2019, https://www.consilium. europa.eu/media/39963/a-new-strategic-agenda-2019-2024-de.pdf (letzter Zugriff 10.2.2021).

Europäischer Rechnungshof, Erkenntnisse aus der Entwicklung des Schengener Informationssystems der zweiten Generation (SIS II) durch die Europäische Kommission, Sonderbericht, https://www.eca.europa.eu/lists/ecadocuments/s r14_03/sr14_03_de.pdf (letzter Zugriff 10.2.2021).

European Council, Conclusions of the European Council 26/27 June 2014, Dokument Nr. EUCO 79/14, https://www.consilium.europa.eu/uedocs/cms_Data/doc s/pressdata/en/ec/143478.pdf (letzter Zugriff 28.4.2021).

Gerichtshof der Europäischen Union, Pressemitteilung Nr. 84/17, Gutachten 1/15, vom 26.7.2017, https:/curia.europa.eu/jcms/upload/docs/application/pdf/2017-0 7/cp170084de.pdf (letzter Zugriff 28.4.2021).

Giegerich, Thomas; Schmitt, Desirée; Kreß, Sabihat, Gutachten zu Rechtsfragen betreffend die Erhebung, Speicherung und Verarbeitung personenbezogener Daten von Flüchtlingen, Saar Expert Papers, 1/2016, https://jean-monnet-saar .eu/wp-content/uploads/2013/12/GutachtenDatenschutz.pdf (letzter Zugriff 28.4.2021).

Guild, Elspeth, Merging Security from the Two Level Game: Inserting the Treaty of Prüm into EU Law? CEPS (Centre for European Policy Studies) Policy paper Nr. 124, 2009, http://ssrn.com/abstract=1334608 (letzter Zugriff 28.4.2021). 
Hardt, Moritz, Occupy Algorithms: Will Algorithms Serve the 99\%? Response Paper presented at the Governing Algorithms Conference, New York, 17.3.2013, http://governingalgorithms.org/wp-content/uploads/2013/05/2-response-hardt.p df (letzter Zugriff 28.4.2021).

Jones, Chris, Market Forces: The Development of the EU Security-Industrial Complex, Report by the Transnational Institute and Statewatch, 2017, https://www .tni.org/files/publication-downloads/marketforces-report-tni-statewatch.pdf (letzter Zugriff 28.4.2021).

Kirkhope, Timothy; Ausschuss für bürgerliche Freiheiten, Justiz und Inneres: Bericht des Europäischen Parlaments über den Vorschlag für eine Richtlinie des Europäischen Parlaments und des Rates über die Verwendung von Fluggastdatensätzen zu Zwecken der Verhütung, Aufdeckung, Aufklärung und strafrechtlichen Verfolgung von terroristischen Straftaten und schwerer Kriminalität (COM (2011) 0032 - C7-0039/2011 - 2011/0023(COD)), Dokument A7-0150/2013, vom 9.4.2013, http://www.europarl.europa.eu/sides/getDoc.do?t ype $=$ REPORT\&reference $=$ A7-2013-0150\&format $=$ XML\&language $=$ DE (letzter Zugriff 28.4.2021).

Monroy, Matthias, Projekt Interoperabilität - EU zahlt 300 Millionen Euro für Erkennung von Gesichtern und Fingerabdrücken, in: Netzpolitik.org, 5.6.2020, https://netzpolitik.org/2020/eu-zahlt-300-millionen-euro-fuer-erkennung-von-ges ichtern-und-fingerabdruecken/ (letzter Zugriff 23.2.2021).

---, Schengener Informationssystem - Abgleich von Fingerabdrücken jetzt EU-weit verpflichtend, in: Netzpolitik.org, 27.1.2021, https://netzpolitik.org/2021/abgleic h-von-fingerabdruecken-jetzt-eu-weit-verpflichtend/ (letzter Zugriff 15.2.2021).

Morozov, Evgeny, Why the internet of things could destroy the welfare state, in: The Observer, 20.6.2014, https://www.theguardian.com/technology/2014/jul/2 0/rise-of-data-death-of-politics-evgeny-morozov-algorithmic-regulation (letzter Zugriff 28.4.2021).

Rat der EU, Detaillierte Beschreibung jüngster und geplanter Maßnahmen zur Bekämpfung von Terrorismus und gewalttätigem Extremismus, Ratsdokument 14260/16 ADD 1 EXT 1 vom 20.12.2016, https://data.consilium.europa.eu/doc/d ocument/ST-14260-2016-ADD-1-EXT-1/de/pdf (letzter Zugriff 28.4.2021).

---, Das Stockholmer Programm - Ein offenes und sicheres Europa im Dienste und zum Schutz der Bürger, Dokument Nr. 17024/09, vom 2.12.2009, http://register .consilium.europa.eu/doc/srv?l=DE\&f=ST\%2017024\%202009\%20INIT (letzter Zugriff 28.4.2021).

---, Schlussfolgerungen des Rates zur Umsetzung der „PRÜMER BESCHLÜSSE“ zehn Jahre nach ihrer Annahme, Dokument Nr.11227/18 vom 18.7.2018, https://data.consilium.europa.eu/doc/document/ST-11227-2018-INIT/de/pdf (letzter Zugriff: 12.2.2021).

---, Schlussfolgerungen des Rates zur Ausweitung des Umfangs der Nutzung von PNR-Daten auf andere Beförderungsformen als den Luftverkehr-vom 2. Dezember 2019, Dok. Nr. 14746/19, https://data.consilium.europa.eu/doc/docume nt/ST-14746-2019-INIT/de/pdf (letzter Zugriff: 18.2.2021). 
Reuter, Markus, TKG-Novelle. Seehofer will Personalausweis-Pflicht für E-Mail und Messenger einführen, in: Netzpolitik.org, 03.03.2021, https://netzpolitik.or g/2021/tkg-novelle-seehofer-will-personalausweis-pflicht-fuer-e-mail-und-messen ger-einfuehren/, (letzter Zugriff 22.06.2021)

Schindehütte, Alexandra, Das Schengener Informationssystem unter besonderer Berücksichtigung der Vereinbarkeit einer verdeckten Registrierung nach Art. 99 SDÜ mit Art. 8 der Charta der Grundrechte der Europäischen Union, 2013, http://hdl.handle. net/11858/00-1735-0000-0001-BC1D-C (letzter Zugriff 28.4.2021).

Stellungnahme zu den verbundenen Ersuchen um Vorabentscheidung C-148/20 bis C-150/20, Deutsche Lufthansa u.a. (Vorlegendes Gericht: Amtsgericht Köln - Deutschland) vom 26.8.2020, https://freiheitsrechte.org/home/wp-co ntent/uploads/2020/09/GFF-Stellungnahme-an-den-EuGH-zur-Fluggastdatenspei cherungPNR-Richtlinie-2020.pdf (letzter Zugriff 17.2.2021).

Töpfer, Eric, Die Trias digitaler Grenzen: Eurodac, SIS II und VIS | CILIP Institut und Zeitschrift 109, 5.4.2016, https:/www.cilip.de/2016/04/05/die-trias-digitaler -grenzen-eurodac-sis-ii-und-vis/ (letzter Zugriff 28.4.2021).

Yeung, Karen, Algorithmic regulation: A critical interrogation, in: Regulation \& Governance 2017, https://onlinelibrary.wiley.com/doi/abs/10.1111/rego.12158 (letzter Zugriff 28.4.2021).

Zweig, Katharina, Algorithmische Entscheidungen: Transparenz und Kontrolle, in: Analysen und Argumente aus der Konrad-Adenauer-Stiftung, 2019, https://www .kas.de/analysen-und-argumente/detail/-/content/algorithmische-entscheidungen -transparenz-und-kontrolle (letzter Zugriff 22.2.2021). 
